\title{
La organización de la tecnología lítica y el uso del espacio en la costa centro- septentrional de Patagonia
}

Lic. Anahí Banegas

TESIS PARA OPTAR POR EL TITULO DE DOCTOR EN CIENCIAS NATURALES

Directores

Dra. Julieta Gómez Otero (CONICET-CENPAT)

Dr. Mariano Bonomo (CONICET-FCNyM) 
INDICE

RESUMEN

CAPÍTULO 1

INTRODUCCIÓN

Objetivos Generales

Objetivos Particulares

Hipótesis

Estructura de la Tesis

ESTADO DE LA CUESTIÓN

El área de estudio 15

CAPÍTULO 3

Estado de las investigaciones arqueológicas en la costa pampeana y patagónica: conocimiento actual y modelos arqueológicos

Síntesis sobre el estado actual de las investigaciones 34

CAPÍtulo 4 35

MATERIALES Y MÉTODOS 35

Metodología de campo 35

Métodos de laboratorio 39

CAPÍTULO 5 44

CARACTERIZACIÓN DE LA BASE REGIONAL DE RECURSOS LÍTICOS 44

Sistematización y delimitación de las unidades geológicas de muestreo 44

Estudios de disponibilidad de materias primas líticas 45

Síntesis e integración de la base regional de recursos líticos 65

Expectativas sobre uso de las materias primas y tecnológicas en relación con la base regional de rocas.

CAPÍTULO 6 68

TAFONOMÍA LÍTICA 68

Diseño y montaje de las pistas experimentales 71

Síntesis comparativa e integración de los resultados 77 
CARACTERIZACIÓN TECNOLÓGICA DE LA UNIDAD DE ANÁLISIS PENÍNSULA VALDÉS (PV)

GOLFO SAN MATÍAS 80

Localidad arqueológica playa Las Lisas 80

Localidad arqueológica Los Abanicos 95

GOLFO SAN JOSÉ 105

Localidad arqueológica Punta Cono 105

GOLFO NUEVO PENÍNSULA VALDÉS 118

Localidad arqueológica Punta Cormoranes 118

Localidad arqueológica San Pablo 131

Localidad arqueológica Punta Pardelas 147

CAPÍTULO 8 151

CARACTERIZACIÓN TECNOLÓGICA DE LA UNIDAD DE ANÁLISIS FUERA DE PENÍNSULA VALDÉS 151

COSTA DEL GOLFO SAN MATÍAS OESTE

Localidad arqueológica Arroyo Verde 152

Localidad arqueológica Rincón de Elizalde 168

COSTA DEL GOLFO NUEVO SUR 183

Localidad arqueológica Bahía Cracker 183

CAPÍTULO 9 198

DISCUSIÓN Y CONSIDERACIONES FINALES 198

BIBLIOGRAFÍA 251

ANEXOS 274

MUESTRAS NATURALES 274

MUESTRAS ARQUEOLÓGICAS 277 


\section{RESUMEN}

Esta tesis aborda la organización de la tecnología de la piedra tallada en las sociedades cazadoras-recolectoras de la costa centro septentrional de Patagonia. El área de estudio se extiende entre la desembocadura del Arroyo Verde, en el límite entre las provincias de Río Negro y Chubut, y el extremo sur del golfo Nuevo (Chubut). La investigación se llevó a cabo desde la perspectiva de la organización tecnológica (Nelson 1991) que permite explorar de qué manera y en qué grado de intensidad las decisiones humanas sobre la tecnología interactuaron con los demás aspectos de la vida social, el uso del espacio y la explotación de recursos.

El objetivo general es estudiar la variabilidad espacial y temporal de la organización tecnológica lítica de los grupos del área de estudio y discutir esta información dentro de un contexto más amplio que incluye el registro arqueológico de las costas pampeana y nordpatagónica. Se plantearon además objetivos específicos tales como: (1) caracterizar la estructura regional de recursos líticos (Ericson 1984); (2) evaluar el grado de intensidad y modos de aprovechamiento de los recursos líticos a través del tiempo; (3) explorar relaciones sociales a través de la identificación de rocas de procedencia no local; (4) analizar la estructura y composición de los conjuntos artefactuales líticos a través de variables tecno-morfológicas y de diseño; (5) identificar las técnicas de reducción y las secuencias de producción en las materias primas más utilizadas; (6) aportar datos cronológicos que permitan contextualizar temporalmente la antigüedad de distintos rasgos tecnológicos, entre ellos la talla bipolar, la técnica de talla bifacial y la laminaridad; (7) evaluar la incidencia de procesos de formación sobre la preservación de los conjuntos líticos a través de trabajos actualísticos, y (8) contrastar la información obtenida sobre la organización de la tecnología lítica con el modelo de uso del espacio propuesto por Gómez Otero (2006).

En lo que respecta a la escala espacial se distinguieron dos grandes unidades de análisis arqueológico: Península Valdés y Fuera de Península Valdés. Esta segregación se apoya sobre el modelo de uso del espacio de Gómez Otero que propuso mayor intensidad de uso del espacio en la península que en los sectores costeros adyacentes. En cuanto a la escala temporal, se seleccionaron conjuntos artefactuales que contaran con datos radiocarbónicos. Se determinaron tres bloques temporales: Holoceno medio (7400-4000 AP); Holoceno tardío inicial (3900-1000 AP) y Holoceno tardío final (990 en adelante).

En primer lugar se caracterizó la base regional de recursos líticos por medio de prospecciones, transectas y muestreos de rocas. Se realizaron 14 muestreos en depósitos 
secundarios. Con las rocas recolectadas se conformó una litoteca como colección de referencia para la comparación con los conjuntos artefactuales. Posteriormente se efectuaron análisis de laboratorio -macroscópicos y microscópicos- para los que se seleccionaron muestras arqueológicas y actuales en función de los tipos litológicos identificados como mayoritarios en los muestreos. Con relación a los análisis macroscópicos, se estudiaron 15 conjuntos líticos de sitios arqueológicos de distinta ubicación topográfica, cronología y funcionalidad de acuerdo con la variables tecnológicas, morfológicas y métricas propuestas por Aschero (1975/1983), Aschero y Hocsman (2004) y Belelli et al. (1985). También se analizaron tres sitios arqueológicos en posición superficial de la franja de médanos de la costa pampeana trabajados por Bonomo (2005), que permitieron comparar y discutir las estrategias tecnológicas entre el área de estudio y el litoral bonaerense. Como tema especial se indagó sobre la variabilidad morfológica de puntas microlíticas de la costa y del interior del norte de Chubut. Respecto de los estudios microscópicos se realizaron análisis de secciones delgadas de calcedonias y xilópalos con microscopio de barrido electrónico (MEB) y de composición de elementos mediante la técnica de detector de energía dispersiva (EDX) en xilópalos. Además se exploró el efecto de factores postdepositacionales sobre el registro lítico a partir del diseñó y aplicación de un estudio experimental en tafonomía lítica, que incluyó el sembrado de artefactos y núcleos de distintas materias primas y tamaños en tres ambientes diferenciales y representativos del área de estudio: laguna costera, terraza alta y hoyada de deflación en dunas activas.

Los resultados permitieron conocer que las materias primas más utilizadas por los cazadores fueron las sílices y basaltos disponibles en forma de guijarros en los depósitos secundarios locales. Les siguen en orden de importancia las calcedonias, que son locales sólo en la zona de Arroyo Verde en forma de tabletas, y los xilópalos que no son locales. La otra roca alóctona utilizada, aunque en escasa proporción, es la obsidiana. Las fuentes conocidas y potenciales de estas materias primas foráneas se encuentran entre 50 y $450 \mathrm{~km}$ de distancia. Los basaltos se explotaron de manera expeditiva; no así las sílices y las rocas alóctonas que fueron aprovechadas para la elaboración de instrumentos con mayor inversión de trabajo. La técnica bipolar fue aplicada de manera frecuente (entre 37\% y 50\%) para la talla de guijarros ovales y espesos de tamaños pequeños y medianos de rocas de calidad muy buena a excelente de procedencia local y no local. No se observó talla bipolar en nódulos pequeños o medianos de calidad regular, por ejemplo riolitas.

Se comprobó la circulación de materias primas líticas foráneas, como obsidianas y xilópalos ya desde el Holoceno medio. En cuanto a los diseños de las puntas de proyectil, se observa claramente que las triangulares apedunculadas se concentran en la costas bonaerense y nordpatagónica, mientras que desde el río Negro al sur, las puntas diagnósticas son las 
pedunculadas. Esto sugiere redes de relación diferentes, que podrían haber funcionado desde muy temprano. No obstante, en el Holoceno tardío se intensificó el intercambio de diseños de puntas de cabezales liticos y de otras tecnologías o bienes al norte y sur de este río lo que se relacionaría con una ampliación en los circuitos de contactos políticos, sociales y económicos. Se observaron rasgos tecnológicos similares con los conjuntos líticos del litoral bonaerense y rionegrino en cuanto al uso predominante de los guijarros locales; el empleo variable aunque frecuente de la talla bipolar; la producción de lascas como formas bases; una importante proporción de reserva de corteza en los productos de talla; la preponderancia de tamaños artefactuales mediano-pequeños y la formatización preponderante de los instrumentos mediante retoque o microrretoque marginal unifacial. Por último, en cuanto a la contrastación con el modelo de Gómez Otero (2006) que propuso que Península Valdés fue un espacio más intensamente utilizado que los sectores costeros adyacentes, la comparación entre las dos grandes unidades arqueológicas de muestreo permitió establecer una diversidad litológica arqueológica y superior diversidad de clases artefactuales en la unidad Península Valdés que Fuera de Península Valdés. Esto se relacionaría con la funcionalidad de los sitios ya que el registro más abundante de bases residenciales en PV respecto de los dos sectores de FPV aquí analizados indica ocupaciones más prolongadas y la ejecución de mayor variedad de actividades. 


\section{SUMMARY}

This thesis addresses the organization of the carved stone technology in the huntergatherer societies from the central-northern Patagonian coast. The study area stretches between the mouth of the Arroyo Verde creek, in the limit between the Rio Negro and Chubut provinces, and the southernmost point of the Nuevo Gulf (Chubut). The research was carried out from the perspective of the technological organization (Nelson 1991), which allows to explore the manner and intensity in which human decisions about technology interacted with other aspects of social life, the use of the space and resources exploitation.

The general aim is to study the spatial variability and temporal lithic technology organization of the groups from the study area and to discuss this information within a broader background which includes the archaeological records from the Pampas and northern Patagonia coasts. In addition, specific goals were set: (1) to characterize the regional structure of stone resources (Ericson 1984); (2) to assess the degree of intensity and way of lithic resources utilization over time; (3) to explore social relationships through the identification of foreign stones; (4) to analyze the structure and composition of the stone artefactual assemblages by means of techno-morphological and design variables; (5) to identify the reduction techniques and production sequences of the most used raw materials; (6) to provide chronological data in order to temporarily contextualize the antiquity of various technological features, among these: the bipolar carving, bifacial technique and laminarity; (7) to assess the incidence of formation processes on the preservation of lithic assemblages through actualistic work, and (8) to compare the information obtained on the organization of lithic technology with the spatial use model proposed by Gómez Otero (2006).

Regarding the spatial scale, two main archaeological analysis units were observed: Peninsula Valdes and Outside Peninsula Valdes. This segregation is based on the spatial use model by Otero, who proposed a higher intensity of the spatial use in the peninsula than in the adjacent coastal areas. As for the temporal scale, artefactual assemblages that count with radiocarbon data were selected. Three temporal blocks were determined: Middle Holocene (7400 - 4000 BP), Initial Late Holocene (3900-1000 BP) and Final Late Holocene (990 onwards).

First, the lithic resources regional base was characterized by means of field research, transects and stone samplings. 14 samplings were made in secondary deposits. A lithic collection was made with the collected stones as a reference for comparison with the artefactual assemblage. Later, both macroscopic and microscopic laboratory analyses were made; with this purpose, archaeological and present samples were selected according to the lithological types identified as majority in the samplings. Regarding the macroscopic analyses, 15 lithic 
assemblages of archaeological sites of different topographical location, timing and functionality were studied according to the technological, morphological and metric variables proposed by Aschero (1975/1983), Aschero and Hocsman (2004) and Belelli et al. (1985). Three surface archaeological sites from the sand dunes strip in the Pampean coast previously worked by Bonomo (2005) were also analyzed, fact that allowed to compare and discuss the technological strategies between the study area and the Buenos Aires coast. As a special topic, the morphological variability of microlithic points from the coast and northern inland in Chubut was explored. As for the microscopic studies, analyses of chalcedony and xylopal thin sections were performed with scanning electron microscope (SEM) and elemental composition by the Energy-dispersive X-ray Spectroscopy technique (EDS) in xylopal. Furthermore, the effect of post depositional factors on the lithic record was explored from the design and implementation of an experimental study on lithic taphonomy which included the placement of artifacts and cores of different raw materials and sizes in three differential environments, all of them representative of the study area: coastal lagoon, high terrace and active dunes blowouts.

The results allowed to know that the raw materials most frequently used by the hunters were silica and basalts available in the form of pebbles in local secondary deposits. Chalcedony are next in order of importance, which only exists locally in the Arroyo Verde area as tablets, and non-local xylopal. The other allochthonous used stone, in low proportions though, is the obsidian. The known and potential sources for these foreign raw materials are at 50 and $450 \mathrm{~km}$. Basalts were exploited expeditiously; however, silica and other allochthonous stones were exploited for the development of more elaborated instruments. The bipolar technique was applied less frequently (between 37\% and 50\%) for carving oval and thick pebbles of small and medium sizes from very good or excellent quality stones, either local or non-local. No bipolar carving was observed in small or medium regular quality nodules, for example rhyolites.

The circulation of foreign lithic raw materials such as obsidian and xylopal was found since the middle Holocene. Regarding the designs of projectile points, it is clearly observed that the triangular pedunculated ones are concentrated in the Buenos Aires and Northern Patagonia coasts, while from Rio Negro and southwards, the diagnosed points are pedunculated. This suggests different relationship networks, which might have worked from very early. However, in the Late Holocene, the exchange of lithic tip designs and other technologies or goods north and south of the river intensified, fact that could be related to an increase in the circuits of political, social and economic contacts. Similar technological features to those of the lithic assemblages from Buenos Aires and Rio Negro coastline were observed as far as the predominant use of local pebbles; the variable although frequent use of bipolar carving; the production of lithic flakes as base forms; an important proportion of bark reserve in carving 
products; the preponderance of medium to small artefactual sizes and the preponderant formalization of the instruments through retouching or marginal unifacial micro-retouching. Finally, as to the contrast with the Gómez Otero (2006) model which proposed that Peninsula Valdes was a more intensively used space than the adjacent coastal areas, the comparison between the two great archaeological sampling units allowed to establish an archaeological lithological diversity and a higher diversity of artefactual classes at the Peninsula Valdes unit than in the Outside Peninsula Valdes area. This would relate to the functionality of the sites as the most abundant record of residential bases in Peninsula Valdes, in contrast with the two sectors analyzed Outside Peninsula Valdes, indicates longer occupations and the implementation of a greater variety of activities. 


\section{CAPÍTULO 1}

\section{INTRODUCCIÓN}

Esta tesis trata sobre el estudio de la tecnología lítica desarrollada por grupos cazadores que ocuparon la costa centro-septentrional de Patagonia, más específicamente está focalizada en caracterizar la organización tecnológica a partir de la integración de los factores ecológicos y sociales que influyen las estrategias tecnológicas (Nelson 1991). El área de estudio se ubica entre el tramo costero que abarca el arroyo Verde $-41^{\circ} 54$. 043"S y 6 5 $5^{\circ} 03^{\prime} 880$ "O- y Bahía Cracker (42 57'0.69"S y 64²8'47.87"O) hacia el sur (Fig.2.1).

Las investigaciones iniciadas por Gómez Otero en la década de 1990 se focalizaron en conocer y discutir el uso del espacio y la dieta. La información obtenida indicó que este sector litoral fue ocupado entre 7400 años AP y circa 200 años AP (Gómez Otero et al. 1999, Gómez Otero 2006; Gómez Otero et al. 2013a, 2013b). En cuanto a la alimentación, los análisis arqueofaunísticos, tecnológicos e isotópicos $\left({ }^{13} \mathrm{C}\right.$ y $\left.{ }^{15} \mathrm{~N}\right)$ señalan el aprovechamiento de un espectro amplio de recursos tanto terrestres como marinos hasta tiempos post-contacto. A partir de ese período, la dieta se torna básicamente terrestre y se incorporan hidratos de carbono procesados y proteínas de origen europeo (Gómez Otero 2007). Dentro de ese marco se espera contribuir a partir del estudio de la organización de la tecnología lítica, ya que hasta el momento sólo se cuenta con las descripciones básicas de los conjuntos líticos, efectuadas principalmente para determinar la funcionalidad de los sitios, la especialización en el aprovechamiento de determinados recursos alimenticios y la movilidad interior-costa (Gómez Otero et al. 1999; Gómez Otero 2006).

En los últimos años la arqueología del litoral atlántico pampeano-patagónico ha crecido de manera notable, no sólo en lo que respecta a la mayor cantidad de sectores bajo estudio y de grupos de investigación involucrados, sino también a la amplitud de abordajes teóricos y métodos aplicados (véase síntesis en Orquera y Gómez Otero 2008). Estos avances permitieron refutar y superar los modelos que los dos máximos representantes de la Escuela HistóricoCultural de Viena, Osvaldo Menghin (1952, 1963) y Marcelo Bórmida (1964, 1969 y Menghin y Bórmida s.f.) propusieron para interpretar su poblamiento inicial y las sucesivas ocupaciones humanas desde entonces. Entre otros aspectos se logró comprobar lo siguiente: 
1) la presencia de ocupaciones costeras desde por lo menos 8000-7000 años AP en Pampa (Politis y Bayón 1996); 7000-6000 años AP en Norpatagonia (Sanguinetti et al. 2000; Eugenio y Aldazábal 2004; Favier Dubois et al. 2009) y Patagonia central (Castro y Moreno 1998; Gómez Otero 2006; Castro et at. 2008) y cronologías más tardías para Patagonia centro-meridional y meridional (Mansur 2004; Mansur 2008; Borrero et al. 2008; Cruz et al. 2008; Muñoz et al. 2009). No obstante, es muy probable que las variaciones del nivel marino a partir del Holoceno hayan dejado bajo el mar evidencias arqueológicas de ocupaciones humanas anteriores a las registradas.

2) la utilización de la costa por grupos humanos que no diferían étnicamente, ni eran tecnológicamente "más primitivos" de los que también habitaban las planicies del interior, (Bonomo 2005; Gómez Otero 2006; Orquera y Gómez Otero 2008), tal como lo plantearon los referentes de la Escuela Histórico Cultural de Viena.

3) la ausencia de poblaciones humanas cuyas evidencias arqueológicas reflejen adaptaciones marítimas en el sentido de Lyman (1984) y de Orquera y Piana (1999);

4) en escalas espaciales y temporales amplias, variaciones en el modo e intensidad de uso del espacio costero y de los recursos marinos (Bonomo 2005; Caracotche y Cruz 2008; Orquera y Gómez Otero 2008, entre otros).

Respecto del registro tecnológico, no se disponía hasta el inicio de esta tesis de suficientes elementos de juicio para evaluar su variabilidad y discutirla en el nivel macrorregional debido al desigual desarrollo de las investigaciones a lo largo de toda la costa atlántica. Algunos sectores, como el litoral pampeano y norpatagónico (Bórmida 1964; Sanguinetti de Bórmida et al. 2000; Bonomo 2005; Cardillo y Scartascini 2007; Armentano 2014; Alberti 2013; Apolinaire y Silva 2011; Bayón et al. 2011; Manzi et al. 2011; Alberti y Cardillo 2014) y la costa norte de Santa Cruz (Arrigoni et al. 2008; Castro et al. 2008; Ambrústolo et al. 2009; Ambrústolo 2011 y 2012; Ambrústolo et al. 2012) cuentan con numerosas publicaciones producto de décadas de trabajo y en los últimos años de la aplicación de abordajes diversos y novedosos. En contraste, en otros sectores como Patagonia centroseptentrional y meridional, el desarrollo fue menor. En el área de estudio de esta tesis, si bien hubo análisis tecnológicos en los inicios de la investigación (Gómez Otero et al. 1999), la información derivada de las diferentes tecnologías -lítica, ósea, malacológica y cerámica- se utilizó como proxy para estimar funcionalidad de los sitios arqueológicos, evaluar si hubo especialización en el aprovechamiento de determinados recursos alimenticios y contactos intra y extrarregionales (Gómez Otero 2003, 2006). La única tecnología que desde entonces fue estudiada en profundidad es la cerámica (Schuster 2012). 
En el caso de la tecnología lítica, se carece de datos básicos sobre la base regional de recursos líticos, las estrategias tecnológicas seleccionadas, la representación de las técnicas de laminaridad y bipolaridad, la antigüedad de la técnica de reducción bifacial, el uso de rocas alóctonas, entre otros aspectos. No obstante, la información disponible para el litoral atlántico permitió reconocer algunas semejanzas y diferencias. Las mayores similitudes fueron registradas en el tramo que comprende la costa pampeana (Bonomo 2005; Martínez 2008; Armentano 2014), la costa rionegrina (Cardillo y Scartascini 2007 y 2011; Favier Dubois et al. 2008; Alberti 2013; Alberti et. al. 2014) y la costa norte de la provincia de Chubut (Gómez Otero 1995; Gómez Otero et al. 1999; Gómez Otero et al. 2009).

En función de lo anterior se plantearon los siguientes objetivos:

\section{Objetivos Generales}

Entender los cambios espacio-temporales de la organización de la tecnología lítica en las sociedades cazadoras-recolectoras que habitaron la costa centro-septentrional de Patagonia durante el Holoceno medio y tardío final, y a su vez contextualizar su registro arqueológico dentro de un marco más amplio que incluye la ocupación prehispánica de la costa atlántica pampeana y norpatagónica.

\section{Objetivos Particulares}

1. Caracterizar la estructura regional de recursos líticos (Ericson 1984).

2. Evaluar el grado de intensidad y modos de aprovechamiento de los recursos líticos a través del Holoceno medio y tardío final.

3. Explorar posibles derivados materiales de relaciones sociales a través de la identificación de rocas de procedencia no local.

4. Analizar la estructura y composición de los conjuntos artefactuales líticos -en especial el grupo de la piedra tallada- a través de variables tecno-morfológicas y de diseño estilístico.

5. Identificar las técnicas de reducción y las secuencias de producción en las materias primas más utilizadas.

6. Contextualizar cronológicamente los distintos rasgos tecnológicos, entre los que se destacan la talla bipolar, la técnica de talla bifacial y la laminaridad.

7. Evaluar la incidencia de procesos de formación de sitio sobre la preservación de los conjuntos líticos a través de estudios actualísticos. 
8. Contrastar la información obtenida sobre la organización de la tecnología lítica con el modelo de uso del espacio propuesto por Gómez Otero (2006).

Para el cumplimiento de estos objetivos la investigación se abordó desde el enfoque teórico de la "Organización Tecnológica" (Nelson 1991), que permite analizar la selección e integración de las estrategias que intervienen en la manufactura, uso, transporte y descarte de los instrumentos. Este enfoque a su vez explora la interacción de las decisiones humanas sobre la tecnología con los demás aspectos de la vida social, el uso del espacio y la explotación de recursos alimenticios. Según Nelson (1991) las estrategias tecnológicas se materializan a través del diseño y son la consecuencia de decisiones adoptadas durante las distintas etapas de una secuencia de producción. Según distintos autores, estas elecciones están influenciadas por las estrategias de asentamiento-subsistencia (Binford 1980; Kelly 1995), la clase de tecnología o el requerimiento de las tareas (Bleed 2001; Hayden 1896) y la disponibilidad de materias primas (Ericson 1984; Bamforth 1986; Andrefsky 1995; Franco 2004; Charlin 2009). Este último aspecto -disponibilidad así como la calidad de las rocas para la talla- ha sido el menos explorado en el área de estudio, por lo que el primer paso fue caracterizar la estructura regional de recursos líticos (sensu Ericson 1984).

Si bien desde el enfoque de la organización tecnológica se plantea que el análisis tecnológico no puede desvincularse del contexto más amplio en el cual los artefactos se produjeron, usaron y descartaron, en la práctica se han tenido más en cuenta las variables ecológicas que las sociales (véase síntesis en Bayón et al. 1995; Flegenheimer y Bellelli 2007). A partir de la década de 1990, desde una escala de análisis diferente y con énfasis en la dinámica social (Ingold 1990; Pfaffenberger 1992; Hoffman y Dobres 1999; Schiffer 2004), la tecnología comienza a ser tratada como un fenómeno complejo compuesto por múltiples dimensiones económicas, sociales e ideacionales (Lemonnier 1992). Esto implica integrar en los análisis y discusión tanto a los agentes como a las técnicas y conocimientos -incluso las formas de transmisión social- que trasforman a los materiales en bienes culturales (Bamforth y Finlay 2007; Bettinger y Eerkens 1999; Schiffer y Skibo 1987; Pigeot 1990).

En Argentina, una importante contribución a los estudios sobre fuentes de aprovisionamiento fue realizada por Flegenheimer y Bayón (1999) quienes destacaron la importancia del color de las rocas por sobre otros aspectos utilitarios, en la selección de las materias primas. Otro abordaje novedoso y en relación con la agencia social fue realizado por Politis (1999) quien propuso una serie de expectativas derivadas de la información etnográfica y etnohistórica para visualizar la presencia de niños en el registro arqueológico a partir de características métricas y tecnomorfológicas de los artefactos. En cuanto a los mecanismos de 
adquisición del conocimiento y habilidades técnicas, sobre la base del análisis de variables tecno-morfológicas de bifaces, Salomón Hocsman (2006) discute la presencia de aprendices en un contexto de cazadores-recolectores de Antofagasta de la Sierra (Catamarca) en transición a un modo de vida agro-pastoril. Dado que esta tesis representa el primer estudio sistemático sobre la tecnología lítica en el área de estudio, el tratamiento de variables tales como las formas de transmisión social, las relaciones cotidianas intragrupales, la idenficación de aprendices, grupos de trabajo, intervención de niños, etc., quedara en agenda para estudios posteriores más específicos.

Por último, tal como está consignado en el objetivo 8, se contrasta el modelo sobre uso del espacio costero en el área de estudio planteado por Gómez Otero (2006). En su tesis doctoral la autora discriminó dos grandes unidades de análisis "Península Valdés" y "Fuera de Península Valdés", que a su vez incluyen distintos tipos de costa: de golfo, de mar abierto, de espigas e islas de barrera y el estuario del río Chubut, no incluido en el área de estudio de esta tesis. A partir de sus investigaciones observó que de las dos grandes unidades la que mayor densidad y diversidad arqueológicas mostró fue Península Valdés, en especial las costas de los tres golfos: San Matías, San José y Nuevo (Gómez Otero 2006). Por el contrario, los sectores de mar abierto y de espigas e islas de barrera fueron los que aportaron la señal arqueológica más débil.

A partir de lo anterior construyó la siguiente escala jerárquica de mayor a menor intensidad:

$\left.1^{\circ}\right)$ Estuario del río Chubut

$2^{\circ}$ ) Golfo San Matías (PV)

$3^{\circ}$ ) Golfo San José (PV)

$4^{\circ}$ ) Golfo San Matías oeste (FPV) - Golfo Nuevo (PV)

$5^{\circ}$ ) Golfo Nuevo Sur

$6^{\circ}$ ) Espigas e islas de barrera de Caleta Valdés Caleta Valdés y Punta Ninfas a Bajo de los Huesos.

Gómez Otero (2006) propuso que estas diferencias se deberían a la selección de espacios de ocupación sobre la base de la productividad costera en combinación con la del ambiente terrestre adyacente, la topografía y la oferta de ciertos recursos marinos. En este sentido, los lugares más intensamente utilizados fueron los de mayor accesibilidad al mar y próximos a bancos fijos de moluscos donde además podían obtenerse otros recursos marinos como peces, aves y pinnípedos (Gómez Otero 2006). Su modelo también estableció cambios culturales, en especial a partir del Holoceno tardío, a los que relacionó con un aumento 
demográfico paulatino desde 3000 AP. Entre esos cambios se identificó: disminución de la movilidad residencial, concentración de los grupos en los lugares más favorables, diversificación funcional de sitios, uso de áreas formales de entierro, desarrollo de estrategias "procesadoras" (sensu Bettinger y Baumhoff 1982), intensificación en el consumo de plantas y otros recursos e incremento de los contactos dentro y fuera de la región patagónica y aumento de la complejidad social.

\section{Hipótesis}

En función de estos antecedentes se proponen las siguientes hipótesis:

$\boldsymbol{H}_{1}$ La disponibilidad y abundancia de materias primas líticas en el área de estudio habria propiciado el aprovechamiento prioritario de las fuentes secundarias locales y predominio de tecnologías de tipo expeditivo (Binford 1980 y Nelson 1991).

$\boldsymbol{H}_{2}$ El tamaño reducido de los rodados habría fomentado la utilización frecuente de la talla bipolar.

$\mathrm{H}_{3}$ En tiempos tardios se habría incrementado el intercambio de rocas y diseños artefactuales con otras áreas fuera y dentro de Patagonia.

$\boldsymbol{H}_{4}$ Las similitudes entre la tecnología lítica del área de estudio y la costa pampeana y norpatagónica se deben a las limitaciones impuestas por el tamaño y la forma en que se presenta la materia prima. 


\section{Estructura de la Tesis}

El presente trabajo de tesis está estructurado en 9 capítulos. En el primer capítulo (INTRODUCCIÓN) se realiza una breve contextualización de los estudios y modelos propuestos sobre el uso del espacio en las costas de la región pampena y patagónica, y se enuncia el marco teórico desde el que se lleva a cabo la investigación. A continuación se plantean los objetivos y las hipótesis de trabajo.

En el Capítulo 2 (ESTADO DE LA CUESTIÓN) se describe la localización y características ambientales del área de estudio. Se detalla el ambiente actual asi como también los aspectos paleambientales interactuantes.

En el Capítulo 3 (ANTECEDENTES DE INVESTIGACIÓN) se explonen los resultados de las investigaciones realizadas en las costas pampenas y patagonícas en relación con la antigüedad de las ocupaciones, el uso del espacio, la dieta y la tecnología. Posteriormente se realiza una síntesis sobre el estado actual de estos estudios en una escala espacial amplia.

En el Capítulo 4 (CONSIDERACIONES TEÓRICO METODOLÓGICAS) se desarrollan los lineamientos teórico-metodológicos que guiaron el estudio. A continuación se describen las unidades espaciales de análisis y los métodos -de campo y de laboratorioempleados. En primer lugar se detalla la metodología utilizada para la caracterización de la base regional de recursos líticos y a continuación los criterios seleccionados para el estudio tecnológico de los conjuntos artefactuales.

En el Capítulo 5 (CARACTERIZACIÓN DE LA BASE REGIONAL DE RECURSOS LÍTICOS) se dan a conocer los resultados alcanzados en relación con la disponibilidad de materias primas líticas. Se detallan los muestreos sistemáticos realizados en las dos unidades de muestreo. Por último se presentan los resultados del análisis de secciones delgadas de rocas y se comparan las determinaciones litológicas macroscópicas y microscópicas.

En el Capítulo 6 (TAFONOMÍA LÍTICA) se presenta los resultados del estudio actualíticos sobre pistas experimentales líticas sembradas en distintas geoformas del área de estudio. Se informa sobre las observaciones y controles tafonómicos realizados a la fecha. 
En el Capítulo 7 (CARACTERIZACIÓN TECNOLÓGICA DE LA UNIDAD DE ANÁLISIS PENÍNSULA VALDÉS) se exponen los resultados tecnológicos de los muestreos sistemáticos efectuados en la unidad.

En el Capítulo 8 (CARACTERIZACIÓN TECNOLÓGICA DE LA UNIDAD DE ANÁLISIS FUERA DE PENÍNSULA VALDÉS) se presentan los resultados tecnológicos de los muestreos sistemáticos efectuados en la unidad.

En el Capítulo 9 presenta la DISCUSIÓN y las CONCLUSIONES FINALES.. 


\section{CAPÍTULO 2}

\section{ESTADO DE LA CUESTIÓN}

\section{El área de estudio}

El área de estudio abarca el sector de la costa centro-septentrional de Patagonia comprendido entre la desembocadura del arroyo Verde al norte $\left(41^{\circ} 59^{\prime} 44,63^{\prime \prime} \mathrm{S}\right.$ y $65^{\circ} 44^{\prime} 4,19^{\prime \prime}$ O) y Bahía Cracker (4257'0.69"S y 64²8'47.87"O) al sur (Fig. 2.1). En esta tesis se consideró el concepto de costa definido por Gómez Otero (2006: 13-14) como "el espacio comprendido entre el límite de las bajas mareas y las cabeceras de la escorrentía temporaria superficial".

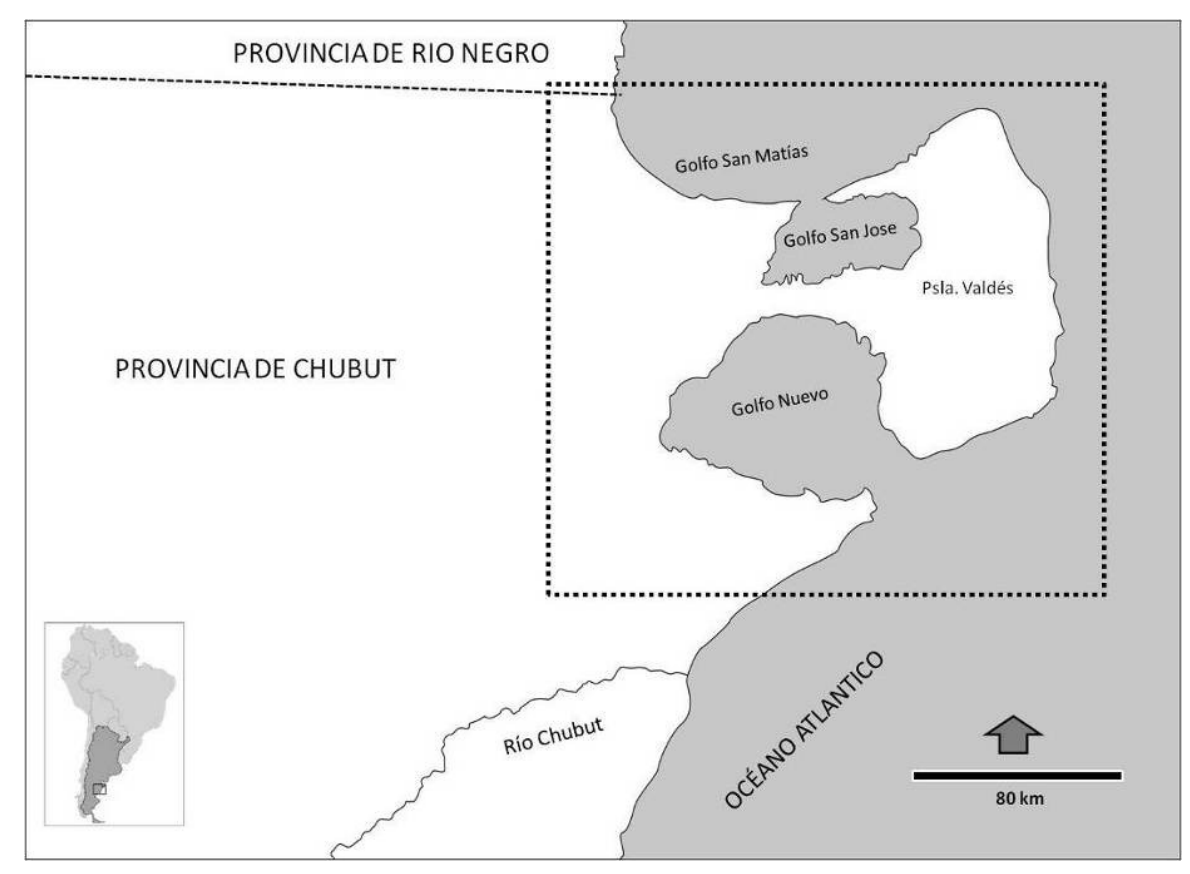

Fig. 2.1. Ubicación geográfica del área de estudio.

\section{Geología y geomorfología}

El paisaje costero se caracteriza por mesetas que apenas superan los 100 m s.n.m., disectadas por cañadones o cárcavas de régimen transitorio, cuyas cabeceras pueden encontrarse a varios kilómetros hacia el interior del continente (Súnico 1997). Series de cordones litorales, paleoacantilados y antiguas planicies de marea reflejan las oscilaciones isostáticas, eustáticas y la tectónica durante el Pleistoceno y el Holoceno (Codignotto et al. 1992; González y Weiler 1994; Monti 1997; Rutter et al. 1989). Este sector se distingue por presentar tres tipos de costa: 1) la de los golfos San Matías, San José y Nuevo (dentro y fuera de península Valdés); 2) la de espiga e islas de barrera de caleta Valdés y 3) la de mar abierto entre punta Ninfas y punta León (Fig. 2.1). En distintos puntos del perímetro costanero, tanto sobre la cima de los acantilados 
como sobre cordones litorales en antiguas bahías interiores, se desarrollan relieves dunarios, compuestos en su mayor parte por dunas transversales con crestas sinuosas y redondeadas (Súnico 1997). Es común que la zona de anteplaya presente importantes secuencias de médanos fijos que, en algunos sectores deflacionados, avanzan sobre las bajadas pudiendo alcanzar los niveles superiores de las mesetas. Una característica importante para la vida humana es la ausencia de fuentes permanentes de agua dulce, con excepción de los manantiales de las salinas Grande y Chica, de posición central en la península Valdés (Fig.2.2).

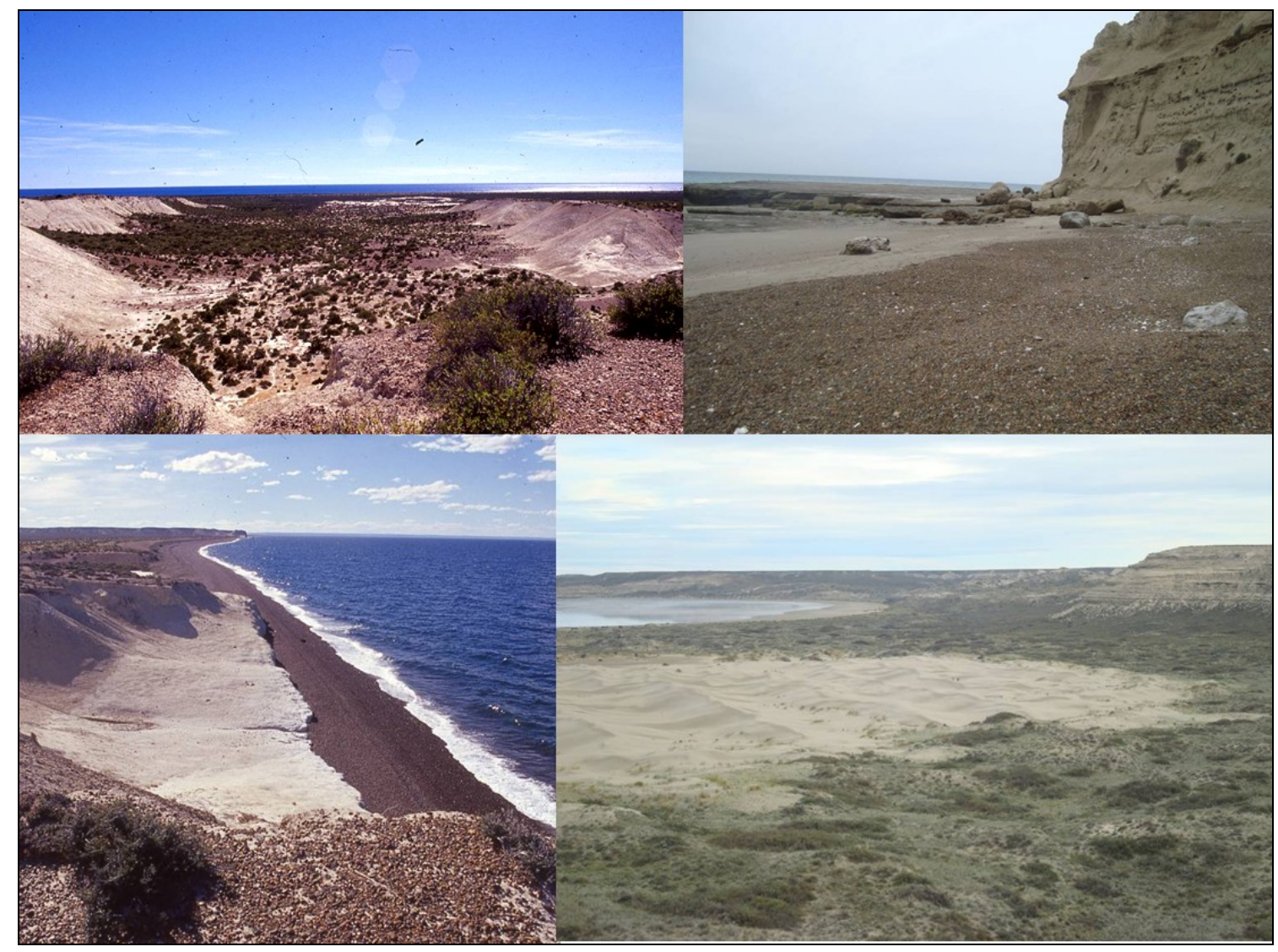

Fig. 2.2. Geomorfología área de estudio.

La geología del área es simple, ya que predominan las rocas sedimentarias de edad terciaria y cuaternaria (Haller 1981); no obstante, la oferta de materias primas líticas para la talla es abundante: hay una única fuente primaria (Fm Marifil) y tres secundarias (Fm. Caleta Valdés, Fm. Rodados Patagónicos y Fm. San Miguel). También hay abundancia de fuentes de materiales arcillosos y de lajas de areniscas consolidadas (Fm. Puerto Madryn y Fm. Gaiman). Estas formaciones geológicas se describen brevemente a continuación:

Fm. Marifil (Malvicini y Llambías 1974): Triásico superior y Jurásico medio, origen volcánico. Se localiza en el norte del área de estudio -zona de Arroyo Verde, en el golfo San 
Matías oeste- a unos $60 \mathrm{~km}$ de distancia de la ciudad de Puerto Madryn (Chubut). Hacia el sur aflora en la zona de punta Clara, a $1500 \mathrm{~km}$. aproximadamente desde Puerto Madryn. Lo integran vulcanitas (ignimbritas, tobas silíceas y riolitas) y epiclastitas subordinadas (tobas y brechas). Massaferro y Haller (2000) identificaron vetas de cuarzo blanquecino de aspecto bandeado asociadas a esta formación. Algunos de sus componentes estructurales son chert silíceo rojizo y texturas de recristalización de calcedonia y de calcita laminar. En playas cercanas a Arroyo Verde, como Puerto Lobos, se registraron tabletas de calcedonia.

Fm. Gaiman (Haller 1981): Eoceno superior y Oligoceno, originada en un ambiente depositacional. Se registra en el valle del río Chubut; el bajo Simpson y los golfos San José y Nuevo. La componen pelitas cineríticas con delgadas intercalaciones de areniscas y fósiles e improntas mal conservadas de bivalvos y gasterópodos.

Fm. Puerto Madryn (Haller 1981): Mioceno (ciclos marinos Entrerriense y Rionegrense). Se localiza en las terrazas del río Chubut y en los acantilados de península Valdés. Está integrada por bancos de areniscas consolidadas y pelitas con abundantes fósiles de moluscos marinos (del Río 1988, 1990, 1991, 1992 y 1994, citado en Haller et al. 2001).

Fm. Rodados Patagónicos (Fidalgo y Riggi 1970): Plio-Pleistoceno, origen glaciofluvial. La conforman espesos mantos de gravas redondeadas de tamaños variables (de 3 a $15 \mathrm{~cm}$ ), que cubren terrazas, cañadones y zonas bajas. Las litologías predominantes son vulcanitas ácidas (riolitas y andesitas) y rocas basálticas de matriz arenosa.

Fm. Caleta Valdés (Roveretto, 1921): Pleistoceno superior, origen marino. Rodados grandes de granitos, granodioritas, areniscas, cuarcitas, andesitas, riolitas y pastas silicificadas y basaltos de variadas calidades tamaño guija y guijón, concentrados entre Caleta y Punta Norte.

Fm. San Miguel (Haller 1981): Holoceno medio, origen marino. Incluye los cordones litorales ubicados entre 5 y 8 m s.n.m. Tiene una amplia distribución en distintos sectores del perímetro costero y está compuesta por gravas de hasta $6 \mathrm{~cm}$ de variadas litologías (granitos; cuarcitas; andesitas; riolitas; silíces y basaltos) y conchillas muy fragmentadas en matriz arenosa.

\section{Clima}

En el área de estudio predomina el clima templado semiárido, con temperaturas medias anuales de $12^{\circ} \mathrm{C}$ a $13^{\circ} \mathrm{C}$. Se distingue por la baja cuantía de las precipitaciones y la acción de fuertes vientos que soplan preferentemente desde el cuadrante oeste, aunque son también 
importantes los del cuadrante norte. La zona más lluviosa corresponde a los bordes oeste, sur y este de la península -225 a $250 \mathrm{~mm}$ anuales- mientras en el resto del área de estudio el promedio es de $175 \mathrm{~mm}$. En comparación, a igual latitud las mesetas interiores presentan valores medios anuales de 100 a $150 \mathrm{~mm}$. La variabilidad interanual en las precipitaciones es muy marcada, alcanzando los valores más elevados de todo el Chubut. Si bien hay un leve incremento de las lluvias en el semestre frío -abril a septiembre- (Beeskow et al. 1987), en verano son frecuentes los episodios de lluvias cortas pero torrenciales con gran acción erosiva. La mayor frecuencia de los vientos se registra en primavera y verano, mientras el invierno es la estación menos ventosa. Con respecto a la velocidad media anual, el Servicio Meteorológico Nacional registró 16,4 km/h para punta Delgada y 25,9 km/h para Trelew (Período 1971-1980). Predominan los vientos del oeste, aunque son también frecuentes los del norte y del este (brisa marina) (Beeskow et al. 1987). El efecto del enfriamiento por el viento es de aproximadamente $3^{\circ} \mathrm{C}$ en invierno y $4^{\circ} \mathrm{C}$ en verano.

El área de estudio es pobre en fuentes de agua dulce. Las de carácter perenne están constituidas por el río Chubut y por los manantiales que alimentan las salinas Grande, Chica y el Gran Salitral (ver acápite sobre Geomorfología, más abajo); las transitorias corresponden a las que dependen de las lluvias -como lagunas en general de tamaños chicos- y al arroyo Verde. En las épocas lluviosas estas fuentes temporarias pueden permanecer varios días con agua. Por otra parte, precipitaciones torrenciales de verano pueden producir la filtración de agua de lluvia a través de grietas en los estratos del Terciario de la Formación Puerto Madryn.

\section{Flora y fauna}

Las especies florísticas representadas y de mayor distribución corresponden a las regiones fitogeográficas del Monte y Patagónica, con presencia de matorral y estepa arbustiva (Coronato y Vallejo 1994). Estos estratos ofrecen variadas especies cuyas raíces, tubérculos, semillas o frutos pueden ser comestibles. Los datos etnográficos obtenidos tanto por viajeros y exploradores durante los siglos XVI y XX, así como los registros actuales en comunidades rurales de la provincia de Chubut indican el uso de diversas plantas con distintos fines, entre ellos los alimenticios (véase Ochoa y Ladio 2011 y Jardín Botánico de la Patagonia Extrandina 2002: 38). Las principales plantas con partes comestibles son el piquillín (Condalia microphilla), el macachín (Arjona tuberosa), cactáceas (géneros Opuntia y Maihueniopsis) y dos variedades de algarrobo: el alpataco (Prosopis alpataco) y el algarrobillo (Prosopis denudens). La mayoría de estas especies ofrecen raíces, frutos o vainas que están disponibles entre primavera y fines del verano.

La fauna terrestre del área corresponde a la Región Neotropical, distrito Patagónico, subdistrito Septentrional (Cabrera y Yepes 1960). Entre los principales recursos terrestres se 
encuentran el guanaco (Lama guanicoe), el choique (Pterocnemia pennata), la mara (Dolichotis australis), dos géneros de armadillos (Zaedyus y Chaetophractus), el zorro gris (Canis griseus), el zorro colorado (Pseudalopex culpeus), gatos monteses (Felis guigna, Felis geoffroyi), ocasionalmente el puma (Felis concolor) y variedad de micromamíferos.

La fauna marina es variada y comprende diversidad de moluscos, peces, aves medianas y mamíferos. La fauna malacológica corresponde a las Provincias Argentina y Magallánica que convergen en la zona de la península Valdés (Escofet et al. 1978). Las características geomorfológicas y topográficas ofrecen sustratos arenosos, fangosos y rocosos para el crecimiento de una gran variedad de especies aptas para el consumo humano. Entre las especies malacológicas se encuentran lapas (familias Patellidae y Fissurellidae), trofones (género Trophon), volutas (géneros Adelomelon y Odontocymbiola), nasas (género Buccinanops), vieiras (Chlamys tehuelcha), almejas (Venus antiqua, Eurhomalea exhalbida), navajas de mar (Ensis macha), mejillones (Mytilus edulis), cholgas (Aulacomya ater) y mejillínes (Brachidontes spp.) (Lasta et al. 1998; Ciocco et al. 1998). Las playas del intermareal ofrecen crustáceos como cirripedios (Balanus y Megabalanus), varias especies de cangrejos (Ovalipes trimaculatus y Platyxanthus patagonicus, Chasmagnatus granulata, Cirtograpsus angulatus y Cirtograpsus altimanus entre otros) y dos especies de erizos (Arbacia dufresneii y Pseudechinus magallanicus). Con respecto a los peces, en las costas continentales pueden obtenerse pejerreyes (Odontesthes sp.), meros (Acanthistius brasiliensis), róbalos (Eleginops maclovinus), salmones de mar (Familia Pinguipedidae), abadejos (Genypterus blacodes) y congrios (Congridae sp.) (Bellisio et al. 1979). Las principales aves marinas están representadas por el pingüino de Magallanes (Spheniscus magallanicus), los cormoranes (Phalacrocorax spp.), los albatros (Fam. Diomedidae) y las gaviotas (Fam. Laridae). En primavera y verano también llegan a la zona flamencos (Phoenicopterus chilensis) y anátidos, en especial cisnes y patos. Los grandes mamíferos marinos son lobos marinos de un pelo (Otaria flavescens), los elefantes marinos (Mirounga leonina), las ballenas franca austral (Eubalaena australis) y diversos géneros de delfines (Cephalorhynchus commersonii y Orcinus orca, entre otros). A través de la arqueología se ha podido determinar la disponibilidad en el pasado del lobo peletero o de dos pelos (Arctocephalus autralis) en distintos puntos del área (Gómez Otero 2006).

\section{Variaciones paleoambientales}

Con respecto a la dinámica costera, en el área de estudio se registraron comportamientos diferentes: la costa oeste del golfo San Matías presenta rasgos de madurez: la relación erosiónacreción estaría indicando condiciones generales de estabilidad. Según Gelos y otros (1994), a partir del Pleistoceno tardío y del Holoceno se acentúa un proceso de continentalización caracterizado por depósitos de arena, gravas y conchillas en forma de cordones y acumulaciones eólicas; para épocas recientes y actuales se observó acentuación de los procesos eólicos. La 
costa sudoeste del golfo San José se destaca por la formación de espigas de barrera y albuferas vinculadas con episodios de nivel marino relativamente elevado ocurridos durante el Holoceno. Entre las cotas de seis y diez metros sobre el nivel del mar, se reconocieron tres sistemas de espigas que cubren un rango temporal entre 6000 años AP y 1000 años AP (Weiler 1998). La zona de caleta Valdés presenta los depósitos elevados más significativos de acreción marina de la costa norte del Chubut. De acuerdo con Monti (1997), los rasgos y depósitos asociados son el resultado de fases marinas regresivas iniciadas aproximadamente entre los $6500 \mathrm{AP}$ y los 7000 años AP, con un nivel del mar entre ocho y diez metros sobre el actual. Los patrones de acreción corresponden a extensas acumulaciones de cordones litorales de gravas que conforman unidades morfológicas mayores, tales como terrazas marinas de acumulación, paleoespigas y espigas actuales de diversa clase y dimensiones. Delimitados y protegidos por los distintos grupos de cordones, se reconocen ambientes semi-rrestringidos correspondientes a una albufera activa. Entre punta Norte y caleta Valdés se identificaron y dataron numerosos cordones litorales (Codignotto 1983; Codignotto y Kokot 1988; Monti y Codignotto 1994). Codignotto (1983) dio a conocer edades C14 de 1330 AP, 4180 AP, 5100 AP y 5720 AP. Por último, Bahía Engaño en la desembocadura del río Chubut, es una amplia paleobahía labrada sobre sedimentitas terciarias y colmatada luego por depósitos marinos elevados que son el resultado de fases regresivas con un nivel del mar que fluctuó entre dos y tres metros desde el Holoceno medio al tardío (Monti 2000). El curso actual del río atraviesa gran parte de los depósitos litorales y separa la bahía en dos sectores de acreción: uno de gran desarrollo areal al norte y otro marcadamente más restringido al sur. Morfoestratigráficamente corresponde a una secuencia sedimentaria caracterizada por sistemas de cordones separados por discordancias producidas por ciclos de acreción y pulsos de erosión o no depositación. Monti (2000) identificó tres sistemas mayores de cordones entre los que se intercalan paleoalbuferas actualmente no funcionales $\mathrm{y}$ parcialmente cubiertas por depósitos eólicos. De acuerdo con cuatro dataciones de restos malacológicos, el último pulso de erosión habría ocurrido entre los 3900 años AP y los 3200 años AP. A partir de entonces se produjo sin interrupciones notorias, un prolongado ciclo de acreción cordoniforme, con una velocidad de progradación de $39 \mathrm{~cm} /$ año (Monti 2000) (Mapa 9 - Anexo).

Desde el punto de vista de la ocupación humana en el pasado, las variaciones locales en las líneas de costa habrían significado:

- mayor disponibilidad de espacio en las costas donde se produjo acreción;

- pérdida de espacio en las costas donde se produjo erosión;

- aumento de la productividad primaria en las costas donde se formaron albuferas y espigas. 


\section{CAPÍTULO 3}

\section{ANTECEDENTES DE INVESTIGACIÓN}

En los últimos años la arqueología del litoral atlántico pampeano y patagónico creció de manera notable, no sólo en lo que respecta a la cantidad de sectores bajo estudio y a los grupos de investigación involucrados, sino también en cuanto a la amplitud de abordajes teóricos y métodos aplicados (véase síntesis en Orquera y Gómez Otero 2008). No obstante, la revisión del estado actual de las investigaciones (véase abajo) muestran que no hay un criterio consensuado en cuanto a la definición de la costa. Por ejemplo, en algunos equipos se utiliza un límite arbitrario, de entre 3 a $10 \mathrm{~km}$ de ancho desde la línea actual de marea (Bonomo 2005; Arrigoni et al. 2008) y en otros casos se define por rasgos geomorfológicos y fitogeográficos (Castro et al. 2008). Por fuera de los límites de influencia del área de estudio, Lanata y Borrero (1988) establecieron como límite costero para el litoral atlántico de Tierra del Fuego la distribución del recurso moluscos, que no supera $10 \mathrm{~s} 10 \mathrm{~km}$ de la línea de marea.

\section{Estado de las investigaciones arqueológicas en la costa pampeana y patagónica: conocimiento actual y modelos arqueológicos}

En el litoral pampeano se destacan los estudios emprendidos por Mariano Bonomo (2005) a lo largo de la costa del área Interserrana, y en el sector sudoccidental los efectuados por Cristina Bayón y Gustavo Politis en la localidad Monte Hermoso (Politis y Bayón 1996; Politis et al. 2009; Bayón et al. 2011). Para el sector transicional pampeano-patagónico, específicamente el curso inferior del río Colorado, Gustavo Martínez y equipo iniciaron a mediados del 2000 trabajos sistemáticos en este sector de ecotono (Martínez 2004, 2008-9). En Patagonia septentrional, Amalia Sanguinetti de Bórmida impulsó a fines de los años noventa un proyecto de carácter regional en la bahía de San Blas (Sanguinetti de Bómida et al. 1999, 2000), liderado en la actualidad por Emilio Eugenio y Verónica Aldazabal (Eugenio et al. 2011), y en la costa norte y oeste del golfo San Matías (provincia de Río Negro), desde el 2003 trabaja un equipo coordinado por Florencia Borella y Cristian Favier Dubois (Dubois et al. 2008, 2009). En el litoral de de Patagonia central, desde la década de los noventa se llevan a cabo de manera continua y creciente investigaciones en distintos espacios marítimos: Julieta Gómez Otero se focalizó en el estudio de la Península de Valdés y la costa centro-septentrional de Patagonia (Gómez Otero 1995; Gómez Otero 2006) y Gloria Arrigoni en el golfo San Jorge (Arrigoni et al. 2008). En Patagonia meridional las investigaciones son encabezadas por Alicia Castro y 
Eduardo Moreno en la costa norte (Castro y Moreno 2000; Castro et al. 2008); por el equipo de Soledad Caracotche e Isabel Cruz en Monte León (Caracotche et al. 2005, 2008); por Estela Mansur en la margen norte de la desembocadura de río Gallegos-Punta Bustamante (Mansur 2004; Mansur 2008), en la margen sur (Punta Loyola) Flavia Carballo Marina y Bettina Ercolano, y en Cabo Vírgenes, Luis Alberto Borrero y equipo (Borrero et al. 2008) (Fig. 3.1). En poco más de veinte años de estudios arqueológicos continuos y sistemáticos pocos espacios costeros quedan sin explorar. La cuantiosa información generada y la elaboración de modelos novedosos permiten integrar y discutir en escalas espaciales amplias la variabilidad sobre los modos de uso del espacio costero, la historia ocupacional y la adaptación de los grupos humanos en estos ambientes.

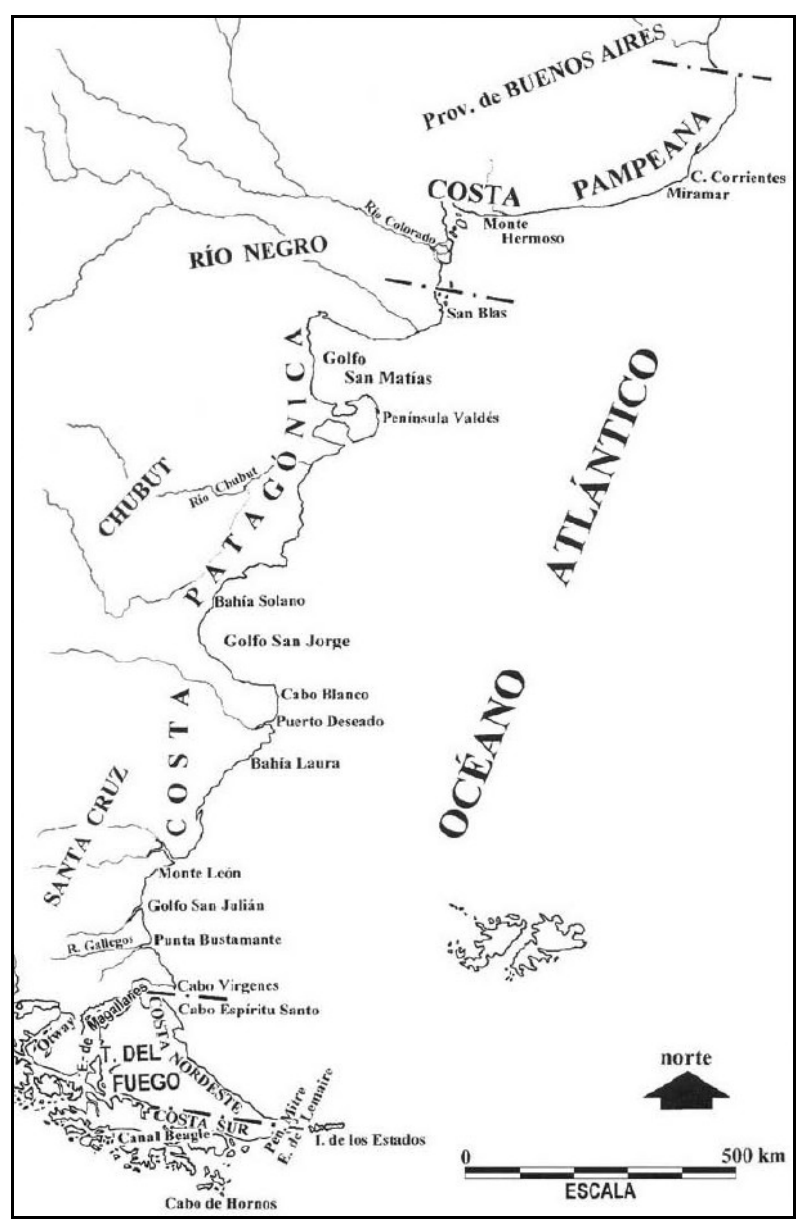

Fig. 3.1. Sectores costeros y localidades arqueológicas de la costa pampeana y patagónica mencionados en el capítulo. Tomado y modificado de Orquera y Gómez Otero (2008).

Los avances en el conocimiento de las costas pampeanas y patagónicas se produjeron a partir de la adopción de los principios sistémicos y procesuales introducidos en la arqueología argentina a fines de la década de los setenta (véase síntesis en Politis 1988 para Pampa y Borrero y Orquera y Gómez Otero 2008 para la Patagonia). La incorporación de estos enfoques 
en los estudios arqueológicos regionales permitió refutar y superar los modelos que los dos máximos representantes de la Escuela Histórico-Cultural de Viena, Osvaldo Menghín y Marcelo Bórmida, formularon para explicar el poblamiento y la evolución cultural desde entonces (Menghín 1952, 1963; Menghín y Bórmida s.f; Bórmida 1964, 1969). En primer lugar se demostró la ausencia de evidencias de adaptaciones marítimas (sensu Lyman 1984 y Orquera y Piana 1999) y la presencia de ocupaciones costeras desde por lo menos fines del Pleistoceno e inicio del Holoceno medio en Pampa (Politis y Bayón 1996; Politis et al. 2009); desde el Holoceno medio en Norpatagonia (Eugenio y Aldazábal 2004; Favier Dubois et al. 2009), Patagonia central (Gómez Otero 2006; Gómez Otero et al. 2013; Castro y Moreno Castro et al. 2004; Zubimendi et al. 2009), entre la desembocadura del río Santa Cruz y Monte León (Cruz et al. 2008; Muñoz et al. 2009) y Holoceno tardío en Punta Bustamante (Mansur 2008), Punta Loyola (Carballo y Ercolano 2008) y Cabo Vírgenes (Borrero et al. 2008). No obstante, es muy probable que las variaciones del nivel marino a partir del Holoceno hayan dejado bajo el mar evidencias de ocupaciones anteriores (2008). Se reconoció además diversidad intra e interregional en cuanto a la intensidad de uso del espacio costero y de sus recursos (2008). Por último, se comprobó la utilización de la costa por grupos humanos no diferentes étnicamente a los del interior, ni tecnológicamente "más primitivos" (Bonomo 2005; Gómez Otero 2006; Orquera y Gómez Otero 2008). En síntesis, los recientes avances en la arqueología del litoral atlántico pampeano-patagónico muestran que las poblaciones humanas habitaron estos entornos marinos y explotaron sus recursos con distinto grado de intensidad: desde cazadores del interior que ocuparon ocasionalmente la costa (Bonomo 2005, 2011) a poblaciones totalmente adaptadas a estos ambientes y sus recursos (Orquera y Gómez Otero 2008).

A continuación se describe de manera sucinta el conocimiento arqueológico sobre el uso del espacio según los distintos sectores costeros.

\section{Costa pampeana}

En lo que respecta al tipo e intensidad de uso de la costa pampeana, las investigaciones indicaron que a principios del Holoceno medio algunos grupos la utilizaron de manera intensiva (Politis y Bayón 1996; Politis et al. 2009; Bayón et al. 2011). Estudios arqueofaunísticos y análisis isotópicos de muestras óseas humanas datadas en el Holoceno temprano a medio mostraron que en ese período los recursos litorales de alto nivel trófico (principalmente pinnípedos) eran importantes en la dieta (Politis et al. 2009; Bonomo y León 2010). Se comprobó además que el consumo de fauna marina disminuyó hacia el Holoceno tardío, mostrando para este período una tendencia hacia la continentalización de la dieta (principalmente guanaco, y en menor frecuencia venado y ñandú) (Bonomo et al. 2012). Se propuso que desde la transición Pleistoceno-Holoceno la costa habría sido utilizada de manera 
oportunista, estacional o esporádica por grupos del interior que la incluyeron dentro de sus circuitos anuales de movilidad (Bonomo 2005). Esto estaría avalado por la presencia de rodados de origen costero y moluscos marinos en los sitios tempranos del interior pampeano. Por último y a diferencia de otros sectores de Patagonia continental no se identificaron acumulaciones antrópicas de invertebrados ("concheros") por lo que se infiere que su aprovechamiento fue ocasional y/o con fines tecnológicos y simbólicos (Bonomo 2007).

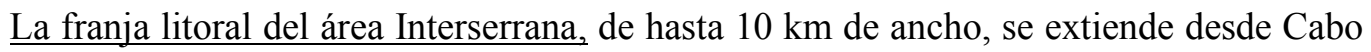
Corrientes hasta la desembocadura del río Quequén Salado. Se determinó mayor densidad artefactual en las costas altas con barrancas, y menor en las costas bajas (Bonomo 2005). En los sitios detectados en la faja de dunas (sitios Mar del Sur, Moromar, Arenas verdes 1 y 3, Faro Guaraní, Caracolero y las localidades La Eufemia y Bellamar,) predominan los desechos de talla y los núcleos, en baja frecuencia se hallaron artefactos formatizados por talla, yunques y percutores. Las materias primas más utilizadas provienen de rodados marinos de rocas ígneas, principalmente basaltos, que ofrecen los abundantes depósitos secundarios locales (Bonomo y Prates 2014). En baja proporción se registraron cuarcitas de la Fm. Sierras Bayas ubicada a 150 $\mathrm{km}$ de distancia y escasos artefactos de obsidiana, cuya procedencia es desconocida (Bonomo 2005:156). En todos los grupos artefactuales se observaron índices de corteza elevados, el predominio de módulos medianos alargados, la aplicación frecuente de la técnica de talla bipolar y la producción, a partir de lascas bipolares y primarias de ciertos instrumentos: raederas, filos de bisel asimétrico, raspadores, cuchillos y artefactos retocados sobre núcleos bipolares (Bonomo 2005). Estas evidencias fueron relacionadas con la presencia de ocupaciones estacionales y de corta duración, durante las cuales se desarrollaron tareas específicas: la explotación de recursos marinos (pinnípedos) y terrestres (guanaco) y la talla in situ de rocas locales mediante reducción bipolar (Bonomo 2005, 2011). Hacia el interior del cordón de médanos (localidades arqueológicas La Estafeta, Residencias y sitio Playa Las Palomas) se registró una mayor diversidad artefactual que incluye materiales de molienda y recipientes de cerámica, el predominio de ortocuarcitas del Grupo Sierras Bayas y en menor frecuencia rodados marinos y ftanita. Estos contextos fueron asociados con campamentos temporarios y/o con sitios de tareas específicas (matanza y procesamiento de presas). En las llanuras adyacentes (localidades arqueológicas Nutria Mansa y Claromecó), por el contrario, se detectaron sitios extensos y mayor densidad y diversidad artefactual, asociados con bases residenciales (Bonomo 2005, Bonomo et al. 2008; Matarrese 2015). Entre las materias primas identificadas sobresale el uso de cuarcitas, representadas en núcleos activos, desechos e instrumentos tallados de tamaños grandes. También se recuperaron numerosos artefactos picados y/o abradidos (morteros, molinos, manos, bolas de boleadoras y percutores) y cerámica (Bonomo 2005; Bonomo y Matarrese 2012). Dada la ausencia de diferencias entre los contextos arqueológicos de la costa y 
del interior adyacente Bonomo $(2005,2006)$ propuso que las similitudes observadas son el resultado de una identidad compartida producto de relaciones históricas y regulares entre poblaciones que ocuparon ambos ambientes al menos durante el Holoceno medio y tardío.

\section{Sector transicional pampeano-patagónico}

Para la costa del estuario del río Colorado, se cuenta con las investigaciones de la localidad arqueológica de San Antonio, ubicada a $4 \mathrm{~km}$ de la línea actual de marea (Martínez 2008-2009; Martínez et al. 2010; Martínez y Martínez 2011; Stoessel et al. 2008; Stoessel 2012). La componen seis sitios arqueológicos en superficie y estratificados, que en su conjunto aportaron materiales faunísticos, líticos y cerámica. Los fechados realizados probaron la ocupación humana desde ca 1000 hasta 800 años AP (Martínez et al.2009). Estudios arqueofaunísticos determinaron el aprovechamiento mayoritario de especies marinas: peces (bagre de mar y corvina) y moluscos; en menor proporción se registró el consumo de recursos fluviales (perca) y terrestres (guanaco) (Martínez et al. 2010 y Stoessel 2012). En cuanto a la tecnología se determinó que fueron seleccionadas las rocas locales de mejor calidad disponibles en forma de rodados: sílices y calcedonias. En menor frecuencia se registran basaltos, andesitas y cuarcitas de Sierras de Ventania (a $200 \mathrm{~km}$ aproximadamente) y solamente tres artefactos en obsidiana, cuya fuente de procedencia es aún desconocida (Armentano 2014). En los conjuntos artefactuales predominan los desechos de talla, destacándose los relacionados con el mantenimiento y el reavivado de instrumentos. Dada la ausencia de núcleos, se infiere que las rocas ingresaron en un estado avanzado de explotación (Armentano 2014). Los instrumentos más característicos son las puntas de proyectil apedunculadas de tamaño pequeño y los raspadores frontales (Martínez 2008-09, Armentano 2014). Sobre la base de estas evidencias y marcadores de estacionalidad, los autores infieren la ocupación de la costa durante el periodo estival, con énfasis en la explotación de recursos marinos (principalmente peces y moluscos). Por último, en cuanto al papel de la costa en el modelo de uso del espacio para el curso inferior del río Colorado durante el Holoceno tardío, Martínez (2008/2009) propone que a partir del 1000 AP tuvo lugar una importante reorganización conductual y cambios en el uso del espacio, la dieta y la tecnología en el marco de un proceso caracterizado por una intensa dinámica poblacional y contactos e interacciones sociales con grupos de áreas y regiones aledañas (Martínez 2008/2009). En este sentido, el curso inferior del río Colorado habría funcionado como "frontera laxa" a través de la cual circulaban personas, ideas y objetos (Martínez 2008/2009).

\section{Costa septentrional de Patagonia}

Los estudios en la bahía San Blas (entre el sector norte de la isla Jabalí hasta la estancia La Noria), mostraron que este sector fue ocupado a partir del 5000 AP cuando se inicia el 
descenso del nivel mar luego de la máxima transgresión (Weiler 1993), y que los recursos marinos se usaron reiteradamente hasta ca. 500 AP (Sanguinetti de Bórmida 1999; Sanguinetti de Bórmida et al. 2000; Eugenio y Aldazábal 2004). Se observó una concentración de concheros de escasa potencia en las proximidades de lagunas costeras y entre relieves dunarios sobre cordones litorales holocénicos muy próximos a la línea de costa actual (Sanguineti et al. 2000; Eugenio y Aldazábal 2004). En los conjuntos arqueofaunísticos hay presencia de recursos marinos (moluscos, peces y pinnípedos) y terrestres (guanacos y pequeños mamíferos como mara, armadillos y vizcacha). En todos los muestreos predominan los pinnípedos (Eugenio y Aldazábal 2004). Las ocupaciones presentan estacionalidad de primavera-verano, aunque no se descarta el uso anual de la costa. Las principales rocas seleccionadas son de origen local: rodados marinos de basalto y en menor frecuencia sílices. Los núcleos predominantes son los de lascados aislados y los bipolares; unos pocos se encuentran agotados. Se registraron lascas de distintos tipos (primarias, secundarias, bipolares y angulares) y tamaños (de grandes a microlascas), la gran mayoría asociadas con actividades de talla y retalla. En los instrumentos sobresalen los raspadores, las raederas, las puntas de puntas triangulares pequeñas apedunculadas. Otros subgrupos frecuentes son los cuchillos, los denticulados, y los filos y puntas naturales con rastros complementarios (Eugenio y Aldazábal 2004). Nami (2000) destaca la gran variabilidad morfológica de los núcleos y la presencia de numerosos bifaces. El registro de puntas de proyectil reactivadas y evidencias de estadios iniciales de manufactura permiten inferir que, entre otras actividades, se llevó a cabo la producción de cabezales líticos y/o el recambio o reparación de artefactos bifaciales. En cuanto a los artefactos relacionados con la obtención de recursos marinos, en el sitio Piche 1 se recuperó un peso de red. No se observan cambios significativos en el instrumental lítico a lo largo del tiempo y la cerámica aparece en la zona hacia 2000 AP (Eugenio y Aldazábal 2004). En síntesis las evidencias fueron relacionadas con campamentos residenciales de ocupación breve donde se llevaron a cabo tareas de manufactura de artefactos y procesamiento y consumo de recursos faunísticos.

La costa del golfo San Matías, entre el balneario El Cóndor y Puerto Lobos, se divide en los sectores norte y oeste según la orientación de la costa. Los estudios indican que fue poblada entre 6000 AP y 400 años AP, con variaciones espaciales y temporales en la intensidad y continuidad en el uso del espacio y sus recursos (Favier Dubois et al. 2008). En el sector norte se registró la mayor cantidad, variedad de sitios y diversidad artefactual, en especial hacia el Holoceno tardío, en contraste con el sector oeste donde la señal arqueológica es más débil y predominan los sitios chicos con baja diversidad artefactual y faunística. Esto se vincularía con una estructura más rica de recursos (topográficos, faunísticos, aguadas, etc.) en la costa norte. Estudios arqueofaunísticos e isotópicos en restos humanos indicaron diferencias temporales en la dieta: predominantemente marina entre 6000 y 2000 AP, mixta (terrestre-marina) entre 1500 
AP y el contacto con los europeos, y terrestre (abandono de los alimentos litorales) a partir del siglo XVIII (Favier Dubois et al. 2009). Esto podría vincularse con la paleodinámica costera (Favier Dubois y Kokot 2011) y las paleotemperaturas marinas (Favier Dubois y Batres 2011). Con relación a la tecnología, se explotaron las fuentes locales secundarias y primarias -areniscas rionegrenses y vulcanitas- (Dubois et al. 2010; Alberti y Cardillo 2013). Las materias alóctonas están representadas por el basalto vesicular y la obsidiana, que posiblemente provenga de fuentes del Somuncurá y de un nuevo tipo identificado como CPLL1 que procedería del cerro Las Planicies-Lago Lolog, a $560 \mathrm{~km}$ en sentido este (Favier Dubois et al. 2009). Se propuso el predominio de estrategias expeditivas y baja inversión de energía en la confección de instrumentos (Cardillo y Scartascini 2007), salvo las puntas de proyectil que muestran variaciones morfológicas, predominando las triangulares pedunculadas (Favier Dubois et al. 2010). Las diferencias morfológicas fueron relacionadas con el uso y la evolución de distintos sistemas técnicos (Cardillo y Alberti 2014). El grupo de la piedra pulida está conformado por molinos, morteros y manos, confeccionados sobre rocas locales: areniscas rionegrenses, ignimbritas y rodados patagónicos (Orlando 2009). También recientemente se registraron grabados rupestres abstractos en rocas metamórficas (Borella et al. 2015) próximas a la playa y cáscaras de huevo de choique decoradas (Fiore y Borella 2010). Respecto de la cerámica, se cuenta con escasas descripciones sobre las características del registro en el área, por otra parte, muy fragmentario, con baja frecuencia de hallazgos y sin decoración (Favier Dubois et al. 2008).

\section{Costa central de Patagonia}

En la costa centro-septentrional, que abarca desde el límite sur de la provincia de Río Negro hasta la margen sur del río del Chubut, e incluye la Península de Valdés. Las investigaciones probaron que el área fue ocupada entre 7400 años AP y 200 años AP y que hubo variaciones respecto del uso del espacio costero (Gómez Otero 2006; Gómez Otero et al. 1999, 2009, 2013). La más alta densidad arqueológica fue registrada en el estuario del río Chubut, siguiéndole en orden decreciente las costas de los tres golfos en Península Valdés, los golfos San Matías Oeste y Nuevo Sur y por último dos tramos de costa de mar abierto: Punta NortePunta Delgada y Punta Ninfas-Bajo de los Huesos. Se comprobó menor densidad arqueológica a mayor distancia del mar, lo que indica que la movilidad y el asentamiento estuvieron sobre todo restringidos al perímetro litoral (Gómez Otero 2006). En cuanto a las tendencias temporales se registró un aumento progresivo en la cantidad de sitios a partir de los 2000 años AP, y una mayor diversidad de contextos: bases residenciales, campamentos transitorios, localizaciones y enterratorios. La dieta fue de amplio espectro, combinando el consumo prioritario de guanacos, moluscos y plantas, con el de pinnípedos, peces, aves y mamíferos menores (Gómez Otero 2006; Gómez Otero 2007; Gómez Otero et al. 1999). Por su parte, estudios arqueofaunísticos y 
análisis de isótopos estables de $\mathrm{C}^{13} \mathrm{y} \mathrm{N}^{15}$ indican variaciones temporales respecto del consumo de recursos marinos: relativamente importante en tiempos prehispánicos y escaso a nulo en momentos posteriores al contacto europeo (Gómez Otero 2007a, 2007b). Hacia 1000 AP se observaron cambios organizacionales y tecnológicos en el marco de un paulatino crecimiento demográfico: innovaciones tecnológicas (incorporación de la tecnología cerámica); aumento de la complejidad social, e incremento en los contactos e intercambios dentro y fuera de Patagonia (Gómez Otero 2006). Asimismo, en los enterratorios múltiples tardíos aparecieron cuentas de piedra de procedencia extrarregional, como serpentina, turquesa y malaquita, que sugieren una amplia red de circulación de bienes y materias primas (Gómez Otero 2003). Un aspecto muy interesante es la alta variabilidad en diseños, tamaños de puntas de proyectil. La mayoría son pedúnculadas con aletas (77\%), el resto apedunculadas. Con relación a los diseños, algunos son similares a los de puntas de distinta antigüedad halladas en otras partes de Patagonia (Campo Volcánico de Pali-aike, precordillera y meseta de Neuquén); otros parecen originales del área de estudio (Gómez Otero et al. 2009). Respecto de los instrumentos vinculados a la captura de recursos marinos se hallaron pesas de red, probables rompecráneos y un anzuelo de madera (Gómez Otero 2006). Con relación a otras tecnologías, la malacológica se caracteriza por la fabricación de cuentas de valvas, cucharas y recipientes (Gómez Otero 2006). La tecnología ósea, al igual que en otros sectores de la costa patagónica, tuvo poco desarrollo: algunos pocos perforadores, espátulas y retocadores.

Para la costa centro-meridional de Patagonia, desde Punta Clara hasta la bahía Bustamante (Chubut) se cuenta con escasas referencias, exceptuando los trabajos de Gómez Otero en la bahía de Camarones y punta Bustamante, y la descripción de artefactos líticos recuperados por Brunet (1987) en Punta Atlas (Punta Clara). En la bahía de Camarones se identificó un sitio con pinturas rupestres asignadas al estilo de grecas (sensu Menguín 1958) (Gómez Otero y Vallejo 1993). No se registraron materiales líticos asociados ni restos arqueofaunísticos. Se infiere una cronología relativa posterior al 1000 AP (Gómez Otero y Vallejo 1993). Para el sitio de superficie El Medanal (Gómez Otero y Paz 1994) el análisis tecnológico mostró la selección de rocas locales de muy buena calidad: sílices y xilópalos; otras rocas (basaltos, calcedonias, cuarcitas) se encuentran por debajo del 5\%. El grupo más representado es el de los artefactos formatizados, seguidos por los desechos. Los núcleos, los nucleiformes, y los filos naturales son escasos. Entre los desechos se destacan las lascas internas, las hojas y las láminas, y el rango de tamaño predominante es el pequeño a muy pequeño. Los talones son de distinto tipo y sobresalen los preparados. Se determinó bajo índice de corteza. Entre los artefactos tallados predominan los cuchillos filos retocados, seguidos por los raspadores y los perforadores. Otros menos frecuentes son los artefactos burilantes, muescas, raclettes, raederas y denticulados. Se recuperó solo una preforma de punta de proyectil 
triangular pedunculada. También en baja frecuencia se hallaron percutores, yunques, pesas de red e instrumentos de molienda. Dada la presencia de cerámica, infieren una cronología de por lo menos 1210 años AP. Sobre estas evidencias las autoras proponen ocupaciones de corta duración por parte de cazadores que se asentaban todo el año en la costa. En este sector se habrían aprovechado recursos marinos y terrestres; mientras que la tecnología indica actividades de extracción y mantenimiento de artefactos.

Costa central del golfo San Jorge, se extiende desde Puerto Visser (Chubut) hasta la localidad La Lobería (norte de Santa Cruz). El límite costero es de hasta tres kilómetros de ancho e incluye la línea de la más baja marea hasta el borde superior de los pedimentos mesetiformes (Arrigoni et al. 2008). Entre las localidades arqueológicas se destacan Bahía Solano (sitios I, II y III), Rocas Coloradas Sur, Restinga Alí, sitio Hipódromo y Playa Alsina. La localidad Bahía Solano fue trabajada en la década del setenta por Borrero y Caviglia (Borrero y Caviglia 1978; Caviglia y Borrero 1978). Las ocupaciones registradas se remontan al Holoceno tardío, desde ca. 2900 a 200 AP (Arrigoni et al. 2008, Caviglia et al. 1982). De acuerdo con estos estudios la dieta se basó en la explotación mayoritaria de recursos marinos (principalmente pinnípedos y moluscos, seguidos por las aves y los peces) y en menor proporción terrestres (choique, piche y escasos especímenes de guanaco) (Arrigoni et al. 2008). En la tecnología lítica se identificó el uso de distintas rocas: xilópalos, sílices, calcedonias, chert y basalto. La gran mayoría (excepto el xilópalo) se encuentra localmente en forma de rodados. Los xilópalos, también de origen local, provienen del denominado "Bosque Petrificado de la Costa" y fueron intensamente explotados (Arrigoni et al. 2008). En muy baja proporción se recuperó obsidiana que procedería de Pampa del Asador (500 km de distancia) o de la Meseta de Somuncurá (aproximadamente a $900 \mathrm{~km}$ ). En los conjuntos predominan los núcleos y los desechos de talla. También son numerosos los instrumentos terminados y los artefactos formatizados por abrasión, picado y pulido. Los núcleos son de distintas morfologías, varios con porcentajes elevados de corteza y otros agotados. Entre los desechos se registran lascas primarias, secundarias e internas. También hay láminas y hojas de distintos tamaños. El alto porcentaje de talones lisos señala el predominio de la técnica de talla por percusión directa (Arrigoni et al. 2008; Borrero y Caviglia 1978). Los instrumentos más estandarizados son los raspadores de filo frontal simple sobre hojas cortas y las puntas de proyectil pedunculadas. Entre estas se destaca la presencia de dos apedunculadas, de limbos convexos y base escotadas inusuales para el área (Arrigoni et al. 2008). Se registró además tecnología cerámica (Arrigoni 2002; Caviglia et al. 1982) y artefactos en hueso (agujas y retocadores) (Arrigoni et al. 2008). Sobre la base de estas evidencias, los autores proponen la presencia de ocupaciones de corta duración y esporádicas, centradas en primavera-verano donde se llevaron a cabo el consumo de recursos marinos (moluscos, pinnípedos y peces) y en algunos casos terrestres (guanaco). 
La costa norte de Santa Cruz, comprende el límite sur de Chubut hasta la localidad Bahía Laura, en la provincia de Santa Cruz. El área costera fue delimitada como el sector comprendido entre la línea de vegetación contigua a la máxima línea de mareas altas y $25 \mathrm{~km}$ hacia el interior (Castro et al. 2008). Los estudios probaron que fue ocupada desde el Holoceno medio (ca.6700-5700 años AP) aunque la mayoría de las dataciones proviene de sitios del Holoceno tardío (ca.3000-920 años AP) (Castro et al. 2007; Zubimendi et al. 2005, 2009). Predominan los sitios registrados muy cerca de la línea de costa actual sobre terrazas marinas bajas próximas a bancos de moluscos (Castro et al. 2008). Se observaron diferencias en la intensidad de uso del espacio: continuo y uniforme en el golfo San Jorge, prácticamente nulo entre cabo Blanco y la ría de Puerto Deseado, e intenso pero heterogéneo entre esta ría y Bahía Laura (Castro et al. 2008; Zubimendi et al. 2004). En los conjuntos arqueofaunísticos son ampliamente dominantes los recursos marinos, en especial pinnípedos, moluscos y aves (Castro et al. 2000, 2001; Moreno 2008). No obstante, estudios de isotopos estables de carbono y nitrógeno sobre restos humanos indicaron dietas mixtas (marina y terrestre) (Moreno et al. 2011). Sobre estas evidencias se hipotetizó el uso complementario de la costa y del interior adyacente, que pudo haber sido de carácter estacional (primavera-verano) o continuo a lo largo del año (Moreno et al. 2011). Respecto de la oferta de materias primas líticas se registró alta variabilidad de rocas disponibles localmente: fuentes secundarias de rodados marinos y glaciofluviales y de diversas litologías (ślices, basaltos, riolitas, entro otras), así como una fuente primaria de calcedonia rojiza en forma de vetas y vesículas asociadas a la Formación Bahía Laura (Ambrústolo 2011). En muy baja frecuencia se identificaron dos rocas no locales: obsidiana negra y xilópalo. La obsidiana proviene de la fuente de pampa del Asador, en la Meseta Central de Santa Cruz, a $500 \mathrm{~km}$ de la costa (Ambrústolo et al. 2013), y el xilópalo, que posiblemente provenga del Bosque petrificado de Santa Cruz, distante a más de $150 \mathrm{~km}$ hacia el interior (Ambrústolo 2011). En cuanto a los núcleos, la mayoría son amorfos, siguiéndoles los de lascados aislados y los poliédricos (Ambrústolo 2013). Se identificó preponderancia de la talla por percusión directa y muy baja frecuencia de la talla bipolar (restringida solo a las rocas no locales). En cuanto a los subgrupos tipológicos son frecuentes los raspadores de filo frontal corto, las raederas unifaciales y bifaciales, los denticulados y las puntas de proyectil triangulares pedunculadas (Castro et al. 2008). Se destacan algunas puntas similares a las definidas como tipo Bird III (Ambrústolo 2011). Se hallaron varios ejemplares relacionados con la captura de fauna marina: arpones en hueso- de probable manufactura local-, romprecráneos y pesas de red (Castro et al. 2008; Moreno 2009; Zubimendi et al. 2013). 


\section{Costa Meridional de Patagonia}

La costa sur del río Santa Cruz, incluye las localidades de Monte León y Punta Entrada, habiéndose registrado edades del Holoceno medio ( $c$ a. 5500 años AP) en Parque Nacional Monte León y del Holoceno tardío ( $c a$. 2000 años AP) en la misma localidad y Punta Entrada (Muñoz et al. 2009: Cruz et al. 2010; Caracotche et al. 2005). Los estudios arqueofaunísticos indican que la dieta estuvo basada principalmente sobre recursos marinos (principalmente pinnípedos, moluscos, peces y aves) y en menor proporción terrestres (guanaco) (Cruz et al. 2011). Sin embargo, las evidencias isotópicas realizadas sobre restos humanos (ca. 1770 y 70 años AP) sugieren un consumo predominante de recursos terrestres con una ingesta baja de alimentos marinos (Suby et al. 2009). Sobre estos resultados se propuso la ocupación discontinúa de la costa, en especial durante el verano (Cruz et al. 2011). Los estudios tecnológicos, señalan el uso de diversas materias primas con predominio de tres rocas locales de buena calidad para la talla: dacita verde y gris, basalto y calcedonia (Caracotche 2003; Caracotche et al. 2008). Tres variedades de obsidianas fueron identificadas: la de coloración negra que procedería de Pampa del Asador (Stern 1999) a $320 \mathrm{~km}$ hacia el NO; la verde del Mar de Otway (Stern y Prieto 1991) en Magallanes (Chile) a 340 hacia el SO; y la gris verdosa veteada de la cordillera de los Baguales (Stern y Franco 2000), a $240 \mathrm{~km}$ al O. Nuevos estudios mencionan la presencia de un tipo de obsidiana gris porfídica, cuya probable fuente se encontraría en el Volcán Chaltén a más de $1100 \mathrm{~km}$ en dirección NE (Stern et al. 2012). En los conjuntos prevalecen los desechos, siguiéndoles los núcleos y las raederas. Se observaron porcentajes elevados de corteza (Caracotche et al. 2008). Respecto de las técnicas de manufactura en casi la totalidad de los conjuntos se determinó la presencia de la bifacialidad (principalmente puntas de proyectil) y evidencias de toda la cadena de producción a partir de lascas de adelgazamiento bifacial de distintos tamaños y bifaces en distintos estadios de manufactura. Respecto de los artefactos vinculados con la captura y/o procesamiento de recursos marinos se recuperó un arpón en hueso en el sitio conchero Punto 35 (Cruz et al. 2010). Los autores también destacan la presencia de concentraciones líticas muy densas en sectores acotados lo que estaría indicando un uso recurrente de esos espacios.

Para la margen norte del estuario del Río Gallegos, se cuenta con los estudios de la localidad Punta Bustamante. La antigüedad de las ocupaciones se remontan al Holoceno tardío (ca. 3600 a 700 años AP) (Mansur 2008). Los grupos cazadores-recolectores de este tramo costero basaron su subsistencia sobre los recursos terrestres (guanaco), mientras que los marinos (pinnípedos) habrían sido complementarios en la dieta (Mansur 2008; Mansur et al. 2004). Otros recursos identificados son las aves (pingüino y cormorán), peces en escaso porcentaje y mamíferos de tamaño menor (roedores). También se documenta la presencia de un cánido extinguido (Canis avus) (Mansur 2008; Mansur et al. 2004). Respecto de los recursos líticos se 
menciona el uso de guijarros de distintos tamaños disponibles en los acantilados del norte del río Gallegos y en los cordones marinos. Entre las rocas seleccionadas para la talla se registró el basalto, representado en lascas (de percusión y bipolares), núcleos, hemiguijarros y fragmentos bipolares. En segundo lugar se encuentra el xilópalo, disponible en muy baja frecuencia a partir de rodados, que fueron reducidos por técnica bipolar. Por el contrario, otras rocas criptocristalinas (riolitas, dacitas y cuarcitas) fueron talladas por percusión directa (Mansur 2008). En baja proporción se mencionan ftanitas, calcedonias, ópalos, obsidianas, areniscas y tobas. Respecto de los instrumentos retocados, los más estandarizados son los raspadores pequeños de filo frontal, confeccionados sobre lascas de guijarros. Le siguen en importancia las raederas de filo retocado lateral sobre lascas medianas y grandes. Entre los retoques bifaciales, se destacan las puntas de proyectil pedunculadas con aletas, preferentemente manufacturadas en basalto. Otros instrumentos retocados identificados en bajo porcentaje son los perforadores simples y múltiples, las raclettes, las muescas y los denticulados. Se recuperaron además instrumentos confeccionados por técnica de piqueteado y pulidos, percutores y seis litos discoidales. Los artefactos de hueso son escasos (un punzón sobre tibia de cánido; fragmento de hueso de ave decorado). Entre los artefactos en valvas solo se halló una "cuenta" (Mansur 2008). Sobre las bases de las distintas evidencias se propone que este espacio fue utilizado por grupos de cazadores de la estepa que hacían uso complementario de los recursos del mar (Mansur 2008). Por una parte los sitios extensos indicarían reocupaciones discontinuas en el tiempo pero espacialmente próximas, mientras que los sitios pequeños se asociarían con campamentos de corta duración durante las cuales se realizaron actividades específicas relacionadas con lugares de matanza, trozamiento y eventualmente consumo de pinnípedos, así como también cuereado, despostamiento y consumo de guanacos (Mansur 2008).

La margen sur del estuario del Río Gallegos. Se cuenta con los trabajos de Carballo Marina y Ercolano (2008) quienes prospectaron la franja costera de $35 \mathrm{~km}$ desde la desembocadura del río Gallegos hasta Chorillo de los Frailes. La costa se considera como una zona de ecotono continente-mar (Carballo y Ercolano 2008). Los estudios probaron que el área fue ocupada desde por lo menos fines del Holoceno tardío. Los principales hallazgos son concentraciones líticas de densidades variables. No hay evidencias arqueofaunísticas. Respecto a la oferta local de materias primas líticas se menciona disponibilidad de rocas en distintas geoformas (espigas, bancos de gravas, playa del estuario, cordones marinos) que ofrecen rodados glacio-fluviales principalmente basalto y dacita, de tamaños mediano-pequeño (Carballo Marina 2007). En cuanto a la densidad artefactual se registró que en el sector de la costa atlántica es menor respecto al estuario. La materia prima más utilizada es el basalto ( $80 \%)$, siguiéndoles las dacitas. En muy baja frecuencia se hallaron otras rocas de mejor calidad: calcedonias, ópalos y obsidiana. Esta última proviene del Seno de Otway (Chile) a $150 \mathrm{~km} \mathrm{al}$ 
SO del área (Carballo y Ercolano 2008). Sobresalen las lascas, siendo muy escasos los núcleos y las raederas. En síntesis, las escasas evidencias muestran la presencia de actividades de talla, a partir de nódulos de basalto y de dacitas disponibles localmente, y bajos costos de búsqueda y selección de rocas y en la manufactura de artefactos (Carballo y Ercolano 2008). Esto se condice con el uso y abandono de los artefactos con baja reactivación de los filos. No hay registros de tecnologías especializadas para la obtención y/o procesamiento de recursos marinos. Las autoras proponen un uso humano diferencial entre ambos ambientes (estuario vs. costa): la costa habría sido un sector marginal en los circuitos de movilidad, mientras que el estuario fue un espacio jerárquicamente más importante (Carballo y Ercolano 2008).

Cabo Vírgenes: las investigaciones evidencian que este sector fue ocupado desde $c a$. 2000 AP y de forma discontinúa hasta tiempos históricos (Borrero y Franco 2002; Borrero et al. 2008). Los estudios arqueofaunísticos mostraron claro predominio de pinnípedos por sobre otros recursos marinos (aves y moluscos). En baja frecuencia se encuentran los recursos terrestres (guanacos). Sin embargo también se propuso que cormoranes y pingüinos podrían ser complementos importantes en la dieta. Por su parte, estudios isotópicos sobre dos individuos adultos recuperados en CV 17 indican dietas mixtas: terrestres y marinas. Se interpreta que esta área formó parte de los rangos de acción de grupos que también ocupaban el interior (Barberena et al. 2004). El registro de crías de pinnípedos permitió plantear ocupaciones en verano. En cuanto a la disponibilidad local de rocas se mencionan rodados de dacita, ROGF (sensu Charlín 2004) (aunque en baja frecuencia y restringidos al Cañadón Gap), gabro, granito y nódulos pequeños de calcedonia. Se observó mayor variedad de rocas en Cañadón Gap que en Cabo Vírgenes donde predominan las rocas de calidad inferior (Borrero et al. 2008). En los conjuntos líticos prevalecen las dacitas y las ROGF, en menor proporción se seleccionaron calcedonias, ópalos, xilópalos y obsidiana verde, cuya fuente procede del seno de Otway. En los conjuntos sobresalen las lascas de dacita y RGFO. Entre los instrumentos se destacan las raederas y los cuchillos, aunque también se registran preformas bifaciales, puntas de proyectil y bolas de boleadoras (Borrero et al. 2008). Se infiere aprovechamiento expeditivo de las dacitas y mayor inversión energética de las ROGF, que se trasladarían a otros sectores. Se registran núcleos, percutores, lascas de reactivación y porcentajes altos de corteza, lo que avalaría la presencia de las primeras etapas de talla. También se identificaron estadios iniciales de talla de puntas de proyectil sobre ROGF. En cuanto a las puntas de proyectil la mayoría son pedunculadas bifaciales medianas (Franco 1999, Franco y Borrero 2003). Se infiere que las puntas terminadas fueron transportadas hacia otros lugares. Se registró técnica bipolar para los núcleos pequeños de las ROGF. Con la excepción del hallazgo de dos probables pesas de red en Cañadón Gap (Charlín y Cardillo 2010) no se identificaron otros artefactos relacionados con la obtención de recursos marinos. 


\section{Síntesis sobre el estado actual de las investigaciones}

En síntesis, en líneas generales -y en escalas espaciales y temporales amplias- el registro arqueológico del litoral entre la región pampeana y Patagonia muestra variaciones no sólo en el modo e intensidad de uso de la costa y de sus recursos, sino también en lo que respecta a la tecnología lítica. Con respecto a los conjuntos artefactuales y rasgos tecnológicos, las mayores semejanzas fueron registradas en el extenso sector comprendido entre el litoral pampeano y la margen norte del río Chubut. Al sur de dicho río, a medida que se avanza en latitud, parecen acentuarse las diferencias. Las semejanzas tecnológicas observadas podrían relacionarse con diferentes causas: (a) vinculaciones culturales de larga data y sostenidas a lo largo del tiempo, propiciadas por la presencia de una presunta antigua ruta de poblamiento costero (Miotti 2007), y/o b) también podrían relacionarse con la distinta oferta de recursos líticos al norte y al sur del río Chubut: predominio absoluto de rodados en la porción pampeana y septentrional, afloramientos volcánicos y rodados en la meridional. Esto habría favorecido la aplicación de estrategias tecnológicas diferentes. Sin embargo, y para la costa centro-septentrional no cuenta hasta el momento con un análisis tecnológico sistemático; su estudio permitirá profundizar y discutir las implicancias de la variabilidad del registro lítico a un nivel macro-regional.

La variabilidad del registro arqueológico de la costa atlántica pampeano-patagónica plantea interesantes desafíos a los arqueólogos. Por ejemplo conocer la antigüedad del poblamiento en la costa, evaluar contactos o circulación de diseños y materias primas a través del tiempo y del espacio, o la evolución de determinados rasgos tecnológicos, entre ellos la talla bifacial, la técnica bipolar, la laminaridad, la proporción de artefactos expeditivos y conservados, el uso de rocas alóctonas, entre otros. También sería importante explorar distintas teorías o hipótesis ya planteadas, como por ejemplo la existencia de una antigua ruta de poblamiento costero (Miotti 2006), o el papel del río Chubut como filtro o barrera cultural tal como lo proponen ciertos modelo biogeográficos y etnohistóricos (Escalada 1949; Casamiquela 1990). 


\section{CAPÍTULO 4}

\section{MATERIALES Y MÉTODOS}

\section{Metodología de campo}

Esta tesis se enmarca en los estudios que desde 1993 se están realizando en el área bajo la dirección de la Dra. Julieta Gómez Otero. En consecuencia se cuenta con un conjunto de miles de piezas líticas recuperadas en distintas instancias de investigación. Por lo tanto, los trabajos de campo estuvieron principalmente orientados a caracterizar la base regional de recursos líticos (Ericson 1984). No obstante, se realizaron nuevas prospecciones, excavaciones y muestreos arqueológicos, que aplicaron los mismos criterios y técnicas de los trabajos llevados a cabo previamente por Gómez Otero (2006).

Como se mencionó casi la totalidad de los conjuntos líticos analizados en esta tesis fueron recuperados durante campañas arqueológicas realizadas por Julieta Gómez Otero y equipo. No obstante, también se incluyeron los materiales recolectados durante nuevos trabajos de campo: en la localidades de San Pablo, Península Valdés y Bahía Cracker (golfo Nuevo sur) (Gómez Otero et al. 2013a y b). Para todos los casos se siguió el diseño de muestreo utilizado para el área (Gómez Otero 2006: 99). En los sitios de superficie se llevaron a cabo muestreos de $4 \mathrm{~m}$ de lado. En los casos de lentes de fogones o concheros en perfiles de médanos o cárcavas se realizaron muestreos en estratigrafía, cuyo tamaño varío entre $0,25 \mathrm{~cm}$ a $0,50 \mathrm{~cm}$ de lado por la potencia máxima del depósito (entre 4,5 cm y $20 \mathrm{~cm}$ ). En todos los casos se utilizó zaranda de 4 mm de malla.

\section{La segmentación espacial y las unidades de análisis}

El diseño de muestreo para la construcción de la base regional de recursos líticos y el análisis tecnológico de los conjuntos líticos tuvieron en cuenta el modelo de uso del espacio costero planteado por Gómez Otero (2006) para el área de estudio. De manera preliminar la autora discriminó dos grandes unidades de análisis "Península Valdés" y "Fuera de Península Valdés", que a su vez incluyen distintos tipos de costa (Tabla 4.1). 


\begin{tabular}{|l|l|}
\hline UNIDAD DE ANÁLISIS & SECTORES COSTEROS INCLUIDOS \\
\hline \multirow{4}{*}{ Península Valdés } & Golfo San Matías \\
\cline { 2 - 2 } & Golfo San José \\
\cline { 2 - 2 } & $\begin{array}{l}\text { Golfo Nuevo } \\
\text { Caleta Valdés } \\
\text { Mar abierto }\end{array}$ \\
\hline \multirow{3}{*}{ Fuera de Península Valdés } & Golfo San Matías Oeste \\
\cline { 2 - 2 } & Golfo Nuevo Sur \\
\cline { 2 - 2 } & Mar abierto entre Punta Ninfas y Bajo de los Huesos \\
\cline { 2 - 2 } & Estuario del río Chubut \\
\hline
\end{tabular}

Tabla 4.1. Sectorización espacial y unidades de análisis arqueológicas ( Gómez Otero 2006).

Los resultados de su investigación le permitieron determinar, en líneas generales, una mayor densidad y diversidad arqueológicas en Península Valdés que fuera de ella, así como también diferencias en estas dos variables entre los distintos sectores de costa. A partir de ello construyó una escala jerárquica de intensidad de uso del espacio en orden decreciente:

$\left.1^{\circ}\right)$ Estuario del río Chubut

$2^{\circ}$ ) Golfo San Matías (PV)

$3^{\circ}$ ) Golfo San José (PV)

$4^{\circ}$ ) Golfo San Matías oeste (FPV) - Golfo Nuevo (PV)

$5^{\circ}$ ) Golfo Nuevo Sur

$6^{\circ}$ ) Espigas e islas de barrera de Caleta Valdés Caleta Valdés y Punta Ninfas a Bajo de los Huesos.

Gómez Otero (2006) propuso que estas diferencias se deberían a la selección de espacios de ocupación sobre la base de la productividad costera en combinación con la del ambiente terrestre adyacente, la topografía y la oferta de ciertos recursos marinos. En este sentido, los lugares más intensamente utilizados por las poblaciones humanas fueron los de mayor accesibilidad al mar y próximos a bancos fijos de moluscos, donde además podían obtenerse otros recursos marinos como peces, aves y pinnípedos. Su modelo también estableció cambios culturales, en especial a partir del Holoceno tardío, a los que relacionó con un aumento demográfico gradual desde 3000 años AP. Entre esos cambios identificó: (a) disminución de la movilidad residencial y concentración de los grupos en los lugares más favorables para la subsistencia; (b) diversificación funcional de los asentamientos; (c) desarrollo de estrategias económicas, de movilidad y tecnológicas del tipo llamadas "procesadoras" por Bettinger y Baumhoff (1982); (d) intensificación en el consumo de plantas y otros recursos (p. ej. 
pinnípedos); (e) uso de áreas formales de entierro; (f) incremento de los contactos poblacionales dentro y fuera de la región patagónica, y (g) aumento de la complejidad social.

Dado que en el área de estudio de esta tesis no están incluidos el sector de costa de mar abierto entre Punta Ninfas y Bajo de los Huesos y la costa del estuario del río Chubut se espera verificar mayor intensidad de ocupación en las costas de los golfos San Matías, San José y Nuevo en Península Valdés, intensidad media en las costas del golfo San Matías Oeste y Golfo Nuevo Sur, y baja intensidad en la zona de Espigas de barrera de Caleta Valdés y costas de mar abierto de Península Valdés.

De manera operativa y sobre la base de los fechados obtenidos y las características del registro arqueológico (Gómez Otero 2006) se establecieron tres bloques temporales:

- Holoceno medio: 7400 AP - 4000 AP

- Holoceno tardío inicial: 3900 AP - 1000 AP

- Holoceno tardío final: $1000 \mathrm{AP}-300 \mathrm{AP}$

\section{Construcción de la base regional de recursos líticos}

Los estudios orientados a caracterizar la estructura regional de recursos líticos (Ericson 1984) permiten generar información de base para integrar y discutir las estrategias de aprovisionamiento de materias primas en relación con la movilidad y el uso del espacio, la elección de los diseños y de las técnicas de reducción, y también sobre las preferencias o restricciones que intervienen en la selección de las rocas (Binford 1980; Nelson 1991; Andrefsky 1995, 2009; Flegenheimer y Bayón 1999). De esta manera, las elecciones tecnológicas se analizan en el marco más amplio de las estrategias generales de subsistencia y de la organización social (Nelson 1991).

Para la elaboración de la base regional de recursos líticos se necesita conjugar información proveniente de distintas vías. Una primera vía se sustenta sobre la compulsa de antecedentes geológicos y tiene por objetivo establecer las fuentes potenciales de aprovisionamiento de materias primas mediante la identificación y localización de las formaciones geológicas y sus litologías asociadas. Otra es el relevamiento de campo y los muestreos de roca que permiten establecer la disponibilidad, abundancia relativa y formas de presentación de las rocas (Franco y Borrero 1999, Charlín 2009). La última vía es la contrastación de este corpus de datos con los resultados del análisis del registro arqueológico lítico. A partir de la información obtenida se podrá hipotetizar sobre los mecanismos de 
adquisición de recursos, los rangos de movilidad y el tipo de uso o valoración que los grupos humanos le otorgaron a las rocas.

\section{Estudios de campo para conocer la oferta local de materias primas}

Dado que en el área de estudio predominan los depósitos secundarios, el diseño de muestreo se basó sobre la metodología de Franco y Borrero (1999), que consiste en contabilizar y caracterizar los nódulos recolectados por un número determinado de personas durante un tiempo prefijado. Para esta tesis los muestreos fueron realizados por una a dos personas durante 10 a 35 minutos. A los fines de lograr una unidad de tiempo comparable, se calculó el porcentaje de nódulos obtenidos por una persona en un minuto. Sólo se recogieron los nódulos que mostraron calidad regular a excelente, por lo tanto no fueron levantados aquellos que mostraron texturas granulares gruesas y fractura no concoide, como por ejemplo las areniscas consolidadas. Para cada muestreo se estimó el valor porcentual de rocas de calidad buena a excelente.

De cada nódulo recolectado se identificó la litología in visu o en muestra de mano. El reconocimiento de las rocas se llevó a cabo a partir de la descripción de los siguientes atributos:

Formas de presentación de los nódulos: gravas, bloques, lajas.

Tamaño (sensu Bonorino y Teruggi 1952): bloque ( $>256 \mathrm{~mm}$ ); guijón $(<256$ a 64 $\mathrm{mm})$; guijarro $(<64$ a $16 \mathrm{~mm})$ y guija $(<16$ a $0,4 \mathrm{~mm})$.

Morfología de los clastos: de acuerdo con el grado de redondamiento de los clastos se diferenciaron cuatro formas: redondeado, subredondeado, subangular y angular (Fig. 4.1).

Textura: forma, tamaño y disposición de los minerales constitutivos y de la composición estimativa de los minerales;

Color: esta variable se halla estrechamente relacionada con su composición mineralógica. En este sentido, los minerales oscuros como el olivino, piroxenos, anfíbol, o la biotita se denominan máficos o ferromagnesianos. Los minerales claros como feldespatos, cuarzo, feldespatoides son denominados félsicos.

Granularidad: faneríticas cuando los cristales y elementos se distinguen a simple vista $(>0.1 \mathrm{~mm})$ y afaníticas cuando no pueden distinguirse $(<0.1 \mathrm{~mm})$.

Calidad de las rocas para la talla: se estableció según los criterios propuestos por Aragón y Franco (1997) a partir de la textura de la matriz, el contenido de fenocristales y el tamaño de los minerales. Sobre esta base distinguen cinco calidades: mala, regular, buena, muy buena y excelente. 


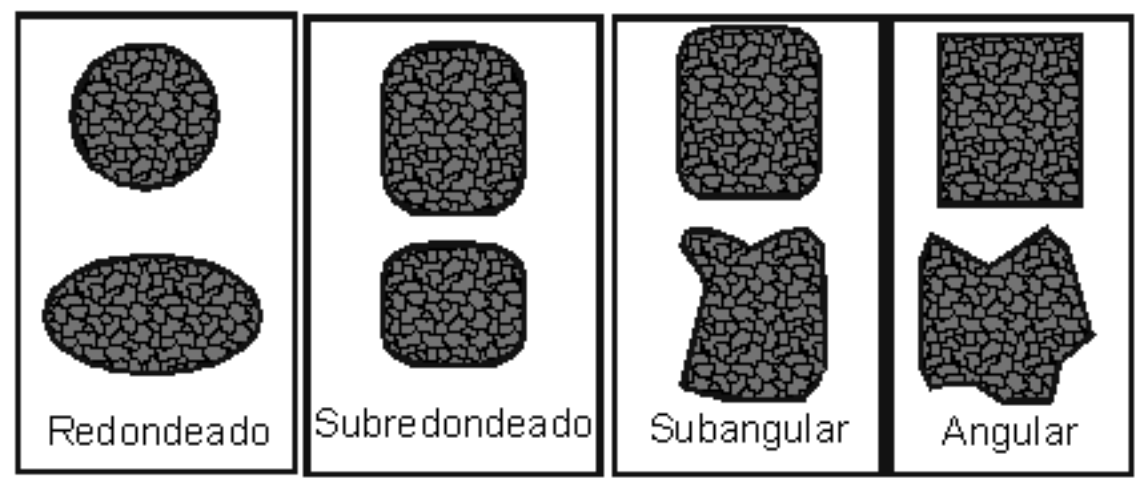

Fig. 4.1. Grafíco de comporación visual del grado de redondeamiento de los clastos.

\section{Métodos de laboratorio}

Dada la alta cantidad de sitios localizados en el área $(\mathrm{N}=125)$ y atendiendo a los objetivos específicos 4 y 8 planteados en la Introducción, por cada sector de costa se seleccionó una muestra representativa de sitios de distinta cronología y funcionalidad (según Gómez Otero 2006). Para caracterizar las secuencias de producción de los distintos artefactos y explorar las tendencias en el uso y aprovechamiento de las materias primas líticas, se desarrollaron estudios tecno-morfológicos macroscópicos tanto de los núcleos como los desechos de talla e instrumentos (Aschero 1975, 1983; Aschero y Hocsman 2004; Hocsman 2006 y Belleli et al. 1985). A los efectos de la comparación a nivel macro-regional se analizaron algunos conjuntos artefactuales líticos de los sitios arqueológicos La Eufemia, Bellamar 1, 2 y 3 localizados en la costa atlántica pampeana (Bonomo 2005) y se consideraron los mismos atributos (véase abajo) utilizados por este autor.

\section{Estudios tecnológicos}

El estudio tecnológico de los artefactos líticos se realizó de acuerdo con la metodología de Aschero (19875-1983) y Aschero y Hocsman (2004) y las propuestas de análisis de desechos de talla de acuerdo con Bellelli et al.1985-1987 y modificaciones de Bonomo (2005) para los productos de talla bipolar. La primera segmentación de cada conjunto se basó en la delimitación de las grandes clases de la piedra tallada: núcleos, desechos de talla, artefactos formatizados por talla y artefactos con rastros complementarios. No obstante, para la caracterización general de cada conjunto y la vinculación con la selección de materias primas, también se tuvieron en cuenta otras clases como los artefactos modificados por el uso, los piqueteados y los pulidos.

Para todas las clases talladas se registraron las siguientes variables:

1) Materia prima: tipo de roca, color -de acuerdo con la Tabla de Munsell (2011)-, calidad y presencia de alteraciones. La calidad, al igual que las rocas muestreadas, se evaluó según los criterios de Aragón y Franco (1997). 
2) Métricas: por una parte se consideró el tamaño absoluto (largo, ancho y espesor máximo) medidos en calibre digital DIGIMESS para los núcleos, artefactos tallados y rastros complementarios. Por otra, se tomaron las medidas relativas: índices de los módulos longitudanchura y el módulo anchura-espesor- según el gráfico de Bagolini (1968) para los desechos y formas bases de los instrumentos tallados. Estas variables solo fueron consignadas para los artefactos enteros. Se consideró la distinción entre láminas y hojas de Aschero (1975:11) de acuerdo con las características señaladas por el autor que a continuación se detallan:

\begin{tabular}{|l|l|}
\hline \multicolumn{1}{|c|}{ Hojas } & \multicolumn{1}{c|}{ Láminas } \\
\hline Longitud variables (menor o mayor a dos anchos) & Longitud igual o mayor a dos anchos \\
\hline Bordes (laterales) paralelos o sub-paralelos & Bordes sub-paralelos \\
\hline $\begin{array}{l}\text { Cara dorsal con aristas de lascado sub-paralelas } \\
\text { (dos como mínimo) }\end{array}$ & $\begin{array}{l}\text { Cara dorsal con reserva de corteza, con aristas de } \\
\text { lascado angulares o con arista única longitudinal } \\
\text { (láminas triédricas) }\end{array}$ \\
\hline $\begin{array}{l}\text { Talones lisos, diedros, facetados y puntiformes, } \\
\text { "rectos" (inclinación entre } 80^{\circ} \mathrm{y} 100^{\circ} \text { ). }\end{array}$ & $\begin{array}{l}\text { Talones lisos-naturales, lisos, diedros y facetados, } \\
\text { "rectos". }\end{array}$ \\
\hline
\end{tabular}

Tabla 4.2. Características y atributos para diferenciar hojas y láminas. Tomado de Aschero (1975:12).

3) Presencia de corteza: se determinó la presencia o ausencia y el porcentaje que cubre la corteza sobre la cara dorsal. La cantidad de corteza se midió en intervalos de $25 \%$

4) Presencia de fractura: posición y, en el caso que se pudo determinar, el tipo de fractura.

Para los artefactos tallados se tuvo en cuenta:

- Grupo y subgrupo tipológico:

- Forma base.

- Cantidad de filo por grupo tipológico y presencia de filos complementarios

- Sección transversal de la pieza y forma geométrica del contorno

- Forma y dirección de los lascados de formatización

- Conformación del borde.

- Angulo del filo, sección y forma geométrica del filo.

Para los $\underline{\text { Núcleos: }}$ :

- Forma base

- $\quad$ Tipo morfológico

- Número de negativos de lascado

- Estado de abandono 
Los núcleos bipolares se clasificaron en tres tipos de acuerdo con el estado de modificación de los polos del rodado siguiendo la propuesta de Bonomo (2005): (a) un polo modificado; (b) dos polos y (c) no diferenciado por fractura.

Para los desechos de talla:

- Estado: entero o fracturado

- Tipo de lasca o de hoja:

- Morfología del talón, y se incluyó el astillado (Bonomo 2005)

- Rastros complementarios del talón

- Regularización del frente de extracción

- Tipo de bulbo

- Labio: presencia/ausencia

- Estrías

- Punto de percusión

- Ondas

- Lascas adventicias

- Curvatura de la cara ventral y tipo de terminación

Para el subgrupo de las puntas de proyectil se efectuaron análisis tecnomorfológicos y métricos más detallados en función de explorar y explicar la variabilidad de diseños en el área de estudio y su vinculación con: (a) cambios temporales en los sistemas técnicos y/o (b) presencia de intercambios y circulación de diseños e información con otras áreas de Patagonia. Las determinaciones morfológicas se realizaron para cada ejemplar y sus partes constitutivas (ápice, limbo, aletas y pedúnculo); mientras que las variables tecnomorfológicas incluyeron la sección transversal, la serie técnica y el tratamiento de la base. Por su parte, dado que el pedúnculo es el sector de la pieza más conservado (Franco et al 2009; Banegas et al. 2014) las variables métricas ancho y espesor de la raíz; ancho, largo y espesor de la base del pedúnculo, se sometieron a análisis estadísticos univariados (ANOVA) y multivariados (ACP).

Por último para cada conjunto lítico y, a los fines de unificar medidas de abundancia relativa que permitieran la comparación entre muestreos, se determinó la densidad por $\mathrm{dm}^{3}$. Asimismo se determinaron los índices de bipolaridad, bifacialidad y laminaridad.

\section{Análisis microscópicos}

Para corroborar las determinaciones litológicas efectuadas en muestra de mano se llevó a cabo el estudio microscópico de muestras naturales y arqueológicas. El uso de terminologías clasificatorias establecidas e equiparables por parte de los arqueólogos es indispensable para poder efectuar comparaciones entre equipos de investigación que desarrollan sus proyectos en 
una misma área o región (Cattáneo 2004). De esta manera, entre otros aspectos es posible detectar la presencia de rocas no locales y discutir los mecanismos de adquisición de estas materias primas, tales como la circulación de bienes o personas y los intercambios.

Se realizaron dos tipos de estudios: a) la determinación petrográfica de secciones delgadas de rocas y de artefactos líticos, y b) el análisis de la estructura interna y la composición química de secciones delgadas de muestras naturales y arqueológicas de xilópalos (Banegas et al. 2016).

\section{Determinación petrográfica}

Para este estudio se efectuó un total de 26 cortes petrográficos de muestras naturales ( $\mathrm{n}=$ 10) y arqueológicas $(n=15)$. La confección de las láminas delgadas fue realizada por el Lic. Ricardo Ponti, de una medida estándar de 27 x $26 \mathrm{~mm}$ y un espesor de 30 micrones. Cada sección fue impregnada en resina epoxi, pulida y montada en un cubreobjetos. Para la interpretación de los cortes se contó con el asesoramiento y colaboración de la Dra. Yolanda Aguilera (FCNyM-UNL). Se utilizó un microscopio petrográfico marca Nikon Eclipse E 400 Pol, de 3 objetivos $(10 \times 0,25 / 40 \times 0,65 / 4 \times 0,10)$. De cada muestra se describieron los minerales y sus alteraciones, el tamaño, la forma y la distribución de tamaños de los cristales, su disposición espacial y el tipo de agrupamiento, el conteo modal de los de los porcentajes minerales y el análisis de las texturas (Tabla 4.3). Para las determinaciones de rocas y minerales se siguieron las propuestas de Kerr (1965); González Bonorino (1976); Williams et al. (1980); Dong et al. (1995) y McPhie et al. (1993).

\begin{tabular}{|c|c|c|}
\hline \multicolumn{3}{|c|}{ CRITERIOS DE IDENTIFICACIÓN MICROSCOPICOS } \\
\hline \multirow{4}{*}{$\begin{array}{l}\text { Propiedades } \\
\text { sin analizador }\end{array}$} & Color & $\begin{array}{l}\text { Incoloros o leve coloración. } \\
\text { Coloreados: anfíboles, biotita y algunos piroxenos. }\end{array}$ \\
\hline & Relieve & $\begin{array}{l}\text { Se produce en la superficie del mineral debido a la } \\
\text { diferencia entre su } n \text { de refracción y el de la sustancia que } \\
\text { lo rodea. }\end{array}$ \\
\hline & Clivaje & $\begin{array}{l}\text { Se observan las trazas de los planos de clivaje como líneas } \\
\text { rectas que atraviesan el cristal. }\end{array}$ \\
\hline & Pleocroísmo & $\begin{array}{l}\text { Cambio de color producido en un mineral al girar la platina } \\
\text { dada la diferente absorción de la luz según las direcciones } \\
\text { de vibración del cristal. }\end{array}$ \\
\hline \multirow[t]{3}{*}{$\begin{array}{l}\text { Propiedades } \\
\text { con analizador }\end{array}$} & $\begin{array}{c}\text { Color de } \\
\text { interferencia }\end{array}$ & $\begin{array}{l}\text { Es el resultado de la interferencia de las ondas luminosas a } \\
\text { la salida del cristal, y depende de: } \\
\text {-Birrefringencia } \\
\text {-Orientación del cristal } \\
\text { - Espesor del cristal }\end{array}$ \\
\hline & $\begin{array}{l}\text { Angulo de } \\
\text { extinción }\end{array}$ & $\begin{array}{l}\text { Es el ángulo entre las trazas de clivaje o bordes rectos de un } \\
\text { mineral y las direcciones de vibración. }\end{array}$ \\
\hline & Maclas & $\begin{array}{l}\text { Conjunto de dos o más cristales que crecen juntos de } \\
\text { acuerdo a un plano o un eje de simetría. }\end{array}$ \\
\hline
\end{tabular}

Tabla 4.3. Síntesis de los criterios utilizados para la descripción microscópica de los minerales, elaborado y modificado en base a Kerr (1965). 


\section{Determinación de la estructura interna y la composición de muestras de xilópalos}

A los fines de controlar la atribución macroscópica de la materia prima de algunos artefactos a madera fósil y también explorar potenciales fuentes de aprovisionamiento, se analizaron muestras pequeñas $(<50 \mathrm{~mm})$ de xilópalos arqueológicos $(\mathrm{N}=5)$ y paleontológicos $(\mathrm{N}=3)$ en microscopio de barrido electrónico (MEB) marca Philips XL30. Las muestras fueron orientadas en sección longitudinal, pegadas en un taco y posteriormente bañadas con oropaladio. El estudio fue realizado por el Dr. Roberto Pujana, de la Sección Paleobotánica del Museo Argentino de Ciencias Naturales "Bernardino Rivadavia".

En una segunda instancia, los ejemplares fueron sometidos a análisis de composición de elementos mediante la técnica de detector de energía dispersiva EDX (Energy Dispersive X-ray) que permite determinar la composición elemental de las muestras mediante un software. Para esta técnica se utilizó un microscopio de barrido electrónico LSM JEOL-6460 LV (ALUARSAIC) y se contó con el asesoramiento en el preparado de las muestras y captura de las imágenes de los Sres. Jaime Groizard (ALUAR) y Norberto De Garín (CONICET-CENPAT). Este estudio se realizó de manera complementaria y con el objetivo de explorar la validez de la técnica de EDAX para identificar fuentes de aprovisionamiento distintas a partir de las diferencias composicionales de los minerales y elementos de las muestras. 


\section{CAPÍTULO 5}

\section{CARACTERIZACIÓN DE LA BASE REGIONAL DE RECURSOS LÍTICOS}

De acuerdo a como estaba planteado en el capítulo 4 (Metodología), en primer lugar se realizó una recopilación de antecedentes geológicos. En segunda instancia se aplicó una estrategia de muestreo de materias primas líticas en el campo con el propósito de por un lado caracterizar las potenciales fuentes de aprovisionamiento de rocas en relación con la abundancia, forma de presentación y aptitudes de los nódulos para la talla, y, por otro lado, de jerarquizar distintos sectores del espacio en función de la disponibilidad y la productividad relativa de cada fuente (Franco et al. 2012). Por último con el fin de ajustar las denominaciones de las rocas y evaluar potenciales fuentes de proveniencia, se efectuaron 26 cortes delgados para estudios petrográficos de rocas naturales y artefactos arqueológicos representativos de distintas litologías. Sobre la base de estos análisis complementarios se establecieron expectativas arqueológicas respecto de la selección de las materias primas en las dos unidades espaciales de análisis.

\section{Sistematización y delimitación de las unidades geológicas de muestreo}

La caracterización y delimitación de las unidades geológicas se llevó a cabo a partir de la recopilación de la bibliografía geológica disponible. La información provino de la Hoja 4366II de Puerto Madryn (Haller 1981) y la Hoja 4363-I de Península Valdés (Haller et al. 2001), ambas de la región nororiental de la provincia del Chubut. La primera comprende el área adyacente a la costa de los golfos San Matías, San José y Nuevo, y la segunda incluye la península Valdés, la zona de la punta Ninfas de la margen suroriental del golfo Nuevo y la punta Quiroga del extremo noroccidental del golfo San José.

Por su parte, y a los efectos de la contrastación del modelo de uso del espacio de Gómez Otero (2006), los resultados se distribuyeron de acuerdo a las dos grandes unidades arqueológicas de análisis: Península Valdés y Fuera de Península Valdés. Asimismo la unidad Fuera de Península Valdés incluye dos sectores de muestreo: el norte, entre Arroyo Verde y Punta Quiroga, y el sur, entre Punta Ameghino y Bahía Cracker. Esta segmentación espacial se basó sobre dos criterios: un criterio geológico, ya que el sector norte ofrece los únicos afloramientos primarios en el área de estudio (véase capítulo 2: Estado de la Cuestión), y un 
criterio espacial, que tuvo en cuenta la gran extensión de esta unidad de análisis, que por otra parte se encuentra intersectada por el istmo Ameghino.

De acuerdo con la información geológica recopilada se observa que la disponibilidad local de rocas para la talla proviene en su gran mayoría de los depósitos secundarios de rodados (Tablas 5.1 y 5.2). Como se mencionó, en el área de estudio el único afloramiento primario Formación Marifil- se ubica en el límite norte del área de estudio, cuyas litologías predominantes son las ignimbritas, tobas silíceas y riolitas, y las subordinadas son las epiclastitas (tobas y brechas). Asociadas a esta formación, Massaferro y Haller (2000) reconocen vetas de cuarzo blanquecino de aspecto bandeado asociadas a chert silíceo rojizo y texturas de recristalización de calcedonia y de calcita laminar.

Las unidades geológicas de interés arqueológico de mayor distribución espacial están representadas por los Rodados Patagónicos y la Fm. San Miguel que ofrecen gravas de tamaño guija y guijarro, cuyas litologías predominantes son las vulcanitas. Otras formaciones, como la Fm. Caleta Valdés, la Fm. Puerto Lobos y la Fm. Eizaguirre en el sector norte, y la Fm. Bajo Simpson en el sur, presentan una distribución más acotada y restringida a ciertos sectores del espacio (Haller et al. 1997) (Fig. 5.1).

Respecto de las unidades más ubicuas, los Rodados Patagónicos (Fidalgo y Riggi 1970), de origen poligenético -principalmente glaciofluvial- (Lapido y Pereyra 1999), conforman depósitos de hasta ocho metros de espesor que se emplazan sobre las superficies mesetiforme más elevadas (Haller et al. 2001). La Fm. San Miguel (Haller 1981), de edad holocénica (Codignotto 1987; Codignotto y Kokot 1988), se ubica en las playas actuales y en los cordones litorales elevados (a 8 m s.n.m.) y en Puerto Lobos se dispone en forma de dos cordones litorales paralelos a la costa (Haller et al. 2001). Haller et al. (2001) distinguen dos subambientes depositacionales: (a) los depósitos rodeados por paleoacantilados formados por guijarros redondeados y subesféricos que relacionan con un ambiente de playa de alta a mediana energía y sometidos a la acción de las olas, y (b) los depósitos que enfrentan el mar abierto, sin protección de acantilados, formados por cantos rodados de tamaños guijón y guijarro y formas subesféricas y achatadas, que se habrían acumulados por la acción de corrientes de deriva litoral en forma de espigas.

En cuanto a las unidades restringidas espacialmente, la Fm. Caleta Valdés -asignada a una edad post miocénica y pre-holocénica- (Codignotto 1983; Fasano et al.1983), se extiende por toda la margen occidental de la caleta Valdés, y alcanza los $25 \mathrm{~m}$ de potencia. Según los autores, las gravas de esta unidad fueron depositadas por la acción de corrientes litorales y 
representan, en consecuencia, depósitos de acreción marina (Haller et al. 2001). Es importante aclarar en la zona de Caleta Valdés, hay dos grandes espigas de barrera de crecimiento opuesto la norte y la sur- que comenzaron a formarse depués de la máxima transgresión del Holoceno y continúan progradando en la actualidad (Monti y Codignotto 1994).

Por fuera de la unidad Península Valdés y en el límite norte del área de estudio, se ubica la Fm. Puerto Lobos (Cortés 1987) de edad post-pleistocénica temprana y pre-holocénica (Bayarsky y Codignotto 1982). Estos depósitos, que fueron formados por la acreción marina, se distribuyen por la margen occidental del golfo San Matías en forma de cuatro cordones litorales antiguos paralelos a la costa actual y en cotas de hasta $10 \mathrm{~m}$ (Haller et al. 2001). La Fm Eizaguirre (Cortés 1981), asignada al Pleistoceno superior temprano, se desarrolla en una faja de aproximadamente $8 \mathrm{~km}$ de ancho, que con rumbo sur-sudoeste se extiende desde Puerto Lobos hasta el cerro Mesa (Haller et al. 2001). Estos depósitos, cuyo espesor se atenúa de oeste a este, se disponen en bancos estratificados cuyo espesor varía de 2 a $5 \mathrm{~cm}$.

Por último, en el sector meridional de la Hoja 4366-II Puerto Madryn se ubica la Fm Bajo Simpson, de edad pleistocénica y origen fluvial (Haller et al. 2001), relacionados con el antiguo cauce del río Chubut (Stampone 1997). Conforma una faja en forma de arco que rodea la loma María por el oeste, norte y este, y su ancho máximo alcanza 7,5 kilómetros. La unidad está compuesta por rodados tamaño guija, asociados con arenas y limos. Estos depósitos apoyan sobre una depresión labrada en las unidades terciarias aflorantes en la comarca y se encuentran por debajo de los conglomerados de los Rodados Patagónicos.

En síntesis, de la bibliografía consultada se desprende que el sector que ofrece mayor diversidad de formaciones geológicas de interés arqueológico es el sector norte de la unidad de análisis F PV. En el resto, la disponibilidad local de rocas proviene de los rodados de origen marino y glaciofluvial. Con excepción de la Fm. Caleta Valdés y la Fm. San Miguel, que se formaron luego de la máxima transgresión del Holoceno, todas las demás formaciones ya estaban disponibles desde los inicios de la ocupación humana en el área, cuya cronología más antigua es por el momento de 7400 años AP (Gómez Otero 2006). 


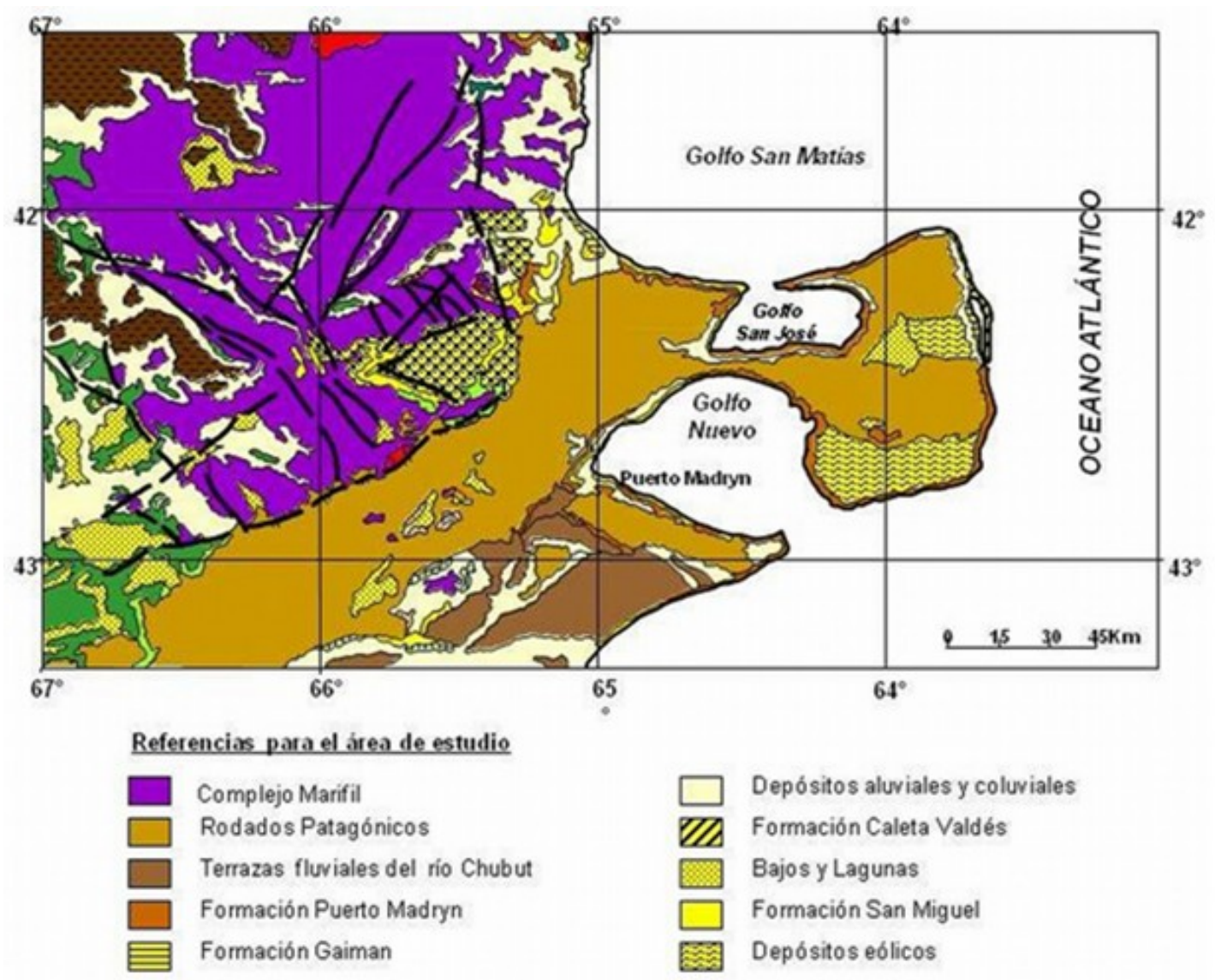

Fig. 5.1. Geología del área de estudio, tomado y modificado de Gómez Otero (2006) 


\begin{tabular}{|c|c|c|c|c|c|}
\hline \multirow[b]{3}{*}{ Período } & \multirow{3}{*}{$\begin{array}{c}\text { UNIDAD } \\
\text { GEOLÓGICA }\end{array}$} & \multirow{3}{*}{ LITOLOGÍA } & \multicolumn{3}{|c|}{ DISTRIBUCIÓN } \\
\hline & & & \multirow[b]{2}{*}{ PENÍNSULA VALDÉS } & \multicolumn{2}{|c|}{ FUERA DE PENÍNSULA VALDÉS } \\
\hline & & & & Sector Norte & Sector Sur \\
\hline \multirow{4}{*}{ 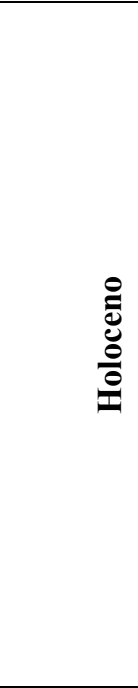 } & $\begin{array}{l}\text { Depósitos aluviales } \\
\text { y coluviales }\end{array}$ & Arenas, gravas y arcillas & $\begin{array}{l}\text { Cubren sectores diseminados } \\
\text { por todo el ámbito de la } \\
\text { Península }\end{array}$ & \multicolumn{2}{|c|}{$\begin{array}{l}\text { Conforman depósitos no consolidados de color gris claro a castaño } \\
\text { oscuro, tamaño arena fina a mediana, mezclada en proporciones } \\
\text { variables con limos, arcillas y rodados dispersos que cubren sectores } \\
\text { diseminados por toda la comarca }\end{array}$} \\
\hline & Depósitos eólicos & Arenas y limos & $\begin{array}{l}\text { En el tercio meridional de la } \\
\text { península Valdés }\end{array}$ & -- & $\begin{array}{l}\text { Al oeste de punta Ninfas, en la } \\
\text { costa sur del golfo Nuevo }\end{array}$ \\
\hline & $\begin{array}{l}\text { Sedimentos finos } \\
\text { de bajos y lagunas }\end{array}$ & $\begin{array}{l}\text { Limos, arcillas, evaporitas } \\
\text { (halita, glauberita y yeso) }\end{array}$ & En las depresiones endorreicas & -- & -- \\
\hline & Fm. San Miguel & $\begin{array}{l}\text { Gravas medianas a gruesas, y } \\
\text { matriz de gravilla, arena gruesa y } \\
\text { fragmentos de bivalvos. Las } \\
\text { gravas son de vulcanitas } \\
\text { mesosilíceas, plutonitas y sílex }\end{array}$ & $\begin{array}{l}\text { Se ubica a } 8 \mathrm{~m} \text { s.n.m, en la } \\
\text { Punta San Román, al norte y } \\
\text { sur de Punta Cono, en Punta } \\
\text { Pardelas y en la margen } \\
\text { oriental de la península }\end{array}$ & $\begin{array}{l}\text { En Puerto Lobos forma } \\
\text { dos cordones litorales } \\
\text { paralelos a la costa, de un } \\
\text { espesor de } 500 \text { metros }\end{array}$ & $\begin{array}{l}\text { En el golfo Nuevo conforma fajas } \\
\text { angostas de terrazas de acreción marina } \\
\text { cercanas a la costa que se disponen al } \\
\text { norte de Puerto Madryn, en la playa El } \\
\text { Doradillo. Hacia el sur, se ubica } \\
\text { conforman elevaciones en el sector } \\
\text { costero entre punta Loma y cerro } \\
\text { Avanzado }\end{array}$ \\
\hline \multirow{4}{*}{ 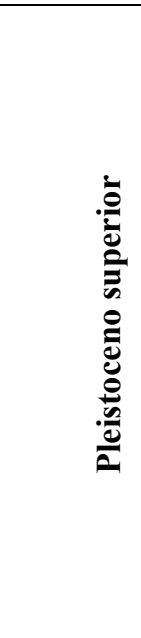 } & Fm. Caleta Valdés & Gravas medianas a gruesas & $\begin{array}{l}\text { Margen occidental de caleta } \\
\text { Valdés }\end{array}$ & -- & -- \\
\hline & Fm. Bajo Simpson & $\begin{array}{l}\text { Gravas tamaño guija, con arenas } \\
\text { y limos }\end{array}$ & -- & -- & $\begin{array}{l}\text { Sector meridional, en el Bajo Simpson, } \\
\text { y conforma una faja con forma de arco } \\
\text { que rodea la loma María por el oeste, } \\
\text { norte y este }\end{array}$ \\
\hline & Fm. Puerto Lobos & $\begin{array}{l}\text { Gravas medianas a gruesas, bien } \\
\text { redondeadas, y conglomerados }\end{array}$ & -- & $\begin{array}{l}\text { Margen occidental del } \\
\text { golfo San Matías, en } \\
\text { forma de cuatro cordones } \\
\text { litorales antiguos } \\
\text { paralelos a la costa actual }\end{array}$ & -- \\
\hline & Fm. Eizaguirre & $\begin{array}{l}\text { Gravas tamaño guija a guijarro, } \\
\text { subangulosos, de volcánicas, } \\
\text { plutónicas, sedimentitas y limos }\end{array}$ & -- & $\begin{array}{l}\text { Se distribuye en una faja } \\
\text { de } 8 \mathrm{~km} \text { de ancho, desde } \\
\text { Puerto Lobos } \\
\text { hasta el cerro Mesa }\end{array}$ & -- \\
\hline
\end{tabular}

Tabla 5.1. Distribución de las Unidades Geológicas y litologías asociadas del Cuaternario, tomado y modificado de Haller 1981 ; Haller et al. 1987,2001 ; Cortés 1987. 


\begin{tabular}{|c|c|c|c|c|c|}
\hline \multirow[t]{3}{*}{ Período } & \multirow{3}{*}{$\begin{array}{c}\text { UNIDAD } \\
\text { GEOLÓGICA }\end{array}$} & \multirow{3}{*}{ LITOLOGÍA } & \multicolumn{3}{|c|}{ DISTRIBUCIÓN } \\
\hline & & & \multirow[t]{2}{*}{ PENÍNSULA VALDÉS } & \multicolumn{2}{|c|}{ FUERA DE PENÍNSULA VALDÉS } \\
\hline & & & & Sector Norte & Sector Sur \\
\hline 童 & $\begin{array}{c}\text { Rodados } \\
\text { Patagónicos }\end{array}$ & $\begin{array}{l}\text { Gravas subesféricos a } \\
\text { subelongados, de vulcanitas, } \\
\text { silíces, andesíticas y basálticas }\end{array}$ & $\begin{array}{l}\text { Sector central del istmo } \\
\text { Ameghino y en la comarca } \\
\text { occidental y central de la } \\
\text { península }\end{array}$ & \multicolumn{2}{|c|}{$\begin{array}{l}\text { Se distribuyen desde el ángulo suroccidental de la Hoja en dirección } \\
\text { noroeste hasta alcanzar la costa del golfo San Matías }\end{array}$} \\
\hline$\stackrel{\circlearrowright}{\stackrel{\Xi}{\circlearrowright}}$ & Fm. Puerto Madryn & Areniscas, pelitas y coquinas & $\begin{array}{l}\text { Aflora en forma continua hacia } \\
\text { el sur, hasta la punta Delgada y } \\
\text { desde allí, hacia el oeste, por } \\
\text { toda la margen meridional de } \\
\text { la península }\end{array}$ & \multicolumn{2}{|c|}{$\begin{array}{l}\text { En el sector septentrional, con rumbo noroeste desde el paralelo } 42^{\circ} \text {, } \\
\text { al este de la ruta } \mathrm{N}^{\circ} 3 \text {, hasta el bajo del Gualicho }\end{array}$} \\
\hline 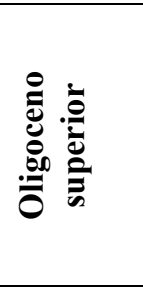 & Fm. Gaiman & $\begin{array}{l}\text { Limos cineríticos, } \\
\text { arcillitas y areniscas }\end{array}$ & $\begin{array}{l}\text { Asomos reducidos en las } \\
\text { barrancas que limitan el golfo } \\
\text { san Matías, desde el extremo } \\
\text { occidental hasta la punta } \\
\text { Buenos Aires. Desde hasta la } \\
\text { margen oeste del golfo San } \\
\text { José }\end{array}$ & \multicolumn{2}{|c|}{ En la zona costera y sectores adyacentes al mar } \\
\hline 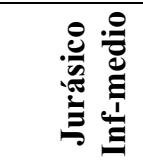 & Complejo Marifil & $\begin{array}{l}\text { Lavas. Piroclasticas y rocas } \\
\text { hipabisales asociadas }\end{array}$ & -- & $\begin{array}{l}\text { Se registra en el sector centro- } \\
\text { occidental y nor-occidental y su límite } \\
\text { meridional coincide con la traza de la } \\
\text { ruta prov. } \mathrm{N}^{\circ} 4\end{array}$ & -- \\
\hline
\end{tabular}

Tabla 5.2. Distribución de las Unidades Geológicas y litologías asociadas del Mesozoico y Cenozoico en el área de estudio, tomado y modificado de Haller (1981); Haller et al. $(1987,2001)$ y Cortés (1987). 


\section{Estudios de disponibilidad de materias primas líticas}

Sobre la base de la información geológica y los antecedentes previos (Gómez Otero 2006; Gómez Otero et al. 1999) se llevaron a cabo muestreos sistemáticos y al azar en las dos grandes unidades de análisis arqueológicas y en distintas geoformas marinas características del área del área de estudio (Fig. 5.2 y 5.7). Se muestrearon todos los sectores costeros. En primer lugar se describen los muestreos de la unidad Península Valdés, y luego los resultados alcanzados para la unidad de análisis Fuera de Península Valdés (sector norte y sur).

\section{Muestreos de rocas en Península Valdés}

En esta unidad de análisis se realizaron seis muestreos, representativos de distintos sectores de costa: los golfos San José, San Matías y Nuevo, y Caleta Valdés (Figura 5.2).

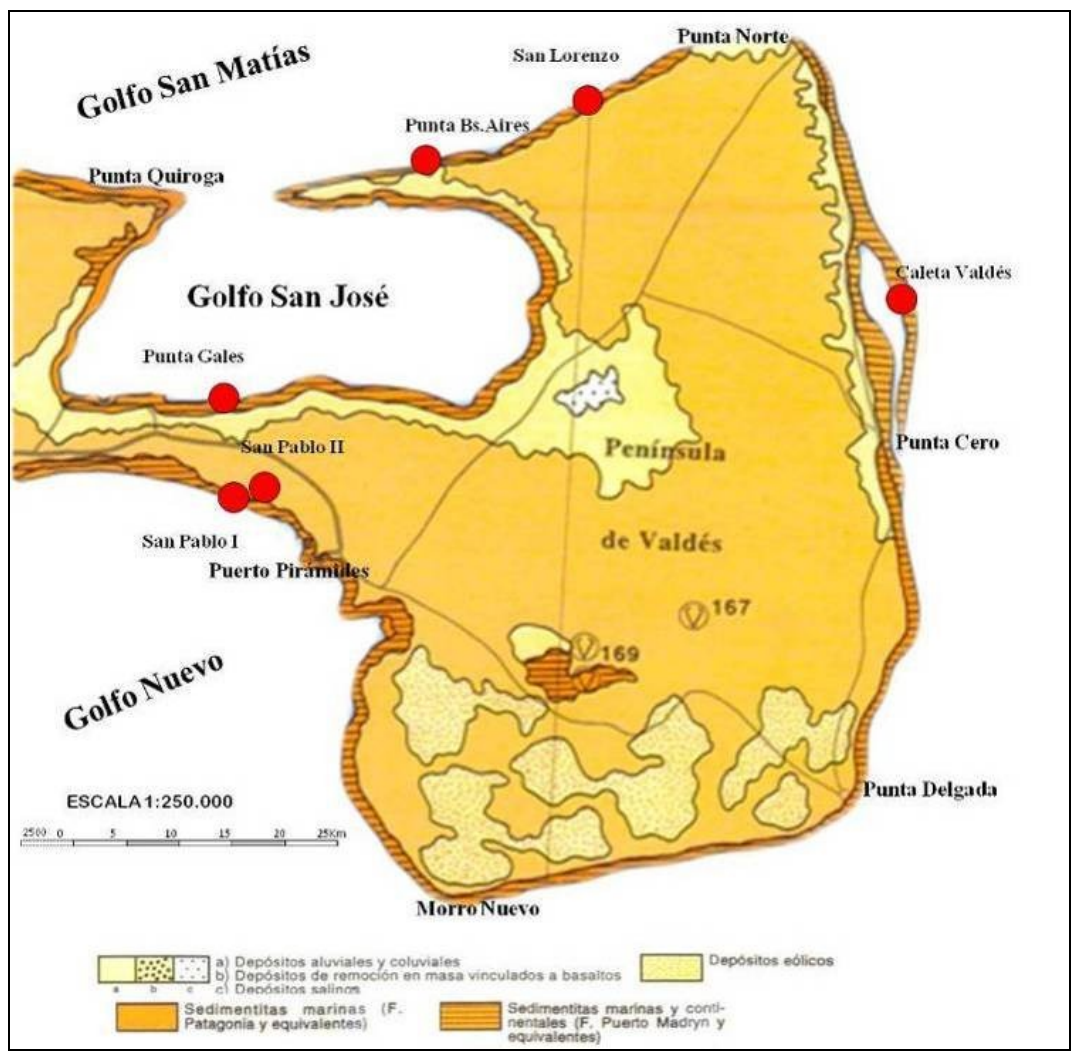

Fig.5.2. Hoja Geológica de Chubut, modificada de Haller et al. 1981. Los puntos rojos indican la localización de los muestreos.

Se recolectó un total de 80 nódulos en distintas geoformas: en tres cordones litorales $(n=39$ rodados $)$, en dos bermas $(n=32)$ y en la espiga de barrera norte de Caleta Valdés $(n=9)$. 
Tal como se consignó en el capítulo 4 de Metodología, solamente se seleccionaron los de calidad regular a excelente. En la tabla 5.3 se consigna la ubicación de los muestreos, el tiempo y la cantidad de nódulos obtenidos por una sola persona. A los efectos de evaluar comparativamente el rendimiento de cada de muestreo se calculó el promedio de nódulos obtenibles por minuto.

\begin{tabular}{|c|c|c|c|c|c|c|}
\hline Muestreo rocas & Geoforma & Altitud m s.n.m. & Lat. S/ Long. O & $\begin{array}{c}T \\
\text { (minutos) }\end{array}$ & $\begin{array}{c}\mathrm{N}= \\
\text { nódulos }\end{array}$ & $\begin{array}{c}\text { Prom/ } \\
\text { min }\end{array}$ \\
\hline Pta. BsAs I & $\begin{array}{l}\text { Cordon } \\
\text { litoral }\end{array}$ & 5 & $\begin{array}{l}42^{\circ} 12^{\prime} 53.49^{\prime \prime} \\
64^{\circ} 14^{\prime} 59.33^{\prime \prime}\end{array}$ & 10 & 12 & 1,2 \\
\hline San Lorenzo I & $\begin{array}{l}\text { Cordon } \\
\text { litoral }\end{array}$ & 4 & $\begin{array}{l}42^{\circ} 29^{\prime} 29.07^{\prime \prime} \\
64^{\circ} 34^{\prime} 4.04^{\prime \prime}\end{array}$ & $10^{\prime}$ & 14 & 1,4 \\
\hline San Pablo I & $\begin{array}{l}\text { Cordon } \\
\text { litoral }\end{array}$ & 7 & $\begin{array}{l}42^{\circ} 30^{\prime} 1.19^{\prime \prime} \\
64^{\circ} 29^{\prime} 22.48^{\prime \prime}\end{array}$ & $15^{\prime}$ & 13 & 0,86 \\
\hline San Pablo II & Berma & 3 & $\begin{array}{l}42^{\circ} 30^{\prime} 18.21^{\prime \prime} \\
64^{\circ} 27^{\prime} 34.56^{\prime \prime}\end{array}$ & $20^{\prime}$ & 26 & 1,3 \\
\hline Pta. Gales I & Berma & 4 & $\begin{array}{l}42^{\circ} 25^{\prime} 43.02^{\prime \prime} \\
64^{\circ} 30^{\prime} 50.61^{\prime \prime}\end{array}$ & $10^{\prime}$ & 6 & 0,6 \\
\hline Caleta Valdés I & Espiga & 5 & $\begin{array}{l}42^{\circ} 18^{\prime} 37.67^{\prime \prime} \\
63^{\circ} 36^{\prime} 49.07^{\prime \prime}\end{array}$ & $10^{\prime}$ & 9 & 0,9 \\
\hline
\end{tabular}

Tabla 5.3. Sectores y geoformas muestreados en Península Valdés. Referencias: $(\mathrm{T})$ : tiempo; $(\mathrm{Pe})$ : personas; (Prom): promedio de nódulos por minutos.

En el muestreo de Punta Buenos Aires I (Fig. 5.2) se reconocieron cuatro litologías (Tabla 4.4), destacándose los basaltos (76\%); el resto se distribuye entre dacitas, cuarcitas y sílices ( $8 \%$ de cada una). De acuerdo con la aptitud para la talla, los basaltos presentan muy buena a excelente calidad, buena la cuarcita y la sílice, y regular la dacita. El tamaño promedio de los rodados es de $62,7 \mathrm{~mm}$ (Tabla 5.5), distinguiéndose redondeados espesos $(\mathrm{n}=5)$, redondeados chatos $(n=4)$ y subredondeados $(n=3)$. Para el muestreo de San Lorenzo I (Fig. 5.3) las clases litológicas son ocho (Tabla 5.4), con predominio de sílices (36\%) y basalto (22\%); para el resto -andesita, riolita, cuarcita, ópalo, calcedonia y xilópalo- solo se halló un nódulo de cada una (7\%). Las rocas de calidad excelente son calcedonia y ópalo, el xilópalo y la cuarcita presentan muy buena calidad, los basaltos, sílices y riolitas son de buena calidad y la andesita es regular. En cuanto al tamaño máximo de los rodados se estableció que en promedio miden 52,2 mm (Tabla 5.5), destacándose los redondeados -chatos $(\mathrm{n}=8)$ y espesos $(\mathrm{n}=4)$ sobre los subredondeados $(\mathrm{n}=2)$.

En San Pablo I (Fig. 5.4) se identificaron dos tipos de rocas (Tabla 5.4), distribuidas entre basaltos (92\%) y sílices (8\%). Los basaltos son de muy buena a buena calidad y el único rodado de sílice es de muy buena calidad. El tamaño promedio de los rodados es de 66,7 mm 
(Tabla 5.5). En cuanto a la morfología de los clastos hay subredondeados $(n=8)$ y redondeados chatos $(n=5)$. Para el muestreo de San Pablo II las litologías reconocidas son cuatro (Tabla 5.4); sobresalen los basaltos (50\%), seguidos por sílices (27\%) y en tercer lugar riolitas (19\%). Una roca no pudo ser identificada (4\%). Basaltos y sílices muestran calidades variables (de muy buena a regular), las riolitas y la roca indeterminada son de calidad regular. El tamaño promedio de los rodados es de 54,1 mm (Tabla 5.5) y las formas son mayoritariamente subredondeadas $(n=19)$, seguidas por las redondeadas espesas $(n=6)$ y chatas $(n=1)$.

En el muestreo Punta Gales I (Fig. 5.5) se identificaron dos litologías (Tabla 5.4): basaltos $(83 \%)$ y una riolita (17\%). Los primeros son de calidad muy buena a buena y la riolita, de calidad regular. El tamaño promedio es de 50,1 mm (Tabla 5.5), con formas subredondeadas $(n=4)$ y subangulares $(n=2)$.

Del muestreo de la espiga de Caleta Valdés (Fig.5.6) se reconocieron tres litologías (Tabla 5.4): riolitas (56\%), basaltos (33\%) y una roca indeterminada (11\%). Todas las rocas son de calidad regular para la talla. El tamaño promedio de los nódulos es de 83,7 mm (Tabla 5.5) y predominan los redondeados -seis espesos y uno chato- sobre los subredondeados $(n=2)$.

\begin{tabular}{|c|c|c|c|c|c|c|c|c|c|c|c|c|c|c|c|c|c|c|c|c|}
\hline \multirow{2}{*}{ Muestreos } & \multicolumn{2}{|c|}{$\mathbf{B a}$} & \multicolumn{2}{|c|}{ Da } & \multicolumn{2}{|c|}{ Ad } & \multicolumn{2}{|c|}{$\mathbf{R i}$} & \multicolumn{2}{|c|}{$\mathrm{Cc}$} & \multicolumn{2}{|c|}{ Op } & \multicolumn{2}{|c|}{ Si } & \multicolumn{2}{|c|}{$\mathrm{Ca}$} & \multicolumn{2}{|c|}{$\mathbf{X i}$} & \multicolumn{2}{|c|}{ Ind } \\
\hline & $\mathrm{N}$ & $\%$ & & $\%$ & $\mathrm{~N}$ & $\%$ & $\mathrm{~N}$ & $\%$ & $\mathrm{~N}$ & $\%$ & $\mathrm{~N}$ & $\%$ & $\mathrm{~N}$ & $\%$ & $\mathrm{~N}$ & $\%$ & $\mathrm{~N}$ & $\%$ & $\mathrm{~N}$ & $\%$ \\
\hline PBsAs I & 9 & 76 & 1 & 8 & - & - & - & - & 1 & 8 & - & - & 1 & 8 & - & - & - & - & - & - \\
\hline SLorenzo I & 3 & 22 & & - & 1 & 7 & 1 & 7 & 1 & 7 & 1 & 7 & 5 & 36 & 1 & 7 & 1 & 7 & - & - \\
\hline SPablo I & 12 & 92 & 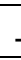 & - & - & - & - & - & - & - & - & - & 1 & 8 & - & - & - & & - & - \\
\hline SPablo II & 13 & 50 & 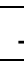 & - & - & - & 5 & 19 & - & - & - & - & 7 & 27 & - & - & - & - & 1 & 4 \\
\hline PGales I & 5 & 83 & & - & - & - & 1 & 17 & - & - & - & - & - & - & - & - & - & - & - & - \\
\hline CValdés I & 3 & 33 & 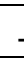 & - & - & - & 5 & 56 & - & - & - & - & - & - & - & - & - & - & 1 & 11 \\
\hline Total & \multicolumn{2}{|c|}{$\begin{array}{c}45 \\
(56 \%)\end{array}$} & \multicolumn{2}{|c|}{$\begin{array}{c}1 \\
(1 \%)\end{array}$} & \multicolumn{2}{|c|}{$\begin{array}{c}1 \\
(1 \%)\end{array}$} & \multicolumn{2}{|c|}{$\begin{array}{c}12 \\
(15 \%)\end{array}$} & \multicolumn{2}{|c|}{$\begin{array}{c}2 \\
(3 \%)\end{array}$} & \multicolumn{2}{|c|}{$\begin{array}{c}1 \\
(1 \%)\end{array}$} & \multicolumn{2}{|c|}{14} & \multicolumn{2}{|c|}{$\begin{array}{c}1 \\
(1 \%)\end{array}$} & \multicolumn{2}{|c|}{$\begin{array}{c}1 \\
(1 \%)\end{array}$} & \multicolumn{2}{|c|}{$\begin{array}{c}2 \\
(3 \%)\end{array}$} \\
\hline
\end{tabular}

Tabla 5.4. Frecuencias litológicas $x$ muestreo. Referencias. Ba (basalto); Da (dacita); Ad (andesita); Ri (riolita); Cc (cuarcita); Op (ópalo); Si (sílice); Ca (calcedonia); Xi (xilópalo); Ind (indeterminada). 


\begin{tabular}{|c|c|c|c|c|c|c|c|c|c|c|c|}
\hline \multicolumn{2}{|l|}{ Muestreos } & \multirow{2}{*}{$\begin{array}{c}\mathbf{B a} \\
34-81 \\
\end{array}$} & \multirow{2}{*}{$\begin{array}{c}\text { Ad } \\
--\end{array}$} & \multirow{2}{*}{$\begin{array}{l}\mathbf{D a} \\
97\end{array}$} & \multirow{2}{*}{$\begin{array}{c}\mathbf{R i} \\
--\end{array}$} & \multirow{2}{*}{$\begin{array}{l}\text { Cc } \\
62 \\
\end{array}$} & \multirow{2}{*}{$\begin{array}{c}\text { Op } \\
-- \\
\end{array}$} & \multirow{2}{*}{$\begin{array}{l}\mathbf{S i} \\
38 \\
\end{array}$} & \multirow{2}{*}{$\begin{array}{c}\mathbf{C a} \\
-- \\
\end{array}$} & \multirow{2}{*}{$\begin{array}{c}\mathbf{X i} \\
--\end{array}$} & \multirow{2}{*}{$\begin{array}{c}\text { Ind } \\
--\end{array}$} \\
\hline \multirow{3}{*}{ Pta.BsAS I } & Larmax & & & & & & & & & & \\
\hline & Anc-max & $32-54$ & -- & 64 & -- & 56 & -- & 23 & -- & -- & -- \\
\hline & Espmax & $19-33$ & -- & 38 & -- & 23 & -- & 22 & -- & -- & -- \\
\hline \multirow{3}{*}{ SLorenz I } & Larmax & $50-82$ & 68 & -- & 37 & 35 & 48 & $30-56$ & 74 & 53 & -- \\
\hline & Anc-max & $29-48$ & 28 & -- & 32 & 32 & 34 & $25-47$ & 56 & 25 & -- \\
\hline & Espmax & $25-27$ & 22 & -- & 24 & 23 & 22 & $17-23$ & 37 & 26 & -- \\
\hline \multirow{3}{*}{ SPablo I } & Larmax & $50-80$ & -- & -- & -- & -- & -- & 60 & -- & -- & -- \\
\hline & Anc-max & $20-27$ & -- & -- & -- & -- & -- & 40 & -- & -- & -- \\
\hline & Espmax & $20-50$ & -- & -- & -- & -- & -- & 33 & -- & -- & -- \\
\hline \multirow{3}{*}{ SPablo II } & Larmax & $27-70$ & -- & -- & $51-80$ & -- & -- & $38-60$ & -- & -- & 58 \\
\hline & Anc-max & $25-40$ & -- & -- & $30-40$ & -- & -- & $28-32$ & -- & -- & 28 \\
\hline & Espmax & $15-45$ & -- & -- & $27-40$ & -- & -- & $17-27$ & -- & -- & 27 \\
\hline \multirow{3}{*}{ PGales I } & Larmax & $43-63$ & -- & -- & 46 & -- & -- & -- & -- & -- & -- \\
\hline & Anc-max & $24-41$ & -- & -- & 33 & -- & -- & -- & -- & -- & -- \\
\hline & Espmax & $11-26$ & -- & -- & 26 & -- & -- & -- & -- & -- & -- \\
\hline \multirow{3}{*}{ CValdés I } & Larmax & $66-71$ & -- & -- & $78-108$ & -- & -- & -- & -- & -- & 92 \\
\hline & Anc-max & $54-60$ & -- & -- & $57-79$ & -- & -- & -- & -- & -- & 76 \\
\hline & Espmax & $26-36$ & -- & -- & $29-59$ & -- & -- & -- & -- & -- & 37 \\
\hline
\end{tabular}

Tabla 5.5. Tamaños de los nódulos (en $\mathrm{mm}$ ) por materia prima.

Sobre la base de los muestreos de rocas realizados en la unidad Península Valdés se pudo corroborar que las únicas formaciones geológicas que contienen gravas y guijarros potencialmente utilizables para la talla lítica son los Rodados Patagónicos, la Fm. San Miguel y la Fm. Caleta Valdés. Estos depósitos presentan una distribución espacial concentrada; sin embargo la superposición de las distintas unidades geológicas en algunas de las geoformas impide correlacionar el origen de los depósitos con una formación geológica específica. Por ejemplo, los rodados asignados a la Fm. San Miguel (Haller 1981) se ubican tanto en los depósitos de las playas actuales como también en los cordones litorales elevados de las márgenes de la Península Valdés y de los golfos Nuevo, San José y San Matías (Haller et al. 2001).

En cuanto a la litología, se determinaron diez variedades entre las que preponderan los basaltos $(56 \%)$, seguidos por las sílices (18\%) y las riolitas (15\%). Los basaltos presentan calidad buena a excelente, las sílices buena calidad y las riolitas regular. Por su parte, la calidad de las materias primas varía entre los distintos muestreos: los rodados de las bermas y los cordones litorales ofrecen en porcentaje materias primas de mejor aptitud (buena a muy buena): $92,3 \%$ en los cordones litorales y más del $71,8 \%$ en las bermas. En contraste, los nódulos de la 
espiga de barrera son todos de calidad regular. Respecto de la forma y tamaño de los rodados también se observaron diferencias entre las distintas geoformas: en los cordones litorales son mayoría los clastos redondeados chatos $(66,6 \%)$, en las bermas sobresalen los subredondeados de formas elípticas $(62,5 \%)$ y en la espiga son mayoría los redondeados espesos $(77,7 \%)$. En cuanto al largo máximo de los nódulos (Tabla 5.5), el promedio varía entre las geoformas: los más chicos están disponibles en las bermas $(53,1 \mathrm{~mm})$ y los cordones litorales $(58,4 \mathrm{~mm})$, y los mayores en la espiga $(83,7 \mathrm{~mm})$. Por último, respecto de la cantidad de nódulos por unidad de tiempo, en las bermas osciló entre 0,6 y 1,3 rodados por minuto; en los cordones litorales entre 0,86 y 1,4 y en la espiga se obtuvo un valor de 0,9 nódulos.

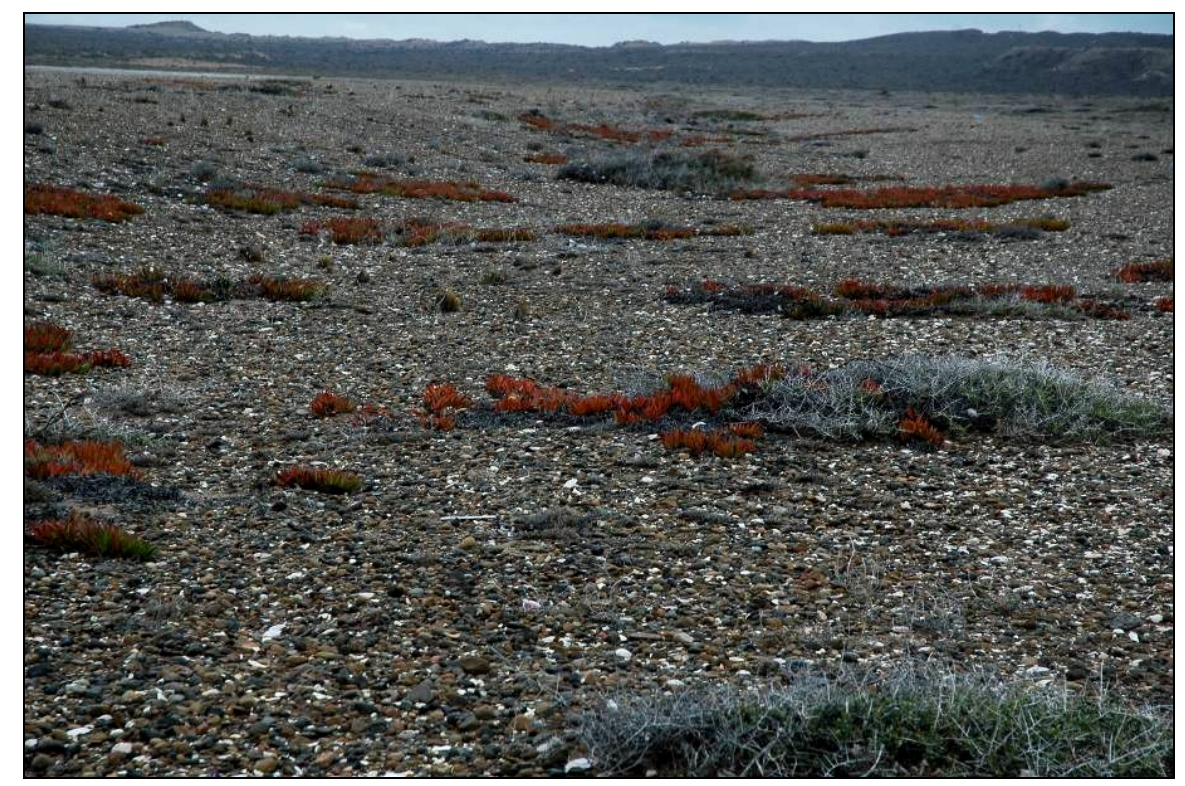

Fig. 5. 3. Muestreo cordón litoral, Punta Buenos Aires.

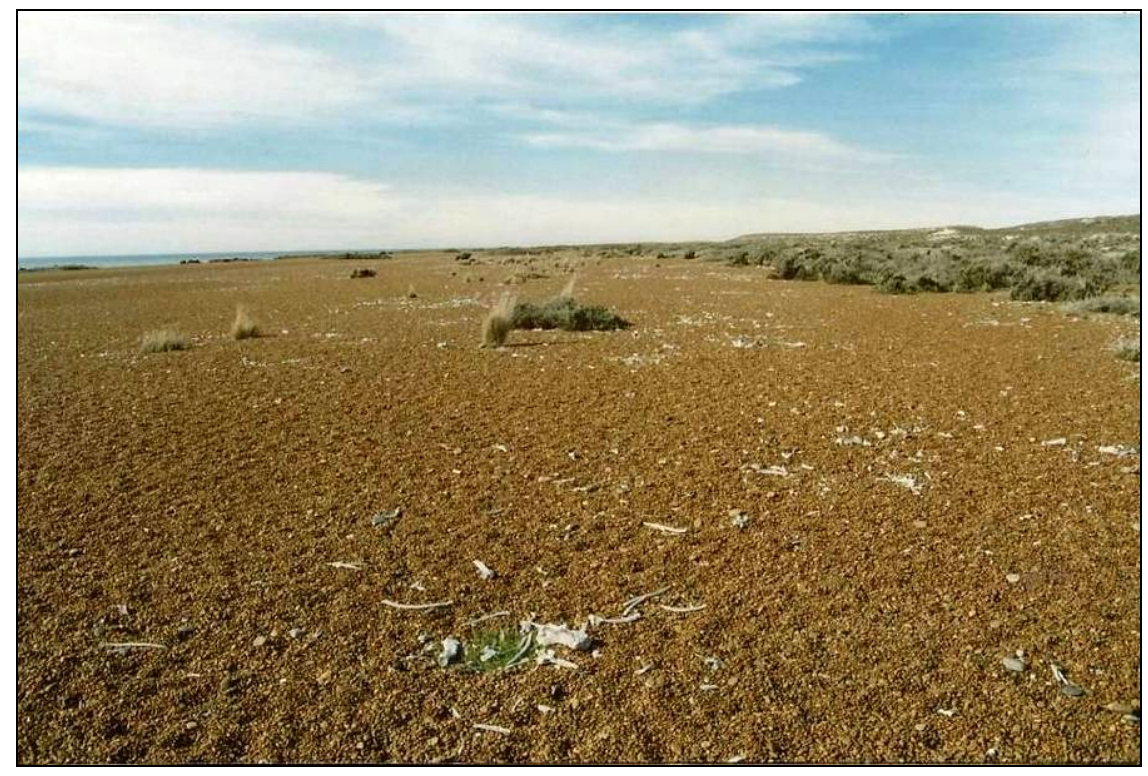


Fig. 5.4. Muestreo playa San Lorenzo.

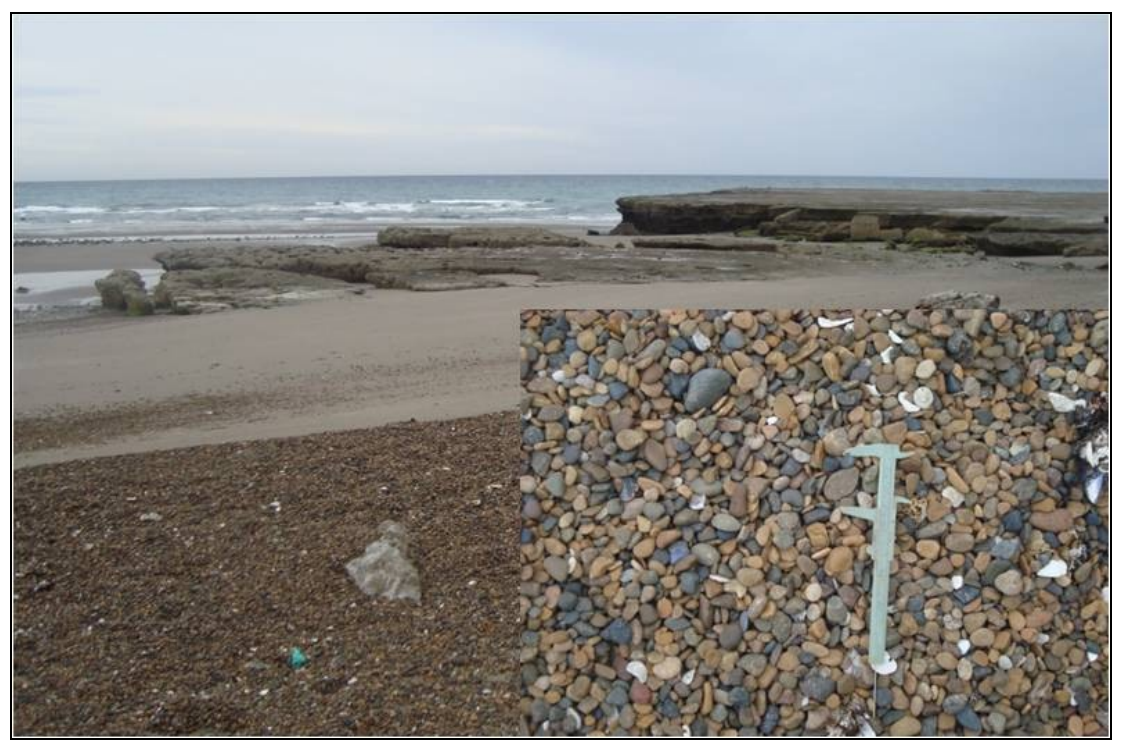

Fig. 5.5. Muestreo berma, Playa del medio, San Pablo.

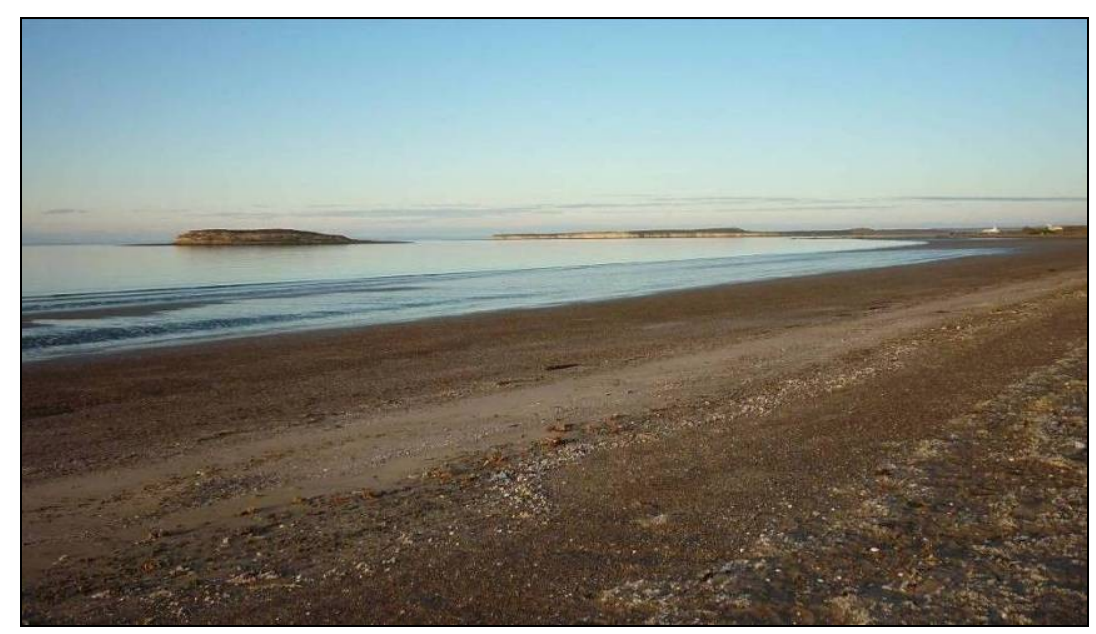

Fig. 5. 6. Muestreo playa actual, Punta Gales.

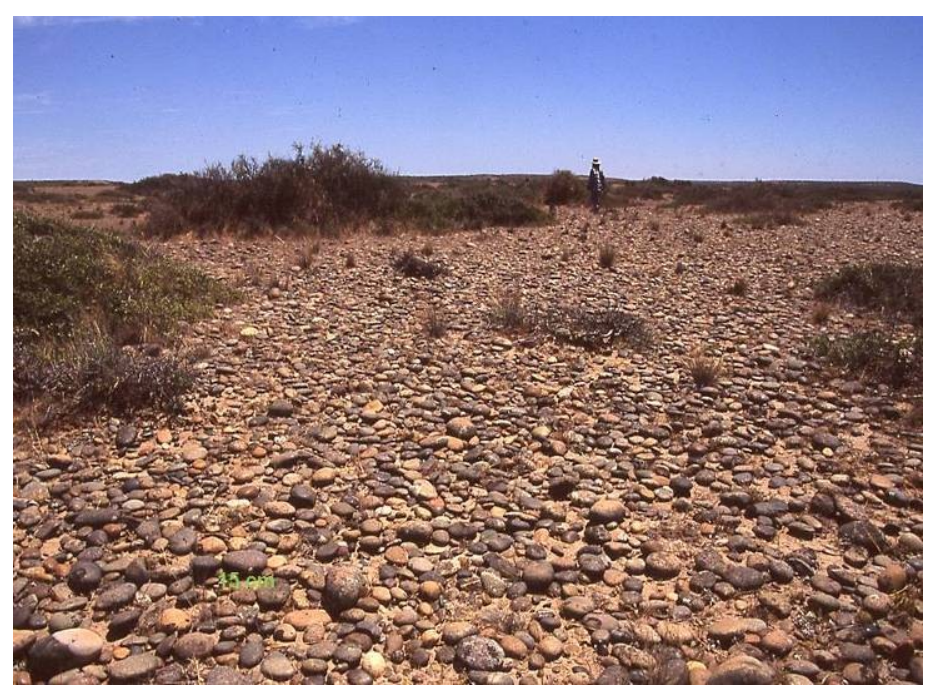

Fig. 5.7. Muestreo en Caleta Valdés. 


\section{Muestreos de rocas Fuera de Península Valdés}

Sector Norte: golfo San Matías Oeste (GSMO)

Se realizaron tres muestreos sistemáticos y una recolección asistemática en arroyo Verde (Fig. 5.8 y Tabla 5.6). Si bien esta última localidad se encuentra en Río Negro y no corresponde al área de estudio, fue prospectada y muestreada por su oferta de fuentes primarias y su proximidad con Puerto Lobos (20 kilómetros).

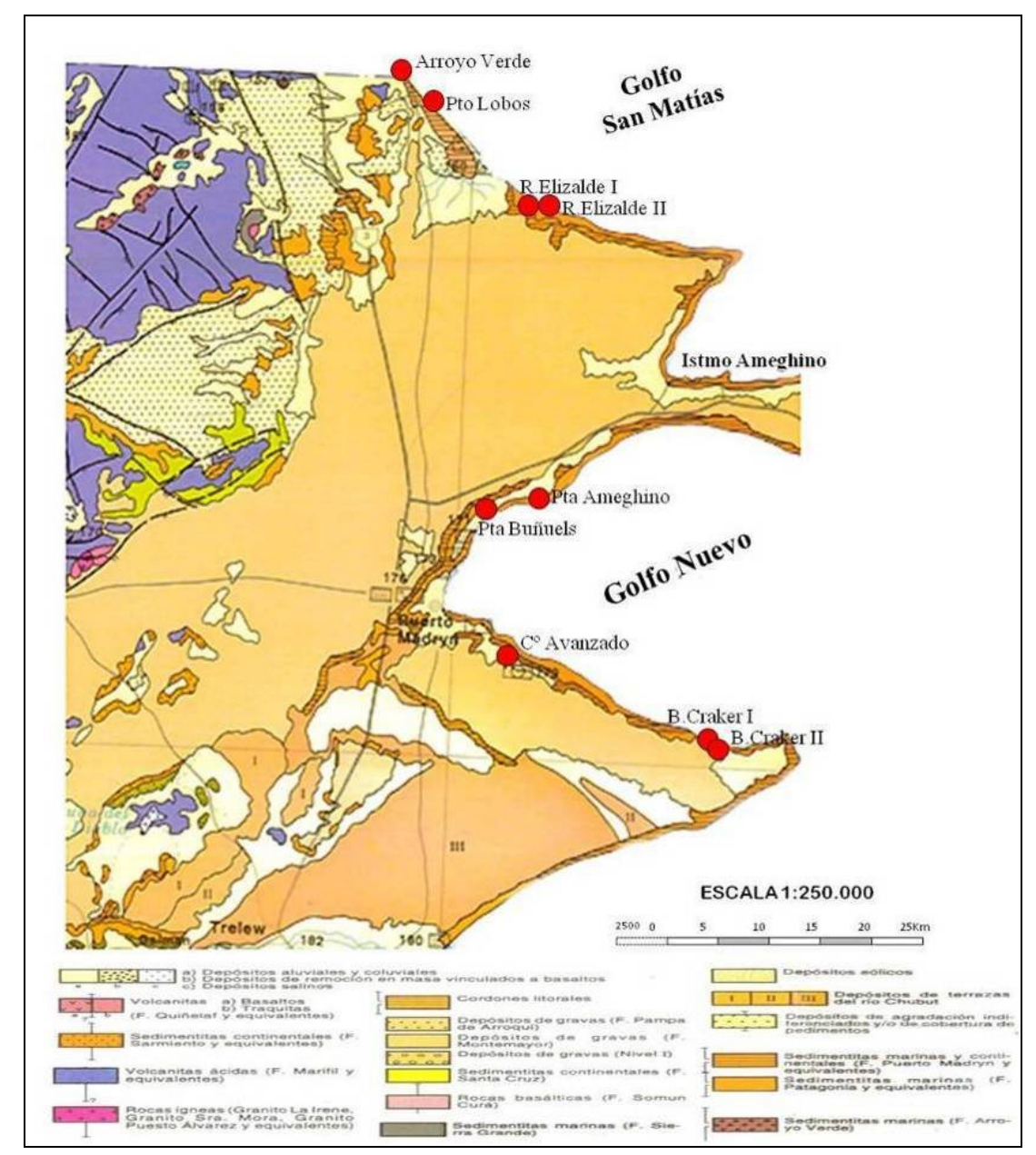

Fig.5. 8. Hoja Geológica de Chubut, modificada de Haller et al. 1981. Los puntos rojos indican la localización de los muestreos.

Los nódulos recolectados suman un total de 60. La recolección de arroyo Verde consistió en un muestreo asistemático $(n=10)$ en la margen norte de su desembocadura y también se efectuó una prospección costa-interior de seis kilómetros, que cubrió una superficie total de $1200 \mathrm{~m}^{2}$. Durante la misma se describieron y fotografiaron las rocas y los afloramientos. 
En Puerto Lobos se muestreó un cordón litoral $(\mathrm{n}=24)$ y en Rincón de Elizalde un cordón litoral $(\mathrm{n}=14)$ y una berma $(\mathrm{n}=12)$, (Tabla 5.6). Los muestreos fueron realizados por una única persona.

\begin{tabular}{|c|c|c|c|c|c|c|}
\hline $\begin{array}{l}\text { GSMO } \\
\text { Muestreos }\end{array}$ & Geoforma & $\begin{array}{l}\text { Altitud } \\
\text { m s.n.m }\end{array}$ & $\begin{array}{l}\text { Lat. S/ } \\
\text { Long. O }\end{array}$ & $\begin{array}{c}T \\
\text { (minutos) }\end{array}$ & $\begin{array}{c}\mathrm{N}= \\
\text { Nódulos }\end{array}$ & $\begin{array}{c}\text { Prom } \\
\text { T x Pers. }\end{array}$ \\
\hline Arroyo & & & $41^{\circ} 55^{\prime} 40.44 "$ & & 10 & \\
\hline Verde & Cordón litoral & 8 & $65^{\circ} 3^{\prime} 57.10^{\prime \prime}$ & & & \\
\hline Inicio-final & & 25 & $\begin{array}{l}41^{\circ} 56^{\prime} 42.93^{\prime \prime} \\
65^{\circ} 5^{\prime} 11.40^{\prime \prime}\end{array}$ & -- & & -- \\
\hline $\begin{array}{l}\text { Puerto } \\
\text { Lobos I }\end{array}$ & Cordón litoral & 7 & $\begin{array}{l}42^{\circ} 0^{\prime} 16.86^{\prime \prime} \\
65^{\circ} 4^{\prime} 11.37^{\prime \prime}\end{array}$ & $15^{\prime}$ & 24 & 1,6 \\
\hline REliz I & Cordón litoral & 13 & $\begin{array}{c}42^{\circ} 08.02 .2 \\
64^{\circ} 68.03 .9\end{array}$ & $15^{\prime}$ & 14 & 0,9 \\
\hline REliz II & Berma & 8 & $\begin{array}{l}42^{\circ} 07.57 .4 \\
64^{\circ} 58.16 .0\end{array}$ & $15^{\prime}$ & 12 & 0,8 \\
\hline
\end{tabular}

Tabla 5.6. Sectores y geoformas muestreados en el GSMO. Referencias: (T): tiempo; $(\mathrm{Pe})$ : personas; (Prom): promedio, (min) minuto.

En el muestreo asistemático de Arroyo Verde (Fig. 5.8) se recolectaron diez nódulos: tres rodados respectivamente de calcedonias y riolitas, dos de cuarcitas, un basalto vesicular y un conglomerado (Tabla 5.7). Las calcedonias son de excelente a muy buena calidad, y se presentan como nódulos de entre 38 y $53 \mathrm{~mm}$ de largo máximo. Las riolitas y las cuarcitas muestran calidad regular y tamaño superior (55 a $110 \mathrm{~mm}$ ) (Tabla 5.8). La gran mayoría de los clastos son subredondeados $(\mathrm{N}=5)$; subangulares $(\mathrm{N}=3)$ y angulares $(\mathrm{N}=2)$. Por su parte, la prospección costa-interior permitió registrar asomos de la Fm. Marifil a distancias entre 1,5 y 2 $\mathrm{km}$ de la línea de marea, así como también concentraciones de tabletas de calcedonias con corteza en forma globular (Fig. 5.9 y 5.10).

En el muestreo de Puerto Lobos (Fig. 5.11) se reconocieron cinco litologías (Tabla 5.7), con predominio de riolitas $(37 \%)$ y basaltos $(21 \%)$, seguidos por andesitas e ignimbritas $(17 \%$ cada una). En menor proporción se encuentran las calcedonias (8\%). Respecto de la aptitud de las rocas para talla se determinó que los basaltos varían entre calidad muy buena a regular; riolitas, andesitas e ignimbritas son todas regulares, y la calcedonia es de muy buena calidad. El tamaño máximo de los clastos es en promedio de $80 \mathrm{~mm}$ (Tabla 5.8), y predominan los subredondeados $(n=12)$ sobre los redondeados $(n=2)$ y angulares $(n=2)$.

En Rincón de Elizalde I/CL (Fig. 5.12) se identificaron ocho variedades de rocas (Tabla 5.7): riolitas (29\%), andesitas (21\%), sílices (15\%) y en menor proporción ignimbrita, granito, cuarcita, ópalo y calcedonia ( $7 \%$ cada una). El tamaño promedio de los clastos es de 63,5 mm (Tabla 4.8), entre los que se destacan las formas subredondeadas $(n=12)$. 
En Rincón de Elizalde II/B las variedades litológicas son cinco (Tabla 5.7): basaltos y riolitas (33\%), seguidas por calcedonias (17\%), y cuarcita e ignimbrita ( $8,5 \%$ cada una). El tamaño promedio de los clastos es de 63,3 mm (Tabla 5.8), subredondeados $(n=7)$ en su mayoría, seguidos por los redondeados $(n=4)$ y una ignimbrita de forma angular. En cuanto a la aptitud de las rocas para la talla se determinaron distintas calidades: excelente a muy buena las calcedonias; buena los basaltos, ópalos y cuarcitas; regular a buena las riolitas, y regular las dacitas, ignimbritas, granitos y cuarcitas.

En síntesis, para los muestreos del sector norte de la unidad Fuera de Península Valdés, se determinaron en total once variedades litológicas, entre las que predominan las riolitas $(33,3 \%)$, seguidas por basaltos $(15 \%)$ y calcedonias $(13,3 \%)$ y en tercer lugar andesitas $(11,6 \%)$ e ignimbritas (10\%). El resto -sílice; cuarcita, ópalo, granito, conglomerado y basalto vesicularno supera el 3\%. Riolitas, ignimbritas y calcedonias están disponibles localmente a través de la Fm. Marifil, cuyos asomos más cercanos a la costa se encuentran entre 1,5 y $2 \mathrm{~km}$ de distancia de la actual línea de marea.

En cuanto a la calidad de las rocas para la talla, dado que las más abundantes son las de textura porfídica, como las riolitas y las ignimbritas, en general predominan las materias primas de calidad regular. No obstante se observaron diferencias entre las geoformas: en la berma sobresalen los rodados de excelente a buena calidad (66,7\%) mientras que en los cordones litorales las materias primas de calidad regular (52,3\%) están parejas con las de mayor aptitud. En cuanto a la morfología de los clastos, prevalecen las formas subredondeadas ( $63,1 \%$ y 58,3\% en la berma y cordones litorales respetivamente), seguidas por las redondeadas, mayoritariamente espesas $(28,9 \%$ y 33,3$)$ y con valores bajos las angulares $(7,8 \%$ y $5,3 \%)$. En relación con el largo máximo promedio de los rodados los de la berma son más chicos $(63,3$ $\mathrm{mm})$ que los de los cordones litorales $(73,9 \mathrm{~mm})$. Respecto de la cantidad de nódulos recolectados por minuto, en los cordones litorales varió entre 0,9 a 1,6 y en la berma fue de 0,8. 


\begin{tabular}{|c|c|c|c|c|c|c|c|c|c|c|c|c|c|c|c|c|c|c|c|c|c|c|}
\hline \multirow{2}{*}{$\begin{array}{l}\text { GSMO } \\
\text { Muestreos }\end{array}$} & \multicolumn{2}{|c|}{$\mathbf{B a}$} & \multicolumn{2}{|c|}{ Ad } & \multicolumn{2}{|c|}{ BV } & \multicolumn{2}{|c|}{$\mathrm{Cn}$} & \multicolumn{2}{|c|}{ Ign } & \multicolumn{2}{|c|}{$\mathbf{R i}$} & \multicolumn{2}{|c|}{ Gr } & \multicolumn{2}{|c|}{ Cc } & \multicolumn{2}{|c|}{ Op } & \multicolumn{2}{|c|}{ Si } & \multicolumn{2}{|c|}{$\mathrm{Ca}$} \\
\hline & $\mathrm{N}$ & $\%$ & $\mathrm{~N}$ & $\%$ & $\mathrm{~N}$ & $\%$ & $\mathrm{~N}$ & $\%$ & $\mathrm{~N}$ & $\%$ & $\mathrm{~N}$ & $\%$ & $\mathrm{~N}$ & $\%$ & $\mathrm{~N}$ & $\%$ & $\mathrm{~N}$ & $\%$ & $\mathrm{~N}$ & $\%$ & $\mathrm{~N}$ & $\%$ \\
\hline AVerde & - & - & - & - & 1 & 10 & 1 & 10 & - & - & 3 & 30 & - & - & 2 & 20 & - & - & - & - & 3 & 30 \\
\hline Pto Lobos & 5 & 21 & 4 & 17 & - & - & - & - & 4 & 17 & 9 & 37 & - & - & - & - & - & - & - & - & 2 & 8 \\
\hline Reliz I/CL & - & - & 3 & 21 & - & - & - & - & 1 & 7 & 4 & 29 & 1 & 7 & 1 & 7 & 1 & 7 & 2 & 15 & 1 & 7 \\
\hline Reliz II/B & 4 & 33 & - & - & - & - & - & - & 1 & 8,5 & 4 & 33 & - & - & 1 & 8,5 & - & - & - & - & 2 & 17 \\
\hline Total & & $\%$ & (11 & $\%$ & & $1 \%$ & & $1 \%$ & & 6 & & $\%$ & & $\%)$ & & & & $\%)$ & & & & \%) \\
\hline
\end{tabular}

Tabla 5.7. Frecuencias litológicas $x$ muestreo sistemático. Referencias. Ba (Basalto); Ad (Andesita); BV (basalto vesicular);

Cn (conglomerado); Ign (Ignimbrita); Ri (Riolita); Gr (Granito); Cc (Cuarcita); Op (Ópalo); Si (Sílice); Ca (Calcedonia).

\begin{tabular}{|c|c|c|c|c|c|c|c|c|c|c|c|c|}
\hline GSMO Muestreos & & $\mathrm{Ba}$ & Ad & $\mathrm{BV}$ & $\mathrm{Cn}$ & Ign & $\mathrm{Ri}$ & $\mathrm{Gr}$ & $\mathrm{Cc}$ & Op & $\mathrm{Si}$ & $\mathrm{Ca}$ \\
\hline \multirow{3}{*}{$\begin{array}{c}\text { Arroyo } \\
\text { Verde }\end{array}$} & Larmax & - & - & 86 & 69 & - & $55-100$ & - & $62-113$ & - & - & $38-78$ \\
\hline & Ancmax & - & - & 66 & 44 & - & $48-77$ & - & $49-98$ & - & - & $36-53$ \\
\hline & Espmax & - & - & 48 & 31 & - & $30-52$ & - & $20-56$ & - & - & $15-30$ \\
\hline \multirow{3}{*}{$\begin{array}{l}\text { Puerto } \\
\text { Lobo I }\end{array}$} & Larmax & $51-90$ & $60-97$ & - & - & $77-132$ & 46-106 & $\mathrm{nc}$ & $\mathrm{nc}$ & $\mathrm{nc}$ & $\mathrm{nc}$ & $75-102$ \\
\hline & Ancmax & $38-55$ & 44-54 & - & - & 49-77 & 34-64 & $\mathrm{nc}$ & $\mathrm{nc}$ & $\mathrm{nc}$ & $\mathrm{nc}$ & 44-52 \\
\hline & Espmax & $19-40$ & $23-27$ & - & - & $25-36$ & $22-53$ & $\mathrm{nc}$ & $\mathrm{nc}$ & $\mathrm{nc}$ & $\mathrm{nc}$ & $33-45$ \\
\hline \multirow{3}{*}{ Reliz I/CL } & Larmax & $\mathrm{nc}$ & $59-94$ & - & - & 87 & $42-90$ & 105 & 34 & 45 & $46-53$ & 34 \\
\hline & Ancmax & $\mathrm{nc}$ & $40-50$ & - & - & 52 & $38-57$ & 55 & 30 & 21 & $27-31$ & 32 \\
\hline & Espmax & $\mathrm{nc}$ & $29-35$ & - & - & 36 & $23-39$ & 35 & 23 & 23 & $19-22$ & 15 \\
\hline \multirow{3}{*}{ Reliz II/B } & Larmax & $51-66$ & $\mathrm{nc}$ & - & - & 58 & $67-91$ & $\mathrm{nc}$ & 34 & $\mathrm{nc}$ & $\mathrm{nc}$ & 54-63 \\
\hline & Ancmax & $33-42$ & $\mathrm{nc}$ & - & - & 43 & $47-60$ & $\mathrm{nc}$ & 29 & $\mathrm{nc}$ & $\mathrm{nc}$ & $42-43$ \\
\hline & Espmax & $22-31$ & nc & - & - & 28 & $25-40$ & $\mathrm{nc}$ & 17 & $\mathrm{nc}$ & $\mathrm{nc}$ & $26-28$ \\
\hline
\end{tabular}

Tabla 5.8: tamaños de los nódulos (en mm) 


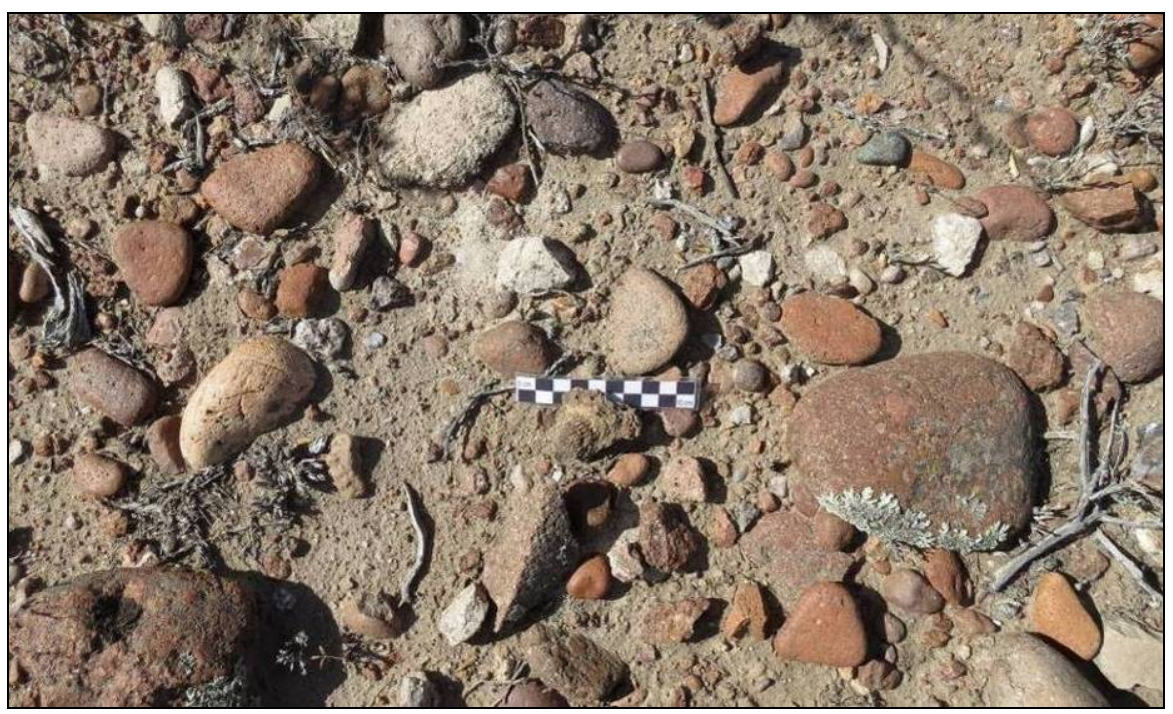

Fig. 5.8. Muestreo al azar, margen norte del arroyo Verde.

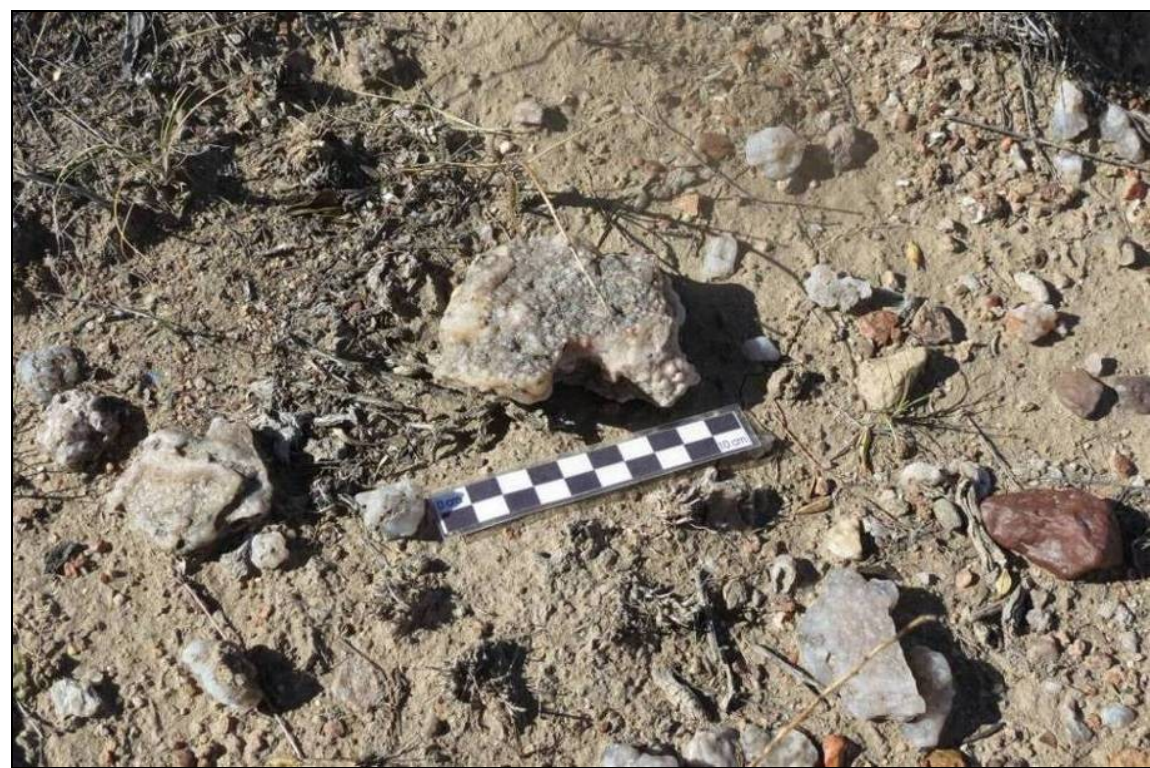

Fig. 5.9. Muestreo de Arroyo Verde: concentración de tabletas de calcedonia blanquecina de textura globulosa. 


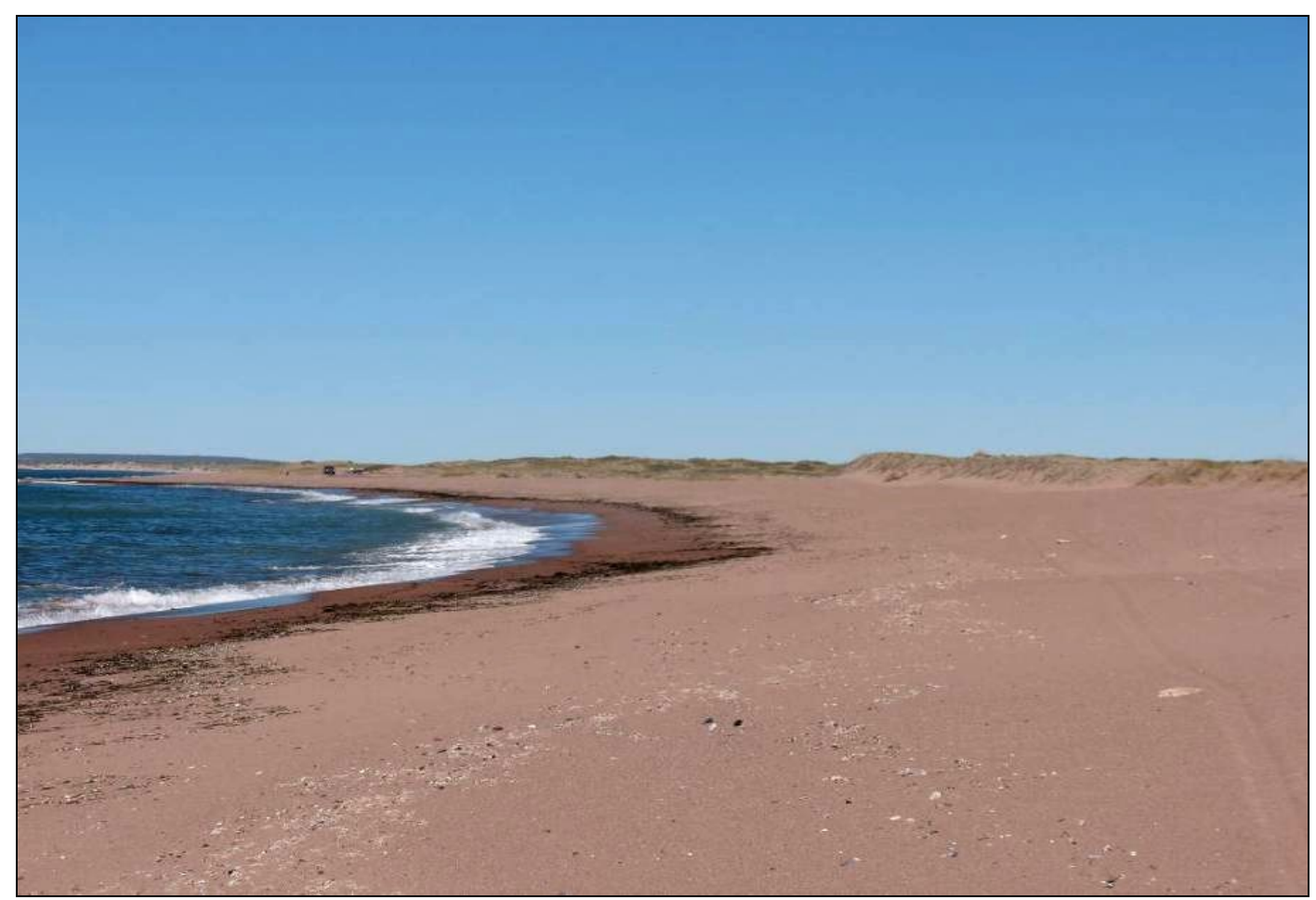

Fig. 5.11. Muestreo en playa Puerto Lobos.

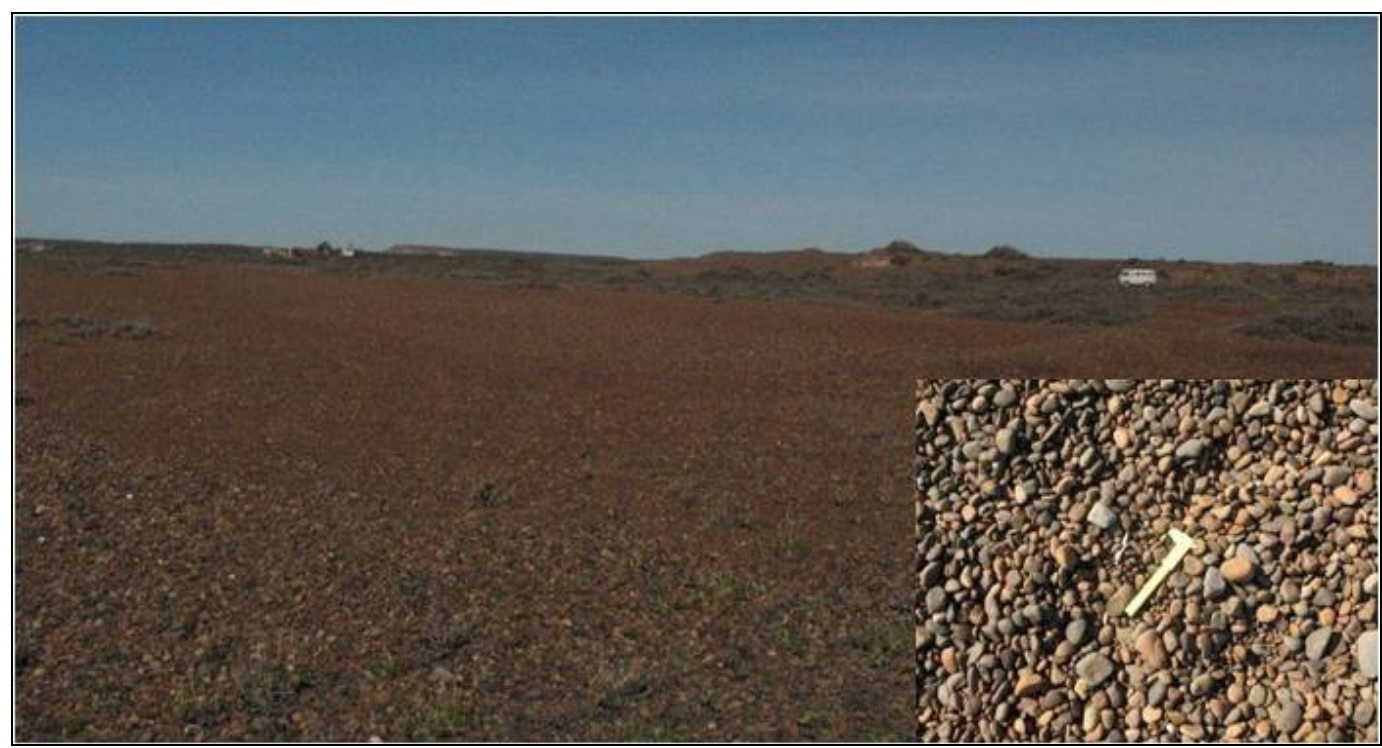

Fig. 5.12. Muestreo Ea. La Esperanza, Fundación Patagonia Natural.

\section{Sector Sur: Golfo Nuevo (GN)}

En el tramo costero que incluye el golfo Nuevo se llevaron a cabo cinco muestreos sistemáticos (Fig. 5.7), recolectándose 92 nódulos en total. Dos muestreos se efectuaron sobre terrazas marinas (Cerro Avanzado y Bahía Cracker II), dos sobre cordones litorales (punta Ameghino y Bahía Cracker I) y uno en una berma: playa Buñuels (Tabla 5.9). Con excepción de 
cerro Avanzado donde el muestreo fue realizado por dos personas, en el resto las recolecciones fueron hechas por una sola persona.

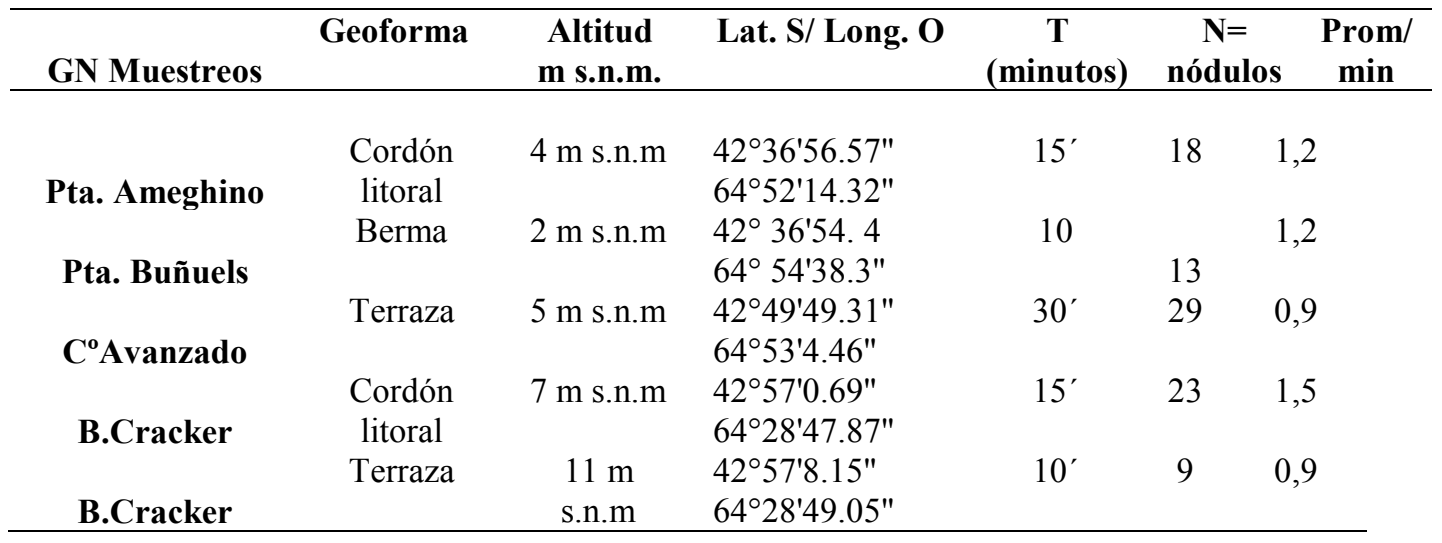

Tabla 5.9. Sectores y geoformas muestreados en FP-GNvo Sur. Referencias: T: tiempo; Pe: personas.

En el muestreo de Punta Ameghino I se identificaron cinco litologías (Fig. 5.13 y Tabla 5.10), entre las cuales sobresalen los basaltos (67\%), seguidos por las riolitas (16,5\%); por último, $\mathrm{y}$ en baja frecuencia, se ubican ignimbritas, sílices y calcedonias $(5,5 \%$ respectivamente). Entre los basaltos prevalecen los rodados de buena calidad $(n=8)$, la calcedonia es de muy buena y el resto -ignimbrita, riolita y sílice- de buena calidad. El tamaño promedio de los clastos es de $56,7 \mathrm{~mm}$ (Tabla 5.11) con predominio de los redondeados chatos $(n=13)$, seguidos por los redondeados espesos $(n=2)$ y los subredondeados $(n=3)$.

En Punta Buñuels (Fig. 5.14) las variedades litológicas son ocho: basaltos (30\%), andesitas y cuarcitas (15\% respectivamente), y dacita, ignimbrita, riolita, ópalo y calcedonia (8\% cada una) (Tabla 5.10). La calidad de las rocas es mayoritariamente buena, excepto la calcedonia y el ópalo, que son de muy buena calidad y las dacitas e ignimbritas, de calidad regular. El tamaño promedio de los rodados es de 71,3 $\mathrm{mm}$ (Tabla 5.11), sobresaliendo los subredondeados $(n=10)$, y en segundo lugar los subangulares $(n=3)$.

En Cerro Avanzado I (Fig. 5.15) se reconocieron siete variedades de rocas: más de la mitad corresponde a basaltos (55\%), el resto se distribuye en riolitas (16,5\%); dacitas $(10 \%)$, sílices $(6,8 \%)$ y en tobas, ópalos y calcedonia (3,4\% para cada una) (Tabla 5.10). Los basaltos son de distintas calidades (de muy buena a regular); calcedonia y ópalo son de muy buena calidad y las demás de calidad buena. El tamaño promedio de los nódulos es de 49,3 mm (Tabla 5.11). La mayoría de los clastos son de forma redondeada (chatos y espesos) $(n=20)$, el resto son subredondeados $(\mathrm{n}=8)$ y sólo se registró un rodado subangular de basalto 
En el muestreo de bahía Cracker I CL (Fig. 5.16) las litologías son cuatro; en frecuencias similares se ubican basaltos y sílices (39\%), seguidas por cuarcita (18\%) y por ultimo un nódulo de calcedonia (4\%) (Tabla 5.10). Basaltos y sílices presentan calidades variables (regular, buena y muy buena); las cuarcitas buena calidad y la calcedonia muy buena. El tamaño promedio de los rodados es $66 \mathrm{~mm}$ (Tabla 5.11) con formas mayoritariamente redondeadas: chatas $(n=16)$ y espesas $(n=2)$; el resto $(n=5)$ son subredondeados. En bahía Cracker II B las variedades litológicas son tres, destacándose sílices (56\%) y basaltos (33\%) y por último, las cuarcitas (11\%). Los rodados de basalto y de sílice son de calidad regular a buena, y la cuarcita de buena calidad. El tamaño promedio es de $89,3 \mathrm{~mm}$, y entre las formas hay redondeados - chatos $(n=4)$ y espesos $(n=2)$ - y tres son subredondeados.

En síntesis, en los muestreos del golfo Nuevo se identificaron diez litologías, entre las que predominan los basaltos (48\%), en segundo lugar sílices (18\%) y en baja frecuencia (inferior al 10\%) el resto de las litologías. En cuanto a la calidad de las rocas para la talla, en todas las geoformas prevalecen las de buena a muy buena calidad: 92,6\% en los cordones litorales, $76,9 \%$ en la berma y $73,6 \%$ en las terrazas. Respecto de la forma de los clastos, en todas las geoformas se destacan los redondeados chatos: en las bermas $(76,9 \%)$, en los cordones litorales $(70,7 \%)$ y en las terrazas $(64,5 \%)$. Por su parte, el largo máximo de los nódulos varía en promedio entre los distintos sectores: $60,1 \mathrm{~mm}$ en las terrazas; $61,8 \mathrm{~mm}$ en los cordones litorales y 71, $3 \mathrm{~mm}$ para los rodados de la berma. No obstante, hay notorias diferencias en el tamaño de los rodados en las terrazas: en Bahía Cracker (89,8 mm) y en Cerro Avanzado (50,9 $\mathrm{mm})$. Por último y en relación con la productividad de cada depósito muestreado, en las terrazas se obtuvieron 0,9 rodados por unidad de tiempo; en los cordones litorales entre 1,2 y 1,5 nódulos y en la berma 1,2 . 


\begin{tabular}{|c|c|c|c|c|c|c|c|c|c|c|c|c|c|c|c|c|c|c|c|c|}
\hline \multirow{2}{*}{ Muestreos } & \multicolumn{2}{|c|}{$\mathrm{Ba}$} & \multicolumn{2}{|c|}{$\mathrm{Da}$} & \multicolumn{2}{|c|}{$\mathrm{Ad}$} & \multicolumn{2}{|c|}{ Ign } & \multicolumn{2}{|c|}{$\mathrm{Ri}$} & \multicolumn{2}{|c|}{ Tob } & \multicolumn{2}{|c|}{$\mathrm{Cc}$} & \multicolumn{2}{|c|}{ Op } & \multicolumn{2}{|c|}{$\mathrm{Si}$} & \multicolumn{2}{|c|}{$\mathrm{Ca}$} \\
\hline & $\mathrm{N}$ & $\%$ & $\mathrm{~N}$ & $\%$ & $\mathrm{~N}$ & $\%$ & & $\%$ & $\mathrm{~N}$ & $\%$ & $\mathrm{~N}$ & $\%$ & $\mathrm{~N}$ & $\%$ & $\mathrm{~N}$ & $\%$ & $\mathrm{~N}$ & $\%$ & $\mathrm{~N}$ & $\%$ \\
\hline P. Ameghino I & 12 & 67 & - & - & - & - & 1 & 5,5 & 3 & 16,5 & - & - & - & - & - & - & 1 & 5,5 & 1 & 5,5 \\
\hline Playa Buñuels I & 4 & 30 & 1 & 8 & 2 & 15 & 1 & 8 & 1 & 8 & - & - & 2 & 15 & 1 & 8 & - & - & 1 & 8 \\
\hline $\mathrm{C}^{\mathrm{o}}$ Avanzado I & 16 & 55 & 3 & 10 & - & - & - & - & 5 & 17 & 1 & 3,4 & - & - & 1 & 3,4 & 2 & 6,8 & 1 & 3,4 \\
\hline B Cracker I CL & 9 & 39 & - & - & - & - & - & - & - & - & - & - & 4 & 18 & - & - & 9 & 39 & 1 & 4 \\
\hline BCrack II T & 3 & $33 \%$ & - & - & - & - & - & - & - & - & - & - & 1 & 11 & - & - & 5 & 56 & - & - \\
\hline Total & \multicolumn{2}{|c|}{$\begin{array}{c}44 \\
(48 \%) \\
\end{array}$} & \multicolumn{2}{|c|}{$\begin{array}{c} \\
(4 \%) \\
\end{array}$} & \multicolumn{2}{|c|}{$\begin{array}{c}2 \\
(2 \%) \\
\end{array}$} & \multicolumn{2}{|c|}{$\begin{array}{c}2 \\
(2 \%)\end{array}$} & \multicolumn{2}{|c|}{$\begin{array}{c}9 \\
(10 \%) \\
\end{array}$} & \multicolumn{2}{|c|}{$\begin{array}{c}1 \\
(1 \%) \\
\end{array}$} & \multicolumn{2}{|c|}{$\begin{array}{c}7 \\
(9 \%) \\
\end{array}$} & \multicolumn{2}{|c|}{$\begin{array}{c}2 \\
(2 \%) \\
\end{array}$} & \multicolumn{2}{|c|}{$\begin{array}{c}17 \\
(18 \%) \\
\end{array}$} & \multicolumn{2}{|c|}{$\begin{array}{c}4 \\
(4 \%) \\
\end{array}$} \\
\hline
\end{tabular}

Tabla 5.10. Frecuencias litológicas x muestreo. Referencias. Ba (basalto); Da (dacita); Ad (andesita); Ign (ignimbrita); Ri (riolita); Cc (cuarcita); Op (ópalo); Si (sílice); Ca (calcedonia).

\begin{tabular}{|c|c|c|c|c|c|c|c|c|c|c|c|}
\hline \multicolumn{2}{|c|}{$\mathrm{N}^{\mathrm{o}}$ muestreo } & $\mathrm{Ba}$ & Ad & $\mathrm{Da}$ & Ign & $\mathrm{Ri}$ & $\mathrm{Cc}$ & Op & $\mathrm{Si}$ & $\mathrm{Ca}$ & $\mathrm{Tb}$ \\
\hline \multirow{3}{*}{ Pta. Ameghino I } & Larmax & 41-79 & $\mathrm{nc}$ & $\mathrm{nc}$ & 57 & $59-87$ & $\mathrm{nc}$ & $\mathrm{nc}$ & 43 & 47 & $\mathrm{nc}$ \\
\hline & Ancmax & $31-64$ & $\mathrm{nc}$ & $\mathrm{nc}$ & 36 & $46-59$ & $\mathrm{nc}$ & $\mathrm{nc}$ & 33 & 34 & $\mathrm{nc}$ \\
\hline & Espmax & $21-57$ & $\mathrm{nc}$ & $\mathrm{nc}$ & 40 & $37-42$ & $\mathrm{nc}$ & $\mathrm{nc}$ & 22 & 28 & $\mathrm{nc}$ \\
\hline \multirow{3}{*}{ Pta Buñuels I } & Larmax & $59-82$ & $77-109$ & 63 & 59 & 91 & 51-89 & 59 & $\mathrm{nc}$ & 56 & $\mathrm{nc}$ \\
\hline & Ancmax & $34-48$ & $51-74$ & 45 & 42 & 59 & $31-78$ & 46 & $\mathrm{nc}$ & 29 & $\mathrm{nc}$ \\
\hline & Espmax & $13-29$ & $18-31$ & 29 & 29 & 28 & $28-36$ & 14 & $\mathrm{nc}$ & 21 & $\mathrm{nc}$ \\
\hline \multirow{3}{*}{$\mathrm{C}^{\mathrm{o}}$ Avanzado I } & Larmax & $32-88$ & $\mathrm{nc}$ & $36-63$ & $\mathrm{nc}$ & $49-76$ & $\mathrm{nc}$ & 35 & $39-49$ & 40 & 39 \\
\hline & Ancmax & $25-52$ & $\mathrm{nc}$ & $30-53$ & $\mathrm{nc}$ & $32-61$ & $\mathrm{nc}$ & 34 & $27-33$ & 35 & 38 \\
\hline & Espmax & $14-38$ & $\mathrm{nc}$ & $21-34$ & $\mathrm{nc}$ & $16-34$ & $\mathrm{nc}$ & 15 & $13-24$ & 20 & 24 \\
\hline \multirow{3}{*}{ BCracker I CL } & Larmax & $50-83$ & $\mathrm{nc}$ & $\mathrm{nc}$ & $\mathrm{nc}$ & $\mathrm{nc}$ & $54-67$ & $\mathrm{nc}$ & $54-82$ & 66 & $\mathrm{nc}$ \\
\hline & Ancmax & $42-54$ & $\mathrm{nc}$ & $\mathrm{nc}$ & $\mathrm{nc}$ & $\mathrm{nc}$ & $37-57$ & $\mathrm{nc}$ & $38-61$ & 50 & $\mathrm{nc}$ \\
\hline & Espmax & $22-39$ & $\mathrm{nc}$ & $\mathrm{nc}$ & $\mathrm{nc}$ & $\mathrm{nc}$ & $20-34$ & $\mathrm{nc}$ & $17-38$ & 35 & $\mathrm{nc}$ \\
\hline \multirow[t]{3}{*}{ BCracker II T } & Larmax & $70-82$ & $\mathrm{nc}$ & $\mathrm{nc}$ & $\mathrm{nc}$ & $\mathrm{nc}$ & 100 & $\mathrm{nc}$ & $62-126$ & $\mathrm{nc}$ & $\mathrm{nc}$ \\
\hline & Ancmax & $40-59$ & $\mathrm{nc}$ & $\mathrm{nc}$ & $\mathrm{nc}$ & $\mathrm{nc}$ & 50 & $\mathrm{nc}$ & $57-79$ & $\mathrm{nc}$ & $\mathrm{nc}$ \\
\hline & Espmax & $25-30$ & $\mathrm{nc}$ & $\mathrm{nc}$ & $\mathrm{nc}$ & $\mathrm{nc}$ & 37 & $\mathrm{nc}$ & $26-71$ & $\mathrm{nc}$ & $\mathrm{nc}$ \\
\hline
\end{tabular}

Tabla 5.11. Tamaños (en mm) de los nódulos recuperados en Fuera de Península Valdés, sector sur. 


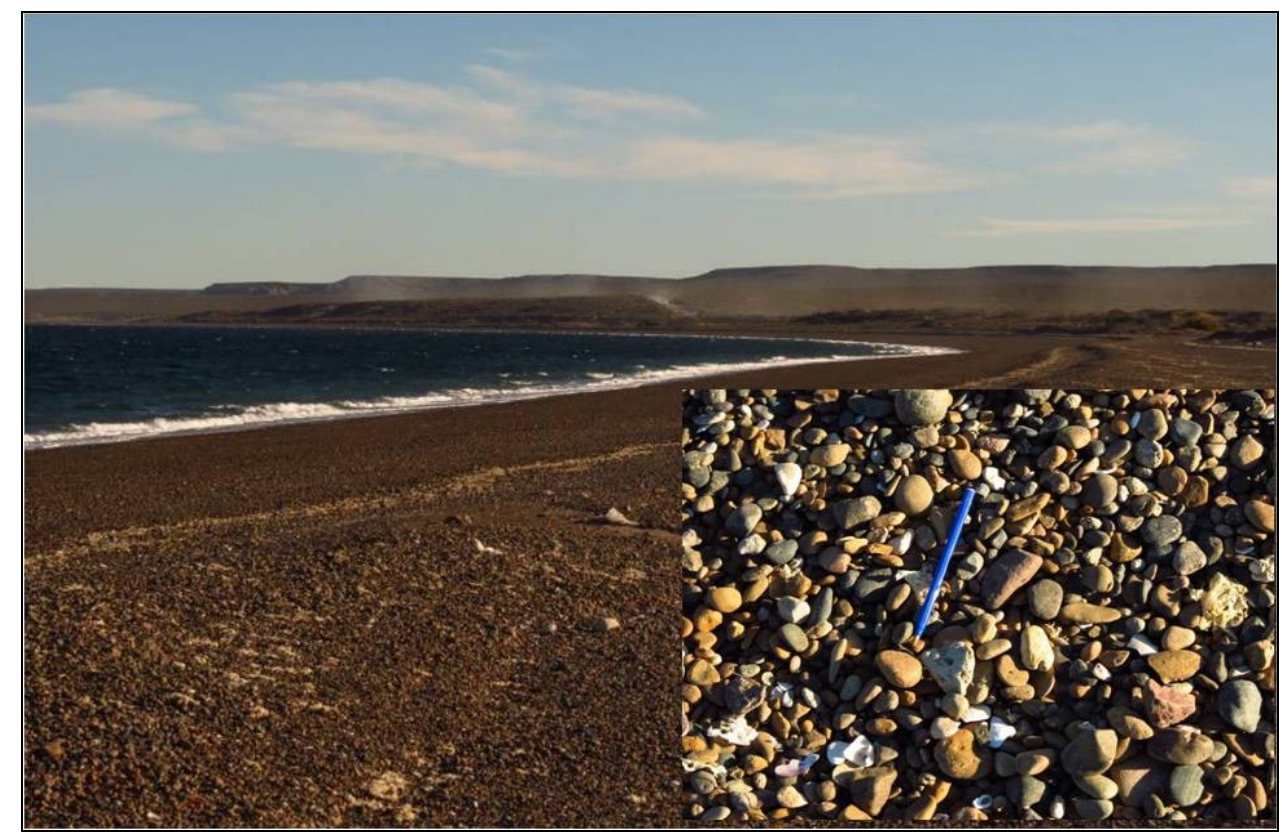

Fig. 5.13. Muestreos de rocas en Playa Buñuels

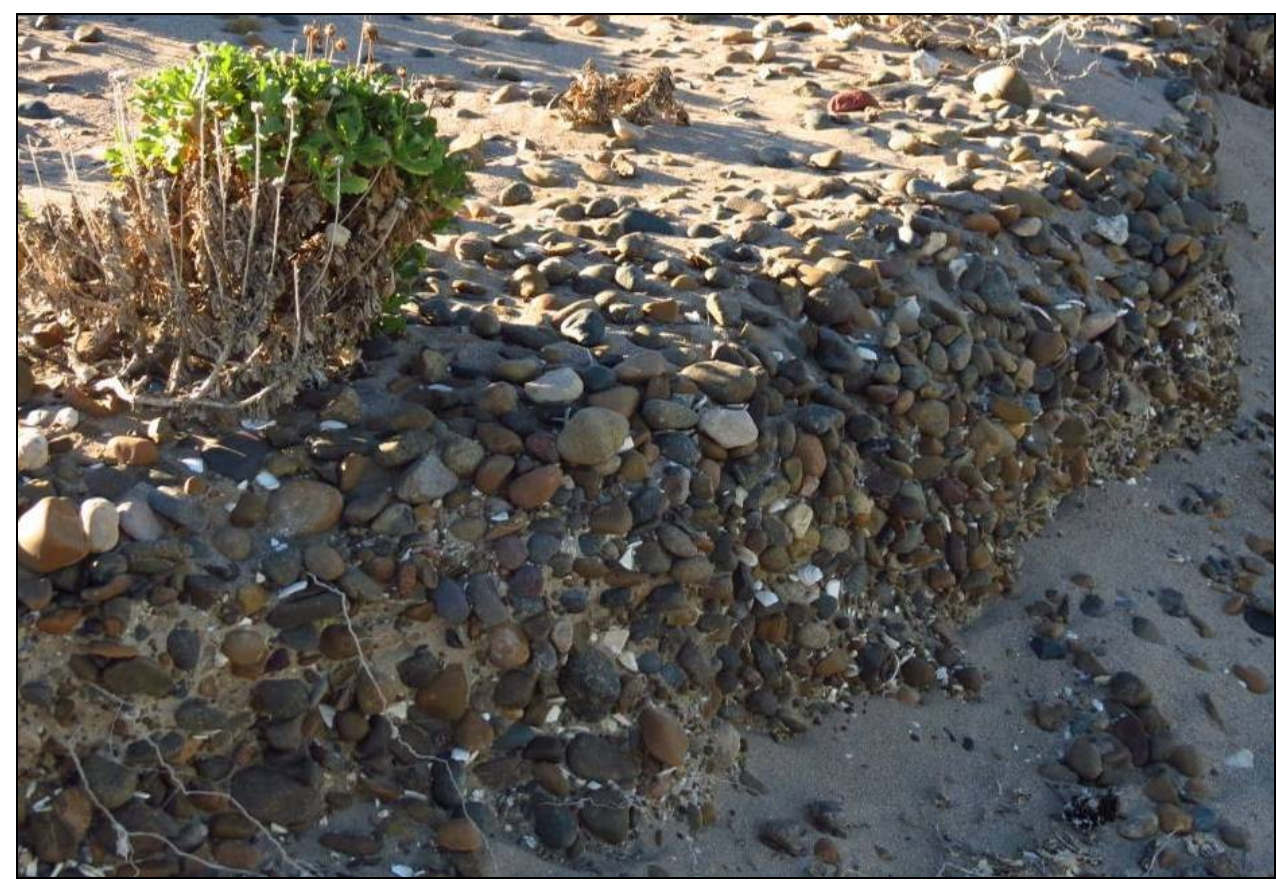

Fig. 5.14. Muestreos de rocas en Playa Buñuels 


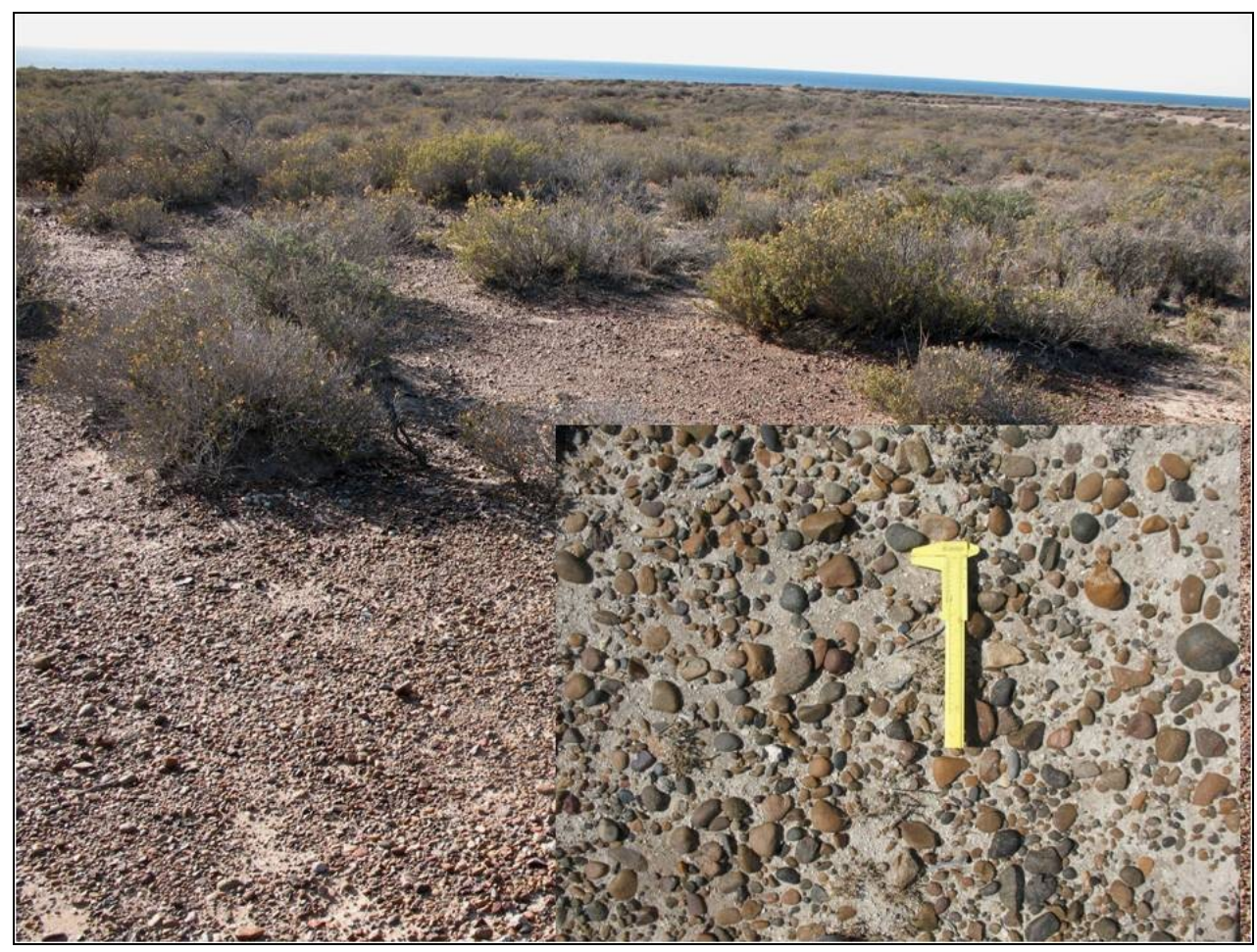

Fig. 5.15. Muestreo de rocas en cerro Avanzado, terraza marina.

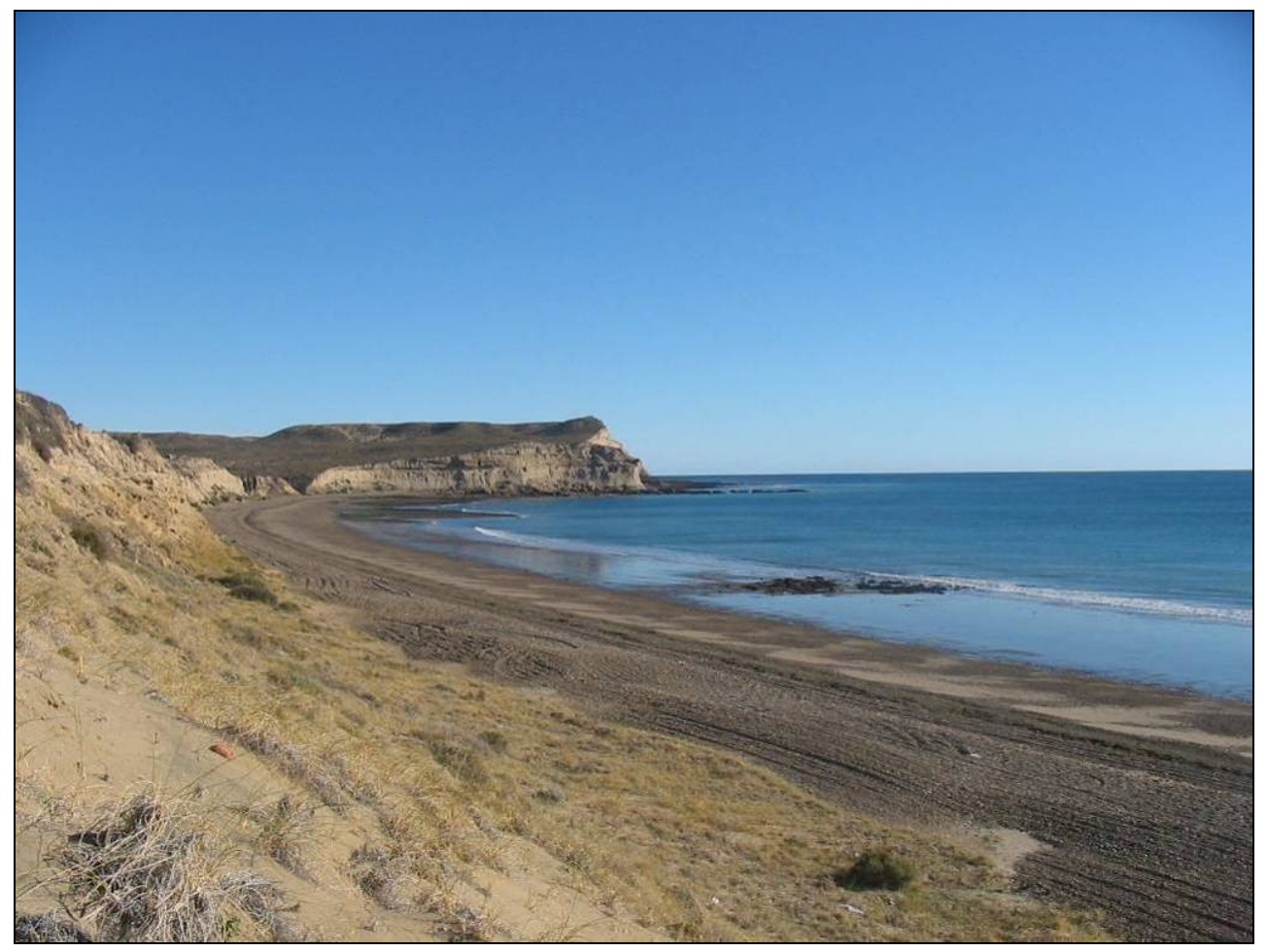

Fig. 5.16. Muestreo playa bahía Cracker. 


\section{Determinaciones litológicas microscópicas}

El estudio petrográfico permitió ajustar las determinaciones litológicas a partir de criterios independientes a las observaciones en muestra de mano. Estas consideraciones son importantes ya que la atribución macroscópica de las rocas que componen las fuentes secundarias presenta varias dificultades (Bonomo 2005:70). Por otra parte, en algunos casos los análisis de las secciones delgadas permitieron establecer la correspondencia de las muestras con el afloramiento primario.

La comparación entre las atribuciones macro y microscópicas (Tabla 5.12 y 5.13) permitió determinar: coincidencia en la gran mayoría de las muestras $(n=13)$, discrepancia en siete casos y mayor especificidad en la clasificación de cuatro muestras. Por otra parte, el análisis petrográfico posibilitó clasificar la materia prima de un artefacto (ver AV1 M1/4; Tabla $5.13)$.

Sin embargo, y para las rocas con alto grado de silicificación, las determinaciones fueron variables. Por una, entre las clasificadas como silexita de acuerdo con la IUGS, se destacan los ejemplares naturales $\mathrm{N}^{\circ} \mathrm{AV} / 1$; AV 1B y AV2 A recolectados en los muestreos al azar de Arroyo Verde, y las piezas arqueológicas SLM1-169 y RE1M1-125, del muestreo 1 del sitio Rincón de Elizalde de coloración blanquecina y traslúcida. Para este grupo y de acuerdo con la clasificación de Dong et al. (1995), se observó que predominan las texturas modificadas entre las que se reconocieron las del tipo plumoso. También se observaron texturas laminares fantasmas y reemplazo seudomórfico de cuarzo con morfología laminar (calcita). En menor escala, se identificaron estructuras en rosetas y crecimiento radial de cuarzo. Dada la correspondencia entre las texturas identificadas en los cortes analizados con las descripciones texturales y mineralógicas de las vetas de la Fm. Marifil estudiadas por Massaferro y Haller (2000: Fig 4-7) se concluye su asociación directa. Sólo para este grupo se adoptó la denominación calcedonia.

Otras muestras también atribuidas a silexitas (ejemplares arqueológicos RE/260 RE1M1/211y Av1m1-3) se diferencian por su coloración rojiza en muestra de mano (5R 4/6; 5R $3 / 4$ y 5 R2/6). Por su parte el análisis petrográfico mostró la presencia de texturas masivas muy fina (cripto a microcristalina), constituídas por cuarzo recristalizado. También se observaron lentes de cuarzo policristalinos y la presencia de venillas dispuestas en forma transversal y rellenas de cuarzo fibroso. Debido a la presencia de óxido de hierro presentan coloración rojiza. Massaferro y Haller (2000) identificaron dos episodios de brechamiento y cementación en la veta principal y determinaron que el cemento es chert silíceo rojo o pardo, debido a las 
numerosas inclusiones de hierro que presenta (op. cit: 314 ). Por lo tanto, es probable que las muestras analizadas se correspondan con este afloramiento. De esta manera y para este grupo se adoptó la denominación chert síliceo.

Para la única muestra restante (pieza arqueológica SL M1/195), también designada como silexita, dado que no presenta características texturales especificas que permitan su atribución a la fuente primaria, se optó por denominarla con el nombre genérico de sílice.

En cuanto a la muestra asignada a caliza, correspondería al Miembro La Jarilla de la Fm. Puerto Lobos (Cortés 1987: 47) localizado en la margen sur del arroyo Verde. Se caracteriza por calizas rosadas lumachélicas, con abundantes restos de conchillas calcáreas de pelecípodos y gasterópodos.

\begin{tabular}{|c|c|c|c|c|c|c|}
\hline UA & $\mathrm{N}^{\mathrm{o}}$ muestra & $\begin{array}{l}\text { Determinación } \\
\text { Macroscópica }\end{array}$ & $\begin{array}{l}\text { Determinación } \\
\text { Microscópica }\end{array}$ & Color* & Tipo & $\begin{array}{l}\text { Nueva } \\
\text { clasificación }\end{array}$ \\
\hline \multirow{3}{*}{$\begin{array}{l}\frac{\pi}{\pi} \\
\frac{\pi}{\pi} \\
\frac{\pi}{\pi}\end{array}$} & $\mathrm{PD} / 27$ & Andesita & Andesita & $10 \mathrm{Y} 4 / 2$ & Vulcanita & Andesita \\
\hline & $\mathrm{PC} / 23$ & Basalto & Traquita-andesita & N1 & Vulcanita & $\begin{array}{l}\text { Traquita- } \\
\text { andesita }\end{array}$ \\
\hline & $\mathrm{CVI} / 25$ & Dacita? & $\begin{array}{l}\text { Pórfido riolítico- } \\
\text { dacítico }\end{array}$ & N3 & Vulcanita & Pórfido \\
\hline \multirow{7}{*}{ 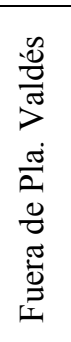 } & $\mathrm{AV} / 2 \mathrm{~B}$ & Riolita & Pórfido riolítico & $10 \mathrm{R} 5 / 4$ & Vulcanita & Pórfido \\
\hline & $\mathrm{AV} / 1 \mathrm{~A}$ & Sílice & Silexita & 5YR8/1 & Sedimentaria & Calcedonia \\
\hline & AV 1B & Calcedonia & Silexita & $5 Y R 8 / 1$ & Sedimentaria & Calcedonia \\
\hline & AV2 A & Calcedonia & Silexita & traslúcido & Sedimentaria & Calcedonia \\
\hline & AV1M1/2 & Sílice & $\begin{array}{l}\text { Ignimbrita- } \\
\text { riolítica }\end{array}$ & 10R5/4 & Vulcanita & Ignimbrita \\
\hline & AV M1/7 & Ignimbrita & Ignimbrita & $5 \mathrm{R} 3 / 4$ & Piroclástica & Ignimbrita \\
\hline & AV1M1/9 & Riolita & Fenoriolita & $10 \mathrm{R} 6 / 2$ & Vulcanita & Riolita \\
\hline
\end{tabular}

Tabla 5.12. Comparación entre las determinaciones litológicas macro y microscópicas en muestras naturales. * El color está basado en la Tabla Munsell (2011). 


\begin{tabular}{|c|c|c|c|c|c|c|}
\hline UA & $\mathrm{N}^{\mathrm{o}}$ muestra & $\begin{array}{l}\text { Determinación } \\
\text { Macroscópica }\end{array}$ & $\begin{array}{l}\text { Determinación } \\
\text { Microscópica }\end{array}$ & Color* & Tipo & $\begin{array}{l}\text { Nueva } \\
\text { clasificación }\end{array}$ \\
\hline \multirow{3}{*}{$\begin{array}{l}\frac{\tilde{D}}{\frac{0}{\pi}} \\
\frac{\pi}{2} \\
\frac{\pi}{2}\end{array}$} & ERch/28 & Cuarcita & $\begin{array}{l}\text { Arenisca } \\
\text { cuarzosa }\end{array}$ & 5YR6/1 & metamórfica & Cuarcita \\
\hline & SL M1/195 & Xilópalo & Silexita & $10 \mathrm{YR} 6 / 2$ & Ópalo? & Sílice \\
\hline & $\mathrm{LB} / 7$ & Riolita & Ignimbrita & $10 \mathrm{R} 5 / 4$ & Piroclástica & Ignimbrita \\
\hline \multirow{13}{*}{ 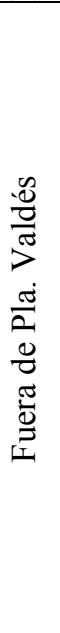 } & AV1 M1/4 & Indet & Ignimbrita & $5 \mathrm{YR} 8 / 1$ & Piroclástica & Ignimbrita \\
\hline & AV1-10 & Cuarcita & $\begin{array}{l}\text { Arenisca } \\
\text { cuarzosa }\end{array}$ & $5 \mathrm{RP} 4 / 2$ & metamórfica & Cuarcita \\
\hline & RE1M1/169 & Calcedonia & Silexita & traslúcido & Sedimentaria & Calcedonia \\
\hline & RE1M1/125 & Calcedonia & Silexita & $10 \mathrm{YR} 8 / 2$ & Sedimentaria & Calcedonia \\
\hline & $\mathrm{RE} / 260$ & Sílice & Sílixita & 5R3/4 & Sedimentaria & Chert \\
\hline & RE1M1/211 & Sílice & Sílixita & $10 \mathrm{R} 5 / 4$ & Sedimentaria & Chert \\
\hline & Av1m1-3 & Sílice & Silexita & $10 \mathrm{r} 4 / 6$ & Sedimentaria & Chert \\
\hline & AV M1/6 & Ignimbrita & Ignimbrita & $5 \mathrm{R} 4 / 6$ & Piroclástica & Ignimbrita \\
\hline & $\mathrm{AV} / 5$ & Riolia & Ignimbrita & $5 Y R 4 / 4$ & Piroclástica & Ignimbrita \\
\hline & RE 1M1/18 & Basalto & Andesita-basalto & N1 & Vulcanitas & Basalto \\
\hline & $\operatorname{Re} 21$ & Andesita & Andesita-basalto & N1 & Vulcanitas & Basalto \\
\hline & $\mathrm{AV} / 2$ & Sílice & $\begin{array}{l}\text { Ignimbrita- } \\
\text { riolítica }\end{array}$ & 10YR6/6 & Piroclástica & Ignimbrita \\
\hline & AV1M1sn & Silice & caliza & 5R6/4 & Sedimentaria & Caliza \\
\hline
\end{tabular}

Tabla 5.13. Comparación entre las determinaciones litológicas macro y microscópicas en muestras arqueológicas.* Color según la Tabla Munsell (2011).

Sobre la base de estos resultados, en el caso exclusivo de las calcedonias y en orden decreciente de exactitud, se atribuirán a esta roca:

(a) aquellos artefactos que cuenten con análisis petrográficos cuyas texturas permitan su asociación con episodios hidrotermales (depósitos de vetas);

(b) los artefactos que no cuenten con cortes delgados, pero que mediante el remontaje se determine la correspondencia de la pieza con el mismo nódulo o artefacto que fue analizado microscópicamente;

(c) a los artefactos cuyos módulos sean mayores a los rodados de calcedonias registrados en los muestreos $(>74 \mathrm{~mm})$ y/o cuyas formas bases permitan identificar que corresponden a filones.

Los análisis petrográficos pueden además brindar información adicional sobre la calidad de la roca para la talla, ya que permiten evaluar los dos factores principales en la determinación de la calidad para la talla: la textura de las rocas y las proporciones relativas de vidrio y cristales (cristalinidad) u otras heterogeneidades (Aragón y Franco 1997). Por ejemplo, en el caso de los basaltos analizados, se observó que las pastas compuestas exclusivamente por vidrio (Holohialina) resultaron de mejor aptitud para la talla que las demás. Por lo tanto, la cristalinidad puede utilizarse como un criterio complementario. 


\section{Síntesis e integración de la base regional de recursos líticos}

El diseño de muestreo aplicado permitió corroborar que el área de estudio se caracteriza por una oferta amplia y variada de rocas que proviene en su gran mayoría de depósitos secundarios de rodados que habrían sido utilizados como potenciales fuentes de aprovisionamiento de materias primas líticas. Estas fuentes están emplazadas en distintas geoformas marinas -playas actuales, cordones litorales, bermas, terrazas y espigas-, cuya distribución espacial es variable entre los distintos sectores costeros.

En cuanto a las litologías, se registró mayor diversidad en la unidad FPV (N=13 tipos de rocas) que en PV $(\mathrm{N}=10)$. En el sector norte de FPV predominan las riolitas (34\%) de calidad regular. La mayor representación de esta roca estaría relacionada con la cercanía a los afloramientos primarios de la Fm. Marifil. Esta subunidad también se diferencia por la presencia de calcedonias, de muy buena a excelente calidad, en porcentaje más elevado (13\%) que en el sector sur de FPV (4\%) y en PV (1\%). En la unidad PV y en el sector sur de FPV la materia prima más abundante es el basalto (56\% y $48 \%$ respectivamente), aunque en PV la calidad es superior: buena a excelente versus regular a buena. Los rodados de basalto se encuentran en todas las geoformas marinas, aunque los de mejor calidad se localizan en los depósitos de las playas actuales y en los cordones litorales adosados a las mismas. La obtención de estos nódulos implicaría bajos costos: son fácilmente reconocibles y relativamente abundantes (promedio 0,56 rodado por minuto).

Los tamaños promedio de los rodados también mostraron variaciones entre las unidades. Los nódulos de las bermas de PV son menores $(50 \mathrm{~mm})$ que los de FPV (60 mm), mientras que los rodados de los cordones litorales presentan valores parejos (60 y $65 \mathrm{~mm}$ respectivamente), excepto en la espiga de Caleta Valdés que son considerablemente mayores $(80 \mathrm{~mm})$. Por su parte, en las terrazas se observó la mayor variabilidad interna de tamaños (Fig.5.17). 

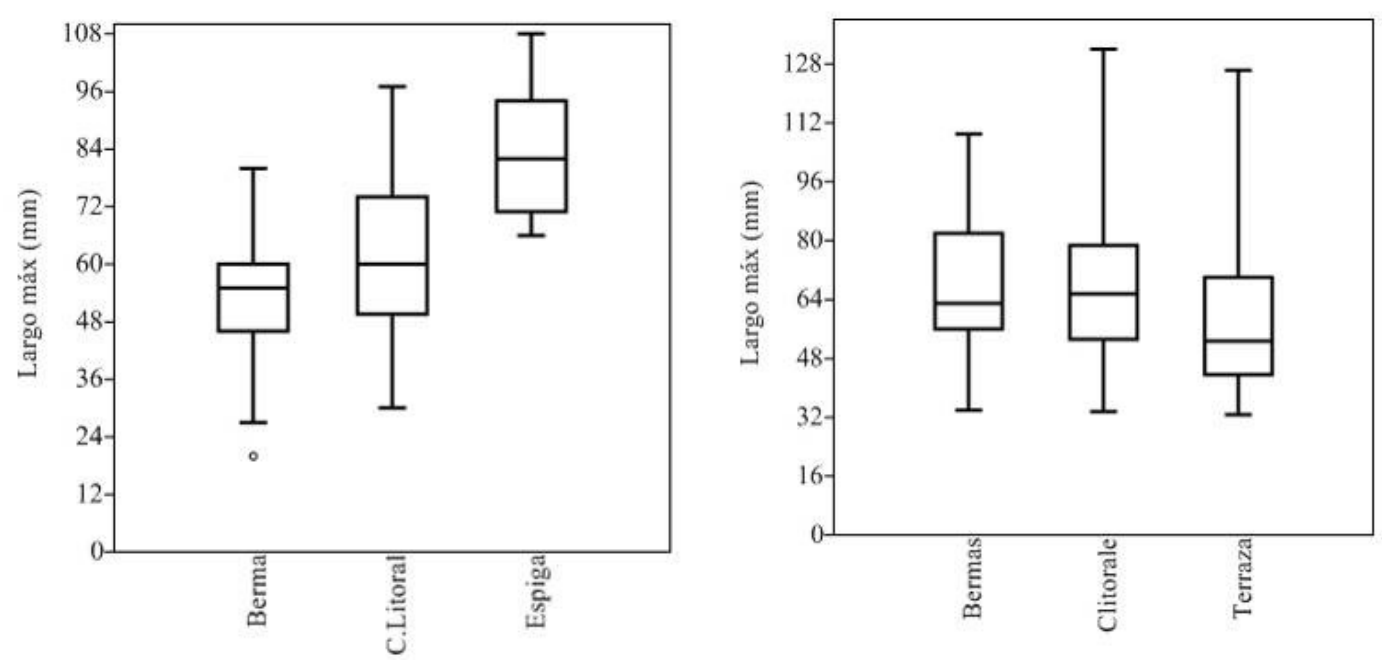

Fig. 5.17. Largo máximo de los rodados entre las unidades de análisis y geoformas muestreadas: Península Valdés (der.) y Fuera de Península Valdés (izq.).

Respecto de la forma de los clastos también se observaron diferencias: en PV y en el sector sur de FPV sobresalen los redondeados chatos; salvo en la espiga de Caleta Valdés donde la gran mayoría son redondeados espesos. Por el contrario, en el sector norte de FPV prevalecen las formas subredondeadas y también se registraron angulosas. Las diferencias morfológicas para este último sector -más angulosas o facetadas- estarían relacionadas con la cercanía a los afloramientos primarios.

\section{Expectativas sobre uso de las materias primas y tecnológicas en relación con la base regional de rocas.}

Sobre la base de estos resultados se establecen las siguientes expectativas para su contrastación con el registro tecnológico:

En los conjuntos arqueológicos de la unidad PV se espera:

- Baja diversidad litológica entre los grupos artefactuales

- Mayor porcentaje de artefactos en basalto respecto de las restantes rocas locales (riolitas, sílices) de calidad inferior

- Aprovechamiento expeditivo de basaltos, riolitas y sílices y conservado de calcedonias de buena a excelente calidad

- Presencia de núcleos pequeños abandonados por imposibilidad de seguir tallando

- Porcentajes elevados de corteza, ya que en un nódulo no se pueden sacar más de tres lascas.

- Predominio de lascas de tamaños chicos entre los productos de talla 
- Porcentajes elevados de talla bipolar, tanto para los nódulos de basalto como para los rodados del resto de las materias primas locales

En los conjuntos de la unidad Fuera de PV:

En el sector norte:

- Mayor variabilidad de materias primas, de acuerdo con la oferta más diversificada de rocas

- Porcentajes altos o significativos de calcedonias, dada su provisión local y buena calidad para la talla

- Presencia de estrategias expeditivas y conservadas para las rocas locales en función de las distintas calidades

- Núcleos no agotados de mayor tamaño

- Bajo porcentaje de corteza

- Productos de talla más grandes que en el resto del área de estudio y mayor frecuencia de módulos laminares.

- Uso predominante de la técnica de talla directa

En el sector sur:

- Baja diversidad litológica entre los grupos artefactuales

- Porcentajes altos y parejos de artefactos confeccionados en basalto y sílice, ya que si bien predominan basaltos, la calidad es regular a buena

- Aprovechamiento expeditivo de basaltos y sílices

- Presencia combinada de talla bipolar y directa, dado que algunos rodados son en promedio mayores 


\section{CAPÍTULO 6}

\section{TAFONOMÍA LÍTICA}

El estudio de la variabilidad en los conjuntos líticos requiere identificar y explicar las causas que podrían haber intervenido en su conformación (Borrazzo 2009). En general las variaciones señaladas respecto de la composición, abundancia y estado del registro lítico son en la gran mayoría de los casos atribuidas a aspectos conductuales (Nelson 1991). Entre estos aspectos se encuentran los criterios de selección de las materias primas, la implementación de las estrategias tecnológicas y el grado de intensidad en que el espacio es ocupado (Binford 1980; Franco 2004). Sin embargo, los aportes recientes de la tafonomía lítica (Borrazzo 2009; Gifford 1981; Hiscock 1985) junto con el desarrollo de un corpus teórico-metodológico adecuado para abordar su análisis (Borrazzo 2009, 2011), muestran la importancia de considerar los efectos que distintos agentes y procesos post-depositacionales ejercen sobre el registro lítico. Según estos estudios, la acción combinada de cada uno de los factores modifica la morfología, composición y dispersión de los artefactos, por lo que el registro y evaluación de estas alteraciones constituyen una vía de análisis complementaria al análisis tecnológico y permiten generar expectativas para luego confrontar con el registro arqueológico (Borrazzo 2009).

Para diseñar un método de tafonomía aplicado al registro lítico de una determinada área de estudio, es importante considerar las condiciones locales, es decir los factores exógenos y conocer los procesos que modifican las propiedades de las rocas disponibles en ese espacio. Según Borrazzo $(2006,2010)$ los factores exógenos que intervienen en la modificación de los artefactos líticos se denominan agentes; entre ellos los principales son el agua, el viento, los animales y la gravedad. La acción de estos agentes genera distintos procesos (transporte, meteorización química, pisoteo, entre otros) y que potencialmente pueden generar efectos sobre los artefactos, entre los que se destacan el desplazamiento, la exposición, el sepultamiento, la fractura, la corrasión y el pulido de las superficies, entre otros.

Diversas experiencias y estudios actualísticos han evaluado el efecto que distintos agentes tafonómicos ejercen sobre el registro lítico en ambientes y geoformas con características similares a las del área de estudio (Borrazzo 2006, Oria et al 2009). Estos estudios mostraron 
que en dunas litorales, el tipo de sustrato (tamaño y cohesión de las partículas) en combinación con la acción eólica (dirección y velocidad del viento) genera modificaciones espaciales y morfológicas en los conjuntos líticos. Por lo tanto, para estos contextos de depositación la expectativa de hallar microartefactos es baja, tanto por la "voladura" de las piezas de menor tamaño como por el sepultamiento de las mismas producido por la dinámica propia de los médanos (Bonomo 2005; Borrazzo 2006, Gómez Otero 2006).

En ambientes donde el agente hídrico es dominante (como por ejemplo los cuerpos de agua permanentes o temporarios) intervienen distintos procesos como el transporte hídrico, la meteorización química y la evaporación (Borrazzo 2010). Entre los efectos que produce el transporte hídrico sobre los conjuntos líticos se destacan: (a) el desplazamiento horizontal y/o reacomodamiento por peso y tamaño de los artefactos; (b) la abrasión de las superficies; (c) impactos y fracturas en el caso de cuerpos de agua de alta energía; (d) el sepultamiento de los artefactos (en condiciones de baja energía) y (e) la exposición de los artefactos. Por su parte, en el caso de la meteorización química se espera la formación de anillos de meteorización (weathering rinds) en la superficie de las rocas. La evaporación, por su parte, genera la formación de costras salinas sobre los artefactos generalmente compuestas por carbonato, sulfato o cloruro de sodio (Borrazzo 2009).

Por último, en sectores altos -como las terrazas- la mayor exposición de los materiales a la acción eólica (viento) y la pendiente (gravedad) constituyen los principales factores de modificación de la estructura del registro lítico. Borrazzo (2009) señala además que la gravedad también promueve cambios morfológicos en los artefactos, entre ellos el pulido de las aristas y la formación de la que Mansur (1999) denomina pátina del desierto producida por la depositación de minerales en la microsuperficie de las rocas. Asimismo en ambientes con pendiente mayor a $0^{\circ}$ es esperable que se produzcan procesos relacionados con la reptación, es decir el movimiento descendente de los artefactos (Borrazzo 2009). Otro proceso que amplifica los efectos sobre los conjuntos y piezas artefactuales en matrices sedimentarias de granulometría gruesa (mayor que el tamaño de arena) es el pisoteo/pateo. El principal agente es el tránsito de animales (en general los de mayor porte), de personas y de vehículos. Entre los efectos que producen estos agentes se mencionan los desplazamientos de las piezas (horizontales y verticales); el sepultamiento y la exposición de los artefactos, las fracturas transversales y marginales ("pseudoretoques" sensu Borrazzo 2009), las estrías y la abrasión, y por último la remoción de la cobertura vegetal. 
Un interesante estudio relacionado con la influencia que puede ejercer la dinámica geomorfológica en las características de los conjuntos líticos es el caso de los pseudoartefactos estudiados por Borrazzo (2011) en la península El Páramo, en la provincia de Tierra del Fuego. Este sector del espacio, formado por cordones litorales contiguos, fue caracterizado como una potencial fuente secundaria de materias primas líticas. Por su parte, el estudio tafonómico y tecnológico señaló que la totalidad de las evidencias arqueológicas consideradas en una primera instancia como artefactos eran en realidad producto de la intervención de procesos tafonómicos locales.

De acuerdo con lo antes mencionado y considerando la totalidad de los factores que influyen en la conformación de los conjuntos artefactuales líticos, en este capítulo se presenta la información obtenida a partir de observaciones tafonómicas realizadas sobre pistas experimentales líticas montadas para su estudio en el año 2013. Sobre la base de experiencias y estudios actualísticos previos sobre materiales líticos (Borrazzo 2009) se elaboró un diseño de tafonomía lítica cuyo objetivo principal fue conocer y caracterizar, de manera preliminar, los principales efectos que los distintos agentes y procesos tafonómicos producen sobre el registro arqueológico lítico del área de estudio. En cuanto a los objetivos específicos, se propuso:

1. Identificar y evaluar la incidencia de los distintos agentes y procesos postdepositacionales en la conformación del registro arqueológico lítico -distribución, morfología, tamaño, preservación- según dos variables: (a) el contexto de depositación de los artefactos (tipo de geoforma, sustrato y cota); y (b) las materias primas utilizadas para la confección de los artefactos

2. Establecer una jerarquización de los principales agentes de formación para cada una de las geoformas

Se establecieron dos hipótesis de trabajo que parten de la premisa que el clima, la vegetación, la fauna y la acción antrópica impactan de manera pareja en el sector donde se realizaron los trabajos actualísticos:

$\mathbf{H}_{1}$ : Los principales agentes y procesos tafonómicos que intervienen en la formación el registro lítico generan efectos diferenciales según el tipo y características del sustrato sobre el que se depositen los materiales. 
$\mathbf{H}_{2}$ : El grado y modo en que los agentes y procesos tafonómicos afectan las rocas depende de las propiedades internas (textura, granulometría, densidad) y externas (color y brillo) de las mismas.

\section{Diseño y montaje de las pistas experimentales}

En base a la propuesta de Borrazzo (2011) se elaboró el siguiente protocolo para el diseño y montaje de las pistas líticas experimentales (Tabla 6.1).

\begin{tabular}{|c|c|c|c|}
\hline $\begin{array}{c}\text { Preparación de las } \\
\text { pistas }\end{array}$ & Registro de las pistas & Sembrado de las pistas & $\begin{array}{l}\text { Observaciones } \\
\text { tafonómicas }\end{array}$ \\
\hline $\begin{array}{l}\text { Selección de nódulos de } \\
\text { las rocas más } \\
\text { representativas del } \\
\text { registro lítico del área. }\end{array}$ & $\begin{array}{l}\text { Medición (largo, ancho } \\
\text { y espesor máximo y } \\
\text { peso). } \\
\text { Rotulado y registro de } \\
\text { cada nódulo. }\end{array}$ & $\begin{array}{l}\text { Selección de los sectores } \\
\text { para el sembrado de las } \\
\text { pistas. }\end{array}$ & -- \\
\hline $\begin{array}{l}\text { Talla de los nódulos }{ }^{1} \text { : } \\
\text { mediante percusión } \\
\text { directa: desechos de } \\
\text { talla y núcleos de } \\
\text { distintos tamaños. }\end{array}$ & $\begin{array}{l}\text { Idem para los productos } \\
\text { de talla de cada nódulo. }\end{array}$ & -- & $\begin{array}{l}\text { Reserva de una } \\
\text { muestra experimental } \\
\text { de cada tipo de roca } \\
\text { para su posterior } \\
\text { evaluación y } \\
\text { comparación con las } \\
\text { pistas sembradas. }\end{array}$ \\
\hline-- & $\begin{array}{l}\text { Dibujo y fotografía de la } \\
\text { vista en planta de cada } \\
\text { pista y de la ubicación } \\
\text { de las piezas } \\
\text { experimentales en los } \\
\text { distintos microsectores. }\end{array}$ & $\begin{array}{l}\text { Sembrado de las pistas } \\
\text { con la cara siglada hacia } \\
\text { arriba dentro de la } \\
\text { cuadrícula. La misma se } \\
\text { ubica indicando el norte y } \\
\text { profundidad sobre la que } \\
\text { apoyan los materiales. Se } \\
\text { deja una estaca en el } \\
\text { extremo norte de la } \\
\text { cuadricula en cada pista. }\end{array}$ & $\begin{array}{l}\text { Registro periódico } \\
\text { (cada } 4 \text { meses) de las } \\
\text { pistas. En todas las } \\
\text { observaciones se } \\
\text { registran las mismas } \\
\text { variables. }\end{array}$ \\
\hline
\end{tabular}

Tabla 6.1: Diseño para la preparación y montaje de las pistas experimentales líticas.

\section{Las pistas experimentales}

Las pistas experimentales fueron sembradas en tres sectores diferentes en cuanto a tipo de geoforma, cota y sustrato, ubicados en la costa del golfo Nuevo sur, entre 15 y $30 \mathrm{~km}$ respectivamente de la ciudad de Puerto Madryn (véase abajo).

\footnotetext{
${ }^{1}$ La talla de los nódulos fue realizada por el Lic. Mariano Reyes (CONICET-CENPAT).
} 


\section{1- Médano Grande}

2- Playa Paraná

3- Cerro Avanzado

A los efectos de verificar la Hipótesis II, para cada pista experimental se tallaron mediante percusión directa tres guijarros de distintas materias primas: basalto, cuarcita y obsidiana (Fig. 6.1). Se buscó que los nódulos de cada materia prima $(\mathrm{N}=3)$ tuvieran tamaño y peso similar. Las dos primeras rocas fueron recolectadas durante muestreos geológicos asistemáticos en el área de estudio, mientras que los nódulos de obsidiana provienen de una recoleccion en la fuente Sacanana I (Gómez Otero y Stern 2005). De cada nódulo tallado se conservaron lascas de distintos tamaños y el núcleo resultante. De acuerdo con el diseño o protocolo de trabajo experimental, estas piezas se rotularon, midieron, pesaron, dibujaron y fotografiaron. Para el sembrado de las pistas y el posterior registro de las posiciones de los artefactos se utilizó un bastidor de $50 \mathrm{~cm}$ de lado con grilla de $5 \times 5 \mathrm{~cm}$.

El montaje de los artefactos experimentales se realizó en el mes de julio del año 2013 y los controles posteriores septiembre y diciembre de 2013, y febrero de 2014).
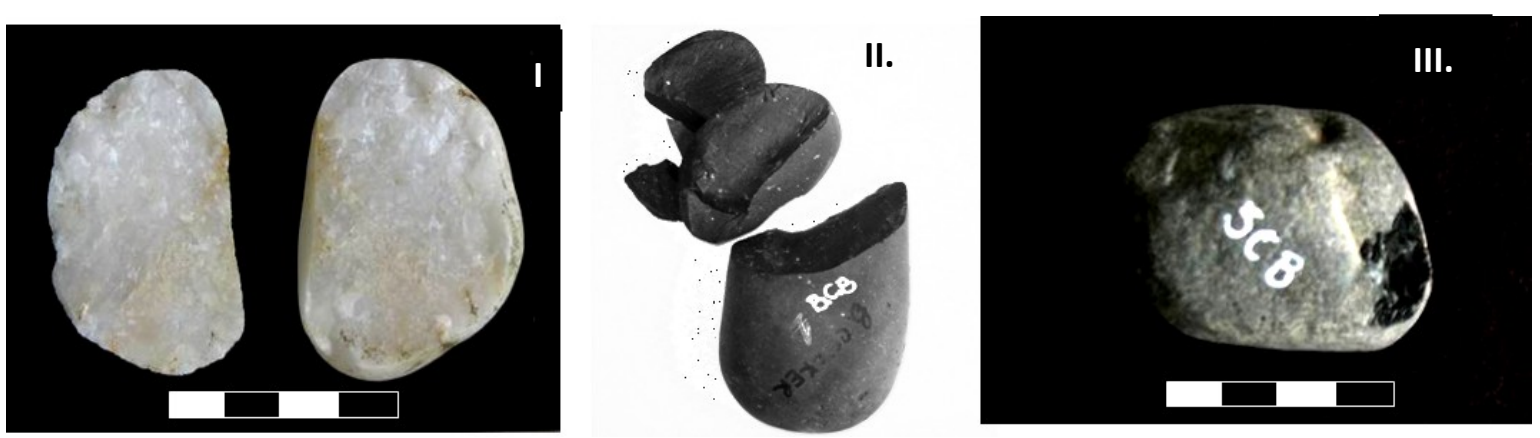

Figura 6.1: Nódulos utilizados para la confección de las pistas experimentales: I. Cuarcita, II. Basalto y

III. Obsidiana negra.

\section{Pista 1: Médano Grande}

La primera pista se ubicó en un relieve dunario costero conformado por médanos activos de arena que apoyan sobre el borde de un acantilado a $10 \mathrm{~m} \mathrm{snm}$. La cuadrícula se orientó al sur (Fig. 6.3 y 6.4). En este sector es muy frecuente el tránsito de personas, cuatriciclos y camionetas 4 x 4, y además en las dunas se realizan actividades extractivas de arena y prácticas de sandboard.. Gómez Otero (2006) registró la presencia de materiales líticos $\mathrm{y}$ arquefaunísticos en superficie, lentes de conchero y dos esqueletos humanos alterados 
antrópicamente. Entre 2011 y 2014 aparecieron tres esqueletos más y se excavaron tres relictos de conchero.
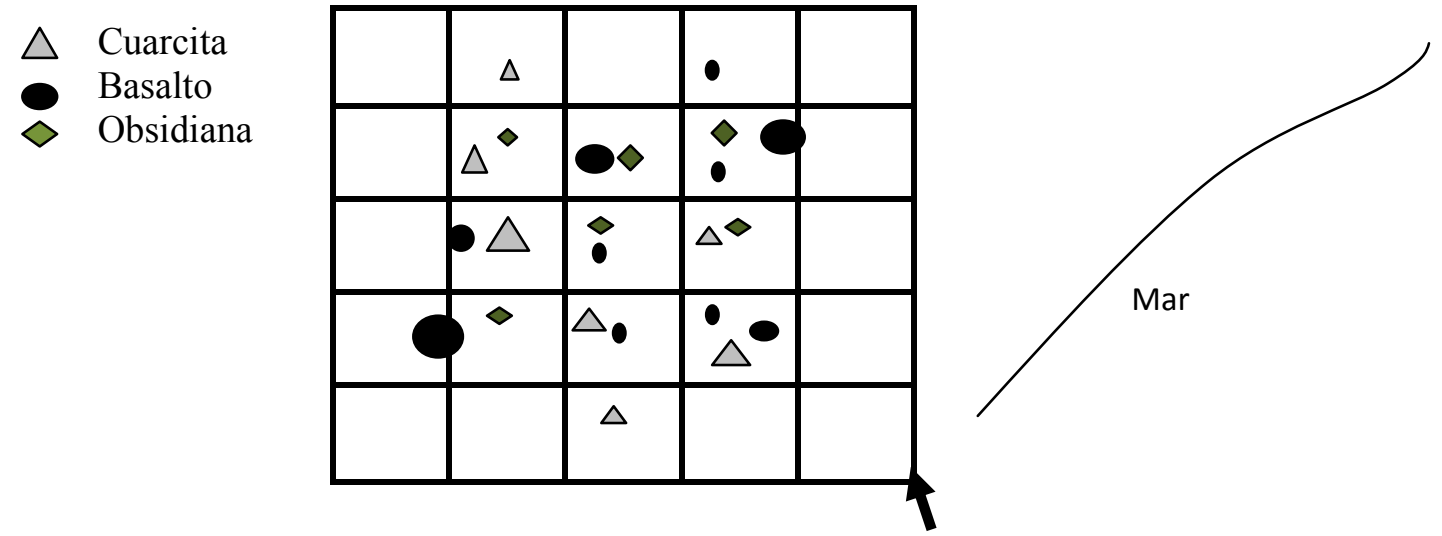

Fig. 6.3: Esquema de la cuadrícula experimental montada en el médano. Referencias:

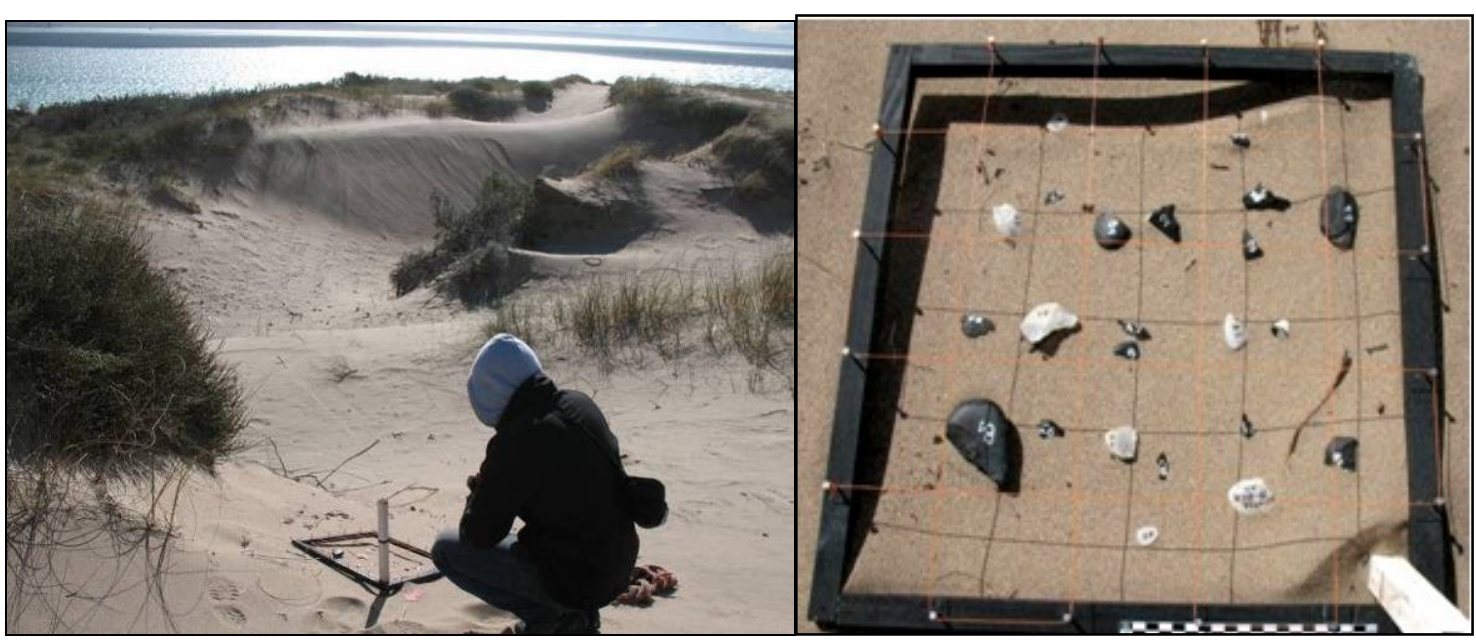

Fig.6.4. Pista experimental médano grande

\section{Pista 2- Cerro Avanzado}

La pista experimental se montó sobre la cima del cerro a 55 m s.n.m., con orientación hacia el norte, en un sustrato conformado por sedimentitas del Terciario y rodados pequeños con "barniz del desierto" (Fig. 6.5 y 6.6). Si bien la accesibilidad al sitio es dificultosa debido a la altura y pendiente, es frecuente el tránsito de vehículos y cuatriciclos. El sector de la playa además es visitado durante todo el año por personas del lugar y turistas que desarrollan actividades recreativas (pesca, buceo, acampe). En esta área, Gómez Otero, identificó dos sitios arqueológicos (Cerro Avanzado 1 y 2) con evidencias de tareas extractivas y de mantenimiento (Gómez Otero 2006). 


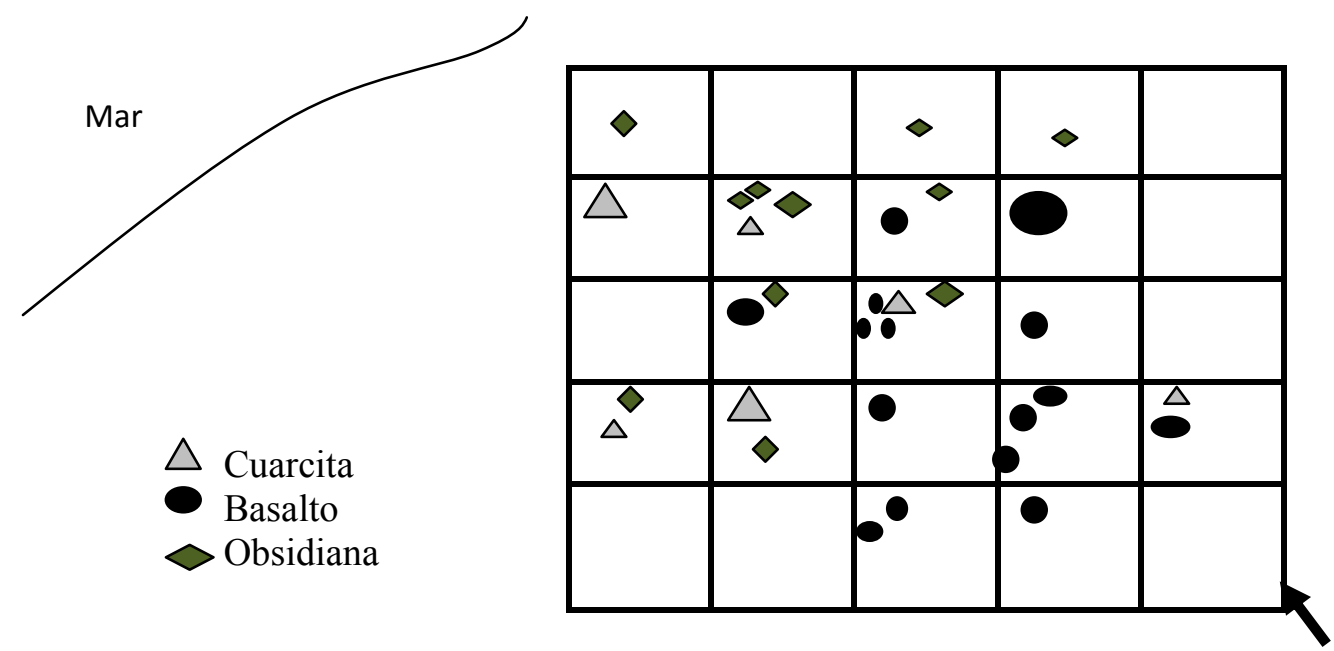

Fig. 6.5: Esquema de la cuadrícula experimental montada en la tarraza

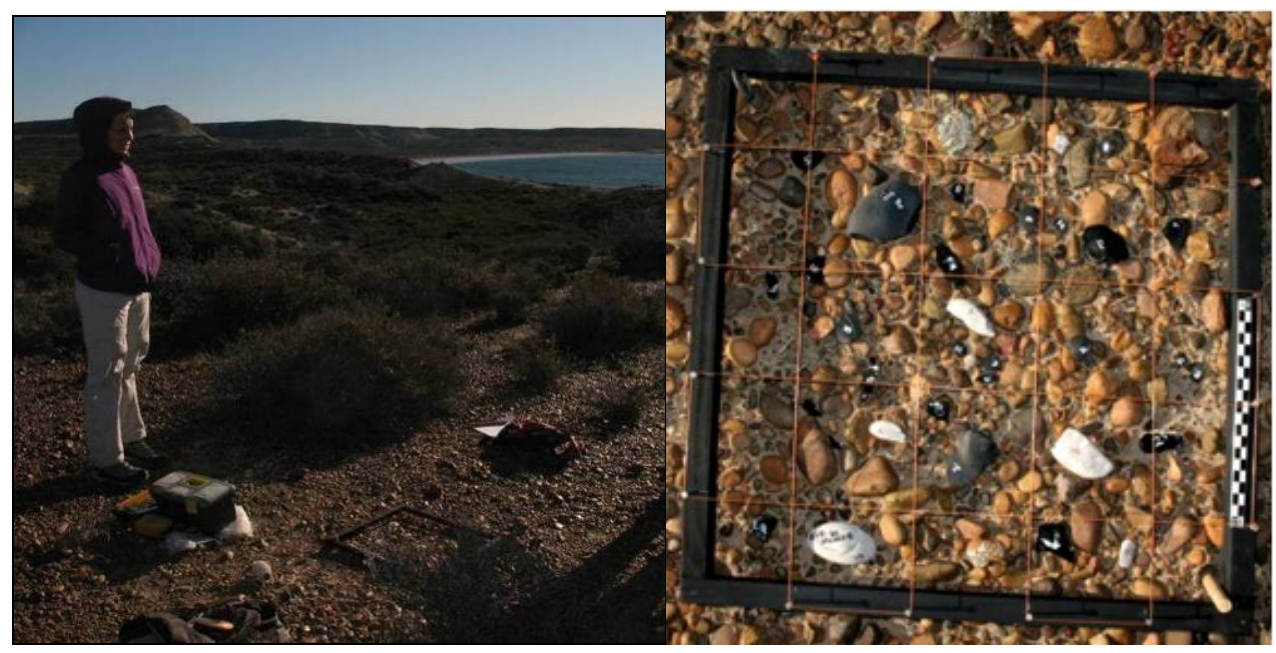

Fig.6.6. Pista experimental cerro Avanzado.

\section{Pista 3- Playa Paraná}

La pista se ubicó en el borde de una laguna temporaria, formada en los sectores bajos entre depresiones de cordones litorales holocénicos, a 7 m s.n.m. La cuadrícula experimental se orientó en dirección norte (Fig. 6.7 y 6.8). La laguna se ubica a pocos metros de la ruta que conecta distintas playas del sector sur de la ciudad de Puerto Madryn, por lo tanto es frecuente el tránsito de vehículos y personas por actividades recreativas (pesca, buceo y acampe). En el momento del sembrado de la pista la laguna se encontraba seca. El sustrato es arcilloso y la vegetación está en forma de parches. En 2011 se registraron material lítico en superficie y valvas dispersas. 
$\triangle$ Cuarcita

Basalto

Obsidiana

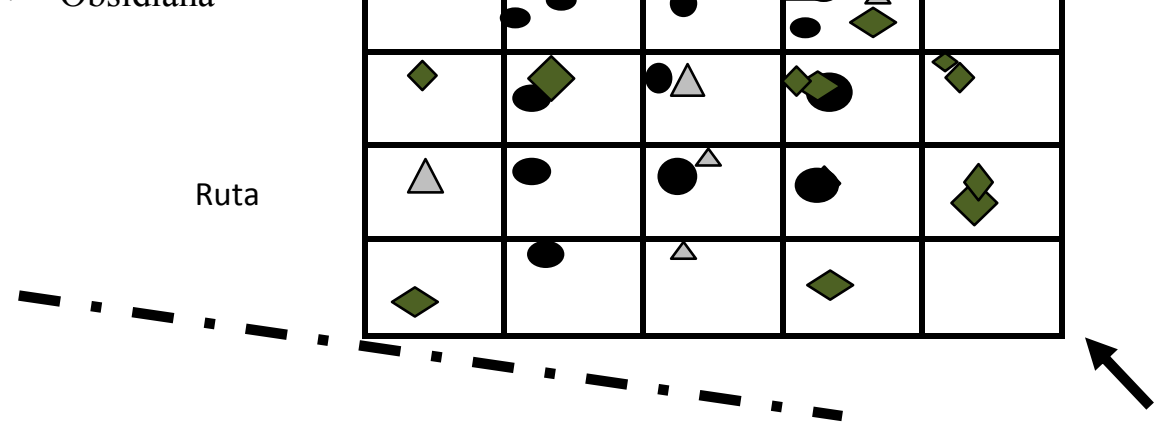

Fig. 6.7: Esquema de la cuadrícula experimental montada en playa Paraná (laguna temporaria)

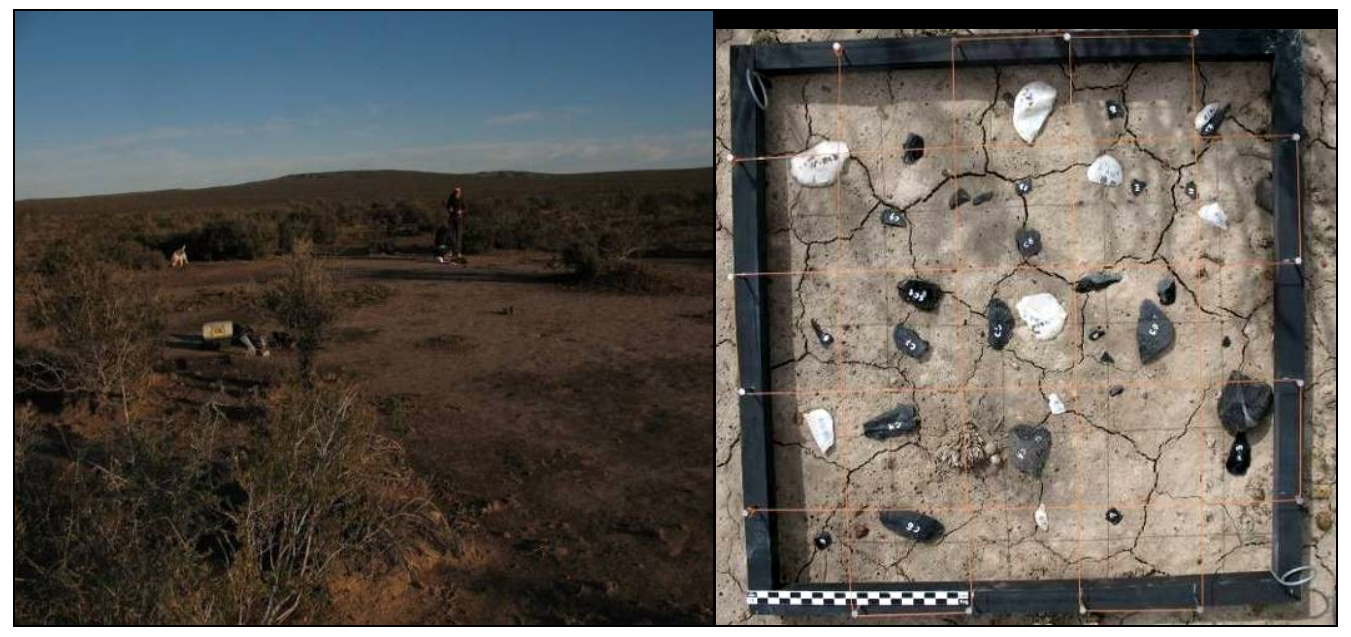

Fig.6.8. Pista experimental montada en playa paraná.

\section{Controles tafonómicos}

Los controles realizados cada tres meses permitieron determinar cambios de distinta magnitud en las tres pistas sembradas. A continuación se sintetiza la información obtenida para cada pista (Tabla 1).

En la cuadrícula montada sobre el médano de arena se registró la pérdida total de las piezas $(n=24)$ en un lapso temporal inferior a los dos meses (primera observación). Incluso, durante el montaje de la pista, varios artefactos (microlascas y lascas pequeñas) quedaron cubiertos por el sedimento y se desplazaron hasta 20 centímetros desde su posición inicial. En las siguientes observaciones no se pudo encontrar ninguna de las piezas ni tampoco la estaca de referencia.

En el sector de la laguna temporaria, en todo el experimento se perdieron 30 artefactos, se habían perdido dos artefactos: una microlasca de obsidiana y una de basalto. La pérdida de la gran mayoría de las piezas se registró en el mes de febrero, período en el cual la 
actividad turística en la zona es intensa. Por lo tanto, y debido a que solo se recuperaron seis artefactos de cuarcita de distintos tamaños (Fig 6.9), se infiere que el principal agente estaría relacionado con la recolección selectiva por parte de coleccionistas o aficionados. Respecto del desplazamiento, inversión y enterramiento de los artefactos se observó que es mayor que en el primer contexto (terraza). No se observaron cambios morfológicos.

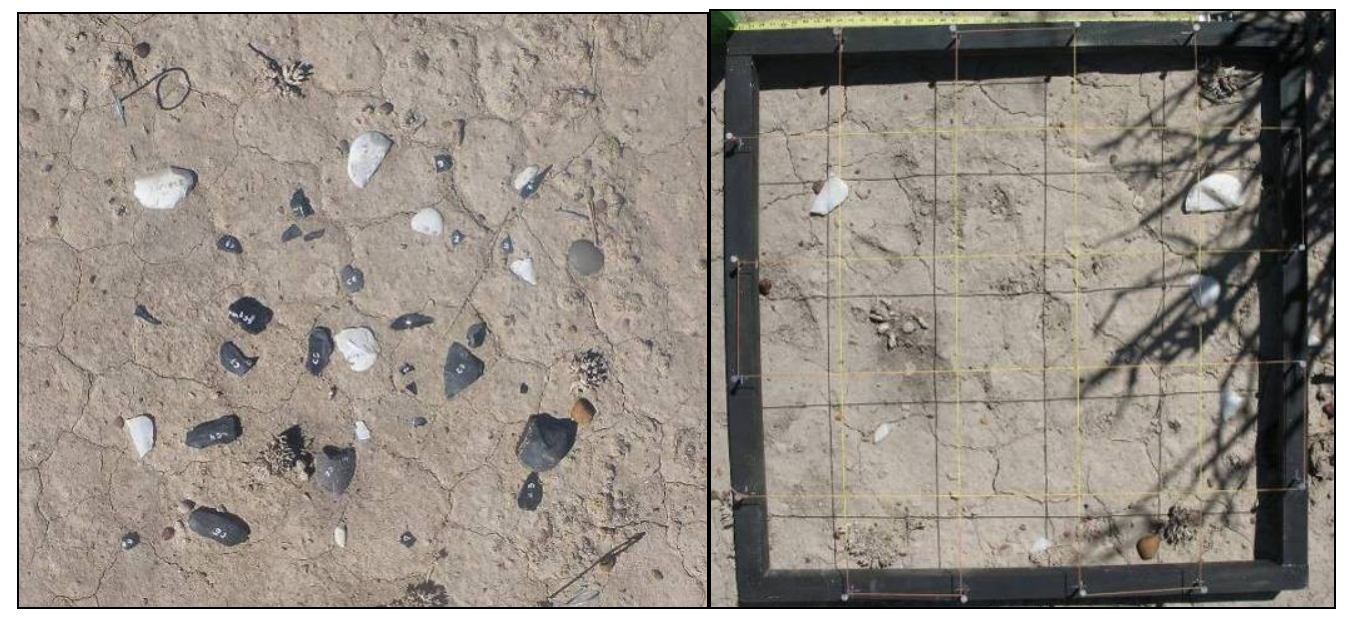

Figura 6.9. Pistas Laguna costera. Izquierda: registro fotográfico realizado el 6 de diciembre de 2013 (Fotografía tomada por la Lic. Ariadna Svoboda) donde se observan las pistas. Derecha: relevamiento realizado el día 25 de febrero de 2014, se observa la pérdida de las pistas de las rocas de color oscuro (basaltos y obsidianas) y la marca de los artefactos ausentes.

En cuanto a la pista sembrada en la terraza, de un total inicial de 34 piezas en el primer control se determinó la ausencia de 4 piezas. Todas ellas eran microlascas $(<2 \mathrm{~cm})$ : tres de obsidiana y una de cuarcita. En el tercer control tafonómico se observó el desplazamiento de una única pieza de obsidiana, a una distancia de $27 \mathrm{~cm}$ aproximadamente desde su posición inicial. La inversión de piezas se registró en seis casos. No se observaron fracturas, lo que indicaría poco impacto del pisoteo o pateo por animales. Por último, respecto de cambios morfológicos se observó la presencia de cambios en la coloración (más opacas) en algunas piezas de obsidianas. 


\begin{tabular}{|c|c|c|c|c|}
\hline \multicolumn{2}{|c|}{ Observaciones tafonómicas } & Terraza & Laguna Costera & Dunas móviles \\
\hline \multicolumn{2}{|c|}{$\mathbf{N}=$ pistas experimentales } & 32 & 36 & 24 \\
\hline \multirow{3}{*}{ Presencia } & $1^{\mathrm{a}}$ observación & $32 / 32$ & $35 / 36$ & $0 / 24$ \\
\hline & $2^{\mathrm{a}}$ observación & $30 / 32$ & $34 / 36$ & Ídem \\
\hline & $3^{\mathrm{a}}$ observación & $25 / 32$ & $6 / 36$ & Ídem \\
\hline \multirow{3}{*}{ Desplazamiento } & $1^{\mathrm{a}}$ observación & $\mathrm{NO}$ & $\mathrm{NO}$ & sin registro \\
\hline & $2^{\mathrm{a}}$ observación & $\mathrm{NO}$ & $\mathrm{NO}$ & Ídem \\
\hline & $3^{\mathrm{a}}$ observación & SI (a $27 \mathrm{~cm})$ & SI (a $30 \mathrm{~cm})$ & Ídem \\
\hline \multirow{3}{*}{ Inversión } & $1^{\mathrm{a}}$ observación & SI $(1 / 32)$ & $\mathrm{NO}$ & Ídem \\
\hline & $2^{\mathrm{a}}$ observación & SI $(3 / 32)$ & SI (4 micl. obsidiana) & Ídem \\
\hline & $3^{\mathrm{a}}$ observación & SI $(6 / 32)$ & $\mathrm{NO}$ & Ídem \\
\hline \multirow{3}{*}{ Enterramiento } & $1^{\mathrm{a}}$ observación & $\mathrm{NO}$ & SI $(1 \mathrm{~cm})$ & sin registro \\
\hline & $2^{\mathrm{a}}$ observación & SI $(0-1 \mathrm{~cm})$ & SI $(2-3 \mathrm{~cm})$ & Ídem \\
\hline & $3^{\mathrm{a}}$ observación & SI $(0-2 \mathrm{~cm})$ & $\mathrm{SI}(3.3,5 \mathrm{~cm})$ & Ídem \\
\hline Fractura & Observaciones & No & No & No \\
\hline \multirow{3}{*}{ Corrasión } & $1^{\text {a }}$ observación & No & No & No \\
\hline & $2^{\mathrm{a}}$ observación & No & No & No \\
\hline & $3^{\mathrm{a}}$ observación & SI (opacamiento) & No & No \\
\hline
\end{tabular}

Tabla 6.2: Registro de los controles tafonómicos

\section{Síntesis comparativa e integración de los resultados}

1. Pérdida de piezas. Fue mayor (totalidad de la piezas) y más veloz (mes y medio) en el sector de dunas. El segundo lugar lo ocupa el sector de la laguna, en este caso un gran número ( $\mathrm{n}=30$ ) desapareció en la tercera observación (seis meses). En este caso lo llamtivo fue que todas las piezas ausentes fueron todas -independientemente del tamaño- las de coloración oscura (basalto y obsidiana). En la terraza, durante todo el lapso que duró el control, se perdieron siete piezas, que corresponden dos microlascas de basalto y a cinco microlascas de obsidinas.

2. El enterramiento. De aceptar que todas las piezas del médano desaparecieron por sepultamiento de sedimentos, la mayor velocidad e intensidad de este efecto se habría dado en este ambiente. Le sigue la pista de la laguna, en la cual 16 artefactos se habían enterrado entre 1 y 3,5 cm en la primera observación. En la terraza también se produjo el enterramiento. Ver qué materias primas y relacionar con el sustrato.

3. Desplazamiento. Se produjo desplazamiento en la terraza y en la laguna.

4. Inversión/rotación. Fue mayor en la laguna $(\mathrm{n}=4)$ que en la terraza.

5. Corrasión. No se observó en ninguna de las pistas, aunque las piezas de la laguna presentaron depositación de una delgada costra calcárea. 
6. Fractura. No se produjo en ninguna de las pistas, ni siquiera en el caso de la matriz sedimentaria arcillosa de la pista de cerro Avanzado. Se deduce que durante ese lapso no hubo tránsito de animales ni de vehículos.

En este capítulo se presentaron y caracterizaron de manera preliminar los principales agentes y procesos tafonómicos que podrían haber intervenido en la conformación del registro lítico del área de estudio. Si bien hasta el momento se cuenta solo con tres observaciones realizadas durante el año 2013 y principios del 2014, se pudo identificar la magnitud de los cambios operados sobre los conjuntos artefactuales experimentales en el corto plazo. Estos valores mínimos permiten comenzar a discutir los factores naturales y antrópicos que podrían estar operando en la conformación y estructuración del registro lítico bajo estudio. En cuanto al comportamiento diferencial de las pistas según el contexto de depositación, las observaciones tafonómicas iniciales sugieren que el sector de la terraza es el que presenta mayor estabilidad (Borrero 2007, Borrazzo 2011). Por el contario, los ambientes dunarios y la laguna costera serían menos estables, ya que en estos contextos la pérdida de los artefactos fue total o parcial en menos de siete meses de su montaje. Respecto de las materias primas, en los tres contextos las obsidianas fueron más propensas a "volarse", desplazarse e invertirse. Esto se debería a la menor densidad que presenta este tipo de materia prima. En cuanto a los tamaños, independientemente del tipo de roca, las piezas de menor tamaño son las que mostraron mayores cambios espaciales.

Resta continuar con los estudios actualísticos y sus registros al mismo tiempo que realizar nuevos análisis tecnológicos de conjuntos arqueológicos líticos que tengan en cuenta variables tafonómicas, para de esta manera comenzar a delinear trayectorias o historias tafonómicas propias de cada microsector. 


\section{CAPÍTULO 7}

\section{CARACTERIZACIÓN TECNOLÓGICA DE LA UNIDAD DE ANÁLISIS PENÍNSULA VALDÉS (PV)}

De acuerdo con la segmentación espacial mencionada en el capítulo 4 y sobre la base de la jerarquización del uso del espacio propuesta por Gómez Otero (2006) se describen los resultados del estudio tecnológico según los sectores costeros y tipos de golfos que abarca la unidad de análisis Península Valdés. Asimismo y como se indicó anteriormente, la totalidad de los conjuntos líticos considerados para este estudio provienen de muestreos realizados por Gómez Otero y equipo en distintas instancias y períodos de investigación. Por lo tanto la información contextual, los fechados radiocarbónicos y las inferencias en cuanto al uso del espacio y la dieta fueron extraídos de su tesis doctoral (Gómez Otero, 2006 y Gómez Otero et al. 2012). Sobre esta base, y a luz de las nuevas evidencias presentadas en este estudio se integran y discuten las inferencias realizadas previamente por los autores.

Para esta tesis se analizaron muestreos sistemáticos de sitios arqueológicos datados y representativos de distintas funcionalidades y cronologías, que abarcan un rango temporal desde el Holoceno medio hasta el Holoceno tardío final (340 años AP). De esta manera, y para la unidad Península Valdés se estudiaron las siguientes localidades arqueológicas: Las Lisas y Los Abanicos, ubicadas en el golfo San Matías; Flechero del 39 del golfo San José, y Punta Cormoranes, San Pablo y Punta Pardelas del golfo Nuevo (Fig.7.1).

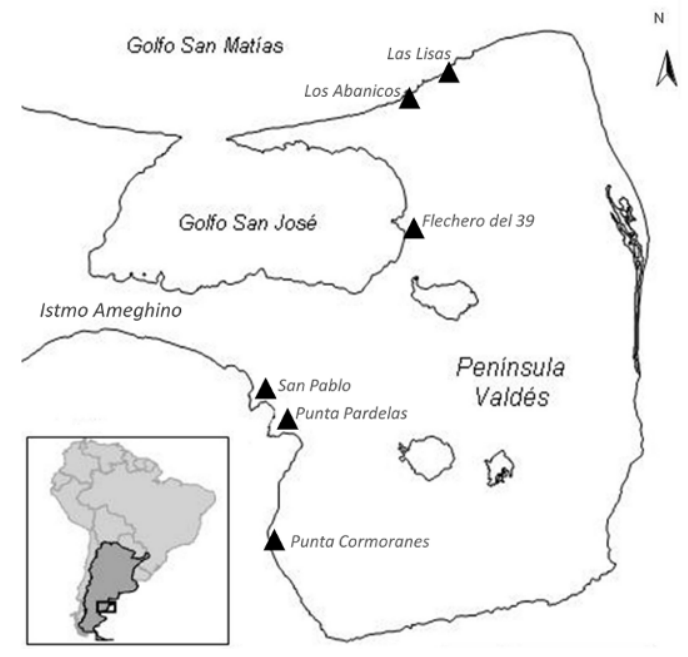

Fig. 7.1. Unidad de análisis Península Valdés: Localidades arqueológicas analizadas en esta tesis. 


\section{GOLFO SAN MATÍAS}

\section{Localidad arqueológica playa Las Lisas}

Playa Las Lisas se ubica próxima a las localidades arqueológicas San Lorenzo, La Armonía, El Progreso y los Abanicos (Fig. 7.1). Se encuentra asociada con una bajada litoral extensa y ancha cubierta por relieves dunarios (Fig.7.2). Para su estudio se seleccionaron los conjuntos líticos asociados a los sitios Las Lisas 1 Conchero 1 y Las Lisas 2 Conchero 1, cuyos muestreos fueron de $25 \mathrm{~cm}$ de lado por $10 \mathrm{~cm}$ de potencia. También se analizó el conjunto lítico del muestreo superficial de 2 por 4 metros de lado del sitio Las Lisas 2 Conchero 2.

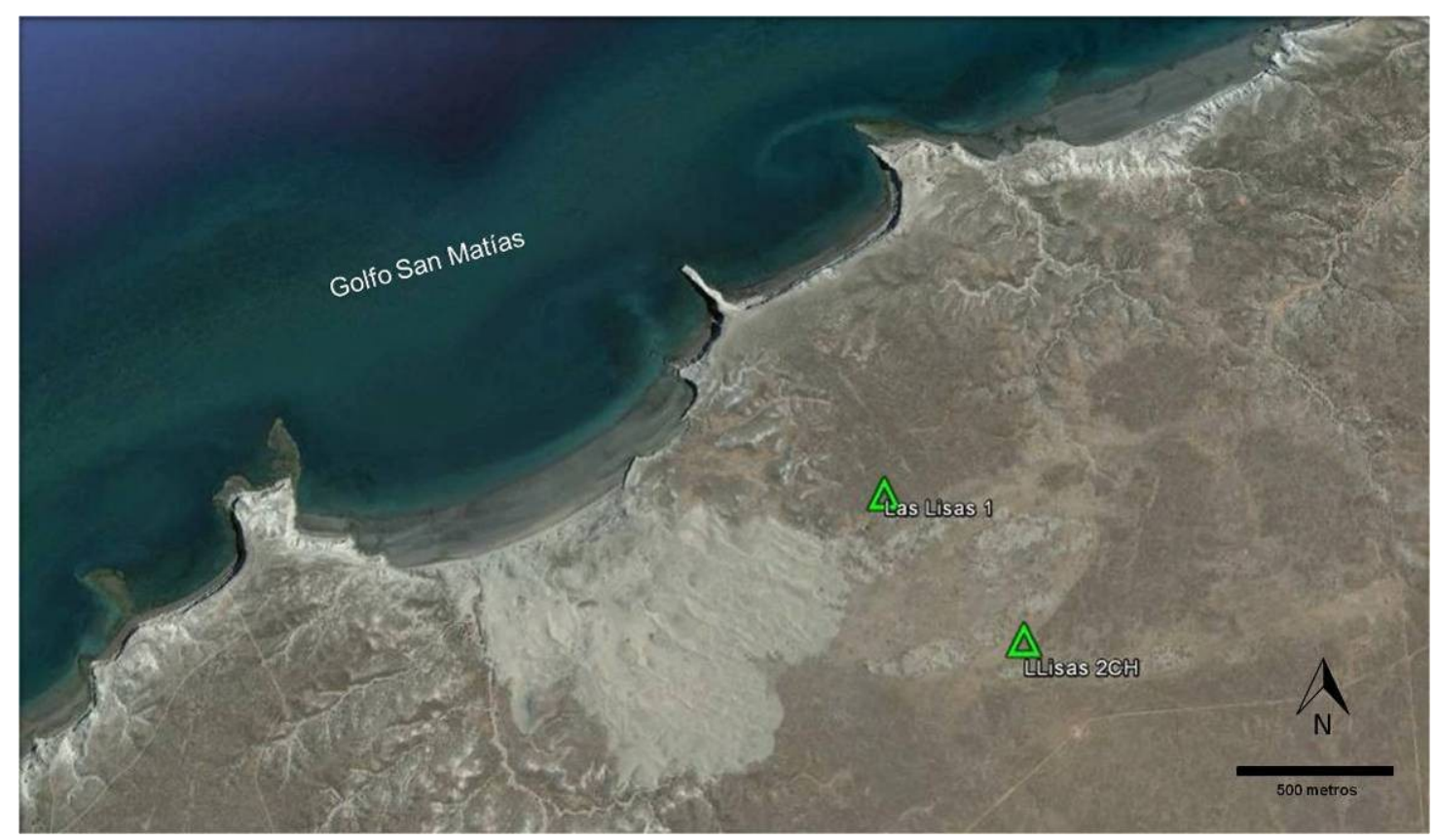

Fig.7.2. Localidad arqueológica Las Lisas.

\section{Las Lisas 1}

Es un sitio en posición superficial compuesto por varios relictos de concheros que apoyaban sobre el cordón de médanos, a unos 70 metros de distancia del mar. Sobre la superficie del terreno se observaron escasos materiales líticos redepositados por erosión eólica, entre ellos un raspador (LLis $1 \mathrm{C} 1 \mathrm{~N}^{\circ} 1$ ) y una preforma de punta de proyectil (LLis $1 \mathrm{C} 1 \mathrm{~N}^{\circ} 2$ ) (Fig. 7.3). 


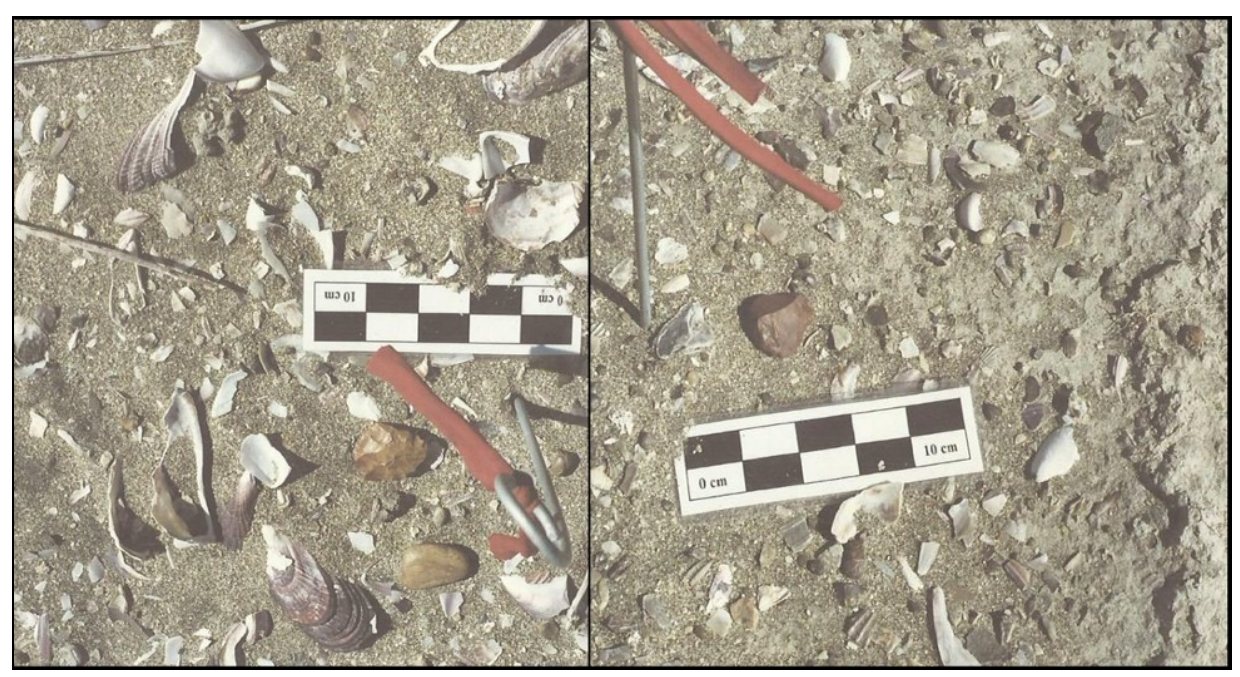

Fig. 7.3. Las Lisas 1 conchero 1: detalle de los dos instrumentos recuperados en el muestreo del conchero 1. Izquierda: preforma bifacial pequeña de sílice (LLis $1 \mathrm{C} 1 \mathrm{~N}^{\circ}$ 2), y derecha: raspador microlítico de sílice (LLis $1 \mathrm{C} 1 \mathrm{~N}^{\circ} 1$ ).

También se registraron restos óseos de guanaco (Lama guanicoe) -algunos de crías- y correspondientes a todas las partes del esqueleto, huesos aislados de pingüino (Spheniscus sp.) y cáscaras de huevo de choique (Rhea pennata). En los concheros se determinó predominio de valvas de cholga (Aulacomya ater) de tamaño grande, y en menor proporción de mejillón (Mytilus edulis), almeja blanca (Venus antiqua) y gasterópodos (Buccinanops spp.) de tamaños chicos. Se dató una muestra de valva de un pequeño conchero, que dio una antigüedad de $380 \pm$ 70 años $C^{14}$ AP (Tabla 7.1).

\section{Las Lisas 2}

Es un sitio en posición superficial ubicado sobre el segundo cordón de médanos, a unos 150-200 metros del mar. Está compuesto por varios relictos de concheros y delgadas lentes de valvas (Fig. 7.4). Los estudios arqueofaunísticos mostraron variabilidad malacológica intersitio, y presencia de cholgas (Aulacomya ater), lapas (Patinigera) y gasterópodos (Buccinanops spp.) (Gómez Otero 2006). Por fuera del muestreo faunístico se recolectaron numerosos artefactos líticos dispersos en las inmediaciones del sitio. Se registraron además molinos, manos de molienda, yunques simples y dobles, lajas de arenisca (con varias incisiones rectas que se interpretaron como huellas de corte $)^{2}$, pesas de red o de línea, un percutor en hematita, sobadores, un núcleo de obsidiana, puntas de proyectil fracturadas, preformas bifaciales, preformas de bolas y tres tiestos cerámicos. También se recuperó un yunque-sobador sobre un

\footnotetext{
${ }^{2}$ Según Gómez Otero (2006), estas lajas de areniscas consolidadas eran utilizadas como apoyo para cortar carne.
} 
rodado grande como los que se encuentran depositados en los cordones litorales de Caleta Valdés (Gómez Otero 2006). Asimismo a escasos metros del muestreó se identificó una concentración de desechos de xilópalos, probablemente un taller de esta materia prima. Dado el mayor tamaño de estos artefactos respecto de los nódulos locales de xilópalos se propuso que la materia prima sería de procedencia no local. En relación con las potenciales fuentes potenciales de abastecimiento de xilópalo, las más próximas al área de estudio se han registrado en el valle inferior del río Chubut a $150 \mathrm{~km}$ de la desembocadura (zona del Dique Ameghino), y también a $450 \mathrm{~km}$ al sur en el "Bosque Petrificado de la Costa", en el golfo San Jorge (Arrigoni et al. 2008) y en el "Bosque Petrificado Ormaechea", cercano a los lagos Musters y Colhue Huapi (Banegas et al. 2016).

Los restos faunísticos incluían huesos de lobo marino (Otaria flavescens), guanaco (Lama guanicoe), y escasos especímenes de aves indeterminadas. Se obtuvieron las siguientes dataciones radiocarbónicas de muestras de valvas: Las Lisas 2 Conchero 1: $2600 \mathrm{C}^{14}$ años AP y Las Lisas 2 Conchero Perfil 1: 2140 años $C^{14}$ AP (Tabla 7.1). Según Gómez Otero (2006) las evidencias señalan ocupaciones reiteradas en un lapso de dos mil años. Los concheros representarían sitios de actividades específicas -localizaciones- y el resto, bases residenciales.

\begin{tabular}{|c|c|c|c|c|c|c|}
\hline Sitio & $\begin{array}{c}\text { Latitud } \\
\text { Longitud }\end{array}$ & $\begin{array}{c}\text { Altura } \\
\text { S.n.m }\end{array}$ & $\begin{array}{l}\text { Dist. } \\
\text { mar }\end{array}$ & Edad C $^{14}$ AP & Muestra & $\begin{array}{c}\text { Código } \\
\text { Lab. }\end{array}$ \\
\hline Las Lisas 1-CH 1 & $\begin{array}{l}42^{\circ} 10,091^{\prime} \mathrm{S} \\
64^{\circ} 02,613^{\prime} \mathrm{O}\end{array}$ & 5 a $7 \mathrm{~m}$ & $70 \mathrm{~m}$ & $380 \pm 70$ & Valvas & LP-862 \\
\hline Las Lisas 2- $\mathrm{CH} 1$ & \multirow{2}{*}{$\begin{array}{l}42^{\circ} 10,806^{\prime} \mathrm{S} \\
64^{\circ} 04,438^{\prime} \mathrm{O}\end{array}$} & \multirow[b]{2}{*}{$10 \mathrm{~m}$} & \multirow[b]{2}{*}{$150 \mathrm{~m}$} & $2600 \pm 60$ & Valvas & LP-868 \\
\hline Las Lisas 2 - $\mathrm{CH} 2$ & & & & $2140 \pm 50$ & Valvas & LP-875 \\
\hline
\end{tabular}

Tabla 7.1. Localidad Playa Las Lisas: localización y fechados obtenidos de los concheros. Referencias: Dist. Distancia; Lab. Laboratorio. Datos obtenidos de Gómez Otero 2006.

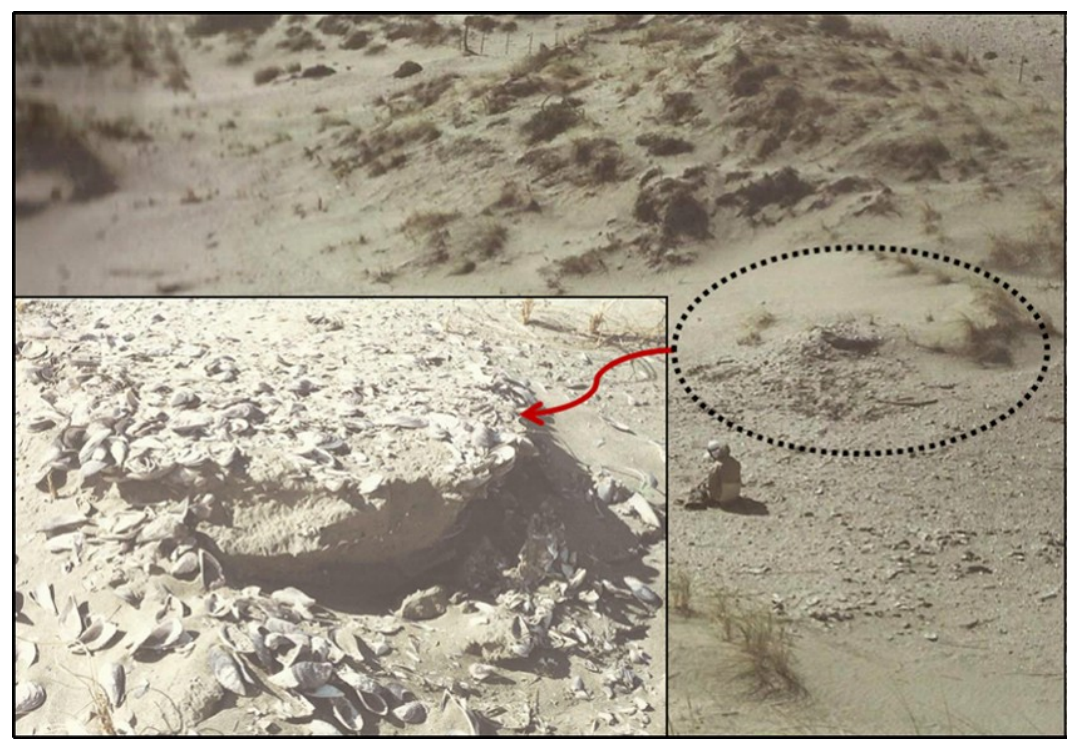

Fig. 7.4. Las Lisas 2 conchero 1: área de dispersión y detalle del conchero. 


\section{Análisis tecnológico}

En Las Lisas 1, conchero 1 (en adelante LLis $1 \mathrm{C} 1$ ) se hallaron dos artefactos $(0,003 /$ $\mathrm{dm}^{3}$ ); en Las Lisas 2, conchero 1 (LLis $2 \mathrm{C} 1$ ) el total de artefactos recuperados es de 14, con una densidad de $0,022 / \mathrm{dm}^{3}$. En el muestreo 1 del sitio 2 (LLis 2 C2 M1), los artefactos hallados son 363 y la densidad artefactual de $4,53 / \mathrm{dm}^{2}$.

\section{Materias primas:}

Los dos instrumentos de LLis 1 C1 están manufacturados sobre rocas silíceas, de muy buena calidad para la talla. En el conjunto artefactual de LLis $2 \mathrm{C} 1$ las materias primas mayoritarias se distribuyen en proporciones parejas entre basaltos y calcedonias $(n=4$ y 3 de cada una), y el resto $(n=6)$ están representadas por un artefacto de cuarcita, ignimbrita, obsidiana gris-verdosa, riolita, sílice y xilópalo respectivamente (Tabla 7.2). Para LLis 2 C2 M1, las variedades litológicas son diez y una indeterminada. Entre las materias primas predominan las sílices (37\%), seguidas por basaltos $(24,5 \%)$ y en tercer lugar calcedonias (16 $\%)$. En frecuencias bajas $(0,4$ a $7 \%)$ se ubican en orden creciente andesita, hematita, riolita, cuarcita, obsidiana (gris-verdosa y negra), xilópalo e ignimbrita (Tabla 7.2).

Con la excepción de las obsidianas, xilópalos y hematita, de procedencia no local en el área (Gómez Otero y Stern 2006; Banegas et al. 2016), el resto de las rocas es local y se encuentra disponible en forma de rodados mediano-pequeños $(60-65 \mathrm{~mm})$.

\begin{tabular}{|c|c|c|c|c|}
\hline \multirow{2}{*}{ Materias primas } & LLis 1 & LLis C2 & \multicolumn{2}{|c|}{ LLis 2 M1 } \\
\cline { 2 - 5 } & $\mathbf{N}$ & $\mathbf{N}$ & $\mathbf{N}$ & $\mathbf{\%}$ \\
\hline Basalto & -- & 4 & 65 & 24,5 \\
\hline Andesita & -- & -- & 1 & 0,4 \\
\hline Calcedonia & -- & 3 & 42 & 15,8 \\
\hline Cuarcita & -- & 1 & 7 & 2,6 \\
\hline Hematita & -- & -- & 1 & 0,4 \\
\hline Ignimbrita & -- & 1 & 19 & 7,2 \\
\hline Obsidiana verde & -- & 1 & 5 & 1,9 \\
\hline Obsidiana negra & -- & -- & 5 & 1,9 \\
\hline Riolita & -- & 2 & 2 & 0,8 \\
\hline Sílice & 2 & 1 & 98 & 37 \\
\hline Xilópalo & -- & 1 & 13 & 4,9 \\
\hline Indeterminadas & -- & -- & 7 & 2,6 \\
\hline Total & $\mathbf{2}$ & $\mathbf{1 4}$ & $\mathbf{3 3 0}$ & $\mathbf{1 0 0}$ \\
\hline
\end{tabular}

Tabla 7.2. Localidad Playa Las Lisas: tipos y frecuencias de las variedades litológicas. 


\section{Clases artefactuales:}

Los únicos artefactos líticos de LLis $1 \mathrm{C} 1$ están representados por dos instrumentos tallados, mientras que los recuperados en el Conchero 2 son todos desechos de talla. En el Muestreo 1 del sitio 2 la clase sobresaliente son los desechos de talla (85\%), en segundo lugar los artefactos formatizados por talla (7\%) y los núcleos (5\%), y en tercer lugar las lascas con rastros complementarios $(2,8 \%)$. Se rescataron además dos artefactos modificados por el uso $(0,6 \%)\left(\right.$ LLis $1 \mathrm{C} 1 \mathrm{~N}^{\mathrm{o}} 1 \mathrm{~A}$ y $\left.\mathrm{N}^{\mathrm{o}} 1 \mathrm{~B}\right)$ (Tabla 7.3$)$.

\begin{tabular}{|c|c|c|c|c|c|}
\hline Muestreos & \multirow{2}{*}{ Núcleos } & \multirow{2}{*}{ Desechos } & \multicolumn{2}{|c|}{ Instrumentos } & $\begin{array}{c}\text { Art.Form. } \\
\text { por talla }\end{array}$ \\
\hline LLis 1 C1 & -- & -- & 2 & $\begin{array}{c}\text { Rastros } \\
\text { complement. }\end{array}$ & $\begin{array}{c}\text { Art. Modif. } \\
\text { por el uso }\end{array}$ \\
\hline LLis 2 C2 & -- & 14 & -- & -- & -- \\
\hline LLis 2C2 M1 & 18 & 307 & 26 & -- & - \\
\hline Total & $5 \%$ & $84,6 \%$ & $7,2 \%$ & $2,8 \%$ & $0,6 \%$ \\
\hline
\end{tabular}

Tabla 7.3. Localidad Playas Las Lisas: distribución de las clases tipológicas.

\section{Desechos de talla:}

En LLis 2 C2 los desechos están representados por seis lascas enteras, cinco fracturadas con talón, dos fracturadas sin talón y un desecho no clasificable. Prevalecen las lascas de reactivación directa $(n=3)$ y en segundo lugar y con dos de cada tipo, se encuentran primarias y secundarias, de reactivación directa, y por ultimo una lámina de arista doble y una lasca con dorso natural. Dos desechos no pudieron ser determinados (Tabla 7.4).

En LLis 2 C2 M1 también son mayoría las lascas enteras ( $\mathrm{n}=134 ; 44 \%)$, seguidas por las fracturadas sin talón $(n=68 ; 22 \%)$ y los desechos no clasificables $(n=62 ; 20 \%)$ y en tercer lugar las lascas fracturadas con talón ( $\mathrm{n}=43 ; 14 \%)$. Entre los tipos de lascas se destacan las de dorso natural (22\%) y las primarias $(11 \%)$ y en segundo lugar bipolares $(9 \%)$, con dorso preparado (7\%) y de arista recta y secundarias (6\% cada una). En baja frecuencia (entre $1 \%$ y $5 \%$ ) se ubican las de reactivación directa y en cresta, de arista inclinada, oblicuas, nucleiformes y una lasca en punta. Un porcentaje considerable (14 \%) no pudo ser determinado (Tabla 7.4). 


\begin{tabular}{|c|c|c|c|}
\hline \multirow{2}{*}{ Tipo de lascas } & LLis 2 C1 & \multicolumn{2}{|c|}{ LLis 2 M1C2 } \\
\cline { 2 - 4 } & $\mathbf{N}$ & $\mathbf{N}$ & $\mathbf{\%}$ \\
\hline Punta de arista oblicua & -- & 7 & 2,9 \\
\hline Punta de arista inclinada & -- & 10 & 4,1 \\
\hline Con dorso natural & 1 & 53 & 21,6 \\
\hline De arista recta & 3 & 15 & 6,1 \\
\hline Primaria & 2 & 28 & 11,4 \\
\hline En cresta/flanco de núcleo & -- & 13 & 5,3 \\
\hline Con dorso preparado & -- & 17 & 6,9 \\
\hline Secundaria & 2 & 14 & 5,7 \\
\hline De reactivación directa & 2 & 13 & 5,3 \\
\hline De reactivación indirecta & -- & 2 & 0,8 \\
\hline Nucleiforme & -- & 6 & 2,4 \\
\hline Lámina de arista doble & 2 & 4 & 1,6 \\
\hline Lasca en punta & -- & 7 & 2,9 \\
\hline Bipolar & -- & 21 & 8,6 \\
\hline Indeterminada & 2 & 35 & 14,3 \\
\hline Total & $\mathbf{1 4}$ & $\mathbf{2 4 5}$ & $\mathbf{1 0 0 \%}$ \\
\hline
\end{tabular}

Tabla7.4. Localidad Playas Las Lisas: tipos y frecuencias de lascas.

En cuanto al tamaño de las lascas, en el Conchero 1 más de la mitad son pequeñas ( $\mathrm{n}=$ $8)$, el resto son microlascas $(\mathrm{n}=5)$ y una sola mediana. El modulo más frecuente es el mediano normal $(\mathrm{n}=7)$, al que siguen los cortos anchos y los medianos alargados (Tabla 7.5). Para el sitio LLis 2 C2 M 1 también sobresalen las microlascas (46,5\%) seguidas por las pequeñas (38 $\%)$ y las hipermicrolascas (10\%); las demás están representadas por las medianas (5\%) y una sola es muy grande $(0,4 \%)$. El módulo que prevalece es el mediano normal (66 \%), seguido por el mediano alargado (23\%), y en porcentajes inferiores y parejos (entre $5 \%$ y $3 \%$ ) se ubican los cortos anchos, los laminares normales y los angostos (Tabla 7.5).

\begin{tabular}{|c|c|c|c|c|c|c|c|c|}
\hline \multirow{2}{*}{\multicolumn{2}{|c|}{$\begin{array}{l}\text { Tamaño } \\
\text { Módulo }\end{array}$}} & \multirow{3}{*}{$\begin{array}{c}\begin{array}{r}\text { Corto } \\
\text { ancho }\end{array} \\
2 \\
\end{array}$} & \multirow{3}{*}{$\begin{array}{c}\text { Laminar } \\
\text { angosto }\end{array}$} & \multirow{3}{*}{$\begin{array}{c}\text { Laminar } \\
\text { normal }\end{array}$} & \multirow{2}{*}{$\begin{array}{c}\text { Med. } \\
\text { alargado }\end{array}$} & \multirow{2}{*}{$\begin{array}{c}\text { Med. } \\
\text { normal }\end{array}$} & \multicolumn{2}{|c|}{ Total } \\
\hline & & & & & & & $\mathbf{N}$ & $\%$ \\
\hline \multirow{4}{*}{ 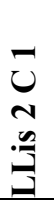 } & Microlasca & & & & 1 & 2 & 5 & -- \\
\hline & Lasca Pequeña & 2 & -- & -- & 2 & 4 & 8 & -- \\
\hline & Lasca Mediana & -- & -- & -- & -- & 1 & 1 & -- \\
\hline & $\mathbf{N}$ & 4 & -- & -- & 3 & 7 & 14 & -- \\
\hline \multirow{7}{*}{ 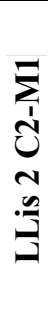 } & Hipermicrolasca & -- & 3 & 5 & 1 & 16 & 25 & 10 \\
\hline & Microlasca & 1 & -- & -- & 33 & 80 & 114 & 46 \\
\hline & Lasca Pequeña & 10 & 4 & 3 & 20 & 56 & 93 & 38 \\
\hline & Lasca Mediana & 2 & -- & -- & 2 & 8 & 12 & 4,9 \\
\hline & Lasca M.Grande & -- & -- & -- & -- & 1 & 1 & 0,4 \\
\hline & $\mathbf{N}$ & 13 & 7 & 8 & 56 & 161 & \multirow{2}{*}{245} & \multirow{2}{*}{100} \\
\hline & $\%$ & 5,3 & 2,9 & 3,3 & 22,9 & 66 & & \\
\hline
\end{tabular}

Tabla 7.5. Localidad Playas Las Lisas: tamaño y módulo largo/ancho de las lascas. 
En cuanto al tipo de talón, para las lascas de LLis 2 C2 se registran corticales y facetados ( $n=3$ de cada uno), seguidos por los diedros, filiformes y ausentes por fractura $(n=2$ respectivamente). También se identificó un talón puntiforme y otro astillado (Tabla 7.6). En el Muestreo 1 , los talones se distribuyen en valores equitativos (entre $14 \%$ y $18 \%$ ) en filiformes, ausentes, lisos y facetados; le siguen los astillados, corticales y diedros (entre $10 \%$ y 9\%) y en valores más bajos se encuentran los puntiformes (3\%) y los fracturados (2\%). El 4,5\% no pudo ser determinado (Tabla 7.6).

\begin{tabular}{|c|c|c|c|}
\hline \multirow{2}{*}{ Tipo de talón } & \multirow{2}{*}{ LLis 2 C1 } & \multicolumn{2}{|c|}{ LLis 2 C2-M1 } \\
\cline { 3 - 4 } & & $\mathbf{N}$ & $\mathbf{\%}$ \\
\hline Cortical & 3 & 22 & 9 \\
\hline Liso & -- & 36 & 14,7 \\
\hline Diedro & 2 & 25 & 10,2 \\
\hline Facetado & 3 & 34 & 13,9 \\
\hline Filiforme & 2 & 43 & 17,6 \\
\hline Puntiforme & 1 & 8 & 3,3 \\
\hline Astillado & 1 & 24 & 9,8 \\
\hline Fracturado & -- & 5 & 2 \\
\hline Ausente & 2 & 37 & 15,1 \\
\hline Indeterminado & -- & 11 & 4,5 \\
\hline Total & $\mathbf{1 4}$ & $\mathbf{2 4 5}$ & $\mathbf{1 0 0}$ \\
\hline
\end{tabular}

Tabla7.6: Localidad Playas Las Lisas: tipos y frecuencias de los talones.

\section{Artefactos formatizados por talla}

Los dos instrumentos tallados (LLis $1 \mathrm{C} 1 \mathrm{~N}^{\circ} 1$ y $\mathrm{N}^{\circ}$ 2) rescatados del Conchero 1 corresponden a un raspador frontal de sílice pequeño y una preforma bifacial (Estadio 4 de Nami 1987) en roca silícea y tamaño pequeño (Fig. 7.4 y 7.5). Los dos fueron confeccionados sobre lascas y la situación de los lascados es unifacial para el raspador y bifacial para la preforma. El filo del raspador se encuentra activo (Tabla 7.9). 


\begin{tabular}{|c|c|c|c|c|c|c|}
\hline $\mathbf{N}^{\mathbf{0}}$ & Subg-tipológico & \multicolumn{2}{c}{ M.prima } & \multicolumn{2}{c}{ Forma base } & \multicolumn{2}{c}{$\begin{array}{c}\text { Largo } \\
(\mathbf{m m})\end{array}$} & $\begin{array}{c}\text { Ancho } \\
(\mathbf{m m})\end{array}$ & $\begin{array}{c}\text { Espesor } \\
(\mathbf{m m})\end{array}$ \\
\hline 1 & Raspador & Sílice & Lasca de arista inclinada pequeña & 24,9 & 22,1 & 6,5 \\
\hline 2 & Preforma bifacial & Sílice & Lasca pequeña & 31,4 & 23,2 & 9,3 \\
\hline
\end{tabular}

Tabla 7.7. Localidad Playas Las Lisas: características de los artefactos tallados de LLis 1 C1.

\begin{tabular}{|c|c|c|c|c|c|c|c|c|}
\hline $\mathbf{N}^{\mathbf{o}}$ & Subg-tipológico & $\begin{array}{c}\text { Serie } \\
\text { Técnica }\end{array}$ & Sit lasc. & F.G.contorno & Posic. Filo & F.Lasc. & $>$ Filo & Estado \\
\hline 1 & $\begin{array}{l}\text { Raspador } \\
\text { frontal }\end{array}$ & $\begin{array}{l}\text { Microrretoque } \\
\text { marginal }\end{array}$ & unifacial & oval irregular & Fronto lateral & $\begin{array}{c}\text { Escamoso } \\
\text { Irregular }\end{array}$ & $30^{\circ}$ & Activo \\
\hline 2 & $\begin{array}{l}\text { Preforma } \\
\text { Bifacial }\end{array}$ & $\begin{array}{l}\text { Retalla } \\
\text { extendida }\end{array}$ & bifacial & lanceolado & Perimetral & $\begin{array}{l}\text { Marginal } \\
\text { Corto }\end{array}$ & $\mathrm{nc}$ & nc \\
\hline
\end{tabular}

Tabla 7.8. LLis 2 C2: Rasgos morfotécnicos de los artefactos tallados. Referencias: Sit. Lascados: situación de los lascados; F. Geom.: forma geométrica, Posic.Fil: Posición del filo; F.Lasc. Forma de los lascados; Ang. Ángulo del filo; restr. Restringido; Unif: Unificial; Indet: indeterminado. 
En el Muestreo 1 los instrumentos formatizados por talla $(n=26)$ se distribuyen en los siguientes grupos tipológicos: puntas burilantes y muescas (30,7 \% cada uno), raspadores $(19,2$ $\%)$, retoques sumarios $(15,3 \%)$ y un cuchillo de filo retocado $(3,8 \%)$. Del total, once están manufacturados sobre sílices coloreados, cinco sobre calcedonias blanquecinas, cuatro en xilópalos, y los restantes en basalto y obsidiana (dos de cada uno) y uno en cuarcita y en ópalo respectivamente (Tabla 7.8). Salvo la cuarcita, el basalto y algunas silíceas de calidad buena, el resto de las materias primas se destaca por su calidad excelente a muy buena. En cuanto a las formas base, predominan las lascas $(n=23)$ que se distribuyen en distintos tamaños: pequeños $(n=14)$ medianos $(n=6)$, lascas grandes $(n=2)$ y una microlasca. También se identificaron dos soportes laminares y un flanco de núcleo (Tabla 7.8). Predomina el retoque marginal (53,8 \%), seguido por el microrretoque $(23,1 \%)$, por último y en frecuencias parejas la talla y el lascado simple de formatización (11,5\% cada uno). La situación de los lascados es en todos los casos unifacial. Casi la totalidad de los artefactos $(n=22)$ presenta sus filos activos. Se registraron seis filos dobles: dos en las puntas burilantes confeccionadas sobre ópalo y basalto de muy buena calidad; sobre una muesca, un raspador y un retoque sumario todos de sílices y de calidad buena a muy buena, y por último en el cuchillo de filo lateral retocado de calcedonia de muy buena calidad (Tabla 7.10).

\section{Lascas con rastros complementarios}

En el Muestreo 1 se identificaron diez lascas con rastros complementarios; de las cuales seis son de sílices de calidad buena para la talla; dos de calcedonia y una respectivamente de ópalo y de toba. Todas estas materias primas son de muy buena a excelente calidad. En cuanto a los tamaños, prevalecen los pequeños $(n=5)$, el resto son lascas medianas y dos grandes.

\section{Núcleos}

Del total de núcleos de LLis 2 C2 M1 (n=18), siete provienen de rodados de sílices y cuatro de basalto, el resto corresponde a calcedonias y xilópalos (dos de cada una) y uno respectivamente de obsidiana, riolita e Ignimbrita (Fig. 7.6). En cuanto a los tamaños, prevalecen los pequeños $(n=14)$, excepto dos grandes de sílices y dos medianos de basalto. Respecto de los tipos de núcleos, son mayoría los bipolares $(\mathrm{n}=9)$ y en segundo lugar los discoidales $(n=3)$. El resto son de lascados aislados $(n=2)$, piramidal $(n=1)$ e indeterminados $(n=3)$. Sobre la base del porcentaje de corteza y grado de modificación se determinó que la mayoría $(n=17)$ se encuentran agotados $(n=15)$. Por su parte y en relación con la forma de los negativos de los lascados todos corresponden a lascas (Tabla 7.11). 


\begin{tabular}{|c|l|c|l|c|l|l|l|}
$\begin{array}{c}\text { Materia } \\
\text { prima }\end{array}$ & \multicolumn{2}{|c|}{ Tipo } & $\begin{array}{l}\mathbf{N}^{\mathbf{0}} \text { mín } \\
\text { p.perc. }\end{array}$ & $\begin{array}{l}\text { Forma sup plat } \\
\text { perc. }\end{array}$ & $\begin{array}{l}\mathbf{N}^{\mathbf{0}} \\
\text { lasc. }\end{array}$ & $\begin{array}{l}\text { F. Neg. } \\
\text { Lascados }\end{array}$ & \multicolumn{2}{l|}{$\begin{array}{l}\text { Grado } \\
\text { modific }\end{array}$} & Estado \\
\hline \multirow{5}{*}{ Basalto } & Lasc. aislados & 2 & Cortical & 2 & Lascas & Medio & Agotado \\
\cline { 2 - 8 } & Lasc.aislados & 3 & Cortical & 3 & Lascas & Alto & Agotado \\
\cline { 2 - 8 } & Bipolar & 2 & Astillada & 3 & Lascas & Alto & Agotado \\
\cline { 2 - 8 } & Bipolar & 2 & Astillada & 3 & Lascas & Alto & Agotado \\
\hline \multirow{5}{*}{ Sílices } & Bipolar & 2 & Cortical & 3 & Lascas & Alto & Agotado \\
\cline { 2 - 8 } & Bipolar & 2 & Cortical & 2 & Lascas & Alto & Agotado \\
\cline { 2 - 8 } & Bipolar & 2 & Astillada & 3 & Lascas & Alto & Agotado \\
\cline { 2 - 8 } & Bipolar & 2 & Astillada & 4 & Lascas & Alto & Agotado \\
\cline { 2 - 8 } & Bipolar & 2 & Astillada & 3 & Lascas & Medio & Activo \\
\cline { 2 - 8 } & Discoidal & 3 & Liso & 6 & Lascas & Medio & Activo \\
\cline { 2 - 8 } & Piramidal & 3 & Cortical & 4 & Lascas & Alto & Activo \\
\hline Calcedonia & Indet. & 3 & Liso & 4 & Lascas & Alto & Agotado \\
\cline { 2 - 8 } & Bipolar & 2 & cortical & 3 & Lascas & Alto & Agotado \\
\hline Obsidiana* & Bipolar & 3 & Astillada & 3 & Lascas & Alto & Agotado \\
\hline Riolita & Frag. Indet & -- & Cortical & 3 & Lascas & Alto & Agotado \\
\hline Ignimbrita & Frag Indet & -- & Cortical & 3 & Lascas & Alto & Agotado \\
\hline Xilópalo & Discoidal & 4 & Liso & 4 & Lascas & Alto & Agotados \\
\hline Xilópalo & Discoidal & 3 & Liso & 4 & Lascas & Alto & Agotado \\
\hline
\end{tabular}

Tabla 7.11. LLis 1 M1: características morfológicas y técnicas de los núcleos. * La obsidiana es del tipo gris-verdoso. 
a)

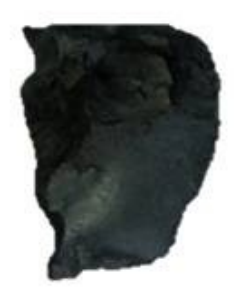

d)

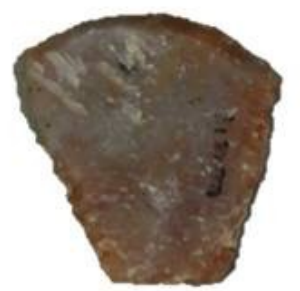

g)

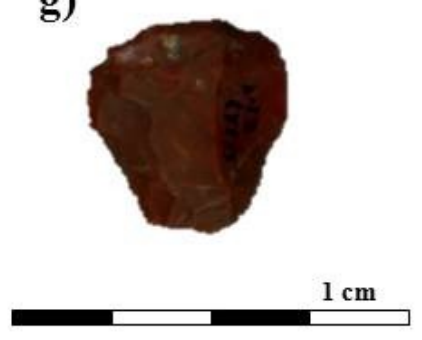

b)

e) c)
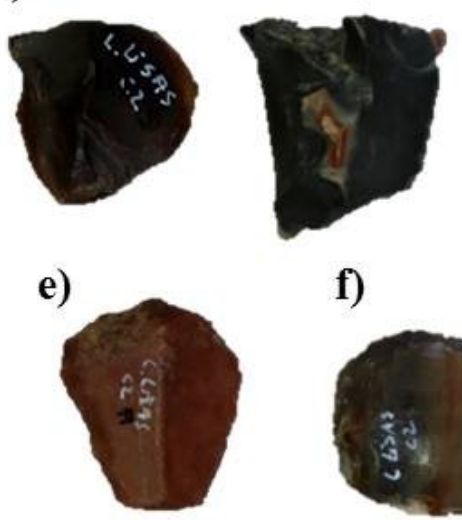

f)

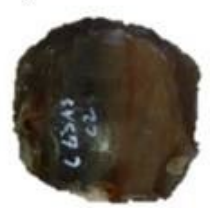

h)

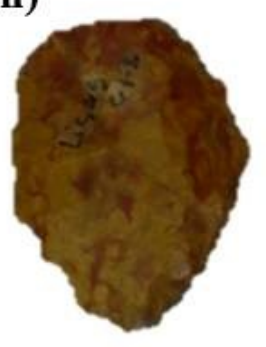

Fig. 7.5. Instrumentos tallados Localidad Las Lisas: a); b) y c): Puntas burilantes ( $\mathrm{N}^{\mathrm{o}} 1,3$ y 2); d); e) y f) raspadores recolectados en Las Lisas 2 C2 M1 ( ${ }^{\circ} 17,19$ y 16); g) Raspador frontal (LLis 1 C1 No 1); h) Pieza bifacial (LLis $1 \mathrm{C} 1 \mathrm{~N}^{\circ}$ 2).

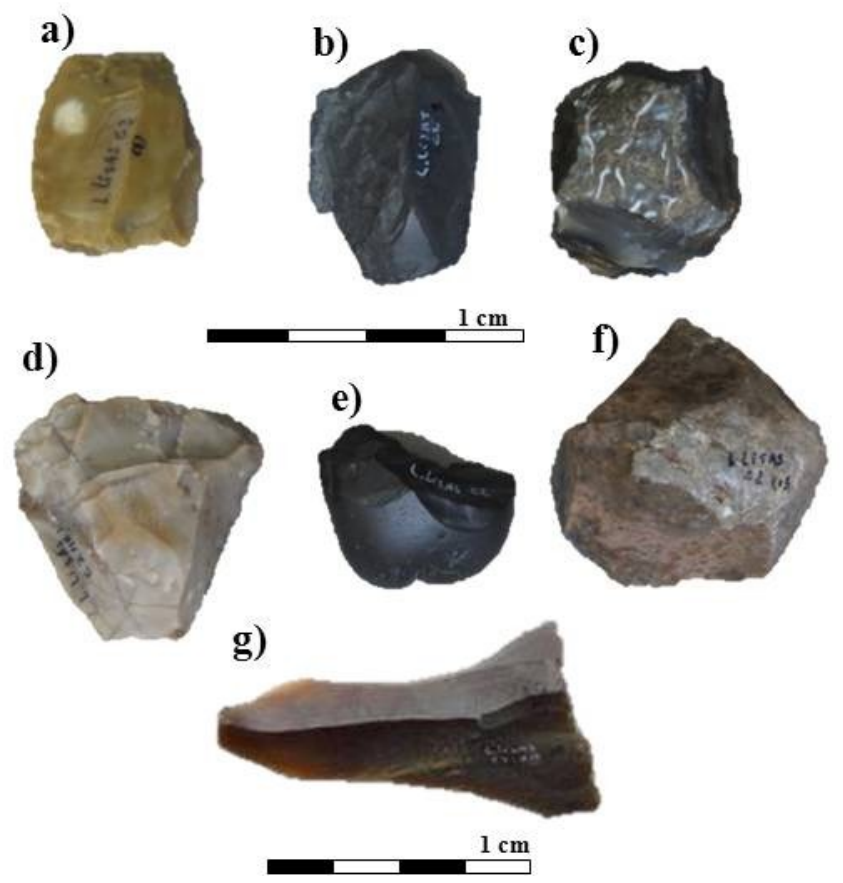

Fig. 7.6. Núcleos recuperados en Las Lisas 2 C2 M1: a) LLisas C2 7; b) LLisas C2 2; c) LLisas C2 15; d) y e LLisas C2 116) LLisas C2 2B; f) LLisas C2 15; g) Lasca de flanco de núcleo de xilópalo LLisas C2. 


\begin{tabular}{|c|c|c|c|c|c|c|}
\hline $\mathbf{N}^{0} \operatorname{Inv}$ & Subg-tipológico & M.prima & Forma base & Largo (mm) & Ancho (mm) & Espesor (mm) \\
\hline 1 & Punta burilante & Basalto & Lasca secundaria pequeña & 28 & 22 & 6,3 \\
\hline 2 & Punta burilante & Xilópalo & Flanco núcleo pequeña & 24 & 22,6 & 10,3 \\
\hline 3 & Punta burilante & Xilópalo & Lasca reactivación pequeña & 21 & 20 & 6.7 \\
\hline 4 & Punta burilante & Ópalo & Lasca alargada, mediana & 43,2 & 19,7 & 6,4 \\
\hline 5 & Punta burilante & Calcedonia & Lam normal mediana & 39,4 & 16,6 & 8,2 \\
\hline 6 & Punta burilante & Silice & Lasca con dorso natural mediana & 24,2 & 21,4 & 6,7 \\
\hline 7 & Punta burilante & Silice & Lasca con dorso natural pequeña & 26 & 19,5 & 6,4 \\
\hline 8 & Punta burilante & Silice & Lasca secundaria pequeña & 27,5 & 28,7 & 10,7 \\
\hline 9 & Muesca & Basalto & Lasca con dorso natural pequeña & 23,9 & 26 & 7,5 \\
\hline 10 & Muesca & Calcedonia & Lasca pequeña & 31 & 23,5 & 5,8 \\
\hline 11 & Muesca & Calcedonia & Microlasca de arista inclinada & 20 & 18 & 5,3 \\
\hline 12 & Muesca & Calcedonia & Lasca pequeña de arista inclinada & 26 & 27,5 & 9,5 \\
\hline 13 & Muesca & cuarcita & Lasca pequeña indet. & 25,7 & 27 & 6 \\
\hline 14 & Muesca & Xilópalo & Lasca pequeña, con dorso natural & 23,8 & 21 & 7 \\
\hline 15 & Muesca & Silice & Lasca grande indet & 46,7 & 32,6 & 13 \\
\hline 21 & Muesca & Sílice & Lasca grande de arista inclinada & 67,3 & 41,4 & 13,6 \\
\hline 16 & Raspador & Xilópalo & Lasca mediana arista doble & 25,5 & 23,6 & 5,9 \\
\hline 17 & Raspador & Sílice & Lasca mediana & 34 & 29,8 & 5,2 \\
\hline 18 & Raspador & Sílice & Lasca pequeña primaria & 26,6 & 21 & 7,7 \\
\hline 19 & Raspador & Sílice & Lasca mediana ancha & 19 & 28 & 7,8 \\
\hline 20 & Raspador & Sílice & Lasca pequeña & 37,9 & 14,7 & 7,4 \\
\hline 22 & Filo retocado & Calcedonia & Lamina normal de arista inclinada & 54,4 & 28,3 & 10,6 \\
\hline 23 & Retoques sumarios & Sílice & Lasca mediana normal & 35,6 & 31 & 7,1 \\
\hline 24 & Retoques sumarios & Sílice & Lasca mediana & 36,1 & 22 & 5,1 \\
\hline 25 & Retoques sumarios & Obs GV & Lasca pequeña con dorso natural & 20 & 16,6 & 5,3 \\
\hline 26 & Retoques sumarios & Obs GV & Lasca pequeña & 31 & 18,6 & 2,6 \\
\hline
\end{tabular}

Tabla 7.9. Localidad Playas Las Lisas: características de los artefactos tallados de LLis2 C2 M1. 


\begin{tabular}{|c|c|c|c|c|c|c|c|c|}
\hline $\mathbf{N}^{0}$ Inv & Subg-tipológico & Serie Técnica & Sit lasc. & F. G.contorno & Posic. Filo & F.Lasc & >Filo & Estado \\
\hline 1 & Punta burilante & Retoque & unifacial & Triangular irregular & Fronto lateral & Marginal corto & nc & Activo \\
\hline 2 & Punta burilante & Lascado simple & unifacial & Trapezoidal simétrico & Fronto lateral & Marginal corto & nc & Activo \\
\hline 3 & Punta burilante & Retoque & unifacial & Oval irregular & Fronto lateral & Marginal corto & nc & Activo \\
\hline 4 & Punta burilante & Retoque & unifacial & Elíptica irregular & Fronto lateral & Marginal corto & nc & Activo \\
\hline 5 & Punta burilante & Retoque & unifacial & Triangular irregular & Frontal & Marginal corto & nc & Activo \\
\hline 6 & Punta burilante & Lascado simple & unifacial & $\begin{array}{l}\text { Cuadrangular } \\
\text { redondeado }\end{array}$ & Fronto lateral & No diferenciado & nc & Activo \\
\hline 7 & Punta burilante & Lascado simple & unifacial & Triangular irregular & Frontal & Marginal corto & nc & Activo \\
\hline 9 & Muesca & Retoque marginal & unifacial & Rectangular & Fronto lateral & Marginal corto & nc & Activo \\
\hline 10 & Muesca & Retoque marginal & unifacial & Trapezoidal asimétrico & Fronto lateral & Marginal corto & nc & Activo \\
\hline 11 & Muesca & $\begin{array}{l}\text { Microrretoque } \\
\text { restringido }\end{array}$ & unifacial & Indet. & Fronto lateral & Marginal corto & nc & Activo \\
\hline 12 & Muesca & $\begin{array}{l}\text { Microrretoque } \\
\text { restringido }\end{array}$ & unifacial & Piriforme & Fronto lateral & Marginal corto & $\mathrm{nc}$ & Activo \\
\hline 13 & Muesca & Retoque marginal & unifacial & Cuadrangular & Fronto lateral & Marginal corto & nc & Activo \\
\hline 14 & Muesca & Talla marginal & unifacial & Indet. & Fronto lateral & Marginal corto & nc & Activo \\
\hline 16 & Raspador & Retoque marginal & unifacial & Circular incompleto & Perimetral & Escamoso irreg & $50^{\circ}$ & Activo \\
\hline 17 & Raspador & Microrretoque marginal & unifacial & Romboide & Perimetral & Marginal corto & $30^{\circ}$ & Activo \\
\hline 18 & Raspador & Retoque marginal & unifacial & Oval irregular & Fronto-lateral & Escamoso irreg & $20^{\circ}$ & Activo \\
\hline 19 & Raspador & Retoque marginal & unifacial & Indet. & Frontal & Paralelo corto irreg & $30^{\circ}$ & Activo \\
\hline 20 & Raspador & Microrretoque marginal & unifacial & Indet. & Fronto lateral & Marginal corto & $40^{\circ}$ & Agotado \\
\hline 22 & Cuchillo filo retocado & Microrretoque marginal & unifacial & Rectangular & Perimetral & Escamoso reg & $30^{\circ}$ & Activo \\
\hline 23 & Retoques sumarios & Microrretoque marginal & unifacial & Indet. & Lateral & Marginal corto & $35^{\circ}$ & Agotado \\
\hline 24 & Retoques sumarios & retoque marginal alterno & unifacial & Amigdoloide irregular & Perimetral & Marginal corto & $35^{\circ}$ & Activo? \\
\hline 25 & Retoques sumarios & Retoque marginal & unifacial & Indet. & Lateral & Marginal corto & $40^{\circ}$ & Agotado \\
\hline 26 & Retoques sumarios & Retoque marginal & unifacial & Indet. & Indet & Marginal corto & $40^{\circ}$ & Agotado \\
\hline
\end{tabular}

Tabla 7.10. LLis 1M1: Rasgos morfotécnicos de los artefactos tallados. Referencias: Sit. Lascados: situación de los lascados; F. Geom.: forma geométrica, Posic.Fil: Posición del filo; F.Lasc. Forma de los lascados; Ang. Ángulo del filo; restr. Restringido; Unif: Unificial; Indet: indeterminado. 


\section{Artefactos modificados por el uso}

Sólo en el muestreo de LLis 2 C2 M1 se hallaron artefactos modificados por el uso. Se trata un yunque doble y percutor sobre rodado de tamaño grande de basalto $\left(\mathrm{N}^{\circ}\right.$ LLis $1 \mathrm{C} 1 \mathrm{~N}^{\circ}$ 1A) (Fig. 7.7), y el otro corresponde a un fragmento de yunque simple sobre un guijarro de riolita $\left(\mathrm{N}^{\circ}\right.$ LLis $\left.1 \mathrm{C} 1 \mathrm{~N}^{\circ} 2 \mathrm{~B}\right)$.

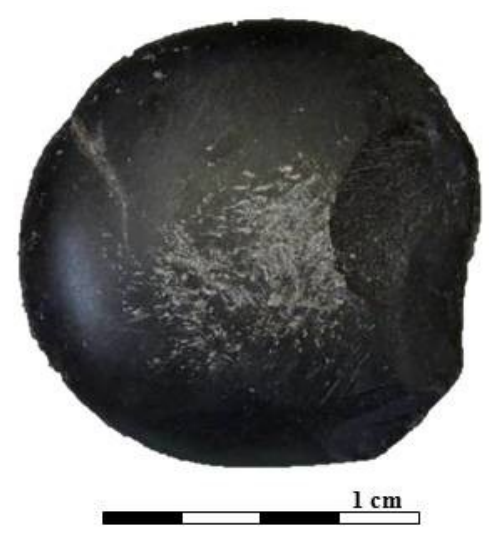

Fig.7.7: Yunque doble y percutor sobre rodado de basalto (LLis $\left.1 \mathrm{C} 1 \mathrm{~N}^{\mathrm{o}} 1 \mathrm{~A}\right)$.

\section{Índice de fractura}

En LLis 2 C1 la mitad $(n=7)$ de los desechos de talla se encuentra fracturada. Para el muestreo de LLis $2 \mathrm{C} 1$ la presencia de fracturas también se registró en varios de los artefactos (35\%). Entre los desechos la proporción de fracturas representa el 45,6 \%; en los instrumentos formatizados por talla 34,6\% y en los núcleos el 33,3\% (Tabla 7.12).

\begin{tabular}{|c|c|c|}
\hline \multirow{2}{*}{ Clase Tipológica } & \multicolumn{2}{|c|}{ Fractura } \\
\cline { 2 - 3 } & LLis 2 C1 & LLis 2 C2 M1 \\
\hline Artef. Pic. Pulido & -- & -- \\
\hline Artf. Mod. Por uso & -- & 1 \\
\hline Desechos & 7 & 111 \\
\hline Art. Form. Talla & -- & 9 \\
\hline Rastros comp. & -- & -- \\
\hline Núcleos & -- & 6 \\
\hline N & $\mathbf{7}$ & $\mathbf{1 2 7}$ \\
\hline \% & -- & $\mathbf{3 4 , 9}$ \\
\hline
\end{tabular}

Tabla 7.12 Localidad Playas Las Lisas: frecuencia de fracturas por clase tipológica.

\section{Relaciones de ensamblaje}

No se logró establecer ninguna asociación (ensamblaje) entre los artefactos recuperados en los tres muestreos. 


\section{Frecuencia de módulos laminares, bipolaridad y bifacialidad:}

En primer lugar cabe aclarar que la categoría "módulos laminares", que se utiliza en este y los subsiguientes capítulos, está definida por la relación largo-ancho de los artefactos y no por la técnica de extracción; es decir, incluye tanto hojas como láminas. En LLis 1 C1 y LLis 2 C1 no se hallaron artefactos con evidencias de estas técnicas, exceptuando la pieza bifacial recuperada en el sitio 1. Para el Muestreo 1 de LLis 2 C2 los módulos laminares se identificaron en un total de dieciocho artefactos (6,3\%), distribuidos en desechos de talla $(n=15)$, instrumentos tallados $(\mathrm{n}=2)$ y en una lasca con rastros complementarios. La bipolaridad se identificó en 30 artefactos $(9,9 \%)$ : núcleos $(n=9)$ y en desechos de talla $(n=21)$, principalmente de sílices y en basalto. La bifacialidad está ausente.

\section{Tendencias generales de los conjuntos líticos de la localidad arqueológica Las Lisas}

Sobre la base del registro arqueológico de la localidad Las Lisas, se propuso la presencia de ocupaciones humanas reiteradas desde por lo menos dos mil años (Gómez Otero 2006: cap. 5). Para los concheros del sitio 1 y 2, la autora interpretó que representarían sitios de actividades específicas -localizaciones- y el resto, bases residenciales (Gómez Otero 2006). No obstante se determinaron algunas diferencias entre los materiales asociados a cada uno de estos contextos. En cuanto a los muestreos de los concheros LLis $1 \mathrm{C} 1$ y LLis 2 C2 se caracterizan por: (a) escasa diversidad faunística y predominio de valvas de moluscos; (b) nula a baja densidad lítica; (c) selección predominante de materias primas locales de calidad variable; (d) presencia de artefactos expeditivos, representativos de dos clases artefactuales, entre ellos instrumentos tallados y desechos de talla y (e) lascas de tamaños pequeños, entre las que sobresalen las internas. Para estos dos casos las evidencias líticas no permiten inferir con certeza su relación con alguna actividad tecnológica simultánea con el consumo y descarte de los moluscos (Goye et al. 2015).

Por otra parte, los escasos materiales líticos recuperados en LLis 2 C2 podrían haber ingresado naturalmente al registro arqueológico tanto por factores post-depositacionales como por descarte humano. En este sentido, estudios tafonómicos y de los procesos de formación de sitio en ambientes dunarios (Bonomo 2005; Borrazzo 2009; Gómez Otero 2006 y Capítulo 5 de esta tesis) muestran que las piezas pequeñas $(>5 \mathrm{~cm})$ pueden ser sepultadas o desplazadas a distancias variables, principalmente por la acción eólica. En cuanto a los dos instrumentos hallados en el muestreo de LLis 1 C 1 (la pieza bifacial y el raspador) la primera podría haber sido descartada en el lugar por defectos en la reducción. Para el caso del raspador, que carece de fractura y su filo se encuentra activo no se puede determinar cuál podría haber sido el motivo de su abandono en el lugar (Goye et al. 2015). 
Por otra parte, el Muestreo 1 del sitio 2 que incluye numerosos núcleos agotados, desechos de distintos tamaños y tipos, un percutor, yunques y artefactos formatizados por talla permite inferir el desarrollo de actividades de taller y también de formatización de instrumentos in situ. Para la manufactura de estos instrumentos se seleccionaron mayoritariamente los rodados locales disponibles en los cordones litorales. En este sentido, se observó la presencia de varios núcleos de sílices y basaltos que fueron reducidos por medio de la talla bipolar. Esta técnica habría sido seleccionada debido al tamaño pequeño y a la forma espesa y sin superficies planas naturales de estos rodados que dificultan la reducción a través de la talla directa. De los rodados locales se extrajeron lascas primarias y con dorso natural de tamaños pequeños y medianos que fueron seleccionadas como soportes para la manufactura de los instrumentos tallados, entre ellos puntas burilantes y muescas.

Las materias primas no locales son dos variedades de obsidiana (la de coloración grisverdosa y la negra) cuyas fuentes se ubican en la zona de Telsen y en Sacanana, respectivamente (Gómez Otero y Stern 2005); el xilópalo de fuente desconocida (Banegas et al. 2016) y la hematita que provendría del yacimiento de hierro que aflora en el sudeste de la provincia de Río Negro (Formación Sierra Grande). Por su parte, el soporte de los dos artefactos modificados por el uso (el percutor y el yunque) son rodados grandes probablemente traídos desde los cordones litorales de la Caleta Valdés, a $35 \mathrm{~km}$ de distancia desde el sitio. En síntesis, el registro arqueológico de Playa Las Lisas muestra varias ocupaciones en un lapso de dos mil años: algunas habrían sido localizaciones (los concheros) y otras campamentos transitorios o bases residenciales más duraderas donde se ejecutaron entre otras tareas aquellas relacionadas con la caza, el procesamiento, la preparación de alimentos y la elaboración de artefactos. La presencia de hematita, xilópalos y de obsidianas demuestra la circulación de rocas no locales a distancias de entre 200 a 300 kilómetros de distancia.

\section{Localidad arqueológica Los Abanicos}

La estancia Los Abanicos se encuentra sobre la costa del golfo San Matías, en los campos que pertenecen a la Armada Argentina. El paisaje se caracteriza por la presencia de tres bajadas litorales, que limitan con la zona de los acantilados activos que caen a pique al mar (Gómez Otero 2006). En cada una de las bajadas litorales, Gómez Otero y equipo reconocieron tres sitios arqueológicos, todos emplazados sobre la terraza marina ubicada a $10 \mathrm{~m}$ s.n.m (Fig. 7.8). En el sector de la costa las playas son angostas y de arena y gravas asociadas con depósitos litorales formados durante la última transgresión del Holoceno medio. Se destaca además la presencia de amplias plataformas de abrasión o restingas que ofrecen gasterópodos y mejillones. En la playa, intransitable durante las mareas altas, también se observan apostaderos de lobos de 
un pelo y elefantes marinos (Gómez Otero 2006). Para esta tesis se llevó a cabo el análisis del conjunto artefactual recuperado en el muestreo del fogón 1 del sitio Los Abanicos 1.

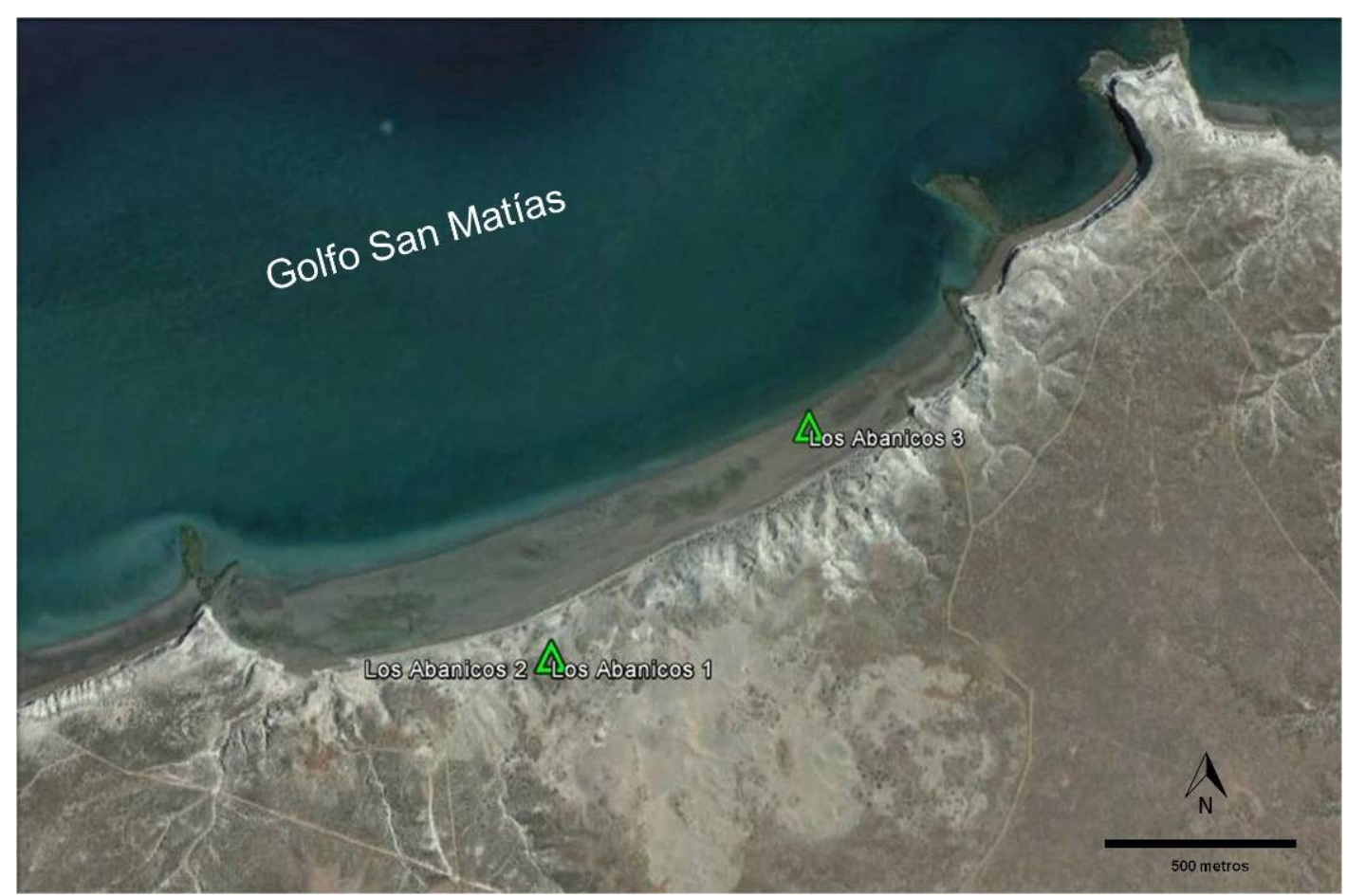

Fig. 7.8. Localidad Los Abanicos: localización de los sitios arqueológicos.

\section{Los abanicos 1}

Sitio de superficie, ubicado en el borde de la terraza marina de $10 \mathrm{~m}$ s.n.m. con presencia de materiales líticos y restos faunísticos de valvas, y huesos de lobo marino (Otaria flavescens) y guanaco (Lama guanicoe) en superficie, así como también se identificaron cinco lentes de fogón superpuestas en el talud de la terraza (Gómez Otero y Suárez 2005). Para esta tesis se realizó el estudio de los materiales líticos del fogón 1 debido a que cuenta con fechado radiocarbónico. La datación de la muestra de carbón arrojó una antigüedad de $380 \pm$ años $\mathrm{C}^{14}$ AP (Tabla 7.13).

\begin{tabular}{|l|c|c|c|c|c|c|c|}
\hline \multicolumn{1}{|c|}{ Sitio } & $\begin{array}{c}\text { Latitud } \\
\text { Longitud }\end{array}$ & $\begin{array}{c}\text { Altura } \\
\text { s.n.m }\end{array}$ & $\begin{array}{c}\text { Dist. } \\
\text { mar }\end{array}$ & $\begin{array}{c}\text { Edad } \\
\mathbf{C}^{\mathbf{1 4}} \mathbf{A P}\end{array}$ & $\begin{array}{l}\text { Edad } \\
\text { Calibrada } \\
\mathbf{2} \text { sigmas AP }\end{array}$ & $\begin{array}{c}\text { Muestra } \\
\text { Código } \\
\text { Lab }\end{array}$ \\
\hline $\begin{array}{l}\text { Los Abanicos } \\
\text { 1-Fogón 1 }\end{array}$ & $\begin{array}{c}42^{\circ} 11,037^{\prime} \mathrm{S} \\
64^{\circ} 06,186^{\prime} \mathrm{O}\end{array}$ & $10 \mathrm{~m}$ & $50 \mathrm{~m}$ & $380 \pm 60$ & $0-154$ & Carbón & LP-862 \\
\hline
\end{tabular}

Tabla 7.13. Localidad Los Abanicos: localización y fechados obtenidos de los concheros. Referencias: Dist. Distancia; Lab. Laboratorio. Datos obtenidos de Gómez Otero 2006. 


\section{Los Abanicos 1 Fogón 1.}

El Fogón 1 afloraba a 1,37 metros de profundidad en el perfil de un acantilado activo y a unos $6 \mathrm{~m}$ s.n.m. El perfil se encontraba disectado por un cañadón a través del cual se puede acceder al mar desde las terrazas interiores y viceversa. En superficie se observaron numerosas valvas y huesos arqueológicos de pinnípedos (Otaria flavescens) y en menor proporción guanacos (Lama guanicoe). Todos los restos arqueofaunísticos evidenciaban meteorización y redepositación por erosión hídrica y eólica (Gómez Otero y Suárez 2005). Se reconocieron tres niveles de ocupación separados por sedimentos estériles. Los materiales faunísticos eran similares a los registrados en la superficie del terreno y caídos al pie del perfil. Estas evidencias indicaban que al menos cinco ocupaciones tuvieron lugar en ese espacio en los últimos 400 años (Gómez Otero y Suárez 2005). En la lente más profunda se realizó un muestreo de 200 x 50 x 7 cm de potencia (Fig. 7.9).

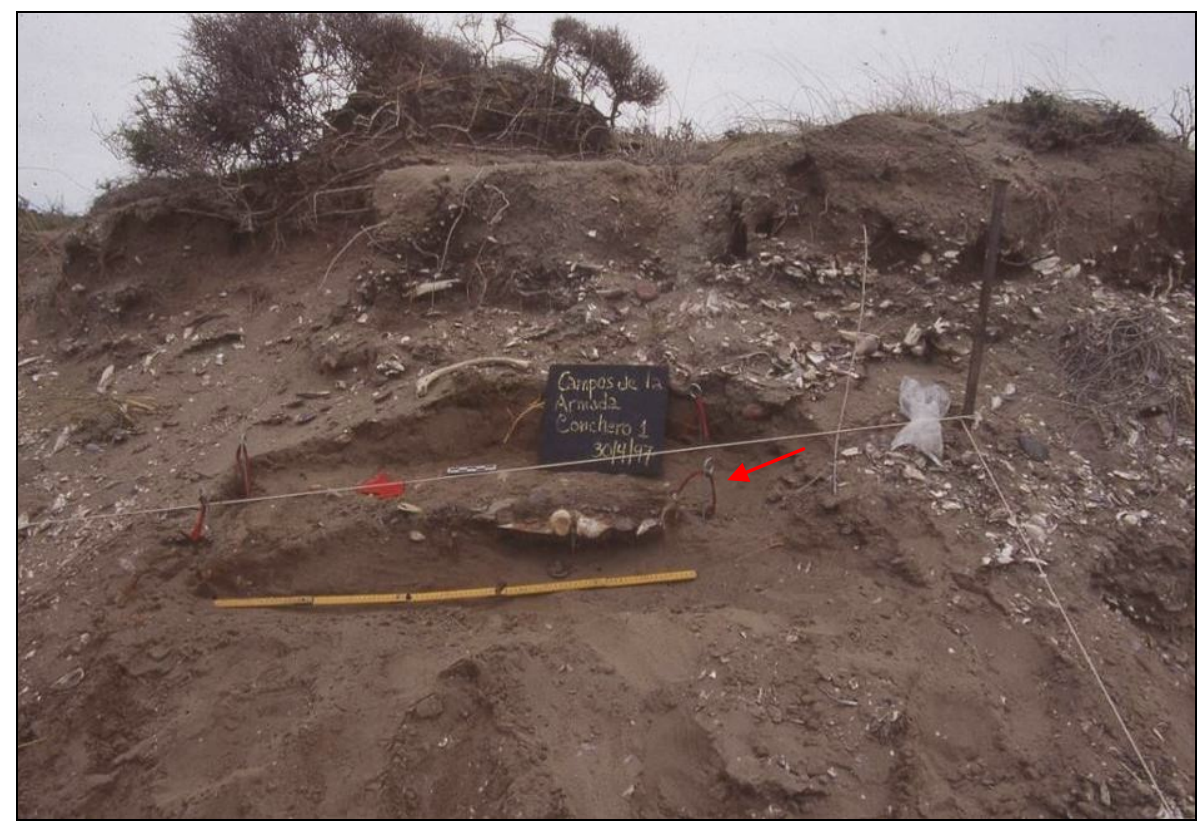

Fig. 7.9. Fogón Sitio Los Abanicos 1 en Campos de La Armada. Fotografía tomada por Juan Carlos Aguerrebere (1996). La flecha roja señala el fogón.

El estudio arqueofaunístico (Gómez Otero y Suárez 2005) identificó un NISP de 2.592 especímenes distribuidos entre 22 taxones. Entre los moluscos son mayoría las cholgas (Aulacomya atra), seguidas por las lapas (Patinigera). También se registraron restos óseos de peces; cormoranes, lobo marino (Otaria flavescens) y guanacos (Lama guanicoe). Se determinó que los lobos marinos habrían sido cazados y consumidos in situ. En cuanto a los guanacos se infirió caza y consumo completo de las dos crías y de parte del tronco del guanaco adulto; el 
resto de los elementos de este último, se habría transportado a otro lugar, probablemente a un campamento-base cercano (Gómez Otero y Suárez 2005).

En relación con el conjunto artefactual se recuperaron escasos líticos, entre ellos una raclette sobre lasca de tamaño mediano de obsidiana negra cuyo análisis geoquímico determinó su correspondencia con el tipo MSI, de fuente aun desconocida (Gómez Otero y Stern 2005).

De acuerdo con el análisis realizado por Gómez Otero y Suárez (1999) el fogón del sitio Los Abanicos 1 representaría un sitio de actividades restringidas vinculado con la obtención, preparación y consumo de recursos faunísticos marinos -principalmente pinnípedos- y también terrestres, entre ellos guanaco y otros vertebrados pequeños. Respecto de la estacionalidad, un estudio de secciones delgadas de dientes de los lobos marinos machos demostró que habían muerto a fines de marzo/principios de abril, es decir a inicios del otoño. Esto se ve reforzado por la presencia de las crías de guanaco de dos a tres meses de edad (Gómez Otero y Suárez 2005).

\section{Análisis tecnológico}

En el muestreo del Fogón 1 (en adelante LAban 1 F1) se recuperaron 34 artefactos líticos y una densidad artefactual de $0,005 \mathrm{dm}^{2}$.

\section{Materias primas:}

En LAban $1 \mathrm{~F} 1$ se identificó un total de seis variedades litológicas y predominio de las materias primas locales de calidad regular a buena. Sobresalen las riolitas (39\%), varias de ellas representadas por nódulos grandes con daño térmico y presencia de hollín. Le siguen los basaltos y sílices en la misma proporción (19\%), y el resto de las materias primas identificadas cuarcita, andesita, calcedonia y obsidiana- no supera el 9\% (Tabla 7.14). Casi la totalidad de los desechos $(n=19)$ muestran alteraciones en la superficie de las rocas relacionadas con la exposición al fuego (daño térmico), entre ellas hoyuelos y craquelados.

\begin{tabular}{|c|c|c|}
\hline \multirow{2}{*}{ Materias primas } & \multicolumn{2}{|c|}{ LAban 1 F1 } \\
\cline { 2 - 3 } & N & $\mathbf{\%}$ \\
\hline Basalto & 7 & 19 \\
\hline Andesita & 1 & 2,9 \\
\hline Calcedonia & 2 & 5,9 \\
\hline Cuarcita & 3 & 8,8 \\
\hline Obsidiana & 1 & 2,9 \\
\hline Riolita & 14 & 39 \\
\hline Sílice & 6 & 17 \\
\hline Total & $\mathbf{3 4}$ & $\mathbf{1 0 0} \%$ \\
\hline
\end{tabular}

Tabla 7.14. Los Abanicos $1 \mathrm{~F} 1$ : tipos y frecuencias de las variedades litológicas. 


\section{Clases artefactuales:}

La clase que predomina son los desechos de talla (78 \%) seguidos por los artefactos modificados por el uso (15,6 \%). En valores bajos y equilibrados se registraron instrumentos tallados $(9 \%)$, rodados sin modificación antrópica -ecofactos- $(6,5 \%)$ y por último, lascas con rastros complementarios (3\%). No se hallaron núcleos (Tabla 7.15).

\begin{tabular}{cccccc}
\hline Clases & Desechos & \multicolumn{2}{c}{ Instrumentos } & Ecofactos \\
\cline { 3 - 5 } & & $\begin{array}{c}\text { Art.Form. } \\
\text { por talla }\end{array}$ & $\begin{array}{c}\text { Rastros } \\
\text { complement. }\end{array}$ & $\begin{array}{c}\text { Art. Modif. } \\
\text { por el uso }\end{array}$ & \\
\hline LAban 1 F1 & & & & & \\
N & 25 & 3 & 1 & 5 & 2 \\
$\%$ & 78 & 9,3 & 3,1 & 15,6 & 6,5 \\
\hline
\end{tabular}

Tabla 7.15. Los Abanicos 1 Fogón 1: distribución de las clases artefactuales.

\section{Desechos de talla:}

En cuanto al estado de las lascas la mitad corresponde a las fracturadas con talón (52\%) y el resto son lascas enteras (48\%). El tipo mayoritario son las primarias (40\%) y las secundarias (32\%). En baja frecuencia -entre 4 y $8 \%$ - se identificó un nucleiforme y dos lascas con dorso natural. El 12\% no pudo ser determinado (Tabla 7.16).

\begin{tabular}{|c|c|c|}
\hline \multirow{2}{*}{ Tipo de lascas } & \multicolumn{2}{|c|}{ LAban 1 F1 } \\
\cline { 2 - 3 } & $\mathbf{N}$ & $\mathbf{\%}$ \\
\hline Con dorso natural & 2 & 8 \\
\hline Primaria & 10 & 40 \\
\hline Secundaria & 8 & 32 \\
\hline Nucleiforme & 1 & 4 \\
\hline Indeterminada & 3 & 12 \\
\hline Total & $\mathbf{2 5}$ & $\mathbf{1 0 0} \%$ \\
\hline
\end{tabular}

Tabla 7.16. Los Abanicos 1 Fogón 1: tipos y frecuencias de lascas.

El tamaño de las lascas se distribuye en frecuencias equitativas entre pequeño (40 \%) y microlascas $(32 \%)$, le siguen las medianas $(16 \%)$ y en menor proporción las muy pequeñas hipermicrolascas- (12\%). Casi la totalidad de los módulos es mediano normal (96 \%) (7.17).

\begin{tabular}{|c|c|c|c|c|c|}
\hline & Tamaño & Lasca-ancho & Mediana-normal & & \\
\hline & Módulo & & & $\mathbf{N}$ & $\%$ \\
\hline & Hipermicrolasca & -- & 3 & 3 & 12 \\
\hline 厌 & Microlasca & 1 & 7 & 8 & 32 \\
\hline $\bar{z}$ & Lasca Pequeña & -- & 10 & 10 & 40 \\
\hline$\sum^{\frac{\pi}{2}}$ & Lasca Mediana & -- & 4 & 4 & 16 \\
\hline 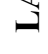 & $\mathbf{N}$ & 1 & 24 & 25 & 100 \\
\hline & $\%$ & 4 & 96 & & \\
\hline
\end{tabular}

Tabla 7.17. Los Abanicos 1 Fogón 1: tamaño y módulo largo/ancho de las lascas 
En relación con los talones sobresalen los corticales (36\%), seguidos por los lisos (20 $\%)$; en frecuencias más bajas y parejas (12\%) se ubican los filiformes, ausentes y fracturados. Se registró además un talón astillado y otro indeterminado (4 \% cada uno) (Tabla 7.18).

\begin{tabular}{|c|c|c|}
\hline \multirow{2}{*}{ Tipo de talón } & \multicolumn{2}{|c|}{ LAban 1 F1 } \\
\cline { 2 - 3 } & $\mathbf{N}$ & $\mathbf{\%}$ \\
\hline Cortical & 9 & 36 \\
\hline Liso & 5 & 20 \\
\hline Filiforme & 3 & 12 \\
\hline Astillado & 1 & 4 \\
\hline Fracturado & 3 & 12 \\
\hline Ausente & 3 & 12 \\
\hline Indeterminado & 1 & 4 \\
\hline Totales & $\mathbf{2 5}$ & $\mathbf{1 0 0} \%$ \\
\hline
\end{tabular}

Tabla 7.18: Los Abanicos 1 Fogón 1: tipos y frecuencias de los talones.

\section{Artefactos formatizados por talla}

De los tres instrumentos tallados (LAban $\mathrm{N}^{\mathrm{o}} 43,41$ y 11), dos de ellos son puntas de proyectil bifaciales, y el otro una punta entre muescas confeccionada sobre una lasca nucleiforme mediana de cuarcita de color gris claro ( $\mathrm{N}^{\circ} 7$ de Munsell 2011) y calidad regular para la talla. En cuanto a las piezas bifaciales, una es un fragmento de ápice de una materia prima indeterminada debido a la acción del fuego; la otra, una preforma bifacial en estado avanzado de manufactura (Estadio 5, sensu Nami 1987) o una punta de proyectil, elaborada sobre lasca mediana de sílice marrón oscuro rojizo (10 R 3/4 de Munsell 2011) de muy buena calidad para la talla (Fig. 7.10).

\begin{tabular}{|c|cccccc|}
\hline $\begin{array}{c}\mathbf{N}^{\mathbf{0}} \\
\text { Inv }\end{array}$ & $\begin{array}{c}\text { Muestreo 1 } \\
\text { Subgrupos }\end{array}$ & $\begin{array}{c}\text { Materia } \\
\text { prima }\end{array}$ & Forma base & $\begin{array}{c}\text { Largo } \\
\mathbf{( m m )}\end{array}$ & $\begin{array}{c}\text { Ancho } \\
(\mathbf{m m})\end{array}$ & $\begin{array}{c}\text { Espesor } \\
(\mathbf{m m})\end{array}$ \\
\hline 43 & Punta de proyectil & Indeterminada & Indeterminada & 24,5 & 13,9 & 4 \\
\hline 41 & Punta de proyectil & Sílice & Lasca mediana & 42,9 & 23,5 & 7,4 \\
\hline 11 & Punta entre muesca & Cuarcita & Lasca mediana & 42 & 36,8 & 23,4 \\
\hline
\end{tabular}

Tabla 7.19. Los Abanicos 1 Fogón 1: características de los artefactos tallados de M1.

En cuanto a la serie técnica, dos instrumentos presentan microrretoque marginal, y retoque la preforma bifacial. La situación los lascados de la pieza $\mathrm{N}^{0} 11$ es unifacial y la punta se encuentra activa. No se registraron filos dobles ni compuestos (Tabla 7.20). 


\begin{tabular}{|c|c|c|c|c|c|c|c|c|}
\hline & Sub-grupo & $\begin{array}{l}\text { Serie } \\
\text { Técnica }\end{array}$ & $\begin{array}{l}\text { Sit } \\
\text { lasc. }\end{array}$ & $\begin{array}{l}\text { F. Geom. } \\
\text { Contorno }\end{array}$ & $\begin{array}{l}\text { Posic. } \\
\text { Filo }\end{array}$ & F.Lasc. & $\begin{array}{l}> \\
\text { Filo }\end{array}$ & Estado \\
\hline 43 & Frag. ápice & $\begin{array}{l}\text { Microrretoque } \\
\text { marginal }\end{array}$ & Bifacial & Rectangular & Frontal & $\begin{array}{l}\text { Paralelo } \\
\text { corto irreg. }\end{array}$ & $\mathrm{nc}$ & $\mathrm{nc}$ \\
\hline 41 & $\begin{array}{l}\text { Preforma } \\
\text { bifacial }\end{array}$ & $\begin{array}{l}\text { Retoque } \\
\text { marginal }\end{array}$ & Bifacial & Rectangular & Frontal & $\begin{array}{l}\text { Paralelo } \\
\text { corto irreg. }\end{array}$ & nc & nc \\
\hline 11 & $\begin{array}{l}\text { Punta entre } \\
\text { muesca }\end{array}$ & $\begin{array}{l}\text { Microrretoque } \\
\text { restringido }\end{array}$ & $\begin{array}{l}\text { Unifaci } \\
\text { al }\end{array}$ & Rectangular & Frontal & $\begin{array}{l}\text { Paralelo } \\
\text { corto irreg. }\end{array}$ & $\mathrm{nc}$ & Activo \\
\hline
\end{tabular}

Tabla 7.20. Los Abanicos 1 Fogón 1: rasgos morfotécnicos de los artefactos tallados. Referencias: Sit. Lascados: situación de los lascados; F. Geom.: forma geométrica, Posic.Fil: Posición del filo; F.Lasc. Forma de los lascados; Ang. Ángulo del filo; restr. Restringido; Unif: Unificial; Indet: indeterminado.

\section{Lascas con rastros complementarios}

En una lasca de tamaño pequeño de obsidiana de coloración gris-verdosa y de excelente calidad para la talla, se observó la presencia de un filo natural lateral. Sus características visuales son similares a las del tipo T/SCI, por lo tanto, dada la presencia de un artefacto de la fuente MSI (Gómez Otero y Stern 2005), al sitio ingresaron dos tipos de obsidiana.

\section{Artefactos modificados por el uso y ecofactos}

Los artefactos modificados por el uso lo componen un percutor simple sobre rodado grande de andesita y cuatro rodados con presencia de daño térmico. Las materias primas de las piedras quemadas están representadas por rodados grandes de riolitas $(n=3)$ y de basalto $(n=1)$ (Fig. 7.10). Se recuperaron además dos rodados grandes de riolita y de sílice sin evidencias de modificación antrópica (ecofactos).

\section{Índice de fractura}

La proporción de artefactos con presencia de fracturas es de $47,1 \%$, y se registran en todas las clases artefactuales. Para el caso de las lascas, la mayoría de las fracturas se ubica en el sector distal de la pieza (Tabla 7.21).

\begin{tabular}{|l|c|}
\hline Clase Tipológica & Fracturas \\
\hline Ecofactos & -- \\
\hline Artf. Mod. Por uso & 2 \\
\hline Desechos & 13 \\
\hline Art. Form. Talla & 1 \\
\hline Rastros comp. & -- \\
\hline $\mathbf{N}$ & $\mathbf{1 6}$ \\
\hline $\mathbf{\%}$ & $\mathbf{4 7 , 1}$ \\
\hline
\end{tabular}

Tabla 7.21. Los Abanicos 1 Fogón 1: frecuencia de fracturas por clase tipológica. 


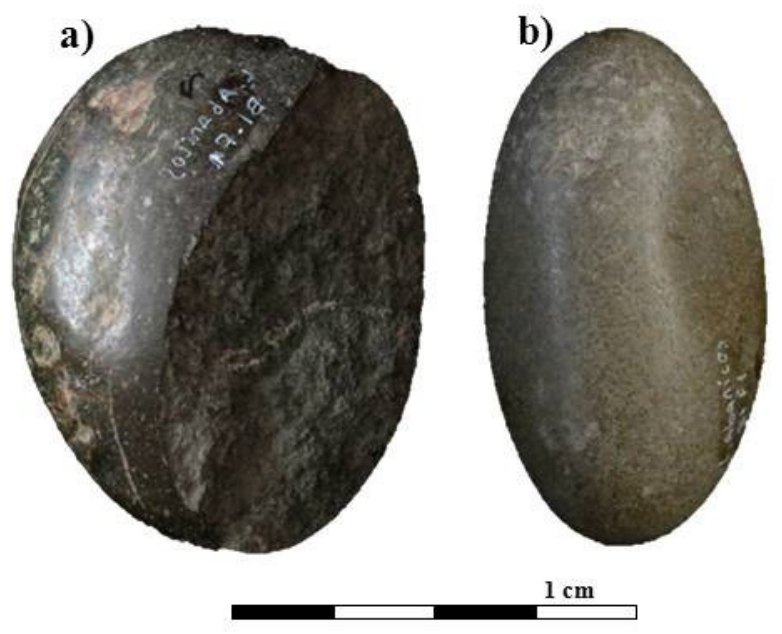

c)

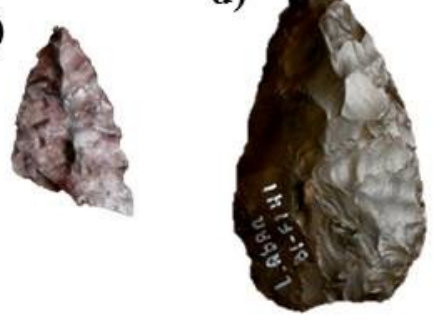

Fig. 7.10. Artefactos recuperados en el sitio Los Abanicos 1 Fogón 1: a) piedra termófora de andesita; b) Percutor sobre rodado de tamaño pequeño-mediano; c) ápice de punta de proyectil con daño térmico $\left(\mathrm{N}^{\circ}\right.$ 43) y d) pieza bifacial en sílice ( $\left.\mathrm{N}^{\circ} 41\right)$.

\section{Relaciones de ensamblaje}

En total se pudieron establecer tres relaciones de ensamblaje: la primera entre dos lascas de tamaño mediano y otra pequeña de riolita; la segunda entre dos lascas medianas y una microlasca también de la misma materia prima. Para ambas asociaciones la fractura estaría relacionada con la exposición al fuego. El tercer remontaje se realizó entre la punta entre muescas de cuarcita y dos microlascas que remontaron con ese nódulo. Para este remontaje la causa sería tecnológica, es decir producto de lo formatización del instrumento (Fig. 7. 11). 


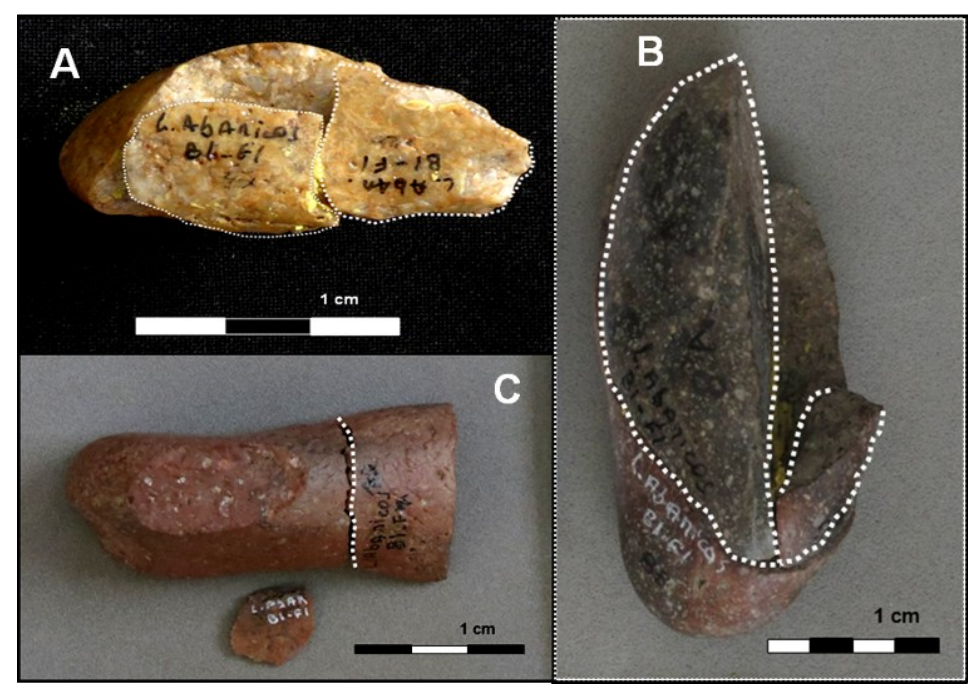

Fig. 7.11. Relaciones de ensamblajes Los Abanicos 1 F1. (a) Relación de ensamblaje II tres fragmentos de la misma piedra termófora; (b): relación I entre dos fragmentos de un misma piedra termófora de riolita, y (c) relación de ensamblaje III: Punta entre muesca de cuarcita y dos microlascas.

\section{Frecuencia de módulos laminares, bipolaridad y bifacialidad:}

Solo se identificó la presencia de bifacialidad y en una baja frecuencia $(5,8 \%)$, representada por el ápice de la punta de proyectil y la pieza bifacial en estado avanzado de formatización.

\section{Tendencias generales de los conjuntos líticos de la localidad arqueológica Los Abanicos}

En cuanto a la tecnología lítica se destaca la densidad artefactual muy baja $\left(0,005 \mathrm{dm}^{2}\right)$ y la presencia de varios grupos tipológicos: desechos e instrumentos tallados, una lasca con rastros complementarios, un percutor y varios rodados con y sin presencia de alteración térmica. Entre los artefactos tallados predominan ampliamente los de tipo expeditivo y vinculados con la talla in situ de rodados locales de riolita, basalto y sílices de calidad regular a buena. Hay lascas de distintos tamaños, y casi la totalidad presenta rastros de daño térmico. Con respecto al ápice de la punta de proyectil y la pieza bifacial no se recuperaron desechos de las rocas con las que fueron confeccionadas. Esto podría atribuirse a distintas causas: a) que fueron introducidas ya terminadas formando parte de armas; b) que la punta fracturada ingresó en la carcasa de alguno de los guanacos cazados (Gómez Otero y Suárez 2005), luego se extrajo del cuerpo del animal y se descartó por rotura; y c) que los desechos de reducción bifacial asociados a la fabricación de estas piezas quedaron fuera del muestreo o bien que se removilizaron por acción eólica o hídrica. Por el contrario, y para el caso de la punta burilante confeccionada sobre un rodado local de cuarcita, la presencia de una relación de remontaje entre el instrumento y dos lascas del mismo nódulo indicaría que la misma fue tallada en el lugar. 
En relación con los guijarros termoalterados, algunos de ellos con fracturas por estrés térmico, se propuso que se relacionarían con la cocción de los alimentos. En este sentido, Musters (1964) menciona que los tehuelches cocinaban los avestruces introduciéndoles piedras calientes dentro del estómago (ampliar en Gómez Otero y Suárez 2005). Otra posibilidad que consigan estos autores es que los rodados hayan ingresado al fogón dentro del aparato digestivo de alguno de los pinnípedos machos, ya que en el estómago de ejemplares actuales se han registrado guijarros del tamaño de los observados en el fogón (Koen Alonso et al. 2000, en Gómez Otero y Suárez 2005). Por lo tanto, independientemente de cómo ingresaron, es factible que fueran utilizados como piedras de cocción, sea introduciéndolos en el abdomen de algún animal, o como piedras de fogón sobre las cuales se apoyaron los alimentos.

En síntesis, sobre la base de la presencia de carbón, valvas, restos óseos con evidencias de procesamiento antrópico, y los rasgos tecnológicos del conjunto artefactual, se estimó que en este lugar se realizaron distintas actividades: obtención, procesamiento y consumo de invertebrados y vertebrados diversos, talla in situ de rodados locales, y descarte de alimentos y probablemente también de puntas de armas. Esto refuerza la inferencia de Gómez Otero (2006), de que correspondería a un fogón asociado a una base residencial. 


\section{GOLFO SAN JOSÉ}

Se trata de un pequeño golfo -cuyo eje máximo y mínimo es de 45 por 25 kilómetrosde forma semicircular, formado en algún momento de la última transgresión del Holoceno medio (Weiler 1998). Según la autora habría sido un gran bajo sin salida que el mar inundó cuando alcanzó sus niveles máximos (ampliar en Gómez Otero 2006). Sus playas son amplias y bajas, con presencia de acantilados que no superan los $25 \mathrm{~m}$ s.n.m. Otra particularidad del golfo es la alta productividad malacológica e ictiológica, por lo que sus playas han sido seleccionadas por marisqueros y pescadores para el establecimiento permanente de sus puestos, como por ejemplo en el paraje conocido como El Riacho (Fig. 7.12).

Para este golfo Gómez Otero y equipo $(1999,2006)$ detectaron siete localidades arqueológicas, a las que se le suman los sitios y hallazgos aislados realizados a principios de siglo pasado por Outes (1905) en el Cerrito de las Calaveras, y posteriormente por Menghín y Bórmida (s/f) en la Estancia Niermann (Gómez Otero 2006).

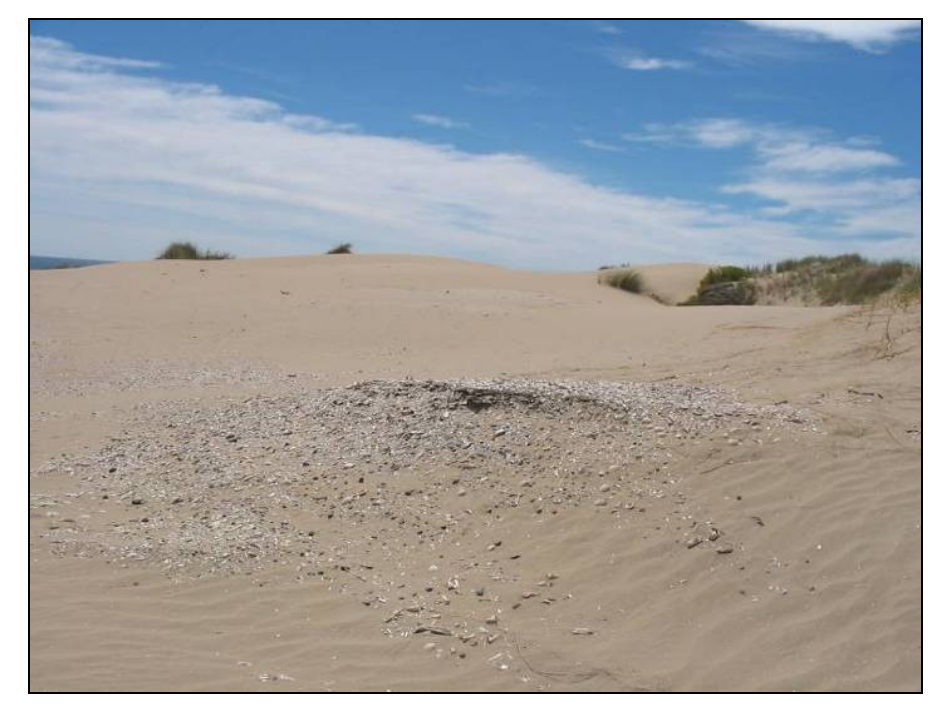

Fig. 7.12. Relicto de conchero en superficie. Sitio El Riacho (Pla. Valdés). Fotografía tomada por Julieta Gómez Otero (2005).

\section{Localidad arqueológica Punta Cono}

La localidad Punta Cono incluye tres sitios de superficie, denominados Lote 39, Flechero del 39 y terraza Punta Cono (Fig. 7.13). La misma se caracteriza por la presencia de médanos entre los que se observaron varias hoyadas deflacionadas con gran cantidad de restos arqueofaunísticos y líticos (Gómez Otero 2006). El conjunto faunístico lo componen moluscos, entre ellos lapas (Fissurellidae sp.) y picorocos (Balanus sp.), cáscaras quemadas de choique 
(Pterocnemia pennata), huesos de guanaco (Lama guanicoe), lobo marino (Otaria flavescens) y pingüinos (Spheniscus sp.). Además se registró un agrupamiento de huesos de cetáceos, algunos de ellos quemados (Gómez Otero 2006). Por su parte, los artefactos líticos lo integran yunques, percutores, lajas de pórfidos y de arenisca consolidada, y núcleos, entre otros.

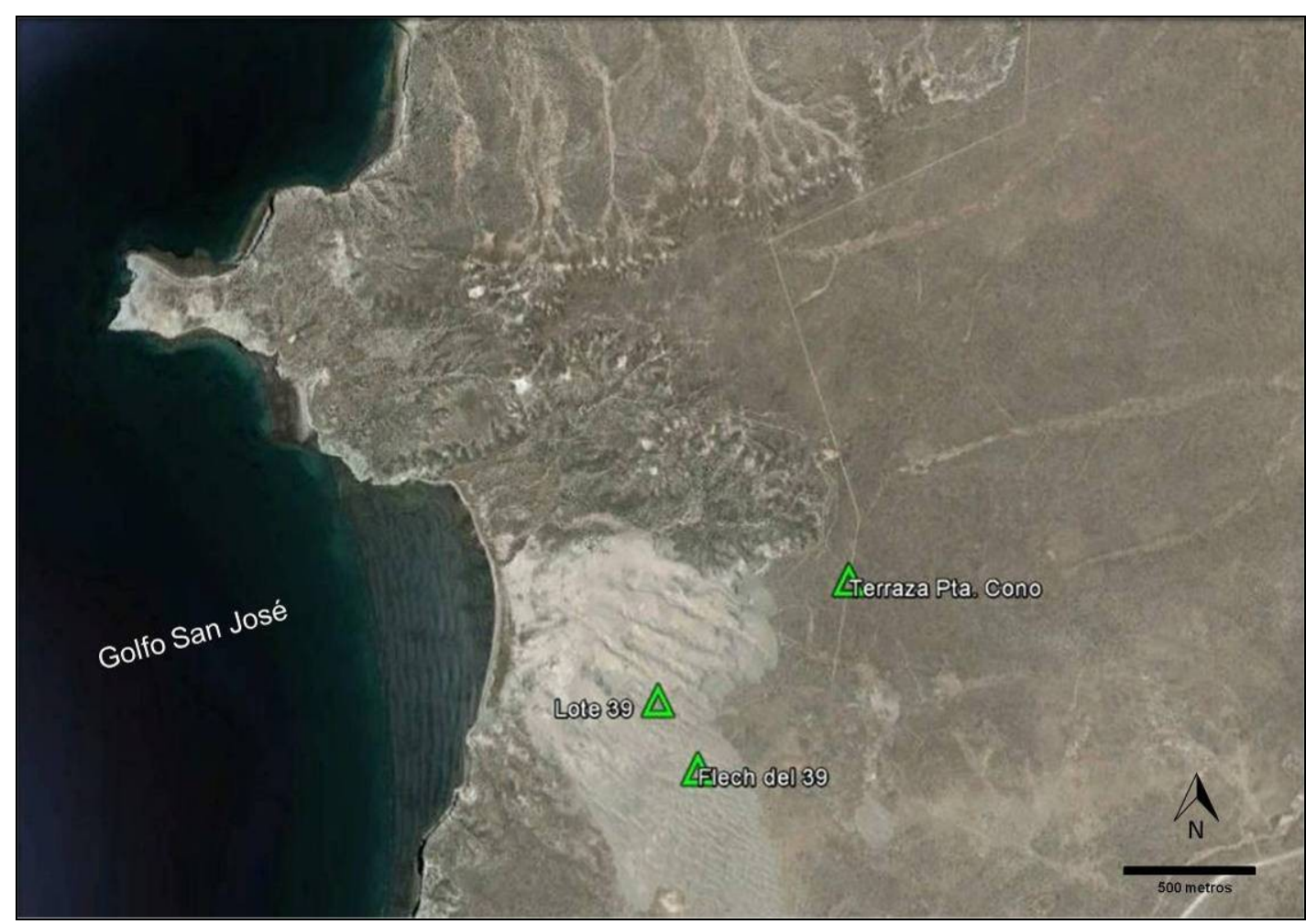

Fig. 7.13. Localidad Punta Cono: localización de los sitios arqueológicos.

En uno de los relictos de concheros, denominado Fogón 1 y ubicado en la misma hoyada, se efectuó un sondeo de $50 \mathrm{~cm}$ de lado y capas artificiales cada $5 \mathrm{~cm}$. Se determinó que prevalecen las valvas de cholgas (Aulacomya ater) y mejillones (Mytilus edulis) así como también restos óseos de guanaco (entre ellos un subadulto y una cría). Fechados obtenidos de una muestra de valvas arrojaron una antigüedad de $2640 \pm 40$ años $\mathrm{C}^{14}$ AP (Tabla 7.22).

Para esta tesis se analizó el conjunto lítico recuperado en el segundo muestreo de superficie, de 4 metros de lado. Fuera de ese muestreo, Gómez Otero (2006) consigna la presencia de raspadores, varias láminas y lascas de obsidiana, un sobador y un fragmento de bola con surco. Los análisis geoquímicos de dos muestras de obsidiana determinaron que una de ellas corresponde al tipo T/SCII y la otra al tipo MSI, ambas de fuente desconocida, aunque se estima que la del segundo tipo estaría localizada en la meseta de Somuncurá (Gómez Otero y Stern 2005). 


\begin{tabular}{|c|c|c|c|c|c|c|c|}
\hline Sitio & Lat/Long & $\begin{array}{c}\text { Altura } \\
\text { s.n.m }\end{array}$ & $\begin{array}{c}\text { Dist. } \\
\text { mar }\end{array}$ & $\begin{array}{c}\text { Edad } \\
\mathbf{C}^{\mathbf{1 4}} \mathbf{A P}\end{array}$ & $\begin{array}{c}\text { Edad } \\
\text { Calibrada }\end{array}$ & $\begin{array}{c}\text { Muestra } \\
\text { Código } \\
\text { Lab. }\end{array}$ \\
\hline Flech del 39 & $\begin{array}{c}42^{\circ} \text { 20, 432' S } \\
\text { Fogón 1 N 4 }\end{array}$ & $54^{\circ}$ 02, $463^{\prime} \mathrm{m}$ & $100 \mathrm{~m}$ & $2640 \pm 40$ & Sin calib. & Valvas & LP-1022 \\
\hline
\end{tabular}

Tabla 7.22. Flechero del 39 Muestreo 2. Localización y fechado obtenido del nivel 4 del Fogon 1. Referencias: Dist. Distancia; Lab. Laboratorio. Sin calib; sin calibración por Efecto Reservorio. Datos obtenidos de Gómez Otero 2006.

\section{Análisis tecnológico}

En Flechero del 39 Muestreo 2 (en adelante Flech 39 M2) se recogieron 229 artefactos que representan una densidad de $1,43 \mathrm{dm}^{2}$.

\section{Materias primas:}

Se identificaron once variedades litológicas, entre las que sobresalen las sílices de muy buena calidad (59\%), en segundo lugar se ubican las calcedonias de calidad excelente $(16 \%)$ seguidas por el basalto (12\%) de buena calidad. El resto de las materias primas identificadas son las andesitas, granitos, cuarcitas, hematitas, obsidianas, xilópalos y hueso fosilizado de cetáceo, que se registran en valores bajos y parejos (entre $0,5 \%$ y $4 \%$ ) (Tabla 7.23).

De acuerdo con los muestreos de rocas realizados (véase Capítulo 6) las no locales corresponden a las hematitas, obsidianas y xilópalos. También es probable que la andesita y las dos lascas de granito registradas provengan de los rodados de tamaños grandes de los depósitos secundarios de caleta Valdés.

\begin{tabular}{|c|c|c|}
\hline Materias primas & $\mathbf{N}$ & $\mathbf{\%}$ \\
\hline Andesita & 4 & 1,7 \\
\hline Basalto & 26 & 11,4 \\
\hline Calcedonia & 36 & 15,7 \\
\hline Cuarcita & 2 & 0,9 \\
\hline Hematita & 10 & 4,4 \\
\hline Obsidiana negra & 2 & 0,9 \\
\hline Obsidiana gris-verdosa & 2 & 0,9 \\
\hline Riolita & 2 & -- \\
\hline Sílice & 135 & 59 \\
\hline Xilópalo & 9 & 3,9 \\
\hline Granito & 2 & 0,9 \\
\hline Otra & 1 & 0,4 \\
\hline Total & $\mathbf{2 2 9}$ & $\mathbf{1 0 0}$ \\
\hline
\end{tabular}

Tabla 7.23. Flechero del 39 Muestreo 2.

Tipos y frecuencias de las variedades

litológicas. 


\section{Clases artefactuales:}

En el M1 sobresalen los desechos de talla (83\%) y en segundo lugar (9\%) los artefactos formatizados por talla; en porcentajes inferiores a $5 \%$ se encuentran los núcleos, las lascas con rastros complementarios, un artefacto modificado por el uso y un ecofacto $(0,4 \%$ cada uno) (Tabla 7.24).

\begin{tabular}{ccccccc}
\hline Clases & Núcleos & Desechos & \multicolumn{2}{c}{ Instrumentos } & Ecofactos \\
\cline { 3 - 5 } & & & $\begin{array}{c}\text { Art.Form. } \\
\text { por talla }\end{array}$ & $\begin{array}{c}\text { Rastros } \\
\text { complement. }\end{array}$ & $\begin{array}{c}\text { Art. Modif. } \\
\text { por el uso }\end{array}$ & \\
\hline Flech del 39 & 6 & 191 & 20 & 10 & 1 & 1 \\
N & 2,6 & 83,4 & 8,7 & 4,3 & 0,4 & 0,4 \\
$\%$ & &
\end{tabular}

Tabla 7.24. Flechero del 39 Muestreo 2. Distribución de las clases tipológicas.

\section{Desechos de talla:}

Para los desechos, predominan las lascas enteras $(76 ; 39,8 \%)$, seguidos por los desechos no clasificables $(54 ; 28,3 \%)$ y por último las fracturadas con y sin talón $(38 ; 19,9 \%$ y $23 ; 12 \%$ respectivamente). Entre los tipos de lascas se destacan las de dorso natural (23\%) y las primarias (12\%); en valores más bajos se encuentran las de arista recta y dorso preparado ( $7 \%$ cada una), seguidas por las láminas de arista recta y doble (6\%) y las lascas en punta (5\%); el resto de los tipos de lascas -de reactivación directa, de arista oblicua e inclinada, bipolares, en cresta, etc.están representadas en frecuencias muy bajas y parejas (entre 4 y 0,7\%) (Tabla 7.25).

\begin{tabular}{|c|c|c|}
\hline Tipos de lascas & $\mathbf{N}$ & $\mathbf{\%}$ \\
\hline Punta de arista oblicua & 4 & 2,9 \\
\hline Punta arista inclinada & 5 & 3,6 \\
\hline Con dorso natural & 31 & 22,6 \\
\hline De arista recta & 10 & 7,3 \\
\hline en punta & 7 & 5,1 \\
\hline Primaria & 16 & 11,7 \\
\hline En cresta & 3 & 2,2 \\
\hline Con dorso preparado & 10 & 7,3 \\
\hline Secundaria & 5 & 3,6 \\
\hline De reactivación directa & 6 & 4,4 \\
\hline Lámina de arista recta & 8 & 5,8 \\
\hline Sobrepasada & 1 & 0,7 \\
\hline Bipolar & 4 & 2,9 \\
\hline Bifacial & 2 & 1,5 \\
\hline Indeterminada & 25 & 18,2 \\
\hline Total & $\mathbf{1 3 7}$ & $\mathbf{1 0 0 \%}$ \\
\hline
\end{tabular}

Tabla 7.25. Flechero del 39 Muestreo 2. Tipos y frecuencias de lascas. 
El tamaño que predomina es el pequeño (34\%), le siguen en orden de importancia las microlascas (30\%), las microláminas (12\%) y las hipermicrolascas $(9,5 \%)$, las láminas pequeñas (8\%) y las lascas medianas (6\%). Solo se recuperó una lasca de tamaño grande $(0,7 \%)$. El modulo predominante es el mediano normal (68\%), seguido por el laminar normal (20\%) y en tercer lugar el mediano alargado (7\%) y el corto-ancho (4\%) (Tabla 7.26).

\begin{tabular}{|c|c|c|c|c|c|c|}
\hline \multirow{2}{*}{$\begin{array}{c}\text { Tamaño } \\
\text { Módulo }\end{array}$} & $\begin{array}{c}\text { Corto } \\
\text { ancho }\end{array}$ & $\begin{array}{c}\text { Laminar } \\
\text { normal }\end{array}$ & $\begin{array}{c}\text { Mediano } \\
\text { alargado }\end{array}$ & $\begin{array}{c}\text { Mediano } \\
\text { normal }\end{array}$ & Total \\
\hline Hipermicrolasca & -- & -- & -- & 13 & 13 & 9,5 \\
\hline Microlasca & 2 & -- & 5 & 34 & 41 & 29,9 \\
\hline Lasca Pequeña & 3 & 1 & 5 & 38 & 47 & 34,3 \\
\hline Lasca mediana & 1 & -- & -- & 7 & 8 & 5,8 \\
\hline Lasca grande & -- & -- & -- & 1 & 1 & 0,7 \\
\hline Microlámina & -- & 16 & -- & -- & 16 & 11,7 \\
\hline Lámina peq & -- & 11 & -- & -- & 11 & 8 \\
\hline N & $\mathbf{6}$ & $\mathbf{2 8}$ & $\mathbf{1 0}$ & $\mathbf{9 3}$ & \multirow{2}{*}{$\mathbf{1 3 7}$} & $\mathbf{1 0 0}$ \\
\hline \% & $\mathbf{4 , 4}$ & $\mathbf{2 0 , 4}$ & $\mathbf{7 , 3}$ & $\mathbf{6 7 , 9}$ & & \\
\hline
\end{tabular}

Tabla 7.26. Flechero del 39 Muestreo 2. Tamaño y módulo largo/ancho de las lascas.

Respecto del tipo de talón, se destacan los ausentes por fractura (20\%), los filiformes (18\%) y lisos (15\%); le siguen los diedros $(11 \%)$ y corticales $(9,5 \%)$ y en valores bajos y parejos (entre $5 \%$ y $2,9 \%$ ) astillados, fracturados, facetados y puntiformes (Tabla 7.27).

\begin{tabular}{|c|c|c|}
\hline Tipo de talón & $\mathbf{N}$ & $\mathbf{\%}$ \\
\hline Cortical & 13 & 9,5 \\
\hline Liso & 20 & 14,6 \\
\hline Diedro & 15 & 10,9 \\
\hline Facetado & 4 & 2,9 \\
\hline Filiforme & 25 & 18,2 \\
\hline Puntiforme & 4 & 2,9 \\
\hline Astillado & 7 & 5,1 \\
\hline Fracturado & 6 & 4,4 \\
\hline Ausente & 28 & 20,4 \\
\hline Indeterminado & 15 & 10,9 \\
\hline Total & $\mathbf{1 3 7}$ & $\mathbf{1 0 0}$ \\
\hline
\end{tabular}

Tabla 7.27. Flechero del 39 Muestreo 2. Tipos y frecuencias de los talones. 


\section{Artefactos formatizados por talla}

Entre los instrumentos tallados $(\mathrm{n}=20 ; 8,7 \%)$ son amplia mayoría los raspadores $(\mathrm{n}=$ 14) de distintos tamaños y morfologías: frontales, perimetrales y dobles. Las formas bases predominantes son lascas de sílices de muy buena calidad, y en menor proporción de calcedonias de aptitud para la talla excelente a muy buena. El resto de los instrumentos está integrado por un perforador sobre lámina mediana de basalto, una raedera sobre lasca grande de calcedonia y tres puntas burilantes sobre lasca de sílice de distintos tamaño. Se recuperó además un guijarro con lascado simple apical de tamaño grande, cuya función es indeterminada (Tabla 7.28 y Fig. 7.14).

Respecto de la serie técnica predomina el microrretoque marginal $(n=17)$, y la situación de los lascados en la totalidad de las piezas es unifacial. No se registran filos dobles ni compuestos (Tabla 7.29).

\section{Lascas con rastros complementarios}

De los diez rastros complementarios $(4,3 \%)$, ocho están asociados a lascas con filos laterales naturales y los dos restantes corresponden a puntas naturales. En relación con las materias primas se registraron sílices $(n=7)$ y una de calcedonia, hematita y andesita respectivamente. Con excepción de la hematita de calidad regular a mala para la talla, el resto de las rocas son de calidad excelente a muy buena. Para todos los filos naturales se utilizaron lascas pequeñas, algunas de ellas con dorso natural $(n=6)$ y el resto son secundarias y de arista inclinada. Para el caso de las puntas naturales el soporte seleccionado son lascas de menor tamaño (microlascas).

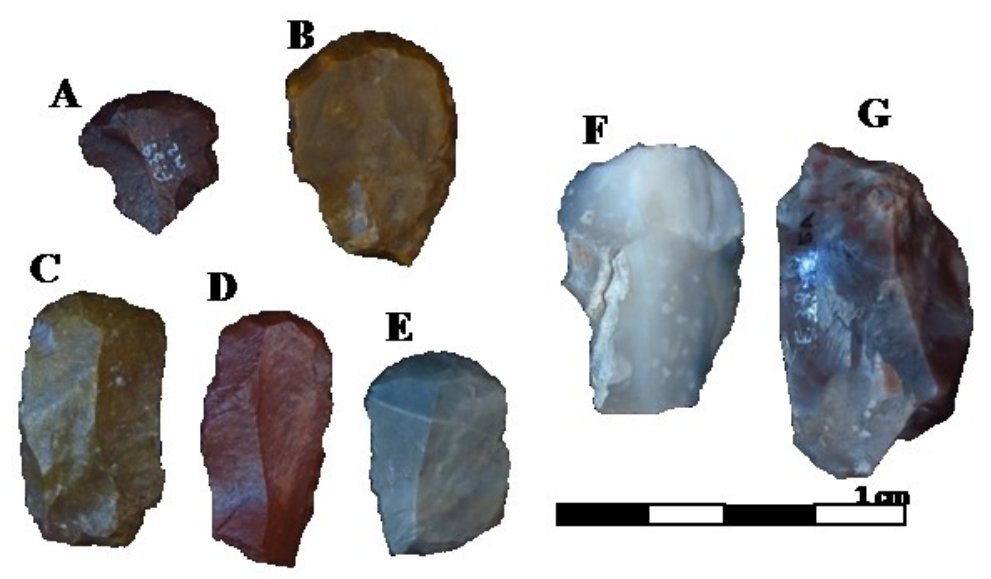

Fig. 7.14. Flechero del 39 Muestreo 2: A- F: raspadores y (G) punta burilante 


\begin{tabular}{|c|c|c|c|c|c|c|}
\hline $\mathrm{N}^{\mathrm{o}}$ & Subg-tipológico & Materia prima & Forma Base & Largo (mm) & Ancho (mm) & $\operatorname{Esp}(\mathrm{mm})$ \\
\hline 1 & Raspador & Calcedonia & Lasca con dorso natural mediana & 34,5 & 24,8 & 11,9 \\
\hline 2 & Raspador & Calcedonia & Lasca pequeña & 26,6 & 22,9 & 7,5 \\
\hline 3 & Raspador & Calcedonia & Lasca pequeña & 23,8 & 21,8 & 5,1 \\
\hline 4 & Raspador & Calcedonia & Lasca de arista inclinada pequeña & 28,7 & 19 & 5 \\
\hline 5 & Raspador & Sílices & Lámina de arista recta pequeña & 32,5 & 19,3 & 6,6 \\
\hline 6 & Raspador & Sílices & Lámina de arista recta pequeña & 32,6 & 15,5 & 5,5 \\
\hline 8 & Raspador & Sílices & Lasca primaria pequeña & 25,8 & 26,2 & 6,5 \\
\hline 9 & Raspador & Sílices & Lasca arista inclinada pequeña & 30,4 & 22,6 & 4,8 \\
\hline 10 & Raspador & Sílices & Lasca arista inclinada pequeña & 25,4 & 17,9 & 4,5 \\
\hline 11 & Raspador & Sílices & Lasca pequeña fracturada & 18,8 & 17,9 & 2,6 \\
\hline 12 & Raspador & Sílices & Lasca pequeña fracturada & 18,5 & 23,1 & 4,4 \\
\hline 16 & Raedera & Calcedonia & Lasca de arista inclinada grande & 46,8 & 34,5 & 10,5 \\
\hline 17 & Punta burilante & Sílice & Lasca nucleiforme mediana & 42,9 & 25,4 & 17,5 \\
\hline 18 & Punta burilante & Sílice & Lasca pequeña & 23,3 & 23,5 & 7,7 \\
\hline 19 & Punta burilante & Sílice & Lasca microlíticas en punta & 17,3 & 13,2 & 4,5 \\
\hline 20 & Guijarro c/ lasc & Indet. & Rodado chato muy grande & 92,9 & 47,1 & 18,2 \\
\hline
\end{tabular}

Tabla 7. 28. Flechero del 39 Muestreo 2 . Características tecnológicas y métricas de los artefactos formatizados por talla. 


\begin{tabular}{|c|c|c|c|c|c|c|c|c|}
\hline $\mathbf{N}^{\mathbf{0}}$ & Subg-tipológico & Serie Técnica & Sit. Lascados & F. G.Contorno & Posic. Filo & F.Lascados & Filo & Estado \\
\hline 1 & Raspador & Microrretoque marginal & Unifacial directo & Piriforme irregular & Frontal & Escamoso escalonado & $35^{\circ}$ & Activo \\
\hline 2 & Raspador & Microrretoque marginal & Unifacial directo & Piriforme irregular & Frontal & Paralelocorto irreg & $58^{\circ}$ & Activo \\
\hline 3 & Raspador & Microrretoque marginal & Unifacial directo & Piriforme irregular & Frontal & Escamoso irreg & $30^{\circ}$ & Activo \\
\hline 4 & Raspador & Microrretoque marginal & Unifacial directo & Piriforme irregular & Frontal & Escamoso irreg & $30^{\circ}$ & Activo \\
\hline 5 & Raspador & Microrretoque marginal & Unifacial directo & Piriforme irregular & Frontal & Paralelo corto irreg & $55^{\circ}$ & Activo \\
\hline 6 & Raspador & Microrretoque marginal & Unifacial directo & Piriforme irregular & Doble & Ultramaginal & $38^{\circ}$ & Activo \\
\hline 7 & Raspador & Microrretoque marginal & Unifacial directo & Piriforme irregular & Frontal & No diferenciado & $30^{\circ}$ & Agotado \\
\hline 8 & Raspador & Microrretoque marginal & Unifacial directo & Piriforme irregular & Frontal & Escamoso irregular & $40^{\circ}$ & Activo \\
\hline 9 & Raspador & Microrretoque marginal & Unifacial directo & Piriforme irregular & Frontal & Paralelo corto irreg & $30^{\circ}$ & Activo \\
\hline 10 & Raspador & Microrretoque marginal & Unifacial directo & Semieliptica & Frontal & Paralelo corto irreg & $25^{\circ}$ & Activo \\
\hline 11 & Raspador & Microrretoque marginal & Unifacial directo & Indet (fracturado) & Frontal & Ultramarginal & $30^{\circ}$ & Activo \\
\hline 12 & Raspador & Microrretoque marginal & Unifacial directo & Indet (fracturado) & Frontal & Ultramarginal & $35^{\circ}$ & Activo \\
\hline 13 & Raspador & Microrretoque marginal & Unifacial directo & Indet (fracturado) & Frontal & Ultramarginal & $30^{\circ}$ & Agotado \\
\hline 14 & Raspador & Microrretoque marginal & Unifacial directo & Indet (fracturado) & Frontal & Ultramarginal & $30^{\circ}$ & Activo \\
\hline 15 & Raedera & Microrretoque marginal & Unifacial directo & Triangular irregular & Lateral & Escamoso regular & $50^{\circ}$ & Activo \\
\hline 16 & Perforador & Retoque marginal & Unifacial directo & Rectangular? & Frontal & Marginal corto & -- & Fracturado \\
\hline 17 & Punta burilante & Lascado simple & Unifacial directo & Triangular irregular & Frontal & Golpe en buril? & -- & Activo \\
\hline 18 & Punta burilante & Lascado simple & Unifacial directo & Rectangular & Frontal & Golpe en buril? & -- & Activo \\
\hline 19 & Punta burilante & Microrretoque marginal & Unifacial. directo & Triangular & Frontal & Indet & -- & Activo \\
\hline 20 & Guijarro c/lasc. & Lascado simple & Unifacial directo & Elíptica & Apical & nc & -- & $\mathrm{nc}$ \\
\hline
\end{tabular}

Tabla 7.29. Flechero del 39 Muestreo 2. Referencias: Sit. Lascados: situación de los lascados; F. Geom.: forma geométrica, Posic.Fil: Posición del filo; F.Lasc. Forma de los lascados; Ang. Ángulo del filo; restr. Restringido; Unif: Unificial; Indet: indeterminado. 


\section{Núcleos}

Todos los núcleos $(n=6)$ son de rocas silíceas de muy buena calidad para la talla y entre ellos al menos cuatro provienen de rodados. Para los dos restantes, y debido al alto grado de modificación no se pudo determinar la forma base original. En cuanto al tamaño, se registraron cinco pequeños y uno grande. Por su parte, se reconocieron distintos tipos: dos discoidales, uno bipolar, otro de lascados aislados, y dos cuyas formas no pudieron determinarse (Fig.7.15). La mayoría de los negativos de lascado corresponden a lascas aunque en un núcleo bipolar son de forma laminar. El grado de modificación de los núcleos es predominantemente alto, y sólo dos uno discoidal y el otro de lascados aislados- se encuentran activos (Tabla 7.30).

\begin{tabular}{|c|c|c|c|c|c|c|c|}
\hline $\begin{array}{c}\text { Materia } \\
\text { prima }\end{array}$ & Tipo de núcleo & $\begin{array}{l}N^{0} \text { mín } \\
\text { p perc. }\end{array}$ & $\begin{array}{l}\text { Forma sup } \\
\text { plat perc. }\end{array}$ & $\begin{array}{l}\mathbf{N}^{\mathbf{0}} \\
\text { lasc. }\end{array}$ & $\begin{array}{l}\text { F.negat } \\
\text { lasc }\end{array}$ & $\begin{array}{l}\text { Grado } \\
\text { modific }\end{array}$ & Estado \\
\hline Sílice & Discoidal & 1 & Liso & 3 & Lasca & Bajo & Activo \\
\hline Sílice & Discoidal & 3 & Liso & 5 & Lasca & Alto & Agotado \\
\hline Sílice & Lascado aislado & 1 & Cortical & 3 & Lasca & Bajo & Activo \\
\hline Sílice & Bipolar & 2 & Liso & 2 & Laminas & Alto & Agotado \\
\hline Sílice & Indet. (fragmento) & Indet & Liso & 3 & Lasca & Alto & Agotado \\
\hline Sílice & Indet. (fragmento) & Indet & Liso & 4 & Lasca & Alto & Agotado \\
\hline
\end{tabular}

Tabla 7.30. Flechero del 39 Muestreo 2. Características morfológicas y técnicas de los núcleos.

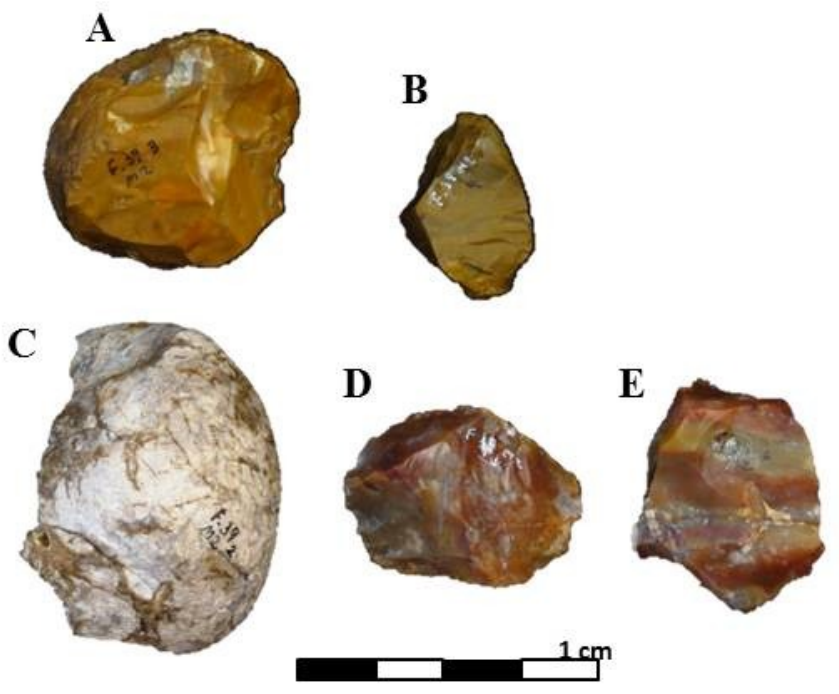

Fig. 7.15. Flechero del 39 Muestreo 2. Tipos de núcleos rescatados en el sitio el muestreo 2 de Flechero del 39. A y C: discoidales; B: bipolar; D: fragmento de núcleo y E: lascado aislado. 


\section{Artefactos modificados por el uso y ecofactos}

Se halló un rodado de tamaño mediano de $6 \mathrm{~cm}$ de largo x $4 \mathrm{~cm}$ de ancho, fracturado y con daño térmico (Fig.7.14-A). También se registró un hueso mineralizado de cetáceo, probablemente una vértebra, que presenta marcas de picado en la porción central, como los rastros característicos de los yunques (Fig. 7.14-B). Como se consignó en el capítulo 2 "Marco Ambiental", los huesos mineralizados de cetáceos fósiles representan otra fuente de materias primas en el área de estudio. Se destacan por su tamaño grande y su dureza, lo que los hace aptos para el machacado y la percusión.

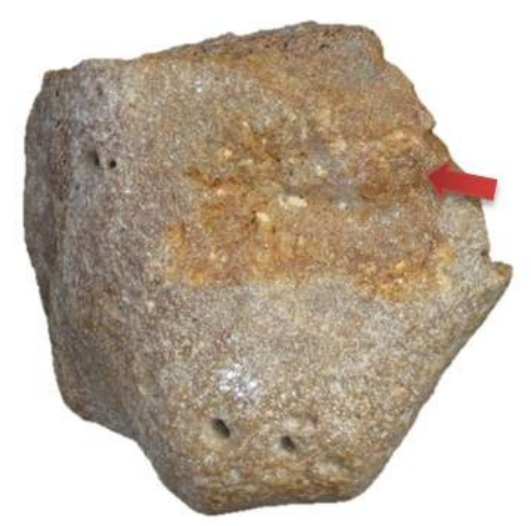

Fig. 7.16. Flechero del 39 Muestreo. Artefacto sobre hueso de cetáceo.

\section{Índice de fractura}

En el conjunto artefactual el porcentaje de fracturas es de $31,4 \%(n=72)$, registrándose en su gran mayoría en los desechos de talla y también en el resto de las clases artefactuales (Tabla 7.31).

\begin{tabular}{|c|c|}
\hline Fracturas por Clase Tipológica & Flech 39 Muestreo 2 \\
\hline Ecofacto & 1 \\
\hline Artefactos modificados por el uso & 1 \\
\hline Desechos de talla & 61 \\
\hline Artefactos formatizados por talla & 6 \\
\hline Rastros complementarios & 1 \\
\hline Núcleos & 2 \\
\hline $\mathbf{N}$ & $\mathbf{7 2}$ \\
\hline $\mathbf{\%}$ & $\mathbf{3 1 , 4}$ \\
\hline
\end{tabular}

Tabla 7.31. Flechero del 39 Muestreo 2. Frecuencia de fracturas por clase tipológica. 


\section{Relaciones de ensamblaje}

La primera relación de ensamblaje se realizó entre dos microlascas de hematita (Fig. 7.17-B); la otra corresponde a dos fragmentos de una misma piedra termófora, cuyas partes se habrían desprendido por la acción del fuego (Fig.7.17-A).

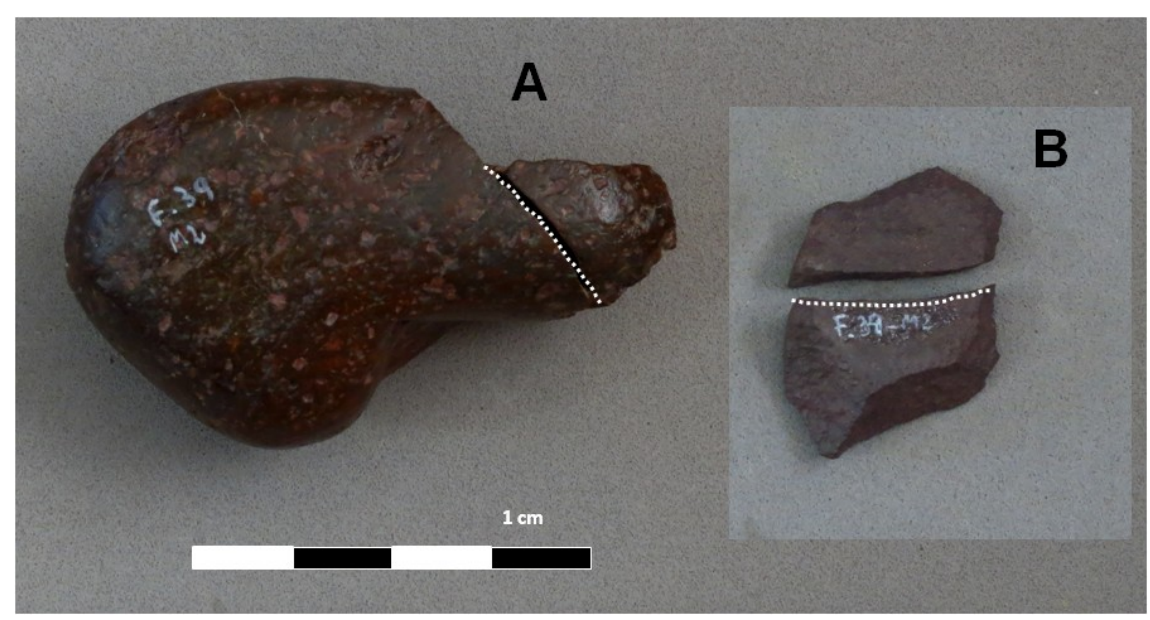

Fig.7. 17. Flechero del 39 Muestreo 2. Relaciones de ensamblaje: (A) Dos fragmentos remontados de una misma piedra de fogón de riolita ( $\mathrm{N}^{\mathrm{o}} \mathrm{F} 39 \mathrm{M} 2$ 1); (B) remontaje entre dos lascas de hematita.

\section{Frecuencia de módulos laminares, bipolaridad y bifacialidad:}

En el conjunto artefactual la proporción de módulos laminares es de 17,5\% ( $\mathrm{n}=40$ artefactos) y se registró en desechos de talla $(\mathrm{n}=35)$, en tres artefactos tallados y en dos láminas con rastros complementarios. La técnica bipolar y la reducción bifacial se identificaron en frecuencias más bajas (2,2\% y 0,9\% respectivamente). La primera se determinó en tres lascas y en un núcleo, y la segunda sólo en dos desechos de talla.

\section{Tendencias generales del conjunto lítico de Flechero del 39}

En cuanto al conjunto lítico, en primer lugar se pudo determinar el predominio en la selección de materias primas locales, principalmente rodados de sílice de muy buena calidad. También se aprovecharon rocas de procedencia no local como hematitas, obsidianas y xilópalos. Se destaca la presencia de un artefacto de función indeterminada sobre hueso fosilizado de cetáceo. Instrumentos manufacturados sobre este tipo de materia prima también fueron registrados en otros sitios de la Península Valdés como una mano de moler de tamaño grande 
hallada en la localidad La Armonía ${ }^{3}$ (Gómez Otero 2006) (Figura 7.18-A) y fragmentos indeterminados en el sitio San Pablo 4 (veáse abajo).

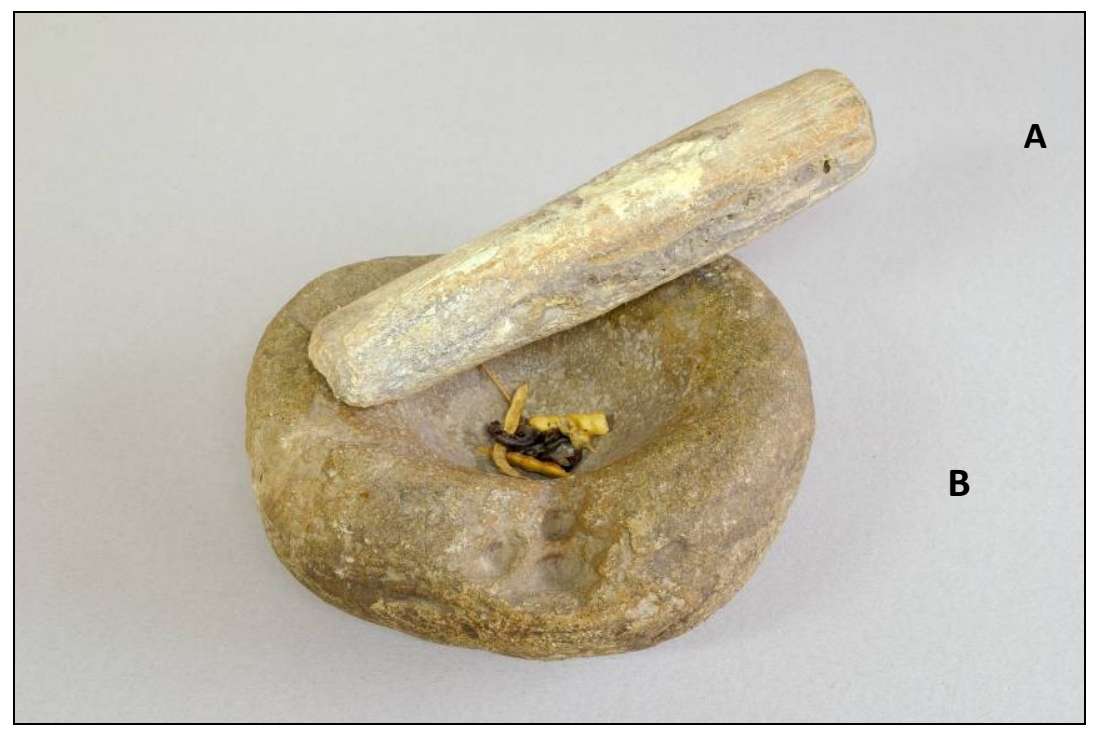

Figura 7.18. (A) Mano de molino en hueso mineralizado de cetáceo con (B) mortero hallado en Península Valdés.

Por su parte, la presencia de núcleos, desechos cuyos tamaños varían desde muy pequeños a medianos-grandes, distintos tipos de lascas internas y externas, instrumentos terminados y lascas con rastros complementarios, se infiere la ejecución de todas las etapas de la secuencia de talla. En relación con los desechos, el predominio de lascas primarias y las de dorso natural, sugieren que en el sitio se llevaron a cabo las primeras etapas de descortezamiento de los núcleos, y también la selección de formas bases (lascas primarias y con dorso natural) para la confección de artefactos tallados como raspadores y puntas burilantes. En este sentido, para la producción de los artefactos tallados se observó la selección de los rodados locales pequeños de sílices, tal como lo indica la presencia de núcleos pequeños, en su mayoría agotados y las similitudes entre estas materias primas silíceas y las de los soportes de los instrumentos terminados. En cuanto a los raspadores, subgrupo tipológico más representado en el conjunto, se identificó una clara selección de láminas de tamaño pequeño y mediano de sílices coloreadas y calcedonias. Estos raspadores presentan distintas morfologías y tamaños (Fig. 7.12) y casi la totalidad de sus filos se encuentra activa.

\footnotetext{
${ }^{3}$ Este instrumento fue hallado por un aficionado quien lo prestó al Laboratorio del CENPAT durante un año para su estudio.
} 
En síntesis, sobre la base de la abundancia y diversidad de recursos faunísticos consumidos, sumadas a las buenas condiciones de habitabilidad que ofrece el lugar para el asentamiento humano -fácil acceso a sus costas y alta productividad malacológica- se propuso que el sitio habría funcionado como una base residencial donde se llevaron a cabo distintas actividades entre ellas captura, procesamiento y descarte de recursos faunísticos y también procesamiento de vegetales $\mathrm{u}$ otros alimentos dada la presencia de artefactos de molienda (Gómez Otero 2006). Las investigaciones realizadas para esta tesis permitieron reconocer otras actividades como la talla lítica inicial (desbaste de nódulos), extracción de formas base y formatización de artefactos mediante retoque y microrretoque. Por último, y sobre la base de indicadores de estacionalidad -huesos de pingüinos (Spheniscus magellanicus)- se infiere la ocurrencia de ocupaciones en primavera avanzada-verano. 


\section{GOLFO NUEVO PENÍNSULA VALDÉS}

De este golfo se analizaron los conjuntos artefactuales de tres localidades arqueológicas: Punta Cormoranes, Punta Alta y Punta Pardelas (Fig. 7.1).

\section{Localidad arqueológica Punta Cormoranes}

El paisaje costero está configurado por una amplia bajada al mar formada por cordones litorales pleistocénicos y holocénicos, sobre los que apoyan relieves dunarios, y por otro sector de difícil acceso a la costa con presencia de acantilados de gran altura -más de 100 metros(Gómez Otero 2006). En la playa no hay plataformas de abrasión y en las bermas se encuentran rodados de tamaños pequeños a grandes (tipo guijón sensu Bonorino y Teruggi 1952). Gómez Otero y equipo prospectaron la franja costera de siete kilómetros que abarca desde punta Cormoranes hasta el cerro homónimo, registrando un total de siete sitios arqueológicos: Las

Ollas 1 y 2, y cuatro cerca del cerro, denominados Cormoranes 1, 2, 3 y 4 (Fig. 7.19). Para esta tesis se estudiaron los materiales líticos asociados al sitio Las Ollas 1 Conchero 1 (en adelante LOll 1 C1) y el muestreo lítico superficial de Las Ollas 1 Muestreo 1 (LOll 1 M1). Se analizó además el conjunto artefactual asociado al muestreo del Fogón 1 del Sitio Los Cormoranes 3 (Corm 3 F1).

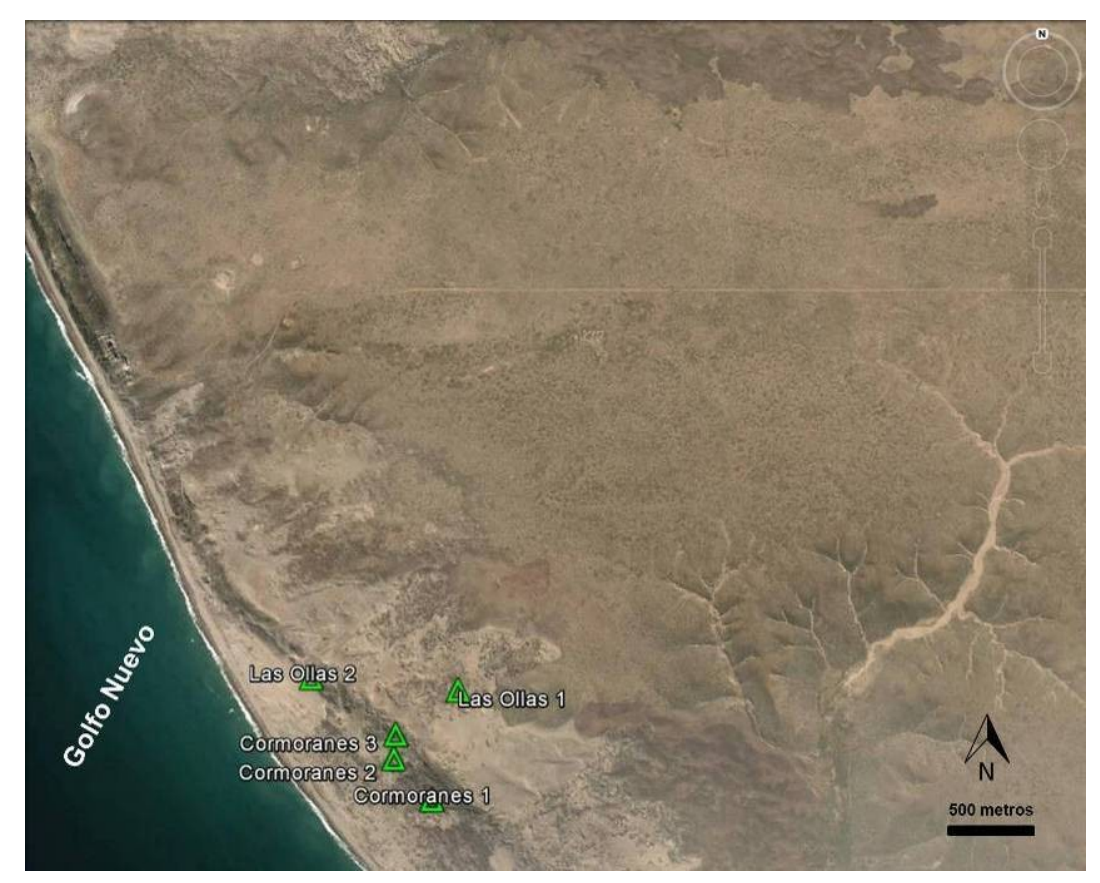

Fig. 7. 19. Localidad Punta Cormoranes: ubicación de los sitios arqueológicos. 


\section{Las Ollas 1}

Se trata de un sitio extenso emplazado en un ambiente dunario, a 400 metros de la playa y a 20 m s.n.m. Se observaron valvas, restos óseos faunísticos, artefactos líticos y tres concentraciones de tiestos cerámicos de tamaño grande (Gómez Otero 2006; Gómez Otero et al. 1999). Entre los materiales líticos dispersos en la hoyada se registraron 10 puntas de proyectil fracturadas, tres bolas, una manija de hematita, percutores, molinos planos de arenisca y manos y percutores en rodados grandes. Se realizó un muestreo sistemático de cuatro metros de lado y se plantearon cuadrículas de $1,50 \mathrm{~m}$ x $2 \mathrm{~m}$ de lado alrededor de cada concentración cerámica (Gómez Otero 2006: Cap. 5). Por su parte, el estudio de los restos cerámicos determinó un número mínimo de ocho vasijas y la presencia de características tecnológicas tales como formas abiertas y orificios pequeños -entre 10 a $12 \mathrm{~cm}$ - las cuales permitieron relacionarla con actividades culinarias como la preparación, el hervor y la cocción de los alimentos, más que con el almacenamiento (Schuster 2015). Estos resultados también son avalados por los valores isotópicos obtenidos en un fragmento del sitio Las Ollas 1 -LO1 (9)- que indica la presencia de proteínas terrestres y plantas del tipo $\mathrm{C}_{3}$ (Gómez Otero et al. 2014). Además de las tres concentraciones cerámicas se registró un fogón bajo una delgada capa de arena (Fig. 7.20-A).
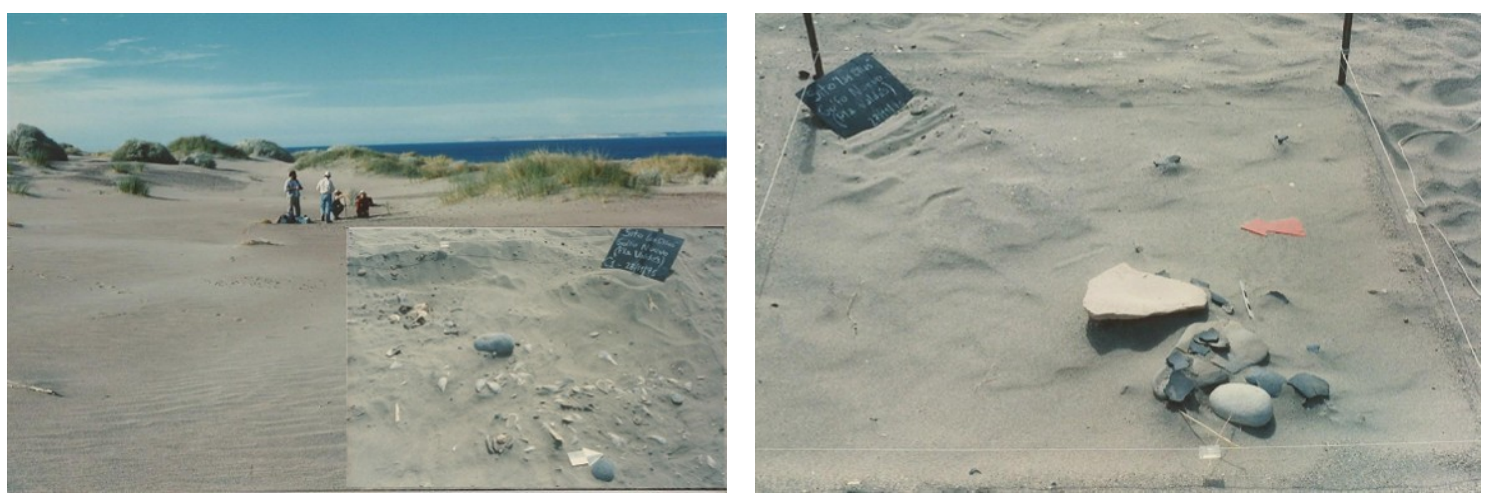

Fig. 7.20. Vista general del sitio Las Ollas (izquierda) y detalle del muestreo de superficie en la concentración cerámica (derecha).

El muestreo del fogón -de dos metros de lado por la potencia máxima $(13 \mathrm{~cm})$ - mostró la presencia predominante de valvas de cholgas (Aulacomya ater; $\mathrm{NMI}=176$ ), huesos partidos de guanaco (Lama guanicoe; NMI=1) y dos vértebras quemadas de pingüino (Spheniscus sp.). Dos dataciones de muestras de valvas arrojaron las siguientes edades radiocarbónicas: $610 \pm 40$ años $C^{14}$ AP y $640 \pm 40$ años $C^{14}$ AP, no corregidas por el Efecto Reservorio (Tabla 7.32). Sobre la base de las evidencias arqueológicas se infirió que el sitio representaría una base residencial (Gómez Otero 2006). 


\section{Los cormoranes 3}

Se trata de una lente restringida de carbones, rodados termoalterados y tres instrumentos que afloraba a $80 \mathrm{~cm}$ de profundidad sobre el perfil de una cárcava en cota $50 \mathrm{~m}$ s.n.m (Fig. 7.21). No se hallaron restos arqueofaunísticos asociados (Gómez Otero 2006). De los carbones se obtuvo una datación radicoarbónica (Tabla 7.32), cuya antigüedad lo posiciona entre uno de los sitios más antiguos de la Península Valdés (Gómez Otero 2006). De acuerdo con esta autora, los rasgos arqueológicos identificados se asemejan a los esperados por Binford (1980) para una "estación", es decir una parada en el contexto de alguna partida que estaba realizando actividades en el lugar, probablemente el aprovisionamiento de los guijones de la playa.
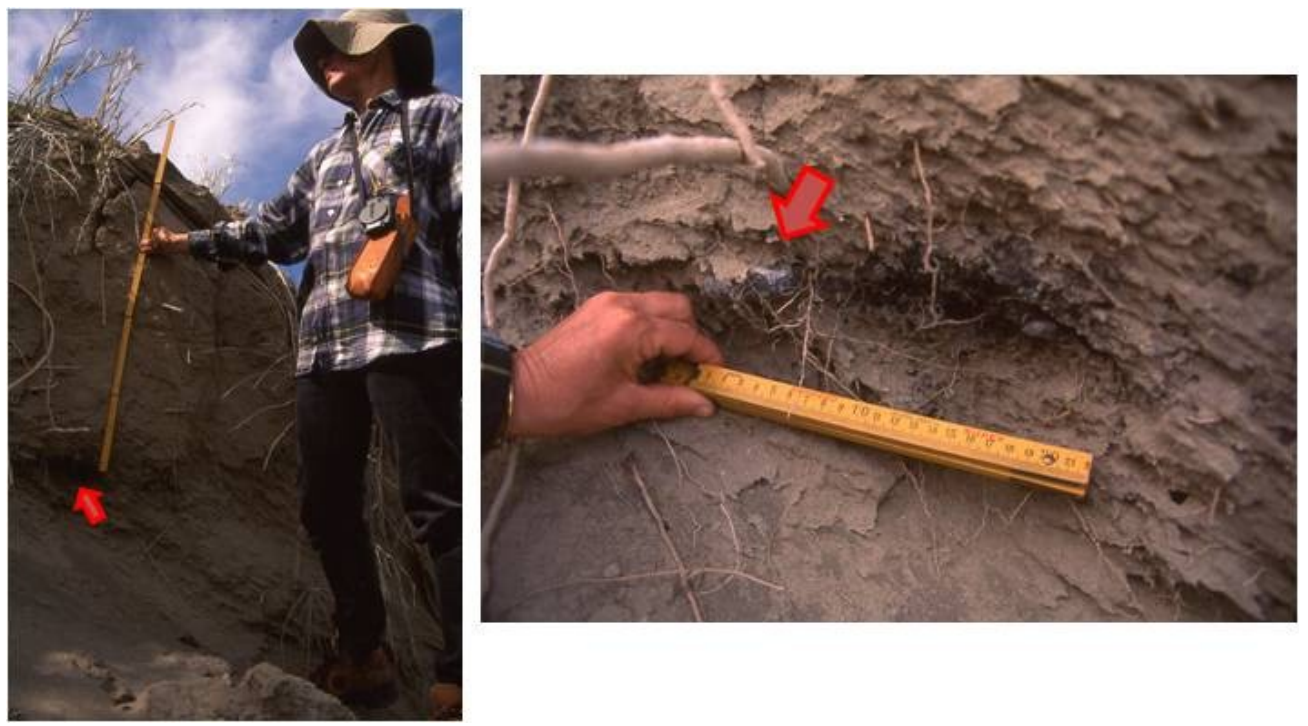

Fig. 7.21. Vista general de la lente del sitio Cormoranes 3 (izquierda) y (derecha) detalle de la lente. La flecha roja señala el rodado entremezclado con los carbones.

\begin{tabular}{|c|c|c|c|c|c|c|c|}
\hline Sitio & $\begin{array}{c}\text { Latitud } \\
\text { Longitud }\end{array}$ & $\begin{array}{c}\text { Altura } \\
\text { s.n.m }\end{array}$ & $\begin{array}{c}\text { Dist. } \\
\text { mar }\end{array}$ & Edad C $^{\mathbf{1 4}}$ & $\begin{array}{l}\text { Edad Calibrada } \\
\text { 2 } \text { sigmas * }^{*}\end{array}$ & Muestra & Lab. \\
\hline Las Ollas 1 & $42^{\mathbf{0}} 38,328 \mathrm{~S}$ & $10 \mathrm{~m}$ & $400 \mathrm{~m}$ & $610 \pm 60$ & sin calibrar & valvas & LP-819 \\
Conchero 1 & $64^{\mathrm{o}} 05,414 \mathrm{O}$ & & & $640 \pm 60$ & & valvas & LP-834 \\
\hline Corm 3 & $42^{\mathbf{0}} 46,717 \mathrm{~S}$ & $50 \mathrm{~m}$ & $50 \mathrm{~m}$ & $4340 \pm 70$ & $4654-5245$ & carbón & LP-1085 \\
Fogón 1 & $64^{\mathbf{0}} 14,583 \mathrm{O}$ & & & & & \\
\hline
\end{tabular}

Tabla 7.32. Localidad Punta Cormoranes: localización y fechados obtenidos de los concheros Referencias: Dist. Distancia; Lab. Laboratorio. *Stuiver y Reimer 1993. Datos obtenidos de Gómez Otero 2006.

\section{Análisis tecnológico}

En LOll $1 \mathrm{C} 1$ se hallaron nueve artefactos $\left(0,06 / \mathrm{dm}^{3}\right)$, mientras que en el muestreo superficial el total de artefactos rescatados es de 81 y la densidad de 2,71/ $\mathrm{dm}^{2}$. En el muestreo del fogón 1 de Corm 3, los artefactos hallados son once $\left(0,14 / \mathrm{dm}^{2}\right)$. 


\section{Materias primas:}

Para el conjunto de LO1l $1 \mathrm{C} 1$ se identificaron tres clases de rocas: basaltos $(n=6)$, calcedonia $(n=2)$ y una sílice. Para LOll 1 M 1 las variedades litológicas son diez, más una que no pudo ser determinada. La amplia mayoría de los artefactos son de basalto (67 \%) -casi la totalidad de ellos con presencia de lustre y pulido- y segundo lugar las calcedonias (16\%). Le siguen en orden de importancia las sílices $(7,4 \%)$ y el resto de las litologías se encuentra en valores muy bajos y parejos (entre $3,7 \%$ y $1,2 \%$ ): basalto vesicular, cuarcita, hematita, xilópalo, riolita, arenisca consolidada y obsidiana. Por último, los once artefactos rescatados en Corm 3 F1 se distribuyen en cinco materias primas: riolita $(n=4)$; ignimbrita y calcedonia $(n=2$ de cada una), y un artefacto de sílice, de basalto y de xilópalo (Tabla 7.33).

Las rocas no locales están representadas por obsidianas, basalto vesicular, hematita y xilópalos (Gómez Otero y Stern 2006; Banegas et al. 2016). El resto de las materias primas son locales y se encuentran disponibles en forma de rodados, no obstante algunas rocas como los nódulos de calcedonia son escasos en los depósitos secundarios de rodados.

\begin{tabular}{|c|c|c|c|c|}
\hline \multirow{2}{*}{ Materias primas } & LOll 1 C1 & \multicolumn{2}{|c|}{ LOIl 1 M1 } & Corm 3 F1 \\
\cline { 2 - 5 } & $\mathbf{N}$ & $\mathbf{N}$ & $\mathbf{\%}$ & $\mathbf{N}$ \\
\hline Basalto & 6 & 54 & 66,7 & 1 \\
\hline Basalto vesicular & -- & 1 & 1,2 & -- \\
\hline Calcedonia & 2 & 16 & 16 & 2 \\
\hline Cuarcita & -- & 1 & 1,2 & -- \\
\hline Hematita & -- & 1 & 1,2 & -- \\
\hline Ignimbrita & -- & -- & -- & 2 \\
\hline Obsidiana verde & -- & 2 & 2,5 & -- \\
\hline Riolita & -- & 1 & 1,2 & 4 \\
\hline Sílice & 1 & 6 & 7,4 & 1 \\
\hline Xilópalo & -- & 3 & 3,7 & 1 \\
\hline Arenisca consolidada & -- & 2 & 2,5 & -- \\
\hline Indeterminada & -- & 1 & 1,2 & -- \\
\hline Total & $\mathbf{9}$ & $\mathbf{8 5}$ & $\mathbf{1 0 0}$ & $\mathbf{1 1}$ \\
\hline
\end{tabular}

Tabla 7.33. Localidad Punta Cormoranes: tipos y frecuencias de las variedades litológicas.

\section{Clases artefactuales:}

Los escasos artefactos recuperados en LO11 1 C1 están representados por desechos ( $\mathrm{n}=$ 8) y un solo instrumento formatizado por talla. En el Muestreo 1 de LOll 1 sobresalen los desechos de talla $(74,1 \%)$, en menor frecuencia se ubican los artefactos formatizados por talla (9 $\%)$ y los núcleos (7\%), por ultimo -en las mismas proporciones (2,4\%)- las lascas con rastros complementarios, los modificados por el uso, los instrumentos formatizados por picado y pulido 
y dos ecofactos. En el Fogón 1 de Corm 3 de los once artefactos, seis son piedras de fogón y tres instrumentos formatizados por talla; el resto de las clases la componen un núcleo y una lasca con rastros complementarios (Tabla 7.34).

\begin{tabular}{|c|c|c|c|c|c|c|c|}
\hline \multirow[t]{2}{*}{ Clases } & \multirow[t]{2}{*}{ Núcleos } & \multirow[t]{2}{*}{ Desechos } & \multicolumn{4}{|c|}{ Instrumentos } & \multirow[t]{2}{*}{ Ecofactos } \\
\hline & & & $\begin{array}{l}\text { Art.Form } \\
\text { por talla }\end{array}$ & $\begin{array}{c}\text { Rastros } \\
\text { complement. }\end{array}$ & $\begin{array}{c}\text { Art.Form } \\
\text { PyP. }\end{array}$ & $\begin{array}{c}\text { Art. M. } \\
\text { uso }\end{array}$ & \\
\hline \multicolumn{8}{|l|}{ LOll C1 } \\
\hline $\mathrm{N}$ & -- & 8 & 1 & -- & -- & -- & -- \\
\hline \multicolumn{8}{|l|}{ LOll 2 M1 } \\
\hline $\mathrm{N}$ & 6 & 63 & 8 & 2 & 2 & 2 & 2 \\
\hline$\%$ & $7,1 \%$ & $74,1 \%$ & $9,4 \%$ & $2,4 \%$ & $2,4 \%$ & $2,4 \%$ & $2,4 \%$ \\
\hline \multicolumn{8}{|l|}{ Corm 3 F1 } \\
\hline $\mathrm{N}$ & 1 & -- & 3 & 1 & -- & 6 & -- \\
\hline
\end{tabular}

Tabla 7.34. Localidad Punta Cormoranes: distribución de las clases tipológicas. Referencias: Art. Artefactos; complemento: complementarios; Form. Formatizado; PyP: picado y pulido; M. Modificado.

\section{Desechos de talla:}

En LOll $1 \mathrm{C} 1$ seis lascas se encuentran enteras y dos fracturadas con talón. El tipo de lascas registradas son: con dorso natural $(n=3)$, secundarias $(n=2)$ y una lasca en punta, de reactivación directa y primaria respectivamente. En LO1l 1 M1 más de la mitad de los desechos se encuentran enteros (51\%), en segundo lugar los no clasificables (21\%) y las lascas fracturadas con talón (19\%); por último un porcentaje minoritario lo conforman las fracturadas sin talón (9,5\%). Prevalecen las lascas con dorso natural (24\%) y las indeterminadas $(22 \%)$ seguidas por las bipolares y las primarias (16\% cada una), y por último las secundarias (12\%). En muy baja frecuencia se registraron las lascas en punta $(6 \%)$ y las de reactivación directa (4\%). En Corm 3 F1 no se hallaron desechos de talla (Tabla 7.35).

\begin{tabular}{|c|c|c|c|}
\hline \multirow{2}{*}{ Tipo de lascas } & LOll 1 C1 & \multicolumn{2}{|c|}{ LOll 1 M1 } \\
\cline { 2 - 4 } & $\mathbf{N}$ & $\mathbf{N}$ & $\mathbf{\%}$ \\
\hline Con dorso natural & 3 & 12 & 24 \\
\hline Primaria & 1 & 8 & 16 \\
\hline Secundaria & 2 & 6 & 12 \\
\hline De reactivación directa & 1 & 2 & 4 \\
\hline Punta de arista & 1 & 3 & 6 \\
\hline Bipolar & -- & 8 & 16 \\
\hline Indeterminada & -- & 11 & 22 \\
\hline Total & $\mathbf{8}$ & $\mathbf{5 0}$ & $\mathbf{1 0 0}$ \\
\hline
\end{tabular}

Tabla7.35. Localidad Punta Cormoranes: tipos y frecuencias de lascas. 
En relación con el tamaño de las lascas, las de LOll 1 C1 se distribuyen en seis microlascas, una hipermicrolasca y otra pequeña. Ocho son de módulo normal y uno mediano alargado. Por el contrario, en el Muestreo 1 son mayoría las pequeñas (30\%), seguidas por las medianas, y en tercer lugar las microlascas e hipermicrolascas (22\% cada una). El módulo que prevalece es el mediano-normal $(76 \%)$ y en baja frecuencia se ubican los medianos-alargados $(18 \%)$ y cortos-anchos (6\%) (Tabla 7.36).

\begin{tabular}{|c|c|c|c|c|c|c|}
\hline & \multirow{2}{*}{$\begin{array}{l}\text { Tamaño } \\
\text { Módulo }\end{array}$} & \multirow{2}{*}{$\begin{array}{l}\text { Corto } \\
\text { ancho }\end{array}$} & \multirow{2}{*}{$\begin{array}{c}\text { Med. } \\
\text { alargado }\end{array}$} & \multirow{2}{*}{$\begin{array}{c}\text { Med. } \\
\text { normal }\end{array}$} & \multicolumn{2}{|c|}{ Total } \\
\hline & & & & & $\mathbf{N}$ & $\%$ \\
\hline \multirow{4}{*}{$\begin{array}{l}\bar{U} \\
\overline{\overline{0}}\end{array}$} & Hipermicrolasca & -- & -- & 1 & 1 & -- \\
\hline & Microlasca & -- & 2 & 4 & 6 & -- \\
\hline & Lasca pequeña & -- & -- & 1 & 1 & -- \\
\hline & $\mathbf{N}$ & -- & 2 & 6 & 8 & -- \\
\hline \multirow{6}{*}{$\begin{array}{l}\sum_{N} \\
\stackrel{\bar{\sigma}}{0}\end{array}$} & Hipermicrolasca & -- & -- & 11 & 11 & $22 \%$ \\
\hline & Microlasca & 1 & 3 & 7 & 11 & $22 \%$ \\
\hline & Lasca Pequeña & -- & 6 & 9 & 15 & $30 \%$ \\
\hline & Lasca mediana & 2 & -- & 11 & 13 & $26 \%$ \\
\hline & $\mathbf{N}$ & 3 & 9 & 38 & \multirow[t]{2}{*}{50} & \multirow[t]{2}{*}{100} \\
\hline & $\%$ & 6 & 18 & 76 & & \\
\hline
\end{tabular}

Tabla 7.36. Localidad Punta Cormoranes: tamaño y módulo largo/ancho de las lascas.

En LOll $1 \mathrm{C} 1$ los talones son de cuatro tipos: tres filiformes, dos diedros, uno puntiforme y uno astillado (Tabla 7.37). Para el conjunto de LOll 1 M1 prevalecen los talones corticales (32\%), en segundo lugar se ubican los ausentes (18\%), filiformes (16\%) y astillados (12\%) y por último en valores bajos y parejos lisos (4\%), diedros y puntiformes ( $2 \%$ cada uno). El 8\% permanece indeterminado (Tabla 7.37)

\begin{tabular}{|c|c|c|c|}
\hline \multirow{2}{*}{ Tipo de talón } & \multirow{2}{*}{ LOll 1 C1 } & \multicolumn{2}{|c|}{ LOIl 1 M1 } \\
\cline { 2 - 4 } & & N & \% \\
\hline Cortical & -- & 16 & 32 \\
\hline Liso & -- & 2 & 4 \\
\hline Diedro & 2 & 1 & 2 \\
\hline Filiforme & 3 & 8 & 16 \\
\hline Puntiforme & 1 & 1 & 2 \\
\hline Astillado & 1 & 6 & 12 \\
\hline Ausente & 1 & 9 & 18 \\
\hline Indeterminado & -- & 4 & 8 \\
\hline Totales & $\mathbf{8}$ & $\mathbf{5 0}$ & $\mathbf{1 0 0}$ \\
\hline
\end{tabular}

Tabla7.37. Localidad Punta Cormoranes: tipos y frecuencias de los talones. 


\section{Artefactos formatizados por talla}

El único instrumento hallado en LOll $1 \mathrm{C} 1$ es un fragmento de punta triédrica (LOll 1C1 $\mathrm{N}^{\mathrm{o}}$ 19) sobre lasca de calcedonia de muy buena calidad para la talla. La pieza presenta filo frontal unifacial por retoque marginal y se encuentra fracturada en el sector proximal, no obstante su filo se encuentra activo. Por su parte, entre los ocho instrumentos rescatados en LOll 1 M1 hay cuatro puntas de proyectil pedunculadas microlíticas, una punta burilante y otra destacada, un retoque sumario y un peso lítico o rodado chato pequeño con escotaduras. Rodados chatos con escotaduras dobles o cuádruples, hallados en varios sitios del área de estudio, fueron interpretados como pesos líticos utilizados en la pesca (Gómez Otero 2006, Gómez Otero et al. 1999, Gómez Otero et al. 2015). Artefactos similares también se registraron en la costa norte del golfo San Matías (Scartascini 2012).

El peso lítico (LOll $1 \mathrm{M} 1 \mathrm{~s} / \mathrm{n}$ ) es el único elaborado en basalto, y los demás artefactos se confeccionaron en calcedonias, xilópalos, sílices y obsidianas, todas de excelente a muy buena aptitud para la talla. En cuanto a los soportes, corresponden a lascas de tamaño mediano y pequeño, excepto en el caso de las puntas de proyectil para las que no se logró establecer la forma base (Tabla 7.38). Cuatro de los instrumentos presentan lascados bifaciales y el resto son unifaciales. Sobresalen los retoques marginales o extendidos, seguidos por el micro retoque, y hay un solo caso de lascado simple. Salvo el retoque sumario, el resto de los filos se encuentra activo (Tabla 7.39).

Por último, y en el sitio Corm 3 F1 los instrumentos tallados son cuatro: un perforador sobre lasca grande bifacial de sílice; dos artefactos compuestos manufacturados en calcedonia el raspador frontal y filo lateral retocado sobre lámina mediana, y el cortante y punta entre muesca sobre una lasca pequeña- (Fig. 7.22), y una preforma bifacial de basalto. Todas las materias primas seleccionadas son de calidad muy buena (Tabla 7.38). Para los instrumentos tallados de Corm 3 F1 la situación de los lascados es también bifacial y unifacial ( $\mathrm{n}=2$ de cada uno). El raspador y el cortante presentan filo frontal por micro retoque marginal, el perforador por lascado simple y la preforma bifacial por medio de retoque marginal. Se registraron dos filos dobles en las calcedonias de muy buena calidad para la talla. Todos los filos se encuentran activos (Tabla 7.39). 


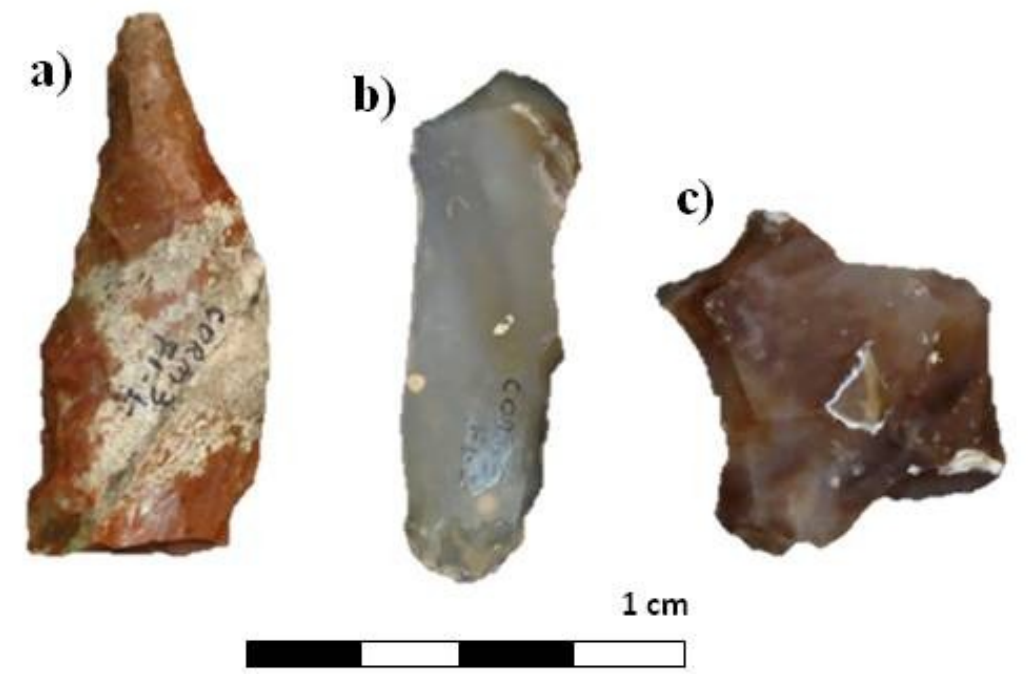

Fig.7.22. Cormoranes 3. Instrumentos líticos tallados: a) perforador sobre pieza bifacial de sílice (Corm $3 \mathrm{~N}^{\circ}$ 1); b) Raspador sobre lámina de calcedonia blanquecina (Corm $3 \mathrm{~N}^{\circ} 2$ ); y c) punta entre muesca sobre lasca de calcedonia (Corm $\left.3 \mathrm{~N}^{\circ} 4\right)$. 
Calcedonia

\begin{tabular}{|c|c|c|c|c|c|c|c|}
\hline Loll $1 \mathrm{C} 1$ & 19 & Fragmento de punta triédrica & Calcedonia & Lasca pequeña & 21,6 & 14 & 5,1 \\
\hline \multirow{8}{*}{ LOll 1 M1 } & 69 & Punta de proyectil & Xilópalo & Indeterminada & 25 & 16,1 & 3,1 \\
\hline & 71 & Punta de proyectil & Xilópalo & Indeterminada & 34,4 & 17,1 & 2,9 \\
\hline & 72 & Punta de proyectil & Calcedonia & Indeterminada & 21,2 & 15 & 3,2 \\
\hline & 76 & Punta de proyectil & Sílice & Indeterminada & 14,1 & 18 & 3,3 \\
\hline & $\mathrm{Sn}$ & Punta burilante & Calcedonia & Lasca mediana & 39,4 & 16,6 & 8,2 \\
\hline & $\mathrm{Sn}$ & Punta destacada & Calcedonia & Microlasca & 19 & 19 & 10 \\
\hline & $\mathrm{Sn}$ & Retoque sumario & Obsidiana & Lasca pequeña & 22 & 22,4 & 7,4 \\
\hline & $\mathrm{Sn}$ & Peso lítico & Basalto & Rodado pequeño & 56,9 & 42,7 & 14,6 \\
\hline \multirow{4}{*}{ Corm 3 F1 } & 1 & Perforador & Sílice & Lasca grande & 58,9 & 24,3 & 11,4 \\
\hline & 2 & Raspador frontal y filo retocado & calcedonia & Lámina mediana & 56,1 & 18,3 & 4,4 \\
\hline & 4 & Cortante y punta entre muesca & calcedonia & Lasca pequeña & 35 & 42,6 & 10,4 \\
\hline & 5 & Preforma bifacial & Basalto & Lasca pequeña & 21 & 24,5 & 22,9 \\
\hline
\end{tabular}

Tabla 7.38. Localidad Punta Cormoranes: características de los artefactos tallados. 


\begin{tabular}{|c|c|c|c|c|c|c|c|c|c|}
\hline Sitio & $\begin{array}{l}\mathrm{N}^{\mathrm{o}} \\
\mathrm{Inv}\end{array}$ & Subgrupo & Serie Técnica & Sit lasc. & F. G.Contorno & Posic. Filo & F.Lasc. & Filo & Estado \\
\hline LOll 1C1 & 19 & Punta burilante & Retoque marginal & Unifacial & Indeterminada & Frontal & Marginal corto & -- & Fracturada \\
\hline \multirow{8}{*}{$\begin{array}{c}\text { LOll } 1 \\
\text { M1 }\end{array}$} & 69 & Punta de proyectil & Retoque extendido & Bifacial & Triangular alargada & Frontal & Paralelo transversal & -- & nc \\
\hline & 71 & Punta de proyectil & Retoque extendido & Bifacial & Triangular alargada & Frontal & Paralelo transversal & -- & nc \\
\hline & 72 & Punta de proyectil & $\begin{array}{l}\text { Microrretoque } \\
\text { extendido }\end{array}$ & Bifacial & Triangular corta & Frontal & Escamoso extendido & -- & nc \\
\hline & 76 & Punta de proyectil & Retoque extendido & Bifacial & Triangular corta & Frontal & Escamoso extendido & $\mathrm{nc}$ & -- \\
\hline & sn & Punta burilante & Retoque marginal & Unifacial & Triangular irregular & $\begin{array}{l}\text { Fronto } \\
\text { lateral }\end{array}$ & Marginal corto & $\mathrm{nc}$ & Activo \\
\hline & sn & Punta destacada & $\begin{array}{l}\text { Microrretoque } \\
\text { restringido }\end{array}$ & Unifacial & Rectangular & Frontal & $\begin{array}{l}\text { Paralelo corto } \\
\text { irregular }\end{array}$ & $\mathrm{nc}$ & Activo \\
\hline & $\mathrm{Sn}$ & Retoque sumario & Retoque marginal & Unifacial & Indeterminada & Lateral & Marginal corto & -- & Agotado \\
\hline & $\mathrm{Sn}$ & Peso lítico & Talla simple & Unifacial & Circular & -- & Talla & -- & -- \\
\hline \multirow{4}{*}{$\begin{array}{c}\text { Corm } 3 \\
\text { F1 }\end{array}$} & 1 & Perforador & Lascado simple & Bifacial & $\begin{array}{l}\text { Amigdoloide } \\
\text { irregular }\end{array}$ & Frontal & Marginal corto & -- & Activo \\
\hline & 2 & $\begin{array}{l}\text { Raspador y filo } \\
\text { retocado }\end{array}$ & $\begin{array}{l}\text { Microrretoque } \\
\text { marginal }\end{array}$ & Unifacial & Elíptica irregular & Frontal & Marginal corto & $55^{\circ}$ & Activo \\
\hline & 4 & $\begin{array}{l}\text { Cortante y punta } \\
\text { entre muesca }\end{array}$ & $\begin{array}{l}\text { Microrretoque } \\
\text { marginal }\end{array}$ & Unifacial & Rectangular & Frontal & Marginal corto & -- & Activo \\
\hline & 5 & Preforma bifacial? & Retoque marginal & Bifacial & Triangular irregular & -- & Escamoso regular & $35^{\circ}$ & -- \\
\hline
\end{tabular}

Tabla 7.39. Localidad Punta Cormoranes: Rasgos morfotécnicos de los artefactos tallados. Referencias: Sit. Lascados: situación de los lascados; F. Geom.: forma geométrica, Posic.Fil: Posición del filo; F.Lasc. Forma de los lascados; Áng. Ángulo del filo; restr. Restringido; Unif: Unificial; Indet: indeterminado. 


\section{Lascas con rastros complementarios}

En el conjunto artefactual de LO1l 1 M1 se recuperaron dos lascas pequeñas con rastros complementarios de calcedonia y de xilópalo, ambas materias primas de muy buena calidad para la talla. Para el muestreo de Corm 3 F1 el único rastro complementario se identificó sobre una lasca de tamaño mediano de xilópalo de muy buena aptitud para la talla.

\section{Núcleos}

Los seis núcleos de LO11 1 M1 provienen de rodados locales de muy buena calidad y tamaño pequeño, de los cuales cuatro son de sílices y los dos restantes de basalto. En cuanto a la morfología de los núcleos prevalecen los bipolares $(\mathrm{n}=4)$ y menor proporción los de lascados asilados $(n=2)$. De todos los núcleos se extrajeron lascas y los seis se encuentran agotados. El único núcleo rescatado del Fogón 1 de Corm 3 proviene de un rodado de basalto de tamaño pequeño y de muy buena calidad para la talla. La morfología es bipolar y se encuentra agotado (Tabla 7.40).

\begin{tabular}{|c|c|c|c|c|c|c|c|c|}
\hline Sitio & M prima & Tipo & $\begin{array}{l}\mathbf{N}^{0} \text { mín } \\
\text { p.p }\end{array}$ & $\begin{array}{l}\text { F. sup } \\
\text { p. perc. }\end{array}$ & $\mathrm{N}^{0}$ lasc. & $\begin{array}{l}\text { F. negat } \\
\text { lasc }\end{array}$ & $\begin{array}{l}\text { Grado } \\
\text { modif }\end{array}$ & Estado \\
\hline \multirow{6}{*}{$\begin{array}{l}\bar{\Sigma} \\
\overline{\bar{\sigma}}\end{array}$} & Sílice & Bipolar & 2 & Cortical & 4 & Lascas & Alto & Agotado \\
\hline & Sílice & Bipolar & 2 & Cortical & 4 & Lascas & Alto & Agotado \\
\hline & Sílice & Bipolar & 2 & Cortical & 4 & Lascas & Alto & Agotado \\
\hline & Sílice & Bipolar & 2 & Cortical & 4 & Lascas & Alto & Agotado \\
\hline & Basalto & Lasc.aisl & 2 & Cortical & 2 & Lascas & Alto & Agotado \\
\hline & Basalto & Lasc.aisl & 2 & Cortical & 2 & Lascas & Alto & Agotado \\
\hline 㩆 & Basalto & Bipolar & 2 & Liso & 3 & Lascas & Alto & Agotado \\
\hline
\end{tabular}

Tabla 7.40. Localidad Punta Cormoranes: características morfológicas y técnicas de los núcleos.

\section{Artefactos formatizados por picado y pulido}

Para LOll 1 M1 se registró la presencia de dos bolas de boleadora: una de basalto y de tamaño grande y la otra de hematita y tamaño pequeño. Las dos presentan surco ecuatorial.

\section{Artefactos modificados por el uso}

En LOll 1 M1 se recuperaron dos fragmentos de areniscas consolidadas, que probablemente formen parte de un sobador. En relación con el conjunto artefactual de Corm 3 F1 se hallaron seis piedras de fogón, con evidencias de daño y fracturas térmicas. Cuatro de ellas provienen derodados grandes a muy grandes de riolitas, mientras que las dos restantes corresponden a dos rodados grandes de ignimbritas. 


\section{Ecofactos}

Solo se registraron en LOll $1 \mathrm{M}$. Se trata de un fragmento de rodado de cuarcita sin evidencias de modificación antrópica, y un nódulo de tamaño grande de basalto vesicular, cuya función se desconoce.

\section{Índice de fractura}

En LOll1 C1 el total de artefactos con presencia de fracturas es de 3/9; en LOll 1 M1 el total de piezas fracturadas es de $25(29,4 \%)$ y en Corm 3 F1 de 6 sobre un total de 11 artefactos (Tabla 7.41)

\begin{tabular}{|c|c|c|c|}
\hline \multirow{2}{*}{ Clase Tipológica } & \multicolumn{3}{|c|}{ Con fractura } \\
\cline { 2 - 4 } & LOll 1 C1 & LOll 1M1 & Corm 3 F1 \\
\hline Artefacto formatizado por P y P & -- & 1 & -- \\
\hline Artefacto modificado por el uso & -- & 2 & 6 \\
\hline Desechos de talla & 2 & 18 & -- \\
\hline Ecofactos & -- & -- & -- \\
\hline Artefactos Formatizados por talla & 1 & 3 & -- \\
\hline Rastros complementarios & -- & 1 & -- \\
\hline Núcleos & -- & -- & -- \\
\hline N & $\mathbf{3}$ & $\mathbf{2 5}$ & $\mathbf{6}$ \\
\hline $\mathbf{\%}$ & -- & $\mathbf{2 9 , 4}$ & -- \\
\hline
\end{tabular}

Tabla 7.41. Localidad Punta Cormoranes: frecuencia de fracturas por clase tipológica. Referencias: Artefacto formatizado por P y P: artefacto formatizado por picado y pulido.

\section{Relaciones de ensamblaje}

En ninguno de los tres muestreos se logró efectuar relaciones de ensamblaje entre las piezas.

\section{Frecuencia de módulos laminares, bipolaridad y bifacialidad:}

En el conjunto de LOll 1 M1 la bipolaridad está presente en 16\% $(n=13)$ de los artefactos (mayoritariamente lascas y núcleos); mientras que la bifacialidad $(n=4)$ se presenta en frecuencias más bajas $(4,9 \%)$ y se restringe a las puntas de proyectil. No se registraron módulos laminares. En Corm 3 la bipolaridad se identificó en un núcleo (1/11 artefactos), la bifacialidad en dos instrumentos (2/11) y la módulos laminares en un solo artefacto (1/11). 


\section{Tendencias generales de los conjuntos líticos de la localidad arqueológica Punta Cormoranes}

En cuanto a los muestreos analizados del sitio Las Ollas 1 (LOll 1 C1 y LOll 1 M1) el estudio tecnológico señaló diferencias y similitudes entre los conjuntos artefactuales. Por una parte, el sitio de superficie -LOll 1M1- mostró una densidad artefactual alta $\left(2,71 \mathrm{dm}^{2}\right)$ y la mayor diversidad artefactual, ya que se encuentran representadas todas las clases. Se determinó el uso de distintos tipos de rocas, aunque con un claro predominio de basalto y en menor proporción de calcedonias. Entre las no locales se registraron obsidianas, hematitas y basalto vesicular- que indican circulación de materias primas entre 100 y $300 \mathrm{~km}$ (Gómez Otero et al. 1999). En cuanto a los desechos de talla, sobresalen los de basalto y están representados por distintos tipos de lascas, entre ellas bipolares, primarias y con dorso natural. Estas evidencias, sumadas al alto porcentaje de talones corticales, permiten inferir que se trata de un taller de reducción de nódulos locales de basalto. Entre los instrumentos tallados predominan las puntas de proyectil microlíticas, todas ellas confeccionadas sobre rocas de excelente calidad; el único artefacto de basalto es el peso lítico sobre rodado pequeño, lo que indicaría el uso expeditivo de esta materia prima. Un sitio con características similares e interpretado como un taller de producción de puntas pedunculadas de basalto, fue registrado en la localidad de San Pablo (Gómez Otero et al. 1999), a menos de $25 \mathrm{~km}$ de distancia.

Por el contrario, en el conchero 1 la densidad artefactual es muy baja $\left(0,06 / \mathrm{dm}^{3}\right)$ y está representada por unos pocos desechos de talla de tamaños pequeños. Entre las materias primas también sobresale el basalto y en menor frecuencia calcedonias y sílices. Dado el escaso número de $\operatorname{artefactos}(n=3)$, que representan-sólo dos clases artefactuales (dos desechos y un solo instrumento tallado), no se puede probar la ejecución simultánea, en el mismo espacio, de consumo de moluscos y actividades de talla. De acuerdo con el tamaño muy pequeño de los artefactos, es probable que hayan ingresado al sitio por factores post-depositacionales (Shelley y Nails 1986; Camuffo 1995; Wandsnider 1988; Bonomo 2004; Borrazzo 2009 entre otros), y que posteriormente hayan quedado "atrapados" entre los restos de valvas y la matríz sedimentaria. Para el caso de la punta triédrica, la presencia de fracturas en la pieza sugiere que fue descartada en el lugar.

En síntesis, el registro arqueológico de Las Ollas permite sostener que la localidad funcionó como un campamento residencial (Gómez Otero 2006) donde se llevaron a cabo distintas actividades, entre ellas el procesamiento y consumo de recursos faunísticos y vegetales, la recolección y descarte de moluscos y también la talla in situ de artefactos líticos. Por su parte, 
la presencia de distintos rasgos de ocupación como en el conchero y el taller lítico de basalto indicarían una estructuración espacial de las actividades. No obstante, dada la posición topográfica más elevada y la mayor distancia al mar del muestreo 1 respecto del conchero, no se descarta que el primero corresponda a un sitio más antiguo. Cabe mencionar que en este muestreo casi la totalidad de los artefactos de basalto presentan pátina y lustre, que podrían indicar más tiempo de exposición a los agentes naturales, como la acción eólica que moviliza granos de arena que pueden producir pulido sobre los materiales líticos. Por último y de acuerdo con el hallazgo de por lo menos ocho vasijas y de dos molinos planos, se propuso que esta localidad habría sido utilizada de manera planificada y reiterada a lo largo del tiempo, y que estos artefactos habrían sido dejados en los sitios como equipamiento del espacio (Gómez Otero 2006; Gómez Otero et al. 1999). La presencia de huesos quemados de pingüino (Spheniscus sp.) permite inferir estacionalidad centrada en primavera.

En cuanto al sitio Cormoranes 3 las escasas evidencias artefactuales corresponden a materias primas líticas locales de calidad regular, entre ellas las gravas de riolitas que fueron aprovechadas como piedras de fogón, y también por otras rocas de calidad superior -calcedonia, xilópalos y basalto- representadas solo en los tres instrumentos tallados. No se recuperaron desechos de talla y solo se registró un núcleo pequeño de basalto. Por lo tanto es factible que los instrumentos terminados hayan sido transportados hacia el lugar como parte del equipamiento personal. En suma, para el muestreo de Corm 3, la ausencia de restos faunísticos y la muy baja presencia de artefactos líticos $\left(0,14 \mathrm{dm}^{2}\right)$ permiten corroborar las inferencias realizadas por Gómez Otero (2006) respecto de la funcionalidad del sitio. En este sentido, se propuso que se trataría de un lugar de paso, tipo "estación” (sensu Binford 1980) donde se llevó a cabo el aprovisionamiento de rodados grandes (que sólo están disponibles en lugares restringidos de la península) por parte de pequeñas partidas que aprovechaban de paso los recursos marinos y terrestres del lugar.

\section{Localidad arqueológica San Pablo}

Se encuentra entre el sector costero que abarca desde punta Alta hasta punta Pardelas, caracterizado por la presencia de campos de médanos vivos y playas formadas por cordones litorales (Fig. 7.25 y 7.26). En el año 1998 Gómez Otero y equipo prospectaron el área e identificaron un sitio arqueológico (San Pablo 1) y la presencia de un taller de manufactura de puntas de proyectil pedunculadas de basalto (Gómez Otero et al. 1999). En el año 2012 a pedido de la Fundación Vida Silvestre se llevó a cabo un estudio de base arqueológica. Se realizaron 
dos nuevas campañas y se registró un total de diez sitios arqueológicos ${ }^{4}$, cuyos estudios específicos permitieron determinar la presencia de ocupaciones de distinta antigüedad -entre $400 \pm 50$ años $C^{14}$ AP y $2930 \pm 60$ años $C^{14}$ AP- y funcionalidad, entre ellos bases residenciales, un basural, un taller de xilópalo, concentraciones de piezas cerámicas, una disposición artificial de huesos de guanaco y dos enterratorios humanos: uno múltiple de alrededor de tres mil años de antigüedad, y uno individual, no datado (Fig. 7.25). Los sitios se encontraban, en su gran mayoría, altamente impactados por procesos naturales y antrópicos, entre los primeros se encuentran la erosión eólica e hídrica, el pisoteo por parte de animales de gran porte como los guanacos, la bioturbación por roedores, la destrucción por el tránsito de cuatriciclos y la recolección por parte de aficionados y coleccionistas.

Para esta tesis se analizaron los sitios San Pablo 4 Muestreo 3 y San Pablo 6 CC2 M2.

\begin{tabular}{|c|c|c|c|c|c|c|}
\hline Sitio & Lat/Long & $\begin{array}{c}\text { Altura } \\
\text { s.n.m }\end{array}$ & $\begin{array}{l}\text { Dist. } \\
\text { mar }\end{array}$ & Edad $C^{14}$ & Muestra & Lab. \\
\hline $\begin{array}{c}\text { San Pablo } 4 \\
\text { sector } 1\end{array}$ & \multirow{2}{*}{$\begin{array}{l}42^{\circ} 37^{\prime} 51.3^{\prime \prime} \mathrm{S} \\
64^{\circ} 11^{\prime} 28.7^{\prime \prime} \mathrm{O}\end{array}$} & \multirow{2}{*}{$10-14 \mathrm{~m}$} & \multirow{2}{*}{$1500 \mathrm{~m}$} & $2780 \pm 90$ & Óseo humano & LP-2899 \\
\hline $\begin{array}{c}\text { San Pablo } 4 \\
\text { sector } 2\end{array}$ & & & & $2930 \pm 60$ & Guanaco & LP-2890 \\
\hline San Pablo 6 & $\begin{array}{l}42^{\circ} 37^{\prime} 57.9^{\prime \prime} \mathrm{S} \\
64^{\circ} 12^{\prime} 20.4^{\prime \prime} \mathrm{O}\end{array}$ & $3 \mathrm{~m}$ & $500 \mathrm{~m}$ & $400 \pm 50$ & Carbón & LP-2807 \\
\hline
\end{tabular}

Tabla 7.42. Localidad San Pablo: localización y fechados obtenidos de los concheros Referencias: Dist. Distancia; Lab. Laboratorio. Datos obtenidos de Gómez Otero et al. 2013.

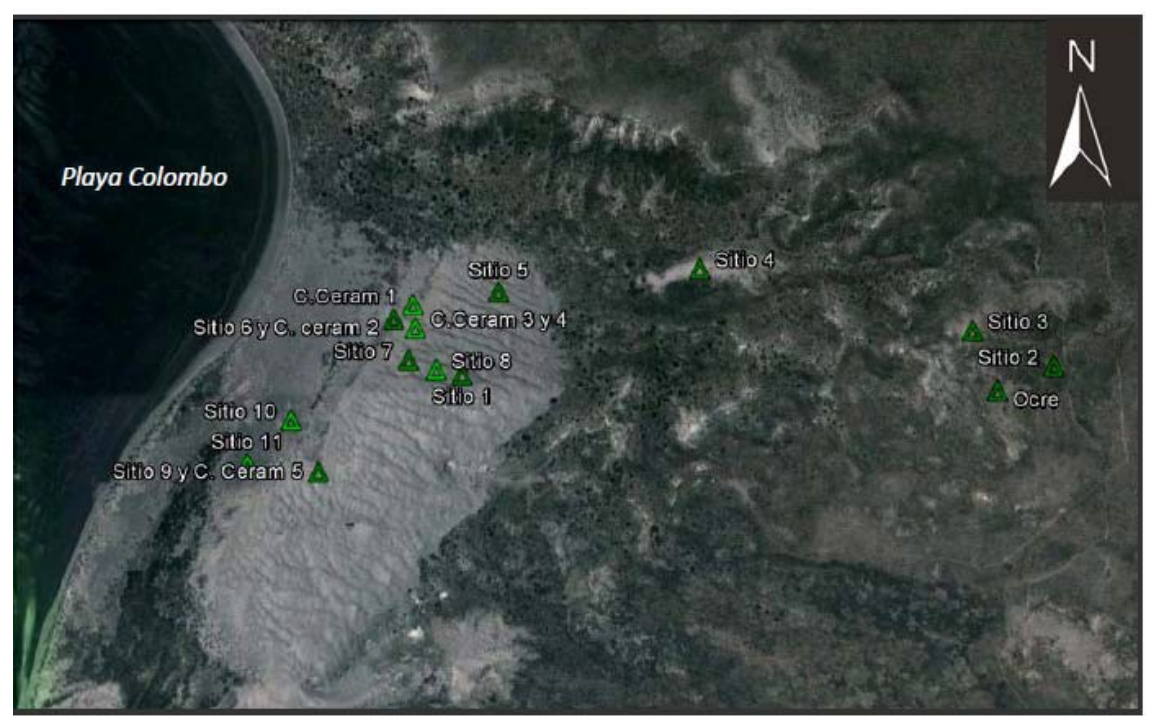

Fig. 7.25. Ubicación de los sitios arqueológicos registrados durante la campaña arqueológica de abril de 2012 (tomado de Gómez Otero et al. 2012).

\footnotetext{
${ }^{4}$ En los trabajos de campo participaron integrantes del laboratorio de arqueología del Instituto de Diversidad y Evolución Austral (IDEAus-CENPAT), conformado por Ariana Svoboda, Soledad Goye, Delfina Palleres, Verónica Schuster, Roberto Taylor y Mariano Reyes, bajo la dirección de la Dra. Julieta Gómez Otero. El estudio geomorfológico fue realizado por la geológa de costas Dra. Nilda Weiler.
} 


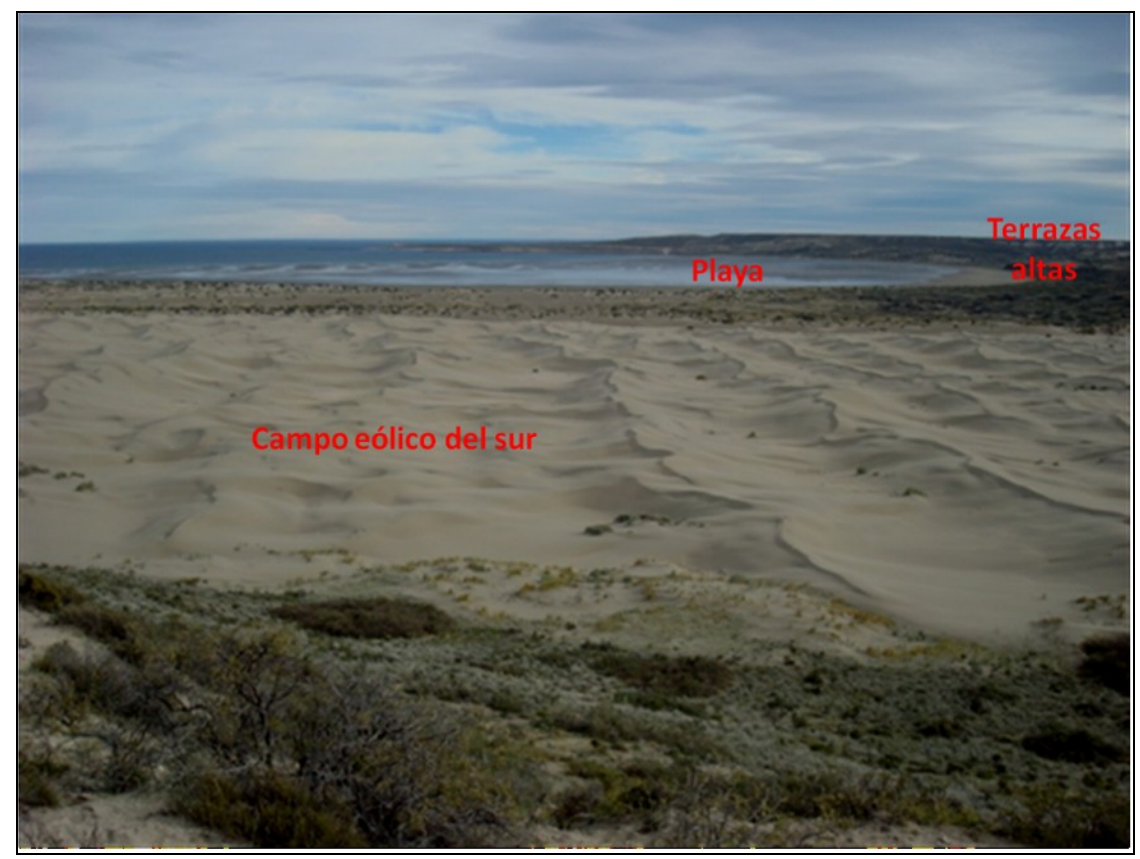

Fig. 7.26 Vista general de lo Localidad Punta Alta: campo eólico de dunas, sector de playa y terrazas altas.

\section{San Pablo 4}

Se trata de un sitio de superficie sobre una amplia hoyada de 240 × 56 metros, entre médanos vivos y vegetados por Sporobolus, Hyalix y Festuca gracillima (coirón) (Fig. 7.27). El sustrato está formado por arena gruesa suelta entremezclada con numerosos fragmentos de valvas de gasterópodos y bivalvos de distintos taxones y tamaños, cirripedios (Balanus sp. y Megabalanus sp.); erizos (Pseudechinus magallanicus), cangrejos (Ovalipes trimaculatus y Platyxanthus patagonicus) entre otros. También se observaron restos de huesos de cetáceos. Sobre el este y norte de la hoyada se visualizó un nivel de ceniza volcánica. La presencia de esta enorme cantidad de valvas de moluscos -la mayoría muy pequeñas $\mathrm{y}$, por lo tanto no aprovechables por los humanos-, sumada a la altura y distancia del sitio con respecto a la actual línea de costa, permiten estimar que esta habría sido una playa antigua, probablemente formada durante la máxima transgresión del Holoceno medio (7000 años AP) (Gómez Otero et al. 2012). Se practicaron tres muestreos en diversos sectores de la hoyada:

Muestreo 1: de artefactos líticos de 4 metros de lado;

Muestreo 2: de dos metros de lado sobre una concentración de valvas de mitílidos;

Muestreo 3: de dos metros de lado sobre una concentración de valvas y huesos. 
Para todos los muestreos se utilizó zaranda de malla fina $(1 \mathrm{~mm})$. También se realizaron sondeos al azar -no registrándose materiales en estratigrafía- y una recolección asistemática de materiales de todo tipo. Se obtuvieron dos dataciones radiocarbónicas: $2780 \pm 90$ años ${ }^{14} \mathrm{C}$ para un hueso humano hallado en el Sector 1 , y de $2930 \pm 60$ años ${ }^{14} \mathrm{C}$ para un hueso de guanaco del Sector 2 (Tabla 7.42). Para esta tesis se analizó el material lítico del muestreo 3. Por fuera del muestreo se registraron percutores sobre rodados grandes, yunques, sobadores, pesos líticos, cepillos, mano de molienda, un molino plano muy grande sobre areniscas consolidadas y fragmentos de piedras quemadas. También se halló una punta microlítica pedunculada.
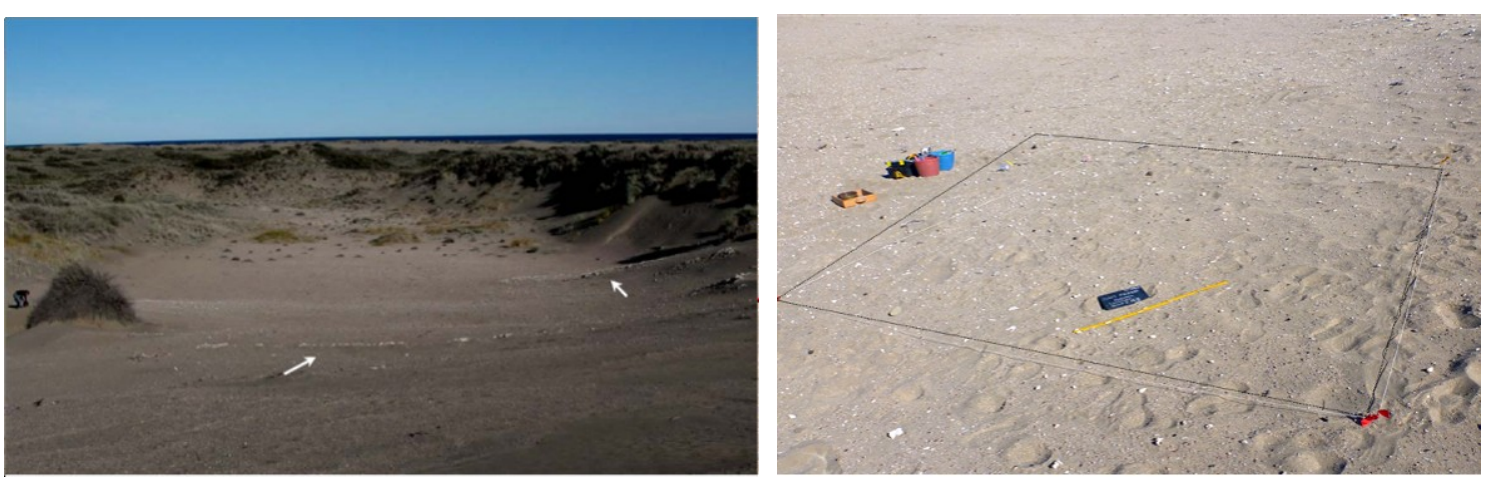

Fig. 7.27. (A): vista general del sitio San Pablo 4 (las flechas indican los sectores con restos humanos y las concentraciones líticas) y (B): Detalle del Muestreo 3.

\section{San Pablo 6}

Se ubica en una laguna costera enmarcada por dos cordones de médanos vivos paralelos a la costa, a 3 m s.n.m. y a $500 \mathrm{~m}$ de la línea de costa actual. Durante las mareas extraordinarias el mar penetra e inunda esta playa, dejando sobre la misma diversos organismos marinos pequeños, como moluscos, cirripedios y cangrejos (Gómez Otero et al. 2013). El sitio completo se extiende en un área de 60 × 20 m, que contiene diferentes rasgos de ocupación como una acumulación discreta $(15 \mathrm{~m} \times 5 \mathrm{~m})$ de restos faunísticos quemados mezclados con artefactos líticos y tiestos; cuatro concentraciones de fragmentos cerámicos y material lítico disperso. La acumulación de restos faunísticos presenta una alta y destacada visibilidad en el paisaje debido a la potencia y a la coloración oscura de los huesos quemados (Fig.7.28). Entre los materiales arqueofaunísticos hay restos de peces (túnido), guanaco (Lama guanicoe), pinnípedos (Otaria flavescens y Arctocephalus australis) representados por todas las partes del esqueleto, aves marinas (Phalacrocorax y Spheniscus magellanicus), cetáceos indeterminados y dasipódidos (Svoboda, 2015, com. pers.). Se estudió el muestreo SPablo 6 CC2M2, de $2 \mathrm{~m}$ x $2 \mathrm{~m}$ x $4 \mathrm{~cm}$ de profundidad (Fig. 7.28), cuyos materiales faunísticos fueron estudiados por Ariadna Svoboda y 
la cerámica está en proceso de análisis por Verónica Schuster. Se obtuvo una datación de carbón del Muestreo 1 que arrojó una edad de $400 \pm 50$ años $\mathrm{C}^{14} \mathrm{AP}$ (Tabla 7.42)
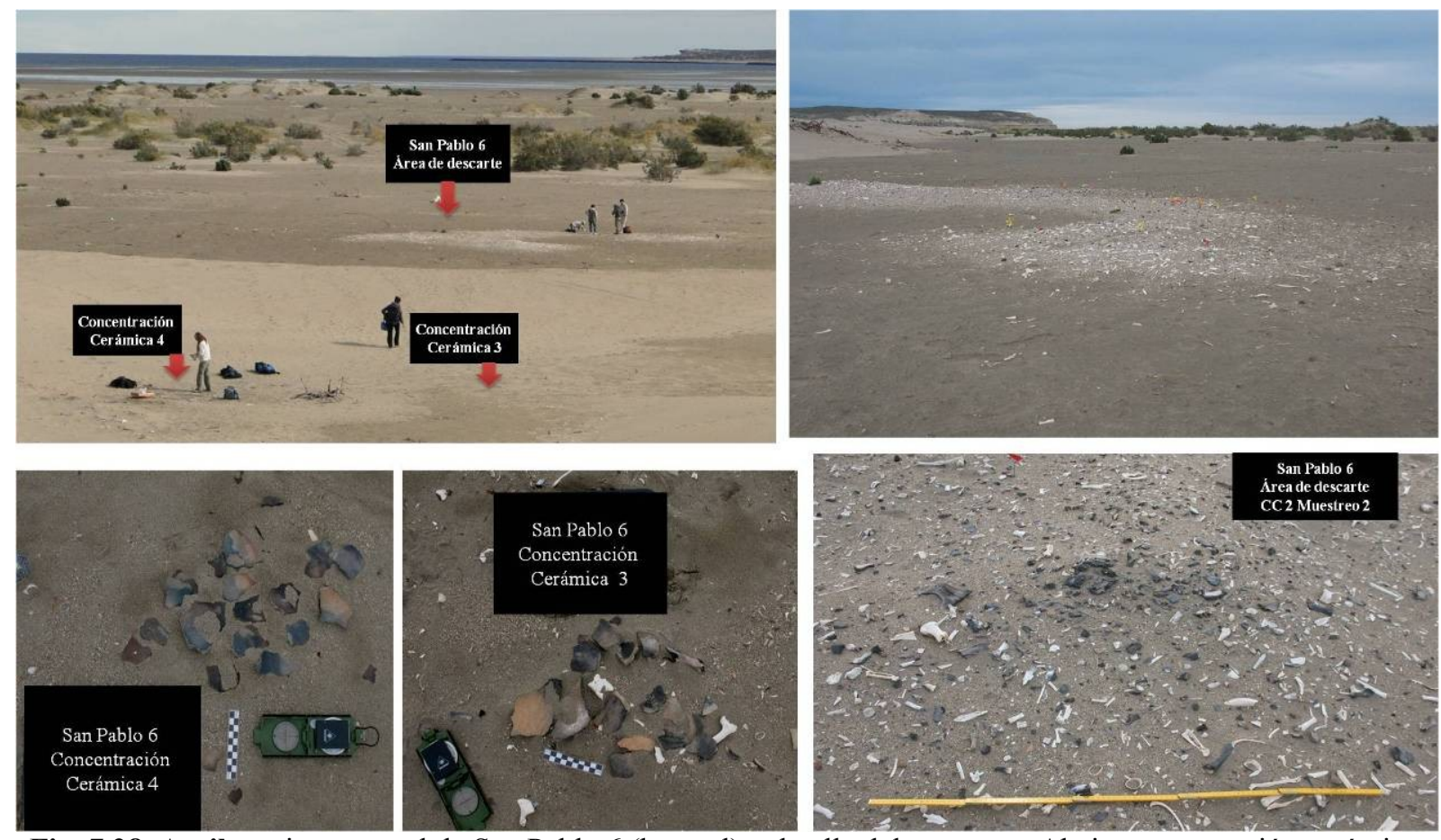

Fig. 7.28. Arriba: vista general de San Pablo 6 (basural) y detalle del muestreo. Abajo concentración cerámica 3 (izquierda) y concentración cerámica 4 (derecha).

\section{Análisis tecnológico}

En el Muestreo 3 de San Pablo 4 (en adelante SP 4 M3) el total de artefactos líticos recuperados es de 101 y la densidad de $2,57 / \mathrm{dm}^{2}$. En el muestreo 2 de la Concentración cerámica 2 de San Pablo 6 (SP 6 CC2 M2) los artefactos líticos suman un total de 61 $\left(0,038 / \mathrm{dm}^{3}\right)$.

\section{Materias primas:}

Para el conjunto artefactual de SP 4 M3 se determinaron ocho variedades litológicas y dos rocas indeterminadas. Sobresale el basalto $(60 \%)$ y en segundo lugar las sílices $(17,5 \%)$ y las calcedonias (14\%). El resto de las materias primas -xilópalos, obsidianas, cuarcitas y tobasse encuentra en muy baja proporción (entre 1\% y 6\%). En SP6 CC2 M2 las clases de rocas identificadas son siete, siendo mayoritaria la proporción de calcedonias (34\%) y sílices (22\%), le siguen en orden de importancia ópalos (12\%), basaltos y andesitas (10\% cada una), riolita (7 \%) y xilópalo (5 \%) (Tabla 7. 43).

Con excepción de las obsidianas, las calcedonias y los xilópalos, que son rocas foráneas de excelente calidad, el resto de las materias primas son locales y se encuentran disponibles en 
forma de rodados de buena calidad para la talla. Los fragmentos de andesita de un rodado de tamaño grande proceden de los cordones de la Caleta Valdés.

En relación con la presencia de alteraciones post-depositacionales en la superficie de las rocas, en el conjunto artefactual de San Pablo 4 M3, 37 desechos de talla $(36,6 \%)$ todos de basalto, presentan lustre. Para los artefactos del muestreo de Pablo 6 CC2 M2 el total de artefactos con daño térmico es de seis (14,6\%): los tres fragmentos de rocas de andesita y dos lascas y un núcleo pequeño de calcedonia. Se registró además carbonatación en dos artefactos de basalto $(4,8 \%)$.

\begin{tabular}{|c|c|c|c|c|}
\hline \multirow{2}{*}{ Materias primas } & \multicolumn{2}{|c|}{ SP 4 M3 } & \multicolumn{2}{c|}{ SP 6 CC2 M2 } \\
\cline { 2 - 5 } & $\mathbf{N}$ & $\mathbf{\%}$ & $\mathbf{N}$ & $\mathbf{\%}$ \\
\hline Basalto & 56 & 54,4 & 4 & 9,8 \\
\hline Andesita & -- & -- & 4 & 9,8 \\
\hline Calcedonia & 14 & 13,6 & 14 & 34,1 \\
\hline Cuarcita & 1 & 1 & -- & -- \\
\hline Obsidiana verde & 3 & 1,9 & -- & -- \\
\hline Obsidiana negra & 1 & 1 & -- & -- \\
\hline Ópalo & -- & -- & 5 & 12,2 \\
\hline Riolita & -- & -- & 3 & 7,3 \\
\hline Sílice & 18 & 17,5 & 9 & 22 \\
\hline Toba & 3 & 2,9 & -- & -- \\
\hline Xilópalo & 6 & 5,8 & 2 & 4,9 \\
\hline Indeterminada & 2 & 1,9 & -- & -- \\
\hline Total & $\mathbf{1 0 1}$ & $\mathbf{1 0 0}$ & $\mathbf{4 1}$ & $\mathbf{1 0 0}$ \\
\hline
\end{tabular}

Tabla 7.43. Localidad San Pablo: tipos y frecuencias de las variedades litológicas.

\section{Clases artefactuales:}

Para SP 4 M3 predominan los desechos de talla $(82,9 \%)$, seguidos por los instrumentos tallados $(8,5 \%)$, las lascas con rastros complementarios $(4,2 \%)$ y por último los núcleos y ecofactos (2,1\% cada uno). En SP 6 CC2 M2 también son mayoría los desechos de talla ( $83 \%$ ) y los instrumentos tallados (10\%), las clases artefactuales restantes están representados por una o dos piezas $(1,7 \%$ y $3,4 \%$ respectivamente) (Tabla 7.44$)$. 


\begin{tabular}{|c|c|c|c|c|c|c|c|}
\hline \multirow[t]{2}{*}{ Clases } & \multirow[t]{2}{*}{ Núcleos } & \multirow[t]{2}{*}{ Desechos } & \multicolumn{4}{|c|}{ Instrumentos } & \multirow[t]{2}{*}{ Ecofactos } \\
\hline & & & $\begin{array}{l}\text { Art.Form } \\
\text { por talla }\end{array}$ & $\begin{array}{c}\text { Rastros } \\
\text { complement. }\end{array}$ & $\begin{array}{c}\text { Art.For } \\
\text { PyP. }\end{array}$ & $\begin{array}{c}\text { Art. M. } \\
\text { uso }\end{array}$ & \\
\hline \multicolumn{8}{|l|}{ SP 4 M3 } \\
\hline $\mathrm{N}$ & 2 & 85 & 8 & 4 & -- & -- & 2 \\
\hline$\%$ & 1,9 & 84,1 & 7,9 & 3,9 & -- & -- & 1,9 \\
\hline \multicolumn{8}{|l|}{ SP 6 CC2 } \\
\hline $\mathrm{N}$ & 1 & 50 & 6 & -- & 2 & -- & 1 \\
\hline$\%$ & 1,7 & 83,3 & 10 & & 1,7 & & 1,7 \\
\hline
\end{tabular}

Tabla 7.44. Localidad San Pablo: distribución de las clases tipológicas. Referencias: Art. Artefactos; complemento: complementarios; Form. Formatizado; PyP: picado y pulido; M. Modificado.

\section{Desechos de talla:}

En SP 4 M3 poco más de la mitad son desechos enteros (55: 64,7\%), seguidos por las lascas fracturadas con talón (12: 14\%) y por último los desechos no clasificables (11: 13\%) y las lascas fracturadas sin talón (7: 8\%). Los tipos de lascas más representadas son las de arista inclinada $(19 \%)$, de dorso natural $(16 \%)$ y las primarias $(12 \%)$. Le siguen en orden de importancia las de arista oblicua y bipolares $(9,5 \%$ cada una) y las de arista recta (8\%). El resto se encuentran en muy baja frecuencia (entre 5,4\% y 1,4\%) (Tabla 7.45). En SP6 CC2 M2 prevalecen los desechos no clasificables (20: 40\%), varios de ellos por fractura y de tamaño muy pequeño (hipermicrolascas), elaborados en calcedonias y sílices; le siguen las lascas fracturadas con talón (17: 34\%) y por último las enteras (13: 26\%). Esto se traduce en un alto porcentaje de fractura en ambos sitios (25,6\% y 56,6\% respectivamente). Los tipos de lascas predominantes se reparten en proporciones parejas entre oblicuas, secundarias y de reactivación directa $(16,7 \%$ cada una) y primarias e indeterminadas (13, 3\% respectivamente); le siguen las de arista oblicua (10\%) y por último las primarias y las de reactivación inversa $(6,7 \%$ de cada una) (Tabla 7.45).

\begin{tabular}{|c|c|c|c|c|}
\hline \multirow{2}{*}{ Tipo de lascas } & \multicolumn{2}{|c|}{ SP 4 M3 } & \multicolumn{2}{c|}{ SP 6 CC2 M2 } \\
\cline { 2 - 5 } & $\mathbf{N}=$ & $\mathbf{\%}$ & $\mathbf{N}=$ & $\mathbf{\%}$ \\
\hline Punta de arista oblicua & 7 & 9,5 & 3 & 10 \\
\hline Punta de arista inclinada & 14 & 18,9 & 5 & 16,7 \\
\hline Con dorso natural & 12 & 16,2 & -- & -- \\
\hline De arista recta & 6 & 8,1 & 2 & 6,7 \\
\hline Primaria & 9 & 12,2 & 4 & 13,3 \\
\hline En cresta/flanco de núcleo & 1 & 1,4 & -- & -- \\
\hline Con dorso preparado & 2 & 2,7 & -- & -- \\
\hline Secundaria & 2 & 2,7 & 5 & 16,7 \\
\hline De reactivación directa & 4 & 5,4 & 5 & 16,7 \\
\hline De reactivación indirecta & -- & -- & 2 & 6,7 \\
\hline Lámina de arista doble & 2 & 2,7 & -- & -- \\
\hline
\end{tabular}




\begin{tabular}{|c|c|c|c|c|}
\hline Lámina secundaria & 2 & 2,7 & -- & -- \\
\hline Bipolar & 7 & 9,5 & -- & -- \\
\hline Indeterminada & 6 & 8,1 & 4 & 13,3 \\
\hline Total & $\mathbf{7 4}$ & $\mathbf{1 0 0 \%}$ & $\mathbf{3 0}$ & $\mathbf{1 0 0 \%}$ \\
\hline
\end{tabular}

Tabla7.45. Localidad San Pablo: tipos y frecuencias de tipo de lascas.

Respecto del tamaño, en SP4 M3 se destacan las microlascas (43\%), seguidas por las pequeñas (16\%) y las hipermicrolascas (12\%); el resto (entre $11 \%$ y $7 \%$ ) se distribuye entre microláminas, láminas pequeñas y por ultimo lascas medianas. El módulo con mayor porcentaje es el mediano normal aunque también se destaca el laminar (22\%); le siguen el mediano alargado (11\%) y por último el corto ancho (7\%) (Tabla 7.46). En SP 6 CC2 M2 prevalecen las hipermicrolascas $(70 \%)$ y en segundo lugar las microlascas $(16,7 \%)$, en baja frecuencia se ubican las medianas $(6,7 \%)$ y una sola es de tamaño pequeño $(3,3 \%)$. En todos los tamaños el modulo más representado es el mediano-normal $(76,6 \%)$ y el resto (mediano-alargado, corto ancho y laminar normal) no supera el 10\% (Tabla 7.46).

\begin{tabular}{|c|c|c|c|c|c|c|c|}
\hline & $\begin{array}{l}\text { Tamaño } \\
\text { Módulo }\end{array}$ & $\begin{array}{l}\text { Corto } \\
\text { ancho }\end{array}$ & $\begin{array}{c}\text { Laminar } \\
\text { normal }\end{array}$ & $\begin{array}{c}\text { Med. } \\
\text { alargado }\end{array}$ & $\begin{array}{c}\text { Med. } \\
\text { normal }\end{array}$ & \multicolumn{2}{|c|}{ Total } \\
\hline \multirow{8}{*}{$\begin{array}{l}\sum^{\infty} \\
\vec{\sigma} \\
\tilde{\sigma}\end{array}$} & Hipermicrolasca & -- & -- & -- & 9 & 9 & 12,2 \\
\hline & Microlasca & 5 & -- & 5 & 22 & 32 & 43,2 \\
\hline & Lasca pequeña & -- & -- & 2 & 10 & 12 & 16,2 \\
\hline & Lasca mediana & -- & -- & 1 & 4 & 5 & 6,8 \\
\hline & Microlámina & -- & 8 & -- & -- & 8 & 10,8 \\
\hline & Lámina pequeña & -- & 8 & -- & -- & 8 & 10,8 \\
\hline & $\mathbf{N}$ & 5 & 16 & 8 & 45 & \multirow{2}{*}{74} & \multirow[t]{2}{*}{100} \\
\hline & $\%$ & 6,8 & 21,6 & 10,8 & 60,8 & & \\
\hline \multirow{6}{*}{ 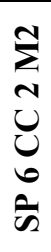 } & Hipermicrolasca & 2 & 1 & 2 & 16 & 21 & 70 \\
\hline & Microlasca & -- & -- & 1 & 4 & 5 & 16,7 \\
\hline & Lasca Pequeña & -- & -- & -- & 1 & 1 & 3,3 \\
\hline & Lasca mediana & -- & -- & -- & 2 & 2 & 6,6 \\
\hline & $\mathbf{N}$ & 2 & 1 & 3 & 23 & \multirow[t]{2}{*}{30} & \multirow[t]{2}{*}{100} \\
\hline & $\%$ & 6,7 & 3,3 & 10 & 76,6 & & \\
\hline
\end{tabular}

Tabla 7.46. Localidad San Pablo: tamaño y módulo largo/ancho de las lascas.

Para SP 4 M3 los talones más frecuentes son los lisos y filiformes (18\% cada uno) y los diedros (16\%), en segundo lugar los ausentes (11\%) e indeterminados $(8 \%)$ y por último los facetados y puntiformes (7\% cada uno) y corticales (4\%) (Tabla 7.47). En el Muestreo 2 de SP 6 CC2 los talones se distribuyen en filiformes (23\%) seguidos en proporciones iguales por los puntiformes y ausentes por una parte $(17 \%$ cada uno) y por otra, corticales, diedros e indeterminados (13\% cada uno). Solo re registró un talón liso (3\%) (Tabla 7.47). 


\begin{tabular}{|c|c|c|c|c|}
\hline \multirow{2}{*}{ Tipo de talón } & \multicolumn{2}{|c|}{ SP 4 M3 } & \multicolumn{2}{c|}{ SP 6 CC2 M2 } \\
\cline { 2 - 5 } & $\mathbf{N}$ & $\mathbf{\%}$ & $\mathbf{N}$ & $\mathbf{\%}$ \\
\hline Cortical & 3 & 4,1 & 4 & 13,3 \\
\hline Liso & 13 & 17,6 & 1 & 3,3 \\
\hline Diedro & 12 & 16,2 & 4 & 13,3 \\
\hline Facetado & 5 & 6,8 & -- & -- \\
\hline Filiforme & 13 & 17,6 & 7 & 23,3 \\
\hline Puntiforme & 5 & 6,8 & 5 & 16,7 \\
\hline Astillado & 9 & 12,2 & -- & -- \\
\hline Fracturado & -- & -- & -- & -- \\
\hline Ausente & 8 & 10,8 & 5 & 16,7 \\
\hline Indeterminado & 6 & 8,1 & 4 & 13,3 \\
\hline Totales & $\mathbf{7 4}$ & $\mathbf{1 0 0}$ & $\mathbf{3 0}$ & $\mathbf{1 0 0}$ \\
\hline
\end{tabular}

Tabla7.47 Localidad San Pablo: tipos y frecuencias de los talones.

\section{Artefactos formatizados por talla}

En el muestreo de SP4 M3 los instrumentos tallados ( $(n=8: 7,9 \%)$ se distribuyen en los siguientes grupos tipológicos: retoques sumarios $(n=3)$, puntas burilantes $(n=2)$, punta triédrica raspador y una probable raclette ( $\mathrm{n}=1$ de cada uno). Del total, tres corresponden a calcedonias, dos a sílices y el resto a xilópalo, ópalo y basalto (Fig. 7.29). Salvo calcedonias y el xilópalo de calidad superior, el resto de las materias primas son de muy buenas a buenas. En cuanto a los soportes tres corresponden a láminas medianas y una pequeña, y los restantes a lascas de distintas formas y tamaños (Tabla 7.48)

Para los instrumentos tallados de SP6 CC2 M2 (n= 6: 10\%) los subgrupos tipológicos se reparten en retoques sumarios $(n=3)$, una punta entre muesca, un fragmento de filo de raspador y un pedúnculo microlítico. Se destaca la selección de la calcedonia de excelente calidad para la manufactura de estos instrumentos, y también de xilópalo y basalto (Fig. 7.29). Las formas bases son predominantemente de tamaño pequeño entre ellas lascas bipolares y con dorso natural (Tabla 7.49). 


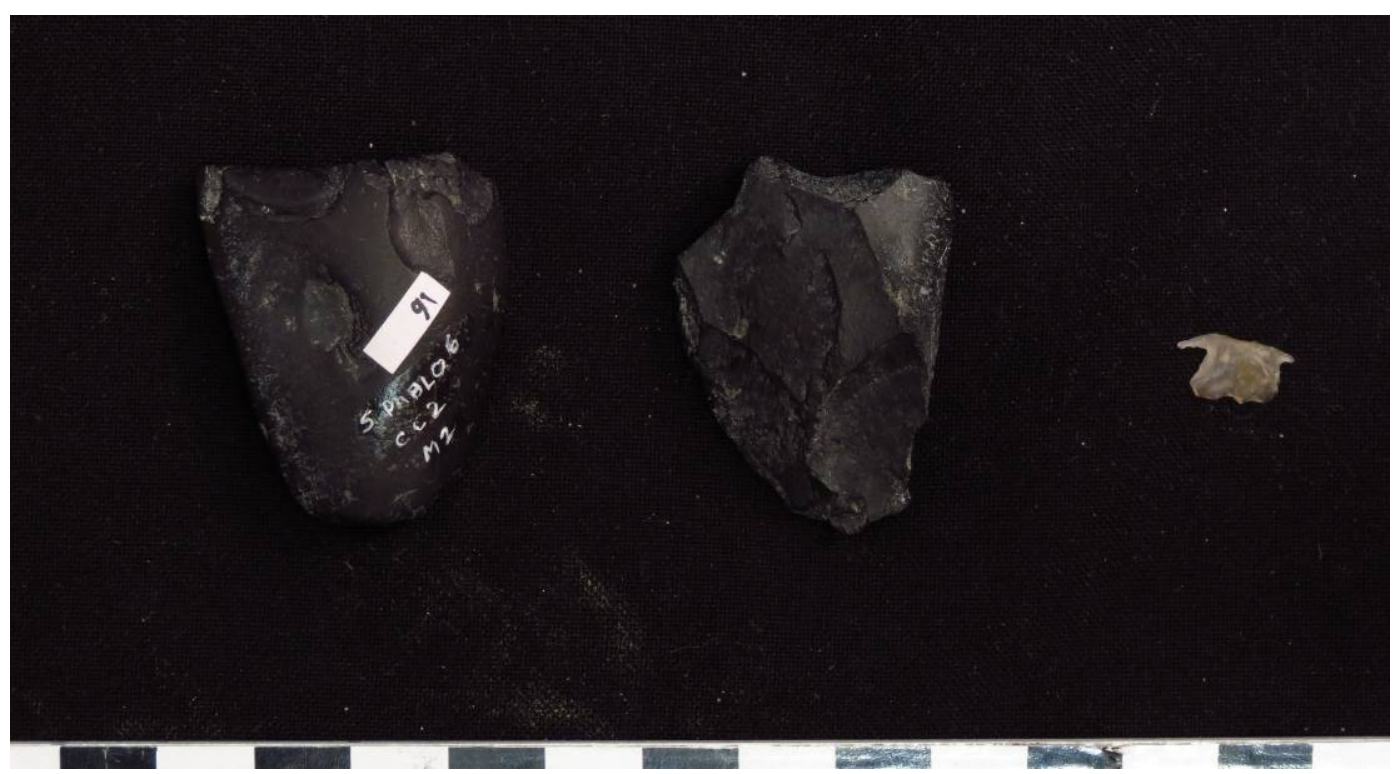

Fig. 7.29. Instrumentos tallados muestreo San Pablo 6

En cuanto a la serie técnica y para el conjunto de SP4 M3 se identificó microrretoque marginal $(n=3)$ y ultramarginal $(n=1)$, seguidos por el retoque $(n=3)$ y un solo caso de lascado simple. La situación de los lascados para todos los instrumentos es unifacial y todos los filos se encuentran activos (Tabla 7.50)

Para los instrumentos tallados de SP 6 CC2 M2 también predominan los microrretoques $(n=3)$, seguido por los retoques $(n=2)$. La situación de los lascados es mayoritariamente bifacial $(n=4)$. Tres de los cuatro filos se encuentran agotados (Tabla 7.51). 


\begin{tabular}{clcc|ccc}
\hline $\mathbf{N}^{\mathbf{0}} \mathbf{I n v}$ & Subg-tipológicos & M.prima & Forma base & Lar (mm) & Anc (mm) & Esp (mm) \\
\hline 56 & Raspador & Xilópalo & Lámina dorso preparado mediana & 37,2 & 17 & 2,8 \\
\hline 71 & Punta burilante & Ópalo & Lasca secundaria mediana & 49,9 & 29,8 & 5,8 \\
\hline 133 & Punta burilante & Sílice & Lasca en punta mediana & 44,6 & 32 & 7,1 \\
\hline 53 & Punta triédrica & Basalto & Lasca con dorso natural pequeña & 32 & 17,1 & 9,7 \\
\hline 62 & Retoque sumario & Sílice & Lasca dorso preparado mediana & 30,3 & 24,9 & 5,5 \\
\hline 55 & Retoque sumario & Calcedonia & Lámina de arista pequeña & 31,1 & 15,4 & 4,7 \\
\hline 54 & Retoque sumario & Calcedonia & Lámina de arista mediana & 40,6 & 19,9 & 8,3 \\
\hline 51 & Raclette? & Calcedonia & Lasca pequeña & 25,4 & 23,2 & 6,5
\end{tabular}

Tabla 7.48. Localidad San Pablo: características de los artefactos tallados.

\begin{tabular}{cllccccc}
$\mathbf{N}^{\mathbf{0}} \mathbf{I n v}$ & Subg- tipológicos & M.prima & Forma base & Lar (mm) & Anc (mm) & Esp(mm) \\
\hline sn & Frag-filo de raspador & Xilópalo & Indeterminada & 12,1 & 14,1 & 5,3 \\
\hline sn & Pedúnculo microlítico & Calcedonia & Indeterminada & 7,1 & 12,7 & 2,3 \\
\hline 9 & Punta entre muesca & Basalto & Lasca con dorso natural mediana & 39,9 & 31,4 & 12,1 \\
\hline 12 & Retoque sumario & Calcedonia & Lasca pequeña & 21,7 & 23,1 & 8,2 \\
\hline 5 & Retoque sumario & Calcedonia & Microlasca bipolar & 18,5 & 19,8 & 3,7 \\
\hline 6 & Retoque sumario & Calcedonia & Microlasca bipolar & 15,1 & 16,5 & 4,7
\end{tabular}

Tabla 7.49. Localidad San Pablo: características de los artefactos tallados. 


\begin{tabular}{|c|c|c|c|c|c|c|c|c|}
\hline $\mathbf{N}^{\mathbf{o}}$ & Subg- tipológicos & Serie Técnica & Sit lasc. & F. G.Contorno & Posic. Filo & F.Lasc. & $>$ Filo & Estado \\
\hline 56 & Raspador & Microrretoque ultra-marginal & unifacial & Amigdoloide irreg & Frontal & Marginal corto & $40^{\circ}$ & Activo \\
\hline 71 & Punta burilante & Lascado simple & unifacial & triangular irregular & Frontal & Golpe buril & nc & nc \\
\hline 133 & Punta burilante & Retoque & unifacial & triangular irregular & Frontal & Lascado simple & nc & nc \\
\hline 53 & Punta triédrica & Retoque & unifacial & Cuadrangular & Lateral & Indeterminado & nc & nc \\
\hline 62 & Retoque sumario & Retoque & unifacial & Indeterminado & Frontal & Marginal corto & $35^{\circ}$ & Activo \\
\hline 55 & Retoque sumario & Microrretoque marginal & unifacial & Rectangular & Lateral & Marginal corto & $35^{\circ}$ & Activo \\
\hline 54 & Retoque sumario & Microrretoque marginal & unifacial & Rectangular & Lateral & Marginal corto & $45^{\circ}$ & Activo \\
\hline 51 & Raclette? & Microrretoque marginal & unifacial & Amigdoloide irreg & Lateral & Marginal corto & $35^{\circ}$ & Activo \\
\hline
\end{tabular}

Tabla 7. 50. Localidad San Pablo, San Pablo 4 M3: Rasgos morfotécnicos de los artefactos tallados. Referencias: Sit. Lascados: situación de los lascados; F. Geom.: forma geométrica, Posic.Fil: Posición del filo; F.Lasc. Forma de los lascados; Ang. Ángulo del filo; restr. Restringido; Unif: Unificial; Indet: indeterminado.

\begin{tabular}{|c|c|c|c|c|c|c|c|c|}
\hline $\mathbf{N}^{\mathbf{0}}$ & Subg- tipológicos & Serie Técnica & Sit lasc. & F. G.Contorno & Posic. Filo & F.Lasc. & $>$ Filo & Estado \\
\hline $\mathrm{sn}$ & Frag.filo de raspador & Microrretoque ultra-marginal & unifacial & Indeterminado & Frontal & Ultramarginal & $35^{\circ}$ & Activo \\
\hline sn & pedúnculo & Indeterminado & bifacial & Indeterminado & $\mathrm{nc}$ & Indeterminado & nc & nc \\
\hline 9 & Punta entre muesca & Retoque & unifacial & Romboide irregular & Frontal & Lascado simple & nc & nc \\
\hline 12 & Retoque sumario & Retoque & bifacial & Indet & Frontal & Marginal corto & $47^{\circ}$ & Agotado \\
\hline 5 & Retoque sumario & Microrretoque marginal & bifacial & Rectangular & Lateral & Marginal corto & $35^{\circ}$ & Agotado \\
\hline 6 & Retoque sumario & Microrretoque marginal & bifacial & Rectangular & Lateral & Marginal corto & $40^{\circ}$ & Agotado \\
\hline
\end{tabular}

Tabla 7. 51. Localidad San Pablo, San Pablo 6 CC2 M2: Rasgos morfotécnicos de los artefactos tallados. Referencias: Sit. Lascados: situación de los lascados; F. Geom.: forma geométrica, Posic.Fil: Posición del filo; F.Lasc. Forma de los lascados; Ang. Ángulo del filo; restr. Restringido; Unif: Unificial; Indet: indeterminado. 


\section{Lascas con rastros complementarios}

En el Muestreo 3 de SP4 se identificaron cuatro rastros complementarios: dos sobre lascas medianas de calcedonia, y los otros dos restantes sobre lascas pequeñas fracturadas de dorso preparado de sílice. Ambas materias primas son de muy buena calidad para la talla.

\section{Núcleos}

Dos núcleos provienen del Muestreo 3 de SP 4: uno de basalto de lascados aislados, el otro de calcedonia y bipolar. Los dos son pequeños y se encuentran agotados. El núcleo de SP6 CC 2 M2 también es de calcedonia, bipolar, de tamaño pequeño y se encuentra agotado (Tabla 7.52 y Fig. 7.30).

\begin{tabular}{|c|c|c|c|c|c|c|c|c|}
\hline Sitio & $\begin{array}{l}\text { Materia } \\
\text { prima }\end{array}$ & Tipo & $\begin{array}{l}\mathrm{N}^{\mathbf{o}} \\
\text { p.p }\end{array}$ & $\begin{array}{l}\text { F. } \\
\text { s.p.p.. }\end{array}$ & $\begin{array}{l}\mathbf{N}^{\mathbf{0}} \\
\text { lasc }\end{array}$ & $\begin{array}{l}\text { F. } \\
\text { lasc }\end{array}$ & $\begin{array}{l}\text { Grad } \\
\text { Mod. }\end{array}$ & Est \\
\hline \multirow[t]{2}{*}{$\begin{array}{l}\text { SP4 } \\
\text { M3 }\end{array}$} & Basalto & $\begin{array}{l}\text { Lascados } \\
\text { aislados }\end{array}$ & 1 & Liso & 2 & Lascas & Alto & $\begin{array}{l}\text { Agota } \\
\text { do }\end{array}$ \\
\hline & Calcedonia & Bipolar & 2 & $\begin{array}{l}\text { Astillad } \\
\text { o }\end{array}$ & 5 & Lascas & Alto & $\begin{array}{l}\text { Agota } \\
\text { do }\end{array}$ \\
\hline $\begin{array}{l}\text { SP } 6 \\
\text { CC2 } \\
\text { M2 }\end{array}$ & Calcedonia & Bipolar & 2 & $\begin{array}{l}\text { Astillad } \\
\text { o }\end{array}$ & 5 & Lascas & Alto & $\begin{array}{l}\text { Agota } \\
\text { do }\end{array}$ \\
\hline
\end{tabular}

Tabla 7.52. Localidad San Pablo: características morfológicas y técnicas de los núcleos.
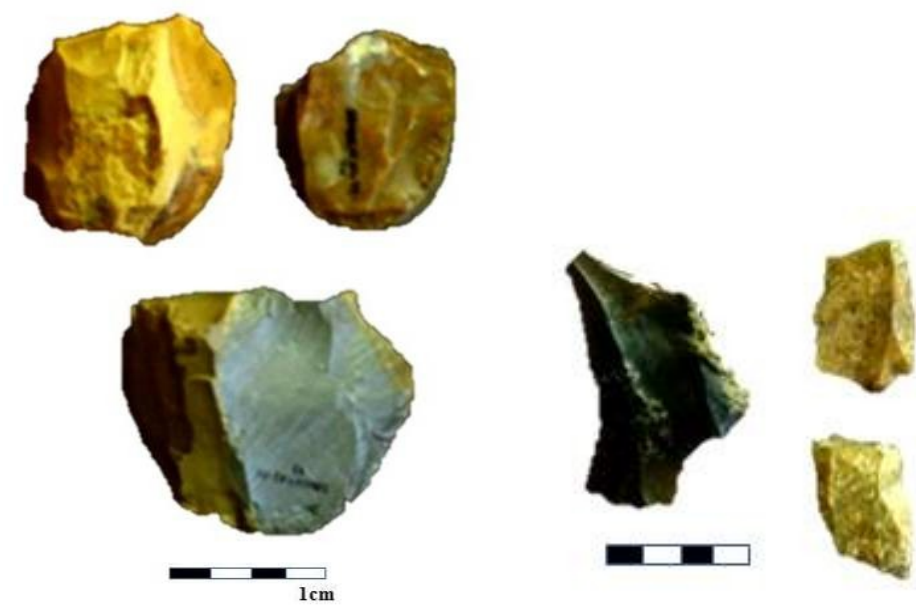

Fig. 7. 30. San Pablo 4: (A) Tipos de núcleos; (B) Instrumentos tallados y lascas con rastros complementarios. 


\section{Artefactos modificados por el uso}

Para el sitio SP 6 CC2 M2 se identificó un fragmento de percutor no determinado ( $\mathrm{N}^{\circ}$ SP6 CC2 M2-2) y tres fragmentos de un mismo yunque $\left(\mathrm{N}^{\circ}\right.$ SP6 CC2 M2-A1; 1B y 1C). Para ambos se usaron rodados grandes de granito y basalto respectivamente (Fig.7.31).

\section{Ecofactos o rodados son modificar}

En total se registraron cuatro ecofactos. En SP4 M3 un fragmento de arenisca consolidada (sobador?) y un rodado grande de andesita, y en SP6 CC2 M2 dos rodados de tamaño pequeño y mediano, uno de riolita y granito el otro.

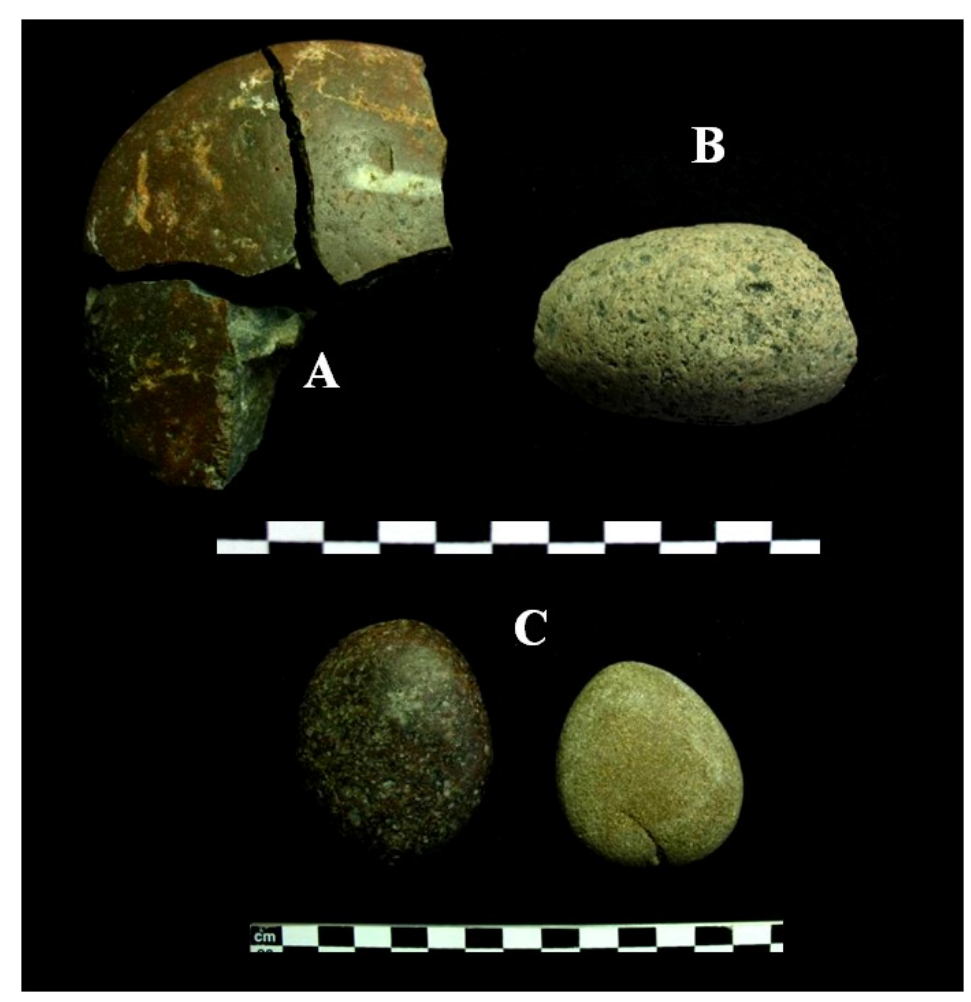

Fig. 7.31. San Pablo 6 CC2 M2: A: remontaje de tres fragmentos de piedra de fogón sobre rodado grande de andesita; B: fragmento de percutor de granito; C: rodados chicos sin modificación antrópica.

\section{Índice de fractura}

El porcentaje general de fracturas en ambos conjuntos es parejo: 32, 9\% en SP4 M3 y 36\% en SP6 CC2 M2 (Tabla 7.53). 


\begin{tabular}{|c|c|c|}
\hline Clase Tipológica /Fracturas & SP4 M3 & SP6 CC2 M2 \\
\hline Artefacto formatizado por P y P & -- & -- \\
\hline Artefacto Modificado por el Uso & 2 & 2 \\
\hline Desechos de talla & 19 & 17 \\
\hline Ecofactos & -- & -- \\
\hline Artefactos Formatizados por talla & 4 & 3 \\
\hline Rastros complementarios & 2 & -- \\
\hline Núcleos & 1 & -- \\
\hline $\mathbf{N}$ & $\mathbf{2 8}$ & $\mathbf{2 2}$ \\
\hline $\mathbf{\%}$ & $\mathbf{3 2 , 9 \%}$ & $\mathbf{3 6 \%}$ \\
\hline
\end{tabular}

Tabla 7.53. Localidad San Pablo: frecuencia de fracturas por clase tipológica.

\section{Relaciones de ensamblaje}

Para el sitio SP4 M3 la única relación entre dos partes de un mismo artefacto se pudo establecer para el raspador de filo frontal sobre lámina de xilópalo. En el muestreo de SP6 CC2 M2 se logró remontar tres fragmentos de un rodado de andesita que pertenecen a un yunque, probablemente fracturado debido al uso (7.31 A).

\section{Frecuencia de módulos laminares, bipolaridad y bifacialidad:}

Para el conjunto artefactual de SP4 M3 el índice de bipolaridad es de $9,4 \%$, registrándose en desechos $(n=8)$ y un núcleo; mientras que la frecuencia de módulos laminares es mayor $(n=19: 22,4 \%)$. No se observó bifacialidad. En SP6 CC2 M2 la técnica bipolar alcanza el 4,9\% $(n=3)$ y la bifacialidad de 6,6\% $(n=4)$. No se registraron módulos laminares.

\section{Tendencias generales de los conjuntos líticos de la localidad arqueológica San Pablo}

A partir del análisis tecnológico se determinaron algunas similitudes y diferencias entre los dos muestreos analizados. En primer lugar, la densidad artefactual es mayor en SPablo $4 \mathrm{M} 3\left(2,57 \mathrm{dm}^{2}\right)$ que en el muestreo de SPablo $6\left(00,38 \mathrm{dm}^{2}\right)$; no obstante la diversidad es pareja en ambos sitios ya que en ambos se encuentran representadas por 5 clases artefactuales, entre ellas núcleos, instrumentos tallados, desechos de talla y ecofactos, entre otros. En relación con las materias primas, en el conjunto de SPablo 4 M3 sobresale el 
basalto, mientras que en SPablo 6 CC2 M2 prevalecen calcedonias y sílices. Se aprovecharon además rocas no locales, como los xilópalos, y en SPablo 4 M3 también obsidianas. Si bien se determinó que para los dos muestreos son amplia mayoría los desechos de talla (más del $80 \%$ en cada uno) difieren en relación con el tipo de lasca y los tamaños representados. En SPablo 4 M3 se destacan las lascas relacionadas con las primeras etapas de talla (primarias y con dorso natural), aunque también hay secundarias y de reactivación de instrumentos. Los tamaños son variados, entre ellos pequeños, medianos y grandes. No se observaron termoalteraciones. Por el contrario, en el muestreo 2 de SPablo 6 CC2 la mayoría de las lascas está relacionada con actividades de reactivación o mantenimiento de los artefactos, y los tamaños predominantes son los muy pequeños ( $70 \%$ son hipermicrolascas). En el conjunto, el daño térmico alcanza el 14\% y el porcentaje de fragmentación es muy alto $(56 \%)$.

En síntesis para el sitio San Pablo 4 las evidencias arqueológicas indican que el espacio habría sido ocupado a través del tiempo para llevar a cabo distintas actividades: caza, pesca, recolección, procesamiento de recursos alimenticios, talla y producción de artefactos, y también inhumación de los muertos (Gómez Otero et al. 2012). De acuerdo con las características del sustrato donde apoyan los materiales arqueológicos se propuso que se trataría de una antigua playa del Holoceno medio, cuando el mar tenía niveles más altos que en la actualidad. No obstante, los procesos postedpositacionales y la intervención de la erosión eólica e hídrica habrían propiciado la formación de un palimpsesto, lo que impide discriminar distintos eventos de ocupación.

Por su parte, y como se propuso anteriormente, San Pablo 6 CC2 M2 estaría representando un basural de un sitio más extenso que habría funcionado como base residencial (Gómez Otero et al. 2012). Esta interpretación se apoyó básicamente sobre dos aspectos. Uno es la morfología en semicirculo y la distribución relativamente pareja de los materiales faunísticos, líticos y cerámicos en la acumulación: no se observó estructuración del espacio. Otro se apoya en el estudio zooarqueológico, que

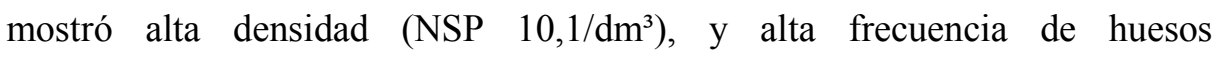
termoalterados (56\% en las aves, $49 \%$ entre los mamíferos) y de fragmentación ósea entre los mamíferos (16,2\%), que estaría relacionada más con la acción térmica que con el procesamiento (Ariadna Svoboda 2015, com. 
pers). Cabe destacar, que a pesar de estas alteraciones, se determinó bajo grado de meteorización ósea (entre 0 y 1 de Behrensmeyer 1978).

En cuanto al registro lítico, el predominio de tamaños muy pequeños (hipermicrolíticos); la presencia de varias lascas relacionadas con actividades de reactivación y mantenimiento de instrumentos $(40,1 \%)$; el alto porcentaje de fragmentación general (56\%), tanto en los desechos como en los artefactos formatizados (3 de 6); la presencia de un núcleo agotado de calcedonia, estaría reforzando la hipótesis de que funcionó como un área de descarte de un sitio más extenso.

\section{Localidad arqueológica Punta Pardelas}

\section{Punta Pardelas 1}

Para esta localidad se ubicó un solo sitio arqueológico compuesto por materiales aislados dispersos en superficie y lentes de concheros estratificadas (Fig. 7. 33). El sitio se encuentra al sudeste de punta Pardelas, en un ambiente de playa y bajadas litorales con profundas cárcavas y cañadones.

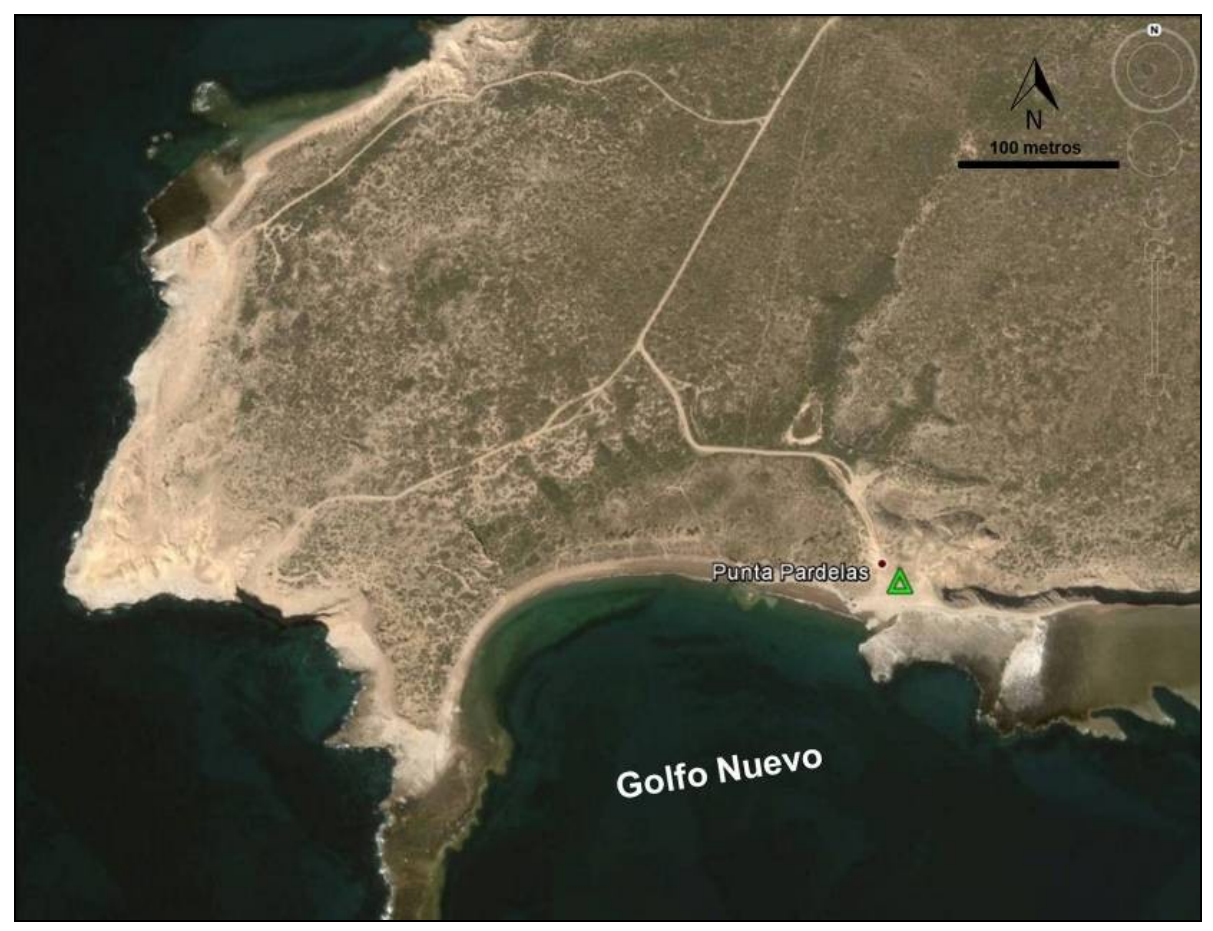

Fig. 7. 32. Localidad arqueológica Punta Pardelas, sitio Pardelas 1.

El material estratificado corresponde a tres delgados depósitos compuestos por carbones pequeños entremezclados con valvas -algunas 
quemadas- de cholgas (Aulacomya ater) y lapas (Patinigera spp.), y escasas vértebras de peces que afloran de manera discontinua en el perfil del acantilado, en cuya base hay una extensa plataforma de abrasión con pozones de marea (Gómez Otero et al. 1999). A escasos diez centímetros por debajo de esas lentes, se registró un depósito de gravas que correspondería al máximo transgresivo holocénico (Alejandro Súnico 1996, com. pers). El sitio mostró importantes evidencias de erosión eólica e hídrica (Gómez Otero 2006). Entre los materiales diseminados en superficie o en canales de escurrimiento hídrico, había desechos de talla en basaltos y sílices coloreadas, rodados partidos con marcas de percusión, cuchillos de filo natural sobre láminas chicas, un raspador en calcedonia, un peso lítico sobre guijarro chato y una falange quemada de lobo marino (Otaria flavescens) (Gómez Otero 2006). Se muestreó material malacológico de dos lentes. Para esta tesis, se estudió el Conchero 2, el único que contenía artefactos líticos.

\section{Punta Pardelas 1 Conchero 2}

Se realizó un muestreo de 50 x $50 \mathrm{~cm}$ de lado por la potencia máxima de la capa -10 cm- (Fig. 7.33), recuperándose valvas de cholgas (Aulacomya ater) y vértebras de peces (NISP: 4): una anchoa de banco (Pomatomus saltatrix), un mero (Acanthistius patachonicus) y un pez indeterminado (Gómez Otero 2006), asociadas con escasos artefactos líticos. Un fechado obtenido de una muestra de valvas arrojó una antigüedad de $5580 \pm 90 \mathrm{C}^{14}$ años AP. Esta datación -la más antigua por el momento para Península Valdés- indicó la ocupación de ese espacio costero durante o inmediatamente después de la última transgresión marina del Holoceno (Gómez Otero 2006). De acuerdo con las evidencias este sitio junto con las dos lentes fueron interpretadas por la autora como una localización.

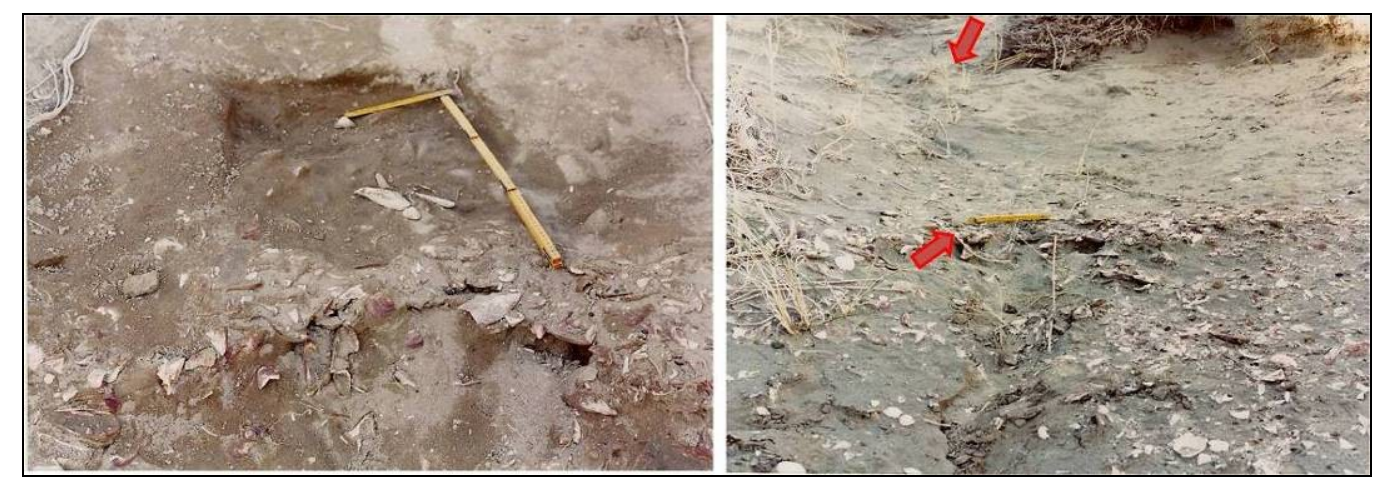

Fig.7.33. Muestreo del sitio Pardelas 1 Conchero 2. 


\begin{tabular}{|c|c|c|c|c|c|c|}
\hline Sitio & $\begin{array}{c}\text { Latitud } \\
\text { Longitud }\end{array}$ & $\begin{array}{c}\text { Altura } \\
\text { S.n.m }\end{array}$ & Edad C $^{\mathbf{1 4}}$ & $\begin{array}{c}\text { Cal } \\
\text { (2 sigmas) }\end{array}$ & Muestra & $\begin{array}{c}\text { Cód } \\
\text { Lab }\end{array}$ \\
\hline Punta & $42^{\circ} 37^{\prime} 10^{\prime \prime} \mathrm{S}$ & $10 \mathrm{~m}$ & $5580 \pm 90$ & $5745-6180$ & Valvas & LP \\
Pardelas & $64^{\circ} 16^{\prime} 15^{\prime \prime} \mathrm{O}$ & & & & & $\begin{array}{c}157 \\
0\end{array}$ \\
Conchero 2 & & & & & & \\
\hline
\end{tabular}

Tabla 7.54. Punta Pardelas: localización y fechados obtenidos de los concheros. Referencias: Dist. Distancia; Lab. Laboratorio. Datos obtenidos de Gómez Otero (2006).

\section{Análisis tecnológico:}

Solo se recuperaron dos artefactos y una densidad artefactual muy baja: $0,008 \mathrm{dm}^{3}$. Se trata de un percutor de arista y una punta burilante, ambos de un rodado de basalto de calidad regular para la talla. Ninguno de los artefactos está fracturado y ni presentan daño térmico, aunque sobre la superficie de las rocas de ambos instrumentos se observó una delgada capa de carbonato de calcio. Si bien la punta y el percutor de arista parecen ser del mismo nódulo, ambas piezas no remontan.

En relación con las características de los instrumentos, el percutor de arista fue manufacturado sobre un rodado de tamaño mediano. El filo de la arista es irregular, unifacial y realizado por talla simple. La punta burilante fue elaborada sobre lasca en punta de tamaño pequeño.

\section{Frecuencia de módulos laminares, bipolaridad y bifacialidad.}

Sin registro.

\section{Tendencias generales de los conjuntos líticos del sitio Punta Pardelas}

La escasa evidencia lítica y la muy baja densidad artefactual $(0,008$ $\mathrm{dm}^{3}$ ), sumada a la ausencia de desechos de talla y de núcleos no permiten sostener para el mismo espacio la ejecución de tareas de talla de manera simultánea al consumo y descarte de moluscos. Asimismo, y dado el tamaño considerable de los dos artefactos (rodado mediano y lasca pequeña) tampoco se puede sostener que hayan ingresado por transporte eólico. No obstante, si se tiene en cuenta la pendiente, es factible que por efecto de la gravedad los artefactos hayan sido desplazados hacia abajo. En este sentido, estudios experimentales pioneros como los realizados por Rick (1976) respecto del desplazamiento de artefactos líticos en taludes mostraron que el ángulo de la pendiente permite estimar el tamaño de las piezas depositadas por la acción gravitatoria (ampliar en Borrazzo 2009). 
En síntesis, el registro arqueológico de Punta Pardelas es consistente con las inferencias de que se trataría de un rasgo de ocupación (Gómez Otero 2006) vinculado con el desarrollo de una única actividad y de corta duración, es decir la recolección y el consumo in situ de moluscos. 


\section{CAPÍTULO 8}

\section{CARACTERIZACIÓN TECNOLÓGICA DE LA UNIDAD DE ANÁLISIS FUERA DE PENÍNSULA VALDÉS}

Esta unidad de análisis espacial incluye el estudio de dos localidades arqueológicas de la costa oeste del golfo San Matías -Arroyo Verde y Rincón de Elizalde- y una de la costa del golfo Nuevo Sur: Bahía Cracker (Fig. 8.1). Las dos primeras localidades fueron estudiadas por Gómez Otero (2006) en su tesis doctoral y cuentan con estudios específicos respecto de la antigüedad de las ocupaciones y la dieta a través de análisis arqueofaunístico e isótopos estables, así como también estudios tecnológicos del registro cerámico (Schuster 2012). Por su parte, la localidad Bahía Cracker fue prospectada por Gómez Otero y equipo en 2007 y 2008, habiéndose analizado en profundidad los sitios 4 y 8 (Gómez Otero et al. 2013). Todos los sitios y muestreos seleccionados para este estudio cuentan con fechados radiocarbónicos y cubren un rango temporal desde el Holoceno medio hasta el Holoceno tardío (Gómez Otero 2006).

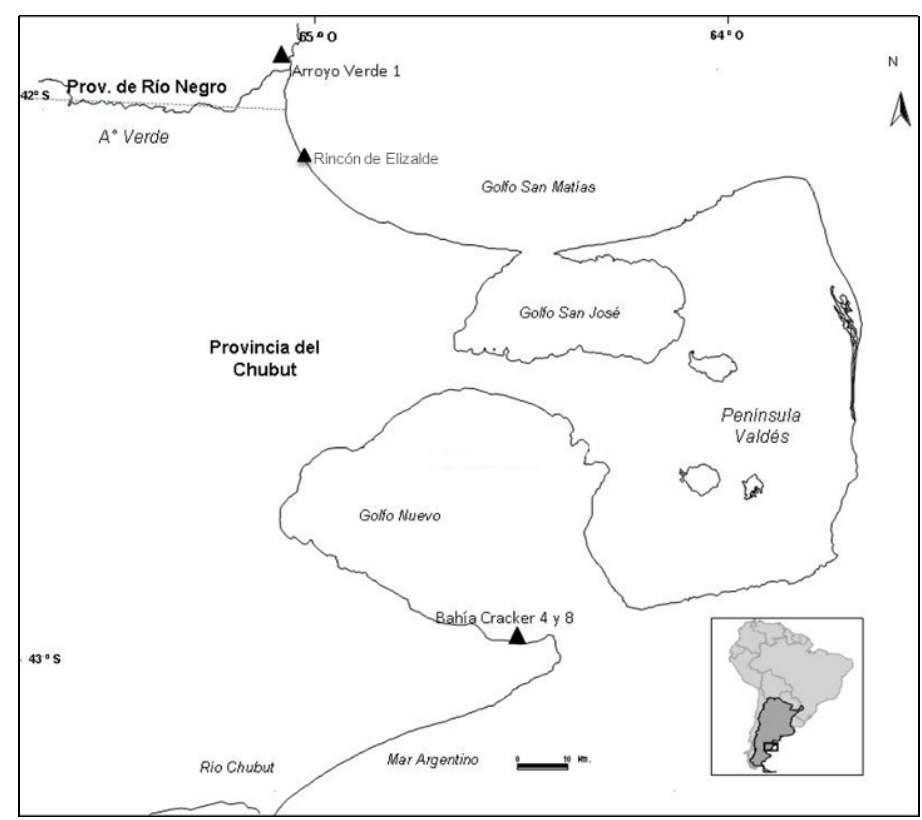

Fig. 8. 1: Ubicación geográfica de las localizaciones arqueológicas analizadas. 


\section{COSTA DEL GOLFO SAN MATÍAS OESTE}

\section{Localidad arqueológica Arroyo Verde}

La localidad se encuentra emplazada sobre la margen norte del arroyo Verde (Provincia de Río Negro) y presenta abundante disponibilidad de recursos abióticos y bióticos: materias primas variadas y de buena calidad para la talla, un manantial de agua dulce a tres kilómetros de la costa, buena accesibilidad al mar y oferta de recursos marino entre los que se destacan mariscos, peces marinos y aves acuáticas (Gómez Otero 2006).

Gómez Otero y equipo identificaron distintos tipos de contexto: cuatro sitios de superficie que incluyen relictos de concheros y materiales arqueofaunísticos dispersos y tres estructuras de entierro del tipo chenque, con alto grado de impacto antrópico (Gómez Otero 2006). Del total de los sitios registrados se seleccionaron para su estudio dos muestreos sistemáticos líticos del sitio Arroyo Verde 1: Muestreo 1 y Muestreo 2.

\begin{tabular}{ccccc}
\hline Sitio & Lat / Long & $\begin{array}{c}\text { Fechado } \\
\text { Años Cal }\end{array}$ & Muestra & Lab. \\
\hline $\mathrm{A}^{\mathrm{o}}$ Verde 1 & $4^{\circ} 54.043^{\prime} \mathrm{S}$ & $7420 \pm 90$ & Valva & LP- 1551 \\
Muestreo 1 & $5691 \pm 6047$ & & \\
$\mathrm{~A}^{\mathrm{o}}$ Verde 1 & $65^{\circ} 03.880^{\prime} \mathrm{O}$ & $\mathrm{s} / \mathrm{d}$ & -- & -- \\
Muestreo 2 & & & & \\
\hline
\end{tabular}

Tabla 8.1. Localidad Arroyo Verde: localización y fechados obtenidos de los muestreos 1 y 2. Referencias: Lab. Laboratorio, BT: bloque temporal.

\section{Arroyo Verde 1}

El sitio Arroyo Verde 1 fue descubierto en el año 2000 en la margen norte del arroyo homónimo, a 100 metros del mar y sobre una extensa hoyada entre médanos altos paralelos a la costa (Gómez Otero 2006:135). En el sector sudoeste de la hoyada se detectaron concentraciones líticas y restos arqueofaunísticos en superficie. También se observaron lentes delgadas de concheros sobre un perfil en desmoronamiento.

La técnica de recuperación de los materiales consistió en dos muestreos sistemáticos: el primer muestreo (Arroyo Verde $1 \mathrm{M} 1$ ) fue de $4 \mathrm{~m}$ de lado y se utilizó zaranda de malla de 1,5 mm. El segundo muestreo (Arroyo 
Verde $1 \mathrm{M} 2$ ) fue de $2 \mathrm{~m}$ de lado y no se tamizaron los materiales. Ambos muestreos fueron interpretados como localizaciones (sensu Binford 1980) por Gómez Otero (2006).

\section{Muestreo 1}

En el muestreo sistemático de 4 metros de lado se recuperaron 254 artefactos líticos relacionados con la talla de nódulos y la producción de filos y puntas naturales. Fuera del muestreo se encontraron dos artefactos formatizados por talla en obsidianas (punta y muesca). No se observaron artefactos vinculados con la obtención o aprovechamiento de ningún recurso, sea terrestre o marino (Gómez Otero 2006), como por ejemplo pesas de red o bolas de boleadoras. Además se muestreó un relicto de conchero con restos de invertebrados y vertebrados. El conjunto de invertebrados estaba dominado por cholgas (Aulacomya ater), seguidas por mejillones (Mytilus sp.) y escasos -aunque variados- géneros de gasterópodos: Trophon, Crepidulla, Patinigera y Fissurella. También se hallaron pinzas de cuatro individuos del cangrejo "pinzas negras" o "buey" (Platyxanthus patagonicus). Entre los vertebrados se destaca la abundancia de peces: 22 individuos de meros (Acanthistius brasilianus) y uno de turco (Pinguipes brasilianus) (Zangrando 2004). Los demás vertebrados están representados por escasas astillas indeterminadas (probablemente de guanaco), un hueso largo de ctenómido (fuera del submuestreo se reconocieron maxilares y mandíbulas de ctenómidos) y placas quemadas de armadillos: doce de peludos (Chaetrophractus villosus) y dos de piche (Zaedyus pichiy). Cabe destacar también el hallazgo de un disco vertebral de ballena en uno de los perfiles de la hoyada. Valvas de cholgas de este muestreo fueron datadas en $7400 \pm 90$ años C14 AP, fecha que representa la cronología más temprana para la costa de Patagonia central (Gómez Otero 2006).

\section{Muestreo 2}

El segundo muestreo se efectuó a pocos metros hacia el nordeste del muestreo 1. Se recuperó un total de 82 artefactos líticos. El análisis previo de estos materiales indicó presencia de artefactos medianos a grandes con alta representación de corteza. Se registraron las mismas materias primas que en el M1 y también otras rocas de procedencia no local: obsidiana negro-oliva (de procedencia desconocida) y un percutor de hematita, cuya fuente se 
encontraría en la zona de Sierra Grande, a $40 \mathrm{~km}$ al noroeste (Gómez Otero, 2006). Sobre la base de la presencia de varias lentes de conchero, la representación mayoritaria de fauna marina (peces y moluscos) y las evidencias de actividades iniciales de talla lítica, Gómez Otero (2006) interpretó que Arroyo Verde 1 representaría una sucesión de ocupaciones de tipo localización (sensu Binford 1980).

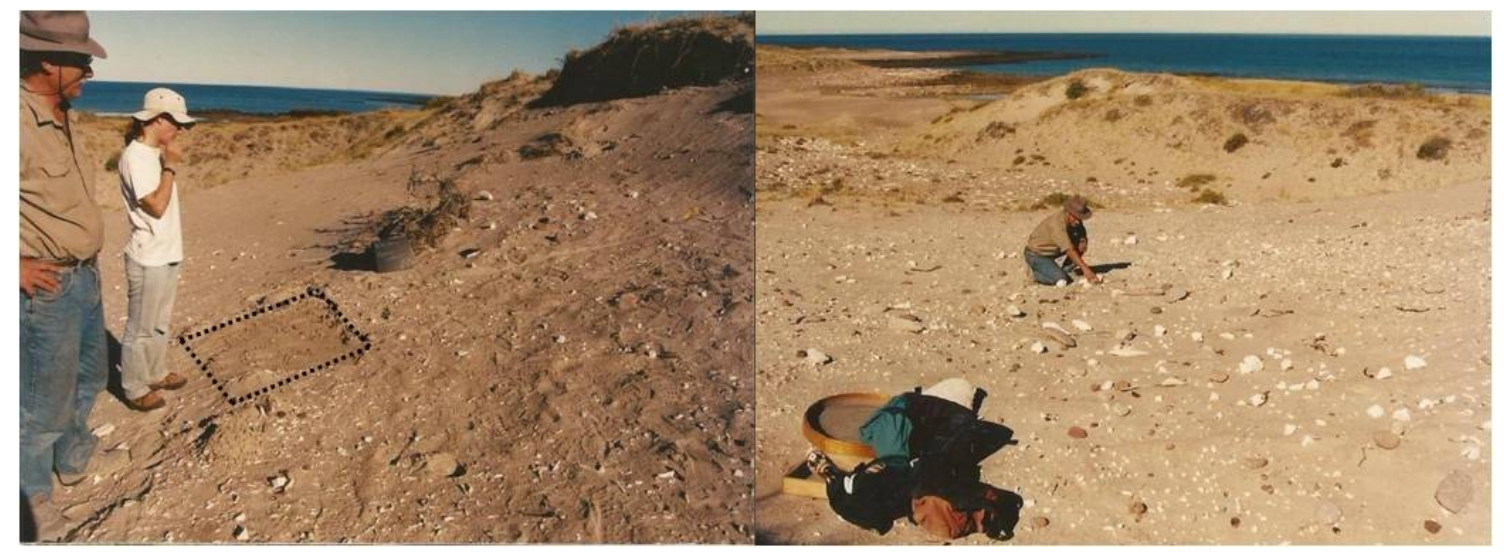

Fig. 8. 2. Sitio Arroyo Verde 1 M1 y Submuestreo 1 (izquierda) y Muestreo 2 (derecha).

\section{Análisis tecnológico}

En el Muestreo 1 (en adelante M1) se recogieron 254 artefactos que representan una densidad de $1,58 / \mathrm{dm}^{2}$. En el Muestreo 2 (en adelante M2) el total de artefactos es de 82 artefactos y una densidad artefactual de $0,37 / \mathrm{dm}^{2}$.

\section{Materias primas:}

En el Muestreo 1 se identificaron trece variedades litológicas, entre las que sobresalen dos rocas de muy buena a excelente calidad: sílices (32\%) y calcedonia (20\%), a las que siguen las riolitas (14\%) e ignimbritas (11\%) de calidad regular, y las tobas $(9 \%)$ y las calizas fosilizadas $(7 \%)$, de buena aptitud para la talla. El resto de las materias primas no supera el $2 \%$ y casi todas son de calidad muy buena y excelente, como por ejemplo la obsidiana, el jaspe y el ópalo (Tabla 8.2).

En el Muestreo 2 las variedades litológicas son cinco, entre las que se destacan ignimbritas (48\%), de calidad regular, y en segundo lugar sílices $(32 \%)$ de muy buena a buena aptitud para la talla. Le siguen en importancia la toba (13\%) de calidad buena y calcedonia $(6 \%)$ y xilópalo (1\%) de excelente a buena calidad. La hematita, de calidad regular a mala para la talla, fue seleccionada en muy baja frecuencia (Tabla 8.2). 


\begin{tabular}{|c|c|c|c|c|}
\hline \multirow{2}{*}{$\begin{array}{c}\text { Materias primas } \\
\text { líticas }\end{array}$} & \multicolumn{2}{|c|}{ Muestreo 1 } & \multicolumn{2}{c|}{ Muestreo 2 } \\
\cline { 2 - 5 } & $\mathbf{N}$ & $\mathbf{\%}$ & $\mathbf{N}$ & $\mathbf{\%}$ \\
\hline Basalto & 1 & $0,5 \%$ & -- & -- \\
\hline Basalto olivínico & 1 & $0,5 \%$ & -- & -- \\
\hline Calcedonia & 37 & $20 \%$ & 4 & $5,6 \%$ \\
\hline Caliza fosilizada & 13 & $7 \%$ & -- & -- \\
\hline Cuarcita & 2 & $1,1 \%$ & -- & -- \\
\hline Hematita & 1 & $0,5 \%$ & -- & -- \\
\hline Ignimbrita & 21 & $11 \%$ & 34 & $47,8 \%$ \\
\hline Jaspe & 3 & $1,6 \%$ & -- & -- \\
\hline Obsidiana & 2 & $1,1 \%$ & -- & -- \\
\hline Ópalo & 1 & $0,5 \%$ & -- & -- \\
\hline Riolita & 26 & $14 \%$ & -- & -- \\
\hline Sílice & 59 & $32 \%$ & 23 & $32,3 \%$ \\
\hline Toba & 17 & $9 \%$ & 9 & $12,6 \%$ \\
\hline Xilópalo & -- & -- & 1 & $1,4 \%$ \\
\hline Total & 182 & $100 \%$ & 71 & $100 \%$ \\
\hline
\end{tabular}

Tabla 8.2. Tipos y frecuencias de las variedades litológicas.

De acuerdo con la base regional de recursos (veáse Capítulo 6), la gran mayoría de las rocas se encuentra disponible localmente (10 de 14 variedades) aunque la forma de presentación varía entre las distintas litologías: sílices, calcedonias, riolitas, ignimbritas, tobas, jaspe, cuarcitas y ópalo en forma de rodados; calcedonia en filones y tabletas y calizas fosilizadas e ignimbritas en bloques. La caliza se logró identificar a través del estudio de secciones delgadas (veáse Anexo 1); el Dr. Haller (Com. Pers 2013) pudo determinar que estas rocas se encuentran a menos de $40 \mathrm{~km}$ del arroyo Verde, en la zona de Playas Coloradas, en el golfo san Matías.

Las materias primas no locales son la obsidiana, el basalto olivínico, la hematita y el xilópalo. En cuanto a la primera, se cuenta con el análisis efectuado por Gómez Otero y Stern (2006) en dos desechos de talla (una variedad de color negro y textura porfírica, y la otra de coloración negra translúcida verde) y el estudio de dos artefactos realizados recientemente por Stern (comunicación personal 2013). Estos resultados indican que una de las muestras procedería de la meseta de Somuncura cuya fuente se ubica a $190 \mathrm{~km}$ de distancia al noroeste de la localidad arqueológica. La otra muestra indicó su correspondencia con la fuente $\mathrm{T} / \mathrm{SC} 2$, que se localiza cerca de Telsen, a 160 $\mathrm{km}$ de distancia hacia el centro sur de la provincia de Chubut (Gómez Otero y 
Stern 2006). El basalto olivínico también se registra en el área de Somuncurá (Banegas et al. 2016) y la hematita está disponible en el sector de Sierra Grande, a menos de $50 \mathrm{~km}$ hacia el noroeste (Gómez Otero et al. 1999). En cuanto a los xilópalos, estudios en curso sobre su procedencia sugieren que provendrían de los bosques petrificados in situ más próximos al área de estudio (Banegas et al. 2016). Estos son el bosque ubicado en la zona del Dique Ameghino (valle inferior del río Chubut), a $220 \mathrm{~km}$ de distancia; el "Bosque Petrificado de la Costa" (golfo San Jorge) y el "Bosque Petrificado Ormaechea (cerca de los lagos Musters y Colhue Huapi), ambos a 360 y a 500 $\mathrm{km}$ de distancia de arroyo Verde.

Respecto de la relación corteza o superficie de la roca y la estructura interna de las mismas, en el M1 se observó que es pareja entre aquellas a las que no se puede reconocer su calidad sin observar el interior de la roca $(n=74$ : $40 \%$ ) -tales como calcedonia, ignimbritas, toba y ópalo-, y las que sí ( $\mathrm{n}=58$ : 31,5\%). El resto ( $\mathrm{n}=54: 29 \%)$ no pudo determinarse. En cuanto a las alteraciones en la superficie de las rocas, se determinó ausencia en la mayoría $(n=170 / 184$ artefactos). Las escasas evidencias están asociadas a lustre $(n=6)$; daño térmico $(n=6)$ y carbonatación $(n=2)$. Por su parte, en el M2 en más de la mitad de los artefactos no se observó relación entre la estructura interna y el exterior de la roca $(\mathrm{N}=48: 66,6 \%)$-calcedonia, sílices e ignimbritas. La única alteración que se registró fue lustre $(n=16: 22,5 \%)$ y está concentrada casi en su totalidad en las rocas silíceas $(n=12)$.

\section{Clases artefactuales:}

En el M1 sobresalen los desechos de talla (89\%) y en menor proporción -inferior al 5\%- los artefactos formatizados por talla, y núcleos y lascas con rastros complementarios. En los límites del muestreo se recuperaron un percutor y un fragmento de bola de boleadora. En el M2 también predominan los desechos (82\%), seguidos por los núcleos $(7 \%)$, los artefactos formatizados por talla $(6 \%)$ y por ultimo las lascas con rastros complementarios (5\%) (Tabla 8.3). 


\begin{tabular}{|c|c|c|c|c|c|c|}
\hline Clases & Núcleos & Desechos & $\begin{array}{c}\text { Artef. } \\
\text { Format. } \\
\text { por talla }\end{array}$ & $\begin{array}{c}\text { Rastros } \\
\text { complement. }\end{array}$ & $\begin{array}{c}\text { Artef. } \\
\text { Modific. } \\
\text { por el uso }\end{array}$ & $\begin{array}{c}\text { Artef. } \\
\text { Format.PyP }\end{array}$ \\
\hline $\begin{array}{c}\text { Muestreo } 1 \\
(n=254)\end{array}$ & $\begin{array}{c}3,5 \% \\
(9)\end{array}$ & $\begin{array}{l}89,7 \% \\
(228)\end{array}$ & $\begin{array}{c}4,3 \% \\
(11)\end{array}$ & $\begin{array}{c}1,5 \% \\
(4)\end{array}$ & $\begin{array}{c}0,4 \% \\
(1)\end{array}$ & $\begin{array}{c}0,4 \% \\
(1)\end{array}$ \\
\hline $\begin{array}{c}\text { Muestreo } 2 \\
(\mathbf{n}=\mathbf{8 2})\end{array}$ & $\begin{array}{l}7,32 \\
(6)\end{array}$ & $\begin{array}{c}81,7 \% \\
(67)\end{array}$ & $\begin{array}{c}6,1 \% \\
(5)\end{array}$ & $\begin{array}{c}4,8 \% \\
(4)\end{array}$ & -- & -- \\
\hline
\end{tabular}

Tabla 8.3. Muestreos 1 y 2: distribución de las clases tipológicas.

\section{Desechos de talla:}

En el M1 predominan las lascas enteras ( $\mathrm{n}=84: 37,2 \%)$ y los desechos no clasificables $(n=70: 31 \%)$ seguidos por las fracturadas sin talón $(n=44: 19,5$ \%) y las fracturadas con talón ( $\mathrm{n}=28: 12,4 \%$ ). Entre los tipos de lascas se destacan las de arista oblicua (15\%), inclinada (13\%) y con dorso natural. El resto de las categorías es poco frecuente y se ubica en porcentajes inferiores al 6\%. Varias no pudieron determinarse ( $\mathrm{n}=46: 29 \%$ ) (Tabla 8.4). En el M2 las lascas enteras dominan $(n=38: 56,7 \%)$, siguen las lascas fracturadas con talón $(\mathrm{n}=12: 18 \%)$ y los desechos no clasificables $(16,4 \%)$. Por último, y en baja frecuencia, se ubican las fracturadas sin talón (6: 9\%).

\begin{tabular}{ccccc}
\hline Tipo de lascas & \multicolumn{2}{c}{ Muestreo 1 } & \multicolumn{2}{c}{ Muestreo 2 } \\
\cline { 2 - 5 } & $\mathbf{N}=$ & $\mathbf{\%}$ & $\mathbf{N}=$ & $\mathbf{\%}$ \\
de arista oblicua & 23 & 14,6 & 2 & $3,6 \%$ \\
de arista inclinada & 21 & 13,3 & 10 & 17,9 \\
con dorso natural & 16 & 10,1 & 6 & 10,7 \\
de arista recta & 10 & 6,3 & 4 & 7,1 \\
Primaria & 9 & 5,7 & 6 & 10,7 \\
de reactivación inversa & 6 & 3,8 & -- & -- \\
En cresta & 1 & 0,6 & 2 & 3,6 \\
con dorso preparado & 4 & 2,5 & 1 & 1,8 \\
Secundaria & 4 & 2,5 & 7 & 12,5 \\
de reactivación directa & 3 & 1,9 & -- & -- \\
Nucleiforme & 3 & 1,9 & 2 & 3,6 \\
Angular recta & 2 & 1,3 & -- & -- \\
Lámina de arista recta & 2 & 1,3 & 2 & 3,6 \\
Lámina secundaria & 1 & 0,6 & 3 & 5,4 \\
Sobrepasada & 1 & 0,6 & -- & -- \\
Indeterminada & 46 & 29,1 & 11 & 19,6 \\
Total & $\mathbf{1 5 8}$ & $\mathbf{1 0 0 \%}$ & $\mathbf{5 6}$ & $\mathbf{1 0 0 \%}$ \\
\hline
\end{tabular}

Tabla 8.4. Tipos y frecuencias de lascas. 
En cuanto al tamaño de las lascas, en el M1 sobresalen las microlascas (39\%) seguidas por las de tamaño pequeño (33\%); el resto se ubica en valores inferiores y parejos (entre 9,5 y 8\%) y sólo se recuperaron dos microláminas. El módulo más representado es el mediano normal (58\%) y en segundo lugar el corto-ancho (29\%). En el M2 el tamaño de las lascas es mayoritariamente grande $(39 \%)$ y mediano (32\%), y en tercer lugar muy grande (23\%). En muy baja frecuencia se encuentran piezas pequeñas (5\%). El modulo predominante es el mediano normal (68\%), seguido por el mediano alargado (14\%); en último lugar y con valores parejos se encuentran los cortos-anchos y el laminar normal (9\% cada uno) (Tabla 8.5).

\begin{tabular}{|c|c|c|c|c|c|c|c|}
\hline & $\begin{array}{l}\text { Tamaño } \\
\text { Módulo }\end{array}$ & $\begin{array}{l}\text { Corto } \\
\text { ancho }\end{array}$ & $\begin{array}{c}\text { Laminar } \\
\text { normal }\end{array}$ & $\begin{array}{l}\text { Mediano } \\
\text { alargado }\end{array}$ & $\begin{array}{c}\text { Mediano } \\
\text { normal }\end{array}$ & & Cotal \\
\hline \multirow{8}{*}{ 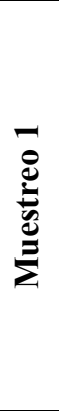 } & Hipermicrolasca & 5 & -- & 1 & 8 & 14 & $8,9 \%$ \\
\hline & Microlasca & 25 & -- & 3 & 34 & 62 & $39,2 \%$ \\
\hline & Lasca Pequeña & 13 & 2 & 7 & 30 & 52 & $32,9 \%$ \\
\hline & Lasca mediana & 2 & -- & 3 & 10 & 15 & $9,5 \%$ \\
\hline & Lasca grande & 1 & -- & 2 & 10 & 13 & $8,2 \%$ \\
\hline & Microlámina & -- & 2 & -- & -- & 2 & $1,3 \%$ \\
\hline & $\mathbf{N}$ & 46 & 4 & 16 & 92 & \multirow{2}{*}{158} & \multirow{2}{*}{100} \\
\hline & $\%$ & 29,1 & 2,5 & 10,1 & 58,2 & & \\
\hline \multirow{8}{*}{ 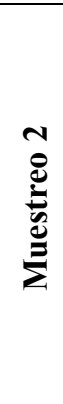 } & Hipermicrolasca & -- & -- & -- & -- & -- & -- \\
\hline & Microlasca & -- & -- & -- & -- & -- & -- \\
\hline & Lasca Pequeña & -- & -- & -- & 3 & 3 & $5,4 \%$ \\
\hline & Lasca mediana & 2 & 1 & 3 & 12 & 18 & $32,1 \%$ \\
\hline & Lasca grande & 1 & -- & 4 & 17 & 23 & $39,3 \%$ \\
\hline & Lasca Muy grande & 2 & 4 & 1 & 6 & 13 & $23,2 \%$ \\
\hline & $\mathbf{N}$ & 5 & 5 & 8 & 38 & \multirow{2}{*}{56} & \multirow{2}{*}{100} \\
\hline & $\%$ & 8,9 & 8,9 & 14,2 & 68 & & \\
\hline
\end{tabular}

Tabla 8.5. M1 y M2: Tamaño y módulo largo/ancho de las lascas.

En relación con los talones, en el M1 casi la mitad está ausente por fracturas $(n=45)$, siguiéndole los lisos $(n=33)$, los diedros $(n=24)$, los corticales $(n=18)$, los puntiformes $(n=12)$ y los facetados y filiformes $(n=10$ cada uno). Se registraron sólo dos astillados y cuatro no pudieron ser determinados. Por su parte, en el M2 son mayoría los corticales $(n=21)$, luego se ubican los lisos $(n=11)$, los ausentes $(n=6)$, los facetados $(n=5)$ y los fracturados $(n=4)$. En valores muy bajos se registraron los diedros, los astillados y los indeterminados ( $\mathrm{n}=2$ respectivamente) (Tabla 8.6) 


\begin{tabular}{ccccc}
\hline Tipo de talón & M1 & M1 (\%) & M2 & M 2 (\%) \\
\hline Cortical & 18 & 11,4 & 21 & 37,5 \\
Liso & 33 & 20,9 & 11 & 19,6 \\
Diedro & 24 & 15,2 & 2 & 3,6 \\
Facetado & 10 & 6,3 & 5 & 8,9 \\
Filiforme & 10 & 6,3 & 3 & 5,4 \\
Puntiforme & 12 & 7,6 & 0 & 0,0 \\
Astillado & 2 & 1,3 & 2 & 3,6 \\
Fracturado & 45 & 28,5 & 4 & 7,1 \\
Ausente & -- & -- & 6 & 10,7 \\
Indeterminado & 4 & 2,5 & 2 & 3,6 \\
Totales & $\mathbf{1 5 8}$ & $\mathbf{1 0 0} \%$ & $\mathbf{5 6}$ & $\mathbf{1 0 0} \%$ \\
\hline
\end{tabular}

Tabla 8.6: Tipos y frecuencias de los talones.

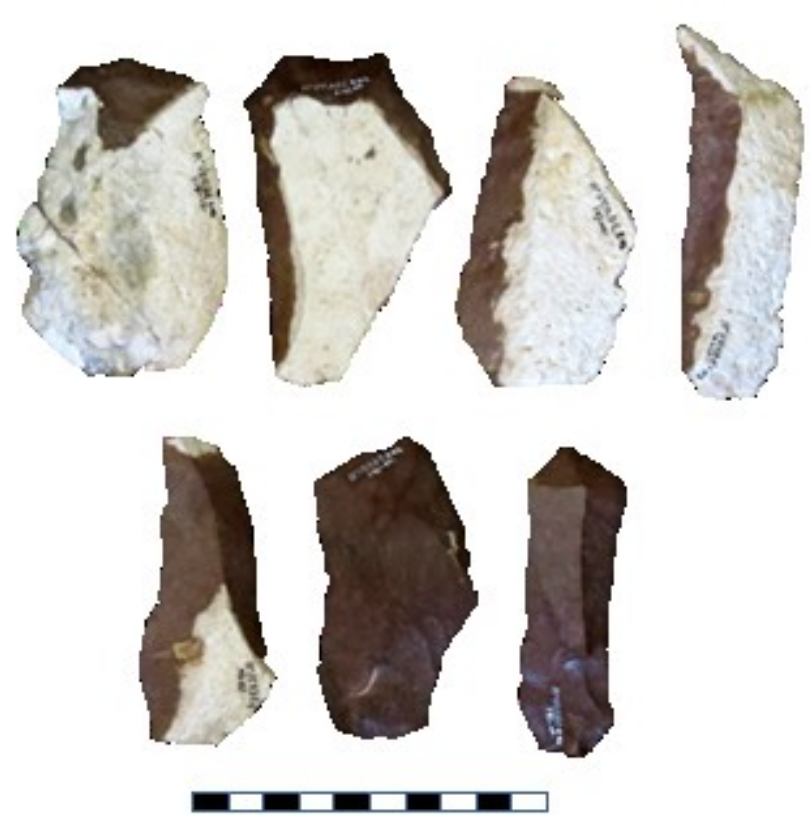

Fig. 8.3. Arroyo Verde 1 M2, concentración lítica: Tamaño de las láminas y hojas de Ignimbrita.

\section{Artefactos formatizados por talla}

En el M1, del total de los instrumentos formatizados por talla $(n=11$; 4,3\%) nueve están confeccionados en calcedonia, dos en sílice y uno en ignimbrita. Las calcedonias corresponden a las variedades traslúcidas de coloración blanca y de calidad excelente para la talla; los sílices son de color marrón claro (código 5YR5/2 según Munsell 2011) y de muy buena calidad, y la ignimbrita es marrón oscuro rojizo (código 10 R 3/4 Munsell 2011), de calidad regular a buena. En cuanto a las formas base, los soportes son lascas 
de distintos tamaños: pequeños $(n=2)$ medianos $(n=7)$ y una lasca muy grande. Solo se registró un filo retocado sobre una lámina mediana (Tabla 8.6).

En el M2, los cinco artefactos formatizados por talla fueron manufacturados en rocas silíceas $(\mathrm{n}=3)$, y los dos restantes en xilópalo y toba. Las sílices son de coloración marrón rojiza y clara (código 5YR 5/6 y 5R4/2), de excelente a muy buena calidad; el xilópalo gris traslúcido de excelente calidad y la toba de color naranja muy claro (10 YR 8/2) y de buena calidad. Las formas-base son de distinto tipo: láminas $(\mathrm{n}=2)$, núcleos $(\mathrm{n}=2)$ y una lasca corta ancha (Tabla 8.7).

Respecto de la serie técnica, en el M1 domina el microrretoque marginal y en algunos casos restringido. En tres instrumentos está presente el retoque marginal y se identificó un solo caso de lascado simple. La situación de los lascados es en todos los casos unifacial, y salvo dos instrumentos cuyos filos se encuentran embotados (un cuchillo retocado y un perforador), el resto de los filos está activo (Tabla 8.8). Cuatro instrumentos tienen filos combinados: el cuchillo retocado, el cortante, el bec y el perforador, todos ellos manufacturados en calcedonia de muy buena y excelente calidad.

En cuanto a los instrumentos tallados de M2, dos presentan microrretoque marginal, dos retoque marginal y el restante talla por extracción simple. También todos los filos son unifaciales y se encuentran activos (Tabla 8.9). Los filos dobles se identificaron en la muesca de sílice y en el raspador de xilópalo, ambas materias primas son de excelente calidad para la talla.

\section{Lascas con rastros complementarios}

En el M1 tres de ellas son lascas medianas y pequeñas de calcedonia de calidad muy buena a excelente, y una lasca mediana de riolita de calidad regular. En el M2 de los cuatro rastros complementarios identificados, uno proviene de una hoja de tamaño muy grande de ignimbrita de buena calidad, otro de una lasca mediana de calcedonia de muy buena aptitud, y los dos restantes de lascas de tamaño grande de sílices coloreados y de muy buena calidad. 


\begin{tabular}{|c|c|c|c|c|c|c|}
\hline \multicolumn{2}{|c}{$\begin{array}{c}\mathbf{N}^{\mathbf{0}} \\
\text { Inv }\end{array}$} & $\begin{array}{c}\text { Muestreo 1 } \\
\text { Subgrupos }\end{array}$ & \multicolumn{2}{c}{$\begin{array}{c}\text { Materia } \\
\text { prima }\end{array}$} & Forma base & \multicolumn{2}{c}{$\begin{array}{c}\text { Largo } \\
(\mathbf{m m})\end{array}$} & $\begin{array}{c}\text { Ancho } \\
(\mathbf{m m})\end{array}$ & $\begin{array}{c}\text { Espesor } \\
(\mathbf{m m})\end{array}$ \\
\hline 23 & Filo retocado & sílice & Lasca mediana & 37 & 18,6 & 3,2 \\
\hline 17 & Filo retocado & sílice & Lasca mediana & 36 & 19,2 & 4,1 \\
\hline 33 & Filo retocado & calcedonia & Lámina mediana & 37,3 & 24,6 & 5,9 \\
\hline 25 & Cortante & calcedonia & Lasca mediana & 34,4 & 30 & 6,2 \\
\hline 10 & Bec & calcedonia & Lasca mediana & 41,6 & 26,6 & 8 \\
\hline 11 & Bec & Ignimbrita & Lasca muy grande & 82 & 51 & 23 \\
\hline 14 & Raspador & calcedonia & Lasca pequeña & 26,2 & 27,7 & 8,8 \\
\hline 15 & Raedera & calcedonia & Lasca mediana & 36 & 25 & 6,6 \\
\hline 18 & Perforador & calcedonia & Lasca mediana & 41,8 & 19,9 & 7,9 \\
\hline 24 & Muesca & calcedonia & Lasca mediana & 29,8 & 23,3 & 5,5 \\
\hline 39 & Muesca & calcedonia & Lasca pequeña & 25 & 22,5 & 7,7 \\
\hline
\end{tabular}

Tabla 8.7. Características de los artefactos tallados de M1.

\begin{tabular}{|c|c|c|c|c|c|c|}
\hline $\begin{array}{l}\mathbf{N}^{\mathbf{o}} \\
\text { Inv }\end{array}$ & $\begin{array}{l}\text { Muestreo } 2 \\
\text { Subgrupos }\end{array}$ & $\begin{array}{l}\text { Materia } \\
\text { prima }\end{array}$ & $\begin{array}{l}\text { Forma } \\
\text { Base }\end{array}$ & $\begin{array}{l}\text { Largo } \\
(\mathrm{mm})\end{array}$ & $\begin{array}{l}\text { Ancho } \\
(\mathrm{mm})\end{array}$ & $\begin{array}{l}\text { Espesor } \\
(\mathbf{m m})\end{array}$ \\
\hline 7 & Muesca & Silíce & Lámina & 50 & 30 & 6 \\
\hline 8 & Denticulado & Sílice & Núcleo & 35,4 & 44 & 15,5 \\
\hline 14 & Punta burilante & Sílice & Lasca & 30,9 & 51 & 13,6 \\
\hline 3 & Raspador & Xilópalo & Lámina & 36,6 & 16,8 & 8,5 \\
\hline 4 & Raspador & Toba & Núcleo & 49,4 & 56,6 & 18,7 \\
\hline
\end{tabular}

Tabla 8.8. Muestreo 2: características tecnológicas y métricas de los artefactos formatizados por talla. 


\begin{tabular}{|c|c|c|c|c|c|c|c|c|}
\hline $\begin{array}{l}\mathbf{N}^{\mathbf{0}} \\
\text { Inv }\end{array}$ & Sub & $\begin{array}{l}\text { Serie } \\
\text { Técnica }\end{array}$ & Sit lasc. & $\begin{array}{l}\text { F. Geom. } \\
\text { Contorno }\end{array}$ & Posic. Filo & F.Lasc. & $\begin{array}{l}\text { Ang } \\
\text { Filo }\end{array}$ & $\begin{array}{l}\text { Estado } \\
\text { filo }\end{array}$ \\
\hline 23 & Filo retocado & Microretoque marginal & Unif.directo & Rectangular & Lateral & Paralelo corto irreg. & $30^{\circ}$ & Activo \\
\hline 17 & Filoretocado(D) & Retoque marginal & Unif. & Rectangular & Asimétrica & Paralelo corto irreg. & $25^{\circ}$ & Embotado \\
\hline 33 & Cortante(D) & Microretoque restr. & Unif. & Rectangular & Asimétrica & Paralelo corto irreg. & $35^{\circ}$ & Activo \\
\hline 25 & $\operatorname{Becs}(\mathrm{D})$ & Microretoque restr. & Unif. & Trapezoidal Asimetrica & Indet. & Escamoso regular & $55^{\circ}$ & Activo \\
\hline 10 & Raspador & Microretoque marginal & Unif.directo & Circular incompleta & Frontal & Paralelo corto irreg & $43^{\circ}$ & Activo \\
\hline 11 & Raedera & Microretoque marginal & Unif.directo & Oval irregular & Lateral & Marginal corto & $34^{\circ}$ & Activo \\
\hline 14 & Perforador(D) & Retoque marginal & Unif.directo & Lanceolada & Frontal & Marginal corto & $55^{\circ}$ & Embotado \\
\hline 15 & Muesca & Microretoque marginal & Unif.directo & Cordiforme Irregular & Lateral & Escamoso & $42^{\circ}$ & Activo \\
\hline 18 & Muesca & Retoque marginal & Unif.directo & Indet. & Lateral & Escamoso irreg. & $40^{\circ}$ & Activo \\
\hline 24 & Filo retocado & Retoque marginal & Unif. & Eliptica Irregular & Lateral & Paralelo corto irreg. & $35^{\circ}$ & Activo \\
\hline 39 & Becs & Lascado simple & Unif. & -- & Distal & -- & -- & Activo \\
\hline
\end{tabular}

Tabla 8.9. Arroyo Verde 1M1: Rasgos morfotécnicos de los artefactos tallados. Referencias: Sit. Lascados: situación de los lascados; F. Geom.: forma geométrica, Posic.Fil: Posición del filo; F.Lasc. Forma de los lascados; Ang. Ángulo del filo; restr. Restringido; Unif: Unificial; Indet: indeterminado

\begin{tabular}{|c|c|c|c|c|c|c|c|c|}
\hline $\begin{array}{l}\mathbf{N}^{\mathbf{o}} \\
\text { Inv }\end{array}$ & Sub & $\begin{array}{c}\text { Serie } \\
\text { Técnica }\end{array}$ & Sit lasc. & $\begin{array}{l}\text { F. Geom. } \\
\text { Contorno }\end{array}$ & Posic. Filo & F.Lasc. & $\begin{array}{l}\text { Ang } \\
\text { Filo }\end{array}$ & $\begin{array}{l}\text { Estado } \\
\text { filo }\end{array}$ \\
\hline 7 & Muesca (D) & Microretoque marginal & Unif. directo & $\begin{array}{l}\text { Lanceolada de bordes } \\
\text { Paralelos }\end{array}$ & Lateral & Marginal corto & $30^{\circ}$ & Activo \\
\hline 8 & Denticulado & Retoque marginal & Unif. directo & $\begin{array}{l}\text { Circular incompleta } \\
\text { Irregular }\end{array}$ & Frontal & Indet. & $60^{\circ}$ & Activo \\
\hline 14 & Punta Burilante & Talla de extracción & Unif. directo & Trapezoidal asimétrico & Lateral & de buril? & -- & Activo \\
\hline 3 & Raspador & Retoque marginal & Unif. directo & Circular Irregular & Perimet. & Escamoso irregular & $55^{\circ}$ & Activo \\
\hline 4 & Raspador (D) & Microretoque marginal & Unif. directo & Elíptica irregular & Fronto-lateral & Marginal corto & $45^{\circ}$ & Activo \\
\hline
\end{tabular}

Tabla 8.10. Arroyo Verde 1M2: Rasgos morfotécnicos de los artefactos tallados. Referencias: Sit. Lascados: situación de los lascados; F. Geom.: forma geométrica, Posic.Fil: Posición del filo; F.Lasc. Forma de los lascados; Ang. Ángulo del filo; restr. Restringido; Unif: Unificial; Indet: indeterminado. 


\section{Núcleos}

Del total $(\mathrm{n}=9)$ del M1, cinco provienen de rodados de sílice, uno de un rodado de basalto, dos de bloques de calizas fosilizadas y uno de una ignimbrita indeterminada. Todos son de procedencia local. Excepto la ignimbrita de calidad regular para la talla, el resto presenta calidad muy buena. En cuanto a los tamaños, excepto los tres núcleos de sílice que son de tamaño mediano (entre 36 y $40 \mathrm{~mm}$ de largo), el resto son grandes con medidas máximas de entre 50 y $60 \mathrm{~mm}$ (Fig.8.5). Respecto de la morfología, son mayoría los discoidales irregulares $(\mathrm{n}=5)$, aunque también se registraron de lascados aislados $(\mathrm{n}=2)$ y uno bifacial y bipiramidal respectivamente. De acuerdo con el grado de modificación y el porcentaje de corteza se identificó que, independientemente de las materias primas, casi todos los núcleos $(n=7)$ se encuentran activos; los únicos agotados son uno de sílice y otro de caliza fosilizada de muy buena calidad. En relación con la forma de los negativos de las extracciones se determinó que la gran mayoría ( $\mathrm{n}=8$ ) son de lascas y solo uno de lámina (Tabla 8.9)

En el M2 los seis núcleos rescatados están manufacturados sobre materias primas locales, cuatro provienen de bloques: dos de calcedonia, otro de ignimbrita y el ultimo de toba; los dos restantes son de rodados de sílice. El tamaño de los núcleos es grande a muy grande; los primeros (entre 50 y $60 \mathrm{~mm}$ de largo) son de sílice y de calcedonia, y los de mayor tamaño (entre 70 y 125) corresponden cada uno a un tipo de roca distinto (Fig.8.4). Se identificaron distintas morfologías: dos bifaciales, dos de lascados aislados y los dos restantes son un discoidal irregular y un poliédrico. Sólo un núcleo se encuentra agotado y corresponde a la pieza bifacial de calcedonia. Todas las extracciones son de lascas (Tabla 8.9 y 8.10).

\begin{tabular}{|ll|clclll|}
\hline $\begin{array}{l}\text { Materia } \\
\text { prima }\end{array}$ & Morfología & $\begin{array}{l}\mathbf{N}^{\mathbf{0}} \text { mín } \\
\text { plat } \\
\text { perc. }\end{array}$ & $\begin{array}{l}\text { Forma sup plat } \\
\text { perc. }\end{array}$ & $\begin{array}{l}\mathbf{N}^{\mathbf{0}} \\
\text { lasc. }\end{array}$ & $\begin{array}{l}\text { Forma } \\
\text { negat } \\
\text { lasc }\end{array}$ & $\begin{array}{l}\text { Grado } \\
\text { modific }\end{array}$ & Estado \\
\hline Sílice & $\begin{array}{l}\text { Discoidal } \\
\text { irregular }\end{array}$ & 2 & Liso natural & 5 & Lasca & Alto & Agotado \\
\hline Sílice & $\begin{array}{l}\text { Discoidal } \\
\text { irregular }\end{array}$ & 3 & Liso & 5 & Lasca & Medio & Activo \\
\hline Sílice & $\begin{array}{l}\text { Lascados } \\
\text { aislados }\end{array}$ & 2 & Cortical & 4 & Lasca & Medio & Activo \\
\hline Sílice & Bipiramidal & 4 & Liso & 3 & Lasca & Medio & Activo \\
\hline Sílice & $\begin{array}{l}\text { Discoidal } \\
\text { irregular }\end{array}$ & 2 & Liso natural & 6 & Lasca & Indet. & Activo \\
\hline Caliza & $\begin{array}{l}\text { Discoidal } \\
\text { irregular }\end{array}$ & 3 & Liso natural & 7 & Lasca & Medio & Activo \\
\hline Caliza & Bifacial & 3 & Liso & 6 & Lámina & Alto & Agotado \\
\hline Basalto & $\begin{array}{l}\text { Lascados } \\
\text { aislados }\end{array}$ & 2 & Liso & 4 & Lasca & Medio & Activo \\
\hline $\begin{array}{l}\text { Ignimbri } \\
\text { ta }\end{array}$ & $\begin{array}{l}\text { Discoidal } \\
\text { irregular }\end{array}$ & 4 & Liso & 4 & Lasca & Medio & Activo \\
\hline
\end{tabular}

Tabla 8.11. Arroyo Verde 1 M1: características morfológicas y técnicas de los núcleos. 


\begin{tabular}{|cc|clclll|}
$\begin{array}{c}\text { Materia } \\
\text { prima }\end{array}$ & Morfología & $\begin{array}{l}\mathbf{N}^{\mathbf{0}} \text { mín } \\
\text { plat } \\
\text { perc. }\end{array}$ & $\begin{array}{l}\text { Forma sup plat } \\
\text { perc. }\end{array}$ & $\begin{array}{l}\mathbf{N}^{\mathbf{0}} \\
\text { lasc. }\end{array}$ & $\begin{array}{l}\text { Forma } \\
\text { negat } \\
\text { lasc }\end{array}$ & $\begin{array}{l}\text { Grado } \\
\text { modific }\end{array}$ & Estado \\
\hline Calcedonia & Bifacial & 3 & Liso natural & 5 & Lasca & Alto & Agotado \\
\hline Calcedonia & Poliédrico & 3 & Cortical & 4 & Lasca & Medio & Activo \\
\hline Sílice & $\begin{array}{c}\text { Lascados } \\
\text { aislados }\end{array}$ & 2 & Cortical & 3 & Lasca & Medio & Activo \\
\hline Sílice & $\begin{array}{c}\text { Lascados } \\
\text { aislados }\end{array}$ & 2 & Liso natural & 2 & Lasca & Bajo & Activo \\
\hline Ignimbrita & $\begin{array}{c}\text { Discoidal } \\
\text { irregular }\end{array}$ & 5 & Liso natural & 6 & Lasca & Medio & Activo \\
\hline Toba & Bifacial & 3 & Liso natural & 5 & Lasca & Alto & Activo \\
\hline
\end{tabular}

Tabla 8.12. Arroyo Verde 1 M2: características morfológicas y técnicas de los núcleos.

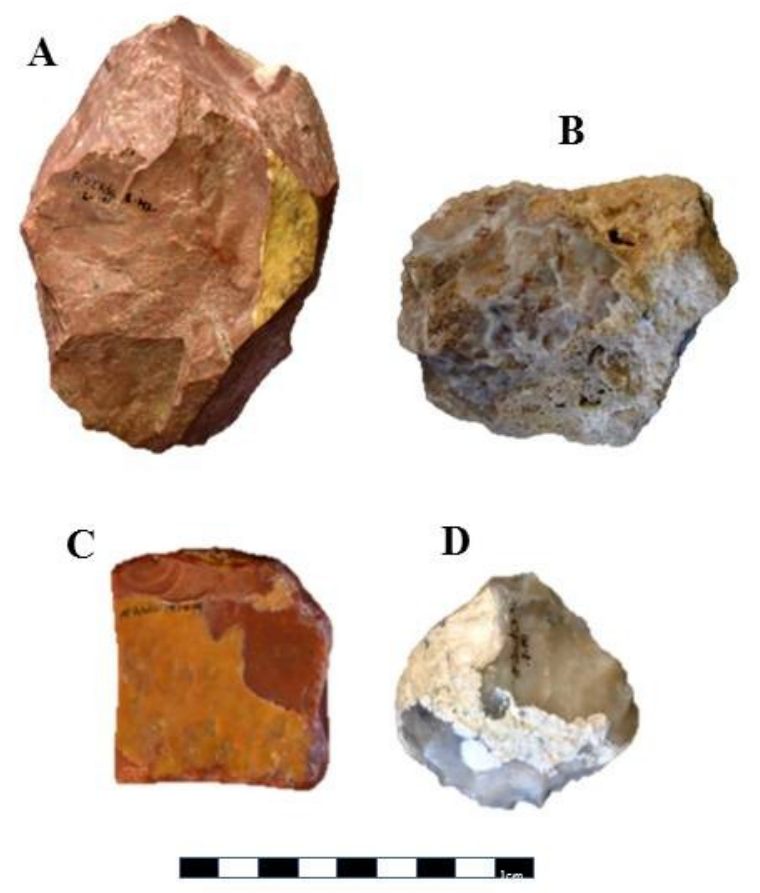

Fig. 8.4. Arroyo Verde 1 M2, tipos de núcleos.

\section{Índice de fractura}

En el M1 se registró un porcentaje elevado de fracturas $(n=81: 44 \%)$, en casi la totalidad de las clases artefactuales, excepto los núcleos y el percutor. En el M2 el valor porcentual de fractura es menor $(n=18: 25 \%)$ y se registra sólo entre los desechos (Tabla 8.13). 


\begin{tabular}{|l|c|c|}
\hline \multirow{2}{*}{$\begin{array}{c}\text { Clase } \\
\text { Tipológica }\end{array}$} & \multicolumn{2}{|c|}{ Fracturas } \\
\cline { 2 - 3 } & $\mathbf{A}^{\mathbf{0}}$ Verde 1M1 & $\mathbf{A}^{\mathbf{0}}$ Verde 1 M2 \\
\hline Artef. Pic. Pulido & 1 & -- \\
\hline Artf. Mod. Por uso & -- & -- \\
\hline Desechos & 73 & 18 \\
\hline Art. Form. talla & 5 & -- \\
\hline Rastros comp. & 2 & -- \\
\hline Núcleos & -- & -- \\
\hline $\mathbf{N}$ & $\mathbf{8 1}$ & $\mathbf{1 8}$ \\
\hline $\mathbf{\%}$ & $\mathbf{4 4 , 2}$ & $\mathbf{2 5}$ \\
\hline
\end{tabular}

Tabla 8.13 Frecuencia de fracturas por clase tipológica.

\section{Relaciones de ensamblaje}

En el M1 se pudieron efectuar tres relaciones de ensamblaje. La primera corresponde a dos lascas de tamaño pequeño de riolita que remontan por fractura. El otro conjunto remontado se asocia a cuatro lascas y un núcleo de calcedonia, que estarían relacionados con actividades de talla (Carballido y Bellelli 1999). El otro ensamblaje también se estableció entre un núcleo y una lasca pequeña de sílice (Fig. 8.5). No obstante si bien no se logró remontar otros conjuntos, se observó que varios de los artefactos presentaban similitudes entre la coloración, tipo de corteza y estructura interna de la roca lo que permitió inferir que provenían del mismo nódulo. Para el M2 por el contrario no se logró efectuar ningún ensamblaje entre las piezas, sin embargo al igual que en el M1 varios artefactos corresponderían a un mismo nódulo dada las similitudes entre las materias primas.

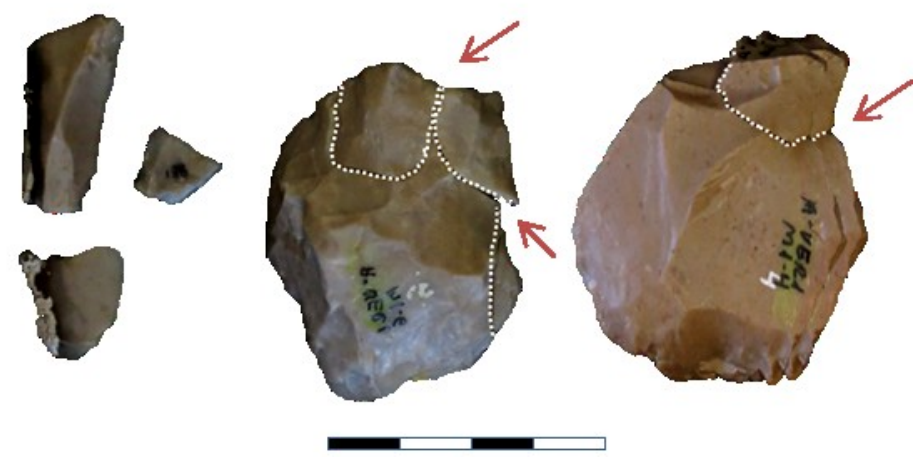

Fig. 8.5. Relación de ensamblaje, núcleos con desechos de talla Arroyo Verde 1 M1 


\section{Frecuencias de módulos laminares, bipolaridad y bifacialidad:}

En el M1 se registró laminaridad en seis artefactos (3,2\% del total): en cinco desechos (uno de caliza fosilizada y cuatro de ignimbrita), y en un cuchillo de filo retocado de calcedonia. La bipolaridad se identificó sólo en un artefacto de sílice $(0,5 \%)$ : se trata de una lasca nucleiforme sobre rodado de tamaño pequeño. Por último, la técnica bifacial se observó únicamente en dos casos (1\%): en el núcleo de caliza bifacial y en un artefacto formatizado por talla de sílice. En el M2 no se registró la presencia de técnica bipolar; la bifacialidad se identificó en los dos núcleos mencionados $(2,7 \%)$, mientras que la laminaridad se encuentra bastante más representada ( $\mathrm{n}=8: 11 \%)$. Esta última se identificó en seis desechos de tamaño muy grande de ignimbrita, en un rastro complementario sobre una hoja muy grande sobre la misma roca y en un raspador de xilópalo, cuyo soporte es una lámina muy pequeña.

\section{Tendencias generales de los conjuntos líticos de la localidad arqueológica Arroyo Verde}

Sobre la base del registro arqueofaunístico y los patrones de asentamiento Gómez Otero (2006: cap. 5) interpretó que los dos muestreos de Arroyo Verde 1 correspondían a sucesivas ocupaciones de tipo localización relacionadas con actividades extractivas. No obstante, el análisis tecno morfológico indica diferencias entre ambos muestreos. El Muestreo 1 presenta mayor diversidad artefactual (seis clases) y superior diversidad litológica con presencia de rocas no locales $(\mathrm{n}=4)$ obtenibles en un radio de hasta $280 \mathrm{~km}$ hacia el interior. Esto sugiere la circulación de materias primas entre la costa y el interior desde por lo menos el Holoceno medio. Por su parte, la diversidad faunística marina y, sobre todo, el NMI de 22 meros sugieren que estos grupos tenían los conocimientos y la tecnología necesarios para la obtención de estos $\mathrm{s}$ recursos del ambiente litoral. En cuanto a la funcionalidad y la duración de la ocupación, la presencia de artefactos en materias primas foráneas implica costos de obtención mayores a los esperados para una ocupación de actividades restringidas y de corta duración. Esto estaría también indicado por las evidencias de talla avanzada (tamaño pequeño de los artefactos, desechos de talla microlíticos, variedad de talones, escasez de corteza) y presencia de todas las clases artefactuales (núcleos, desechos de talla, instrumentos formatizados por talla, entre otros). Se puede argumentar en contra que hay escasez de artefactos formatizados, pero esto podría deberse a la colecta por parte de aficionados; cabe destacar que es una zona ocupada frecuentemente por pescadores artesanales.

El Muestreo 2 presenta menor densidad, variedad litológica y diversidad artefactual (cuatro de seis clases). Por otra parte el tamaño mediano a muy grande de los artefactos, la reserva de corteza en porcentajes importante y el predominio de talones corticales y lisos, señalan etapas iniciales de la producción lítica. 
En síntesis, para el Muestreo 1 se infiere una ocupación en la que tuvieron lugar distintas actividades: a) talla lítica en sus últimas etapas, con producción de artefactos formatizados; b) obtención y consumo in situ de invertebrados, peces y pequeños mamíferos, c) probable caza y procesamiento de mamíferos grandes, posiblemente guanaco (si se acepta que las astillas indeterminadas corresponden a esta presa). 


\section{Localidad arqueológica Rincón de Elizalde}

La localidad arqueológica denominada Rincón de Elizalde abarca un perímetro litoral de aproximadamente diez kilómetros, en un sector de costa de tres kilómetros y medio de ancho máximo, con puntas o promontorios asociados con restingas (Gómez Otero 2006). El área fue declarada Refugio de la Fundación Vida Silvestre en el año 2003, y a partir de entonces la reserva es gestionada por la Fundación Patagonia Natural. Este tramo costero está configurado por cordones litorales pleistocénicos y holocénicos que ofrecen abundantes rodados aptos para la tecnología lítica. También cuenta con arcillas de buena calidad para la tecnología cerámica. No se observaron relieves dunarios ni fuentes permanentes de agua dulce (Gómez Otero 2006: Cap.5).

En el año 2001, Gómez Otero y equipo efectuaron el relevamiento de esta localidad e identificaron seis sitios en superficie y siete acumulaciones artificiales de moluscos (Gómez Otero 2006). Los métodos de campo consistieron en una prospección alrededor de la estancia Rincón de Elizalde, una transecta paralela a la franja costera y tres transectas lineales transversales a la misma (Gómez Otero 2006:138).

Para esta tesis se estudiaron los materiales recuperados en tres muestreos, dos de los cuales provienen del sitio Rincón de Elizalde 1: Muestreo 1 y Conchero 9, y otro del sitio 5. Todos estos contextos cuentan con fechados radiocarbónicos que establecen la presencia de ocupaciones humanas entre el Holoceno tardío inicial y final (Gómez Otero 2006: 133).

\begin{tabular}{cclll}
\hline \multicolumn{1}{c}{ Muestreo } & Lat / Long & $\begin{array}{c}\text { Fechado } \\
\text { Años Cal }\end{array}$ & Muestra & LP-1551 \\
\hline REliz 1 M1- CH1 & $42^{\circ} 09,381^{\prime} \mathrm{S}$ & $2220 \pm 70 / 57-339 \mathrm{AC}$ & Carbón & LP-1348 \\
& $64^{\circ} 55,192^{\prime} \mathrm{O}$ & $2007-2349 \mathrm{AP}$ & & \\
& & & & \\
REliz 1- CH9 & $42^{\circ} 09,381^{\prime} \mathrm{S}$ & $2170 \pm 80 / 67-365 \mathrm{AC}$ & Carbón & LP-1507 \\
& $64^{\circ} 55,192^{\prime} \mathrm{O}$ & $2017-2315$ & & \\
& & & & \\
REliz 5- M1-CH1 & $42^{\circ} 11,090^{\prime} \mathrm{S}$ & $470 \pm 60 / 1397-1621 \mathrm{DC}$ & Carbón & LP-1352 \\
& $64^{\circ} 52,151^{\prime} \mathrm{O}$ & $329-533$ & & \\
\hline
\end{tabular}

Tabla 8.14. Localidad Rincón de Elizalde: localización y fechados obtenidos del sitio 1 y 5 . Referencias: Lab. Laboratorio, BT: bloque temporal; LC: localización. 


\section{Rincón de Elizalde 1}

Este sitio fue ubicado sobre una terraza marina baja, a 50 metros de la línea de marea (Gómez Otero 2006:138). Para su estudio se realizó un muestreo sistemático de 4 metros de lado y un sub-muestreo en el cuadrante oeste de 2 x 4 metros que incluyó el uso de zaranda de malla fina de 1,3 mm. En total se obtuvieron 397 artefactos líticos. Además se registraron relictos de concheros (Fig. 8.6) conformados mayoritariamente por valvas de distintas especies malacológicas: en algunos casos solo por cholgas (Aulacomya ater), en otros por picorocos (Megabalanus) y lapas (Patinigera) y uno solo por vieras (Chlamys). Otros taxones faunísticos están escasamente representados, tales como restos de pinnípedos cría, aves, guanacos y algunas placas de armadillo (Gómez Otero 2006). En algunos concheros además se hallaron artefactos líticos. Muestras de carbón fechadas mediante ${ }^{14} \mathrm{C}$ del Conchero 1 y del Conchero 9 arrojaron una antigüedad de $2220 \pm 70$ años AP y $2170 \pm 80$ años AP, respectivamente (Gómez Otero 2006).

Por fuera de los muestreos sistemáticos se registró una pequeña concentración cerámica compuesta por un borde y dos tiestos (Schuster 2013), fragmentos pequeños grabados de pizarra (uno de ellos con incisiones finas), un percutor sobre huesos de cetáceo fósil y desechos de talla de obsidiana del tipo T/SCI, cuya fuente se localiza en Sierra Negra (zona de Telsen), a poco más de 100 km (Gómez Otero y Stern 2005). La pizarra pudo haber sido obtenida de la Mina Gonzalito, a $200 \mathrm{~km}$ al noroeste (Gómez Otero 2006).

Sobre la base de estas evidencias se propuso que en el sitio se habrían llevado a cabo actividades extractivas y en menor grado de mantenimiento, ambas relacionadas con ocupaciones de tipo localización y/o campamentos transitorios (Gómez Otero 2006:139).

\section{Rincón de Elizalde 5}

Se trata de un sitio de superficie localizado a 150 metros de la línea de marea, emplazado sobre sedimentos del Terciario muy erosionados por acción hídrica. Incluye pequeños relictos de concheros compuestos mayoritariamente por valvas de lapas (Patinigera) y cholgas (Aulacomya ater) (Gómez Otero 2006:140). Se realizó un muestreo se superficie de 4 metros de lado, recuperándose 93 artefactos líticos y un muestreo sistemático de 50 x 50 de lado en el Conchero 1 (Fig.8.6), que arrojó una antigüedad de $470 \pm 60$ años ${ }^{14} \mathrm{C} \mathrm{AP}$, obtenida de restos de carbón. De acuerdo con Gómez Otero (2006) los rasgos arqueológicos detectados señalan la presencia de ocupaciones de tipo localización (sensu Binford 1980). 


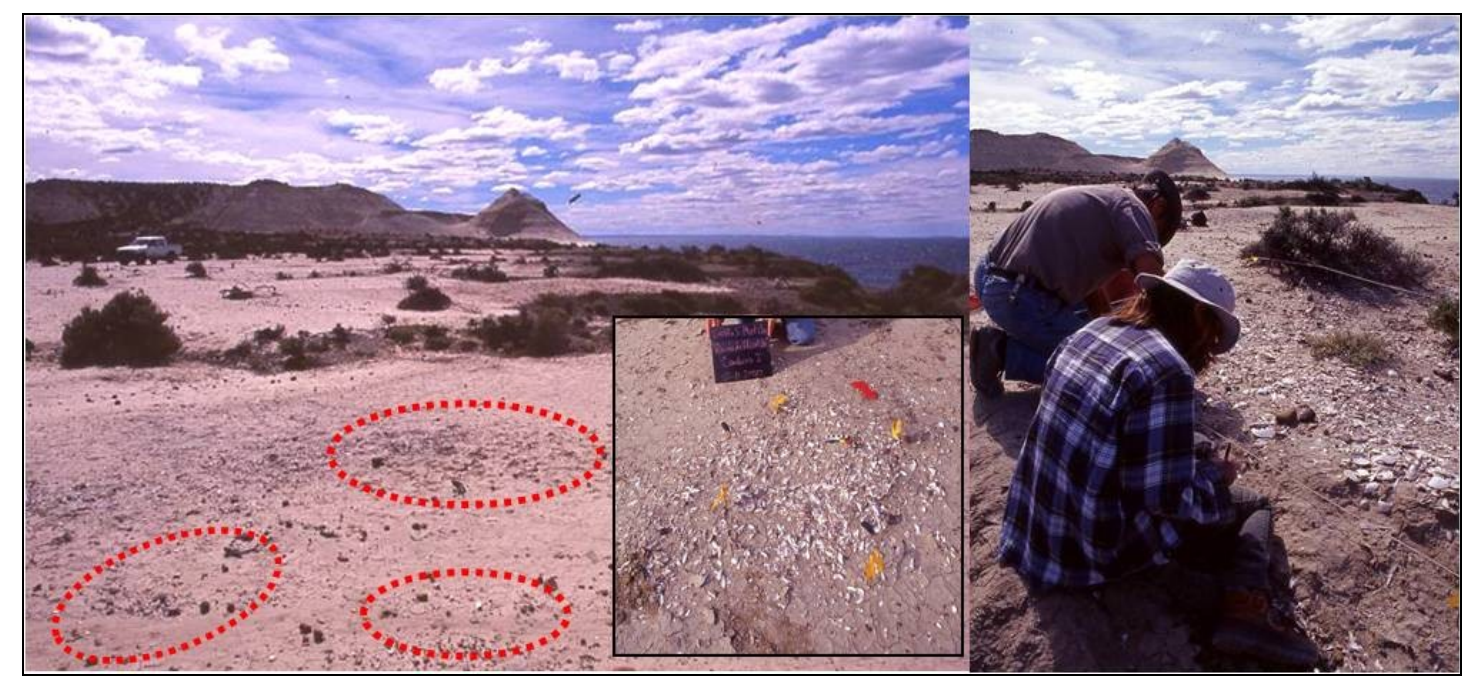

Fig. 8.6. Localidad arqueológica Rincón de Elizalde: REliz 1 M1 (izquierda) y RElíz 5 (derecha).

\section{Análisis tecnológico}

En el muestreo del sitio Rincón de Elizalde 1 (en adelante RElíz 1 M1) se recuperaron

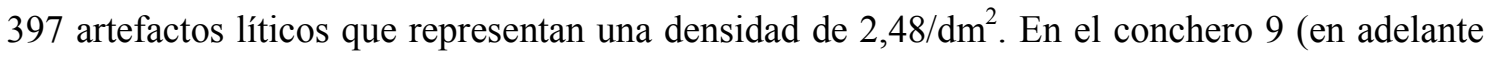
RElíz 1 CH9) ubicado dentro del mismo sitio se registraron 14 artefactos y una densidad artefactual de $0,006 \mathrm{dm}^{2}$. Por último en el muestreo 1 del sitio 5 (en adelante RElíz $5 \mathrm{M} 1$ ) se recogieron 93 artefactos líticos, cuya densidad artefactual resultó de $0,058 / \mathrm{dm}^{2}$.

\section{Materias primas:}

En el REliz 1 M1 se reconocieron doce clases de rocas, destacándose la presencia de sílices (45\%) y basaltos (33\%) ambas de muy buena calidad para la talla. En menor proporción le siguen las calcedonias ( $8 \%$ ) de muy buena a excelente calidad y los xilópalos (6\%) de calidad muy buena a buena. El resto de las litologías -caliza fosilizada, cuarcita, ignimbrita, jaspe, ópalo, riolita, toba y obisidiana gris verdosa- se encuentra muy escasamente representada y en valores parejos (entre 0,5 y $1,4 \%$ ). Salvo el jaspe y la obsidiana, de excelente calidad para la talla el resto son de aptitud regular a buena (Tabla 8.15).

Para los escasos artefactos líticos rescatados en el conchero 9 se reconocieron cuatro clases de rocas: sílices de distintas tonalidades $(n=9)$, basaltos $(n=3)$, calcedonia y xilópalo $(n=$ 1 de cada una). Todas son de muy buena calidad (Tabla 8. 15).

Las variedades litológicas del conjunto artefactual del sitio 5 son nueve y hay una indeterminada. La de mayor importancia es la sílice (40\%) y en segundo lugar el basalto (19\%), ambas de calidad buena a muy buena. Xilópalos, ignimbritas y otras rocas indeterminadas se encuentran en proporciones iguales $(75 \%)$ y el resto -toba; calcedonia, cuarcita, jaspe y basalto olivínico- se registran entre el 2 y $6 \%$. Los xilópalos, las caledonias y el jaspe son de calidad 
excelente a muy buena; cuarcitas, ignimbritas, tobas y el basalto olívinico presentan aptitud buena a regular (Tabla 8.15).

\begin{tabular}{|c|c|c|c|c|c|}
\hline \multirow{2}{*}{$\begin{array}{c}\text { Materias } \\
\text { primas }\end{array}$} & \multicolumn{2}{|c|}{ RElíz 1 M1 } & RElíz 1 CH9 & \multicolumn{2}{|c|}{ RElíz 5 } \\
\cline { 2 - 7 } Basalto & 69 & 33 & $\mathbf{N}$ & $\mathbf{N}$ & $\mathbf{\%}$ \\
\hline Basalto olivínico & -- & -- & -- & 10 & 18,9 \\
\hline Calcedonia & 17 & 8,1 & 1 & 2 & 3,8 \\
\hline Caliza fosilizada & 1 & 0,5 & -- & -- & -- \\
\hline Cuarcita & 3 & 1,4 & -- & 3 & 5,7 \\
\hline Ignimbrita & 1 & 0,5 & -- & 4 & 7,5 \\
\hline Jaspe & 2 & 0,9 & -- & 1 & 1,9 \\
\hline Obsidiana & 3 & 1,4 & -- & -- & -- \\
\hline Ópalo & 1 & 0,5 & -- & -- & -- \\
\hline Riolita & 2 & 0,9 & -- & -- & -- \\
\hline Sílice & 95 & 45,5 & 9 & 21 & 39,6 \\
\hline Toba & 2 & 0,9 & -- & 3 & 5,7 \\
\hline Xilópalo & 13 & 6,2 & 1 & 4 & 7,5 \\
\hline Indeterminado & -- & -- & -- & 4 & 7,5 \\
\hline Total & $\mathbf{2 0 9}$ & $\mathbf{1 0 0}$ & $\mathbf{1 4}$ & $\mathbf{5 3}$ & $\mathbf{1 0 0}$ \\
\hline
\end{tabular}

Tabla 8.15. Tipos y frecuencias de las variedades litológicas.

De acuerdo con el estudio de la disponibilidad local de materias primas líticas (ampliar Capítulo 6) se infiere, que excepto el basalto olivínico, la caliza fosilizada, los xilópalos, el jaspe y la obsidiana gris-verdosa, el resto de las materias primas se encuentra localmente en forma de rodados de tamaños medianos y pequeños.

En relación con la corteza y la estructura interna de la roca, para el sitio RElíz 1 M1 se observó correspondencia en más de la mitad de las piezas $(n=138: 66 \%)$, principalmente en sílices y basaltos. En el $24 \%(\mathrm{n}=49)$ de los casos (otras rocas silíceas, calcedonias y ópalos) no pudo ser determinado, y el $10 \%(\mathrm{n}=21)$ (xilópalos y en las calizas fosilizadas) no se observaron similitudes. Por su parte, la presencia de alteraciones en la superficie de las rocas se observó en doce artefactos: de los artefactos de basalto cuatro tienen pátina y dos lustre; de los de sílices cuatro muestran daño térmico y en un artefacto de un artefacto de basalto y en otro de sílice se registraron rastros de carbonatación.

De los artefactos del muestreo de RElíz $1 \mathrm{CH} 9$ todos evidenciaron similitudes entre la corteza y el interior de la roca. Con excepción de una lasca de calcedonia, en el resto de los 
artefactos se observó la presencia de pátinas o rock coatings ${ }^{5}$ (sensu Borrazzo 2006) probablemente relacionado con la historia depositacional de las piezas y su preservación en la matríz sedimentaria.

En REliz 5, el $31 \%(n=31)$ de los artefactos -mayoritariamente de basalto, sílices, tobas y xilópalos- se pudo determinar semejanzas entre la superficie y el interior de la roca. En cambio, en el $28 \%(n=15)$ la calidad de las materias primas (cuarcitas, calcedonias, jaspe y en otras indeterminadas) solamente se determinó a partir de la observación del interior o la textura interna de la roca; por último y porcentajes inferiores $(\mathrm{n}=7: 13 \%)$ no se pudo evaluar la relación debido a la ausencia de corteza. En cuanto a las alteraciones postdepositaciones, un número elevado de artefactos $(n=35: 66 \%)$ en rocas con alto grado de silicificación (sílices, calcedonias y xilópalos) presenta rock coating $(\mathrm{n}=14)$. En rocas indeterminadas también se identificó daño térmico $(n=3)$ y lustre en una lasca de cuarcita.

\section{Clases artefactuales:}

Para el sitio RElíz 1 M1 predomina la clase de los desechos de talla (86\%), seguidos por los núcleos $(7 \%)$, los artefactos formatizados por talla (4\%) y en tercer lugar las lascas con rastros complementarios $(2,5 \%)$. No se recuperaron artefactos modificados por el uso ni instrumentos formatizados por picado y pulido. En el conchero 9 se rescató un solo núcleo y el resto son desechos de talla $(\mathrm{n}=13)$ (Tabla 8.16$)$.

En RElíz 5 también sobresale el grupo de los desechos (93\%), en baja frecuencia se ubican los núcleos $(4 \%)$ y los artefactos formatizados por talla y por picado y pulido $(1 \% \mathrm{de}$ cada uno) (Tabla 8.16).

\begin{tabular}{|c|c|c|c|c|c|c|}
\hline \multirow[b]{2}{*}{ Clases } & \multirow[b]{2}{*}{ Núcleo } & \multirow[b]{2}{*}{ Desechos } & \multicolumn{4}{|c|}{ Instrumentos } \\
\hline & & & $\begin{array}{c}\text { Art.Form } \\
\text { por talla }\end{array}$ & $\begin{array}{c}\text { Rastros } \\
\text { comp. }\end{array}$ & $\begin{array}{l}\text { Art. Modific } \\
\text { por el uso }\end{array}$ & $\begin{array}{c}\text { Art.Form } \\
\text { PyP. }\end{array}$ \\
\hline $\begin{array}{c}\text { RElíz } 1 \text { M1 } \\
\text { (N= 397) }\end{array}$ & $\begin{array}{c}27: \\
6,8 \%\end{array}$ & $\begin{array}{c}344: \\
86,6 \%\end{array}$ & $\begin{array}{l}16: \\
4 \%\end{array}$ & $\begin{array}{c}10: \\
2,5 \%\end{array}$ & Pon & . \\
\hline $\begin{array}{c}\text { RElíz CH9 } \\
(\mathbf{N}=14)\end{array}$ & $\begin{array}{c}1: \\
7,2 \%\end{array}$ & $\begin{array}{c}13: \\
92,8 \%\end{array}$ & -- & -- & -- & -- \\
\hline $\begin{array}{l}\text { REliz } 5 \\
(\mathrm{~N}=93)\end{array}$ & $\begin{array}{c}4: \\
4,3 \%\end{array}$ & $\begin{array}{c}87: \\
92,6 \%\end{array}$ & $\begin{array}{c}1: \\
1,1 \%\end{array}$ & -- & -- & $\begin{array}{c}1: \\
1,1 \%\end{array}$ \\
\hline
\end{tabular}

Tabla 8.16. Distribución de las clases artefactuales.

\footnotetext{
${ }^{5}$ De acuerdo con Borrazzo (2009: 124) los rock coatings son microdepósitos acrecionales de minerales que se forman en la superficie de las rocas. Incluyen lo que se denomina "pátinas" o "barnices del desierto".
} 


\section{Desechos de talla:}

Para RElíz 1 M1 prevalecen las lascas enteras ( $\mathrm{n}=96: 61,9 \%$ ), en segundo lugar las fracturadas con talón $(n=47: 30 \%)$, y por último las fracturadas sin talón $(n=12: 7,7 \%)$. Entre los tipos de lascas se destacan las primarias (28\%) y las de dorso natural (26,5\%); en porcentajes inferiores y parejos se registran bipolares, indeterminadas (10\% de cada una) y las nucleiformes (6,5\%). El resto no supera el $5 \%$ (Tabla 8.17). En el conchero 9 la mitad de las lascas no pudieron ser determinadas $(\mathrm{n}=6)$, otras $(\mathrm{n}=4)$ son de reactivación inversa y las tres restantes de arista inclinada, secundaria y nucleiforme (Tabla 8.17).

En cuanto al estado de las lascas para el muestreo de RElíz 5 se registró que la gran mayoría se encuentran enteras $(n=33: 70,2 \%)$ y un porcentaje inferior fracturadas con talón ( $\mathrm{n}=$ 13: $27,7 \%$ ). El tipo predominante son las lascas primarias (32\%), seguidas por las de dorso natural $(21 \%)$ y las secundarias (11\%). En muy baja frecuencia -entre 2 y $6 \%$ - se identificaron de arista oblicua y nucleiformes ( $6 \%$ cada una), aristas rectas e inclinadas (4,3\% de cada una) y en cresta, con dorso preparado y bipolar ( $2 \%$ respectivamente). El 8,5\% no pudo determinarse (Tabla 8.17).

\begin{tabular}{|c|c|c|c|c|c|c|}
\hline \multirow{2}{*}{ Tipo de lascas } & \multicolumn{2}{|c|}{ REliz 1 M1 } & \multicolumn{2}{c|}{ RElíz 1 CH9 } & \multicolumn{2}{c|}{ RElíz 5 } \\
\cline { 2 - 8 } & $\mathbf{N}$ & $\mathbf{\%}$ & $\mathbf{N}$ & $\mathbf{\%}$ & $\mathbf{N}$ & $\mathbf{\%}$ \\
\hline de arista oblicua & 3 & 1,9 & -- & -- & 3 & 6,4 \\
\hline de arista inclinada & 5 & 3,2 & 1 & -- & 2 & 4,3 \\
\hline con dorso natural & 41 & 26,5 & -- & -- & 10 & 21,3 \\
\hline de arista recta & -- & -- & -- & -- & 2 & 4,3 \\
\hline Primaria & 44 & 28,4 & -- & -- & 15 & 31,9 \\
\hline de reactivación inversa & 4 & 2,6 & 4 & -- & -- & -- \\
\hline En cresta & 5 & 3,2 & -- & -- & 1 & 2,1 \\
\hline con dorso preparado & 1 & 0,6 & -- & -- & 1 & 2,1 \\
\hline Secundaria & 7 & 4,5 & 1 & -- & 5 & 10,6 \\
\hline Nucleiforme & 10 & 6,5 & 1 & -- & 3 & 6,4 \\
\hline Angular recta & 3 & 1,9 & -- & -- & -- & -- \\
\hline Bipolar & 15 & 9,7 & -- & -- & 1 & 2,1 \\
\hline Indeterminada & 16 & 10,3 & 6 & -- & 4 & 8,5 \\
\hline Hoja de arista doble & 1 & 0,6 & -- & -- & -- & -- \\
\hline Total & $\mathbf{1 5 5}$ & $\mathbf{1 0 0} \%$ & & $\mathbf{1 3}$ & $\mathbf{4 7}$ & $\mathbf{1 0 0 \%}$ \\
\hline
\end{tabular}

Tabla 8.17. Tipos y frecuencias de lascas.

Para el conjunto de RELiz 1 M1 el tamaño de las lascas se distribuye en pequeños (38 \%) y medianos (32\%); en frecuencias inferiores se encuentran las microlíticas (19,4\%), las de tamaño grande $(7,1 \%)$ y por último las hipermicrolíticas $(3,9 \%)$. El módulo más representado es el mediano-normal (75\%), seguidos por alargado (15\%), corto ancho $(4,5 \%)$, mediano 
alargado (3 \%) y laminar normal (1 \%) (Tabla 8.18). En REliz 1 CH9 se rescataron cinco hipermicrolascas y microlascas respectivamente, dos lascas pequeñas y una mediana. Casi la totalidad de las lascas tienen módulo mediano normal $(n=11)$, los dos restantes son medianos alargados (Tabla 8.18).

En REliz 5 gran parte de las lascas son de tamaño pequeño (42\%), en segundo lugar se ubican las microlascas (28\%), y por último las medianas (19\%) y grandes (11\%). El módulo que registra mayor frecuencia es el mediano-normal (72\%), en porcentajes inferiores también se identificaron los medianos alargados (17\%), las lascas anchas (4\%) y en muy baja frecuencia $(2,1 \%)$ corto ancho, laminar normal y lasca alargada (8.18).

\begin{tabular}{|c|c|c|c|c|c|c|c|c|c|}
\hline & $\begin{array}{l}\text { Tamaño } \\
\text { Módulo }\end{array}$ & $\begin{array}{l}\text { Corto } \\
\text { ancho }\end{array}$ & $\begin{array}{c}\text { Lam } \\
\text { normal }\end{array}$ & $\begin{array}{l}\text { Lasca } \\
\text { alarg. }\end{array}$ & $\begin{array}{l}\text { Lasca } \\
\text { ancho }\end{array}$ & $\begin{array}{l}\text { Med. } \\
\text { alarg }\end{array}$ & $\begin{array}{c}\text { Med. } \\
\text { normal }\end{array}$ & \multicolumn{2}{|c|}{ Total } \\
\hline \multirow{7}{*}{ 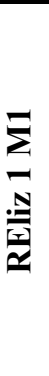 } & Hipermicrolasca & -- & -- & -- & -- & -- & 6 & 6 & $3,8 \%$ \\
\hline & Microlasca & 2 & -- & -- & -- & - & 28 & 30 & $19,3 \%$ \\
\hline & Lasca Pequeña & 3 & -- & 13 & -- & -- & 43 & 59 & $38 \%$ \\
\hline & Lasca Mediana & 1 & 1 & 11 & -- & -- & 36 & 49 & $31,6 \%$ \\
\hline & Lasca Grande & 1 & 1 & -- & -- & 5 & 4 & 11 & $7 \%$ \\
\hline & Microlámina & - & - & -- & -- & -- & - & -- & -- \\
\hline & Total & $7: 4,5 \%$ & $2: 1,2 \%$ & $24: 15,4 \%$ & -- & $5: 3,2 \%$ & $117: 75,4 \%$ & 155 & $100 \%$ \\
\hline \multirow{6}{*}{$\begin{array}{l}\stackrel{\vartheta}{0} \\
\underline{0} \\
\underline{x} \\
\underline{x}\end{array}$} & $\begin{array}{l}\text { Tamaño } \\
\text { Módulo }\end{array}$ & $\begin{array}{l}\text { Corto } \\
\text { ancho }\end{array}$ & $\begin{array}{c}\text { Lam. } \\
\text { normal }\end{array}$ & $\begin{array}{l}\text { Lasca } \\
\text { Alarg. }\end{array}$ & $\begin{array}{l}\text { Lasca } \\
\text { ancha }\end{array}$ & $\begin{array}{l}\text { Med. } \\
\text { Alarg. }\end{array}$ & $\begin{array}{c}\text { Med. } \\
\text { normal }\end{array}$ & & otal \\
\hline & Hipermicrolasca & -- & -- & -- & -- & -- & 5 & & 5 \\
\hline & Microlasca & -- & -- & -- & -- & 1 & 4 & & 5 \\
\hline & Lasca Pequeña & - & - & -- & -- & - & 2 & & 2 \\
\hline & Lasca Mediana & -- & -- & -- & -- & 1 & -- & & 1 \\
\hline & Total & -- & -- & -- & -- & 2 & 11 & & 13 \\
\hline \multirow{6}{*}{ 兄 } & $\begin{array}{l}\text { Tamaño } \\
\text { Módulo }\end{array}$ & $\begin{array}{l}\text { Corto } \\
\text { ancho }\end{array}$ & $\begin{array}{c}\text { Lam. } \\
\text { normal }\end{array}$ & $\begin{array}{l}\text { Lasca } \\
\text { alarg. }\end{array}$ & $\begin{array}{l}\text { Lasca } \\
\text { Ancha }\end{array}$ & $\begin{array}{c}\text { Med. } \\
\text { alargado }\end{array}$ & $\begin{array}{c}\text { Med. } \\
\text { normal }\end{array}$ & & otal \\
\hline & Hipermicrolasca & -- & 1 & -- & 1 & 2 & 9 & 13 & $27,6 \%$ \\
\hline & Microlasca & 1 & -- & 1 & -- & 6 & 12 & 20 & $42,5 \%$ \\
\hline & Lasca Pequeña & -- & -- & -- & -- & -- & 9 & 9 & $19,1 \%$ \\
\hline & Lasca Grande & -- & -- & -- & 1 & -- & 4 & 5 & $10,6 \%$ \\
\hline & Total & $1: 2,1 \%$ & $1: 2,1 \%$ & $1: 2,1 \%$ & $2: 4,3 \%$ & $8: 17 \%$ & $34: 72,3 \%$ & 47 & $100 \%$ \\
\hline
\end{tabular}

Tabla 8.18. Tamaño y módulo largo/ancho de las lascas

En relación con los talones, en RElíz 1 M1 sobresalen los astillados (28\% y los corticales (24\%) seguidos por los filiformes (15\%), los ausentes (11\%) y los lisos (10\%). Los restantes -diedros, facetados, puntiformes, fracturados e indeterminados- se registran en valores bajos y parejos (entre 3,2\% y 1,3\%) (8.19). Para el conchero 9 gran parte de los talones no pudo ser determinado $(n=7)$, el resto se distribuye en cortical y filiforme ( $\mathrm{n}=2$ de cada uno) y uno liso y diedro respectivamente (Tabla 8.19). 
En el muestreo del sitio REliz 5 predominan los talones lisos (30\%) y corticales (28\%), en segundo lugar se ubican los filiformes (19\%) y por último los astillados (8\%). En baja frecuencia se registraron puntiformes $(6 \%)$, diedros $(4 \%)$ y ausentes e indeterminados $(2 \%$ de cada uno) (8.19).

\begin{tabular}{ccccccc}
\hline Tipo de talón & \multicolumn{2}{c}{ RElíz 1 M1 } & \multicolumn{2}{c}{ RElíz 1 CH9 } & \multicolumn{2}{c}{ RElíz 5 } \\
\cline { 2 - 7 } & $\mathbf{N}$ & $\mathbf{\%}$ & $\mathbf{N}$ & $\mathbf{\%}$ & $\mathbf{N}$ & $\mathbf{\%}$ \\
Cortical & 37 & 23,9 & 2 & 15 & 13 & 27,7 \\
Liso & 16 & 10,3 & 1 & 7,6 & 14 & 29,8 \\
Diedro & 5 & 3,2 & 1 & 7,6 & 2 & 4,3 \\
Facetado & 2 & 1,3 & -- & -- & -- & -- \\
Filiforme & 23 & 14,8 & 2 & 15 & 9 & 19,1 \\
Puntiforme & 4 & 2,6 & -- & -- & 3 & 6,4 \\
Astillado & 43 & 27,7 & -- & -- & 4 & 8,5 \\
Fracturado & 4 & 2,6 & -- & -- & -- & -- \\
Ausente & 17 & 11 & -- & -- & 1 & 2,1 \\
Indeterminado & 4 & 2,6 & 7 & 53 & 1 & 2,1 \\
Totales & $\mathbf{1 5 5}(\mathbf{1 0 0 \% )}$ & $\mathbf{1 3}(\mathbf{1 0 0 \% )}$ & $\mathbf{4 7}(\mathbf{1 0 0 \% )}$ \\
\hline
\end{tabular}

Tabla 8.19: Tipos y frecuencias de los talones.

\section{Artefactos formatizados por talla}

En REliz 1 M1 se observó la selección de distintas materias primas para la manufactura de los instrumentos, todas ellas de muy buena a excelente calidad: cinco sobre calcedonias traslúcidas y/o blanquecina; cuatro en sílices de distintas tonalidades de marrones -claros y rosados- (10 R 5/3 y 11 R 5/3 sensu Munsell 2011); cuatro en basalto y otro sobre obsidiana gris- verdosa (Tabla 8.20). Las formas-bases predominantes son las lascas cuyos tamaños varían entre medianos $(n=6)$, grandes $(n=5)$ y pequeños $(n=4)$. Se registró además el uso de un núcleo bipolar pequeño de basalto para la manufactura de una raedera (Tabla 8.20). El subgrupo más representado en el muestreo 1 son los raspadores $(n=4)$ y los becs $(n=3)$, le siguen los denticulados, las muescas y las puntas burilantes ( $\mathrm{n}=2$ de cada uno) y una raedera y un cuchillo de filo retocado (Tabla 8.21). En el muestreo del conchero 9 no se recuperó ningún instrumento formatizado por talla.

Para el sitio 5 el único instrumento rescatado se confeccionó sobre una lasca de tamaño mediano de sílice de color marrón oscuro (10R3/4 sensu Munsell 2011), de muy buena calidad para la talla. Se trata de una punta burilante con muesca (Tabla 8.20).

Respecto de la serie técnica predominan los microrretoques y retoques marginales $(n=4$ de cada uno), seguidos por los lascados simples y por la talla de extracción ( $\mathrm{n}=3$ respectivamente). Salvo la raedera de obsidiana, cuya formatización es bifacial, el resto de los 
instrumentos son unifaciales. La gran mayoría de los filos se encuentra activos $(n=12)$. Por último, casi la totalidad de los instrumentos son simples; el único con filo doble es el bec de xilópalo de muy buena calidad (Tabla 8.21).

\section{Lascas con rastros complementarios}

En el REliz 1 M1 de las diez lascas con rastros complementarios, ocho provienen de lascas de rodados de sílice de tamaño mediano $(n=4)$ y pequeño $(n=4)$; las dos restantes son sobre una lasca mediana bipolar de basalto y sobre una lasca pequeña de xilópalo. Todas las materias primas seleccionadas son de muy buena calidad para la talla. En RElíz 1 CH9 y en RElíz 5 no se registraron lascas con rastros complementarios.

\section{Núcleos}

Más de la mitad ( $\mathrm{n}=15: 56 \%$ ) de los núcleos recuperados en RElíz 1 M1 proviene de rodados de sílice; en segundo lugar de basalto $(n=6: 22 \%)$, y por ultimo de toba $(n=2: 7,4 \%)$, todos de calidad buena a muy buena. Los cuatro núcleos restantes se distribuyen de manera pareja en calcedonia y xilópalos ( $n=2: 7,4 \%$ respectivamente), rocas de excelente a muy buena calidad y cuyas formas base no pudieron ser determinadas. En sílice predominan los medianos $(n=9)$, seguidos por los pequeños $(n=4)$ y los grandes $(n=2)$. Para los de basalto también son mayoría los medianos $(n=4)$ y hay dos respectivamente de tamaño grande y pequeño. Los dos núcleos de toba son medianos, y los de calcedonia y xilópalos pequeños.

Respecto de los tipos de núcleos, predominan los núcleos bipolares (89 \%), y en muy baja frecuencia se registraron de lascados aislados (7\%) y sólo un bipiramidal (4 \%) (Tabla 8.22). En el muestreo de RElíz $1 \mathrm{CH} 9$ se rescató un único núcleo de un rodado de sílice de tamaño pequeño y buena calidad para la talla. La morfología corresponde a la de lascados aislados y se encuentra agotado.

En REliz 5 los cuatro núcleos rescatados provienen de rodados: dos son de sílice y tamaño pequeño y de calidad excelente y regular respectivamente; el otro es de basalto también de tamaño pequeño, de muy buena calidad, y el último es un rodado chato de xilópalo de tamaño grande de aptitud buena para la talla. En cuanto a los tipos, dos son de lascados asilados, uno bipolar y el otro globuloso. Excepto los de lascados aislados, los dos restante se encuentran agotados. En todos los casos la forma de los negativos de lascados corresponde a lascas (Tabla $8.23)$. 


\begin{tabular}{|c|c|c|c|c|c|c|c|}
\hline $\mathbf{N}^{0} \operatorname{Inv}$ & Sitio & Subgrupos & $\begin{array}{c}\text { Materia } \\
\text { prima }\end{array}$ & Forma Base & $\begin{array}{l}\text { Lar } \\
\text { (mm) }\end{array}$ & $\begin{array}{l}\text { Ancho } \\
(\mathrm{mm})\end{array}$ & $\begin{array}{l}\text { Esp } \\
(\mathbf{m m})\end{array}$ \\
\hline 209 & \multirow{15}{*}{$\begin{array}{l}\text { RElíz } \\
1 \text { M1 }\end{array}$} & Denticulado & Sílice & Lasca con dorso natural peq. & 35 & 20 & 8,6 \\
\hline 189 & & Denticulado & Basalto & Lasca primaria grande & 51,5 & 39 & 12 \\
\hline 207 & & Raspador & Sílice & Lasca primaria pequeña & 26 & 30 & 7,6 \\
\hline 126 & & Raspador & Calcedonia & Lasca en cresta meda & 45 & 24 & 11 \\
\hline 208 & & Raspador & Calcedonia & Lasca mediana & 31,7 & 25,8 & 8,1 \\
\hline 206 & & Raspador & Calcedonia & Lasca en cresta pequeña & 26,7 & 17 & 8 \\
\hline 188 & & Bec & Sílice & Lasca grande & 65 & 27,6 & 11 \\
\hline 9 & & Bec & Xilópalo & Lasca grande & 56 & 35 & 11 \\
\hline 24 & & Bec & Xilópalo & Lasca grande & 42,5 & 48,7 & 9,6 \\
\hline 23 & & Muesca & Sílice & Lasca mediana & 41 & 28 & 9,9 \\
\hline 13 & & Muesca & Calcedonia & Lasca grande & 48 & 28 & 13 \\
\hline 127 & & Punta burilante & Basalto & Lasca con dorso natural mediana & 44,4 & 21,6 & 11 \\
\hline 128 & & Punta burilante & Basalto & Lasca de arista inclinada mediana & 47 & 31,6 & 12 \\
\hline 124 & & Raedera & Obsidiana & Lasca mediana & 28 & 31 & 4,5 \\
\hline 120 & & Filo retocado & Calcedonia & Lasca pequeña & 26 & 27 & 10 \\
\hline $\mathbf{x c x}$ & $\begin{array}{c}\text { RElíz } \\
5\end{array}$ & Punta burilante (D) & Sílice & Lasca mediana & 39 & 26,6 & 10 \\
\hline
\end{tabular}

Tabla 8.20. RElíz 1 M 1 y RElíz 5: características tecnológicas y métricas de los artefactos formatizados por talla. 


\begin{tabular}{|c|c|c|c|c|c|c|c|c|}
\hline $\mathbf{N}^{\mathbf{0}}$ & Subgrupo & $\begin{array}{l}\text { Cant } \\
\text { Filo }\end{array}$ & $\begin{array}{c}\text { Serie } \\
\text { Técnica }\end{array}$ & $\begin{array}{l}\text { Situación } \\
\text { lascados }\end{array}$ & $\begin{array}{c}\text { Forma geométrica } \\
\text { Contorno }\end{array}$ & Posic. Filo & $\begin{array}{c}\text { Forma } \\
\text { Lascados }\end{array}$ & $\begin{array}{l}\text { Ang } \\
\text { Filo }\end{array}$ \\
\hline 209 & Denticulado & Simple & Retoque marginal & Unifacial & Rectangular & Lateral & Escamoso irregular & $40^{\circ}$ \\
\hline 189 & Raspador & Simple & Microretoque marginal & Unifacial & Semi-oval & Frontal & Paralelo corto regular & $40^{\circ}$ \\
\hline 207 & Becs & Simple & Lascado simple & Unifacial & Rectangular & Fronto-Lateral & -- & -- \\
\hline 126 & Muesca & Simple & Retoque Marginal & Unifacial & Rectangular & Fronto-Lateral & Escamoso & -- \\
\hline 208 & Becs & Simple & Lascado simple & Unifacial & Rectangular & Frontal & -- & -- \\
\hline 206 & Becs & Doble & Lascado simple & Unifacial & Triangular & Fronto-Lateral & -- & -- \\
\hline 188 & Raspador & Simple & Microretoque marginal & Unifacial & Semielíptica & Frontal & Paralelo corto regular & $35^{\circ}$ \\
\hline 9 & Punta buril & Simple & Talla simple & Unifacial & Amigdaloide irregular & Distal & Golpe buril & -- \\
\hline 24 & Punta buril & Simple & Talla simple & Unifacial & Amigdaloide irregular & Distal & Golpe buril & -- \\
\hline 23 & Denticulado & Simple & Retoque marginal & Unifacial & Elipticairregular & Lateral & Escamoso irregular & $40^{\circ}$ \\
\hline 13 & Raedera & Simple & Microretoque marginal & Unifacial & Cuadrangular & Lateral & Escamoso escalonado & $45^{\circ}$ \\
\hline 127 & Raspador & Simple & Microretoque Marginal & Unifacial & Semielíptica & Fronto lateral & Paralelo corto regular & $55^{\circ}$ \\
\hline 128 & Raspador & Simple & Microretoque Marginal & Unifacial & Semioval & Fronto lateral & Paralelo corto reg & $35^{\circ}$ \\
\hline 124 & Filo retocado & Simple & Microretoque marginal & Unifacial & Rectangular & Frontal & Escamoso regular & $55^{\circ}$ \\
\hline 120 & Muesca & Simple & Talla extendida & Unifacial & Rectangular & Lateral & Indet & -- \\
\hline 251 & Raedera & Simple & Retoque marginal & Bifacial & Cuadrangular & Lateral & Escamoso irregular & $50^{\circ}$ \\
\hline
\end{tabular}

Tabla 8.21. Localidad Rincón de Elizalde: Rasgos morfotécnicos de los artefactos tallados. Referencias: Sit. Lascados: situación de los lascados; F. Geom.: forma geométrica, Posic.Fil: Posición del filo; F.Lasc. Forma de los lascados; Ang. Ángulo del filo; restr. Restringido; Unif: Unificial; Indet: indeterminado. 


\begin{tabular}{|c|c|c|c|c|c|c|c|}
\hline $\begin{array}{l}\text { Materia } \\
\text { prima }\end{array}$ & Morfología & $\begin{array}{l}\mathbf{N}^{0} \text { mín } \\
\text { P.Per }\end{array}$ & $\begin{array}{l}\text { Fm sup } \\
\text { plat perc. }\end{array}$ & $\mathbf{N}^{0}$ lasc. & $\begin{array}{l}\text { Fm. negat } \\
\text { Lasc }\end{array}$ & $\begin{array}{l}\text { Grado } \\
\text { Modif }\end{array}$ & Estado \\
\hline $\begin{array}{l}\text { Sílices } \\
(n=15)\end{array}$ & $\begin{array}{l}\text { Bipolar } \\
(n=15)\end{array}$ & $\begin{array}{c}2 \\
(n=15)\end{array}$ & $\begin{array}{c}\text { Natural } \\
(\mathrm{n}=7) \\
\text { Astillado } \\
(\mathrm{n}=8)\end{array}$ & $\begin{array}{c}4(n=3) \\
3(n=4) \\
2(n=6) \\
\text { Indet }(n=2)\end{array}$ & $\begin{array}{l}\text { De lascas } \\
(\mathrm{n}=14)\end{array}$ & $\begin{array}{l}\text { Total } \\
(\mathrm{n}=11) \\
\text { medio } \\
(\mathrm{n}=4)\end{array}$ & $\begin{array}{l}\text { Agotado } \\
(\mathrm{n}=11) \\
\text { Activo } \\
(\mathrm{n}=4)\end{array}$ \\
\hline $\begin{array}{l}\text { Toba } \\
(n=2)\end{array}$ & $\begin{array}{c}\text { Bipolar } \\
(\mathrm{n}=2)\end{array}$ & $\begin{array}{c}2 \\
(n=2)\end{array}$ & $\begin{array}{l}\text { Natural } \\
\text { Astillada }\end{array}$ & $\begin{array}{c}4 \\
(n=2)\end{array}$ & De lascas & Total & Agotado \\
\hline $\begin{array}{c}\text { Calcedonia } \\
(\mathrm{n}=2)\end{array}$ & $\begin{array}{c}\text { Bipolar } \\
\text { Bipiramidal }\end{array}$ & $\begin{array}{l}2 \\
2\end{array}$ & $\begin{array}{c}\text { Natural } \\
\text { Astillada }\end{array}$ & $\begin{array}{l}4 \\
3\end{array}$ & $\begin{array}{l}\text { De lascas } \\
\text { De lascas }\end{array}$ & $\begin{array}{l}\text { Total } \\
\text { Total }\end{array}$ & Agotado \\
\hline $\begin{array}{c}\text { Basalto } \\
(n=2)\end{array}$ & $\begin{array}{l}\text { Lascados } \\
\text { aislados } \\
(\mathrm{n}=2)\end{array}$ & $\begin{array}{c}2 \\
(n=2)\end{array}$ & $\begin{array}{l}\text { Astillada } \\
(n=2)\end{array}$ & $\begin{array}{c}4 \\
(n=2)\end{array}$ & $\begin{array}{l}\text { De lascas } \\
(\mathrm{n}=2)\end{array}$ & $\begin{array}{l}\text { Total } \\
(n=2)\end{array}$ & $\begin{array}{l}\text { Agotado } \\
(\mathrm{n}=2)\end{array}$ \\
\hline $\begin{array}{l}\text { Basalto } \\
(n=4)\end{array}$ & $\begin{array}{l}\text { Bipolar } \\
(n=4)\end{array}$ & $\begin{array}{c}2 \\
(n=2) \\
2 \\
(n=3)\end{array}$ & $\begin{array}{c}\text { Astillada } \\
(\mathrm{n}=3) \\
\text { Natural } \\
(\mathrm{n}=1)\end{array}$ & $\begin{array}{c}4 \\
(n=3) \\
3 \\
(n=1)\end{array}$ & $\begin{array}{l}\text { De lascas } \\
(\mathrm{n}=4)\end{array}$ & $\begin{array}{l}\text { Total } \\
(\mathrm{n}=4)\end{array}$ & $\begin{array}{l}\text { Agotado } \\
(\mathrm{n}=4)\end{array}$ \\
\hline $\begin{array}{l}\text { Xilópalo } \\
(n=2)\end{array}$ & $\begin{array}{l}\text { Bipolar } \\
(\mathrm{n}=2)\end{array}$ & $\begin{array}{c}2 \\
(n=2)\end{array}$ & $\begin{array}{c}\text { Natural } \\
(n=2)\end{array}$ & $\begin{array}{c}4 \\
(n=2)\end{array}$ & $\begin{array}{l}\text { De lascas } \\
(\mathrm{n}=2)\end{array}$ & $\begin{array}{l}\text { Total } \\
(n=2)\end{array}$ & $\begin{array}{l}\text { Agotado } \\
(\mathrm{n}=2)\end{array}$ \\
\hline
\end{tabular}

Tabla 8.22. RElíz 1 M1: características morfológicas y técnicas de los núcleos.

\begin{tabular}{|lccccccc|}
$\begin{array}{l}\text { Materia } \\
\text { Prima }\end{array}$ & Morfología & $\begin{array}{l}\mathbf{N}^{\mathbf{0}} \text { Mín } \\
\text { PPerc. }\end{array}$ & $\begin{array}{l}\text { Forma Sup } \\
\text { Plat Perc. }\end{array}$ & $\mathbf{N}^{\mathbf{0}}$ Lasc. & $\begin{array}{l}\text { Forma negat } \\
\text { Lasc }\end{array}$ & $\begin{array}{l}\text { Grado } \\
\text { Modif. }\end{array}$ & Estado \\
\hline Basalto & Bipolar & 2 & Natural & Natural & De lascas & Alto & Agotado \\
\hline Xilópalo & $\begin{array}{l}\text { Lascados } \\
\text { Aislados }\end{array}$ & 2 & Natural & Natural & De lascas & Bajo & Activo \\
\hline Sílice & Globuloso & 1 & Liso & Liso & De lascas & Alto & Agotado \\
\hline Ś́lice & $\begin{array}{l}\text { Lascados } \\
\text { Aislados }\end{array}$ & 1 & Natural & Natural & De lascas & Bajo & Activo \\
\hline
\end{tabular}

Tabla 8.23. RElíz 5: características morfológicas y técnicas de los núcleos.

\section{Artefactos formatizados por picado y pulido}

En los muestreos del sitio 1 (REliz 1 M1 y CH 9) no se recuperaron instrumentos formatizados por picado ni pulido. Para el sitio RElíz 5 se recuperó un fragmento de bola con surco en basalto olivínico.

\section{Índice de fractura}

En RElíz 1 M1, la proporción de artefactos con presencia de fracturas es de $32 \%$ ( 67), y se registran en todas las clases artefactuales identificadas. Para el caso de las lascas, la mayoría de las fracturas se ubica en el sector distal de la pieza $(n=37)$ (Tabla 8.24). Para el 
muestreo de RElíz CH9 se identificó la presencia de fracturas en cinco desechos de talla de tamaños muy pequeños (hipermicrolascas) y pequeños.

Para el muestreo del sitio 5, al igual que en el muestreo 1 de RElíz 1, el $32 \%$ de los artefactos presenta fractura, registrándose en todas las clases artefactuales (Tabla 8.24). En relación con los desechos, la gran mayoría de las fracturas $(n=11)$ se observó en el sector distal de la pieza.

\begin{tabular}{|c|c|c|}
\hline \multirow{2}{*}{ Clase Tipológica } & \multicolumn{2}{|c|}{ Fracturas } \\
\cline { 2 - 3 } & REliz1M1 & RElíz 5 \\
\hline Artefacto formatizado por P y P & -- & 1 \\
\hline Artfecto Modificado por el Uso & -- & -- \\
\hline Desechos de talla & 59 & 15 \\
\hline Ecofactos & -- & -- \\
\hline Artefactos Formatizados por talla & 2 & 1 \\
\hline Rastros complementarios & 1 & -- \\
\hline Núcleos & 4 & -- \\
\hline Total & $\mathbf{6 7}$ & $\mathbf{1 7}$ \\
\hline \% & $\mathbf{3 2 , 1}$ & $\mathbf{3 2 , 1}$ \\
\hline
\end{tabular}

Tabla 8.24. Frecuencia de fracturas por clase tipológica.

\section{Relaciones de ensamblaje}

En el muestreo 1 del sitio REliz 1 M1 se realizaron tres relaciones de ensamblaje. La primera corresponde a lascas de sílice de marrón oscuro de tamaño pequeño fracturadas durante las actividades de talla. La segunda se asocia a dos lascas de basalto bipolares, de tamaño grande y pequeño, probablemente separadas durante los primeros golpes de la de la talla (FIG.). Por último, se logró asociar dos lascas de sílice de tamaño pequeño y mediano. En REliz 1 CH9 se estableció un remontaje entre dos elementos: entre un núcleo y una microlasca de un rodado de sílice de buena calidad.

Para el conjunto artefactual del sitio RElíz 5 se efectuaron dos relaciones de ensamblaje: la primera entre dos lascas de tamaño mediano de sílice de muy buena calidad. La asociación se relaciona con fractura de la pieza por daño térmico. La otra corresponde a dos lascas de tamaño pequeño y muy pequeño (microlasca) de sílice de buena calidad. La causa que originó la separación de los dos artefactos es tecnológica, es decir a la talla por manufactura.

\section{Frecuencia de módulo laminar, bipolaridad y bifacialidad:}

La presencia de laminaridad en el sitio RElíz 1 M1 es muy exigua ( $\mathrm{n}=1: 0,45 \%$ ): se trata de una lasca de xilópalo de muy buena calidad y de tamaño mediano. La bipolaridad se identificó en 87 artefactos (41,6 \%), que en su gran mayoría corresponden a desechos de talla y también a núcleos de basalto. Por último la bifacialidad se observó en tres artefactos $(1,4 \%)$ : 
una raedera de obsidiana gris -verdosa de tamaño mediano, y a dos lascas de sílice y calcedonia respectivamente, todas de tamaños pequeños. Por el contrario, en el muestreo del conchero 9 no registró la presencia de laminaridad, bipolaridad ni bifacialidad.

En el sitio 5 la laminaridad se registró en único artefacto $(1,8 \%)$ : una microlasca de arista recta de sílice de muy buena calidad. Por su parte, la talla bipolar está presente en cinco artefactos $(9,4 \%)$ : cuatro lascas pequeñas de rodados de muy buena calidad (tres de basalto y una de xilópalo) y en un núcleo también pequeño de basalto. No se registró bifacialidad.

\section{Tendencias generales de los conjuntos líticos de la localidad arqueológica Rincón de Elizalde}

Gómez Otero (2006: Cap. 5) interpretó que el registro arqueológico de Rincón de Elizalde 1 señala sobre todo la realización de actividades extractivas y algunas de mantenimiento. Propuso considerarlo un área donde tuvieron lugar diversas localizaciones y campamentos transitorios. Entre esas localizaciones incluyó al Conchero 9. Para el sitio Rincón de Elizalde 5 y, sobre la base de la presencia de pequeños relictos de concheros compuestos exclusivamente por valvas, lo consideró representativo de una localización de extracción y consumo in situ de moluscos.

Los estudios tecnológicos indicaron concordancias y diferencias entre los muestreos Reliz 1 M1 y Reliz 5. En cuanto a las similitudes en los conjuntos artefactuales, ambos se asemejan en las litologías seleccionadas (principalmente rodados locales pequeños de sílices y basaltos; en el tamaño de los artefactos (pequeños y en menor frecuencia medianos); la presencia de lascas y talones indicativos de distintas etapas de la secuencia de producción y la presencia de bipolaridad -aunque considerablemente mayor en REliz 1 M1. Por su parte, ambos contextos difieren por la densidad artefactual: en REliz 1 M1 alta $\left(2,48 \mathrm{dm}^{2}\right)$ versus baja en REliz $5\left(0,058 \mathrm{dm}^{2}\right)$ y mayor diversidad litológica y superior cantidad de artefactos formatizados en el primero respecto del segundo. En el conjunto instrumental del Muestreo 1 se destaca la presencia de raspadores, becs, denticulados, puntas burilantes y muescas que se condice con el aprovechamiento de distintos taxones terrestres y marinos. En síntesis, para REliz 1 M1 las evidencias sugieren que se trata de un campamento transitorio, relacionado con la recolección de moluscos por una parte, y por otra la caza, procesamiento y consumo in situ de presas terrestres y marinas.

Por su parte, el Conchero 9 -de muy baja densidad artefactual $\left(0,006 \mathrm{dm}^{2}\right)$ y con solo dos clases (desechos de talla y un núcleo)- se asemeja más a los rasgos tecnológicos del sitio 
RElíz 5. Entre las similitudes se observó la presencia de núcleos locales agotados, desechos de tamaños pequeños y tipo de lascas y talones indicativos de las últimas etapas de talla. Estas evidencias permiten inferir el desarrollo de al menos alguna actividad de talla in situ, como por ejemplo la reactivación o formatización de algún filo o la preparación de núcleos para la extracción de formas bases. Se suman a estas evidencias la presencia de remontajes. Por lo tanto para ambos contextos se infiere la presencia de una localización, restringidas a la obtención y consumo de moluscos y en menor intensidad talla lítica in situ. 


\section{COSTA DEL GOLFO NUEVO SUR}

\section{Localidad arqueológica Bahía Cracker}

La Bahía Cracker es una pequeña bahía de la costa del golfo Nuevo sur enmarcada entre punta Cracker y punta Ninfas. La playa actual está conformada por una serie de cordones litorales depositados por el mar luego de la máxima ingresión del Holoceno. Otros rasgos geomorfológicos de este evento estarían representados por resaltos de antiguos depósitos litorales a 5-7 m s.n.m. adosados en el perfil de los acantilados y por un cañadón muy amplio formado a partir del descenso del nivel marino. Ese cañadón marca la diferencia geomorfológica entre dos sectores costeros: el oriental, caracterizado por acantilados altos (50 - 70 m s.n.m.) que caen a pique al mar; y el occidental, que presenta una sucesión escalonada de acantilados y está disectado por varias cárcavas profundas (Fig. 8.7). En esta última punta hay en la actualidad una colonia de lobos marinos de un pelo (Otaria flavescens) y de elefantes marinos (Mirounga leonina) (Gómez Otero et al. 2013). La diferencia entre los dos sectores también se observó en el registro arqueológico ya que de los once sitios detectados, diez estaban en el occidental. Algunos se encontraban al pie de los acantilados o paleoacantilados y otros sobre el borde de los mismos; la mayoría era de superficie, aunque también se observaron relictos subsuperficiales de fogones y de concheros (Gómez Otero et al. 2013).
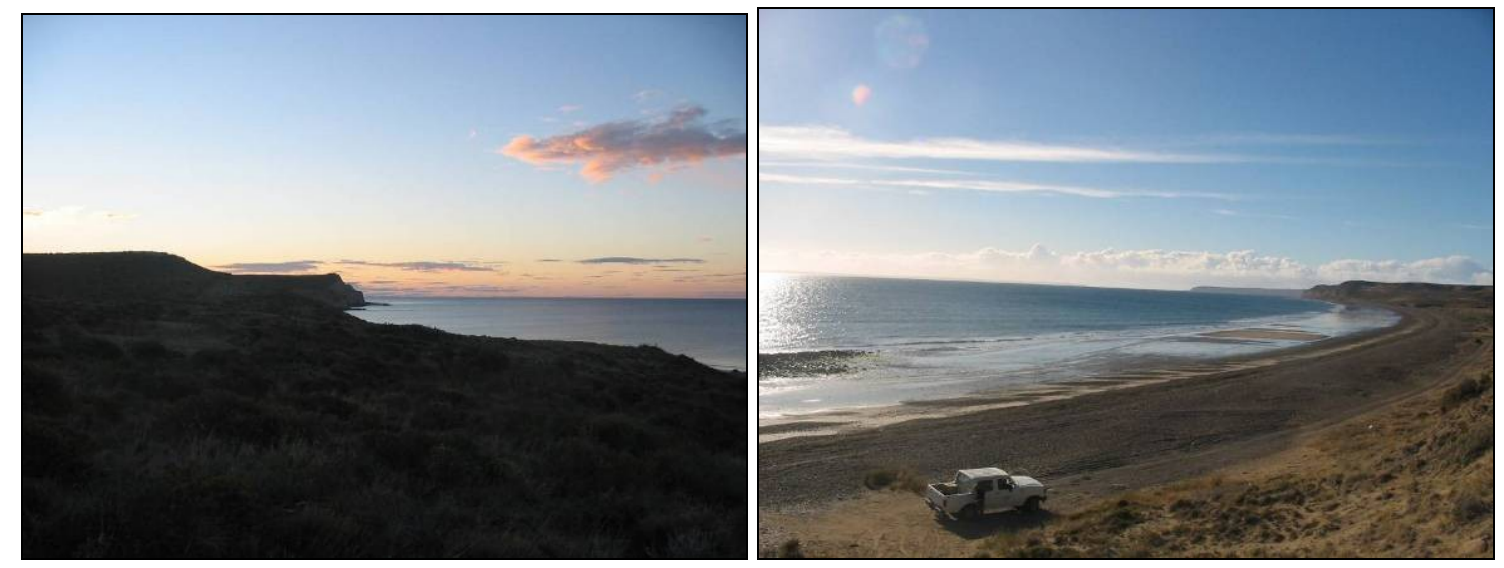

Fig.8.7. Vista genreal de la Bahía Cracker.

Los trabajos de campo incluyeron prospecciones paralelas a la costa, relevamientos geológicos por parte de la Dra. Weiller, muestreos de superficie y excavación de los sitios 4 y 8 (BCrack 4 y BCrack 8 en adelante). También se efectuaron descripciones de rasgos geológicos y de perfiles estratigráficos asociados con los sitios excavados. 
El análisis arqueofaunístico de ambos sitios fue realizado por la Dra. Julieta Gómez Otero y el Dr. Eduardo Moreno (véase Gómez Otero et al. 2013) y consistió en la determinación taxonómica, estimación del NISP, NMI y de las huellas de corte o marcas de procesamiento (Grayson 1984; Lyman 1994; Mengoni Goñalons 1988, 1999). Se dataron muestras de carbones y de valvas que permiten ubicar a estas ocupaciones en el Holoceno medio (Tabla 8. 25).

\begin{tabular}{ccccc}
\hline Muestreo & Lat / Long & $\begin{array}{c}\text { Fechado } \\
\text { Años Cal }\end{array}$ & Muestra & LP-1551 \\
\hline BCrack 4 & $42^{\circ} 95140^{\prime \prime} \mathrm{S}$ & $5390 \pm 130 \mathrm{AP}$ & Hueso & LP-2324 \\
& $64^{\circ} 49^{\prime} 024^{\prime \prime} \mathrm{O}$ & $4284 \mathrm{AC}$ & guanaco & \\
& & $5500 \pm 80 \mathrm{AP}$ & Carbón & LP-2244 \\
& & & \\
BCrack 8 & $42^{\circ} 56^{\prime} 55.5^{\prime \prime} \mathrm{S}$ & $4435 \mathrm{AC}-4081 \mathrm{AC}$ & & \\
& $64^{\circ} 29^{\prime} 39.7^{\prime \prime} \mathrm{O}$ & $5290 \pm 80 \mathrm{AP}$ & Valvas & LP 2037 \\
& & $3790 \mathrm{AC} / 3622 \mathrm{AC}$ & & \\
\hline
\end{tabular}

Tabla 8.25. Localidad Bahía Cracker: localización y fechados obtenidos de los Sitios 4 y 8 . Referencias: Lab. Laboratorio, BT: bloque temporal; H.M: Holoceno medio; LC: localización.

\section{Bahía Cracker 4}

Se trata de una concentración de materiales líticos, de restos faunísticos y carbones muy pequeños sobre el borde de un paleoacantilado, a 20-25 m s.n.m y a unos $200 \mathrm{~m}$ de la línea de marea alta actual. Se realizó un muestreo de superficie de cuatro metros de lado (Muestreo 1) y dentro de esa área se excavó una cuadrícula de un metro de lado (Cuadrícula 1). Se utilizó zaranda de malla de 1,3 mm (Gómez Otero et al. 2013).

De la capa 1 se obtuvo una edad radiocarbónica convencional de $5390 \pm 130 \mathrm{C}^{14}$ años AP (LP-2324) para huesos de guanaco. Dada la existencia de un único estrato arqueológico y su escasa potencia $(11 \mathrm{~cm})$ se infirió que representaba un solo evento de ocupación.

Los estudios arqueofaunísticos indican que prevalecen los recursos marinos, especialmente la ictiofauna, entre ellos dos Acanthistius patachonicus (mero), un Pinguipes brasilianus (turco) y un Sebastes oculatus (escrófalo). Entre los moluscos predominan los gasterópodos Buccinanops; seguidos por las cholgas (Aulacomya ater); las aves corresponden a pingüino Spheniscus y otra. Los pinnípedos están representados por un ejemplar de un Otaria flavescens macho adulto () y otro de Arctocephalus australis hembra. Con respecto a la fauna terrestre, se constató la presencia de un individuo de guanaco (Lama guanicoe), tres placas de un armadillo (Zaedyus pichiy) y de un roedor pequeño indeterminado (Gómez Otero et al. 2013). Además de los artefactos líticos se identificaron cuatro instrumentos de hueso (Fig.8.8), que están total o parcialmente cubiertos por la costra de sedimento fino observada también entre los restos faunísticos. 


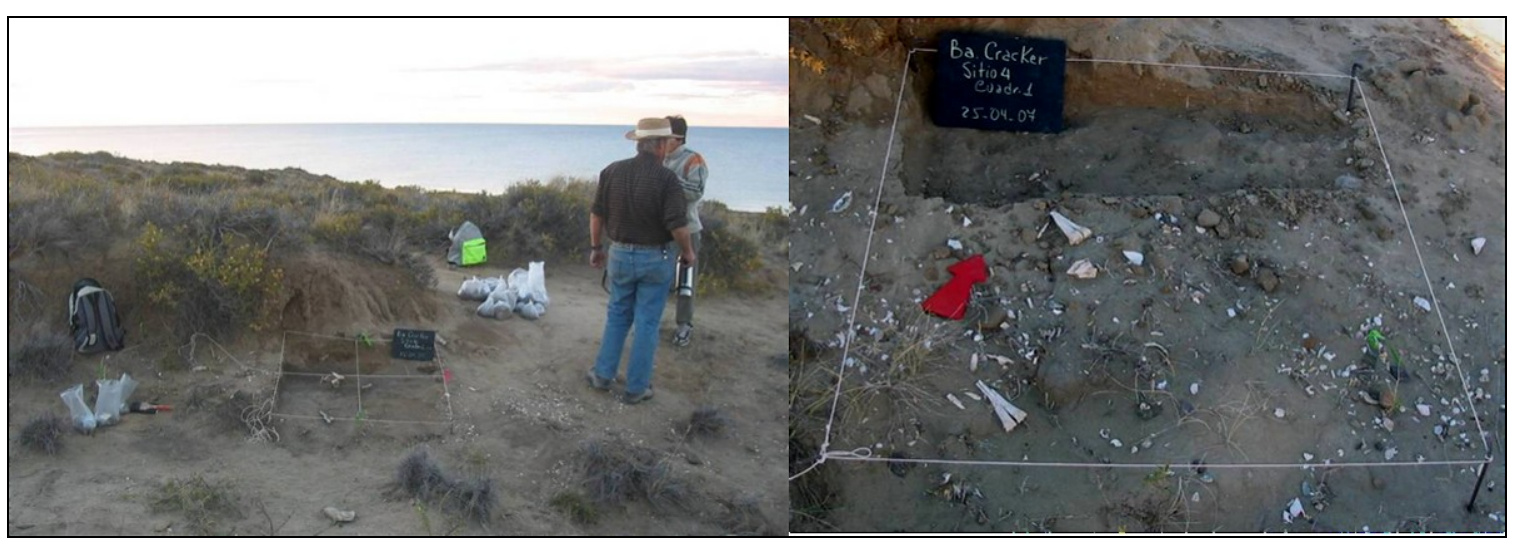

Fig. 8.8. Sitio Bahía Cracker 4. A. vista general, B detalle cuadrícula de excavación

\section{Bahía Cracker 8}

Corresponde a un conchero estratificado localizado a 200 metros al este del Sitio 4, a 10-15 m s.n.m. y a $70 \mathrm{~m}$ de de la línea de marea máxima actual. Se encontraba a un metro de profundidad sobre el perfil de una pared relictual entre dos cárcavas (Fig.8.9). Se excavó todo el relicto hasta el nivel estéril debajo de la capa cultural. Se fecharon dos muestras: una de carbones y otra de valvas. La de carbones (LP-2244) midió una edad radiocarbónica convencional de $5500 \pm 80$ años $\mathrm{C}^{14} \mathrm{AP}$, calibrada para un sigma entre $4435 \mathrm{Cal} \mathrm{AC}$ (6385 Cal AP) y $4081 \mathrm{Cal}$ AC (6031 Cal AP). La de valvas (LP 2037) arrojó una edad radiocarbónica convencional de $5290 \pm 80$ C14 años AP que, corregida por Efecto Reservorio resultó de $4890 \pm$ 80 C14 años AP, calibrada para un sigma entre 3790 AC (5740 Cal AP) y 3622 AC (5572 Cal AP). Si se tiene en cuenta el envejecimiento en carbono de los organismos marinos por el efecto reservorio (Figini 1999), la edad radiocarbónica de la muestra de valvas resulta anómala respecto de la de carbones, lo que sugiere la existencia de dos eventos de ocupación. Es probable entonces, que el asentamiento de los sedimentos del Terciario sobre los estratos arqueológicos haya producido el contacto o la mezcla de las evidencias de ambos (Gómez Otero et al. 2013).

En cuanto a los restos faunísticos se determinó la presencia de moluscos, cirripedios del género Megabalanus y 28 especímenes de peces. Entre los moluscos predominan ampliamente las cholgas (Aulacomya ater), siguiéndoles los gasterópodos (Buccinanops). No se hallaron restos de otros vertebrados, excepto dos fragmentos de cáscaras de huevo de ave no determinada (Gómez Otero et al. 2013). 


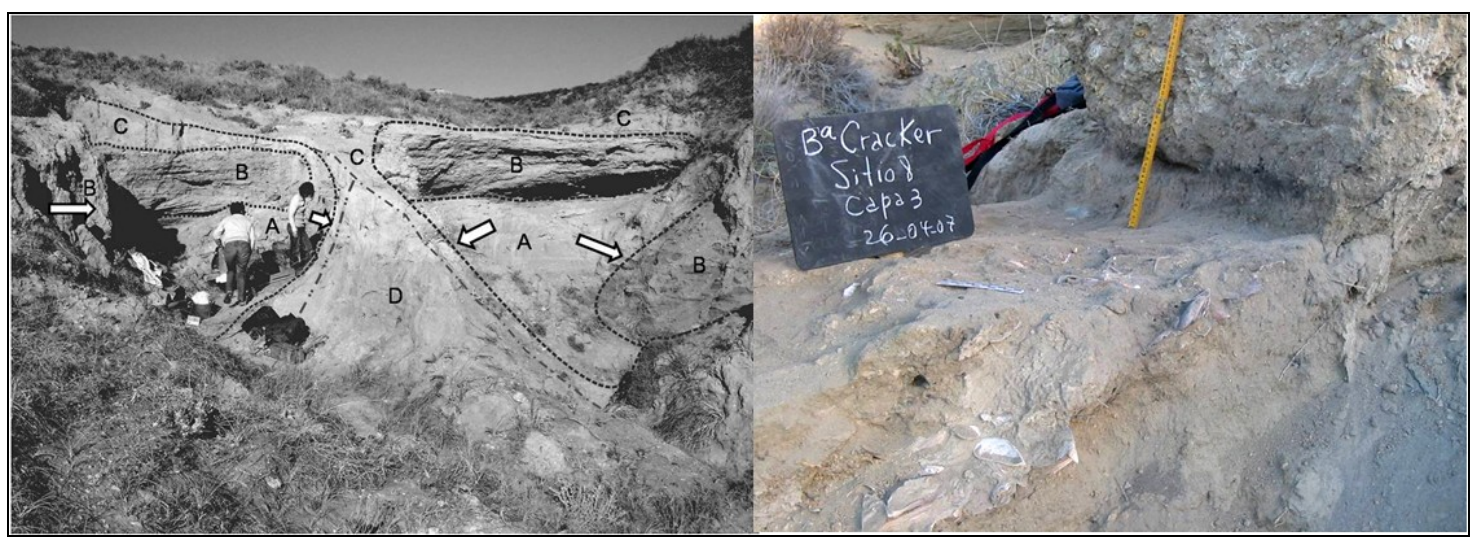

Fig. 8.9. Sitio Bahía Cracker 8 (izquierda). (A) Formación Gaiman; (B) Formación Puerto Madryn; (C) sedimento eólico actual; (D) cono de deyección (imagen tomada de Gómez Otero et al. 2013). Derecha: detalle de la cuadrícula de excavación, capa 3.

\section{Análisis tecnológico}

En Bahía Cracker 4 se recogieron un total de 166 artefactos líticos, distribuidos en 73 artefactos del muestreo 1 (en adelante BCrack4 M1) con una densidad de 0,045/dm²; y 93 artefactos se recolectaron en la cuadrícula de excavación 1 (BCrack4 C1), que representa una densidad de 0,084 $\mathrm{dm}^{2}$. En Bahía Cracker 8 (BCrack8) el total de artefactos es de 86 y la densidad artefactual de $0,066 / \mathrm{dm}^{2}$.

\section{Materias primas:}

En BCrack4 M1se identificaron 12 variedades litológicas y una indeterminada, que se distribuyen en dos clases de rocas: andesitas (18\%) y riolitas $(15 \%)$, de calidad regular. Le siguen en importancia sílices y dacitas (10\% cada una), y granitos ( $8 \%$ de cada una) de calidad regular, y por último calcedonias $(7 \%)$ de muy buena aptitud para la talla. El resto de las materias primas -cuarcitas, gabro, ignimbrita y jaspe- se encuentran en muy baja frecuencia (entre 3 y 1,5\%). Con la excepción de ésta última, de excelente calidad, el resto son regulares para la talla (Tabla 8.26). En el conjunto artefactual de la cuadrícula 1 (BCrack4 C1) las clases litológicas son diez, destacándose sílices (32\%), seguidas de riolitas (18\%) y calcedonias (14\%), y por último, andesitas y dacitas (10 y $8 \%$ ). Entre las rocas con porcentajes inferiores a $6 \%$ se registraron xilópalos, cuarcitas, tobas, gabro, y un basalto y una materia prima indeterminada (Tabla 8.26).

En BCrack8 las variedades litológicas son cinco y un rodado de arenisca, entre las que prevalecen los basaltos (57\%), de calidad buena a muy buena, y en segundo lugar las riolitas (31 \%) de aptitud regular. Le siguen en orden de importancia y en muy baja frecuencia las sílices (6 \%) y las calcedonias (4\%), de muy buena calidad (Tabla 8.26). 


\begin{tabular}{|c|c|c|c|c|c|c|}
\hline \multirow{2}{*}{$\begin{array}{c}\text { Materias primas } \\
\text { líticas }\end{array}$} & \multicolumn{2}{|c|}{ BC 4 M1 } & \multicolumn{2}{c|}{ BC4 C1 } & \multicolumn{2}{c|}{ BC 8 } \\
\cline { 2 - 7 } & $\mathbf{N}$ & $\mathbf{\%}$ & $\mathbf{N}$ & $\mathbf{\%}$ & $\mathbf{N}$ & $\mathbf{\%}$ \\
\hline Dacita & 7 & 9,7 & 6 & 8,3 & -- & -- \\
\hline Andesita & 13 & 18,1 & 7 & 9,7 & -- & -- \\
\hline Cuarcita & 1 & 1,4 & 4 & 5,6 & -- & -- \\
\hline Basalto & 6 & 8,3 & 1 & 1,4 & 47 & 56,6 \\
\hline Gabro & 1 & 1,4 & 2 & 2,8 & 1 & 1,2 \\
\hline Ignimbrita & 2 & 2,8 & -- & -- & -- & -- \\
\hline Riolita & 11 & 15,3 & 13 & 18,1 & 26 & 31,3 \\
\hline Granito & 6 & 8,3 & -- & -- & -- & -- \\
\hline Calcedonia & 5 & 6,9 & 10 & 13,9 & 3 & 3,6 \\
\hline Silice & 7 & 9,7 & 23 & 31,9 & 5 & 6 \\
\hline Xilópalos & 1 & 1,4 & 4 & 4,2 & -- & -- \\
\hline Jaspe & 1 & 1,4 & -- & -- & -- & -- \\
\hline Toba & -- & -- & 3 & 1,4 & -- & -- \\
\hline Arenisca & -- & -- & -- & -- & 1 & 1,2 \\
\hline Indeterminado & 11 & 15,3 & 1 & 1,4 & -- & -- \\
\hline Total & $\mathbf{7 2}$ & $\mathbf{1 0 0 \%}$ & $\mathbf{6 2}$ & $\mathbf{1 0 0 \%}$ & $\mathbf{8 3}$ & $\mathbf{1 0 0 \%}$ \\
\hline
\end{tabular}

Tabla 8.26. Sitios Bahía Cracker 4 y 8: Tipos y frecuencias de las variedades litológicas.

Sobre la base de los muestreos sistemáticos de rocas (ampliar Capítulo 6) se infiere, que exceptuando el basalto, las sílices, las riolitas y la calcedonia -esta última disponible en muy baja frecuencia y en forma de rodados-, el resto de las materias primas no serían locales o al menos no abundantes. No obstante es probable que en los muestreos de rocas no se hayan recolectados nódulos de andesita o dacita por presentar, en algunos casos, calidades inferiores a regulares.

\section{Clases artefactuales:}

El Muestreo 1 está conformado por el $33 \%$ de núcleos, $55 \%$ de desechos, $7 \%$ de instrumentos tallados, y el resto se distribuye entre artefactos modificados por el uso (4\%) y una lasca con rastro complementario (1,4\%). La Cuadrícula 1 por 3,2 \% de núcleos, $90 \%$ de desechos, $5 \%$ de instrumentos tallados y un solo percutor $(1 \%)$. Las diferencias en la representación porcentual de núcleos y desechos en ambos muestreos se deberían a que en la excavación de la cuadrícula se utilizó zaranda de malla muy fina, no así en el muestreo (Tabla 8.27).

Para BCrack 8, sobresalen ampliamente los desechos (92\%), le siguen los núcleos (5 $\%$ y en proporciones muy bajas y parejas, los instrumentos tallados, rastros complementarios y artefactos modificados por el uso (1,2\% de cada uno) (Tabla 8.27). 


\begin{tabular}{|c|c|c|c|c|c|}
\hline Clases & Núcleos & Desechos & $\begin{array}{c}\text { Artef. } \\
\text { Form. talla }\end{array}$ & Rastros Comp. & $\begin{array}{c}\text { Artef. } \\
\text { Modific. uso }\end{array}$ \\
\hline BCrack 4 M1 & $\begin{array}{c}24: \\
32,9 \%\end{array}$ & $\begin{array}{c}40: \\
54,8 \%\end{array}$ & $\begin{array}{c}5: \\
6,8 \%\end{array}$ & $\begin{array}{c}1: \\
1,4 \%\end{array}$ & $\begin{array}{c}3: \\
4,1 \%\end{array}$ \\
\hline BCrack 4 C1 & $\begin{array}{c}3: \\
3,2 \%\end{array}$ & $\begin{array}{c}84: \\
90,3 \%\end{array}$ & $\begin{array}{c}5: \\
5 \%\end{array}$ & -- & $\begin{array}{c}1: \\
1,1 \%\end{array}$ \\
\hline BCrack 8 & $\begin{array}{c}4: \\
4,7 \%\end{array}$ & $\begin{array}{c}79: \\
91,9 \%\end{array}$ & $\begin{array}{c}1: \\
1,2 \%\end{array}$ & $\begin{array}{c}1: \\
1,2 \%\end{array}$ & $\begin{array}{c}1: \\
1,2 \%\end{array}$ \\
\hline
\end{tabular}

Tabla 8.27. Distribución de las clases artefactuales.

\section{Desechos de talla:}

En BCracker 4 M1 predominan las lascas primarias (48 \%), seguidas por las secundarias (38\%) y en tercer orden las indeterminadas que alcanzan el $14 \%$ (Tabla 8.28). Para la Cuadrícula 1 también son mayoría las lascas primarias y las de dorso natural (19\% cada una); en baja frecuencia ( $8 \%$ ) se ubican las secundarias y las de reactivación inversa; las de arista oblicua (5\%), inclinadas y en cresta (2\%). Casi la mitad de las lascas $(41 \%)$ no pudo ser determinada debido a la presencia de fracturas (Tabla 8.28).

El tipo de lascas mayoritario de BCrack 8 son las secundarias (19,5\%), seguidas por las primarias $(16 \%)$, el resto se distribuye entre las de dorso natural $(8 \%)$ y en porcentajes inferiores a $5 \%$ en nucleiformes, de arista inclinada, oblicuas y de reactivación inversa. Al igual que en BCracker $4 \mathrm{C} 1$ un número elevado de lascas (43\%) no pudo ser determinado (Tabla $8.28)$.

\begin{tabular}{|c|c|c|c|c|c|c|}
\hline \multirow{2}{*}{ Tipo de lascas } & \multicolumn{2}{|c|}{ BCrack 4M1 } & \multicolumn{2}{c|}{ BCrack 4C1 } & \multicolumn{2}{c|}{ BCrack 8 } \\
\cline { 2 - 7 } & $\mathbf{N}$ & $\mathbf{\%}$ & $\mathbf{N}$ & $\mathbf{\%}$ & $\mathbf{N}$ & $\mathbf{\%}$ \\
\hline De arista oblicua & -- & -- & 3 & 5,1 & 2 & 2,6 \\
\hline De arista inclinada & -- & -- & 1 & 1,7 & 3 & 3,9 \\
\hline Con dorso natural & -- & -- & 11 & 18,6 & 6 & 7,8 \\
\hline Primaria & 20 & 47,6 & 11 & 18,6 & 12 & 15,6 \\
\hline En cresta & -- & -- & 1 & 1,7 & -- & -- \\
\hline Con dorso preparado & -- & -- & -- & -- & -- & -- \\
\hline Secundaria & 16 & 38,1 & 4 & 6,8 & 15 & 19,5 \\
\hline De reactivación directa & - & - & 4 & 6,8 & 2 & 2,6 \\
\hline Nucleiforme & - & - & -- & -- & 4 & 5,2 \\
\hline Indeterminada & 6 & 14,3 & 24 & 40,7 & 33 & 42,9 \\
\hline Hoja de arista doble & - & - & -- & -- & -- & -- \\
\hline Total & $\mathbf{4 2}$ & $\mathbf{1 0 0} \%$ & $\mathbf{5 9}$ & $\mathbf{1 0 0} \%$ & $\mathbf{7 7}$ & $\mathbf{1 0 0} \%$ \\
\hline
\end{tabular}

Tabla 8.28. Tipos y frecuencias de lascas.

En cuanto al tamaño, para el conjunto de BCracker 4 M1 predominan las microlascas $(40,5 \%)$; le siguen las de tamaño mediano (33\%) y las grandes $(24 \%)$. Sólo se registró una hipermicrolasca (2,4 \%). Respecto del módulo largo/ancho, el porcentaje más elevado 
corresponde al de las lascas mediano-normal (55\%) y alargados (24\%); el resto se encuentran en frecuencias bajas y parejas: laminar normal y lasca ancha $(9,5 \%$ respectivamente) y lasca muy ancha (2,4 \%) (Tabla 8.29). Por su parte, en la Cuadrícula 1 prevalecen las microlascas (39 $\%$ ) y las hipermicrolascas (33\%), y en segundo lugar las pequeñas (17\%) y las medianas $(8,5$ $\%$ ). En valores bajos (entre 5 y $3 \%$ ) se registraron lascas de tamaño grande y láminas muy pequeñas -hiper y microláminas- (Tabla 8.29).

En el sitio BCracker 8 también sobresalen las microlascas (35\%) y las lascas pequeñas (29\%), seguidas por las de tamaño mediano (19,5\%) y por ultimo las hipermicrolascas (13\%) y las lascas grandes (4\%). El módulo más representado es el mediano normal (34\%) si bien también son frecuentes las lascas anchas $(25 \%)$ y las alargadas $(21 \%)$, y en porcentajes menores los laminares normales (12\%) y las lascas muy anchas (9\%) (Tabla 8.29).

\begin{tabular}{|c|c|c|c|c|c|c|c|c|}
\hline & $\begin{array}{l}\text { Tamaño } \\
\text { Módulo }\end{array}$ & $\begin{array}{c}\text { Lam. } \\
\text { normal }\end{array}$ & $\begin{array}{c}\text { Lasca } \\
\text { alargada }\end{array}$ & $\begin{array}{l}\text { Lasca } \\
\text { ancho }\end{array}$ & $\begin{array}{c}\text { Muy } \\
\text { ancha }\end{array}$ & $\begin{array}{c}\text { Med. } \\
\text { normal }\end{array}$ & Total & $\%$ \\
\hline \multirow{6}{*}{ 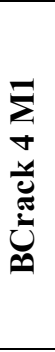 } & Hip.Lasca & -- & -- & -- & -- & 1 & 1 & 2,4 \\
\hline & MicroLasca & 4 & 2 & 1 & -- & 10 & 17 & 40,5 \\
\hline & Lasca Peq. & -- & -- & -- & -- & -- & -- & -- \\
\hline & Lasca med & -- & 4 & 3 & -- & 7 & 15 & 33,3 \\
\hline & Lasca grand & -- & 4 & -- & 1 & 5 & 10 & 23,8 \\
\hline & Total & $\begin{array}{c}4: \\
9,5 \%\end{array}$ & $\begin{array}{c}10: \\
23,8 \%\end{array}$ & $\begin{array}{c}4: \\
9,5 \%\end{array}$ & $\begin{array}{c}1: \\
2,4 \%\end{array}$ & $\begin{array}{c}23: \\
54,8 \%\end{array}$ & 42 & 100 \\
\hline \multirow{9}{*}{ 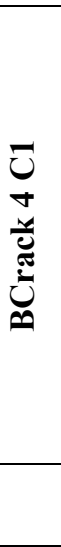 } & $\begin{array}{l}\text { Tamaño } \\
\text { Módulo }\end{array}$ & $\begin{array}{c}\text { Lam. } \\
\text { normal }\end{array}$ & $\begin{array}{c}\text { Lasca } \\
\text { alargada }\end{array}$ & $\begin{array}{l}\text { Lasca } \\
\text { Ancha }\end{array}$ & $\begin{array}{c}\text { Med. } \\
\text { alargado }\end{array}$ & $\begin{array}{c}\text { Med. } \\
\text { normal }\end{array}$ & Total & \\
\hline & Hip.Lasca & -- & -- & -- & -- & 14 & 14 & 23,7 \\
\hline & Hip.Lam. & 3 & - & - & -- & -- & 3 & 5,1 \\
\hline & MicroLasca & - & 3 & 2 & - & 18 & 23 & 39 \\
\hline & Micro.Lam & 2 & -- & -- & -- & -- & 2 & 3,4 \\
\hline & Lasca Peq. & - & 2 & -- & - & 8 & 10 & 16,9 \\
\hline & Lasca med & -- & -- & -- & & 5 & 5 & 8,5 \\
\hline & Lasca Grde & - & -- & -- & -- & 2 & 2 & 3,4 \\
\hline & Total & $\begin{array}{c}5: \\
8,4 \%\end{array}$ & $\begin{array}{c}5: \\
8,4 \%\end{array}$ & $\begin{array}{c}2: \\
3,3 \%\end{array}$ & -- & $\begin{array}{c}47: \\
79,6 \%\end{array}$ & 59 & 100 \\
\hline \multirow{7}{*}{ 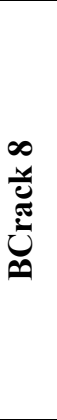 } & $\begin{array}{l}\text { Tamaño } \\
\text { Módulo }\end{array}$ & $\begin{array}{c}\text { Lam. } \\
\text { normal }\end{array}$ & $\begin{array}{c}\text { Lasca } \\
\text { alargada }\end{array}$ & $\begin{array}{l}\text { Lasca } \\
\text { Ancha }\end{array}$ & $\begin{array}{c}\text { Muy } \\
\text { ancha }\end{array}$ & $\begin{array}{c}\text { Mediano } \\
\text { normal }\end{array}$ & Total & \\
\hline & Hip.Lasca & 1 & 2 & -- & 1 & 6 & 10 & 13 \\
\hline & MicroLasca & 6 & 2 & 6 & 2 & 11 & 27 & 35,1 \\
\hline & Lasca Peq. & 1 & 8 & 6 & 3 & 4 & 22 & 28,6 \\
\hline & Lasca Med. & 1 & 3 & 7 & 1 & 3 & 15 & 19,5 \\
\hline & Lasca grande & -- & 1 & -- & -- & 2 & 3 & 3,9 \\
\hline & Total & $\begin{array}{c}9: \\
11,7 \% \\
\end{array}$ & $\begin{array}{c}16: \\
20,8 \%\end{array}$ & $\begin{array}{c}19: \\
24,7 \%\end{array}$ & $\begin{array}{c}7: \\
9,1 \%\end{array}$ & $\begin{array}{c}26: \\
33,8 \%\end{array}$ & 77 & 100 \\
\hline
\end{tabular}

Tabla 8.29. Tamaño y módulo largo/ancho de las lascas 
En cuanto al tipo de talón, para el muestreo 1 de BCracker 4 los talones identificados son tres, entre los que prevalecen ampliamente los corticales (70\%), en porcentajes inferiores se ubican los diedros $(17 \%)$ y los facetados (12\%). En la cuadrícula 1 se destacan tres tipos de talones: corticales, lisos y facetados (14\% de cada uno) y en segundo lugar diedros, fracturados y ausentes $(8,5 \%$ respectivamente). El $32 \%$ de los talones (que incluye a la totalidad de las hipermicrolascas) fueron indeterminados (Tabla 8.30).

En BCrack 8 los talones más representados son los corticales (34 \%) y los lisos (31\%), en segundo lugar y en frecuencias bajas se ubican los diedros ( $8 \%$ ), filiformes y puntiformes (4 $\%$ cada uno). Un porcentaje considerable (20 \%) no pudo ser determinado (Tabla 8.30).

\begin{tabular}{ccccccc}
\hline Tipo de talón & \multicolumn{2}{c}{ BCrack 4 } & \multicolumn{2}{c}{ BCrack 4 C1 } & \multicolumn{2}{c}{ BCrack 8 } \\
& M1 & \% & N & \% & N & \% \\
Cortical & -- & -- & 8 & 13,6 & 26 & 33,8 \\
Liso & 29 & 69 & 8 & 13,6 & 26 & 31,2 \\
Diedro & 7 & 16,7 & 5 & 8,5 & 6 & 7,8 \\
Facetado & 5 & 11,9 & 8 & 13,6 & 26 & 3,9 \\
Filiforme & -- & -- & 1 & 1,7 & -- & -- \\
Puntiforme & -- & -- & -- & -- & 3 & 3,9 \\
Fracturado & -- & -- & 5 & 8,5 & -- & -- \\
Ausente & -- & -- & 5 & 8,5 & -- & -- \\
Indeterminado & 1 & 2,4 & 19 & 32,2 & 15 & 19,5 \\
Total & $\mathbf{4 2}$ & $\mathbf{1 0 0}$ & $\mathbf{5 9}$ & $\mathbf{1 0 0}$ & $\mathbf{7 7}$ & $\mathbf{1 0 0}$
\end{tabular}

Tabla 8.30: Tipos y frecuencias de los talones.

\section{Artefactos formatizados por talla}

En BCrack 4 M1, del total de los instrumentos formatizados por talla $(n=5)$ dos son de dacitas verdes claras (según Munsell 2011) y uno de sílice marrón claro (5YR5/2), de calcedonia blanquecina y de basalto (Tabla 8.31). Las materias primas de mejor calidad -muy buena- corresponden a sílice y calcedonia, el resto son de aptitud regular para la talla. En cuanto a las formas base, los soportes son lascas de tamaño mediano $(n=3)$ y grande $(n=2)$. Por su parte, los cinco instrumentos tallados rescatados en la cuadrícula 1 fueron manufacturados sobre dacitas $(n=3)$ y riolitas $(n=2)$, ambas materias primas de calidad regular para la talla (Tabla $8.31)$.

El único instrumento hallado en BCrack8 está confeccionado sobre una lasca grande de basalto de muy buena calidad para la talla (Tabla 8.31).

Respecto de la serie técnica, para los instrumentos del muestreo 1 de BCrack 4 predomina el microretoque marginal y en algunos casos el retoque y la talla de formatización. En todos los casos la situación de los lascados es unifacial, y los filos se encuentran activos. Los dos 
artefactos de filos dobles (el raspador y la raclette) están manufacturados sobre materias primas de muy buena calidad para la talla (Fig 8.10 y Tabla 8.32 ). Por su parte, todos los instrumentos tallados de la Cuadrícula 1 presentan retoque ultramarginal y marginal. En todos estos artefactos la situación de los lascados es unifacial. Todos los instrumentos tienen filo simple y se encuentran activos (Tabla 8.33).

La punta entre muesca del sitio BCracker 8 fue confeccionada mediante talla marginal sobre una lasca alargada grande, manufacturada mediante talla marginal y tiene filo frontolateral simple (Fig.8.10)

\begin{tabular}{|c|c|c|c|c|c|c|c|}
\hline Sitio & $\mathbf{N}^{0} \operatorname{Inv}$ & Subgrupos & $\begin{array}{c}\text { Materia } \\
\text { Prima }\end{array}$ & Forma base & $\begin{array}{l}\text { Largo } \\
(\mathrm{mm})\end{array}$ & $\begin{array}{c}\text { Ancho } \\
(\mathbf{m m})\end{array}$ & $\begin{array}{c}\text { Espesor } \\
(\mathbf{m m})\end{array}$ \\
\hline \multirow{5}{*}{$\begin{array}{c}\text { BC } 4 \\
\text { M1 }\end{array}$} & 33 & Raspador & Calcedonia & Lasc Mediana & 49,7 & 25,5 & 13,1 \\
\hline & 34 & Racletts & Sílice & Lasca Mediana & 48,6 & 28,4 & 18,5 \\
\hline & 36 & Punta burilante & Dacita & Lasca Grande & 50,3 & 37,1 & 14,7 \\
\hline & 87 & Punta burilante & Dacita & Lasca Grande & 56,1 & 46,3 & 16,7 \\
\hline & 48 & Punta burilante & Basalto & Lasca Mediana & 45 & 24 & 16 \\
\hline \multirow{5}{*}{$\begin{array}{c}\text { BC } 4 \\
\text { C } 1\end{array}$} & 23 & Punta burilante & Dacita & Lasca Mediana & 44,9 & 34,4 & 15,5 \\
\hline & 26 & Punta burilante & Dacita & Lasca Grande & 50,9 & 35,8 & 14 \\
\hline & 5 & Punta burilante & Riolita & Lasca Mediana & 39,5 & 33,9 & 9,2 \\
\hline & 4 & Punta burilante & Riolita & Lasca Grande & 56,3 & 42,7 & 20,3 \\
\hline & sn & Cincel & Dacita & Lasca Mediana & 46,4 & 32,1 & 15,7 \\
\hline BC 8 & sn & Punta entre muesca & Basalto & Lasca Grande & 59,6 & 36,9 & 13 \\
\hline
\end{tabular}

Tabla 8.31. Características tecnológicas y métricas de los artefactos tallados de Bahía Cracker 4 M1 y C1 y Bahía Cracker 8. 


\begin{tabular}{|c|c|c|c|c|c|c|c|c|}
\hline $\begin{array}{l}\mathbf{N}^{o} \\
\text { Inv }\end{array}$ & Sub & $\begin{array}{c}\text { Serie } \\
\text { Técnica }\end{array}$ & Sit lasc. & $\begin{array}{l}\text { F. Geom. } \\
\text { Contorno }\end{array}$ & Posic. Filo & F.Lasc. & $\begin{array}{l}\text { Ang } \\
\text { Filo }\end{array}$ & $\begin{array}{c}\text { Estado } \\
\text { filo }\end{array}$ \\
\hline 33 & Raspador frontal (Doble) & Microretoque ultramarginal & Unif. & Semielíptica & Frontal & Paralelo corto regular & $45^{\circ}$ & Activo \\
\hline 34 & Raclette frontal (Doble) & Microretoque ultramarginal & Unif. & Rectangular & Frontal & Paralelo corto regular & $35^{\circ}$ & Activo \\
\hline 36 & Punta burilante & Microretoque ultramarginal & Unif. & Amigdaloide & Frontal & Golpe buril & -- & Activo \\
\hline 87 & Punta burilante & Retoque marginal & Unif. & Amigdaloide & Frontal & Golpe buril & -- & Activo \\
\hline 48 & Punta burilante & Talla & Unif. & Amigdaloide & Frontal & Golpe buril & -- & Activo \\
\hline
\end{tabular}

Tabla 8.32. BCracke 4 M1: Rasgos morfotécnicos de los artefactos tallados. Referencias: Sit. Lascados: situación de los lascados; F. Geom.: forma geométrica, Posic.Fil: Posición del filo; F.Lasc. Forma de los lascados; Ang. Ángulo del filo; restr. Restringido; Unif: Unificial; Indet: indeterminado.

\begin{tabular}{|c|c|c|c|c|c|c|c|c|}
\hline $\begin{array}{l}\mathbf{N}^{0} \\
\text { Inv }\end{array}$ & Sub & $\begin{array}{c}\text { Serie } \\
\text { Técnica }\end{array}$ & Sit Lasc. & $\begin{array}{l}\text { F. Geom. } \\
\text { Contorno }\end{array}$ & Posic. Filo & F.Lasc. & $\begin{array}{l}\text { Ang } \\
\text { Filo }\end{array}$ & $\begin{array}{c}\text { Estado } \\
\text { Filo }\end{array}$ \\
\hline 23 & Punta burilante & Retoque Ultramarg. & Unif. & Amigdaloide & Frontal & Golpe buril & -- & Activo \\
\hline 26 & Punta burilante & Retoque Ultramarg. & Unif. & Amigdaloide & Frontal & Golpe buril & -- & Activo \\
\hline 5 & Punta burilante & Retoque Ultramarg. & Unif. & Amigdaloide & Frontal & Golpe buril & -- & Activo \\
\hline 4 & Punta burilante & Retoque Marginal & Unif. & Amigdaloide & $\begin{array}{l}\text { Fronto- } \\
\text { Lateral }\end{array}$ & Golpe buril & -- & Activo \\
\hline $\mathrm{sn}$ & Cincel & Retoque Marginal & Unif. & Rectangular & Frontal & Indet. & -- & Activo \\
\hline
\end{tabular}

Tabla 8.33 BCrack4 C1: Rasgos morfotécnicos de los artefactos tallados. Referencias: Sit. Lascados: situación de los lascados; F. Geom.: forma geométrica, Posic.Fil: Posición del filo; F.Lasc. Forma de los lascados; Ang. Ángulo del filo; restr. Restringido; Unif: Unificial; Indet: indeterminado 


\section{Lascas con rastros complementarios}

En BCracker $4 \mathrm{M} 1$ se recuperó un cuchillo de filo lateral sobre lasca de dorso natural tamaño mediano de calcedonia de muy buena calidad. La otra lasca con rastros complementarios corresponde al sitio 8 . Se trata de un filo natural lateral y punta sobre lasca de dorso natural tamaño grande de basalto, de muy buena calidad.

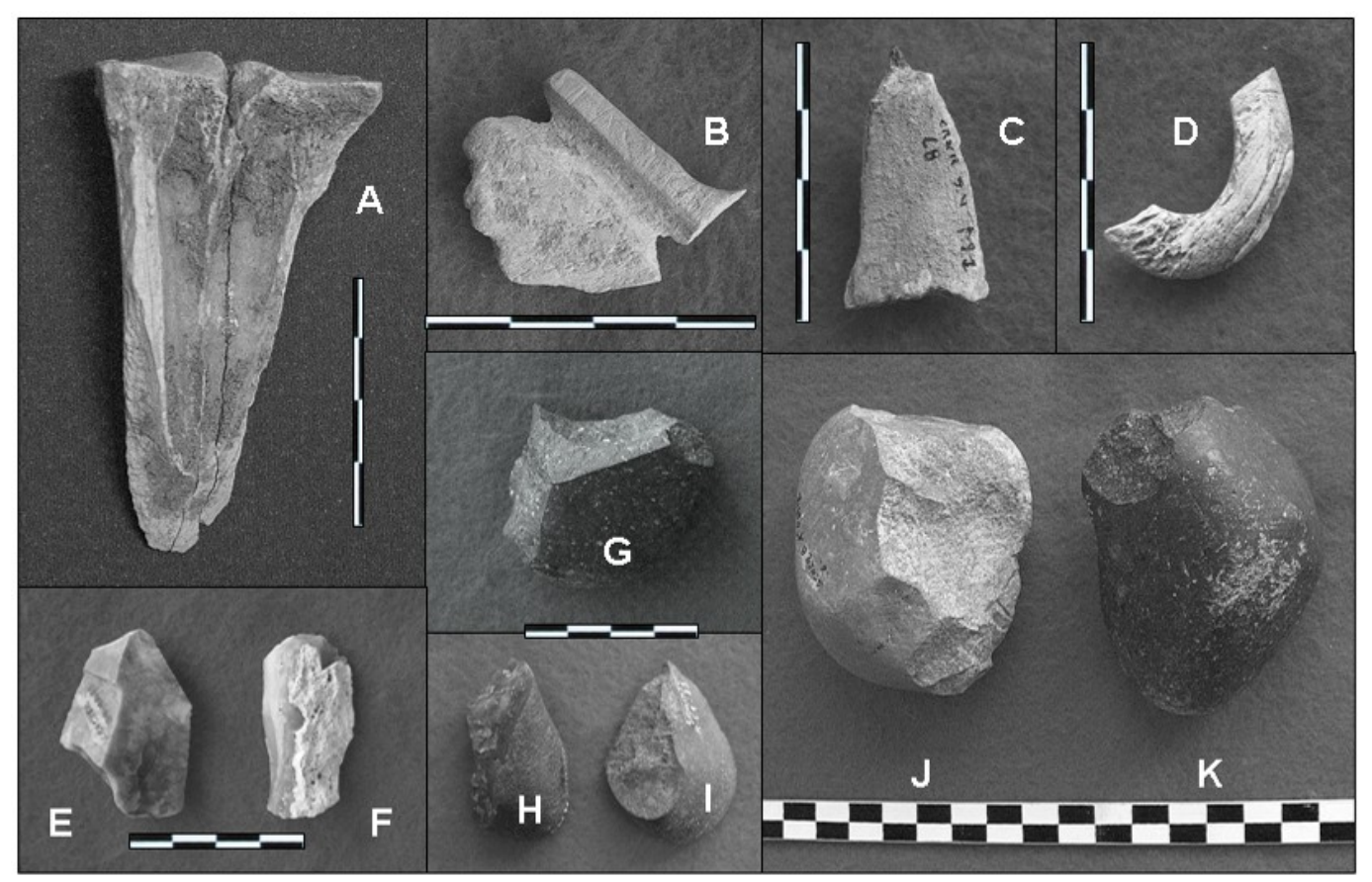

Fig. 8. 10. Artefactos de hueso (A-B-C y D) y líticos (E-K) recuperados en los sitios Cracker 4 y Cracker 8: (A) punta acanalada con ápice romo (espátula?); (B) artefacto de hueso de función desconocida; (C) punzón; (D) ¿argolla?(E) filo bilateral con rastros complementarios (F) raspador sobre lámina; (G) punta destacada; (H e I) artefactos burilantes; (J) núcleo en hemiguijarro; (K) percutor. Figura tomada de Gómez Otero et.al.2013.

\section{Núcleos}

Del total de núcleos del Muestreo $1(\mathrm{n}=24)$ sobresalen los de andesita y riolita $(21 \%$ cada uno), seguidos por dacitas (12,5\%) y en valores bajos y parejos los de basaltos; calcedonias y sílices ( $8 \%$ respectivamente). El resto -cuarcita, gabro, granito, ignimbrita e indeterminadas- $4 \%$ cada una (Tabla 8.32). Todos los núcleos provienen de rocas locales disponibles en forma de rodados. Casi la totalidad de las materias primas son de calidad regular, salvo los núcleos de basaltos y las calcedonias de mejor aptitud para la talla. En relación con el tamaño, predominan los grandes (entre 110 y $60 \mathrm{~mm}$ ) y solo unos poco son medianos y pequeño. Respecto de la morfología, más de la mitad son de lascados aislados (54\%), seguidos por los globulosos (8\%) y bipolar (4\%). 
El resto (33\%) no pudo ser determinado. Asimismo y conforme a la morfología predominante de los núcleos la gran mayoría se encuentra activo $(n=19: 79 \%)$ (Tabla 8.34). En la Cuadrícula 1 los núcleos recuperados provienen de rodados grandes locales de andesita y de cuarcita (dos de cada uno) ambas materias primas de calidad regular para la talla. Respecto de la morfología se reconocieron dos de lascados aislados, uno globuloso y el otro no pudo ser determinado. Con la excepción de este último, los tres restantes se encuentran activos (Tabla 8.35).

Por último, los cuatro núcleos rescatados en el sitio BCrack 8 provienen de rodados de tamaño grande y mediano de riolita y de basalto; los primeros de calidad regular y los de basalto de aptitud superior -muy buena-. Tres de los núcleos son de lascados aislados, y el último de basalto es bipolar. Todos se encuentran activos (Tabla 8.36).

\begin{tabular}{|c|c|c|c|c|c|c|c|}
\hline $\begin{array}{c}\text { Materia } \\
\text { prima } \\
(\mathrm{N}=\mathbf{2 4})\end{array}$ & Morfología & $\begin{array}{l}\mathbf{N}^{\circ} \\
\text { mín } \\
\text { p.p. }\end{array}$ & $\begin{array}{l}\text { Forma } \\
\text { sup } \\
\text { p.p. }\end{array}$ & $\begin{array}{l}\mathrm{N}^{\circ} \\
\text { Lasc }\end{array}$ & $\begin{array}{c}\text { Forma } \\
\text { negat } \\
\text { lasc }\end{array}$ & $\begin{array}{c}\text { Grado } \\
\text { modific }\end{array}$ & Estado \\
\hline $\begin{array}{l}\text { Andesita } \\
(n=5)\end{array}$ & $\begin{array}{l}\text { Lasc. Aislados } \\
(\mathrm{n}=4) \\
\text { Indet }(\mathrm{n}=1)\end{array}$ & 1 & $\begin{array}{l}\text { Cortical } \\
(\mathrm{n}=5)\end{array}$ & 23 & Lasca & $\begin{array}{l}\text { Bajo }(n=4) \\
\text { Alto }(n=1)\end{array}$ & $\begin{array}{l}\text { Activo }(n=4) \\
\text { Agotado }(n=1)\end{array}$ \\
\hline $\begin{array}{c}\text { Cuarcita } \\
(n=1)\end{array}$ & Indet. & 3 & Liso & 4 & Lasca & Medio & Activo \\
\hline $\begin{array}{c}\text { Basalto } \\
(n=2)\end{array}$ & $\begin{array}{l}\text { Lasc. Aislados } \\
\text { Bipolar }\end{array}$ & $\begin{array}{l}2 \\
2 \\
\end{array}$ & $\begin{array}{l}\text { Cortical } \\
\text { Cortical }\end{array}$ & 2 & Lasca & bajo & Activo $(\mathrm{n}=2)$ \\
\hline $\begin{array}{l}\text { Calc. } \\
(\mathrm{n}=2)\end{array}$ & $\begin{array}{l}\text { Lasc. Aislados } \\
\text { Indet. }\end{array}$ & $\begin{array}{l}3 \\
2 \\
\end{array}$ & Liso & 3 y 4 & Lasca & $\begin{array}{l}\text { Medio } \\
\text { Alto }\end{array}$ & $\begin{array}{l}\text { Activo } \\
\text { Agotado }\end{array}$ \\
\hline $\begin{array}{c}\text { Dacita } \\
(\mathrm{n}=3)\end{array}$ & $\begin{array}{l}\text { Lasc. Aislados } \\
\text { Indet. }(\mathrm{n}=2)\end{array}$ & 2 y 3 & $\begin{array}{l}\text { Cortical } \\
(\mathrm{n}=3)\end{array}$ & 2 y 4 & Lasca & $\begin{array}{l}\text { Bajo } \\
\text { Medio } \\
\end{array}$ & $\begin{array}{l}\text { Activo } \\
\text { Agotado }(\mathrm{n}=2)\end{array}$ \\
\hline $\begin{array}{l}\text { Gabro } \\
(n=1)\end{array}$ & Las. Aislado & 2 & Liso & 2 & Lasca & Bajo & Activo \\
\hline $\begin{array}{c}\text { Granito } \\
(n=1)\end{array}$ & Las. Aislado & 1 & Cortical & 2 & Lasca & Bajo & Activo \\
\hline $\begin{array}{c}\text { Ignimb. } \\
(n=1)\end{array}$ & Las. Aislado & 2 & Cortical & 2 & Lasca & Bajo & Activo \\
\hline $\begin{array}{c}\text { Riolita } \\
(n=5)\end{array}$ & $\begin{array}{l}\text { Lasc. Aisl. }(\mathrm{n}=3) \\
\text { Globuloso }(\mathrm{n}=1) ; \\
\text { Indet. }(\mathrm{n}=2)\end{array}$ & 3 y 4 & $\begin{array}{l}\text { Corticales } \\
\text { y liso }\end{array}$ & 3 y 4 & Lasca & $\begin{array}{l}\text { Bajo y } \\
\text { medio }\end{array}$ & Activo $(n=5)$ \\
\hline $\begin{array}{l}\text { Sílice } \\
(n=2)\end{array}$ & $\begin{array}{l}\text { Globuloso } \\
\text { Indet }\end{array}$ & 2 y 3 & Liso & 4 y 5 & Lasca & Medio & Activo $(n=2)$ \\
\hline $\begin{array}{l}\text { Indet } \\
(n=1)\end{array}$ & Indet. & 3 & Liso & $4 ?$ & Lasca & Alto & Agotado \\
\hline
\end{tabular}

Tabla 8.34. Bahía Cracker 4 M1: características morfológicas y técnicas de los núcleos. 


\begin{tabular}{|cc|clllll|}
\hline $\begin{array}{c}\text { Materia } \\
\text { prima } \\
(\mathbf{N}=\mathbf{4})\end{array}$ & Morfología & $\begin{array}{l}\mathbf{N}^{\mathbf{0}} \text { mín } \\
\text { plat } \\
\text { perc. }\end{array}$ & $\begin{array}{l}\text { Forma sup plat } \\
\text { perc. }\end{array}$ & $\begin{array}{l}\mathbf{N}^{\mathbf{0}} \\
\text { lasc. }\end{array}$ & $\begin{array}{l}\text { Forma } \\
\text { negat } \\
\text { lasc }\end{array}$ & $\begin{array}{l}\text { Grado } \\
\text { modific }\end{array}$ & Estado \\
\hline $\begin{array}{c}\text { Andesita } \\
(\mathrm{n}=2)\end{array}$ & $\begin{array}{c}\text { Indet } \\
\text { Las. Aislado }\end{array}$ & 3 & $\begin{array}{l}\text { Liso } \\
\text { Cortical }\end{array}$ & 5 & Lasca & $\begin{array}{l}\text { Alto } \\
\text { Bajo }\end{array}$ & $\begin{array}{l}\text { Agotado } \\
\text { Activo }\end{array}$ \\
\hline $\begin{array}{c}\text { Cuarcita } \\
(\mathrm{n}=2)\end{array}$ & $\begin{array}{c}\text { Lasc.Aislado } \\
\text { Globuloso }\end{array}$ & 2 & $\begin{array}{l}\text { Cortical } \\
\text { Liso }\end{array}$ & 2 & Lasca & $\begin{array}{l}\text { Bajo } \\
\text { Medio }\end{array}$ & $\begin{array}{c}\text { Activo } \\
(\mathrm{n}=2)\end{array}$ \\
\hline
\end{tabular}

Tabla 8.35. Bahía Cracker 4 C1: características morfológicas y técnicas de los núcleos.

\begin{tabular}{|c|c|c|c|c|c|c|c|}
\hline $\begin{array}{c}\text { Materia } \\
\text { prima } \\
(\mathrm{N}=4)\end{array}$ & Morfología & $\begin{array}{l}\mathbf{N}^{0} \text { mín } \\
\text { plat } \\
\text { perc. }\end{array}$ & $\begin{array}{l}\text { Forma sup plat } \\
\text { perc. }\end{array}$ & $\begin{array}{l}\mathbf{N}^{\mathbf{o}} \\
\text { lasc. }\end{array}$ & $\begin{array}{l}\text { Forma } \\
\text { negat } \\
\text { lasc }\end{array}$ & $\begin{array}{l}\text { Grado } \\
\text { modific }\end{array}$ & Estado \\
\hline $\begin{array}{l}\text { Riolita } \\
(\mathrm{n}=2)\end{array}$ & Lasc. Aislados & 2 & Cortical & 2 & Lasca & Bajo & Activo \\
\hline $\begin{array}{c}\text { Basalto } \\
(\mathrm{n}=2)\end{array}$ & $\begin{array}{l}\text { Lasc.Aislado } \\
\text { Bipolar }\end{array}$ & $\begin{array}{l}2 \\
1\end{array}$ & Cortical & 2 & Lasca & Bajo & Activo \\
\hline
\end{tabular}

Tabla 8.36. Bahía Cracker 8: características morfológicas y técnicas de los núcleos.

\section{Artefactos modificados por el uso}

En el Muestreo 1 se hallaron tres percutores sobre rodados grandes de riolita $(n=2)$ y uno de dacita. En BCracker $4 \mathrm{C} 1$ se recuperó un percutor sobre rodado grande de riolita. En el sitio 8 se recuperó un rodado grande de arenisca con forma discoidal que podría haber sido utilizado como sobador.

\section{Índice de fractura}

Para el muestreo 1 el porcentaje de fractura es de $11 \%$, en la Cuadrícula 1 de $22 \%$ y mayor en el sitio 8 (36\%). En los tres muestreos el porcentaje más elevado de fracturas se registró en los desechos de talla (Tabla 8.24).

\begin{tabular}{|l|c|c|c|c|c|c|}
\hline \multirow{3}{*}{$\begin{array}{c}\text { Clase } \\
\text { Tipológica }\end{array}$} & \multicolumn{7}{|c|}{ Fracturas } \\
\cline { 2 - 7 } & \multicolumn{2}{|c|}{ BCrack 4 M1 } & \multicolumn{2}{c|}{ BCrack 4 C1 } & \multicolumn{2}{c|}{ BCrack 8 } \\
\cline { 2 - 7 } & N & $\mathbf{\%}$ & N & $\mathbf{\%}$ & N & \% \\
\hline Artf. Mod. Por uso & -- & -- & 1 & $100 \%$ & -- & -- \\
\hline Desechos & 6 & $15 \%$ & 19 & $26,3 \%$ & 31 & $40,2 \%$ \\
\hline Art. Form. talla & -- & -- & -- & -- & -- & -- \\
\hline Rastros comp. & -- & -- & -- & -- & --- & -- \\
\hline Núcleos & 2 & $8,3 \%$ & -- & -- & -- & -- \\
\hline \multicolumn{1}{|c|}{ Total } & $\mathbf{8}$ & $\mathbf{1 1 , 1 \%}$ & $\mathbf{2 0}$ & $\mathbf{2 1 , 7} \%$ & $\mathbf{3 1}$ & $\mathbf{3 5 , 6 \%}$ \\
\hline
\end{tabular}

Tabla 8.24. Frecuencia de fracturas por clase tipológica. 


\section{Relaciones de ensamblaje}

En total se realizaron dos relaciones de ensamblaje. La primera corresponde a la Cuadrícula 1 del sitio 4; se trata de dos lascas pequeñas de andesita. La segunda, del sitio 8, consiste en la unión de dos lascas de tamaño mediano de riolita, probablemente fracturadas por daño térmico.

\section{Presencia de laminaridad, bipolaridad y bifacialidad:}

La presencia de laminaridad es superior en el sitio $8(10,5)$ y más baja y pareja en el muestreo 1 y en la cuadrícula de excavación del sitio 4 (5,6 y 5,4 \% respectivamente). La bipolaridad está casi ausente, se registró sólo un artefacto en el Muestreo 1 (un núcleo de basalto) y otro en el sitio 8 (1,4\% y 1,2 \% para cada uno). En ninguno de los sitios se identificó la técnica bifacial.

\section{Tendencias generales de los conjuntos líticos de la localidad arqueológica Bahía Cracker}

Los sitios Bahía Cracker 4 y 8 presentan similares antigüedades - circa 5300-5200 años APque son relativamente contemporáneas con el comienzo del descenso del nivel marino luego de la máxima ingresión del Holoceno medio entre 6000 y $6500 \mathrm{C}^{14} \mathrm{AP}$ (Weiler 1998). No obstante se observaron algunas diferencias y similitudes en cuanto a los recursos faunísticos y líticos explotados. En primer lugar, para el registro arqueofaunístico si bien predominan los recursos marinos se registra diferencias entre los taxones representados: en BCracker 8 sólo se registraron moluscos, peces y cirripedios; en Cracker 4 el espectro fue mayor ya que además se agregan aves y presas grandes como el guanaco y los pinnípedos (Gómez Otero et al 2013).

Respecto de la tecnología, los rasgos identificados en los conjuntos líticos de los dos muestreos señalan aprovechamiento in situ de los rodados locales (litorales y patagónicos) y tareas iniciales de la secuencia de producción. El alto porcentaje de núcleos descartados con lascados aislados sugiere que se estaba probando la calidad de los mismos. En ese sentido, los nódulos de rocas más aptas para la talla -sílices coloreadas en Cracker 4 y basaltos en Cracker 8- fueron los más intensamente explotados; no obstante, hubo baja inversión en la manufactura de los artefactos. Sobresale la frecuencia de puntas burilantes, las que podrían haber sido utilizadas para abrir las carcasas de los lobos marinos, y quizás también procesar peces y aves (lo que en un futuro próximo será explorado a través de trabajos experimentales). Con relación a la obtención de los recursos, en 
ninguno de los muestreos se registró algún artefacto que pudiera indicar métodos de captura, aunque sí se detectaron pesas líticas en otros sitios aledaños.

En función de las evidencias faunísticas y líticas se propuso que los dos sitios corresponderían a ocupaciones de corta duración en primavera-verano, representativas de emplazamientos de tipo localización (Gómez Otero et al. 2013). En estas ocupaciones se realizaron tareas extractivas tales como recolección de invertebrados, pesca, y en BCrack 4 también caza, consumo y procesamiento de aves marinas, pinnípedos y guanacos. Es probable que las partes de menor valor económico de las presas grandes hayan sido consumidas in situ y las más nutritivas llevadas a las bases residenciales, que habrían estado en las inmediaciones. Para la realización de todas estas tareas se tallaron expeditivamente los rodados locales, utilizándose lascas con filos naturales o con formatización sumaria. 


\section{CAPÍTULO 9}

\section{DISCUSIÓN Y CONSIDERACIONES FINALES}

En este capítulo se presenta la discusión de los resultados organizados de acuerdo con el objetivo principal de la tesis que es caracterizar la organización de la tecnología lítica de los cazadores-recolectores de la costa centro-septentrional de Patagonia. Asimismo, y como se mencionó en la Introducción, se contrasta el modelo propuesto por Gómez Otero (2006) para la costa norte de Chubut, que plantea una mayor intensidad de uso del espacio en Península Valdés que en los demás sectores costeros. Para ordenar la discusión, el capítulo se organiza en cuatro partes. En la primera, y de acuerdo la segmentación espacial propuesta, se comparan los resultados obtenidos en las dos unidades de análisis arqueológicas (Uarq) "Península Valdés" y "Fuera de Península Valdés". A continuación, y en función de explorar tendencias temporales, se evalúan cambios tecnológicos en los tres bloques definidos: Holoceno medio (7400 - $4000 \mathrm{C}^{14}$ años AP), Holoceno tardío inicial $\left(3900-1000 C^{14}\right.$ años AP) y Holoceno tardío final $\left(1000-300 C^{14}\right.$ años AP). Estos datos se cotejan con estudios previos realizados por Gómez Otero y colaboradores en Península Valdés (Gómez Otero et al. 1999). Paralelamente se integra esta información en el marco más amplio del registro tecnológico lítico de las costas pampeana y patagónica. Para ello se recurre a los trabajos de Mariano Bonomo (2005) y Cristina Bayón para la región pampeana (Politis y Bayón 1995; Bayón et al. 2011); Gustavo Martínez (2008-2009), Cristian Favier Dubois y Florencia Borella para la Nordpatagónica (Favier Dubois et al. 2008); Alicia Castro y Gloria Arrigoni para la costa centro-meridional (Castro et al. 2008, Arrigoni et al. 2008); Isabel Cruz y Soledad Caracotche (2008), Estela Mansur (2008), Flavia Carballo Marina (Carballo y Escorlano 2008), Luis Borrero y Nora Franco para la costa meridional (Borrero et al. 2008)

Para iniciar la discusión se retoman las hipótesis planteadas, las que serán discutidas por separado en una escala espacial y temporal. 


\section{Hipótesis I}

La disponibilidad y abundancia de materias primas líticas en el área de estudio habría propiciado el aprovechamiento prioritario de las fuentes secundarias locales y el predominio de tecnologías de tipo expeditivo.

\section{La selección de materias primas líticas}

Sobre la base del enfoque teórico de la organización tecnológica (Nelson 1991), en primer lugar se sintetiza comparativamente y discute la selección de rocas en función de la base regional de recursos líticos en cada una de las unidades espaciales. Como ya se desarrolló en el capítulo 6 (Base regional), se determinó amplia distribución y abundancia de litologías aptas para distintos tipos de artefactos en las dos unidades de análisis. Entre las de mejor calidad para la talla se encuentran sílices y basaltos; las de calidad regular más abundantes corresponden a riolitas, cuarcitas, andesitas-dacitas y tobas. No obstante, en la unidad FPV hay diferencias entre los dos sectores: el norte (costa del golfo San Matías oeste) y el sur (costa del golfo Nuevo). En el sector más septentrional de esta unidad -la zona de Arroyo Verde- la disponibilidad de rocas para la talla es mayor ya que a las litologías de los depósitos secundarios de rodados (basaltos, riolitas, cuarcitas, etc.), se suma la presencia de bloques de ignimbritas, filones de calcedonias y pórfidos, provenientes de los afloramientos primarios de la Fm. Marifil. No obstante, más allá de estas diferencias entre los sectores, la abundancia de materias primas adecuadas y accesibles en ambas unidades, habría propiciado un aprovisionamiento directo con bajos costos de obtención y el predominio de estrategias tecnológicas expeditivas (sensu Binford 1979; Bamforth 1986; Torrence 1989).

Ahora bien, a los fines de contrastar los resultados de los muestreos de rocas con el registro arqueológico, a continuación se sintetizan comparativamente los resultados del análisis de los conjuntos artefactuales de los sitios de ambas unidades arqueológicas. En la unidad arqueológica PV se determinaron quince variedades de rocas, las nueve disponibles localmente y seis no locales (Tabla 9.1). Las más frecuentes son dos locales -sílices (35\%) y basaltos $(28,4 \%)$, y una no local calcedonia $(16,6 \%)$. Las rocas minoritarias incluyen tanto locales (ignimbritas, riolitas, andesitasdacitas, cuarcitas, arenisca consolidada y toba) como alóctonas (xilópalos, obsidianas, hematita y basalto olivínico). Salvo los xilópalos, que alcanzan 4,4\%, el resto de las materias primas (tanto locales como alóctonas) no supera el 1,6\%. Entre las obsidianas de los conjuntos líticos tratados en esta tesis, se reconocieron macroscópicamente tres variedades: T/SCII, MSI y CC?, cuyas fuentes aún no se localizaron, aunque se estima que estarían en la meseta de Somuncurá de acuerdo con la 
propuesta de Gómez Otero y Stern (2005). En otros sitios de la península se detectaron estas y dos variedades más que proceden de la meseta centro-norte de Chubut: (T/SCI), en la zona de Telsen y SI, en Sacanana (Fig.9.1). Si se toma en cuenta la distancia en línea recta desde el inicio de Península Valdés, se ubican al oeste a 180 y 330 km respectivamente (Gómez Otero y Stern 2005).

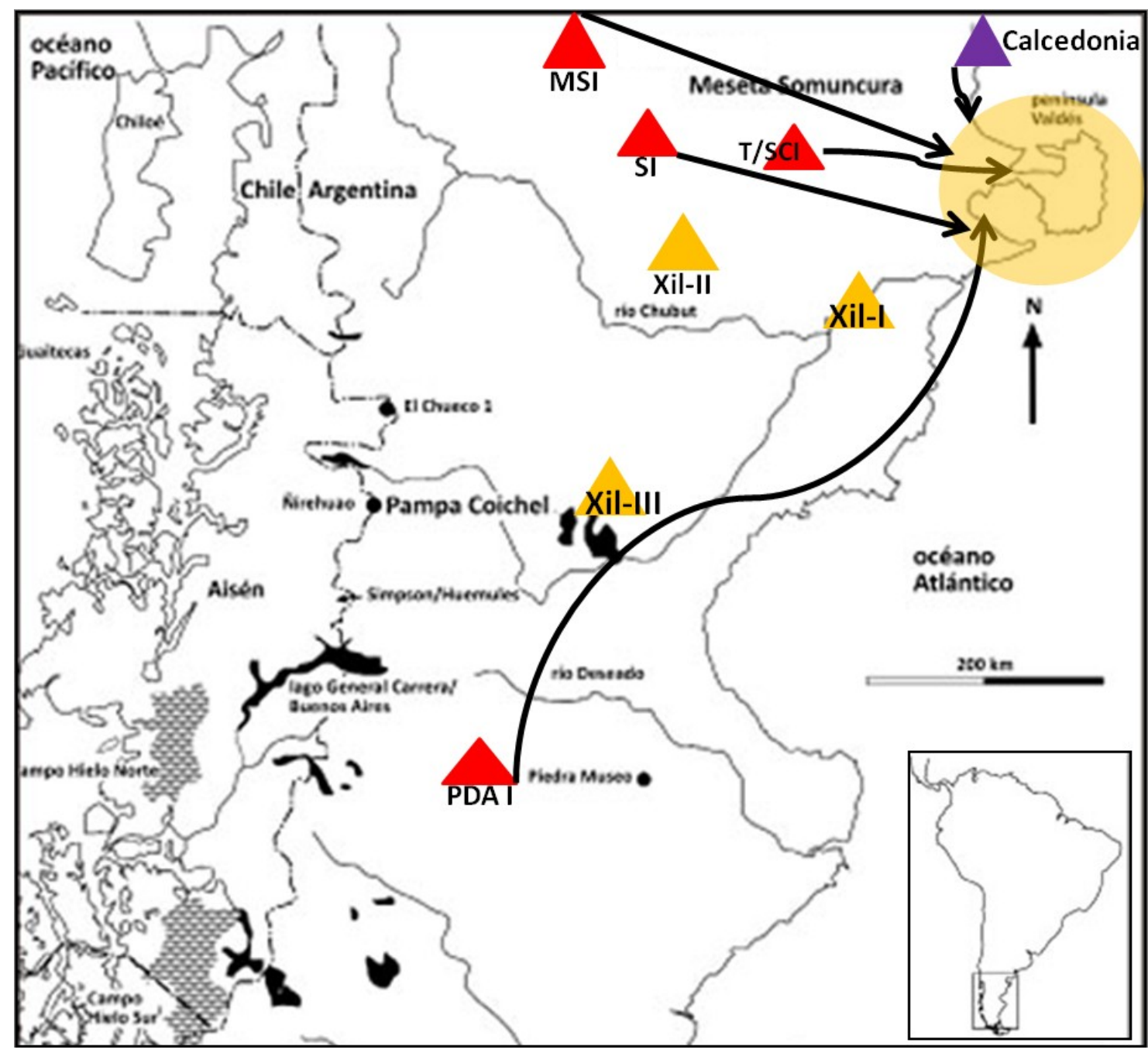

Fig.9.1. Mapa ubicación fuentes potenciales de materiales no locales y su distancia respecto del área de estudio. Referencias: SI (fuente Sacanana); T/SCI (fuente Telsen/Sierra Chata); MSI (fuente Meseta de Somuncurá I); PDAI (fuente Pampa del Asador) (Gómez Otero y Stern 2005); Xil I: Bosque petrificado del Dique Ameghino; Xil II Afloramiento de maderas fósiles Las Plumas; Xil III: boque petrificado de Sarmiento; Xil IV: Bosque petrificado de la Costa (Arrigoni et al.2008).

En los sitios de la Uarq-FPV se identificaron diecisiete tipos de rocas y una indeterminada. Entre las locales sobresalen las sílices $(32,3 \%)$, seguidas por los basaltos (18,3\%) y por último, las calcedonias y riolitas (10,5\%) (Tabla 9.1). Tal como se mencionó, la calcedonia es local en el sector 
oeste del golfo San Matías (zona de Arroyo Verde) y se presenta en forma de filones y tabletas; mientras que en el golfo Nuevo sur se halla en muy baja frecuencia y en forma de rodados. El resto de las materias primas locales -andesitas, dacitas, cuarcitas, tobas, etc.- se encuentra en frecuencias muy bajas y no supera el 4,5\%. De las no locales, los xilópalos fueron las únicas registradas en los dos sectores de costa, alcanzando 3,2\%. Las además rocas alóctonas -obsidiana gris verdosa, basalto olivínico y hematita- solo se identificaron en el golfo san Matías oeste, con una representación inferior a $1 \%$.

En síntesis, se determinó una diversidad litológica arqueológica levemente mayor en la UarqFPV que en la Uarq-PV (diecisiete variedades sobre quince respectivamente), pero se destaca la superior frecuencia de rocas no locales en los sitios de Península Valdés, que triplica la de la UarqFPV (Tabla 9.1, Fig. 9.1). Respecto de la variabilidad interna en la proporción de rocas locales versus las no locales, en cada unidad arqueológica se observa parejo porcentaje de las foráneas entre los distintos sectores: $23,2 \% ; 24,8 \%$ y $25,8 \%$ en los tres golfos de la Uarq-PV, y entre $5,1 \%$ y 6,9 $\%$ respectivamente en los dos golfos de la Uarq-FPV (Fig. 9. 2).
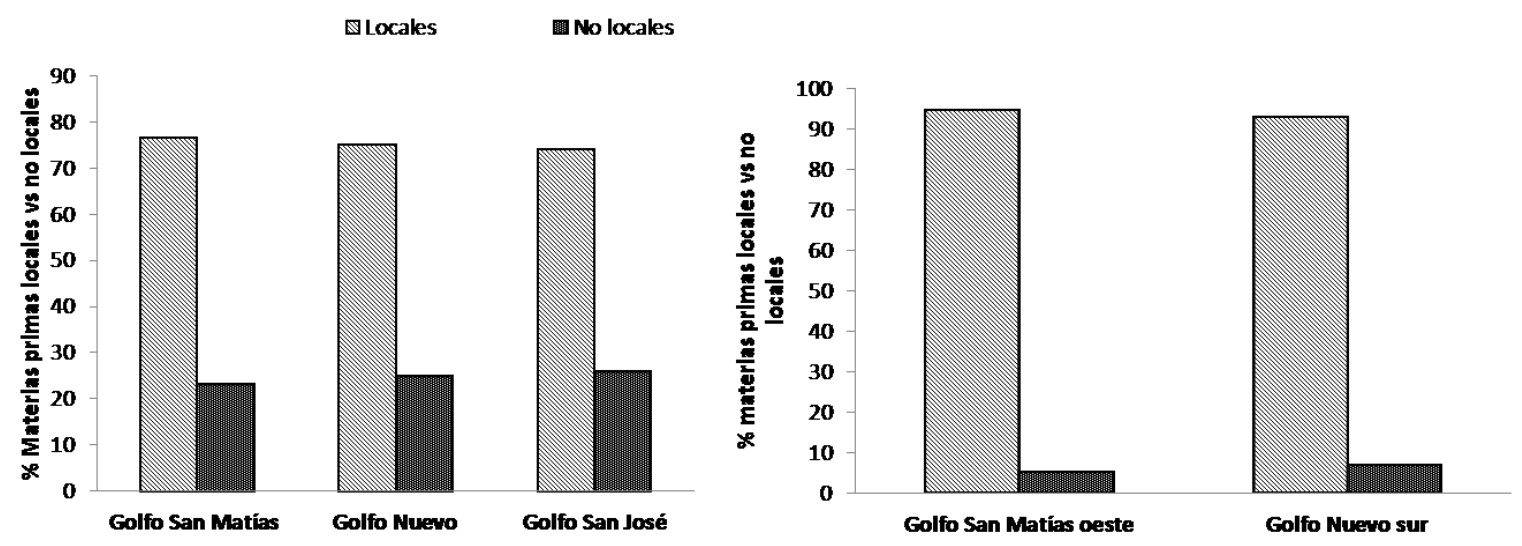

Fig. 9.2 Comparación frecuencias de las materias primas locales versus no locales entre unidades de análisis Izquierda (PV) y derecha (Fuera de PV). 


\begin{tabular}{|c|c|c|c|c|c|c|c|c|c|c|}
\hline \multirow{3}{*}{ 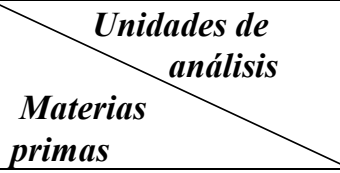 } & \multicolumn{6}{|c|}{ Península Valdés } & \multicolumn{4}{|c|}{ Fuera de Pla. Valdés } \\
\hline & \multicolumn{2}{|c|}{ Golfo San Matías } & \multicolumn{2}{|c|}{ Golfo Nuevo } & \multicolumn{2}{|c|}{ Golfo San José } & \multicolumn{2}{|c|}{ Golfo San Matías oeste } & \multicolumn{2}{|c|}{ Golfo Nuevo Sur } \\
\hline & $\mathbf{N}$ & $\%$ & $\mathbf{N}$ & $\%$ & $\mathbf{N}$ & $\%$ & $\mathbf{N}$ & $\%$ & $\mathbf{N}$ & $\%$ \\
\hline Basalto & 76 & 24,1 & 123 & 44,9 & 26 & 11,4 & 83 & 15,6 & 54 & 24,8 \\
\hline Basalto olivínico & -- & -- & 1 & 0,4 & -- & -- & 2 & 0,4 & -- & -- \\
\hline Andesita - dacita & 2 & 0,6 & 4 & 1,5 & 4 & 1,7 & -- & -- & 33 & 15,2 \\
\hline Calcedonia & 47 & 14,9 & 48 & 17,5 & 36 & 15,7 & 61 & 11,5 & 18 & 8,3 \\
\hline Caliza fosilizada & -- & -- & -- & -- & -- & -- & 14 & 2,6 & -- & -- \\
\hline CUarqcita & 11 & 3,5 & 2 & 0,7 & 2 & 0,9 & 8 & 1,5 & 5 & 2,3 \\
\hline Hematita & 1 & 0,3 & 1 & 0,4 & 10 & 4,4 & 1 & 0,2 & -- & -- \\
\hline Gabro & -- & -- & -- & -- & -- & -- & -- & -- & 4 & 1,8 \\
\hline Ignimbrita & 20 & 6,3 & 2 & 0,7 & -- & -- & 60 & 11,3 & 2 & 0,9 \\
\hline Jaspe-ópalo & -- & -- & 5 & 1,8 & -- & -- & 8 & 1,5 & 1 & 0,5 \\
\hline Obsidiana gris-verdosa & 6 & 1,9 & 5 & 1,8 & 2 & 0,9 & 5 & 0,9 & -- & -- \\
\hline Obsidiana negra & 5 & 1,6 & 1 & 0,4 & 2 & 0,9 & -- & -- & -- & -- \\
\hline Riolita & 18 & 5,7 & 8 & 2,9 & 2 & 0,9 & 28 & 5,3 & 50 & 22,9 \\
\hline Sílice & 108 & 34,3 & 35 & 12,8 & 135 & 59 & 207 & 39 & 35 & 16,1 \\
\hline Toba & -- & -- & 3 & 1,1 & -- & -- & 31 & 5,8 & 3 & 1,4 \\
\hline Xilópalo & 14 & 4,4 & 12 & 4,4 & 9 & 3,9 & 19 & 3,6 & 5 & 2,3 \\
\hline Arenisca consolidada & -- & -- & 2 & 0,7 & -- & -- & -- & -- & 1 & 0,5 \\
\hline Granito & -- & -- & -- & -- & -- & -- & -- & -- & 6 & 2,8 \\
\hline Indeterminada & 7 & 2,2 & 3 & 1,1 & 3 & 1,3 & 4 & 0,8 & 1 & 0,5 \\
\hline Total & 315 & 100 & 247 & 100 & 229 & 100 & 531 & 100 & 218 & 100 \\
\hline
\end{tabular}

Tabla 9.1. Unidades de análisis arqueológicas: PV y FPV. 
En todos los sectores de PV las calcedonias se ubican en primer lugar con valores que oscilan entre $8,3 \%$ y $17,5 \%$; los xilópalos entre $2,3 \%$ y 4,4\% y por último las obsidianas entre $0,4 \%$ y 1,9\% (Tabla 9.1). Esta superioridad de rocas alóctonas en PV no se condice con la mayor distancia a las fuentes respecto de la otra unidad. En este sentido, si sólo se tuviera en cuenta esta variable, se debería haber registrado más proporción de estas rocas fuera de la península. Tampoco incidiría la cantidad de artefactos analizados para cada Uarq, ya la muestra de PV incluye 791 artefactos y la de FPV 749.

Otra explicación podría vincularse con la funcionalidad de los sitios analizados, ya que es esperable registrar superior diversidad de clases artefactuales y quizás también de materias primas en las bases residenciales que en los sitios de actividades específicas o limitadas. En las bases residenciales la cantidad de actividades es mayor y el tiempo de ocupación más prolongado. Esto habría requerido de materias primas diferentes: por ejemplo, las rocas adecuadas para la talla no son las mismas que las apropiadas para la percusión o la molienda $u$ otros usos. Como es sabido, para la molienda las rocas deben presentar texturas durables y abrasivas (Nelson y Adams 1995; Babot 2006, Matarresse 2015, entre otros), como por ejemplo las areniscas, o el caso de los basaltos vesiculares cuyas textura porosa es apta para su uso como sobador. Por su parte, en sitios enterratorio del norte de Chubut, se han registrado rocas muy vistosas por su brillo o coloración, como el yeso o rodados muy pequeños de sílices coloreadas o calcedonia (Gómez Otero et al. 2009, Gómez Otero, com. pers. 2014)

En este sentido, y acorde con el modelo de Binford (1980), Gómez Otero (2006) determinó mayor proporción de bases residenciales en Península Valdés que fuera de ella (Fig. 9.3). Al interior de la Uarq-PV, la mayor frecuencia de bases residenciales se registró en la costa del golfo San Matías, siguiéndole las del golfo san José y Nuevo, mientras que en caleta Valdés y entre punta Delgada y Pico Lobo no se reconoció ninguna base residencial. En cuanto a la Uarq-FPV, el sector con mayor porcentaje de bases residenciales fue la barranca norte del río Chubut (sector espacial no incluido en esta tesis), al que siguen las costas de los golfos Nuevo Sur y San Matías Oeste, y por último, la de mar abierto entre punta Ninfas y Bajo de los Huesos (sector tampoco incluido), donde no se registró ninguna (Figura 9.2). Es decir, que la mayor abundancia de bases residenciales en PV indica un uso más diversificado e intenso del espacio que los dos sectores de FPV aquí analizados, lo que podría explicar la mayor variedad litológica en la primera de las dos unidades espaciales. 


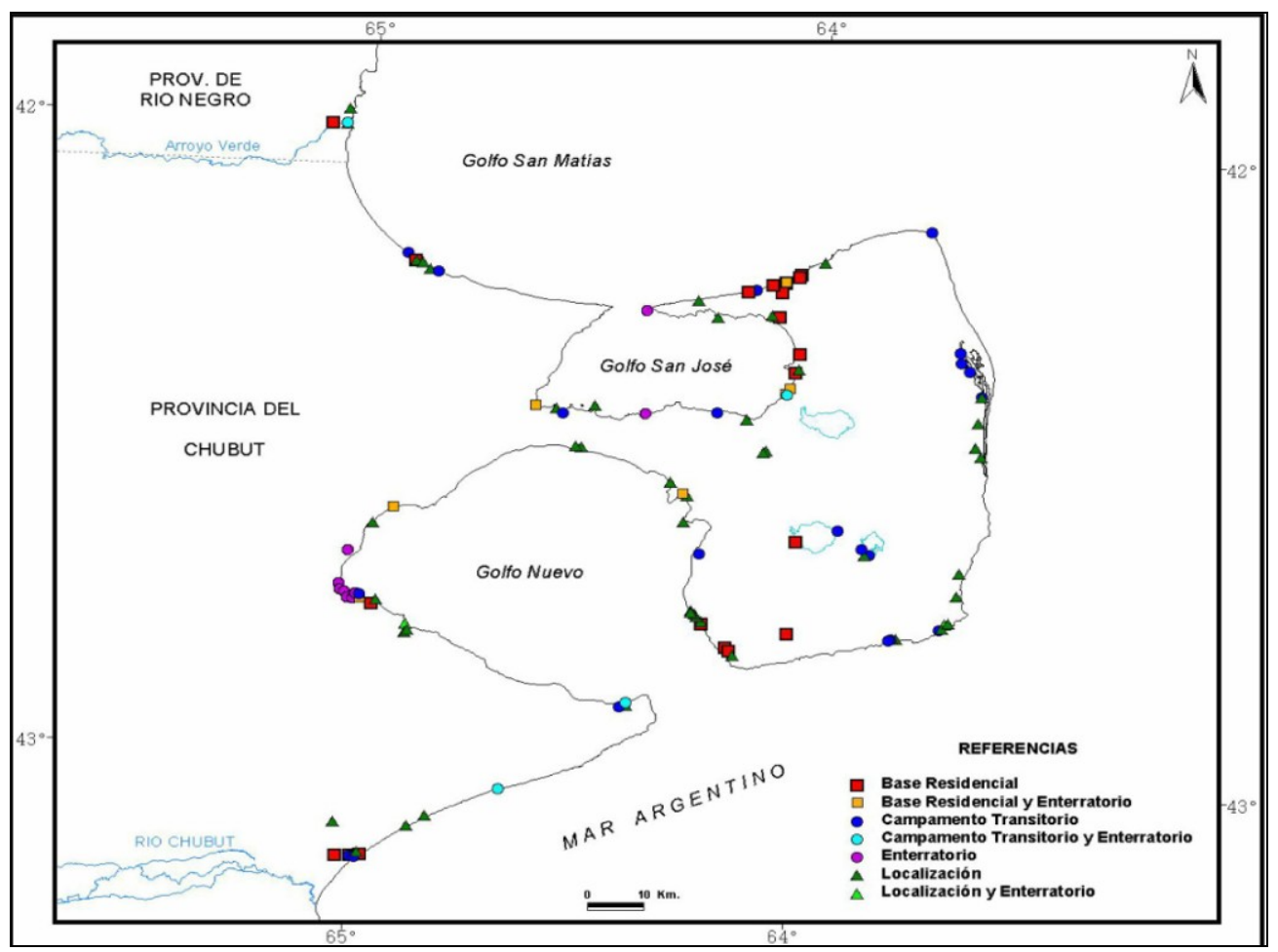

Fig. 9.3. Distribución geográfica de los sitios arqueológicos por funcionalidad en la costa norte de Chubut, tomado de Gómez Otero 2006 (Anexo - Mapa 11).

A los fines de reconocer tendencias entre la funcionalidad de los sitios analizados en esta tesis y la diversidad litológica, se dividieron los muestreos en dos grandes grupos: de "actividades restringidas o limitadas" (entre una y dos actividades), y de "actividades múltiples" (más de dos). La división se fundamenta en lo expresado en párrafos anteriores, dado que en los sitios donde se llevó a cabo un número mayor de actividades se espera que la diversidad de tipos de rocas sea mayor. En el primer tipo se incluyeron los talleres líticos, los concheros y la estación de Cormoranes 3; en el segundo, las bases residenciales, los campamentos transitorios, el fogón de Los Abanicos 1 y el basural de San Pablo 6 (Figura 9.4) 


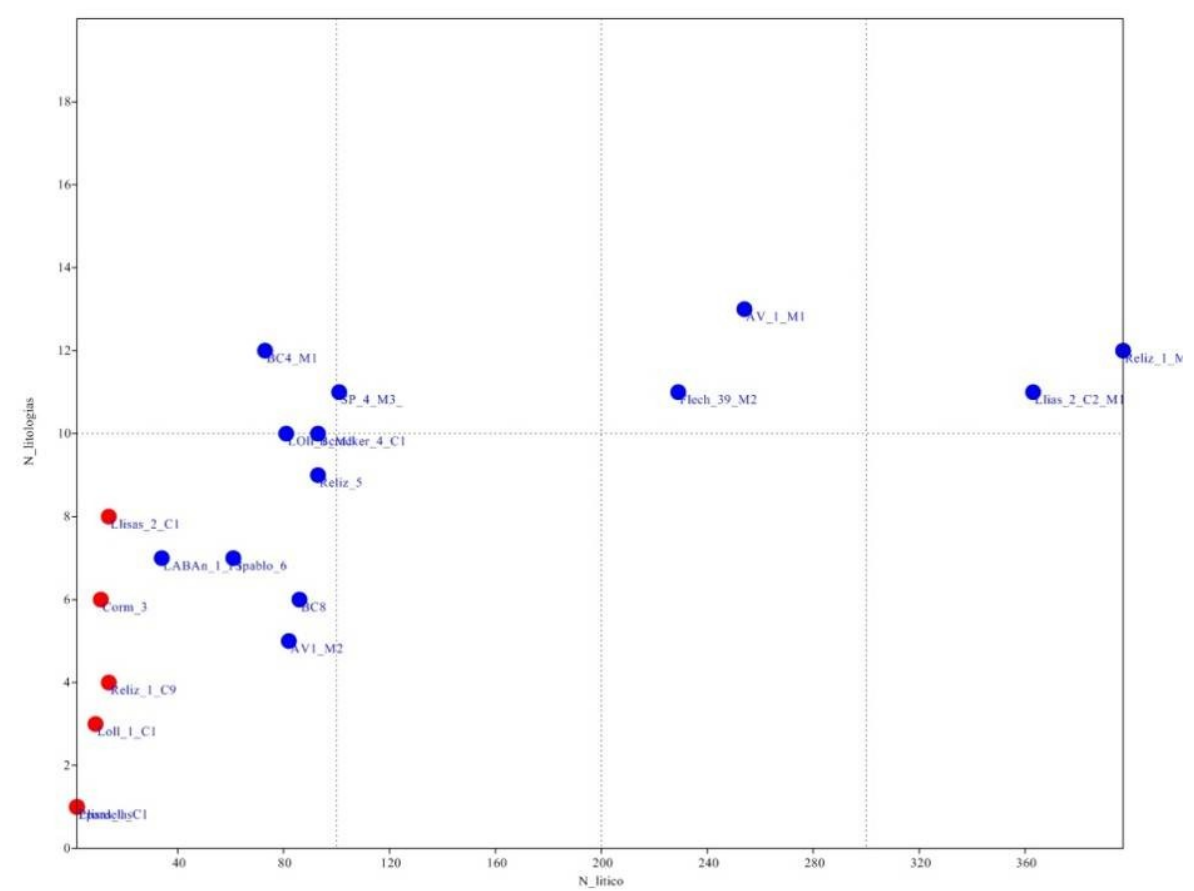

Figura 9.4: Dispersión de los tipos de sitios según la diversidad litológica. Referencias. Rojo: sitios de actividades restringidas o limitadas; Azul: sitios de actividades múltiples.

De acuerdo con la dispersión de los sitios se observa que los conjuntos líticos con mayor diversidad litológica se asocian a los sitios caracterizados por más de una actividad, como por ejemplo los sitios AV1 M1, Flechero del 39 M2, Reliz 1 M1 y LLis 2 C2 M1.

\section{Los modos en que fueron empleadas las rocas locales y no locales}

A continuación, y para evaluar cómo y para qué se utilizaron las materias primas locales y no locales, se discutirá su relación con distintas variables tecnológicas, tales como porcentajes de núcleos, formas base, tamaños, relación filos naturales/retocados entre los instrumentos, subgrupos tipológicos más representados, y porcentajes de bipolaridad, de módulos laminares y de bifacialidad. Cabe aclarar que sólo se tratará el caso de las rocas mayoritarias, ya que la representación del resto de las materias primas es muy exigua (inferior a 6\%). Entre las locales se discutirán basaltos, sílices y riolitas; entre las alóctonas, calcedonias, xilópalos y obsidianas (Tabla 9.2).

\section{Rocas locales}

En cuanto a las sílices, (Fig.9.5) el análisis tecnológico permitió identificar: - presencia de núcleos $(8,3 \%)$ destacándose los de tamaño pequeño y agotados; - superioridad de lascas pequeñas (microlascas); 
- porcentaje alto de filos naturales (35\%) por sobre los instrumentos formatizados;

- mayoría de raspadores entre los instrumentos formatizados por talla, seguidos por las puntas burilantes y en tercer lugar las puntas de proyectil;

- presencia significativa de bipolaridad en núcleos $(58,1 \%)$;

- muy baja frecuencia de módulos laminares;

- bifacialidad restringida a las puntas de proyectil.

Para el basalto (Fig.9.5) sobresalen las siguientes características tecnológicas:

- presencia de núcleos (5,5\%), cuyos tamaños son mayoritariamente pequeños y medianos, mayoritariamente agotados;

- superioridad de lascas pequeñas y medianas (externas e internas);

- mayoría de puntas burilantes, puntas triédricas y muescas entre los instrumentos;

- alto porcentaje de bipolaridad en núcleos (50\%);

- escasez de artefactos laminares;

- ausencia de bifacialidad.

En relación con las riolitas, (Fig.9.5) si bien se encuentran de manera abundante en las dos unidades de muestreo en forma de rodados, el porcentaje de utilización fue de $10 \%$ en PV y $20 \%$ en FPV. Entre los principales rasgos tecnológicos se observó:

- núcleos $(7,5 \%)$, todos activos y de tamaño grande $(n=7$ fueron rescatados en

Bahía Cracker, mientras que en PV solo se registró un ejemplar);

- los desechos -en su mayoría lascas- muestran porcentajes relativamente parejos entre externos e internos;

- utilización predominante para artefactos modificados por el uso (percutores, yunques, piedras de fogón): solamente se registraron tres instrumentos tallados (dos puntas burilantes y un filo natural);

- ausencia de bipolaridad en núcleos;

- ausencia de módulos laminares y de bifacialidad.

En síntesis, de las tres materias primas locales, las silíces (Fig.9.5) fueron las más utilizadas tanto para artefactos con rastros complementarios como formatizados por talla (en especial, raspadores y puntas de proyectil). Esto se debería a su amplia disponibilidad local y a su muy buena calidad para la talla. Aunque también podría deberse a la variedad de colores que presentan las sílices seleccionadas. En este sentido, diversos autores constataron que variables no utilitarias como el brillo y la variedad de colores influyen o son determinantes a la hora de elegir las rocas (Colombo y Flegenheimer 2014; Flegenheimer y Bayón 1999). Este uso 
preponderante de las sílices coloreadas, entre las que sobresalen las rojizas y amarillas, se ve reflejado a través de su representación porcentual en los sitios arqueológicos, que duplica la proporción relativa de nódulos en la base regional (Banegas et al. 2015). En el caso específico de las puntas y piezas bifaciales, dado el escaso número de estos instrumentos en el total de las muestras de ambas Uarq ( $\mathrm{N}=8)$ se incluyó en esta discusión la información obtenida de un estudio de 144 cabezales líticos del nordeste de Chubut (la costa norte y el valle inferior del río Chubut). A través de este trabajo se pudo determinar un porcentaje del $27 \%$ de puntas de sílice, lo que posiciona a esta roca en el segundo lugar después de las calcedonias como la principal materia prima seleccionada para la confección de cabezales líticos (Gómez Otero et al. 2011).

En cuanto al basalto, en las dos Uarq fue explotado en segundo lugar de importancia (entre 18 y 28\%). Cabe resaltar que tal frecuencia no se condice con la proporción de nódulos de esta roca (56\% y $48 \%$ respectivamente) en los muestreos de la base regional de recursos líticos. Se observó su representación en artefactos de filo natural o de formatización sumaria (puntas burilantes, muescas; etc.). Se destaca la ausencia de raspadores y puntas de proyectil. El único caso diferente es el del taller de piezas bifaciales y puntas de San Pablo I (Península Valdés), no estudiado en esta tesis (Gómez Otero et al. 1999), donde los ejemplares son muy similares a las del tipo Magallanes IV (Bird 1988). Por su parte, el análisis de los 144 cabezales líticos del nordeste de Chubut mostró una proporción de 15\% de puntas de basalto, aunque este valor puede estar sobrerrepresentado porque está incluida la muestra de San Pablo I (Gómez Otero et al. 2011). Por último, las riolitas, a pesar de su abundancia local, fueron utilizadas mayoritariamente como percutores, yunques o piedras de fogón. Esto se relacionaría con la resistencia y calidad regular de esta materia prima para la talla. La mayor proporción de lascas de riolitas fue observada en el sitio Cracker 4 del Holoceno medio, interpretado como una localización (Gómez Otero et al. 2013).

\section{Rocas no locales}

Para la calcedonia, (Fig. 9.5) el estudio tecnológico determinó como tendencia general (ambas unidades arqueológicas) la presencia de:

- núcleos (4,8\%), de tamaño mayoritariamente pequeños y agotados;

- predominio de lascas internas de tamaños pequeños (microlascas).

- selección para la manufactura de raspadores y puntas de proyectil;

- de diez núcleos, cuatro son bipolares;

- baja representación de módulos laminares;

- presencia de bifacialidad, sólo en puntas de proyectil.

En cuanto al xilópalo (Fig. 9.5), para ambas unidades de análisis se determinó: 
- presencia de núcleos $(8,5 \%)$; entre los que sobresalen los de tamaño pequeño y agotados;

- predominio de lascas internas de tamaño pequeño entre los desechos;

- alto porcentaje de artefactos formatizados por talla de tamaños mediano-grandes;

- selección para la confección de filos retocados (cuchillos, raspadores y puntas

burilantes);

- de cinco núcleos, dos son bipolares;

- predominio de módulos laminares en los instrumentos;

- bifacialidad restringida a puntas de proyectil.

Respecto de las obsidianas (Fig. 9.5), entre los resultados alcanzados en esta tesis se destacan:

- la casi nula presencia de núcleos (sólo uno: 3,8\%) y de lascas externas;

- mayoría de instrumentos formatizados;

- poca diversidad de instrumentos, entre los que prevalecen los cuchillos retocados

y las raclettes;

- muy baja frecuencia de bipolaridad;

- índices muy bajos de bifacialidad y de laminaridad.

\begin{tabular}{c|ccc}
\hline Materias primas & $N=$ materia prima & $N=$ núcleos & $\%$ \\
\hline Sílice & 520 & 43 & 8,3 \\
Basalto & 362 & 20 & 5,5 \\
Riolita & 106 & 8 & 7,5 \\
Calcedonia & 210 & 10 & 4,8 \\
Xilópalo & 59 & 5 & 8,5 \\
Obsidiana & 26 & 1 & 3,8 \\
\hline
\end{tabular}

Tabla 9.2: Frecuencia de núcleos por materia prima mayoritarias locales y alóctonas- 


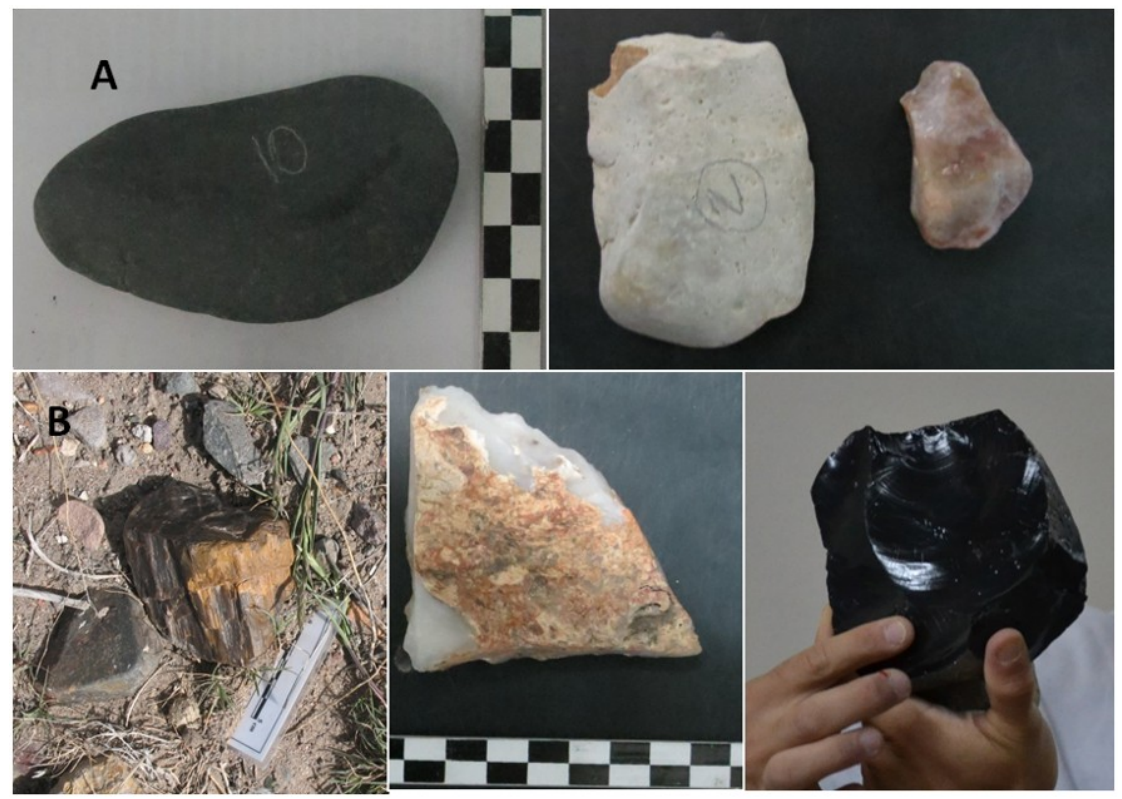

Fig.9.5. (A) Materias primas líticas locales: basalto, sílices y riolitas y (B) no locales: xilópalos, calcedonia y obsidiana.

La evaluación comparativa de las tres rocas muestra que las calcedonias fueron intensamente explotadas -tanto los pequeños y muy escasos rodados locales como las tabletasen cada uno de los sitios analizados, en especial para la confección de raspadores y puntas de proyectil. Esta utilización intensiva fue también corroborada para otros sitios de la costa norte de Chubut (Banegas y Goye 2015; Banegas et al. 2015). Además, el porcentaje de puntas de calcedonia entre los 144 cabezales líticos del nordeste de Chubut se ubica, como se mencionó anteriormente, en primer lugar y con un valor porcentual de 42\% (Gómez Otero et al. 2011). En segundo lugar se posicionan los artefactos de xilópalo, que se destacan por su mayor longitud respecto de los escasísimos rodados locales y por la alta frecuencia de módulos laminares. Esto señala la explotación de nódulos tabulares medianos a grandes, cuya forma habría propiciado una estandarización morfológica de los soportes, aptos para ser utilizados como filos naturales o formatizados como cuchillos. En este sentido, la bipolaridad se observó sólo en núcleos agotados confeccionados a partir de rodados pequeños y en algunos desechos. De manera similar a otras rocas de alta calidad, locales y no locales, esta técnica habría permitido la optimización de los nódulos chicos. A pesar de su muy buena calidad, solamente se registraron dos instrumentos bifaciales (puntas de proyectil). Es interesante señalar que entre la colección estudiada de cabezales líticos del nordeste del Chubut, los xilópalos no superan el 11\% (Gómez Otero et al. 2011). Si bien no se descartan factores postdepositacionales como la recolección por parte de aficionados y coleccionistas, se infiere que la estructura interna de los xilópalos, tal como la presencia de nudos y planos de fractura, habría presentado dificultades para la aplicación de la técnica de reducción bifacial (Banegas et al. 2016). Por último, dentro de la muestra de obsidianas se destaca la escasez de núcleos (sólo se halló en el sitio Rincón de 
Elizalde 2), el predominio de desechos de talla, el bajo porcentaje de instrumentos y el tamaño chico de los artefactos. Esto fue también comprobado por Gómez Otero y Stern (2005) en otros sitios del área de estudio y de la costa sur de Chubut, aunque se diferencian de los estudiados en esta tesis por la alta proporción de corteza en los instrumentos (más de 25\%).

\section{Relación instrumentos más representados y materias primas}

De los instrumentos más representados en ambas Uarq, los raspadores $(\mathrm{N}=30)$ están confeccionados en las mejores materias primas para la talla, principalmente las sílices $(n=16$; $53,3 \%)$ y las calcedonias $(\mathrm{n}=10 ; 27,8 \%)$, mientras que las puntas burilantes $(\mathrm{N}=26)$ fueron manufacturadas con rocas de calidad dispar, todas locales (basalto y sílices en PV; riolitas y sílices en FPV). Son pocas las materias primas de muy buena calidad utilizadas para estos instrumentos. En cuanto a las puntas y piezas bifaciales, tal como se mencionó, las analizadas en esta tesis solo se registraron en Península Valdés y suman un total de nueve, que se distribuyen en sílices $(\mathrm{n}=4)$; calcedonias y xilópalos ( $\mathrm{n}=2$ cada una) y un único ejemplar de basalto. Por último, aunque son muy escasos es importante consignar que los tres denticulados hallados en los sitios de la costa del golfo San Matías Oeste, están elaborados en sílices y calcedonias, al igual que los raspadores. En síntesis, se determinó selección de materias primas -sílices y calcedonias- para la talla de raspadores, denticulados, puntas y piezas bifaciales. Esta relación fue también identificada por Gómez Otero et al. (1999) en distintos sitios de Península Valdés.

\section{Mecanismos de adquisición de las rocas no locales}

A los fines de inferir mecanismos de adquisición de las tres rocas no locales, a continuación se discute sobre sus potenciales fuentes.

Para las calcedonias, los estudios de secciones delgadas de muestras de rocas naturales recolectadas en Arroyo Verde (veáse Capítulo 6) junto con la comparación del análisis petrográfico de piezas arqueológicas rescatadas en los muestreos arqueológicos, permitieron determinar la correspondencia entre las texturas identificadas en los cortes delgados con las descripciones texturales y mineralógicas de las vetas de la Fm. Marifil estudiadas por Massaferro y Haller (2000: Fig 4-7). Por lo tanto se estableció que estos afloramientos serían las potenciales fuentes o área de abastecimiento de las calcedonias. Por su parte, Gómez Otero et al. 1999 localizaron una fuente de calcedonias de filón a 200 km al oste de Península Valdés, entre Telsen y Gan Gan, aunque no es una variedad traslucida sino blanquecina.

Con respecto a los xilópalos, tal como se desarrolló en el capítulo de Metodología, se llevaron a cabo estudios especializados en muestras arqueológicas $(\mathrm{N}=2)$ y naturales $(\mathrm{N}=3)$ de 
maderas fósiles. Las primeras provienen de sitios del área de estudio y las segundas de distintas formaciones geológicas: Sarmiento, Las Plumas y un fragmento hallado en la Fm. Puerto Madryn (Banegas et al. 2015b). Con relación a las muestras arqueológicas, a través de la observación bajo microscopio de barrido electrónico de pequeños fragmentos en sección longitudinal radial, se reconocieron traqueidas, radios y punteaduras areoladas (Fig. 9.6.2 A,2.B y 2.C). Dada la regular a mala preservación de las muestras, varios caracteres anatómicos -por ejemplo, los campos de cruzamiento- fueron difíciles de identificar, lo que impidió realizar la clasificación taxonómica a nivel genérico o específico. No obstante, esta técnica permitió confirmar la asignación macroscópica de los ejemplares arqueológicos de xilópalos a maderas fósiles correspondientes a gimnospermas. En cuanto al análisis de composición mediante EDAX, mostró para los cinco ejemplares altos porcentajes de sílice y oxígeno, con proporciones del 30 al $47 \%$ (Tabla 9.4). Esto señala que los xilópalos se encuentran en su mayor parte permineralizados por silicatos. En los dos artefactos analizados los distintos porcentajes de elementos, tal como se observa en la tabla 9.4, podrían corresponder a fuentes primarias diferentes, aunque por el momento no se puede determinar el origen.
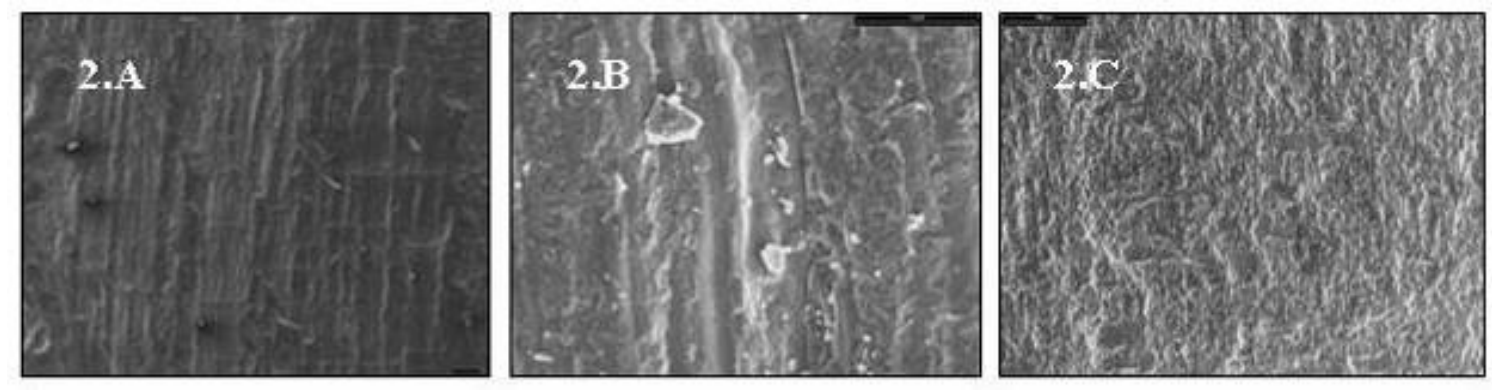

Fig.9.6: Análisis microscópico de muestras arqueológicas recuperadas en el área de estudio: A (No 26SPablo TXil C1) traqueidas (verticales) y los radios (horizontales) en vista longitudinal radial; $\mathrm{B}$ ( $\mathrm{N}^{0} 45-$ LAbanM1) punteaduras areoladas de las traqueidas en vista longitudinal radial; y $\mathrm{C}$ ( $\mathrm{N}^{\mathrm{o}}$ 6-SRom 3) traqueidas y los radios en vista longitudinal radial (tomado de Banegas et al. 2016).

\begin{tabular}{|c|c|c|c|c|c|c|c|c|c|c|c|}
\hline $\begin{array}{c}\text { Muestras } \\
\text { \% Elementos }\end{array}$ & $\mathrm{C}$ & $\mathrm{O}$ & $\mathrm{Na}$ & $\mathrm{Mg}$ & $\mathrm{Al}$ & $\mathrm{Si}$ & $\mathrm{P}$ & $\mathrm{Cl}$ & $\mathrm{K}$ & $\mathrm{Ca}$ & $\mathrm{Fe}$ \\
\hline MFmPM & 17,6 & 37,1 & 0,36 & 0,21 & 0,98 & 42,2 & 0,05 & 0 & 0,35 & 0,47 & 0,66 \\
\hline MFmPtCh & 23,5 & 35,3 & 0,44 & 0,28 & 4,04 & 34,1 & 0 & 0,3 & 0,69 & 0,5 & 1,25 \\
\hline MPta.Bs-As2 & 12,1 & 38,4 & 0,23 & 0,1 & 1,01 & 47,3 & 0 & 0 & 0,26 & 0,23 & 0,48 \\
\hline MSP-TX & 10,6 & 39,1 & 0,37 & 1,14 & 1,46 & 45,4 & 0,1 & 0 & 0,38 & 0,39 & 1,13 \\
\hline MSRom & 14,6 & 34,7 & 0,36 & 0,3 & 1,97 & 30,0 & 4,8 & 0 & 0,38 & 3,7 & 12 \\
\hline
\end{tabular}

Tabla: 9.4. Composición de las maderas fósiles: porcentaje por elementos. Referencias: MFmPM, Muestra Formación Puerto Madryn; MFmPtCh: muestra Formación Puerto Chico; MPta. Bs.As: Muestra Punta Buenos Aires; MSP-TX: muestra San Pablo-taller xilópalo; MSRom: muestra San Román (tomado de Banegas et al. 2016). 
Como se mencionó antes, los afloramientos primarios de maderas fósiles más próximos al área de estudio se encuentran a $180 \mathrm{~km}$ hacia el oeste (Telsen), a 150-200 km al sudoeste (Dique Ameghino) y a $450 \mathrm{~km}$ al sur (Bosque Petrificado de la Costa y Bosque Petrificado Ormaechea, en Sarmiento). Por lo tanto, se infiere la aplicación de estrategias logísticas (sensu Binford 1980) para su adquisición. Esto podría implicar partidas especializadas de búsqueda y obtención, o adquisición por intercambio con grupos que ocupaban las áreas donde están las canteras, lo que explicaría el aprovechamiento intensivo de los nódulos. En relación con los dos primeros afloramientos mencionados, la ausencia de trabajos arqueológicos en esas zonas no permite por el momento estimar la intensidad de la explotación de los troncos ni la calidad de los mismos para la talla. Solamente se cuenta con una mención de Luna Pont (1976) sobre la presencia de una industria de maderas fósiles en el interior de Chubut, cerca de la localidad Paso de Los Indios, y con un estudio de conjuntos artefactuales de xilópalo del sitio Delta Vulcana (Lago Musters) al sur de la provincia de Chubut, en el que el autor señala la calidad regular de esta roca (Reyes 2013).

En cuanto a las obsidianas, entre las dos unidades de análisis se determinó la presencia de cuatro variedades: T/SCI, T/SCII, MSI y CC?; la primera corresponde a la fuente Telsen/Sierra Chata, mientras que las tres últimas se ubicarían en la meseta de Somuncurá (Gómez Otero y Stern 2005). Fuera de los muestreos aquí tratados se registraron otras variedades: SI (Fuente Sacanana) en las dos unidades arqueológicas, y PDAI (Pampa del Asador I) en el golfo Nuevo sur (Gómez Otero y Stern 2005). Por lo tanto, también en el caso de las obsidianas se infiere la aplicación de estrategias logísticas para su adquisición. Por su parte, según Gómez Otero y Stern (2005) los nódulos habrían ingresado enteros a los sitios donde fueron tallados exhaustivamente llevándose a cabo todas las etapas de la secuencia de producción lítica. Esto significa que el tratamiento tecnológico dado a las obsidianas no fue distinto al que se dio a otras rocas de condiciones similares para la talla, como por ejemplo las sílices coloreadas. Si bien, y como se pudo observar en la experimentación tafonómica lítica (Capítulo 5), no se descartan procesos postdepositacionales de origen natural (como la acción eólica sobre artefactos muy pequeños) ni la recolección por parte de coleccionistas, la proporción de obsidianas es muy baja en todos los sitios muestreados $(3 \%$ de promedio sumando todos los tipos), lo que implica una tasa de depositación bajísima para esos tres mil años de circulación (Gómez Otero y Stern 2005: 106).

En síntesis, en cuanto a las materias primas no locales, la baja proporción de núcleos y desechos externos y el predominio de artefactos formatizados sugieren el ingreso de preformas o formas base y también la introducción de artefactos ya terminados. Las distancias a las fuentes -entre 50 y 450 km- implicarían costos de obtención variables según las rocas y las diferentes 
unidades de muestreo. Su adquisición podría haberse dado mediante aprovisionamiento directo en las fuentes más cercanas o indirecto, es decir, por intercambio. No obstante, parece más plausible y menos costosa la segunda alternativa. Esto mismo fue planteado para las obsidianas registradas en el área de estudio (Gómez Otero y Stern 2005: 107). Los autores propusieron que pudieron haberse obtenido por medio de trueques que incluyeran otros items (estrategia embedded, según Binford 1979). En este sentido, es interesante destacar que la localización del bosque de maderas fósiles de Telsen coincide grosso modo con una de las fuentes de obsidianas identificadas geoquímicamente en el norte de Chubut: la Tipo T/SCI (Gómez Otero y Stern 2005). No obstante, para poder determinar con mayor precisión la proveniencia de los xilópalos utilizados por los cazadores locales, es necesario ampliar el número de muestras paleobotánicas y realizar nuevos análisis de composición elemental y mineralógica.

Ahora bien, surge una pregunta que quedará pendiente para cuando se integren todas las evidencias: ¿qué factores habrían propiciado la búsqueda de estas rocas exóticas, en especial las de calidad muy buena a excelente para la talla -xilópalos, obsidianas, calcedonia- si en esta unidad abundan las sílices y basaltos que presentan calidad buena a muy buena? Entre las probables causas que podrían explicar la selección de estas rocas alóctonas se pueden mencionar las siguientes:

1) su calidad superior para la talla y/o el tamaño más grande de sus nódulos respecto de las locales (véase figura 9.3 arriba).

2) sus cualidades visuales especiales como el brillo en el caso de las obsidianas, la transparencia en el de las calcedonias, o los colores en las tres (Colombo y Fleghenheimer 2014; Fleghenheimer y Bayón 1999).

3) su posesión evidenciaría las alianzas estratégicas y/o intercambios con los grupos que controlaban esas fuentes, en el marco de una red de relaciones sociales, políticas y económicas (Gómez Otero 2003)

Es probable que las tres causas hayan intervenido en la selección de estas rocas alóctonas. Sin embargo, y para el caso de la tercera probabilidad, es factible que esta motivación (la de generar alianzas y redes de intercambios como estrategia social para controlar espacios o generar mayor poder/status haya se haya dado hacia momentos más tardíos donde se registra un incremento demográfico (Gómez Otero 2006) (véase más adelante discusión de la Hipótesis III).

Sobre la base de los resultados hasta aquí presentados se da por cumplido el primer enunciado de la Hipótesis I que propone que los cazadores recolectores del área de estudio 
aprovecharon de manera prioritaria las rocas locales disponibles de manera abundante en las fuentes secundarias de rodados. En cuanto al segundo enunciado de la hipótesis, sólo se cumplió parcialmente ya que la explotación expeditiva de las rocas locales únicamente se observó en los basaltos y las riolitas; no así en las sílices que, al igual que las rocas alóctonas, fueron aprovechadas para la elaboración de instrumentos con mayor inversión de trabajo.

Por su parte, para la adquisición de las rocas no locales de buena calidad para la talla calcedonias, obsidianas y xilópalos- se habrían implementado estrategias logísticas. Su obtención podría haberse dado a través de partidas específicas en busca de materias primas y/o por intercambios directos o indirectos. Estas búsquedas también pudieron incluir otros recursos. De esta manera, los grupos de la costa podrían haber intercambiado tales rocas por materias primas y productos marinos (conchillas, artefactos de valva, moluscos y/o grasa de lobos marinos, etc.). Algo interesante surge de estos datos: la adquisición de las materias primas alóctonas no parece haber sido motivada por razones utilitarias o tecnológicas, ya que esas necesidades podían ser adecuadamente cubiertas por las rocas locales, como los basaltos y las sílices. Por lo tanto, quizás la selección de estas rocas exóticas, destacables por su coloración, brillo y calidad, tuvo más que ver con fundamentos sociales y/o políticos. Su posesión y exhibición podían testimoniar los contactos y alianzas con los grupos que controlaban esas canteras. En este sentido, el registro de obsidiana de Pampa del Asador en un sitio de la costa del golfo Nuevo sur (Gómez Otero y Stern 2005), indica la amplitud de la red de relaciones.

\section{La explotación de las calcedonias, xilópalos y obsidianas en otros sectores de las costas de Pampa y Patagonia}

En este apartado se discutirán solamente estas tres rocas porque son las más frecuentes de las alóctonas en el área de estudio y porque se puede llegar a conocer su procedencia y por lo tanto determinar si son o no locales.

En la costa pampeana la explotación de calcedonias o ftanitas, disponibles en forma de rodados, fue mínima (Messioneo et al. 2004; Bonomo 2005). Por el contrario, en el curso inferior del río Colorado, donde también se encuentra en rodados, fue intensamente aprovechada (Armentano 2014). También se utilizó en sitios rionegrinos de la costa oeste del golfo San Matías, área que ofrece nódulos tabulares de calidad muy buena y excelente en sectores puntuales del espacio, desde donde se habrían transportado hacia la costa norte del golfo (Cardillo y Scartascini 2007; Alberti et al. 2015). Hacia el sur, en la costa centro-meridional de Patagonia, aunque la disponibilidad de rodados de calcedonia es baja, fue una de las materias primas más frecuentemente utilizada, por lo tanto se infirió que fue especialmente seleccionada (Ambrústolo 2013). 
Respecto del xilópalo, en la costa pampeana al igual que en nordpatagonia y costa del golfo San Matías se determinó el aprovechamiento de los escasos rodados locales (Bonomo 2005, Armentano 2014; Alberti 2013, Alberti y Cardillo 2015). Lo contrario se constató en la costa del golfo San Jorge, donde el porcentaje de xilópalos alcanzó un 30\% (Gómez Otero y Paz 1994; Arrigoni et al. 2007), lo que era esperable dada la existencia local y buena calidad de las maderas fósiles del "Bosque Petrificado de la Costa". Más al sur, en la costa norte de Santa Cruz, no se identificaron fuentes locales de esta roca y se determinó baja frecuencia en los conjuntos estudiados (Ambrústolo 2013). Este autor propone que los xilópalos habrían sido adquiridos por intercambio con grupos asentados, por ejemplo, en la zona del Bosque Petrificado de Jaramillo (meseta central de Santa Cruz ), a $150 \mathrm{~km}$ al oeste de allí, donde los troncos corresponden a Araucaria mirabilis (Hermo 2005; Terranova 2007). Los artefactos habrían ingresado en forma de núcleos o bifaces con módulos de tamaño probablemente chicos y con rasgos que evidenciarían estadios iniciales o intermedios de reducción.

En relación con las obsidianas, están prácticamente ausentes en los contextos de la costa pampeana, y el análisis geoquímico de dos artefactos determinó que correspondían a fuentes desconocidas en ese momento (Bonomo 2005). En la costa de Río Negro la presencia de obsidianas es en general muy escasa (inferior al $1 \%$ de los conjuntos) y solamente en forma de desechos (Favier Dubois et al. 2009). Se determinaron seis variedades: la mayoría de las muestras analizadas (60\%) corresponde a tipos muy alcalinos (TSCI, TSCII y MSI), y proceden de fuentes relativamente cercanas, como el borde oriental de la Meseta Somuncurá $(<100-250$ $\mathrm{km}$ lineales). Otras provienen de áreas más lejanas (300-400 km lineales) como el tipo SI (Sacanana), mientras que algunas alcanzaron el litoral rionegrino desde más de $500 \mathrm{~km}$ lineales, como en el caso del tipo CL1 del oeste neuquino (lago Lolog), que posee un distintivo bandeado negro y apariencia muy translúcida (Alberti et al. 2015). Para la costa norte de Santa Cruz, los estudios de Zubimendi y Ambrústolo (2014) determinaron la presencia de obsidianas de tres variedades de Pampa del Asador, a $400 \mathrm{~km}$ de distancia. Se observaron nódulos, escasos núcleos y predominio de desechos de tamaño pequeño. Los autores interpretaron obtención directa y traslado de nódulos o rodados, ya que los restos artefactuales evidencian talla inicial e intermedia y porcentajes elevados de corteza.

De la comparación con el registro de otros sectores del litoral pampeano y patagónico surgen diferencias en cuanto a la intensidad y modos de uso de estas tres rocas. Esto podría relacionarse con la distancia respecto de las fuentes y con la forma en que se presentan:

- Calcedonias: tabletas y filones (solo en los sectores cercanos a afloramientos primarios de rocas volcánicas). Dada la cercanía a las fuentes primarias (afloramientos de rocas ignimbríticas de la Fm. Marfil y Fm. Chon-Aike) fueron más intensamente explotadas 
en la costa del golfo San Matías y en menor proporción en la costa norte de Santa Cruz (Alberti 2015; Ambrústolo 2013)

- Obsidianas: rodados y bloques de distintos tamaños y formas (dependiendo de la cercanía a la fuente primaria). Uso de fuentes de obsidianas de la meseta centro-norte de Chubut y la meseta de Somuncurá (sur de río negro) en norte y centro norte de Patagonia; más al sur se usaron fuentes de Pampa del Asador (Gómez Otero y Stern 2005; Stern et al.2013)

- Xilópalos: troncos en los bosques petrificados y rodados y fragmentos de troncos en los lugares más alejados. Esta materia prima es más importante al sur de Patagonia, donde hay bosques petrificados (Arrigoni et al. 2008; Castro et al. 2008?; Ambrústolo 2013). $\mathrm{Al}$ norte, como en el área de estudio, estaría en una posición intermedia.

\section{Hipótesis II:}

El tamaño reducido de los rodados habría fomentado la utilización frecuente de la talla bipolar.

Varios autores sostienen que la reducción bipolar es una estrategia expeditiva, versátil y de aprovechamiento más eficiente de los nódulos pequeños. En general se considera que su aplicación se dio en contextos de alta movilidad residencial, en situaciones de economía de la materia prima y/o para poder garantizar la reducción de rocas de mala o regular calidad para la talla (Shott 1989; Flegenheimer et al. 1995; Odess 1998; Franco 2004; Armentano 2014; Bonomo 2005).

A los fines de discutir la segunda hipótesis, por una parte se explorará la relación entre las variables tamaño, tipo y materia prima de cada núcleo; por otra, se comparará con la base regional de recursos líticos. En primer lugar se grafican los tipos de núcleos hallados en los distintos sectores costeros distribuidos según las dos grandes unidades de análisis arqueológico: Península Valdés y Fuera de Península Valdés. Como se puede observar en la Fig. 9.7, se determinó mayor diversidad morfológica de núcleos en la Uarq-FPV ( $\mathrm{n}=7$ tipos) que en PV ( $\mathrm{n}=$ 4). No obstante, en ambas unidades son mayoría los núcleos bipolares, aunque la bipolaridad en la Uarq-PV es bastante superior (50\%) que en la Uarq-FPV (34\%). 


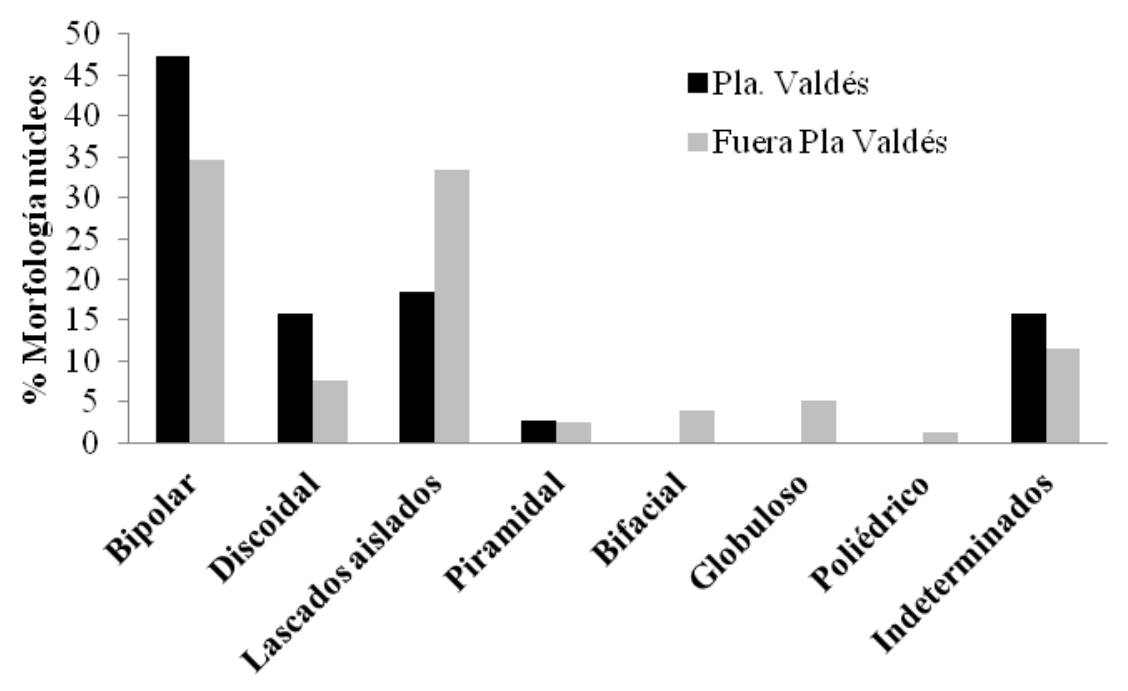

Fig.9.7. Tipos de núcleos por unidad de análisis.

Para la variable tamaño también se observaron diferencias entre ambas unidades; la gran mayoría de los núcleos de PV son pequeños ( $\mathrm{n}=29: 85,3 \%$ ), mientras que en FPV la mitad son de tamaño grande (40: 51\%). Cabe resaltar que no se halló ningún núcleo de tamaño muy grande en los conjuntos analizados (Tabla 9.5.)

\begin{tabular}{ll|cccc}
\hline Uarq & \multirow{2}{*}{ Tamaño núcleos } & \multicolumn{2}{c}{ PV } & \multicolumn{2}{c}{ FPV } \\
\cline { 3 - 6 } & & $\mathrm{N}$ & $\%$ & $\mathrm{~N}$ & $\%$ \\
Grande & 3 & 8,8 & 40 & 51,3 \\
Mediano & 2 & 5,9 & 24 & 30,8 \\
Pequeño & 29 & 85,3 & 14 & 17,9 \\
Total & $\mathbf{3 4}$ & $\mathbf{1 0 0}$ & $\mathbf{7 8}$ & $\mathbf{1 0 0}$ \\
\hline
\end{tabular}

Tabla 9.5. Tamaño de los núcleos por unidad de análisis arqueológica.

En el conjunto de núcleos de la Uarq-PV (Tabla 9.6.) se determinó el amplio predominio de los pequeños (85\%), de los cuales más del 50\% son bipolares y de estos últimos 15 de 17 (88\%) se encuentran agotados o abandonados por imposibilidad de continuar la talla. En los núcleos de mayor tamaño no se registró el uso de reducción bipolar. En cuanto a las materias primas, entre las locales la bipolaridad asciende a $64 \%$ en las sílices y a $50 \%$ en basaltos; en las no locales alcanza el $75 \%$ en calcedonias y el único núcleo de obsidiana es bipolar. No se determinó bipolaridad en xilópalos ni en rocas de calidad regular (categoría 
"Otras") que incluyen riolitas, ignimbritas, etc. Su ausencia en xilópalos podría deberse a la forma y tamaño de los nódulos: en este sentido, los de esta roca corresponden a fragmentos tabulares grandes de troncos silicificados para cuya reducción no habría sido necesaria la técnica bipolar.

\begin{tabular}{|l|c|c|c|c|c|c|c|c|c|}
\hline $\begin{array}{c}\text { Uarq- } \\
\text { PV }\end{array}$ & Sil & Ba & Cal & Xil & Obs & Otras* & Total & Total Bipolares & \% Bipolaridad \\
\hline Pequeño & $14(10)$ & $6(3)$ & $4(3)$ & $2(0)$ & $1(1)$ & $2(0)$ & 29 & 17 & $58,6 \%$ \\
\hline Mediano & 0 & $2(0)$ & 0 & 0 & 0 & 0 & 2 & 0 & 0 \\
\hline Grande & $3(0)$ & 0 & 0 & 0 & 0 & 0 & 3 & 0 & 0 \\
\hline
\end{tabular}

Tabla 9.6. Características de núcleos bipolares de Península Valdés. Referencias: (sil) sílices, (ba) basaltos, (cal) calcedonias, (xil) xilópalos, (obs) obsidiana. (*) Incluye riolitas, ignimbritas, cuarcitas, calizas, andesitas.

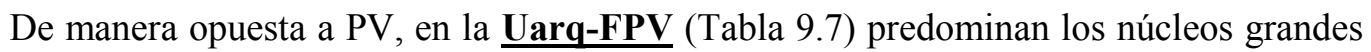
(51\%) siguiéndoles los medianos (30\%) y los pequeños (18\%). El porcentaje de bipolaridad aumenta a medida que disminuye el tamaño de los núcleos: $5 \%$ en grandes, $62 \%$ en medianos y $71 \%$ en pequeños. Con respecto a los porcentajes por materia prima, en FPV los núcleos de basalto son todos bipolares, mientras que entre los de sílices la bipolaridad alcanza $66 \%$ entre los pequeños, $84 \%$ entre los medianos y $8 \%$ entre los grandes. A diferencia de PV se registró reducción bipolar en dos núcleos pequeños de xilópalo, los cuales proceden de rodados tamaño guijarro (sensu Bonorino y Teruggi 1952). En relación con la calcedonia, el único núcleo bipolar fue hallado en el sitio Rincón de Elizalde $1 \mathrm{M} 1$, que está a $20 \mathrm{~km}$ de la fuente primaria de esta roca situada en Arroyo Verde. No obstante, no pudo determinarse el nódulo de origen por el avanzado estado de reducción del núcleo.

\begin{tabular}{|l|c|c|c|c|c|c|c|c|c|}
\hline FPV & sil & ba & cal & xil & obs & Otras* & Total & Total Bipolares & \% Bipolaridad \\
\hline Pequeño & $6(4)$ & $3(3)$ & $2(1)$ & $2(2)$ & 0 & $1(0)$ & 14 & 10 & $71 \%$ \\
\hline Mediano & $13(11)$ & $7(4)$ & 0 & 0 & 0 & $4(0)$ & 24 & 15 & $84,6 \%$ \\
\hline Grande & $6(2)$ & 2 & 3 & 1 & 0 & 24 & 36 & 2 & $5,5 \%$ \\
\hline
\end{tabular}

Tabla 9.7: Características de núcleos bipolares de la Uarq Fuera de Península Valdés. Referencias: (sil) sílices, (ba) basaltos, (cal) calcedonias, (xil) xilópalos, (obs) obsidiana. (*) Incluye riolitas, ignimbritas, cuarcitas, dacitas, andesitas.

La proporción más alta de talla bipolar en PV se relacionaría con la base regional de recursos líticos ya que las mejores materias primas -sílices y basaltos- se presentan en forma de guijarros chicos. Por su parte, en la Uarq-FPV hay que considerar las diferencias entre sectores 
(véase capítulo 6). Como ya se mencionó, en el sector norte las sílices y basaltos están disponibles en rodados de distintos tamaños a los que se suman nódulos de otras materias primas de muy buena calidad en formas de bloques, filones y tabletas. Por su parte, en el sector sur la oferta de materias primas -entre ellas sílices y basaltos- está dada a través de rodados de tamaño guijarro y guijón.

En síntesis, se comprobó que la técnica bipolar fue casi exclusivamente aplicada para la talla de nódulos pequeños y medianos provenientes de guijarros de rocas de calidad muy buena a excelente como sílices, basaltos, calcedonias, xilópalos y obsidianas. No se observó talla bipolar en nódulos pequeños o medianos de calidad regular, por ejemplo riolitas. Por lo tanto, la hipótesis 2 estaría contrastada positivamente en lo que respecta al tamaño, aunque sobre la base de los datos antes presentados y discutidos se pudo conocer que esta variable no fue la única seleccionada para la aplicación frecuente de la talla bipolar, sino también la forma en que se presentan los nódulos (rodados con forma oval y espesos) y la calidad de la materia prima (muy buena a excelente).

En cuanto a las tendencias temporales (Tabla. 9.8.) en el Holoceno medio la presencia de bipolaridad es muy baja (6\%) y significativa hacia momentos posteriores al 2000 años AP. También se registró un incremento hacia el Holoceno tardío final alcanzando poco más de la $\operatorname{mitad}(54 \%)$.

\begin{tabular}{|c|c|c|c|}
\hline $\begin{array}{l}\text { Bloque } \\
\text { Temporal }\end{array}$ & N= Total de núcleos & $\begin{array}{l}\mathrm{N}=\text { núcleos } \\
\text { bipolares }\end{array}$ & $\%$ de bipolaridad \\
\hline Holoceno Medio & 47 & 3 & $6,38 \%$ \\
\hline Holoceno Tardío Inicial & 54 & 26 & $48,15 \%$ \\
\hline Holoceno Tardío Final & 11 & 6 & $54,5 \%$ \\
\hline
\end{tabular}

Tabla. 9.8. Tendencias temporales en la aplicación de la técnica bipolar en el área de estudio.

\section{Comparación con otras áreas de la costa pampeano-patagónica}

Para la costa pampeana varios autores registraron un importante porcentaje de artefactos bipolares. Bonomo (2005) determinó su aplicación para la reducción de rodados chicos de basalto, riolita, andesita, sílice, etc. en sitios del Holoceno tardío de la faja de médanos entre Cabo Corrientes y la desembocadura del río Quequén Salado. Por su parte, en la costa sudoeste de la provincia de Buenos Aires y en contextos del Holoceno medio, se comprobó un altísimo predominio de la talla bipolar (94\%) en nódulos pequeños de basalto disponibles en un radio de $10 \mathrm{~km}$ (Bayón et al. 2011). Esto se relacionaría con la base regional de recursos líticos, ya que los depósitos están compuestos por guijas, guijarros y guijones, entre los cuales hay un gran 
número de rodados menores a tres centímetros (Bonomo y Prates 2014). En este sentido, Flegenheimer et al. (1995), Bonomo (2005) y Bayón (Bayón y Politis 1995, Bayón et al. 2011), plantean que en el litoral pampeano esta técnica fue de aplicación muy frecuente para el aprovechamiento más eficiente de los abundantes rodados costeros pequeños y de origen generalmente volcánico

Respecto de la costa nordpatagónica, también se observó uso reiterado de esta técnica aunque en el sector comprendido entre las desembocaduras de los ríos Colorado y Negro. En la desembocadura del río Colorado se registró el aprovechamiento de guijarros locales chicos de sílices y basaltos en contextos del Holoceno tardío (Martínez 2008-2009, 42013). A modo de ejemplo, el análisis del conjunto del sitio La Primavera mostró que $63 \%$ de los núcleos son bipolares (Bayón et al. 2004). Por su parte Eugenio y Aldazabal (2004) mencionan la presencia de núcleos, lascas y raederas bipolares de basalto en sitios de la costa de San Blas datados entre 5000 AP y 500 AP aunque no informan porcentajes. En contextos no fechados de la zona de Punta Rubia, Bórmida (1964) identificó la aplicación casi exclusiva de la talla bipolar para la reducción de pequeños guijarros achatados de basalto. Más al sur, para la costa rionegrina del golfo San Matías, Alberti (2013) realizó la caracterización de 437 núcleos: 346 correspondientes el bloque temporal "Antiguo" (4800-2200 AP) y 91 al "Reciente" (1500 AP en adelante). Si bien en ambos bloques hay núcleos bipolares -todos pequeños- su porcentaje es bajo en comparación con la costa bonaerense y el área de estudio de esta tesis: 13,48 \% y 8,79 \% del más antiguo al más tardío. Alberti (2013) determinó porcentajes diferentes entre sectores de este golfo, entre ellas menor frecuencia de talla bipolar en los sitios de la costa Norte (Cardillo y Scartascini 2007). Esto se vincularía con la base regional de recursos líticos ya que hay amplia disponibilidad de rodados de tamaños grandes y de rocas de muy buena calidad (Favier Dubois y Alberti 2015).

Para el área de estudio de esta tesis se cuenta con los resultados de un análisis tecnológico de 921 artefactos líticos de sitios de superficie de Península Valdés, que coinciden con los datos presentados en el acápite anterior (Gómez Otero et al. 1999). Se determinó un alto porcentaje de núcleos y lascas de reducción bipolar. Los núcleos, de los cuales $94 \%$ son de basalto, presentan tamaño pequeño a mediano $(2,4$ a $7,1 \mathrm{~cm}$ de largo x 2,4 a 6,2 $\mathrm{cm}$ de ancho $\mathrm{x}$ $1,6 \mathrm{~cm}$ a $5,3 \mathrm{~cm}$ de espesor) y están casi todos agotados. Para la costa norte de la desembocadura del río Chubut (Barranca Norte), Gómez Otero (2006) refiere la presencia de núcleos y lascas bipolares pero no precisa la frecuencia.

Para el golfo San Jorge, no se menciona la existencia de la talla bipolar (Borrero y Caviglia 1978; Arrigoni et al. 2008), mientras que en la costa norte de Santa Cruz se reportó el predominio de la percusión directa: la bipolaridad presenta baja frecuencia y está restringida a nódulos de rocas no locales como la obsidiana negra (Castro et al. 2008; Ambrústolo 2013). 
Por último, el registro de Patagonia meridional muestra ausencia de núcleos bipolares en la zona de Monte León (Cruz et al. 2008, Cañete Mastrángelo 2014), y baja frecuencia entre Punta Bustamante (Mansur et al. 2004; Mansur 2008) y Cabo Vírgenes (Borrero et al. 2008), donde se registraron contextos entre 3600 años AP y 200 AP. La bipolaridad se aplicó para tallar rodados pequeños de rocas disponibles localmente pero en escasa proporción, tales como xilópalos (Mansur et al. 2004) y "Rocas de Grano Fino Oscuras" (RGFO, sensu Charlin 2005).

En síntesis, a lo largo de la costa pampeano-patagónica el registro de la talla bipolar es diferente entre los distintos sectores (Fig. 9.8). En el litoral bonaerense, San Blas, la desembocadura del río Colorado, la del río Negro y el área de estudio de esta tesis, la frecuencia es alta; en la costa rionegrense del golfo San Matías es baja y al sur del área de estudio es muy baja o está ausente. En cuanto a la materia prima, en los sectores más septentrionales se la utilizó casi exclusivamente en guijarros pequeños de basalto; en la costa norte de Chubut tanto en rodados chicos de basalto como de sílices, y más al sur (Costa Norte de Santa Cruz y Punta Bustamante) se usó en guijarros de rocas de muy buena a excelente calidad, algunas no locales (obsidiana) y otras de disponibilidad local pero reducida (xilópalos y RGFO). Por lo tanto, estas evidencias permiten inferir que la talla o reducción bipolar fue una estrategia técnica casi exclusivamente aplicada por los cazadores-recolectores de la costa pampeano-patagónica en aquellos sectores donde la disponibilidad de materias primas de buena a excelente calidad para la talla estaba dada en forma de guijarros predominantemente pequeños.

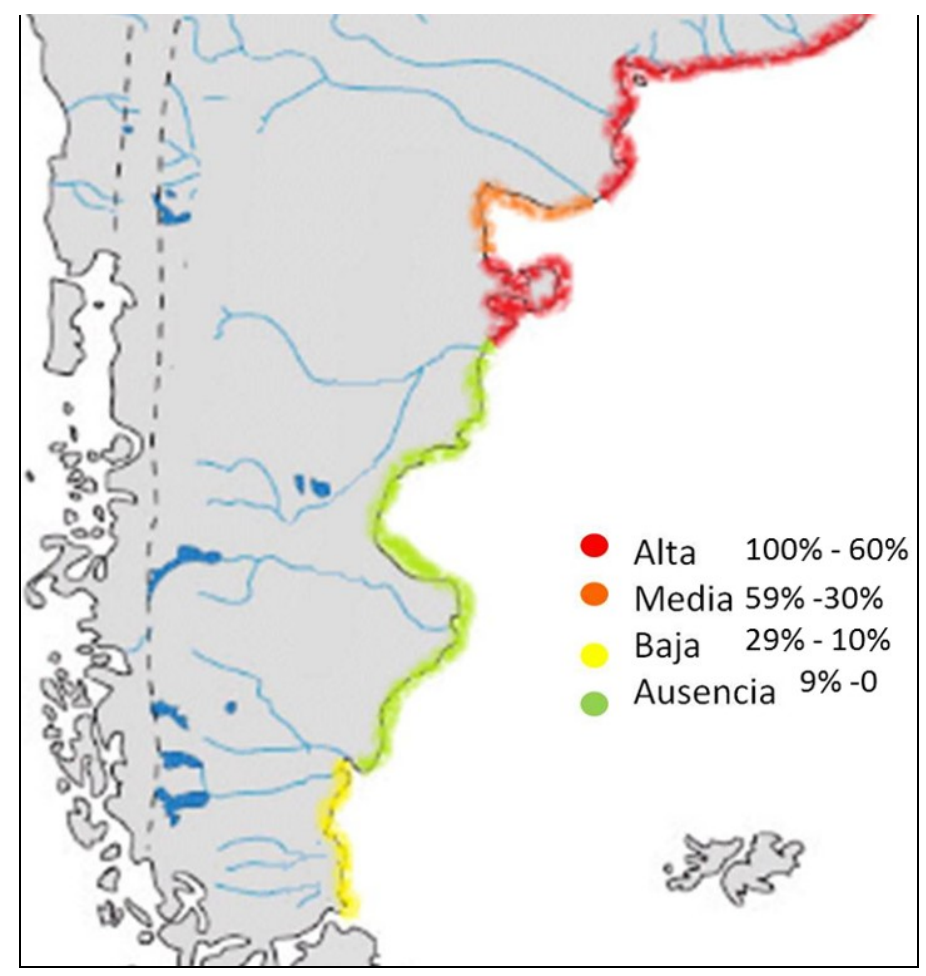

Fig.9.8. Dispersión espacial esquemática e intensidad de aplicación en la talla bipolar a lo largo del litoral pampeano-patagónico. 


\section{Hipótesis III:}

\section{En tiempos tardios se habría incrementado el intercambio de rocas y}

diseños artefactuales con otras áreas fuera y dentro de Patagonia.

Para el área de estudio Gómez Otero $(2003,2006)$ propuso que hacia finales del Holoceno tardío (post 1000 años AP) se produjo un proceso de complejización social que impactó en la subsistencia, los patrones de asentamiento-movilidad y las relaciones sociales intra e intergrupales. Las evidencias de este proceso estarían representadas por innovaciones tecnológicas; modificaciones en los hábitos alimenticios, como por ejemplo un aumento en el consumo de vegetales; un incremento en la cantidad y complejidad de los enterratorios y una intensificación en los intercambios de materias primas y/o manufacturas dentro y fuera de Patagonia (Gómez Otero 2003, 2006, Gómez Otero y Bellelli 2006). Entre ellos delgadas plaquetas de bronce o latón y de cuentas de valvas y/o de rocas ornamentales como malaquita, turquesa, serpentina y crisocola, no oriundas de Patagonia. Se suman a estas evidencias el notable hallazgo de un hacha de bronce del Período Tardío de los valles Calchaquíes (Gómez Otero y Dahinten 1999), que presenta grandes similitudes con las hachas típicas de la cultura Santamariana desarrollada aproximadamente entre el siglo X y el XV DC (Gómez Otero 2003:297-Fig.2A). También Schuster (2014) determina la presencia de piezas cerámicas cuyas formas y composición de las pastas son alóctonas. Estas manufacturas y objetos suntuarios, hallados en su mayoría en entierros, indican relaciones directas o indirectas con pueblos agroalfareros del Noroeste argentino y/o de Chile central.

Para contrastar la hipótesis aquí enunciada, a continuación se explorarán cambios temporales en cada Uarq a través de dos líneas de evidencia: (a) la proporción de rocas alóctonas apropiadas para la talla, y (b) la presencia de puntas de proyectil cuyos diseños son considerados diagnósticos de otras zonas del ámbito pampeano-patagónico. Como se mencionó en el capítulo metodología, se discriminaron tres bloques temporales: el Holoceno medio (HM), entre 7400 y 4000 AP; el Holoceno tardío inicial (HTI), entre 3900 y 1000 AP, y el Holoceno tardío final (HTF), con posterioridad a 1000 AP.

En las páginas anteriores se consignó que los conjuntos artefactuales de las dos unidades arqueológicas comparten tres tipos de materias primas no locales de muy buena a 
excelente calidad para la talla: la calcedonia ${ }^{6}$, el xilópalo y la obsidiana. Hay dos variedades de obsidiana negra -SI (Sacanana) y MS (desconocida)- y dos de obsidiana gris verdosa: T/SCI (Telsen) y TSCII (desconocida). Las fuentes Sacanana y Telsen están ubicadas en el sur de la meseta de Somuncurá, y las desconocidas también se localizarían en alguna parte del centro de esta meseta (Gómez Otero y Stern 2005). Fuera de Península Valdés, en un sitio del golfo

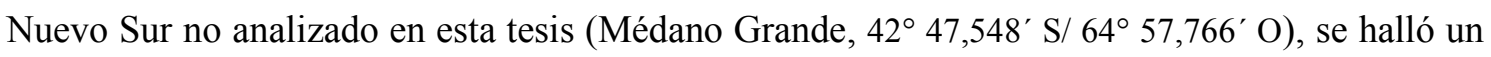
artefacto de obsidiana negra de la fuente Pampa del Asador (PDAI) de la provincia de Santa Cruz, a 800 km al sur (Gómez Otero y Stern 2005).

En cuanto a la variación temporal, se observó que la calcedonia -la más representada de las rocas no locales en los tres bloques temporales- en PV manifiesta un incremento gradual hacia el HTF, mientras que en FPV llega a su pico máximo en el HTI y disminuye en el HTF. Respecto del xilópalo, la segunda roca en orden de importancia, se observa lo opuesto a la calcedonia: en PV declina y en FPV aumenta (Fig. 9.9). Con relación a la obsidiana, en los contextos de PV las dos variedades de gris verdosa y negra se registran a partir del HTF, pero únicamente la gris verdosa (T/SCI) continúa en el siguiente período. En los muestreos de FPV la única variedad presente es la negra (SI), aunque sólo aparece en el HM y el HTI. Si se agregan a la discusión los datos de otros sitios presentados por Gómez Otero y Stern (2005), para PV se repite la ausencia de obsidiana en el HM, mientras que en FPV hay dos variedades negras (SI y PDAI) y también están las dos gris verdosas: T/SCI y T/SCII. Un artefacto de $\mathrm{T} / \mathrm{SCII}$, recuperado en un conchero en Rincón de Elizalde fue datado en $2220 \pm 70$ años ${ }^{14} \mathrm{C}$ AP a partir de una muestra de carbón (Gómez Otero y Stern 2005: 99).

No se observaron tendencias temporales en ambas unidades de análisis, ya que tanto en el conjunto de sitios analizados en esta tesis como en los demás, el promedio de artefactos de obsidiana fue muy bajo y parejo: 2,56\% en PV y de 2,53\% en FPV (Gómez Otero y Stern 2005).

\footnotetext{
${ }^{6}$ Dado que la calcedonia es local en el extremo norte de la UARq-FPV (Arroyo Verde), en esta discusión solamente se considera su presencia y proporción en los conjuntos de Rincón de Elizalde (golfo San Matías Oeste) y Bahía Cracker (golfo Nuevo Sur).
} 


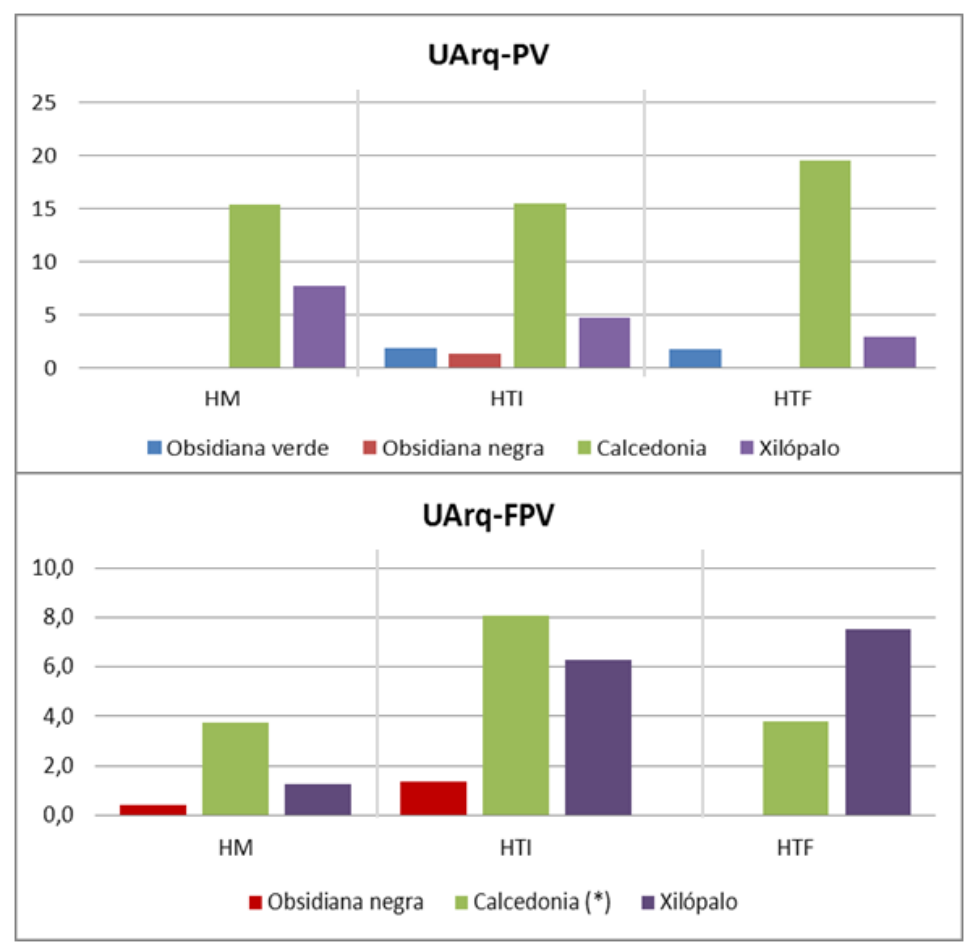

Fig. 9.9: Proporción de rocas de muy buena calidad para la talla de procedencia no local registradas por bloque temporal en cada gran unidad arqueológica de muestreo.

En síntesis, se comprobó que los cazadores-recolectores del área de estudio utilizaron estas tres rocas no locales -obsidiana, xilópalo y calcedonia- desde el Holoceno medio, lo que indica la existencia de una red de relaciones sociales y económicas de por lo menos siete mil años de antigüedad. Con relación a las variaciones temporales entre las dos grandes unidades arqueológicas, se observaron tendencias opuestas en el uso de las calcedonias y los xilópalos: en PV el aprovechamiento de calcedonias se incrementa paulatinamente desde el HM, mientras que esto mismo ocurre en FPV con los xilópalos. La calcedonia es más abundante en la Península Valdés y los xilópalos fuera de ella, sobre todo en el golfo Nuevo sur. Cabe recordar que distintas fuentes de calcedonia fueron localizadas en el límite norte del área de estudio (Arroyo Verde) (Alberti 2015) y al oeste entre Telsen y Gan Gan (Gómez Otero et al. 1999). Por su parte, las potenciales fuentes de xilópalo se encuentran más al sur: en el valle medio del río Chubut, el Bosque Petrificado de la Costa y el Bosque Petrificado Ormaechea, cerca de Colonia Sarmiento (Banegas et al. 2015). A partir de estos datos surge un interrogante: ¿habrán existido circuitos diferenciados de circulación de estas materias primas; es decir, un vector norte para la calcedonia y uno más meridional para el xilópalo?

Una herramienta útil para explorar lo anterior es la información proveniente de la circulación de obsidianas de fuentes identificadas en otras áreas de Patagonia. Las fuentes de Telsen (T/SCI) y Sacanana (SI) fueron utilizadas de manera conjunta entre ca. 3000 AP y 400 
AP en el centro de la meseta de Somuncurá, Maquinchao y la zona de Comallo-Pilcaniyeu (Boschín y Massaferro 2014, véase Fig. 9.10); durante el Holoceno medio y tardío en la costa rionegrina del golfo San Matías (Favier Dubois et al. 2009; Borella et al. 2015) y en la región de Aysén (Chile), aunque en sitios de superficie no datados (Stern et al. 2013, véase Fig. 9.11). La de Sacanana fue también hallada en Cerro Castillo, Gastre y Gan Gan en contextos posteriores a 2200 AP (Stern et al. 2000); en sitios de superficie sin cronología de la desembocadura, valle inferior y valle medio del río Chubut (Stern et al. 2000; Gómez Otero y Stern 2005); en otros de entre 3200 AP y 1900 AP del área de Piedra Parada y la cordillera de la provincia del Chubut (Bellelli y Pereyra 2002), y en las márgenes del río Chico, en el sudeste de Chubut (Stern et al. 2013). La distribución de artefactos de las fuentes SI y T/SC no se extiende más al norte del río Negro: ni Martínez (2008-2009) ni Eugenio y Aldazabal (2004) mencionan su presencia en los sitios del río Colorado y San Blas. Por su parte, Bonomo halló dos piezas: una de coloración marrón y otra negra riolítica. De acuerdo con los análisis de Charles Stern provendrían de alguna fuente desconocida, aunque no descartan que sean de la Meseta de Somuncurá (Bonomo, com. pers. 2016). En síntesis, de las dos fuentes conocidas del centronorte de la provincia del Chubut, SI muestra una distribución amplia que cubre Patagonia central y la porción centro sur y oriental de Nordpatagonia, aunque es más frecuente en el litoral y en la Meseta de Somuncurá. Por su parte T/SCI tiene una dispersión más acotada y restringida a la costa norte de Chubut, la costa rionegrina y el valle inferior del río Chubut. En cuanto a la fuente PDAI, representada en el área por un artefacto hallado en Puerto Madryn (golfo Nuevo sur), es muy abundante en la cuenca del Lago Musters (Reyes et al. 2014), en la región de Aysén (Méndez et al. 2012) y en la costa norte de Santa Cruz (Ambrústolo et al. 2012?), además del resto de la provincia de Santa Cruz (Méndez et al. 2012). Es importante mencionar que para la cuenca del lago Musters, Reyes et al. (2014) destacan la ausencia de las fuentes SI y T/SCI a pesar de que se encuentran a la misma distancia que la de Pampa del Asador. En síntesis, lo que sugiere la circulación de las obsidianas de fuentes conocidas es la existencia de dos grandes espacios de interacción más asidua o frecuente: uno que abarcaría desde la costa norte del golfo San Matías y la mitad sur de la provincia de Río Negro hasta el río Chubut; otro que se extendería al sur del río Chico (provincia de Chubut). Dado que la presencia de calcedonias y xilópalos está incluida en el circuito más septentrional, no se corrobora la existencia de dos vectores de circulación diferentes para ambas materias primas. Es probable entonces que se trate de una cuestión de proximidad a las canteras respectivas. En este sentido, la ampliación de los estudios petrográficos de calcedonias y xilópalos con microscopio de barrido electrónico (MEB) y de composición de elementos mediante la técnica de detector de energía dispersiva (EDX) para xilópalos permitirá explorar la validez de estas primeras conclusiones. 
En síntesis, los datos aquí discutidos mostraron que la circulación de estas tres rocas alóctonas de muy buena calidad para la talla se remontaría a las ocupaciones más antiguas registradas hasta el momento en el área de estudio, es decir al Holoceno medio. En cuanto al incremento de tal circulación durante el Holoceno tardío final, sólo se observó un aumento gradual de la proporción de las calcedonias en Península Valdés y de los xilópalos fuera de la península. No obstante, la presencia en los enterratorios tardíos de manufacturas confeccionadas en rocas suntuarias no locales como malaquita, turquesa y serpentina, entre otras (Gómez Otero 2003), sugiere intensificación de intercambios de materias primas líticas relacionadas más con bienes de prestigio que con funciones utilitarias. Es importante resaltar que sólo una mínima parte de los individuos de los enterratorios múltiples estaba asociada a estos objetos suntuarios, lo que fue interpretado por Gómez Otero $(2003,2006)$ como evidencia de un proceso de complejidad social. Esto se enmarcaría en lo que Hayden (1998) denomina "tecnologías de prestigio", que representan alguna de las estrategias sociales que se aplicaron para marcar o señalar que unos pocos individuos podían tener acceso a esos bienes exóticos, exhibirlos y ostentarlos. 


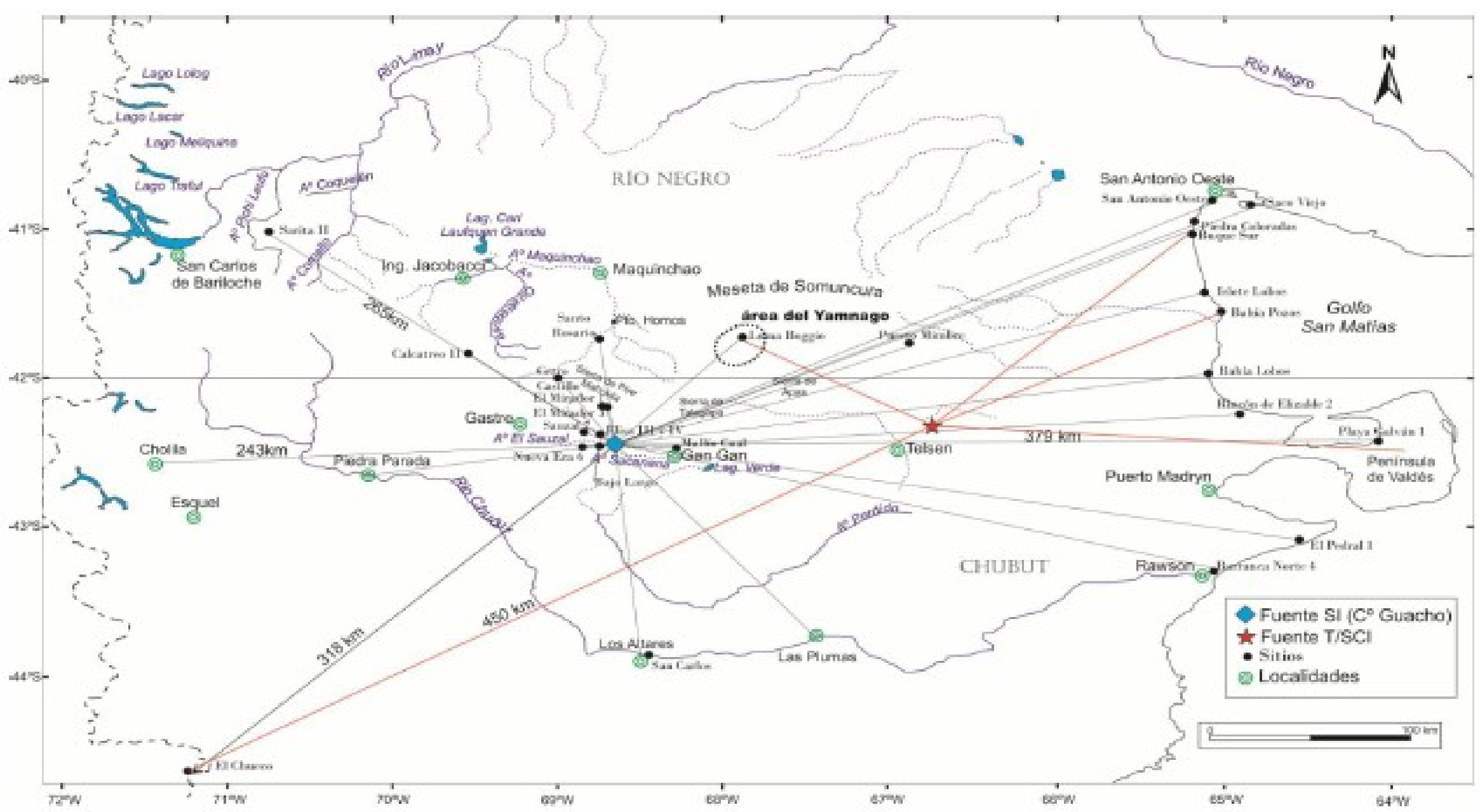

Fig. 9. 10. Mapa de la distribución de obsidianas de las fuentes SI y T/SCI en el norte de Chubut y sur de Río Negro (tomado de Boschín y Massaferro 2014: Fig. 2). 


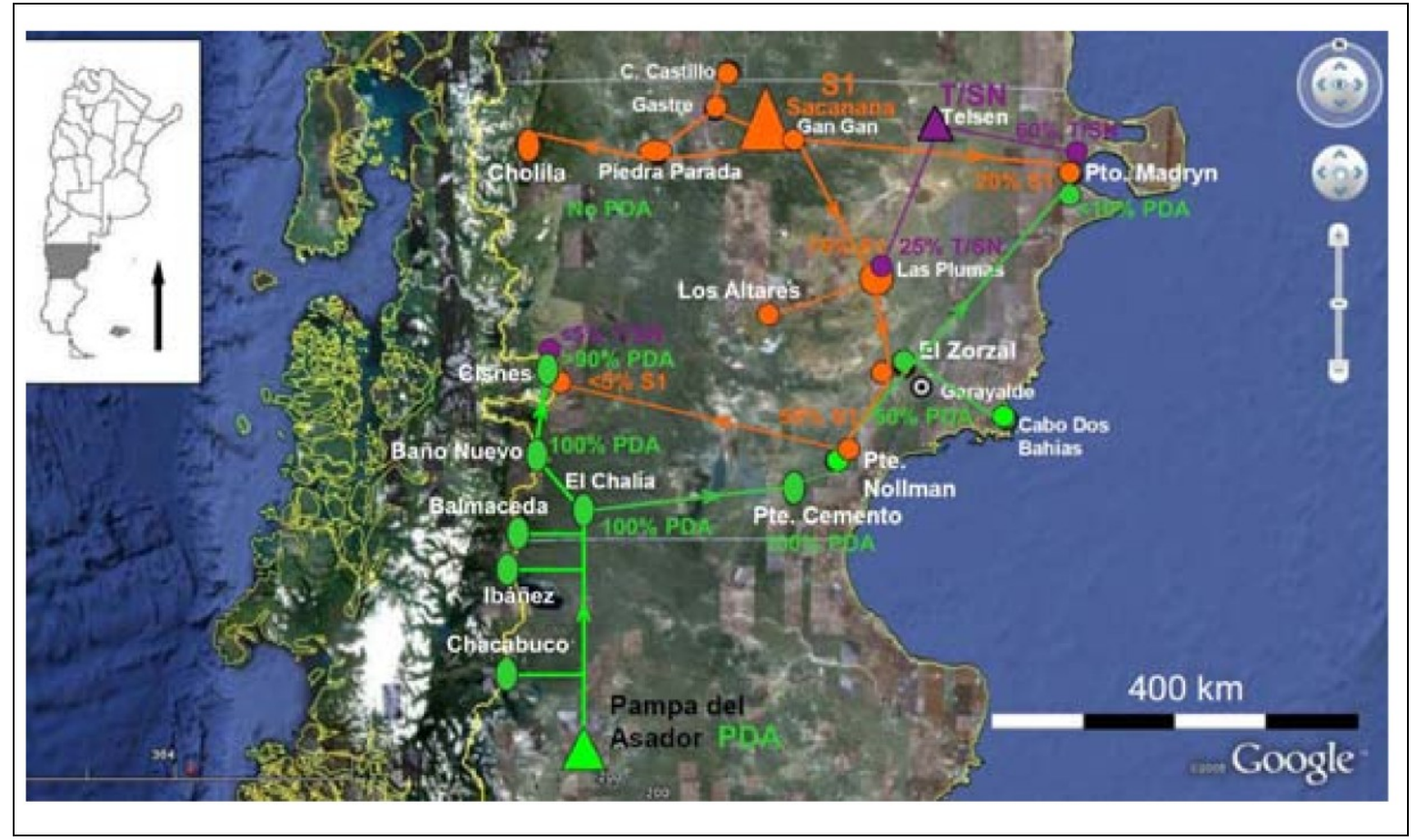

Fig.9.11. Mapa distribucional de obsidianas de los tipos SI, T/SCI y PDAI (triángulos verdes) en Patagonia argentina y chilena (tomado de Stern et al. 2013: Fig. 1).

\section{Intercambio de diseños:}

La importancia de la identificación de los diseños en puntas líticas radica en que se pueden abordar diversos aspectos del modo de vida de las poblaciones humanas del pasado, entre los que se destaca el contexto de uso, las técnicas de caza, aspectos estilísticos así como también la presencia de contactos intra e interpoblaciones (Thomas 1978; Ratto 2003; Martínez 2006; Franco et al. 2010; Bettinger y Eerkens 1999; Alvárez 2012, entre muchos otros). Sin embargo en su trayectoria de vida, las puntas se fracturan y/o se reciclan lo que produce la pérdida del modelo original (Hocsman 2006), es decir de los patrones constructivos seleccionados por el artesano para confeccionar sus herramientas. Esto genera dificultades analíticas para poder reconocer diseños característicos de un sistema técnico y/o los distintivos de una población. No obstante, aproximaciones metodológicas muestran que sectores específicos de las piezas -como por ejemplo el pedúnculo que queda protegido por el enmangue y por lo general no es reactivado- presentan valores diagnósticos tanto para la adscripción funcional como para la identificación de aspectos estilísticos propios de una región (Ratto 2003; Franco et al. 2009; Banegas et al. 2014; Charlin y González-José 2012). Al respecto, cabe destacar la importancia del concepto estilo para el estudio de la comunicación social en sociedades cazadoras-recolectoras (ampliar en Carden y Martínez 2014) ya que permite abordar 
aspectos de la cultura material como la transmisión de información, el conocimiento de lo social y del medio, y la idiosincrasia (Wiessner 1985- 2009; Wobst 1999; Whallon 2011entre otros). No obstante, tal como lo expresa Bonomo (2006) el concepto de estilo ha sido objeto de intensos debates acerca de su significado y de sus posibilidades operativas para distinguirlo de la morfología derivada de la función de los elementos (Binford 1989; Sackett 1985, 1986; Wiessner 1985; Wobst 1999). Por una parte, se ha sostenido su pertinencia para el abordaje de la identidad étnica, a través del examen de variables formales de ítems en los cuales se haya invertido una importante cantidad de energía en su confección y con larga vida útil (Wiessner 1983). Por otra, se ha argumentado que, para explicar la variación en la elección de cómo manufacturar objetos que fueron utilizados para fines similares, pueden ser empleadas cualidades de objetos utilitarios y poco elaborados de la vida cotidiana (Sakett 1982). Esto se debe a que también pueden estar expresando diferencias culturales con relación a otras unidades étnicas. Sin embargo, enfoques recientes sobre tecnología (Dobres 2000; Pfaffenberger 1992) sostienen la inoperatividad del concepto de estilo para establecer patrones culturales. Esto se debe a que en los estudios estilísticos, como en la mayoría de los análisis tecnológicos, los factores sociales y simbólicos son disociados de los aspectos utilitarios y son abordados solo después de examinar las variables materiales consideradas determinantes de la tecnología, como la morfología y la función de los artefactos. Al respecto, el autor puntualiza que este procedimiento metodológico se basa en la premisa de que una vez que se conocen los condicionantes materiales y naturales con una base objetiva sólida, recién en ese momento se puede comenzar la tarea de tratar las particularidades culturales adheridas a la superficie de los artefactos (Bonomo 2006:151-152).

Respecto de los diseños de las puntas de proyectil recuperadas en el área de estudio se presentan y discuten los resultados de tres estudios morfométricos sobre la base del método de Aschero (1975, 1983). En uno de ellos (Gómez Otero et al. 2011) se analizaron 144 cabezales líticos hallados en 23 localidades de la costa norte y el valle inferior del río Chubut (Fig.9.12); en el otro (Banegas y Goye 2012) se estudiaron 50 cabezales microlíticos del norte de Chubut: 26 registrados en la costa y 24 en las mesetas interiores y el valle inferior del río Chubut El tercer estudio, aun inédito, fue parte de una pasantía de investigación realizada bajo la dirección del Dr. Mariano Bonomo. Se analizaron puntas de la costa de la provincia de Buenos Aires y de las colecciones que forman parte de los Depósitos $\mathrm{N}^{\mathrm{o}} 25$ y No 7 de la División Arqueología del Museo de La Plata. Estos ejemplares fueron hallados por Luis María Torres en 1926, en San Blas; Joaquín Frenguelli en Claromecó y por Bonomo (2005) en el sector costero ubicado entre Cabo Corrientes 
y el río Quequén Salado.

En el primero de los estudios mencionados (Gómez Otero et al. 2011) se determinó alta variabilidad en diseños y tamaños. Si bien prevalecen los cabezales pedunculados, también hay varios apedunculados. En cuanto a la cronología, como la mayoría de estos ejemplares proviene de sitios de la superficie del terreno y los únicos datados corresponden a sitios posteriores a 2110 años AP (Gómez Otero 2006), no se pueden evaluar cambios temporales anteriores a esa fecha. A los efectos de indagar similitudes se compararon los rasgos morfométricos de estas puntas con los de puntas halladas en otras partes de Patagonia. Dada la innumerable cantidad de trabajos publicados se seleccionaron sólo aquéllos que presentan los resultados de secuencias estratigráficas temporalmente amplias y representativas de la arqueología de las distintas áreas. Si bien no se aplicó aun el modelo de asignación funcional de Norma Ratto (2003), los atributos morfométricos permiten estimar a priori, el uso de distintas armas: lanzas arrojadizas, dardos y arcos y flechas.

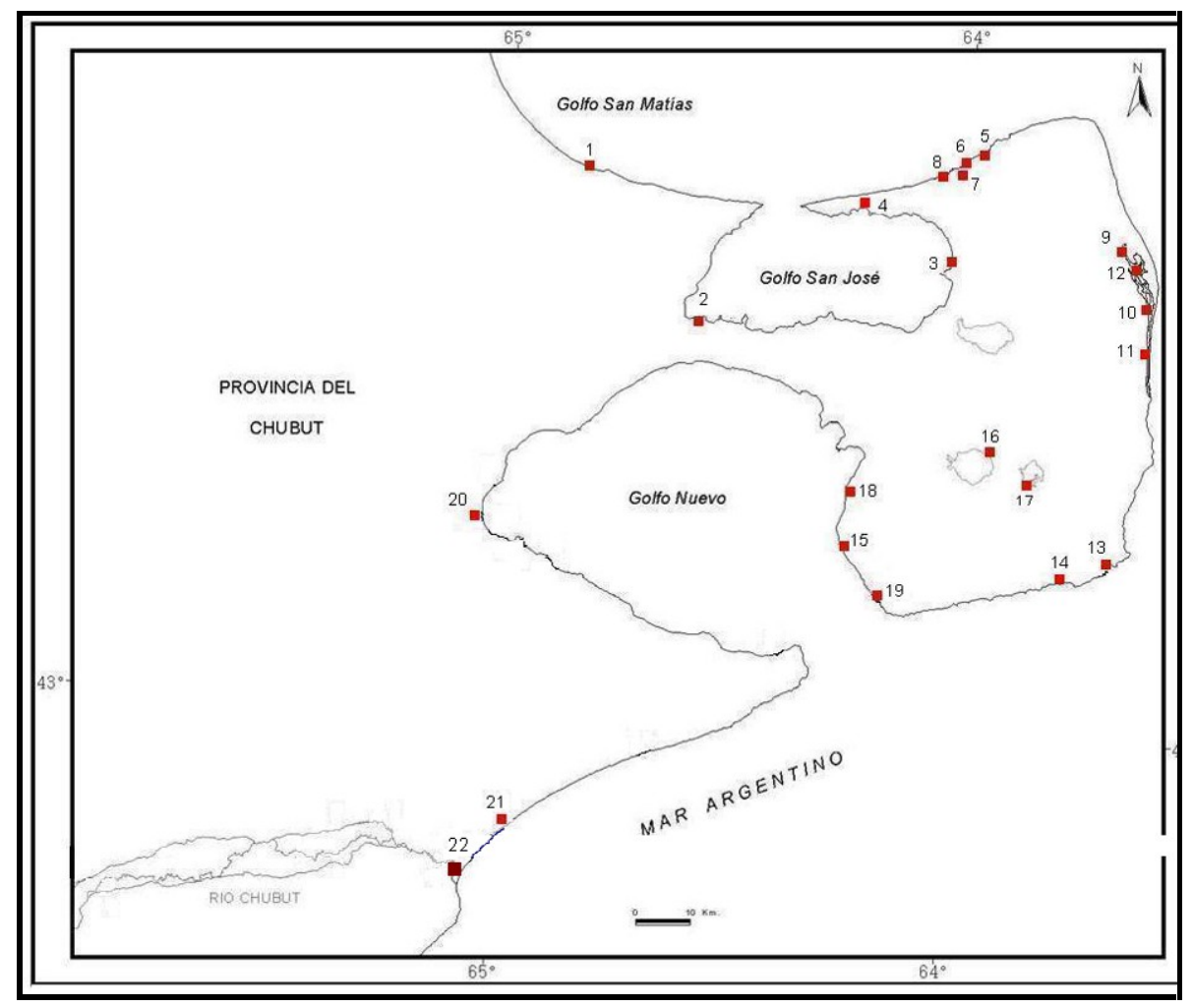

Figura 9.12: Distribución de las localidades con puntas de proyectil del área de estudio. Referencias: (1) Rincón de Elizalde; (2) Juan de la Piedra; (3) Playa Galván; (4) Puerto San Román; (5) La Armonía; (6) Las Lisas; (7) El Progreso; (8) Los Abanicos; (9) Transecta Paralela y Bajo Norte;(10) Transecta Transversal 1 Norte-Este; (11) Transecta Trasversal Sur- Oeste; (12) Isla 1; (13) Punta Delgada; (14) La Pastosa; (15) Pta. Cormoranes; (16) Salina Grande; (17) Salina Chica; (18) Punta Alta; (19) Morro Nuevo; (20) Puerto Madryn; (21) Barranca Norte; (22) Rawson. 
Entre las puntas apedunculadas se distinguieron cuatro tipos (Fig. 9.13). Los tipos 1.a. $(\mathrm{N}=7)$ y 1.c. $(\mathrm{N}=7)$ tienen similitudes con puntas de la industria o fase Toldense de Patagonia central (Cardich et al. 1973; Gradín et al. 1979; Gradin y Aguerre 1994) y Magallanes III de Patagonia meridional (Bird, 1993), así como con las halladas en los niveles más profundos de las cuevas Haichol (Fernández 1988-90) y Traful (Crivelli Montero et al. 1993) en el oeste de Patagonia septentrional. Estos cabezales fueron datados entre el Holoceno temprano y el medio. En el sitio Haichol perduraron hasta las ocupaciones alfareras tempranas (entre 1830 y 1250 años AP) (Fernández 1988-90).

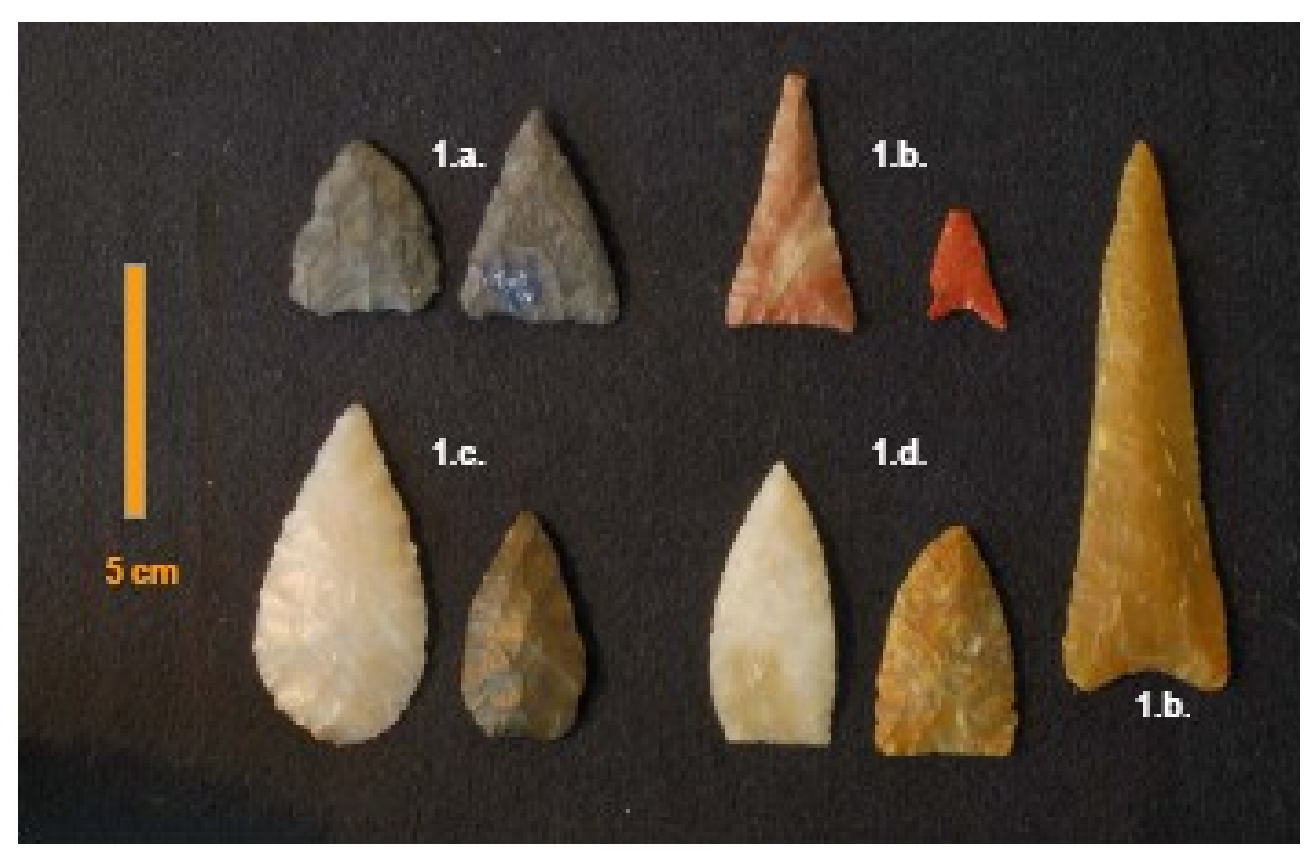

Fig. 9.13. Tipos de diseños de puntas apedunculadas, tomadas de Gómez Otero et al. 2011)

Los tipos 1.b. $(\mathrm{N}=7)$ y 1.d. $(\mathrm{N}=6)$ presentan amplia distribución en el norte de Patagonia (Orquera 1987). Aparecieron en el sitio Haichol desde las ocupaciones alfareras tempranas (1830 años AP) hasta tiempos post-hispánicos: $225 \pm 85$ años AP (Fernández, 1988-90), aunque en estos últimos se observa una notable reducción en tamaño. Estas pequeñas puntas -que se habrían utilizado en arcos y flechas- son características de las ocupaciones tardías de Patagonia septentrional, que algunos autores adscriben a la industria llamada Nordpatagoniense (ver Orquera, 1987:385-390). Puntas semejantes al tipo 1.b. se registraron también en la costa norte del canal Beagle, en Tierra del Fuego (Álvarez 2011: Fig. 2). En todos los casos fueron fechadas con posterioridad a 2000. El ejemplar del tipo 1.b. ubicado en el extremo derecho de la figura 9.13 se destaca por su gran tamaño (102 mm de largo x $30 \mathrm{~mm}$ de ancho x $8 \mathrm{~mm}$ de espesor). Fue hallado en el enterratorio Barranca Norte y está datado entre $310 \pm 70$ AP y 
$250 \pm 60$ AP (edad no calibrada en años calendáricos) (Gómez Otero 2006). El ejemplar más pequeño del tipo 1.b. correspondería a una punta de flecha.

En cuanto a las puntas pedunculadas, las autoras diferenciaron diez tipos de diseños (Fig. 9.14), que según su longitud máxima y el espesor y ancho del pedúnculo podrían haber sido utilizadas en distintas armas. Los tipos 2.a. $(\mathrm{N}=2)$ y 2.b. $(\mathrm{N}=9)$ son similares a puntas asignables a la llamada industria o fase Patagoniense de Patagonia central y centro meridional, datadas con posteridad a 1900 años AP (Cardich et al. 1973; Gradin et al. 1976, 1979; Aschero et al. 1983, 2006; Aguerre et al. 1994). La punta 2.b. de la figura 9.14 fue rescatada de un enterratorio del ejido de Puerto Madryn datado en $770 \pm 50$ años AP (edad no calibrada) (Gómez Otero y Dahinten, 1997-98).

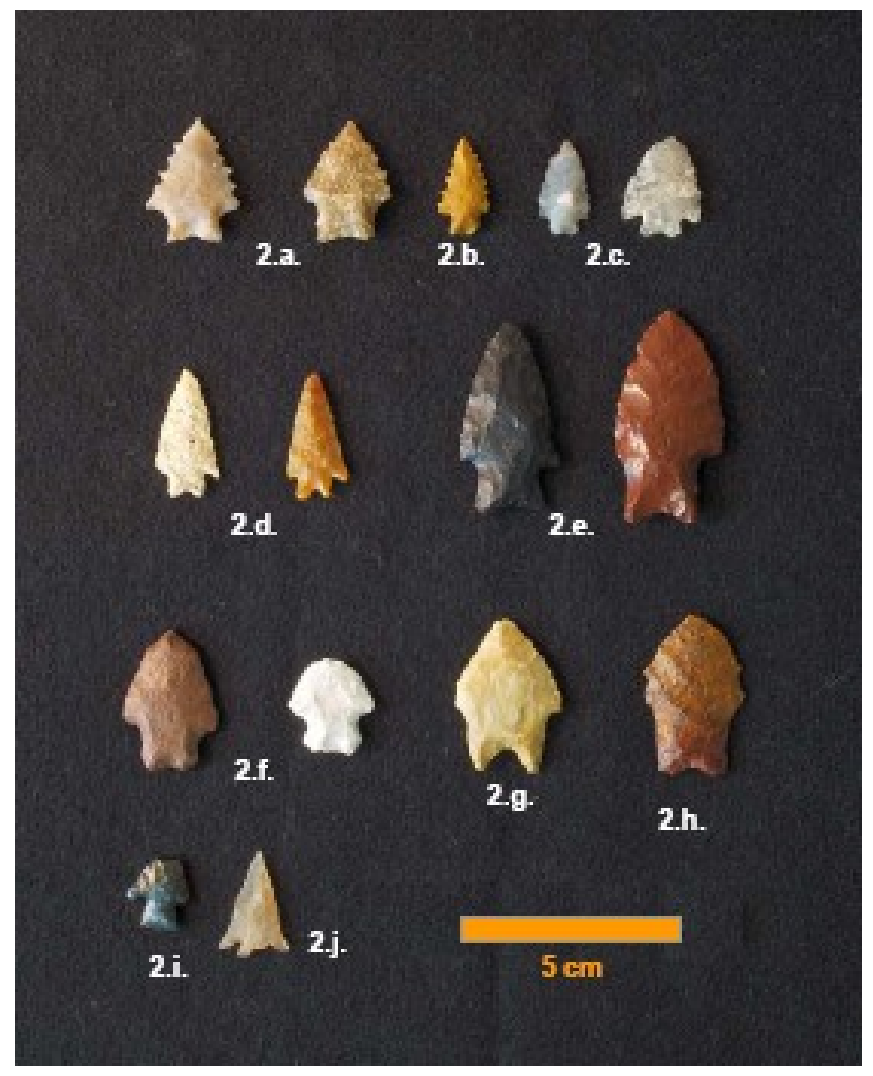

Fig. 9.14. Tipos de puntas pedunculadas del nordeste de Chubut tomadas de Gómez Otero et al. (2011)

Los tipos 2.c. $(\mathrm{N}=19)$ y 2.d. $(\mathrm{N}=19)$ son los más frecuentes en la costa norte y el valle inferior del río Chubut y fueron fechados entre $380 \pm 60$ años AP y de $270 \pm 60$ años AP (edades no calibradas). También estarían vinculados con la utilización de arcos y flechas. No se observaron similitudes con las puntas ilustradas en la bibliografía consultada, lo que sugiere que son diseños propios del área de estudio (ver resultados de Banegas y Goye 2012 abajo). Las variedades 2.e. 
$(\mathrm{N}=12)$ y 2.f. $(\mathrm{N}=5)$ se asemejan a algunas puntas halladas en contextos atribuidos a la fase Magallanes $I V$ de Patagonia meridional, con edades entre 4500 años AP y 200 AP (Massone 1981; Bird 1993; Franco 2002; Franco et al. 2010).

En cuanto al tipo 2.g. $(\mathrm{N}=3)$ una punta similar apareció en niveles cerámicos del sitio Chacra Briones, del valle medio del río Chubut (Aschero et al. 1983-85: Fig. 5: 9). No obstante, tanto éstas como la de Chacra Briones podrían ser ejemplares reactivados. El único ejemplar del tipo 2.h. (Fig. 9.14) es semejante a las llamadas "cola de pescado" o "cola de pez", que se hallaron en los contextos más antiguos de Patagonia meridional: las cuevas Fell y Palli-aike (Massone 1981; Bird 1993). Sin embargo, también es probable que se trate de una punta reactivada. Los dos cabezales de la variedad 2.i. se asemejan a las llamadas Magallanes $V$ o "puntas Ona" de Patagonia meridional, fechadas entre 800 y 200 años AP (Massone 1981; Bird 1993; Banegas et al. 2014); dadas sus características morfométricas estarían vinculadas con el uso del arco y la flecha. El último tipo -2.j.- está representado por una única punta similar a ejemplares del Componente Tardío del Canal Beagle (entre 280 y 100 años AP), que se habrían utilizado en arcos y flechas (Orquera y Piana, 1999:79 y 86).

El segundo estudio morfométrico de puntas de proyectil (Banegas y Goye 2012) incluyó ejemplares pedunculados microlíticos -menos de tres centímetros de largo- hallados en contextos estratificados del Holoceno tardío final y también en superficie. La cronología de las de superficie fue estimada a partir de su asociación con restos cerámicos; por lo tanto se presume que tendrían la misma antigüedad que la registrada para esta tecnología en Chubut: 1210 AP en el SO de Chubut (Gradin 1980), 1500 AP en el valle inferior del río Chubut (Gómez Otero et al. 2010) y 880 AP en Península Valdés (Gómez Otero et al. 2013). Se realizaron análisis estadísticos generales y multivariados (Componentes Principales-ACP) tomando ciertos atributos métricos del pedúnculo (largo, ancho de la base y cuello, espesor), ya que presentan menos modificaciones debido a las actividades de uso, mantenimiento, reciclado y descarte. Los resultados mostraron la presencia de por lo menos cuatro agrupamientos de diseños, cuya distribución espacial es llamativa (Fig.9.15): (I) un grupo de amplia representación, equivalente a los tipos 2.c. y 2.d. de Gómez Otero et al. (2011), registrado tanto en la costa como en el VIRCH; (II) otro acotado a la muestra de las mesetas interiores y similar a diseños de la fase Magallanes IV (Bird 1993); (III) un tercer grupo, identificado sólo entre las puntas de la costa -tipo 2.d. de Gómez Otero et al. (2011), cuyas características se asemejan a las de las puntas típicas de la fase Patagoniense (Gradín 1980; Aschero et al. 2006), y (IV) puntas similares a las recuperadas en el Componente Tardío del Canal 
Beagle (Orquera y Piana, 1999:79 y 86) o grupo 2.j. de Gómez Otero et al. (2011), registradas en la costa y en el valle inferior del río Chubut.

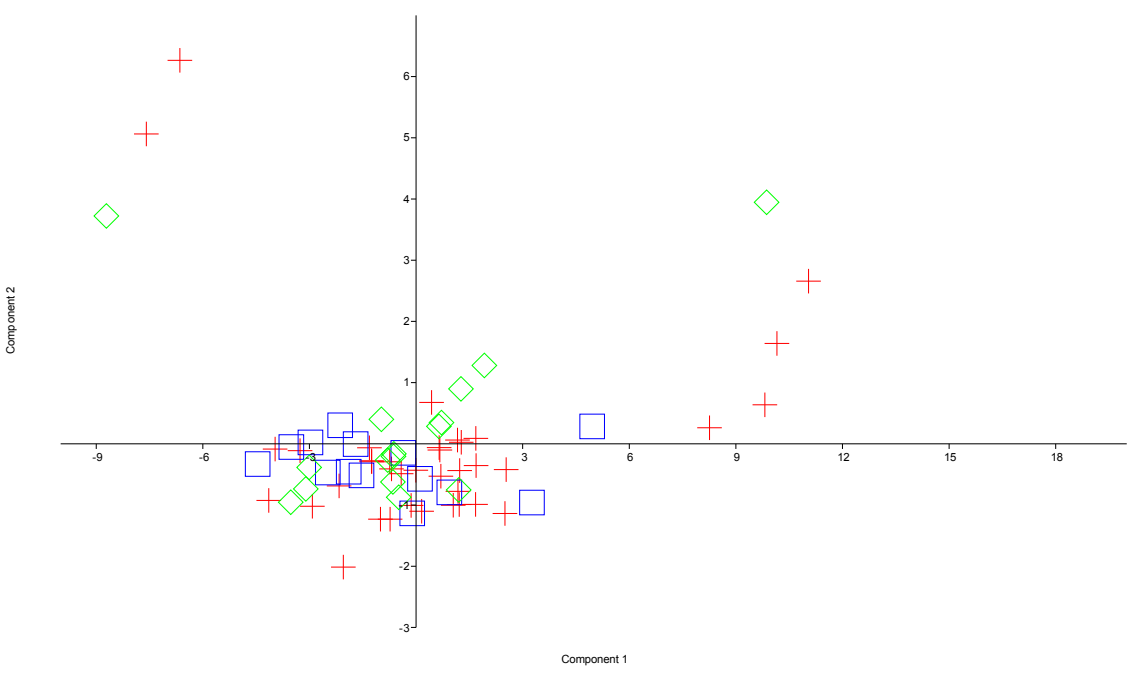

Figura 9.15: Componentes principales cinco variables del pedúnculo. Referencias: rojo: colección costa; verde: valle inferior del río Chubut; azul: mesetas interiores.

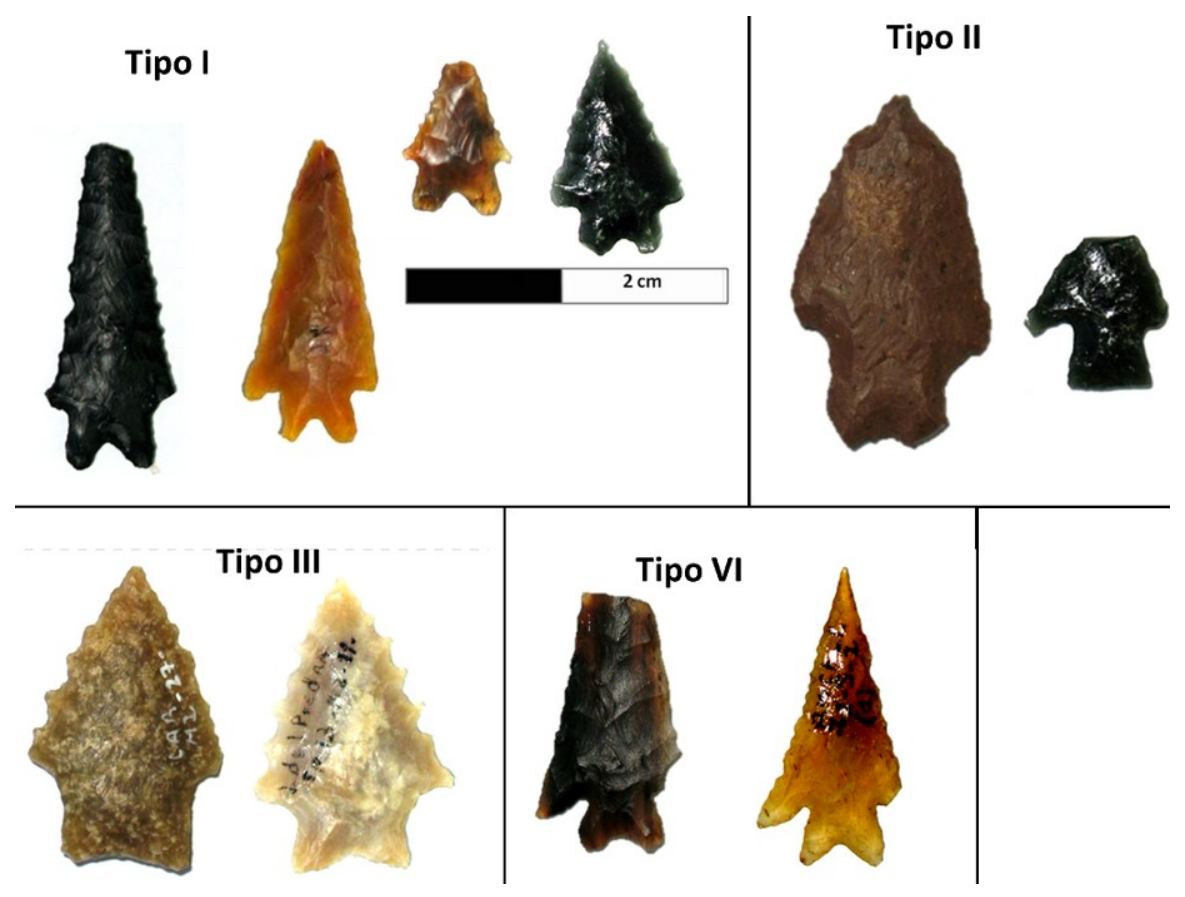

Figura 9.16. Tipos morfológicos de las puntas microlítica 
Por último, se presentan los resultados de la comparación con las puntas halladas en la costa pampeana y de Nordpatagonia. En el litoral pampeano ${ }^{7}$ son mayoría las apedunculadas triangulares $(\mathrm{N}=38)$, aunque también se hallaron ejemplares con pedúnculo $(\mathrm{N}=7)$. Las primeras fueron manufacturadas mediante retoque bifacial tanto en materias primas serranas -cuarcitas y ftanitacomo costeras -basalto- (Fig. 9.17). Estos ejemplares presentan varias similitudes con el tipo 1.a. del área de estudio (Fig.9.14). En cuanto a las pedunculadas, si bien son escasos los hallazgos, se caracterizan por presentar limbo triangular alargado y pedúnculo destacado de bordes paralelos y base escotada. Estas características lo asemejan al diseño 2.e de Gómez Otero et al. (2011).

En la localidad arqueológica de San Antonio (Martínez et al. 2009) y en el área de San Blas (Sanguinetti de Bórmida et al. 2001:345) señalan el predominio de cabezales apedunculados de limbo triangular y bases rectas o escotadas. No obstante, cabe resaltar la presencia de numerosos ejemplares pedunculados ( $\mathrm{N}=19$ de 51 ejemplares) relevados en la colección particular de Torres (Fig.9.18). En este sentido, respecto de la dispersión de las puntas con pedúnculo, Martínez (20082009) y Prates (2008: 258- 259) proponen respectivamente para los cursos inferiores de los ríos Colorado y Limay-Negro un modelo de dispersión de los diseños pedunculados para el Holoceno tardío final de acuerdo con la localización de estos cuerpos de agua: hacia al norte son frecuentes los diseños apedunculados mientras que al sur de dichos ríos la frecuencia de los pedunculados aumenta.

En la costa rionegrina del golfo San Matías, las puntas de proyectil recuperadas presentan una considerable variación morfológica, aunque predominan las puntas triangulares con pedúnculo destacado de entre 30 y $40 \mathrm{~mm}$ de largo y las puntas triangulares apedunculadas de bases grandes y pequeñas (menos de $30 \mathrm{~mm}$ ). Según los autores son similares a las descriptas por Gómez Otero (1995) para distintos sitios de la costa de Chubut (Favier Dubois et al. 2008). Por su parte, un reciente estudio (Cardillo y Alberti 2014) sugiere que las diferencias morfológicas estarían relacionadas con su utilización en distintos sistemas técnicos (Fig.9.19).

\footnotetext{
${ }^{7}$ Se incluyen las puntas de proyectil analizadas por Bonomo (2005) en las colecciones particulares, y la colección de Frenguelli $(\mathrm{N}=12)$ halladas en Claromecó y que relevadas para esta tesis
} 

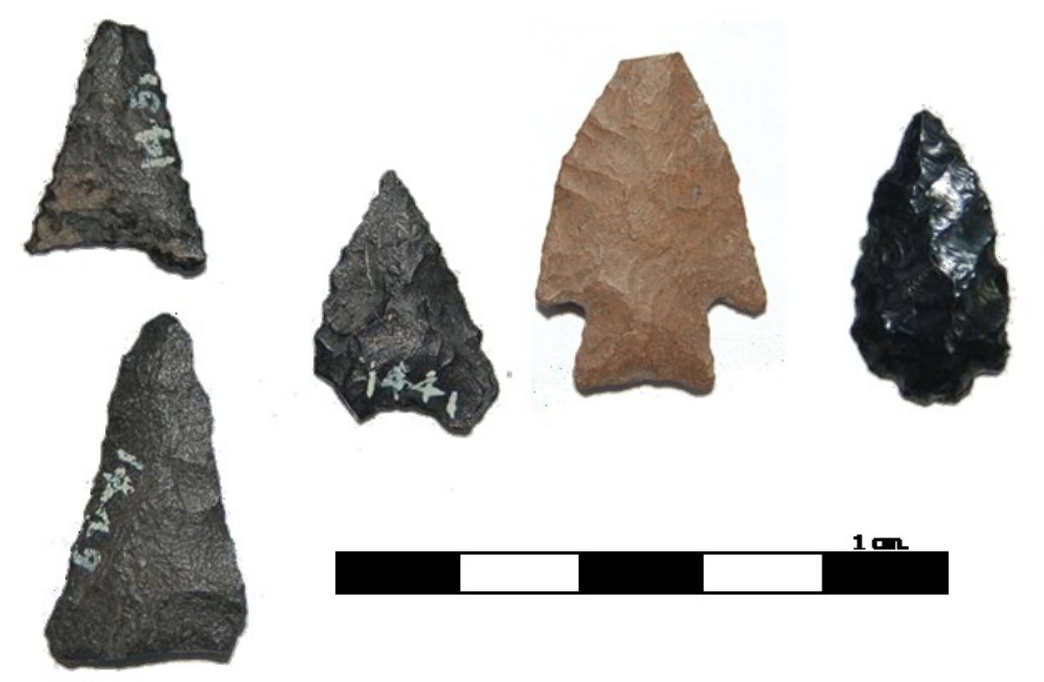

Fig. 9.17. Ejemplares hallados en el litoral marítimo pampeano. Colección Frenguelli, halladas en Claromecó. Depósito 7. MLP-Ar LPCJF000/1451/05.

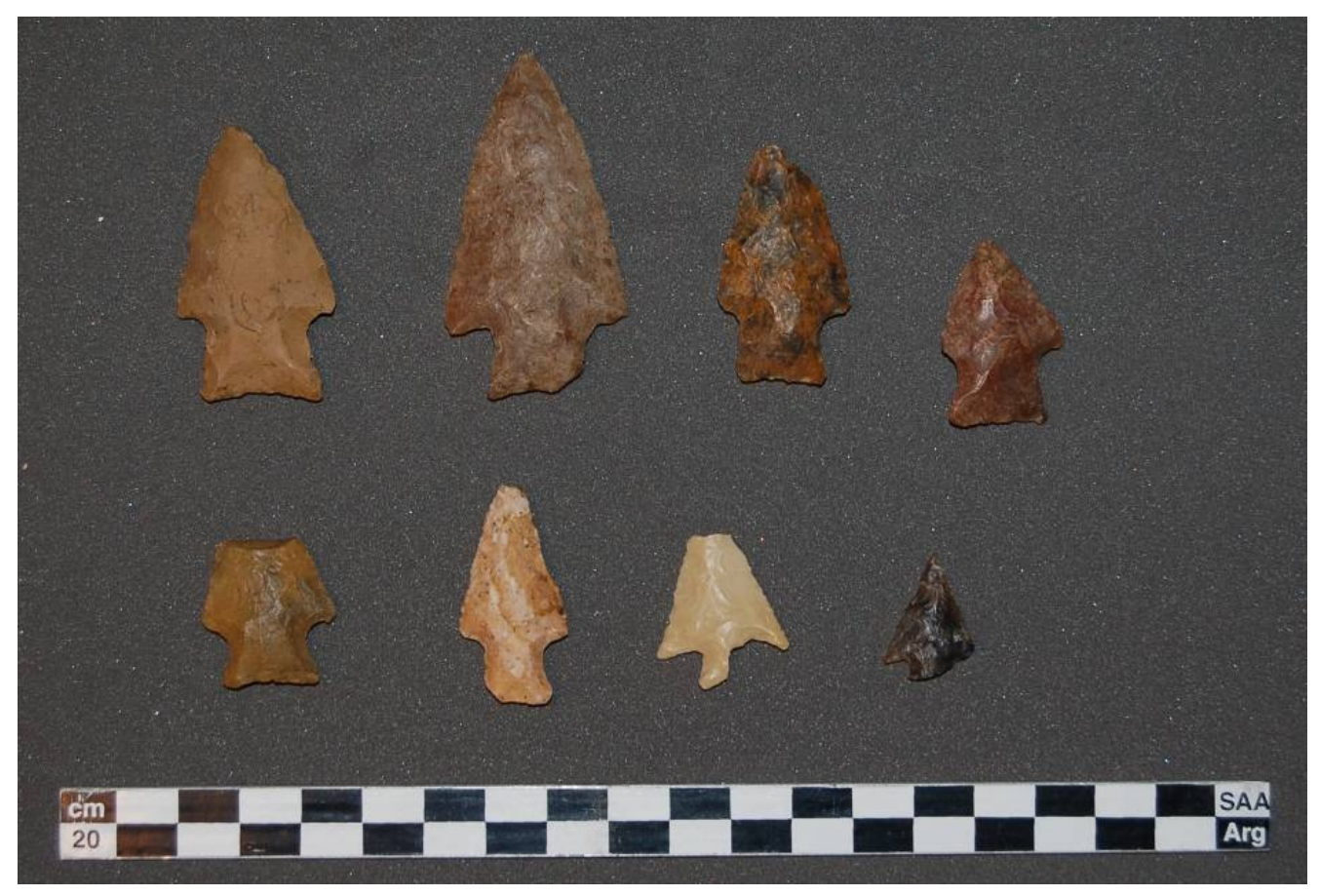

Fig.9.18. Puntas de proyectil recuperadas por Luis maría Torres en la zona de San Blas durante la campaña del año 1926. MLP-Ar. Colección Torres. Depósito 25. 

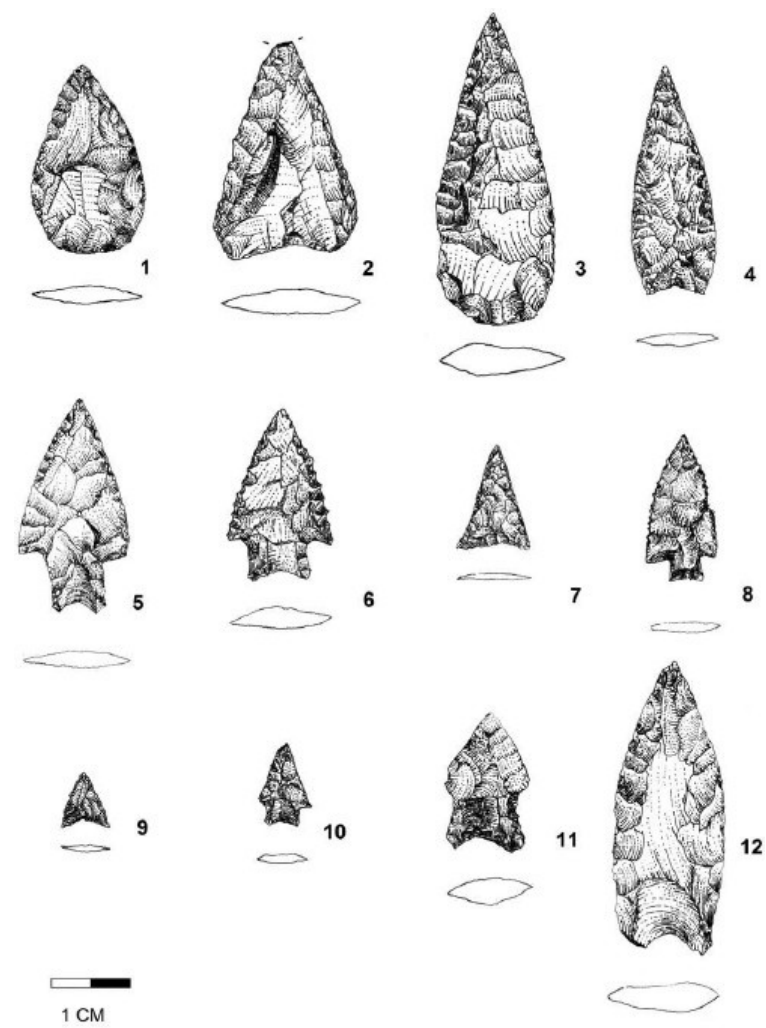

Fig. 9.19. Variabilidad morfológica de los cabezales líticos recuperados en la costa del Golfo San Matías (Río Negro), tomado de Cardillo y Alberti (2014: Figura 3, pp.617).

En síntesis, si bien las obsidianas de las fuentes conocidas de Chubut no parecen haber traspasado los límites del río Negro, se registró la presencia de formas o diseños de puntas triangulares apedunculadas típicas de Nordpatagonia en el área de estudio y de puntas pedunculadas del centro y sur de Patagonia en la costa pampeana y nordpatagónica. Entre las apedunculadas hay ejemplares que se asemejan a cabezales del Holoceno temprano y medio, lo que indica la existencia de antiguos contactos entre las distintas regiones, la circulación, replicación o reciclado de estos diseños para momentos que aun no se conocen. Dada la máxima edad radiocarbónica obtenida para el área -7400 años AP- (Gómez Otero 2006) no habría que descartar que desde ese entonces ya había amplias redes de información e intercambio que se potenciaron hacia el Holoceno tardío. En este sentido, y sobre la base de características métricas -ancho y espesor de la raíz del pedúnculo, y la razón entre el espesor de la raíz y el espesor del limbo- Franco et al. (2010) reconocen la consistencia de algunas puntas registradas con el área de estudio con un diseño denominado "Magallanes IV espesas", que justamente se distingue por el pedúnculo ancho y espeso. Tal diseño 
se habría originado circa 3000 AP en la zona del estrecho de Magallanes y perdurado sin modificaciones sustanciales hasta tiempos postcontacto, lapso durante el cual fue ampliando su área de dispersión. Las autoras, proponen que esto estaría mostrando la replicación de un diseño exitoso (sensu Bettinger y Eerkens 1999), que fue adoptado más por mecanismos de intercambio de información que por circulación de objetos terminados (Franco et al. 2010).

Para el Holoceno tardío se observa mayor variedad de formas, aunque de tamaño pequeño (menos de $35 \mathrm{~mm}$ ), y el área de distribución de diseños tanto apedunculados como pedunculados sería mayor y abarcaría no sólo Patagonia continental sino también el sur de Tierra del Fuego. En la región pampeana esta amplia red de contactos e intercambios se ve manifestada a través de otros aspectos de la cultura material como la presencia de motivos del "estilo de grecas" (Menghin 1952, 1957) o "tendencia abstracta lineal" (Gradin 1987) en soportes fijos y móviles; por ejemplo, placas grabadas, cerámica, cáscaras de huevo y cueros pintados. Según Bonomo (2005:273), estarían mostrando un vínculo estrecho -desde por lo menos el Holoceno tardío- entre las poblaciones del litoral marítimo y las de Nordpatagonia. Con relación al estilo de grecas, Belardi (2004) señaló su distribución en distintos ambientes de Pampa y Patagonia y en un área muy amplia que se extiende entre la Payunia, Neuquén y el sudeste de la región pampeana al norte hasta el paralelo de $47^{\circ} \mathrm{S}$ al sur, y entre el río Ibáñez (región de Aysén) al oeste hasta la costa atlántica al oriente. No obstante, con excepción del sitio Cañadón Encerrado de la zona de Camarones (Gómez Otero y Vallejo 1996), en el litoral el estilo de grecas se expresa en forma de soportes transportables. Más al sur del paralelo $47^{\circ} \mathrm{S}$ su presencia decrece notablemente.

Otra evidencia que se suma a las anteriores es el hallazgo en el nordeste de Chubut de enterratorios secundarios muy similares a los estudiados por Martínez (2010) y su equipo en el valle inferior del río Colorado. Estos se registraron en la costa de Punta León, entre Puerto Madryn y Rawson (Gómez Otero y Dahinten 1997-98) y en Loma Torta, en el valle inferior del río Chubut (Gómez Otero 2012). El primero fue fechado en $1050 \pm 50$ años ${ }^{14} \mathrm{C}$ y el segundo en $250 \pm 70$ años ${ }^{14} \mathrm{C}$. Todos estos rasgos indican, tal como lo destacaron Gómez Otero y Bellelli (2006) para la provincia del Chubut, que en el Holoceno tardío no sólo circularon materias primas y bienes sino también ideas, creencias, diseños y seguramente genes. 
En conclusión, sobre la base de los resultados antes presentados y discutidos se da por avalada la hipótesis III que sostiene que en el Holoceno tardío final se habría incrementado el intercambio de rocas y diseños artefactuales con otras áreas fuera y dentro de Patagonia.

\section{Hipótesis IV}

Las similitudes entre la tecnología lítica del área de estudio y la costa pampeana y norpatagónica se deben a las limitaciones impuestas por el tamaño y la forma en que se presenta la materia prima.

Uno de los objetivos de la tesis es comparar el registro tecnológico del área de estudio con el de los demás sectores de la costa pampeano-patagónica. De esta manera se podrán identificar similitudes y diferencias, indagar en sus probables causas y aportar a la discusión de interrogantes relevantes para la arqueología costera tales como: (a) la existencia de trayectorias históricas compartidas; (b) la existencia de una antigua ruta costera de poblamiento (Mioti y Salemme 2004) o de circulación posterior; (c) convergencia en la base regional de recursos líticos; (d) intercambios directos o indirectos; (e) semejanzas en la forma de vida costera (Lyman: 1984, Orquera y Piana: 1999) o tipo de adaptaciones según el grado de aprovechamiento de los recursos acuáticos (Lyman $1991)$.

De todos estos posibles factores, en esta tesis se eligió explorar el papel de la base regional de recursos líticos (sensu Erickson 1984). A los efectos de ilustrar de manera sencilla las similitudes y diferencias en las variables tecnológicas básicas entre la costa del área de estudio y la de Pampa y Nordpatagonia, se consignarán de manera comparativa en forma de tabla algunas de estas variables. Como la selección de materias primas, tipos de núcleos, porcentaje de bipolaridad y morfología de puntas de proyectil ya fueron tratadas en las hipótesis I, II y III (Tabla 9.9), en este acápite se agregarán otros aspectos tales como: (1) tipo de soporte-índices de laminaridad; (2) tamaños de los instrumentos, (3) serie técnica-índice de bifacialidad, y (4) presencia de instrumentos líticos especializados en la captura y procesamiento de recursos marinos, como pesas líticas y rompecráneos. Esta información será discutida en relación con la funcionalidad de los sitios y el tipo de adaptación -litoral o marítima (sensu Lyman 1984; Orquera y Piana 1999) o terrestre- de los cazadores recolectores de estos sectores. Se aclara que en los trabajos consultados, la descripción de estas variables es desigual: en algunos casos se consignan sin dar cuenta de porcentuales, en otro no se mencionan. 


\section{COSTA BONAERENSE - AREA DE ESTUDIO}

1. Base regional-selección de Materias primas. En las dos áreas se usaron mayoritariamente las materias primas locales de mejor calidad para la talla, disponibles en forma de rodados de distinto tamaño: guijarros de basalto -la roca más abundante en la costa bonaerense (Bonomo 2005, Bonomo y Prates 2014); guijarros y guijas de basalto y sílices en el área de estudio (Tabla 9.9).

2. Técnica de reducción bipolar. En la costa bonaerense como en la del área de estudio, la técnica de talla bipolar está ampliamente representada en los artefactos sobre rodados de basalto. Fue registrada en la totalidad de los núcleos, en gran parte de los desechos de talla (47\%) y en los instrumentos manufacturados mediante lascados (61\%) (Bonomo y Prates 2014). Como ya se mencionó, la bipolaridad fue alta en las dos áreas (Tabla 9.9.), sin embargo, mucho mayor en la bonaerense (90\%) contra 55\% en la UArq-PV y 37\% en la UArq-FPV). No obstante, en el área de estudio todos los rodados de basalto fueron reducidos por talla bipolar (ver Hipótesis I). Esta supremacía casi absoluta de la talla bipolar en el litoral pampeano se debería a que la oferta de rocas de buena calidad está restringida a los guijarros de basalto; en consecuencia, la técnica bipolar permitió superar esta limitación al mejorar el rendimiento de los nódulos. Por su parte, en el área de estudio los rangos de tamaño son más amplios: guijarros y guijones.

3. Soportes o formas-base. En la costa bonaerense sobresale ampliamente la producción de lascas (92,6\%); varias de ellas con restos de corteza, mientras que los módulos mediano alargados y laminares alcanzan un 7\% (Bonomo 2005: 16). También se emplearon cuerpos centrales de rodados de basalto -por ejemplo para la confección de raederas. De manera similar, en el área de estudio prevalece la selección de lascas como formas bases para la manufactura de los instrumentos (77,2\%: 63 de 88 instrumentos) (Tabla 9.9.). La frecuencia de módulos laminares fue de 13,6\% (12 de 88 instrumentos), de los cuales la mitad corresponde a láminas de calcedonia (locales solamente en Arroyo Verde) y el resto se distribuye entre sílices y xilópalos (no locales). Estos soportes laminares fueron preferentemente buscados para la manufactura de un subgrupo tipológico en particular -los raspadores frontales de tamaño pequeño y mediano-pequeño- y en segundo lugar para los retoques sumarios. En otros sitios de PV (Gómez Otero et al. 1999) observaron predominio de artefactos sobre lascas de rodados, aunque las láminas y hojas presentan porcentajes variables: entre $3 \%$ y $33 \%$.

4. Tamaños de los instrumentos. En la costa bonaerense sobresalen los tamaños medianopequeños y mediano-grandes, lo que se condice con el tamaño de los rodados costeros locales de 
basalto y otras rocas de origen volcánico. Asimismo, en sitios del Holoceno tardío se han registrado instrumentos pequeños y muy pequeños, fundamentalmente de basalto, como raspadores de filo frontal corto o perimetral y puntas de proyectil apedunculadas triangulares con base recta o cóncava (Bonomo 2005). En el área de estudio de esta tesis también prevalecen en proporciones similares los tamaños pequeños (42:47,7\%) y mediano-pequeños (41:46,5\%). A estos se suman instrumentos microlíticos, en particular puntas de proyectil pedunculadas y raspadores, que, como se expuso, están asociados a contextos asignados al Holoceno tardío (ver H1 e H3). En ambas áreas los tamaños promedio de los instrumentos elaborados en las rocas locales son consistentes con la dimensión general de los rodados de la base regional.

5. Serie técnica. En la costa bonaerense los instrumentos fueron principalmente confeccionados mediante retoque unifacial, aunque se observaron diferencias entre la serie técnica y la procedencia de las rocas: para los artefactos manufacturados sobre materias primas costeras se aplicaron los retoques y microrretoques marginales; mientras que la retalla y los lascados extendidos sólo se presentan en instrumentos sobre materias primas del interior (2y Silva 2014). También en el área de estudio el microrretoque (49\%) y el retoque (32\%) marginal unifacial fueron las técnicas más aplicadas para la formatización de instrumentos. En ambos sectores costeros, la bifacialidad estuvo restringida a las puntas de proyectil (Bonomo 2005), aunque en la Península Valdés se han registrado también preformas, cuchillos y raederas bifaciales (Gómez Otero et al.1999).

6- Presencia de instrumentos relacionados con la obtención de recursos marinos. Como se trató en la hipótesis I, estos instrumentos estarían representados por: (a) pesas líticas para la pesca con redes o líneas; (b) rompecráneos o rústicas mazas de rocas porfídicas para cazar pinnípedos en tierra (Moreno et al. 2002) y (c) denticulados, de función aún desconocida pero cuya distribución en Patagona es únicamente costera (Ambrústolo et al. 2011). En la tabla 9.9. se puede observar la ausencia de esta clase de instrumentos en la costa bonaerense, a diferencia de la del área de estudio donde se registraron numerosas pesas líticas ( $\mathrm{N}=58)$ (Gómez Otero et al. 2015), algunos raspadores denticulados en la península Valdés y un rompecráneo hallado en El Pedral, en el golfo Nuevo sur (Gómez Otero 2005).

\section{COSTA NORTE DE PATAGONIA-COSTA DEL ÁREA DE ESTUDIO (Tabla 9.9.)}

1. Base regional-selección de Materias primas. En la desembocadura del río Colorado (Martínez 2008, 2009). y San Blas (Sanguinetti et al. 2000) se usaron los guijarros locales de 
sílices, calcedonias y basaltos. En la costa rionegrina se aprovecharon todos los tipos de rocas disponibles, tanto de las fuentes primarias como secundarias, en especial las criptocristalinas, sílices y vulcanitas (Alberti et al. 2015).

2. Técnica de reducción bipolar. En la desembocadura del río Colorado, la bipolaridad está presente en artefactos obtenidos de los guijarros locales de sílices y basaltos (67\% a $86 \%$ de los núcleos y 31\% de las lascas) (Eugenio y Aldazabal 2004; Bayón et al. 2004; Aldazabal et al. 2011). En la costa rionegrina del golfo San Matías, la presencia de núcleos bipolares es media a baja y varía entre el bloque temporal antiguo -4800 a 2200 años AP (13,5\%) - y el reciente -1500 y 500 años AP (8.7\%) (Alberti 2013). En síntesis, hay mayor coincidencia de este rasgo con la desembocadura del río Colorado y San Blas. En la costa rionegrina el porcentaje de bipolaridad es mucho menor, lo que se debería a la amplia base regional de recursos líticos, que además de los guijarros incluye nódulos grandes de fuentes primarias de rocas de muy buena a excelente calidad para la talla.

3. Soportes o formas-base. En la desembocadura del Colorado y San Blas la tecnología estuvo orientada a la producción de lascas (Bayón et al. 2004; Eugenio y Aldazabal 2004; Aldazabal et al. 2011), que conservan la corteza (en un 46\% según Bayón et al. 2004). En los conjuntos de la costa rionegrina también predominan las lascas, de las cuales las de basalto presentan corteza en su mayoría (no se mencionan porcentajes) (Alberti 2013). En la costa norte de Chubut, la reserva de corteza es media a alta entre los desechos de talla (entre 25 y $60 \%$ ), mientras que entre los instrumentos no supera el 13\%. En síntesis, hay coincidencia en la proporción predominante de lascas como formas base y en la presencia de corteza en especial en los artefactos provenientes de la talla de guijarros de basalto.

4. Tamaños de los instrumentos. En general en los trabajos consultados no se mencionan tamaños en artefactos, sino en desechos. En el sitio La primavera, el tamaño más frecuente es el mediano pequeño (66,6\%) seguido por el pequeño (33,3\%) (Armentano 2014). En la costa rionegrina predominan los medianos tanto en lascas como en instrumentos terminados, lo que estaría relacionado con las dimensiones de los guijarros locales (Borella y Cardillo 2011).

5. Serie técnica. Al igual que en el área de estudio, para San Blas Aldazabal et al. (2011) refieren la aplicación del retoque marginal unifacial en la mayor parte de los instrumentos; la talla y el retoque bifacial se observó en puntas, bifaces y preformas. Para la desembocadura del río Colorado Armentano (2011) menciona un 40\% de microrretoque marginal, mientras que Martínez (2008-2009) señala un aumento en la reducción bifacial y mayor inversión de trabajo en la formatización de los instrumentos en el Holoceno tardío. Para la costa rionegrina Alberti (Alberti 
2013: 86) determina ocho categorías, entre las cuales prevalece el trabajo "no invasivo unifacial, seguido por la reducción bifacial, el trabajo no invasivo bifacial, el adelgazamiento bifacial y por último el adelgazamiento unifacial". En síntesis, la costa nordpatagónica y la del área de estudio coinciden con el predominio del retoque o microrretoque marginal unifacial y la bifacialidad restringida a las puntas de proyectil y a preformas o bifaces.

6- Presencia de instrumentos relacionados con la obtención de recursos marinos. Se hallaron denticulados y pesas de red en San Blas y en la costa rionegrina (Eugenio y Aldazabal 2004; Favier Dubois et al. 2009; Borella et al. 2015). El registro de pesas líticas fue mucho mayor en el sector norte del golfo San Matías (Favier Dubois y Scartascini 2012), en especial en contextos datados en el bloque temporal antiguo (circa 6000-4000 años AP). En la costa sur de la provincia de Río Negro apareció un rompecráneos elaborado en una roca volcánica básica (Borella et al. 2015). De todos estos artefactos, los de mayor distribución y abundancia son las pesas líticas, que en la costa rionegrina se habrían usado en redes (Scarstacini 2010), mientras que en el área de estudio se propuso su utilización en líneas (Gómez Otero 1996, 2006). En la costa norte de Chubut y en contraposición con el abundante registro de consumo de pinnípedos, solamente se halló un romprecráneos. Esto podría deberse a la ausencia de afloramientos primarios de las rocas -pórfidoscon los que fueron confeccionados y registrados al sur del río Chubut; por lo tanto Gómez Otero (2006) interpretó que se aplicaron otras tácticas o armas para su captura en tierra. 


\begin{tabular}{|c|c|c|c|c|c|c|c|c|c|}
\hline \begin{tabular}{|l} 
SECTOR \\
COSTERO
\end{tabular} & Base regional & $\begin{array}{l}\text { Selección } \\
\text { rocas }\end{array}$ & Formas-base & $\begin{array}{l}\text { Tamaños } \\
\text { artefactos }\end{array}$ & Serie técnica & Bipolaridad & $\begin{array}{l}\text { Puntas de } \\
\text { proyectil } \\
\text { dominantes }\end{array}$ & $\begin{array}{l}\text { Instrumentos } \\
\text { especializados en la } \\
\text { obtención de recursos } \\
\text { marinos }\end{array}$ & Referencias \\
\hline Costa pampeana & Guijarros de basalto & $\begin{array}{l}\text { Guijarros de } \\
\text { basalto }\end{array}$ & $\begin{array}{l}\text { Lascas } \\
(92,6 \%) \\
\text { Láminas } \\
(7,4 \%)\end{array}$ & $\begin{array}{l}\text { Mediano- } \\
\text { pequeños }\end{array}$ & $\begin{array}{l}\text { Filos naturales, } \\
\text { retalla y retoque } \\
\text { unifacial. } \\
\text { Bifacialidad } \\
\text { asociada a puntas }\end{array}$ & Alta (90\%) & $\begin{array}{l}\text { Triangulares } \\
\text { apedunculadas }\end{array}$ & $\begin{array}{l}\text { No se registran evidencias } \\
\text { claras. }\end{array}$ & $\begin{array}{l}\text { Bayón y Politis (1996); } \\
\text { Bonomo (2005); } \\
\text { Bonomo y Prates } \\
\text { (2014); } \\
\text { Apolinaire y Silva } \\
\text { (2012) }\end{array}$ \\
\hline $\begin{array}{l}\text { Costa } \\
\text { Nordpatagónica }\end{array}$ & $\begin{array}{l}\text { Guijarros y guijones } \\
\text { de rocas } \\
\text { criptocriptalinas y } \\
\text { sílices. Calcedonias de } \\
\text { filón }\end{array}$ & $\begin{array}{l}\text { Guijarros y } \\
\text { guijones } \\
\text { locales y } \\
\text { tabletas de } \\
\text { calcedonias }\end{array}$ & Lascas & Medianos & $\begin{array}{l}\text { Retoque unifacial, } \\
\text { seguido por bifacial }\end{array}$ & $\begin{array}{c}\text { Baja } \\
(13,5 \% \text { a } \\
8.7 \%)\end{array}$ & $\begin{array}{l}\text { Triangulares } \\
\text { pedunculadas y } \\
\text { apedunculadas }\end{array}$ & \begin{tabular}{|l|} 
Ausencia en la \\
desembocadura del río \\
Colorado. Al sur de San Blas \\
presencia creciente de pesas \\
líticas y denticulados. Un \\
rompecráneos en la COGSM
\end{tabular} & $\begin{array}{l}\text { Bayón et al. 2004; } \\
\text { Martínez 2008-2009); } \\
\text { Aldazabal et al. 2011; } \\
\text { Armentano 2014; } \\
\text { Alberti 2015; Borella } \\
\text { et al. 2015. }\end{array}$ \\
\hline UArq-PV & $\begin{array}{l}\text { Rodados chicos de } \\
\text { basalto, sílices y } \\
\text { riolitas. }\end{array}$ & $\begin{array}{l}\text { Guijarros de } \\
\text { basalto y } \\
\text { sílices. }\end{array}$ & $\begin{array}{l}\text { Lascas } \\
(74,4 \%) \\
\text { Láminas } \\
(11,5 \%) \\
\text { Indet. }(10,3 \%) \\
\text { Núcleos } \\
(3,8 \%)\end{array}$ & \begin{tabular}{|l} 
Pequeño \\
$55 \%)$ \\
Mediano \\
$(30 \%)$ \\
Muy \\
pequeños \\
$(12 \%)$ \\
Grande \\
$(3 \%)$
\end{tabular} & \begin{tabular}{|l} 
Microrretoque \\
$(49 \%)$ \\
Retoque \\
$(32 \%)$ \\
Lascados simple \\
$(15 \%)$ \\
Bifacialidad \\
asociada a puntas
\end{tabular} & $\begin{array}{l}\text { Media } \\
(55 \%)\end{array}$ & Pedunculadas & $\begin{array}{l}\text { Pesas líticas, escasos } \\
\text { raspadores denticulados. }\end{array}$ & $\begin{array}{l}\text { Gómez Otero et al. } \\
\text { (1999) } \\
\text { Esta tesis. }\end{array}$ \\
\hline Uarq-FPV & $\begin{array}{l}\text { Rodados chicos a } \\
\text { grandes de sílices, } \\
\text { basaltos y riolitas. } \\
\text { Calcedonias de filón } \\
\text { al norte (Arroyo } \\
\text { Verde) }\end{array}$ & $\begin{array}{l}\text { Guijarros y } \\
\text { guijones de } \\
\text { basalto y } \\
\text { sílices. }\end{array}$ & $\begin{array}{l}\text { Lascas } \\
(88,3 \%) \\
\text { Láminas } \\
(6,9 \%) \\
\text { Núcleos } \\
(4,6 \%)\end{array}$ & $\begin{array}{l}\text { Mediano } \\
(51 \%) \\
\text { Grande } \\
(28 \%) \\
\text { Pequeño } \\
(21 \%)\end{array}$ & $\begin{array}{l}\text { Microrretoque } \\
(26 \%) \\
\text { Retoque } \\
(36 \%) \\
\text { Tallasimple } \\
(37 \%) \\
\text { Bifacialidad } \\
\text { asociada a puntas }\end{array}$ & $\begin{array}{l}\text { Media } \\
(35 \%)\end{array}$ & Pedunculadas & $\begin{array}{l}\text { Pesas líticas y un } \\
\text { rompecráneos. }\end{array}$ & $\begin{array}{l}\text { Gómez Otero (2006). } \\
\text { Esta tesis }\end{array}$ \\
\hline
\end{tabular}

Tabla 9.9. Comparación de rasgos tecnológicos básicos entre las costas bonaerense, la nordpatagónica y las dos unidades espaciales del área de estudio. 


\section{Evaluación de las convergencias y divergencias entre las costas bonaerense, nordpatagónica y del área de estudio}

De acuerdo con los datos consignados en la tabla, se puede observar que tanto la costa pampeana como la nordpatagónica comparten la mayor parte de los rasgos tecnológicos básicos con el área de estudio: uso predominante de los guijarros locales; el empleo variable aunque frecuente de la talla bipolar; la producción de lascas como formas bases; una importante proporción de reserva de corteza en los productos de talla; la preponderancia de tamaños artefactuales mediano-pequeños y la formatización preponderante de los instrumentos mediante retoque o microrretoque marginal unifacial. En primer lugar, salvo en la costa rionegrina, todos estos sectores presentan una base regional de recursos líticos caracterizada por la abundancia y amplia distribución de fuentes secundarias de guijarros y en menor medida guijones, de los cuales los más adecuados para la talla son de basalto y/o de sílices. En cuanto a la costa rionegrina, la diferencia con el resto es la variedad litológica superior y el rango de tamaños más amplio entre los instrumentos. Esto se debería a que en esta costa, además de los rodados hay fuentes primarias de materias primas líticas de muy buena calidad para la talla. Justamente, en el área de estudio estos rasgos sólo fueron observados en la zona de Arroyo Verde, que presenta la misma base de recursos líticos. Por lo tanto, todos estos rasgos avalarían la Hipótesis IV que propone que las similitudes entre la tecnología lítica del área de estudio y la costa pampeana y norpatagónica se deben a las limitaciones impuestas por el tamaño y la forma en que se presenta la materia prima.

Respecto de los diseños de las puntas de proyectil, en coincidencia con Martínez (20082009) y Prates (2008) se observó que las triangulares apedunculadas son las características en la costa bonaerense y a medida que se avanza hacia el sur los diseños predominantes son los pedunculados. No obstante, la presencia de puntas tanto apedunculadas como pedunculadas en los contextos de la costa norte de Patagonia señala que en este espacio se habría dado una interacción frecuente entre los grupos al norte y al sur de las desembocaduras de los ríos Colorado y Negro. Las diferencias en diseños de los cabezales líticos no se explicarían entonces por la base regional de recursos líticos, que es muy semejante, sino por factores no utilitarios que estarían marcando identidades y/o trayectorias culturales diferentes entre esas poblaciones.

Por último, con respecto al instrumental relacionado a la obtención o procesamiento de recursos marinos hay situaciones distintas entre los sectores. En principio en todo este extenso tramo solamente se halló un rompecráneos en la costa oeste del golfo San Matías (Borella et al. 2015) y otro en la costa sur del golfo Nuevo (Gómez Otero 2006). Tampoco se hallaron pesas 
líticas ni denticulados en la costa bonaerense (Bonomo 2005) y la desembocadura del río Colorado (Martínez 2008-2009). En San Blas sí fueron encontrados pero en poca cantidad, mientras que entre el golfo San Matías y el Nuevo se registraron numerosas pesas líticas y escasos denticulados. Esto está mostrando distintas situaciones que no se pueden tampoco explicar por la base regional de recursos líticos. Es bien conocido que en la costa atlántica continental no hubo culturas marítimas como las del sur de Tierra del Fuego y el archipiélago chileno (Orquera y Gómez Otero 2008); sin embargo, en algunos sectores del litoral los alimentos del mar fueron explotados de manera intensiva y en otros solamente tuvieron un papel complementario o estacional. Las costas más intensivamente utilizadas desde el Holoceno medio son la de San Blas (Eugenio y Aldazabal 2004), la del norte del golfo San Matías (Favier Dubois et al. 2008) y Península Valdés (Gómez Otero 2006). En las tres se comprobó el aprovechamiento regular de moluscos y pinnípedos. Sin embargo, en San Blas hay pocas pesas líticas y denticulados, mientras que en los otros dos sectores abundan las pesas. En el lugar opuesto se ubicaría el litoral bonaerense, para el cual Bonomo (2005) propuso que sólo funcionó como un espacio más en los circuitos anuales de movilidad de grupos del interior pampeano y que durante esas estadías los recursos costeros más utilizados fueron los rodados costeros locales y complementariamente los mamíferos marinos (especialmente pinípedos). En cuanto a la desembocadura del río Colorado, si bien durante el Holoceno tardío final se observó una intensificación en la explotación de peces marinos y fluviales (Stoessel 2012), la dieta predominante fue de base terrestre durante los últimos tres mil años (Martínez 2008-2009). Por lo tanto, la ausencia de pesas líticas estaría mostrando la utilización de implementos de pesca perecederos o que no dejaron registro. En cuanto a la costa del golfo San Matías oeste, Borella et al. (2015) interpretan un uso esporádico, no redundante a lo largo del tiempo, con la probable excepción de algunos sectores puntuales como Islote lobos, Punta Pórfido, Punta Odriozola y Arroyo Verde, donde la señal arqueológica es más intensa. En síntesis, la ausencia o escasez de instrumental en distintos sectores costeros tampoco se vincularía con la base regional de recursos líticos, sino con preferencias sociales que influyeron sobre el papel que los recursos marinos habrían cumplido dentro del modo de subsistencia y/o con técnicas de captura que no dejaron evidencias materiales.

\section{Consideraciones finales y perspectivas}

En esta tesis se realizó el estudio de la organización tecnológica (Nelson 1991) de los cazadores-recolectores que habitaron la costa centro-septentrional de Patagonia. Para conocer las secuencias de producción, desde al abastecimiento hasta el momento de la recuperación de los artefactos se llevaron a cabo distintos estudios: 
- caracterización de la base regional a través de muestreos sistemáticos

- determinación de rocas a través de estudios petrográficos mediante cortes delgados

- desarrollo de un diseño tafonómico

- estudio tecno-morfológico de los conjuntos líticos de sitios arqueológicos de dos unidades de análisis espacial PV y Fuera de PV

- comparación con la tecnología lítica y/o con otros rasgos de la cultura material a partir de la información/datos éditos de otros investigadores que trabajan en las costas pampeanas y patagónicas.

En relación con la selección de las materias primas las más utilizadas por los cazadores fueron las que ofrecen los rodados disponibles en los depósitos secundarios litorales y corresponden a dos tipos principales de materias primas: sílices y basaltos. Le siguen en orden de importancia dos rocas: las calcedonias -que aparecen en muy baja frecuencia en forma de guijarros y también en la zona de Arroyo Verde en forma de tabletas, y los xilópalos que no son locales. La otra roca alóctona utilizada, aunque en escasa proporción, es la obsidiana que ha sido traslada por amplias distancias desde sus fuentes de origen. Los instrumentos elaborados en calcedonias son generalmente más grandes que los rodados locales, debido a la forma en que se presenta la materia prima.

Respecto del uso dado a las materias primas locales se observó que las sílices fueron utilizadas por los cazadores-recolectores tanto para confeccionar filos naturales como artefactos formatizados por talla (en especial, raspadores y puntas de proyectil). Esto se debería a su amplia disponibilidad local y a su muy buena calidad para la talla, asimismo también podría estar relacionado con aspectos no utilitarios ligados a su elección por la variedad de colores y el brillo que presentan esta roca. El basalto, por el contrario fue preferentemente seleccionado en artefactos de baja inversión de energía como lo son los filos naturales, las puntas burilantes y las muescas. En cuanto a las materias primas no locales, la baja proporción de núcleos y desechos externos y el predominio de artefactos formatizados sugieren el ingreso de preformas o formas base y también la introducción de artefactos ya terminados. Las distancias a las fuentes -entre 50 y $450 \mathrm{~km}$ - implicarían la aplicación de estrategias logísticas para su adquisición, cuyos costos variarían según las rocas y la distancia respecto de los diferentes sectores costeros. Su adquisición podría haberse dado mediante aprovisionamiento directo en las fuentes más cercanas o bien indirecto, es decir, por intercambio. De esta manera, los grupos de la costa podrían haber obtenido tales rocas a cambio de materias primas y productos marinos (valvas en estado natural, artefactos sobre valva, mariscos secos y/o grasa de lobos marinos, entre otras). La posesión de estas rocas exóticas no parece haber sido motivada por razones utilitarias o 
tecnológicas, ya que esas necesidades podían ser adecuadamente cubiertas por las locales, como los basaltos y las sílices. Por lo tanto, se interpreta que fueron seleccionadas para tecnologías de prestigio que permitieran diferenciar socialmente a algunos individuos durante su vida $\mathrm{y}$ alianzas estratégicas políticas y económicas (Gómez Otero 2003).

En síntesis, sobre la base de los resultados hasta aquí presentados se da por cumplido el primer enunciado de la Hipótesis I que propone que los cazadores recolectores del área de estudio aprovecharon de manera prioritaria las rocas locales disponibles de manera abundante en las cercanas fuentes secundarias de rodados. En cuanto al segundo enunciado de la hipótesis, sólo se cumplió parcialmente ya que la explotación expeditiva de las rocas locales únicamente se observó en los basaltos y las riolitas; no así en las sílices que, al igual que las rocas alóctonas, fueron aprovechadas para la elaboración de instrumentos con mayor inversión de trabajo.

En relación con la segunda hipótesis, se comprobó que la técnica bipolar fue casi exclusivamente aplicada para la talla de nódulos pequeños y medianos provenientes de guijarros de rocas de calidad muy buena a excelente como sílices, basaltos, calcedonias, xilópalos y obsidianas. No se observó talla bipolar en nódulos pequeños o medianos de calidad regular, por ejemplo riolitas. Por lo tanto, la hipótesis 2 estaría contrastada positivamente en lo que respecta al tamaño, aunque sobre la base de los datos antes presentados y discutidos se pudo agregar que esta variable no fue la única seleccionada para la aplicación frecuente de la talla bipolar, sino también la forma en que se presentan los nódulos (rodados con forma oval, achatados, y espesos) y la calidad de la materia prima (muy buena a excelente).

Respecto de la tercera hipótesis, que propone que en tiempos tardíos se habría incrementado el intercambio de rocas y diseños artefactuales con otras áreas fuera y dentro de Patagonia, se pudo verificar que fue así. Los intercambios de materias primas líticas, que ya se daban en el Holoceno medio se potenciaron en el Holoceno tardío final, aunque este aumento se expresó sobre todo en la circulación de rocas exóticas suntuarias. En cuanto a los diseños de las puntas de proyectil, se observa claramente que las triangulares apedunculadas se concentran en la costas bonaerense y norpatagónica, mientras que desde el río Negro al sur, las puntas diagnósticas son las pedunculadas. Esto sugiere redes de relación diferentes y que podrían haber funcionado desde muy temprano. No obstante, en el Holoceno tardío se intensificó el intercambio de diseños de puntas de cabezales liticos y de otras tecnologías o bienes al norte y sur de este río lo que se relacionaría con una ampliación en los circuitos de contactos políticos, sociales y económicos. Esto avalaría la hipótesis de aumento en la complejización social para ese período (Gómez Otero 2003, 2006), que habría propiciado el uso y exhibición de estos bienes valiosos y con diseños alóctonos por parte de los miembros con mayor prestigio dentro de los grupos. 
Por último y en relación con la hipótesis IV que propone que las similitudes entre la tecnología lítica del área de estudio y la costa pampeana y norpatagónica se deben a las limitaciones impuestas por el tamaño y la forma en que se presenta la materia prima, la información discutida también permitieron avalarla. Las evidencias estarían dadas por las similitudes tecnológicas en cuanto al uso predominante de rodados, el tamaño mediano-pequeño de los artefactos; la talla bipolar y la producción de lascas como formas bases, aunque estas tecnologías estuvieron inmersas en trayectorias históricas específicas de cada región.

En cuanto a la contrastación con el modelo de Gómez Otero (2006) que propuso que Península Valdés fue un espacio más intensamente utilizado que los sectores costeros adyacentes, la comparación entre unidades arqueológicas de muestreo permitió establecer dos situaciones. Una es la diversidad litológica levemente mayor en la Uarq-FPV (17 tipos de rocas) que en la Uarq-PV (15), aunque en PV la frecuencia de materias primas alóctonas es tres veces superior. La otra es la abundancia promedio de artefactos formatizados por talla, retoque o microrretoque: en PV es de 8,6\% mientras que en FPV es de 3,6\%. Se interpretó que esto se relacionaría con la funcionalidad de los sitios ya que el registro más abundante de bases residenciales en PV indica un uso más diversificado e intenso del espacio que los dos sectores de FPV aquí analizados.

Agenda a futuro

Durante los años de desarrollo de esta tesis he logrado cumplir, aunque en grado variable, con los objetivos generales y particulares planteados. Sin embargo, también he podido reconocer nuevos interrogantes. Uno de ellos es conocer cómo fueron los mecanismos de obtención y modos de utilización de las rocas alóctonas más importantes para la talla: todavía resta establecer las fuentes de algunas variedades de obsidiana, de las calcedonias y de los xilópalos. Esto permitirá contrastar si hubo circuitos de intercambio diferentes al norte y al sur del río Chico de Chubut y determinar la antigüedad y variaciones temporales de estos contactos en el marco de procesos de complejización social. Otro objetivo será indagar sobre la validez de los cuatro agrupamientos de puntas de proyectil microlíticas del norte de Chubut a partir de la ampliación de muestras provenientes de otras zonas de Patagonia central. Un interés especial es evaluar con una base de datos más grande los rasgos diagnósticos y los cambios temporales en la tecnología lítica de la costa y compararlos con los del valle inferior y desembocadura del río Chubut. Para cumplir con esta agenda se analizarán otros conjuntos artefactuales, se continuará con los análisis especializados en muestras naturales y arqueológicas de xilópalos, calcedonias y obsidianas, y se integrarán estos resultados con otras líneas de evidencia como otras tecnologías 
(de la piedra pulida, la cerámica y la malacológica), estudios zooarqueológicos, bioarqueológicos y de representaciones rupestres, entre otros aspectos de la cultura de los cazadores-recolectores que habitaron Patagonia centro-septentrional. 


\section{BIBLIOGRAFÍA}

AGUERRE, A.M, HOROVITZ, L. y V.K. PATIÑO. 1994. Material lítico del Alero Cárdenas capa 2 y su comparación con la capa 3. En Contribución a la arqueología del Río Pinturas, provincia de Santa Cruz. Ediciones Ayllu, Concepción del Uruguay, Argentina

ALBERTI, G. 2013 Manufactura de núcleos y movilidad en la costa norte del golfo San Matías (Río Negro) durante el Holoceno medio y tardío. Tendencias teórico-metodológicas y casos de estudio en la arqueología de la Patagonia, Museo de Historia Natural de San Rafael p. 19 - 26

ALBERTI, J. y M. CARDILLO. 2013. Fuentes primarias y secundarias de materias primas líticas en la costa oeste del golfo San Matías (Río Negro, argentina). Una primera aproximación a su variabilidad espacial. En Libro de resúmenes del XVIII Congreso Nacional de Arqueología Argentina, pp: 67-68. UNLa Rioja y INCIHUSA-CONICET, La Rioja.

ALBERTI, J., CARDILlO M. y C. FAVIER-DUBOIS. 2015. Fuentes de materias primas líticas en la costa del golfo San Matías (provincia de Río Negro, Argentina). Una síntesis regional. En Materias primas líticas en Patagonia. Localización, circulación y métodos de estudio de las fuentes de rocas de la Patagonia argentino-chilena, eds. J. Alberti and V. Fernandez, Intersecciones en Antropología, Dossier 2: 27 - 38.

ALBERTI, J., M. CARDILLO; C. STERN y C. FAVIER DUBOIS 2016. New Results Concerning expanded networks of Obsidian Procurement in San Matia gulf, Río Negro, Patagonia Argentina. The Journal of Island and Coast ArchaeologyDOI:10.1080/15564894 2016.1163757.

ALDAZABAL, V. E. EUGENIO y M. SILVEIRA. 2010. Arqueología del sector costero al sur de Bahía de San Blas: sitio Las Olas 11. Revista de Estudios Marítimos y Sociales. GesMar- UMdP.

ALDAZABAL, V. N. WEILER y E. EUGENIO. 2004. Una perspectiva geoarqueológica para comprender la ocupación humana en la costa central de la provincia de Buenos Aires. Intersecciones en Antropología 5: 29-38.

ÁlvarEZ, M. 2011. Puntas de arma del extremo sur de Patagonia: algunas consideraciones sobre diseño y contexto de uso. En Armas prehispánicas: múltiples enfoques para su 
estudio en Sudamérica, editado por Damián L. Bozzuto y Jorge Gabriel Martínez, pp. 15-36. Fundación de Historia Natural Félix de Azara, Buenos Aires.

AMBRÚSTOLO, P. 2013. Estudio de las estrategias de aprovisionamiento y utilización de los recursos líticos por grupos cazadores recolectores en la Costa Norte de Santa Cruz (Patagonia Argentina). Tesis Doctoral inédita. Facultad de Ciencias Naturales y Museo. Universidad Nacional de La Plata, La Plata.

AMBRÚSTOLO P. A. CASTRO; M. A. ZUBIMENDI, L. MAZZITELLI. 2011. Instrumentos líticos con filos denticulados en la costa norte de santa cruz. Un análisis tecnofuncional. Cazadores-recolectores del Cono Sur 4: 79-93.

AMBRÚSTOLO, P., V. TROLA y L. MAZZITELLI. 2009. Fuentes potenciales de aprovisionamiento de recursos líticos al sur de la Ría Deseado (Santa Cruz, Argentina). En Arqueología de la Patagonia: una mirada desde el último confin, editado por M. Salemme, F. Santiago, M. Álvarez, E. Piana, M. Vásquez y M. E. Mansur, pp. 283-289. Utopías, Ushuaia.

AMBRÚSTOLO P., M.A. ZUBIMENDI y C. STERN. 2012. Explotación de obsidiana negra en la costa norte de Santa Cruz (Patagonia Argentina). Cazadores Recolectores del Cono Sur 6: 73-81

ANDREFSKY, W. JR. 1995. The Geological Occurrence of Lithic and Stone Tool Production Strategies. Geoarchaelogy 9 (5): 375-391.

APOLINAIRE, E. y C. SILVA. 2012. Estudios de tecnología lítica en el sitio arqueológicoAlfar (partido de General Pueyrredón, provincia de Buenos Aires). En Intersecciones en Antropología, pp. 525 - 536.

ARAGON, E. y N. V. FRANCO. 1997. Características de rocas para la talla por percusión y propiedades petrográficas. Anales del Instituto de la Patagonia (Serie Ciencias Humanas) 25: 87-199.

ARMENTANO, G. 2014. Arqueología del curso inferior del Río Colorado. Estudio tecnológico de las colecciones líticas de Norpatagonia Oriental durante el Holoceno tardío. Departamentos de Villarino y Patagones, Provincia de Buenos Aires. Argentina”. Tesis doctoral inédita. FACSO-UNICEN y Université de Paris Ouest Nanterre- La Défense, Francia, 543 páginas.

ARRIGONI, G. 2002. Los ceramistas prehistóricos del valle del río Desaguadero, Parque Nacional Los Alerces, provincia del Chubut. Relaciones de la Sociedad Argentina de Antropología XXVII: 395-412.

ARRIGONI, G., M. ANDRIEU y C. BAÑADOS. 2008. Arqueología de cazadores-recolectores prehistóricos en la costa central del golfo San Jorge. En Arqueología de la costa patagónica. Perspectivas para la conservación, editado por Isabel Cruz y María 
Soledad Caracotche, pp. 91-107, Universidad Nacional de la Patagonia AustralSubsecretaría de Cultura de la Provincia de Santa Cruz, Río Gallegos.

ARRIGONI, G. y C. PALEO. 1991. Investigaciones arqueológicas en la región central del golfo San Jorge (desde Punta Peligro, Pcia. del Chubut hasta el límite con la Pcia. de Santa Cruz). Shincal 3, T.3: 206-210. Catamarca.

ASCHERO, C. 1975. Ensayo para una clasificación morfológica de artefactos líticos aplicada a estudios tipológicos comparativos. Informe al CONICET, Buenos Aires. MS

ASCHERO, C.1983 a. Ensayo para una clasificación morfológica de artefactos líticos aplicada a estudios tipológicos comparativos. Informe al CONICET (revisión), Buenos Aires. MS.

ASCHERO, C.; C. PEREZ DE MICOU; M. ONETTO; C. BELlELli; L. NACUZZI; A. FISHER 1983. Arqueología del Chubut. El Valle de Piedra Parada. Gobierno de la Provincia del Chubut, Serie Humanidades. Rawson.

ASCHERO, C.; C. BELLELLI; C. FERNANDEZ LANNOT; A. FISHER; M. V. FONTANELLA; J. GÓMEZ OTERO; C. PÉREZ DE MICOU 2006. Un análisis tipológico y técnico-morfológico de siete sitios del complejo patagoniense. En El modo de hacer las cosas. Artefactos y ecofactos en Arqueología, editado por Cecilia Pérez de Micou, pp. 21-34, Departamento de Ciencias Antropológicas, Facultad de Filosofia y Letras, UBA,

ASCHERO, C., C. BELLELli y M.V. FONTANELLA. 1983-85. La industria lítica de la secuencia arqueológica de Chacra Briones (Dique Ameghino, Chubut). Excavaciones de O.F.A. Menghin 1956-1959. Cuadernos del Instituto Nacional de Antropología 10: 319-338.

ASCHERO, C. y S. HOCSMAN. 2004. Revisando cuestiones tipológicas en torno a la clasificación de artefactos bifaciales. En Temas de Arqueología, Análisis lítico, A. Acosta, D. Loponte y M. Ramos (Eds.), pp. 7-25, Universidad de Luján.

BABOT, M.P. 2004. Tecnología y utilización de artefactos de molienda en el Noroeste prehispánico. Tesis de Doctorado en Arqueología. Facultad de Ciencias Naturales e Instituto Miguel Lillo. Universidad Nacional de Tucumán, San Miguel de Tucumán

BAGOLINI, B. 1968. Richerche sulle dimensioni dei manuffati litici preistorici non ritoccati. Annalli dell'Universitá de Ferrara, n. ${ }^{\circ} 10.195-219$. Ferrara.

BAMFORTH, D. 1986. Technological Efficiency and Tool Curation. American Antiquity 51(1): 38-50.

BAMFORTH, D. y N. FINLAY 2008. Introduction: Archaeological Approaches to Lithic Production Skill and Craft Learning. Journal of Archaeological Method and Theory $15: 1-27$. 
BANEGAS, A. y M.S. GOYE. 2012. Análisis tecnomorfológico comparativo de puntas de proyectil microlíticas de la costa e interior de Patagonia centro-septentrional. Póster presentado en el Simposio Paisajes Arqueológicos del Holoceno Tardio: Interacciones entre seres humanos y entorno. Universidad Nacional de Rosario, Mayo 2012.

BANEGAS, A. y M.S. GOYE. 2015. Spatial and Temporal Variability in the Use of Lithic Raw Materials for flaked stone Technology in the Northeast of Chubut Province (North Patagonia) during Late Holocene. En Archaeology of coastal Hunter-Gatherer Occupations in the Southern Cone, editado por P. Ambrústolo and M.A. Zubimendi, Quaternary International 373: 55-62.

BANEGAS, A., J. GÓMEZ OTERO, S. GOYE y N. RATTO. 2014. Cabezales líticos del Holoceno tardío en Patagonia meridional: diseños y asignación funcional. Magallania 42(2):155-174.

BANEGAS, A., R. PUJANA y J GÓMEZ OTERO. 2016 Caracterización tecnológica de xilópalos de la costa centro-septentrional de Patagonia: tendencias temporales y potenciales fuentes de aprovisionamiento. En prensa en Arqueología de la Patagonia: de Mar a Mar, pp. 407-416, CIEP, Coyhaique.

BANEGAS, A., S. GOYE y J. GÓMEZ OTERO. 2015. Caracterización regional de recursos líticos en el nordeste de la provincia del Chubut (Argentina). En Materias primas líticas en Patagonia. Localización, circulación y métodos de estudio de las fuentes de rocas de la Patagonia argentino-chilena, eds. J. Alberti and V. Fernandez, Intersecciones en Antropología, Dossier 2: 39-50.

BAYÓN, C., G.MARTÍNEZ, G. ARMENTANO Y C.SCABUZZO. 2004. Arqueología del valle inferior del río Colorado.El sitio La Primavera. Intersecciones en Antropología 5: 39-53.

BAYÓN, C., FRONTINI R. y R. VECCHI. 2011. Middle Holocene settlements on coastal dunes, southwest Buenos Aires Province, Argentina. Quaternary International .

BAYÓN, C. y G. POLITIS. 1996. Estado actual de las investigaciones en el sitio Monte Hermoso I (prov. de Buenos Aires). Arqueología 6: 83-115.

BEESKOW, A.M., H.F. DEL VALLE y C.M. ROSTAGNO. 1987. Los sistemas fisiográficos de la region árida y semiárida de la provincia del Chubut. Delagación Regional Patagonia, SECyT, Puerto Madryn.

BELARDI, J.B. 2004. Más vueltas que una greca. En Contra Viento y Marea. Arqueología de la Patagonia, editado por T. Civalero, P. Fernández y G. Guraieb, pp.591-603, Instituto Nacional de Antropología y Pensamiento Latianoamericano, SAA. Buenos Aires. 
BELLELLI, C., GURÁIEB, A. G., y J, A GARCIA. 1985-1987. Propuesta para el Análisis y Procesamiento por Computadora de Desechos de Talla Lítica (DELCO - Desechos Líticos Computarizados). Arqueología Contemporánea, Vol. II (1):36-47.

BELLELLI, C. y F. X. PEREYRA. 2002 Análisis geoquímicos de obsidiana: distribución, fuentes y artefactos arqueológicos en el Noroeste del Chubut (Patagonia Argentina).Werken. 3: 99-118.

BELLISIO, N. B., R. B. LOPEZ Y A. TORNO, 1979. Peces marinos patagónicos. Secretaría marítima, pp. 1-279.

BETTINGER, R.L. y M.A. BAUMHOFF. 1982.The Numic Spread: Great Basin cultures in competition. American Antiquity 47 (3): 485-503.

BETTINGER, R. L. y J. EERKENS. 1999. Point Typologies, Cultural Transmission, and the Spread of Bow-and-Arrow Technology in the Prehistoric Great Basin. American Antiquity 64(2):231-242.

BINFORD, L. 1979. Organization and formation processes: looking at curated technologies. Journal of Archaeological Research 35: 255-270.

BINFORD, L.R. 1980. Willow Smoke and Dog's tails: Hunter-Gatherer Settlement Systems and Archaeological Site Formation. American Antiquity 45 (1): 4-20.

BINFORD, L. 1989. Debating Archaeology. Academic Press, New York.

BLEED, P. 2001. Trees or Chains, Links or Branches: Conceptual Alternatives for Consideration of Stone Tool Production and Other Sequential Activities. Journal of Archaeological Method and Theory, Vol. 8, No. 1. 101-127.

BIRD, J. 1993. Viajes y Arqueología en Chile Austral. Editado por J. Hyslop, Ediciones de la Universidad de Magallanes. Punta Arenas.

BONOMO, M. 2005. Costeando las llanuras. Arqueología del litoral marítimo pampeano. Sociedad Argentina de Antropología, Colección Tesis Doctorales, Buenos Aires.

BONOMO, M. 2006. Un acercamiento a la dimensión simbólica de la cultura material en la región pampeana. Relaciones de la Sociedad Argentina de Antropología 31: 89-115.

BONOMO, M. 2007. "Un acercamiento a la dimensión simbólica de la cultura material en la región pampeana”. Relaciones de la Sociedad Argentina de Antropología, XXXI

BONOMO, M., C. LEON, L. TURNES y E. APOLINAIRE. 2008. Nuevas investigaciones sobre la ocupación prehispánica de la costa pampeana en el Holoceno tardío: el sitio arqueológico Claromecó 1 (Pdo. de Tres Arroyos, Pcia. de Bs. As.). Intersecciones en Antropología; pp. 25 - 41

BONOMO, M. C. SCABUZZO y C. LEON. 2013. Cronología y dieta en la costa atlántica pampeana, Argentina. Intersecciones en Antropología, pp. 5 - 5 
BONOMO, M. y C. LEÓN. 2010. Un contexto arqueológico en posición estratigráfica en los médanos litorales. El sitio Alfar (Pdo. Gral. Pueyrredón, Pcia. Bs. As.). En Mamül Mapu: pasado y presente desde la arqueología pampeana. Tomo II: 29-46. Editoral Libros del Espinillo. La Pampa.

BONOMO, M. y A. MATARRESE. 2012. El estado actual de las investigaciones arqueológicas en la localidad Nutria Mansa. Nuevos aportes de los artefactos picados y/o abradidos. Revista Arqueología. pp. 153 - 180.

BONOMO, M. y L. PRATES. 2014. La explotación de depósitos secundarios de rodados en el curso medio del río negro y el litoral marítimo pampeano. En Lithic Artefacts, Mobility and Site Functionality: Problems and Perspectives, editado por P. Escola y S. Hocsman. BAR International Series.

BORELLA , F. y M. CARDILLO 2011 (Eds.). Arqueología de Pescadores y marisqueadores en nordpatagonia. Descifrando un registro de más de 6.000 años. Editorial Dunquen.

BORELlA. F., M. CARDILlO, C. FAVIER DUBOIS y J. ALBERTI. 2015. Nuevas investigaciones arqueológicas entre punta Pórfido y punta Odriozola: implicancias para el entendimiento de la dinámica de las ocupaciones humanas en la costa oeste del golfo San Matías (Río Negro). Relaciones de la Sociedad Argentina de Antropología 40 (1): 233-252.

BÓRMIDA, M. 1964. Arqueología de la costa Nordpatagónica. Trabajos de Prehistoria XIV: $1-108$.

BORRAZZO, K. 2006. Tafonomia lítica en dunas: una propuesta para el análisis de los artefactos líticos. Intersecciones en Antropología 7:247-261.

BORRAZZO, K. 2007. Aporte de la tafonomía lítica al estudio de distribuciones artefactuales en ambientes lacustres: el caso del sistema lacustre al sur del lago Argentino. Comechingonia Virtual 3:132-153. www.comechingonia.com.

BORRAZZO, K. 2010. Arqueología de los esteparios fueguinos. Tesis Doctoral inédita. Facultad de Filosofía y Letras, Universidad de Buenos Aires, Buenos Aires. (Ms).

BORRAZZO, K. 2011. Tafonomía lítica en la estepa patagónica: experiementación y registro arqueológico de superficie. En Bosques, Montañas y cazadores: investigaciones arqueológicas en Patagonia Meridional, compilado por L.A Borrero y K. Borrazzo, pp.127-153. CONICET-IMHICIHU. Buenos Aires.

BORRERO, L.A. y S. CAVIGLIA. 1978. Estratigrafía de los concheros de Bahía Solano: campaña 197677. Comunicación presentada en el V Congreso Nacional de Arqueología Argentina, San Juan. (Ms.)

BORRERO, L.A., R. BARBERENA, N. FRANCO, F.M. MARTÍN, S. CARACOTCHE, L. MANZI, J. CHARLIN y K. BORRAZZO. 2008. Plan de monitoreo del Parque 
Nacional Monte León. La información de superficie. En Arqueología de la costa patagónica. Perspectivas para la conservación, editado por Isabel Cruz y María Soledad Caracotche (eds), pp.161, 172, Universidad Nacional de la Patagonia Austral Subsecretaría de Cultura de la Provincia de Santa Cruz. Río Gallegos.

BOSCHIN, M.T. y G. MASSAFERRO. 2014. La obsidiana: una señal geoarqueológica del alcance de las relaciones sociales en Patagonia pre y post-hispánica. En Arqueología precolombina en Cuba y Argentina: esbozos desde la periferia, editado por Odlanyer Hernández de Lara y Ana María Rocchietti, pp. 227-258. -Aspha, Ciudad Autónoma de Buenos Aires

BRUNET, R. 1987. El yacimiento protolítico de Punta Atlas del Chubut, Argentina. Folias Chubutianas- Sección Arqueológica, Año 1 (1), 49 págs., Puerto Madryn.

CAMUFFO, D. 1995. Physical weathering of stones. The Science of the Total Environment 167:4-14.

CABRERA, A.L. y J. YEPES. 1960. Mamíferos Sudamericanos. Editorial Ediar, Buenos Aires.

CARDEN, N. y G. MARTÍNEZ. 2013. Imágenes sobre cerámicas y cáscaras de huevo de Rheideae: sistemas de comunicación visual en la transición pampeano-patagónica oriental. En Libro de resúmenes del XVIII Congreso Nacional de Arqueología Argentina, pág. 266. UNLa Rioja y INCIHUSA-CONICET, La Rioja.

CARDEN, N. y G. MARTINEZ. 2014. Diseños fragmentados. Circulación social de imágenes sobre huevos de Rheidae en Pampa y Nordpatagonia. En Boletín del Museo Chileno de Arte Precolombino 19 (2): 55-75.

CARDICH, A.; L. A. CARDICH y A. HAJDUCK 1973. Secuencia arqueológica y cronológica radiocarbónica de la cueva 3 de los Toldos (Santa Cruz, Argentina). Relaciones de la Sociedad Argentina de Antropología (Nueva Serie) VII: 85-123.

CARDILLO, M. y J. ALBERTI. 2014. The evolution of projectile points and technical systems. A case from Northern Patagonian coast (Argentina). Journal of Archaeological Science: Reports 2: 612-623.

CARDILLO, M. y SCARTASCINI. 2007. Tendencias observadas en las estrategias de explotación de recursos líticos en el Golfo de San Matías, provincia de Río Negro, Argentina. En Arqueología de Fuego- Patagonia. Levantando piedras, desenterrando huesos... y develando arcanos, editado por Morello, F.,Martinic, M., Prieto, A., Bahamonde, G., pp. 117-127. Ediciones CEQUA, Punta Arenas,

CARDILLO, M. y F. SCARTASCINI. 2011. Diversidad artefactual y explotación de materias primas en la costa norpatagónica. Golfo San Matías, Río Negro. En Arqueología de pescadores 
y marisqueadores en Nordpatagonia. Descifrando un registro de más de 6000 años, compilado por F. Borella y M. Cardillo, pp. 68-86. Buenos Aires, Dunken.

CASAMIQUELA, R. 1990. Los pueblos indígenas. Ciencia Hoy 2 (7): 18-28. Buenos Aires.

CASTRO, A. y J.E. MORENO. 1998. Cabo Tres Puntas, un sitio del Holoceno medio en la costa de Patagonia continental. Palimpsesto 5:135-139.

CASTRO, A., J.E. MORENO, K. MARTINELli y F. PEPE. 2000. Restos faunísticos, artefactos líticos: más información sobre la costa norte de Santa Cruz. En Desde el País de los Gigantes. Perspectivas arqueológicas en Patagonia, pp. 551-561, Universidad Nacional de la Patagonia Austral, Río Gallegos.

CASTRO, A.; J. E. MORENO; M.ZUBIMENDI; M. ANDOLFO; B. VIDELA; L. MAZZITELLI, S. BOGAN Y P. AMBRUSTOLO. 2008. Cazadores recolectores costeros: interpretaciones desde el registro arqueológico de la costa norte de Santa Cruz. En Arqueología de la costa patagónica. Perspectivas para la conservación, editado por Isabel Cruz y María Soledad Caracotche Río Gallegos, Universidad Nacional de la Patagonia Austral - Subsecretaría de Cultura de la Provincia de Santa Cruz, pp. 129145.

CATTANEO, G. 2004. Desarrollo metodológico para el estudio de fuentes de aprovisionamiento lítico en la meseta central santacruceña, Patagonia argentina. Estudios Atacameños 28: 105-119.

CAVIGLIA, S. y L, BORRERO. 1978. Bahía Solano: su interpretación paleoetnozoológica en un marco regional. Comunicación presentada en el V Congreso Nacional de Arqueología Argentina, San Juan. (Ms.)

CAVIGLIA, S., L.A. BORRERO, M. CASIRAGHI, L.C. GARCÍA y V. HORWITZ. 1982 (Ms.). Nuevos sitios arqueológicos para la región de Bahía Solano (Chubut). Comunicación presentada en el VII Congreso Nacional de Arqueología Argentina, San Luis.

CARACOTCHE, M.S.; I. CRUZ; S. ESPINOSA; F. CARBALLO Y J. BELARDI. 2005. "Rescate arqueológico en el Parque Nacional Monte León (Santa Cruz, Argentina)", en Magallania, Vol. 33, $\mathrm{N}^{\circ}$ 2, pp.143-163.

CARACOTCHE, M. S., F. CARBALlO; J. BELARDI, I. CRUZ Y S. ESPINOSA. 2008. Parque Nacional Monte León (Santa Cruz): un enfoque desde la conservación. En Arqueología de la costa patagónica. Perspectivas para la conservación, editado por Isabel Cruz y María Soledad Caracotche (eds), pp. 147-159. Universidad Nacional de la Patagonia Austral - Subsecretaría de Cultura de la Provincia de Santa Cruz Río Gallegos, 
CARBALLO MARINA, F. y B. ERCOLANO. 2008. Paisaje arqueológico entre el estuario del Río Gallegos y Chorrillo de los Frailes, extremo sur de Santa Cruz. En Arqueología de la costa patagónica. Perspectivas para la conservación, editado por Isabel Cruz y María Soledad Caracotche, pp. 195-212, Universidad Nacional de la Patagonia AustralSubsecretaría de Cultura de la Provincia de Santa Cruz. Río Gallegos.

CARBALLO MARINA, 2007. La cuenca superior del río Santa Cruz: las poblaciones humanas y el uso del espacio. Tesis doctoral presentada a la Facultad de Ciencias Naturales UNLP. Ms

CIOCCO, N.F., M.L. LASTA y C. BREMEC. 1998. Pesquerías de bivalvos: mejillón, vieiras (tehuelche y patagónica) y otras especies. En El Mar Argentino y sus recursos pesqueros, T. 2: 143-166, INIDEP, Mar del Plata.

CHARLIN J. 2009. Estrategias de aprovisionamiento y utilización de las materias primas líticas en el campo volcánico Pali Aike (Prov. de Santa Cruz, Argentina). Tesis Doctoral, Editorial BAR International Series 1901.

CHARLIN, J. y M. CARDILLO. 2010. La diversidad de los conjuntos líticos en el extremo sur de Patagonia meridional: una comparación costa-interior. Arqueología de Pali Aike y Cabo Vírgenes (Santa Cruz, Argentina), CONICET-IMHICIHU, Dunken, pp. 81 - 102

CHARLIN, J y R. GONZÁLEZ-JOSÉ. 2012. Size and shape variation in Late Holocene projectile points of Southern Patagonia: a geometric morphometric study. American Antiquity 77 (2): 221-242.

CODiGnOTTO, J. O. 1983. Depósitos elevados y/o de acreción Pleistoceno-Holoceno en la costa Fueguino-Patagónica. En Actas del simposio "Oscilaciones del nivel del mar durante el último hemiciclo deglacial en la Argentina”, pp. 12-26, Mar del Plata.

CODIGNOTTO, J.O. 1987. Glosario geomorfológico marino. Serie B Didáctica $y$ Complementaria Nro 17, Asociación Geológica Argentina. Buenos Aires.

CODIGNOTTO, J. O. y R. R. KOKOT. 1988. Evolución geomorfológica holocena en Caleta Caldés, Chubut. Revista de la Asociación Geológica Argentina 43(4):474-481.

CODIGNOTTO, J.O., R.R. KOKOT y S. MARCOMINI. 1992. Neotectonism and sea-level changes in the coastal zone of Argentina. Journal of Coastal Research 8: 125-133.

COLOMBO, M. y N. FLEGENHEIMER. 2013 La elección de rocas de colores por los pobladores tempranos de las sierras de Lobería (Buenos Aires, Argentina). Nuevas consideraciones desde las canteras. Boletín del Museo Chileno de Arte Precolombino 18: $125-137$.

CORTÉS, J.M. 1981.Estratigrafía cenozoica y estructura al oeste de la península de Valdés, Chubut. Consideraciones tectónicas y paleogeográficas. Revista de la Asociación Geológica Argentina, 36 (4): 424-445. 
CORTÉS, J.M. 1987. Descripción geológica de la Hoja 42 h, "Puerto Lobos", Provincia del Chubut. Boletín 202 de la Dirección Nacional de Minería y Geología, Secretaría de Minería, República Argentina.

CRIVELLI MONTERO, E. , D.E. CURZIO y M.J. SILVEIRA. 1993. La estratigrafía de la Cueva Traful I (provincia de Neuquén). En Praehistoria No 1: 9-161, CONICET, Buenos Aires, Argentina

CRUZ, I. y S. CARACOTCHE. 2008. (Eds.) Arqueología de la costa patagónica. Perspectivas para la conservación, Universidad Nacional de la Patagonia Austral-Subsecretaría de Cultura de la Provincia de Santa Cruz. Río Gallegos.

DOBRES, M.A. 2000. Technology and Social Agency. Blackwell, Great Britain.

DONG Z, BRENNAN A, LIU N, YARDEN Y, LEFKOWITZ G, MIRSKY R, y JESSEN KR. 1995. Neu differentiation factor is a neuron-glia signal and regulates survival, proliferation, and maturation of rat Schwann cell precursors. Neuron 15: 585-596.

ERICSON, J. 1984. Towards the Analysis of Lithic Reduction Systems. In Prehistoric Quarries and Lithic Production, eds. J. E. Ericson and B. Purdy, 11-22. Cambridge: Cambridge University Press.

ESCALADA, F. A. 1949. El complejo "Tehuelche”. Estudios de etnografía patagónica. Instituto Superior de Estudios patagónicos. Impreso y Casa Editorial Coni. Buenos Aires.

ESCOFET, A.M., J.M. ORENSANZ, S.R. OLIVIER y V. SCARABINO. 1978. Biocenología bentónica del golfo San Matías (Río Negro, Argentina): metodología, experiencias y resultados del estudio ecológico de un gran espacio geográfico en América Latina. Anales del Centro Científico del Mar y Limnológico 5 (1): 59-82, Universidad Nacional Autónoma de México.

EUGENIO, E. y V. ALDAZÁBAL. 2004. Los cazadores-recolectores del litoral marítimo del área de Bahía de San Blas, Provincia de Buenos Aires. En Contra Viento y Marea. Arqueología de Patagonia, compilado por M.T. Civalero, P. Férnández y A.G. Guráieb, pp. 687-700, Instituto Nacional de Antropología y Pensamiento Latinoamericano y Sociedad Argentina de Antropología.

FASANO, J.L., ISLA, F.I. y SCHNACK, E.J. 1983. Un análisis comparativo sobre la evolución de ambientes litorales durante el Pleistoceno tardío-Holoceno: Laguna Mar Chiquita (Buenos Aires)-Caleta Valdés (Chubut). Simposio Oscilaciones del nivel del mar durante el último hemiciclo deglacial en la Argentina. IUGSUNESCO No 61, Actas: 2747. Mar del Plata.

FAVIER DUBOIS, C., F. BORELLA, L.M. MANZI, M. CARDILLO, S. LANZELLOTTI, F. SCARTASCINI., C. MARIANO y E. BORGES VAZ. 2008. Aproximación regional al 
registro arqueológico de la costa rionegrina. En Arqueología de la Costa Patagónica. Perspectivas para la conservación Arqueología de la costa patagónica. Perspectivas para la conservación, editado por Isabel Cruz y María Soledad Caracotche, pp. 51-70, Universidad Nacional de la Patagonia Austral-Subsecretaría de Cultura de la Provincia de Santa Cruz, Río Gallegos.

FAVIER DUBOIS, C. M., F. BORELLA y R. H. TYKOT. 2009. Explorando tendencias temporales en el uso del espacio y los recursos en el litoral rionegrino (Argentina) durante el Holoceno medio y tardío. En Arqueología de Patagonia: una mirada desde el último confin, editado por M. Salemme, F. Santiago, M. Alvarez, E. Piana, M. Vázquez y M. E. Mansur, pp. 985-997. Editorial Utopias, Ushuaia. Tierra del Fuego.

FAVIER DUBOIS C. M. y R. KOKOT. 2011. Changing scenarios in Bajo de la Quinta (San Matías Gulf, Northern Patagonia, Argentina): Impact of geomorphologic processes in subsistence and human use of coastal habitats. Quaternary International 245:103-110.

FAVIER DUBOIS, C.M. y F.L. SCARTASCINI. 2012. Intensive fishery scenarios on the North Patagonian coast (Río Negro, Argentina) during the Mid-Holocene. Quaternary International 256: 62-70.

FAVIER DUBOIS, C. y BATRES, D. 2011. Estudios de isótopos estables y elementos traza en valvas arqueológicas de la costa norte del golfo San Matías (Río Negro); alcances y limitaciones. En Libro de resúmenes del II Congreso Nacional de Zooarqueología Argentina. Facultad de Ciencias Sociales UNCPBA-CONICET.

FERNÁNDEZ, J. 1988-1990. Arqueología de la Cueva Haichol. En Anales de Arqueología y Etnología. Universidad Nacional de Cuyo, Facultad de Filosofía y letras, Mendoza, Argentina.

FIDALGO, F. y J.C. RIGGI. 1970. Consideraciones geomórficas y sedimentológicas sobre los Rodados Patagónicos. Asociación Geológica Argentina 25:430-443.

FIORE, D. y BORELLA, F.2010. Geometrías delicadas: Diseños grabados en cáscaras de huevo de Rheidae recuperados en la costa norte del Golfo San Matías, Río Negro. Intersecciones en Antropología 11(2):277-293.

FLEGENHEIMER, N. y C. BAYÓN. 1999. Abastecimiento de rocas en sitios pampeanos tempranos: Recolectando colores. En Los Tres Reinos: Prácticas de Recolección en el Cono Sur de América, C. Aschero, A.Korstanje y P.M. Vuoto (Eds.), pp. 95-107, Ediciones Magna Publicaciones, Tucumán.

FRANCO, N. V. 2002. Estrategias de utilización de la cuenca superior del río Santa Cruz. Tesis doctoral inédita, Facultad de Filosofía y Letras, Universidad de Buenos Aires.

FRANCO Y BORRERO 1999. Metodología de análisis de la estructura regional de recursos líticos. En En los Tres Reinos: Prácticas de Recolección en el Cono Sur de América, pp. 
27-37. Ed. C. A. Aschero, M. A. Korstanje y P. M. Vuoto, Instituto de Arqueología y Museo, FCN e IML, Universidad Nacional de Tucumán.

FRANCO, N.V., J. GÓMEZ OTERO, G. GURÁIEB, M.S. GOYE, N. CIRIGLIANO y A. BANEGAS. 2010. Variaciones espaciales en diseños de puntas pedunculadas medianas en Patagonia argentina: una nueva aproximación. En Actas del XVIII CNAA, Arqueología Argentina en el Bicentenario de la Revolución de Mayo. T.1:281-286, FFyL (UNCu), INCIHUSA-CONICET, Mendoza.

GELOS, E.M., J.O. SPAGNUOLO y R.A. SCHILLIZZI.1994. Las unidades morfológicas de la costa oeste del Golfo San Matías y su evolución. Revista de la Asociación Geológica Argentina 47 (4):365-371.

GIFFORD, D. 1980. Ethnoarchaeological Contributions to the Taphonomy in Human Sites. En Fossils in the Making: Vertebrate Taphonomy and Paleoecology, editado por A.K. Behrensmeyer y A.P. Hill, pp. 93-106, University of Chicago Press, Chicago. (Traducido por L. A. Orquera).

GÓMEZ OTERO J. 1996. Bases para una arqueología de la costa patagónica central. Arqueología 5:61-103.

GOMEZ OTERO, J. 2003. Movilidad y contactos en la costa centro-norte de patagonia argentina en tiempos pre y posthispánicos. En Las fronteras hispanocriollas del mundo indígena latinoamericano en los siglos XVIII-XIX. Un estudio comparativo, compilado por R. Mandrini y C.D. Paz, pp. 287-312, UNCo, UNCPBA, UNS, Neuquén.

GÓMEZ OTERO J. 2006. Dieta, uso del espacio y evolución en poblaciones cazadorasrecolectoras de la costa centro-septentrional de Patagonia durante el Holoceno medio y tardío. Tesis Doctoral, Facultad de Filosofía y Letras, Universidad de Buenos Aires. (Ms.).

GÓMEZ OTERO, J. 2007. Isótopos estables, dieta y uso del espacio en la Costa Atlántica Centro-septentrional y el Valle inferior del Rio Chubut (Patagonia Argentina) En: Arqueología de Fuego-Patagonia. Levantando piedras, desenterrando huesos...y develando arcanos. (Ed. F. Morello, M.Martinic, A.Prieto y G. Bahmonde), pp151-162. Ed. Cequa, Chile.

GÓMEZ OTERO, J. 2012. La importancia de rescatar los enterratorios humanos en riesgo: experiencias en el nordeste de la provincia del Chubut. Cazadores-recolectores del Cono Sur 5: 15-33.

GÓMEZ OTERO, J., A. BANEGAS, M.S. GOYE y N.V. FRANCO. 2011. Variabilidad morfológica de puntas de proyectil en la costa centro-septentrional de Patagonia argentina: primeros estudios y primeras preguntas. En Las fuentes en la construcción de una Historia Patagónica, pp.110-118. Secretaría de Cultura de la Provincia del Chubut. 
GÓMEZ Otero, J., A. BANEGAS, H. D. PALlERES, M. REYES, V. SCHUSTER y A. SVOBODA. 2012a. Línea de Base arqueológica - Fundación Vida Silvestre I (Reserva San Pablo de Valdés, Península Valdés, Prov. del Chubut). STAN 467, CENPAT, Puerto Madryn. MS.

GÓMEZ Otero, J., A. BANEGAS, M. S. GOYE, D. PALlERES, M. REYES, V. SCHUSTER y A. SVOBODA. 2013b. Nuevas investigaciones arqueológicas en la estancia San Pablo (costa del golfo Nuevo, Península Valdés). En Libro de resúmenes del XVIII Congreso Nacional de Arqueología Argentina, pp. 523-524. UNLa Rioja y INCIHUSA-CONICET, La Rioja.

GÓMEZ Otero, J., A. BANEGAS, M. S. GOYE, A. SVOBODA, M. REYES, y D. PALLERES. 2014. Informe línea de base arqueológica, Cantera áridos Fontana, Informe Relevamiento arqueológico Zona de El Sombrerito (Playa Unión- Prov. Chubut). STAN 467, CENPAT, Puerto Madryn. MS.

GÓMEZ OTERO, J., J. BELARDI, A. SÚNICO Y ROBERTO TAYLOR. 1999 Arqueología de cazadores -recolectores en península Valdés (costa central de Patagonia): primeros resultados. En Soplando en el viento, pp. 393-417, Universidad Nacional del Comahue, Neuquén.

GOMEZ OTERO, J. y C. BELLELLI. 2006. La Patagonia central: poblamientos y culturas en el área de Chubut. En Patagonia Total. Antártida e Islas Malvinas. Primera parte: Historias de la Patagonia. Sociedades y Espacios en el tiempo, coordinado por Susana Bandieri y Graciela Blanco, pp. 27-51, Alfa Literario-Patagonia Argentina/BarcelBaires Ediciones, Colombia.

GÓMEZ OTERO, J., D. CONSTENLA y V. SCHUSTER. 2014. Isótopos estables de carbono y nitrógeno y cromatografía gaseosa en cerámica arqueológica del nordeste de la provincia del Chubut (Patagonia Argentina). Arqueología 20 (2): 263-284.

GÓMEZ OTERO, J.; SCHUSTER, V.; MORENO, J.; MILlÁN, G.; PALlERES, D.; WEILER, N. y TAYLOR, R. 2009. El enterratorio múltiple de Loma Torta Argentina): primeros resultados. Comunicación libre (Póster). En Resúmenes de las IX Jornadas Nacionales de Antropología Biológica; Puerto Madryn, 20 al 23 de octubre de 2009, Asociación de Antropología Biológica Argentina, Puerto Madryn, 2009, Pág. 133, Publicación en CDRom.

GOMEZ OTERO, J. y S. DAHINTEN. 1999. Evidencias de contactos interétnicos en el siglo XVI en Patagonia: informe preliminar sobre el sitio enterratorio Rawson (Chubut). En Actas del XII Congreso Nacional de Arqueología Argentina, T. III: 44-55, La Plata. 
GÓMEZ OTERO y S. DAHINTEN 1997-1998 Costumbres funerarias y esqueletos humanos: variabilidad y poblamiento en la costa nordeste de la provincia del Chubut (Patagonia argentina). Relaciones de la Sociedad Argentina de Antropología XXII: 101-124.

GÓMEZ OTERO, J. y M.J. PAZ. 1994. Análisis tipológico y tecno-morfológico de materiales líticos del sitio costero "El Medanal” (Prov. del Chubut). Revista del Museo de Historia Natural de San Rafael XIV (1-4). Volumen en adhesión al XI Congreso Nacional de Arqueología Argentina.

GÓMEZ OTERO, J., V. SCHUSTER y A. SVOBODA. 2015. Fish and plants: the "hidden" resources in the archaeological record of the North-central Patagonian coast (Argentina). Quaternary International 373:72-81.

GÓMEZ OTERO, J. y C. STERN. 2005 Circulación, intercambio y uso de obsidianas en la costa de la provincia del Chubut (Patagonia, Argentina) durante el holoceno tardío. Intersecciones en Antropología 6: 93-108.

GÓMEZ OTERO, J. y F. SUÁREZ. 2005. Lobos marinos y guanacos: análisis arqueofaunístico de un fogón hallado en la costa del Golfo San Matías, Península de Valdés (Chubut). En Actas del XIII Congreso Nacional de Arqueología Argentina. Cabildo Histórico de la Ciudad de Córdoba, Córdoba. Tomo 4:117-124.

GÓMEZ OTERO, J. y M. VALLEJO. 1996. Cañadón Encerrado (Chubut): un sitio con pinturas rupestres muy próximo a la costa en Patagonia. En Arqueología: sólo Patagonia, editado por J. Gómez Otero, pp. 163-171, Centro Nacional Patagónico, Puerto Madryn.

GÓMEZ OTERO, J., N. WEILER, A. BANEGAS y J. E. MORENO. 2013a. Ocupaciones del Holoceno medio en Bahía Cracker, costa atlántica de Patagonia Central. En Tendencias teórico-metodológicas y casos de estudio en la arqueología de la Patagonia, editado por A. F. Zangrando, R. Barberena, A. Gil, G. Neme, M. Giardina, L. Luna, C. Otaola, S. Paulides, L. Salgán y A. Tivoli, pp. 177-186. Museo de Historia Natural de San Rafael, San Rafael.

GÓMEZ OTERO, J., N. WEILER, A. BANEGAS, A. SVOBODA, M. S. GOYE, D. PALLERES y R. TAYLOR. 2012b. Línea de Base arqueológica - Fundación Vida Silvestre II (Reserva San Pablo de Valdés, Península Valdés, Prov. del Chubut). STAN 467, CENPAT, Puerto Madryn. MS.

GONZÁLEZ BONORINO, F. y M.E. TERUGGI.1953. Léxico Sedimentológico. Publ. Ext. Cult. Didáctica Nº6, Museo Argentino de Ciencias Naturales, Bernardino Rivadavia. Buenos Aires.

GONZÁLEZ, M. y N. WEILER. 1994. Argentinian Holocene Transgression: Sideral Ages. Journal of Coastal Research 10 (3): 621-627. 
GOYE S., BANEGAS, A. y J. GÓMEZ OTERO. 2015. Abundancia y diversidad lítica en concheros de la costa Norte de la Provincia del Chubut, Patagonia Argentina. En Arqueometría Argentina. Metodologías científicas aplicadas al estudio de los bienes culturales: Datación, caracterización, prospección y conservación, eds. Pifferetti A. and I. Dosztal, 181-194, Ciudad Autónoma de Buenos Aires: Aspha Ediciones.

GRADIN, C.J, C. ASCHERO y A. AGUERRE. 1976. Investigaciones arqueológicas en la Cueva de las Manos, Estancia Alto Río Pinturas (Provincia de Santa Cruz). Relaciones de la Sociedad Argentina de Antropología, Nueva Serie, Tomo X: 201-250. Buenos Aires.

GRADIN, C. 1980. Secuencias radiocarbónica del sur de la Patagonia Argentina. Relaciones de la Sociedad Argentina de Antropología, Nueva Serie, Tomo XIV (1): 177-194. Buenos Aires.

GRADIN, C.J. 1987. Tendencias estilísticas del arte rupestre de Patagonia central y meridional. En Primeras Jornadas de Arqueología de la Patagonia. Comunicaciones, pp. 139-152, Dirección de Cultura de la Provincia del Chubut, Rawson.

GRADIN, C. y A.M. AGUERRE. 1994. Contribución a la arqueología del Río Pinturas, Provincia de Santa Cruz. Editorial Búsqueda-Ayllu. Concepción del Uruguay.

GRAYSON, D. 1984. Quantitative Zooarchaeology: Topics in the Analysis of Archaeological Faunas. Academic Press, Orlando.

HALleR M. 1981. Descripción Geológica de la Hoja 43h - Puerto Madryn. Servicio Geológico Nacional, Boletín 184, 41 págs.

HERMO, D. 2005. Acerca del aprovechamiento de xilópalo en el Monumento Natural Bosque Petrificado, por parte de los cazadores-recolectores de la meseta central de Santa Cruz. Trabajos de las VI Jornadas de Jóvenes Investigadores en Ciencias Antropológicas. UBA.

HAMMOND, H. y ZUBIMENDI, M.A. 2013. Estudio de la composición de sitios concheros en la Costa Norte de Santa Cruz (Patagonia Argentina). En Tendencias teórico metodológicas y casos de estudio en la arqueología de la Patagonia, editado por A.F., Zangrando; R., Barberena; A., Gil; G., Neme; M., Giardina; L., Luna; C., Otaola; S., Paulides; L., Salgán y A., Tívoli. pp. 405-415.

HAMMOND H., M. A. ZUBIMENDI y L. ZILIO. 2013. Composición de concheros y uso del espacio: aproximaciones al paisaje arqueológico costero en Punta Medanosa. En Anuario de Arqueología, Rosario (2013), 5:67-84.

HAYDEN, B. 1989 From chopper to celt: the evolution of resharpening techniques. En Time, energy and stone tools, editado por R. Torrence, pp. 7-16, Cambridge University Press. Cambridge. 
HISCOCK, P. 1985. The need for a taphonomic perspective in stone artefact analysis, Queensland Archaeological Research 2:82-95.

HOCSMAN, S. 2006. Producción lítica, variabilidad y cambios en Antofagasta de la Sierra. Tesis doctoral. Facultad de Ciencias Naturales y Museo, UNLP. (Ms.)

HOFFMAN, CH. y M. DOBRES. 1999. Introduction: A context for the present and Future of Technology Studies. En The Social Dynamics of Technology, editado por Dobres M. y Ch. Hoffman, pp.1-19, Smithsonian Institution Press, Washington.

INGOLD, T. 2000. The Perception of the Environment. Routledge, London and New York.

JARDIN BOTANICO DE LA PATAGONIA EXTRAANDINA. 2002. Usos tradicionales de las plantas en la meseta patagónica. Centro Nacional Patagónico (CONICET) - ICGB.

KERR, P.F. 1965. 1965 Mineralogía óptica. Mc Graw-Hill Book Company, INC.

LANATA, J.L. y L.A. BORRERO. 1988. Estrategias adaptativas representadas en los sitios Estancia María Luisa y Cabo San Pablo. En Precirculados del IX Congreso Nacional de Arqueología Argentina, pp. 166-174, Buenos Aires.

LAPIDO, O. y F. PEREYRA. 1999. Cuaternario de la Patagonia Extraandina. En Geología Argentina, editado por R. Caminos, Cap. 23, Parte 7, pp. 704-709, Secretaría de Minería de la Nación-Segemar

LASTA, M.L., N.F. CIOCCO, C. BREMEC y A. ROUX. Moluscos bivalvos y gasterópodos. En El Mar Argentino y sus recursos pesqueros, T 2: 115-143, INIDEP, Mar del Plata.

LUNA PONT, 1976 "Una industria sobre madera silicificada de tradición protolítica". En Instituto de Antropología Indigenista. Universidad Nacional de La Patagonia, Serie Académica. Comodoro Rivadavia.

LYMAN, R.L. 1991. Prehistory of the Oregon Coast. Academic Press.

LYMAN, L.R. 1994. Vertebrate Taphonomy. Cambrige University Press, New York. 2008. Quantitative Paleozoology. Cambrige University Press, New York.

MCPHIE, J., DOYLE, M., y ALLEN, R., 1993. Volcanic Textures: a Guide to the Interpretation of Textures in Volcanic Rocks. University of Tasmania Centre for Ore Deposit and Exploration Studies, Hobart. 198 pp.

MALVICINI, L. y LLAMBÍAS, E. 1974. Geología y génesis del depósito de manganeso Arroyo Verde, provincia del Chubut, República Argentina. $5^{\circ}$ Congreso Geológico Argentino, Actas 2: 185-202, Buenos Aires.

MANSUR, E. 2008. Arqueología de la zona de Punta Bustamante (Prov. De Santa Cruz, Argentina). En Arqueología de la costa patagónica. Perspectivas para la conservación, editado por Isabel Cruz y María Soledad Caracotche, pp. 173-193, Universidad Nacional de la Patagonia Austral-Subsecretaría de Cultura de la Provincia de Santa Cruz, Río Gallegos. 
MANSUR, M. E., A. LASA y M. VÁZQUEZ. 2004. Investigaciones arqueológicas en Punta Bustamante (prov. de Santa Cruz): el sitio RUD 01 BK. En Contra viento y marea. Arqueología de Patagonia, editado por María T. Civalero, Pablo M. Fernández y Ana G. Guráieb), pp. 755-774. Buenos Aires, INAPLA-Sociedad Argentina de Antropología.

MARTÍNEZ, G. 2004. Resultados preliminares de la investigaciones arqueológicas realizadas en el curso inferior del río Colorado (Pdos. de Villarino y Patagones; Pcia. de Buenos Aires). En Aproximaciones Contemporáneas a la Arqueología Pampeana: Perspectivas teóricas, metodológicas, analíticas y casos de estudio, G. Martínez; M.A. Gutiérrez; R. Curtoni; M. Berón y P. Madrid Eds., pp. 275-292. FACSO-UNCPBA. Olavarría.

MARTíNEZ, G. 2008-2009. Arqueología del curso inferior del río Colorado: estado actual del conocimiento e implicaciones para la dinámica poblacional de cazadores-recolectores pampeano-patagónicos. En Cazadores Recolectores del Cono Sur 3: 71-92.

MARTÍNEZ, G., G. ARMENTANO, L. STOESSEL; .A. ALCARAZ; N. GONZÁLEZ; F. SANTOS. 2010. Resultados preliminares de la localidad arqueológica San Antonio (curso inferior del rio colorado, pdo. Villarino, pcia. de Buenos Aires). En Mamul Mapú: pasado y presente desde la arqueología pampeana, (Berón et al. Editores). Tomo II: 85-98.

MARTíNEZ, G. 2010. Entierros humanos en lugares sagrados y domésticos durante el Holoceno tardío: el registro bioarqueológico del curso inferior del río Colorado (provincia de Buenos Aires, Argentina). Werkén 13:145-161.

MARTÍNEZ, G. y G.A. MARTÍNEZ. 2011 Late Holocene environmental dynamics in fluvial and aeolian depositional settings: Archaeological record variability at the lower basin of the Colorado river (Argentina). Quaternary International 245:89-102.

MASSAFERRO, G.I. y HALLER, M.J. 2000. Texturas de las vetas epitermales del Macizo Norpatagónico. $5^{\circ}$ Congreso de Mineralogía y Metalogenia, Actas: 312-319, La Plata.

MASSONE, M. 1981. Arqueología de la región volcánica de Pali Aike (Patagonia meridional chilena). Anales del Instituto de la Patagonia, Volumen XII: 95-124.Punta Arenas, Chile.

MATARRESE, A. 2015. Tecnología lítica entre los cazadores-recolectores pampeanos: los artefactos formatizados por picado y abrasión y modificados por uso en el área Interserrana Bonaerense. Tesis doctoral inédita. FCNyM-UNLP.

MAZZITELLI. 2011. Instrumentos líticos con filos denticulados en la Costa Norte de Santa Cruz. Un análisis tecno-funcional. En Cazadores-recolectores del Cono Sur; Lugar: Mar del Plata; Año: 2011 vol. 4 p. 79 - 94 
MENGHIN, O.F.A. 1952. Fundamentos cronológicos de la Prehistoria de Patagonia. Runa V: 23-43.

MENGHIN, O.F.A.1957. Das Protolithikum in Amerikas. Acta Praehistorica I: 5-40.

MENGHÍN, 1963. Industrias de morfología protolítica en Sudamérica. Anales de la Universidad del Norte 2:69-77.

MENGHÍN y BORMIDA SF. (s.f.). Arqueología de la costa patagónica. (Ms.)

MENGONI GOÑALONS, G. 1988. Análisis de materiales faunísticos de sitios arqueológicos. Xama 1:71-120. Mendoza

MENGONI GOÑALONS, G. 1999. Cazadores de guanacos de la estepa patagónica. Colección Tesis Doctorales, Sociedad Argentina de Antropología.

MESSINEO, P.G., M. P. BARROS; DANIEL G. POIRÉ; L. GÓMEZ PERAL. 2004. Características litológicas de los niveles de chert o ftanitas en las Sierras Bayas (Partido de Olavarría, provincia de Buenos Aires).Características litológicas de los niveles de chert o ftanita en las Sierras Bayas (partido de Olavarría, provincia de Buenos Aires). En: Aproximaciones Contemporáneas a la Arqueología Pampeana. Perspectivas Teóricas, Metodológicas y Casos de Estudio. Facultad de Ciencias Sociales (UNCPBA). Olavarría.p. $305-317$.

MIOTI, L. 2006. La fachada atlántica, como puerta de ingreso alternativa de la colonización humana de América del Sur durante la transición Pleistoceno/ Holoceno. En $2^{\circ}$ Simposio Internacional del Hombre Temprano en América, editado por J.C. Jiménez López, pp. 155-188. Instituto Nacional de Antropología e Historia, México. 198 pp.

MIOTTI, L. y M.C. SALEMME. 2004. Poblamiento, movilidad y territorios entre las sociedades cazadoras-recolectoras de Patagonia. Complutum 15: 177-206.

MONTI A.J.A. 2000. Edades 14C y ciclicidad de la acreción en depósitos costeros elevados. Bahía Engaño, Chubut. Revista de la Asociación Geológica Argentina 55 (4): 403-406.

MONTI, A.J. y J.O. CODIGNOTTO. 1994. Caleta Valdés: geomorfología, dinámica y evolución. En Guia de Campo de la VII Reunión de Campo del CADINQUA, pp. 26-29, Centro Nacional Patagónico (CONICET), Puerto Madryn.

MORENO, E. 2008. Arqueología y etnohistoria de la Costa Patagónica Central en el Holoceno Tardío. Fondo Editorial de la Provincia del Chubut, Rawson.

MORENO, J. E., A. CASTRO y F. PEPE. 2000. El rompecráneo: un artefacto probablemente destinado para la caza de pinnípedos, en la costa de Patagonia continental. En Desde el País de los Gigantes, T. 2, pp. 563-572, Universidad Nacional de la Patagonia Austral; Río Gallegos. 
MORENO, E.; A. F. ZANGRANDO; A. TESSONE; A. CASTRO y H. PANARELLO. 2011. Isótopos estables, fauna y tecnología en el estudio de los cazadores-recolectores de la costa norte de Santa Cruz. Magallania 39 (1): 265-276.

MUÑOZ, S. A; M. S., CARACOTCHE e I. CRUZ. 2009. Cronología de la costa al sur del río Santa Cruz: nuevas dataciones en Punta Entrada y Parque Nacional Monte León (Provincia de Santa Cruz, Argentina). Magallania 37, (1): 39-43.

MUSTERS, G.C. 1964. Vida entre los patagones. Solar-Hachette, Buenos Aires.

NAMI, H. 2000. Investigaciones actualísticas y piedra tallada. Criterios experimentales para identificar lascas de talla bipolar: su aplicación en la interpretación de artefactos arqueológicos de los extremos norte y sur de la Patagonia». Actas del III Congreso Argentino de Americanistas 3, PP. 271-292. Buenos Aires.

NELSON, M.C. 1991. The Study of technological Organization. En Archaeological Method and Theory, Vol. 3.

OCHOA, J. y N. LADIO. 2011. Pasado y presente del uso de plantas silvestres con órganos de almacenamiento subterráneos comestibles en la Patagonia. En Bonplandia 20 (2).

ODESS, D. 1998. The archaeology of interaction: views from artifact style and material exchange in Dorset society. American Antiquity, 63 (3): 417-435.

ORLANDO, M. 2009. Instrumentos de molienda y uso del espacio en la costa norte de la provincia de Río Negro: una primera aproximación. M. Salemme, F. Santiago, M. Álvarez, E. Piana, M. Vázquez y E. Mansur (eds.), Arqueología de la Patagonia - Una mirada desde el último confín, 1127-1140, Editorial Utopías, Ushuaia.

ORQUERA, L.A. 1987. Advances in the Archaeology of the Pampa and Patagonia. Journal of World Archaeology 1 (4): 333-413.

ORQUERA, L. y J. GÓMEZ OTERO. 2008. Los cazadores-recolectores de las costas de Pampa, Patagonia y Tierra del Fuego. Relaciones de la Sociedad Argentina de Antropología 32:45-63.

ORQUERA, L. y E. PIANA, 1999. Arqueología de la región del canal Beagle. Publicaciones de la Sociedad Argentina de Antropología, Buenos Aires.

OUTES, F.F. 1905. La edad de la piedra en Patagonia. Estudio de Arqueología comparada. Anales del Museo Nacional de Buenos Aires XII:203-571.

PFAFFENBERGER, B. 1992. Social anthropology of technology. Annual Review of Anthropology 21:491-516

PIGEOT, N. 1990. Technical and Social Actors. Flintknapping Specialists and Apprentices at MagdalenianEtiolles. Archaeological Review of Cambridge 9(1): 126-141. 
POLITIS, G. 1988. Paradigmas, modelos y métodos en la Arqueología de la Pampa Bonaerense. En Arqueología Argentina Contemporánea, pp. 59-107. Ed. Búsqueda, Buenos Aires.

POLITIS, G. 1998. Arqueología de la infancia: Una perspectiva etnoarqueológica (5-19) Trabajos de Prehistoria 55 (2).

POLITIS, G. y C. BAYÓN. 1996. Estado actual de las investigaciones en el sitio Monte Hermoso I (provincia de Buenos Aires). Arqueología 6: 83-116. Buenos Aires.

POLITIS, G., C. SCABUZZO y R. TYKOT. 2009. An approach to prehispanic diets in the pampas during early/middle Holocene. International Journal of Osteoarchaeology 19(2): 66-80.

PRATES, L. 2008. Los indígenas del río Negro. Un enfoque arqueológico. Sociedad Argentina de Antropología. Buenos Aires.

RATTO, N. 2003. Estrategias de caza y propiedades del registro arqueológico en la Puna de Chaschuil (Departamento Tinogasta, Catamarca). Tesis Doctoral, Facultad de Filosofía y Letras, Universidad de Buenos Aires.

Disponible en: http://cambiocultural.homestead.com/ratto.html.

REYES, M.; S. PERALTA GONZÁLEZ y A. LÓPEZ FERRER. 2013. Análisis preliminar de los materiales líticos del sitio Delta Vulcana 1 (lago Musters, Chubut). En Tendencias teórico-metodológicas y casos de estudio en la arqueología de la Patagonia, editado por Zangrando, A. F., Barberena, R., Gil, A., Neme, G., Giardina, M., Luna, L. Otaola, C., Paulides, S., Salgán, L., Tivoli, A. pp. 219-226. Museo de Historia Natural de San Rafael, San Rafael.

RUTTER, N., E.J. SCHNACK, J. DEL RIO, J.L. FASANO, F.I. ISLA y U. RADTKE. 1989. Correlation and Dating of Quaternary Littoral Zones along the Patagonian Coast, Argentina. Quaternary Science Reviews 8: 213-234.

SACKETT, J. 1982 Approaches to style in lithic archaeology. Journal of Anthropological Archaeology 1:59-112.

1985 Style and ethnicity in the Kalahari: a reply to Wiessner. American Antiquity

50 (1): $154-159$.

1986 Style, function, and assemblage variability: a reply to Binford. American

Antiquity 51 (3): 628-634. SACKET 1982

SANGUINETTI DE BORMIDA, 1999. Proyecto Norpatagonia. Arqueología de la Costa Septentrional. Separata de loa Anales de la Academia Nacional de Ciencias de Buenos Aires: 1-35.

SANGUINETTI DE BÓRMIDA, A. C., N. WEILER, V. ALDAZABAL, D. CURZIO, H. NAMI, M. SILVEIRA y E. EUGENIO. 2000. Arqueología de la Costa Atlántica 
Septentrional: Nuevas Perspectivas. En III Congreso Argentino de Americanistas. Tomo 3 pp. 317-350. Buenos Aires.

Scarstacini, F. 2012. Primeras tendencias ictioarqueológicas en la localidad Bajo de la Quinta. Intersecciones en Antropología 13: 3015-326.

SCHIFFER, M. B. 2004. Studying technological change: a behavioral perspective. World Archaeology 36(4): 579-585.

SCHIFFER, M. y J. SKIBO. 1987. Theory and explanation in the study of Technological Change. Current Anthropology 28(5), 595-622.

SCHUSTER, V. 2014. La organización tecnológica de la cerámica de cazadores-recolectores.

Costa norte de la Provincia del Chubut (Patagonia Argentina). Relaciones de la Sociedad Argentina de Antropología XXXIX (1): 203-231.

SHELLEY, P.H. y F. NIALS. 1986. A controlled experimental study of artifact damage in an aeolian environment. Paper preparado para el Simposio sobre procesos de alteración y el registro arqueológico. Society for American Archaeology 51st Annual Meeting, New Orleáns. $M s$.

STAMPONE, J.1997. Informe de impacto ambiental para la etapa de explotación Proyecto Minera Ameghino. SAMIC, FCN; UNPSJB. (Ms.)

STERN, C. 1999. Black obsidian from central-south Patagonia; chemical characteristics, sources and regional distribution of artifacts. Actas de las III Jornadas de Arqueología de la Patagonia: Soplando en el Viento, editado por J. Belardi, P. Fernández, R. Goñi, A. Guráieb y M. De Nigris, pp. 221-234. INAPL, Buenos Aires.

STERN, C., A. CASTRO ESNAL, C. PÉREZ DE MICOU, C. Stern, C., A. Castro Esnal; C. Pérez de Micou; C. Méndez, y F. Mena. 2013. Circulación de obsidianas en Patagonia Central-Sur entre 44 y $46^{\circ} \mathrm{S}$

y F. MENA. 2013. Circulación de obsidianas en Patagonia central-sur entre $44^{\circ}$ y $46^{\circ} \mathrm{S}$ ). En Tendencias teórico-metodológicas y casos de estudio en la arqueología de la Patagonia, compilado por A.F. Zangrando, R. Barberena, A. Gil, G. Neme, M. Giardina, L. Luna, C. Otaola, S. Paulides, L. Salgán y A. Tívoli, pp.243-250. Museo de Ciencias Naturales de San Rafael, INAPL, SAA.

STERN, C. y N. FRANCO 2000. Obsidiana gris verdosa veteada de la cuenca superior del río Santa Cruz, extremo sur de la Patagonia. Anales del Instituto de la Patagonia, Serie CienciasHumanas 28:265-273.

STERN, Ch., J. GOMEZ OTERO y J.B. BELARDI. 2000. Características químicas, fuentes potenciales y distribución de diferentes tipos de obsidianas en el norte de la provincia del Chubut, Patagonia argentina. Anales del Instituto de la Patagonia, Serie Ciencias Humanas 28: 275-290. Punta Arenas. 
STERN, C. y A. PRIETO 1991. Obsidiana verde de los sitios en los alrededores del mar de Otway, Magallanes, Chile. Anales del Instituto de la Patagonia, Serie Ciencias Humanas 20:139-144.

STUIVER, M. y REIMER. 1993. Radiocarbon 35 (1): 215-230.

STOESSEL, L. 2007. Análisis arqueofaunísticos de los sitios Loma Ruíz 1 y El Tigre (partidos de Villarino y Patagones, provincia de Buenos Aires). Aportes para el conocimiento de la subsistencia en el valle inferior del río Colorado durante el Holoceno tardío. Intersecciones en Antropología. 8: 235-251.

STOESSEL, L. 2012. Aportes para el conocimiento de la subsistencia de cazadores-recolectores en el Holoceno tardío. Facultad de Ciencias Sociales, Universidad Nacional del Centro de la Provincia de Buenos Aires, Argentina. 380 páginas. Tesis de postgrado. FACSOUNICEN. Olavarría.

STOESSEL, L., S. BOGAN, G. MARTÍNEZ y FAGNOLIN. 2008. Implicaciones paleoambientales de la presencia del género Ceratophrys (Anura, Ceratophryinae) en contextos arqueológicos de la transición Pampeano-Patagónica en el Holoceno tardío (curso inferior del río Colorado, Argentina). En Magallania vol. 36 p. 195:204. Punta Arenas.

SUNICO, A. 1996. Geología del Cuaternario y Ciencia del Suelo: relaciones geomórficas y estratigráficas con suelos y paleosuelos. Tesis Doctoral, Facultad de Ciencias Exactas y Naturales, Universidad de Buenos Aires. (Ms.).

TERRANOVA, E. 2007. Uso y circulación de xilópalo en cazadores recolectores en la Meseta

Central de Santa Cruz. En: Actas del Congreso Nacional de Arqueología Argentina. San Salvador de Jujuy. MS.

THOMAS, D. 1978. Arrowheads and Atlatl Darts: how the Stones got the Shaft. American Antiquity 43 (3).

TORRENCE, R. 1989. Tools as optimal solutions. En Time, energy and stone tools, editado por R. Torrence, pp. 1-6. Cambridge University Press. Cambridge.

VAllejO, M. y CORONATO, F. 1994. Atlas de la Provincia del Chubut. Saxon Impresores S.R.L. Buenos Aires.

WEILER, N. 1993. Niveles marinos del Pleistoceno tardío y Holoceno en Bahía Anegada, Provincia de Buenos Aires. Geocronología y correlaciones: Revista de la Asociación Geológica Argentina, 48 (3-4), 207-216.

WEILER, N.E. 1998. Mid-holocene littorals deposits at southwest of the golfo San José, Península Valdés, Argentine Republic. International Coastal Symposium, $\mathrm{N}^{\circ} 26$ : 33-38. Palm Beach, May 19-23, 1998. 
WEILER, NE., 2000. Holocene sea levels and volcanic ash at southwest of San José gulf, Peninsula Valdes, Argentina. En: Coastal Interactions during Sea-Level Highstands Proyecto IGCP No 437 (UNESCO-IUGS): Comisión de Líneas de Costa - Unión Internacional para el Cuaternario (INQUA) Comisión de Sistemas Costeros - Unión Geográfica Internacional (IGU). Patagonia 2000 International Conference.Puerto Madryn, Chubut), 29 de octubre al 3 de noviembre de 2000, Abstracts: 83-86.

WHALLON, R., 2011. Introduction to information and its role in Hunter-Gatherer band-level Society. En: R. Whallon, W. Lovis and R. Hitchcok (Eds.). Information and its role in hunter-gatherer bands (pp. 1-27) Los Angeles: Cotsen Institute of Archaeology Press. University Of California.

WIESSNER, P. 1983. Style and social information in Kalahari San projectile points. American Antiquity 48 (2): 253-276.3.

WIESSNER, P. 2009. Experimental games and games of life among the Ju/'hoan Bushmen. Current Anthropology 16 (2): 115-145

WILLIAMS, H., TURNER, F, y GILBERT, M. 1980. Petrografía. Introducción al estudio de las rocas en secciones delgadas. Compañía Editorial continental.

WOBST, H. M., 1999. Stylistic Behavior and Information Exchange. En Papers for the Director: Research Essays in Honor of James B. Griffin (Anthropological Paper 61) Michigan, Museum of Anthropology,University of Michigan, C. E. Cleland, Ed. pp. 317-342.

ZUBIMENDI, M. 2010. Estrategias de uso del espacio por grupos cazadores recolectores en la Costa Norte de Santa Cruz y su interior inmediato. Tesis doctoral inédita. Facultad de Ciencias Naturales y Museo, Universidad Nacional de La Plata. 


\section{ANEXOS}

\section{MUESTRAS NATURALES}

1) Muestra Arroyo Verde 2B:

Atribución macroscópica: En muestra de mano se clasifica como RIOLITA.

Nombre de la roca: PORFIDO - RIOLITICO.

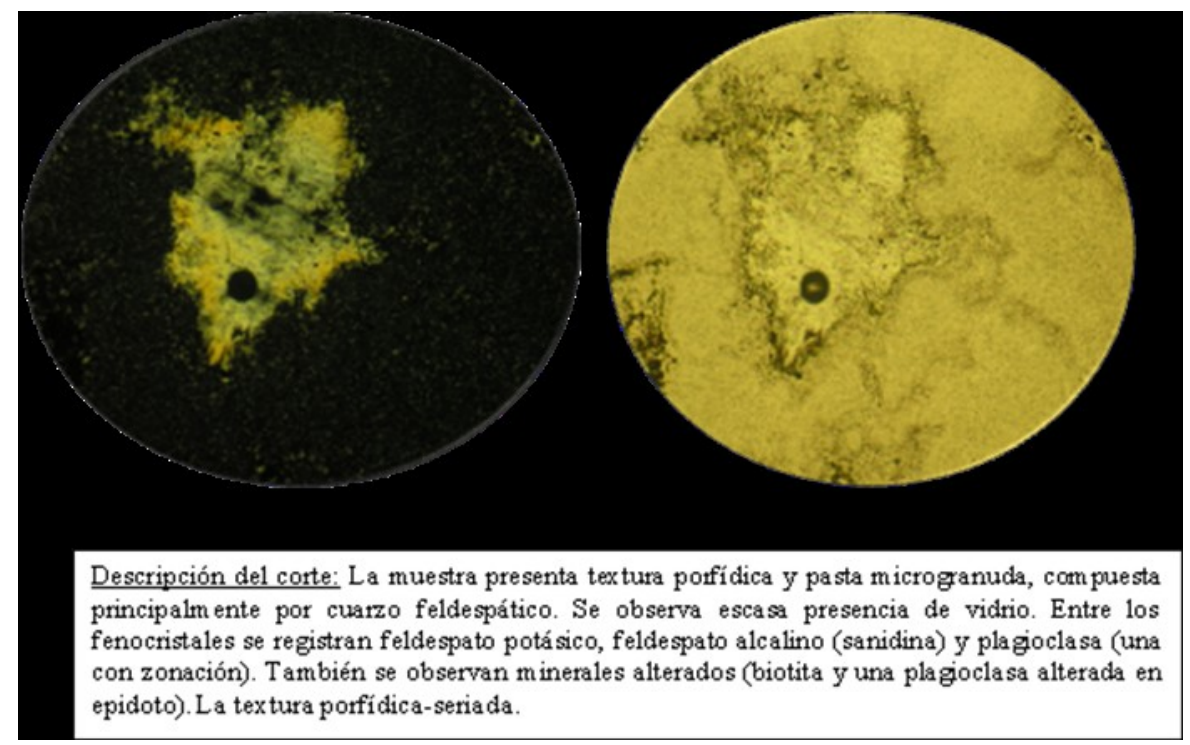

2) Muestra Arroyo Verde $1 \mathrm{~A}$

Atribución macroscópica: Calcedonia

Nombre de la roca: SILEXITA o CUARZO DE RELLENO DE VETA CRIPTOCRISTALINOCALCEDONIA

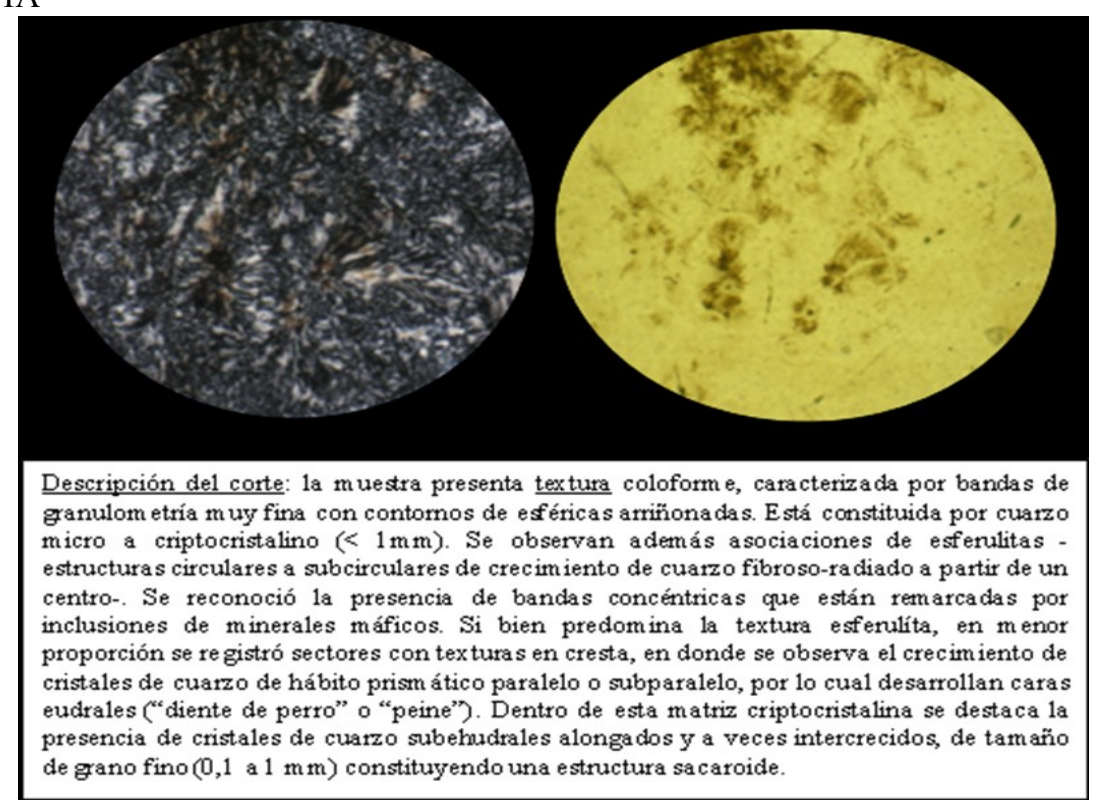




\section{3) Muestra Arroyo Verde 1B:}

Atribución macroscópica: Calcedonia

Nombre de la roca: SILEXITA o CUARZO DE RELLENO DE VETA CRIPTOCRISTALINOCALCEDONIA

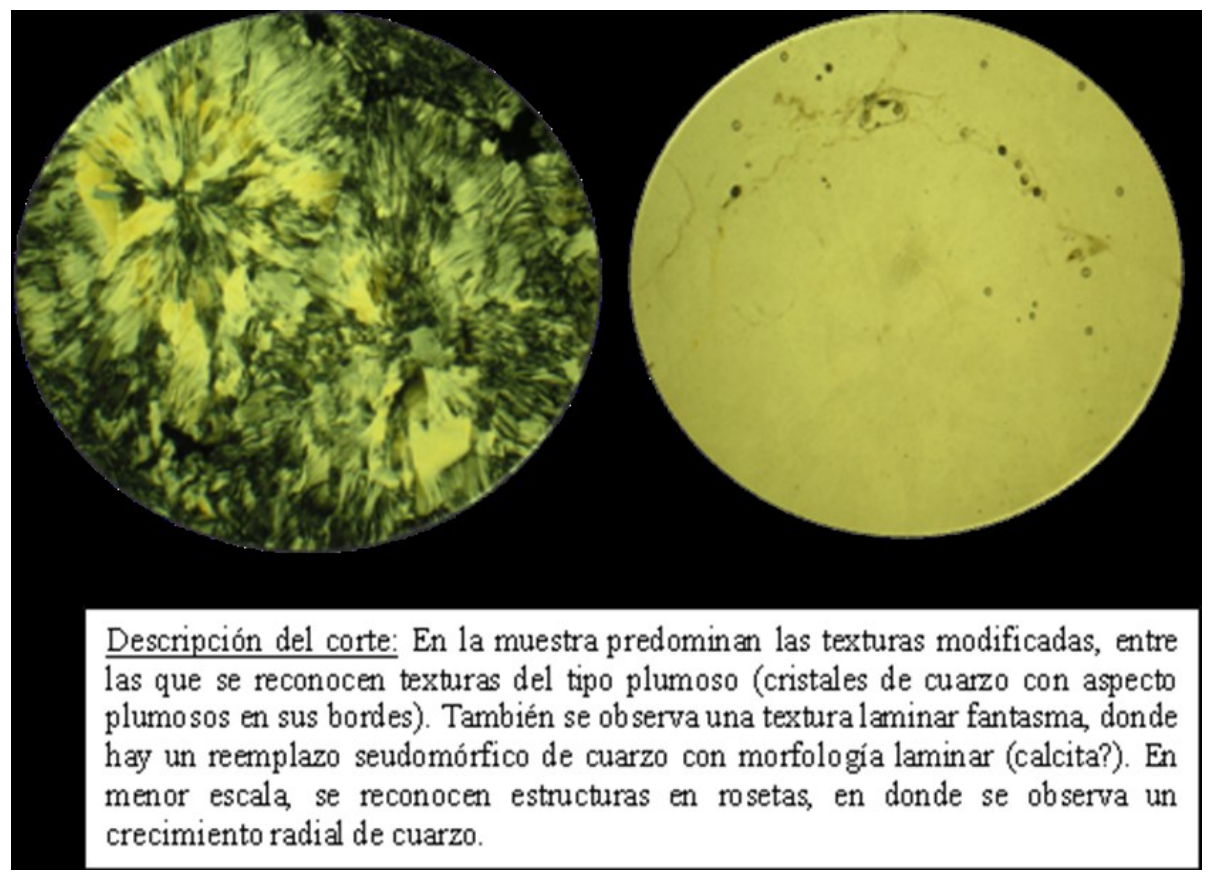

\section{4) Muestra Arroyo Verde 2 A}

\section{Atribución macroscópica: Calcedonia}

\section{Nombre de la roca: CALCEDONIA.}

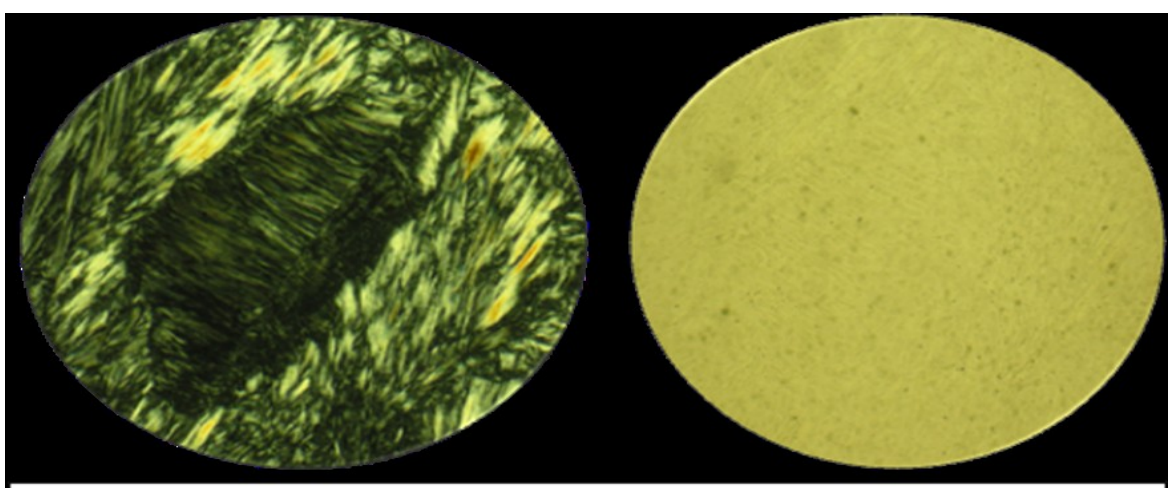

Descripción del corte: En este corte predominan las texturas modificadas, entre las que se reconocen texturas del tipo plumoso donde cristales de cuarzo muestran aspectos plumosos a partir de sus bordes. También se observa a textura laminar fantasma, donde hay un reemplazo seudomórfico de cuarzo con morfología laminar (calcita?). En menor escala se reconocen estructuras en rosetas, en donde se observa un crecimiento radial de cuarzo. A diferencia de $\mathrm{A}^{\circ}$ Verde 1 , en esta muestra se registra la presencia de esferulitas con cristales en el núcleo; es decir, bandas de agregados fibrosos radiales de calcedonia con superficies externas redondeadas que en ocasiones terminan en esferulitas. 


\section{5) Muestra Arroyo Verde 1 M1 \#2}

Atribución macroscópica: Indeterminada.

\section{Nombre de la roca: IGNIMBRITA DE COMPOSICIÓN RIOLÍTICA (POCO SOLDADA)}
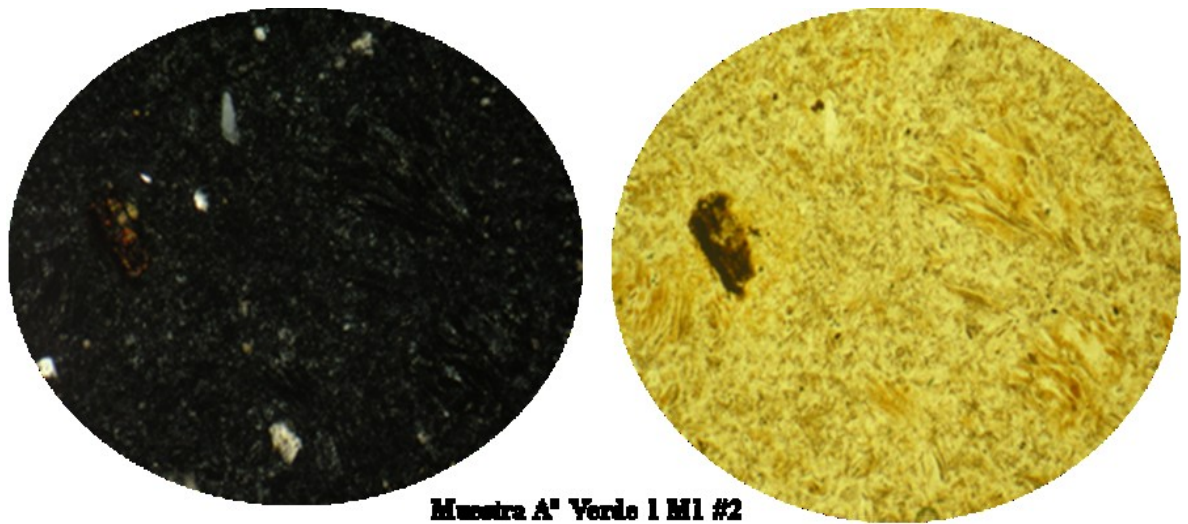

Descripción del corte: El corte presenta matríz vitroclásticay se encuentra desnaturalizada en agregados de cuarzo microcristalino. Predominan los vitroclastos (pómez) sobre los cristaloclástos y están ausentes los litoclastos. Los pómez conservan su morfología distinguiéndose los canavículos. Los cristaloclastos son de cuarzo con bordes corroídos y fracturados. En menor proporción se observan feldespato potásico y escaza biotita alterada.

\section{9) Muestra AV1-10}

Atribución macroscópica: Cuarcita

Nombre de la roca: ARENISCA CUARZOSA

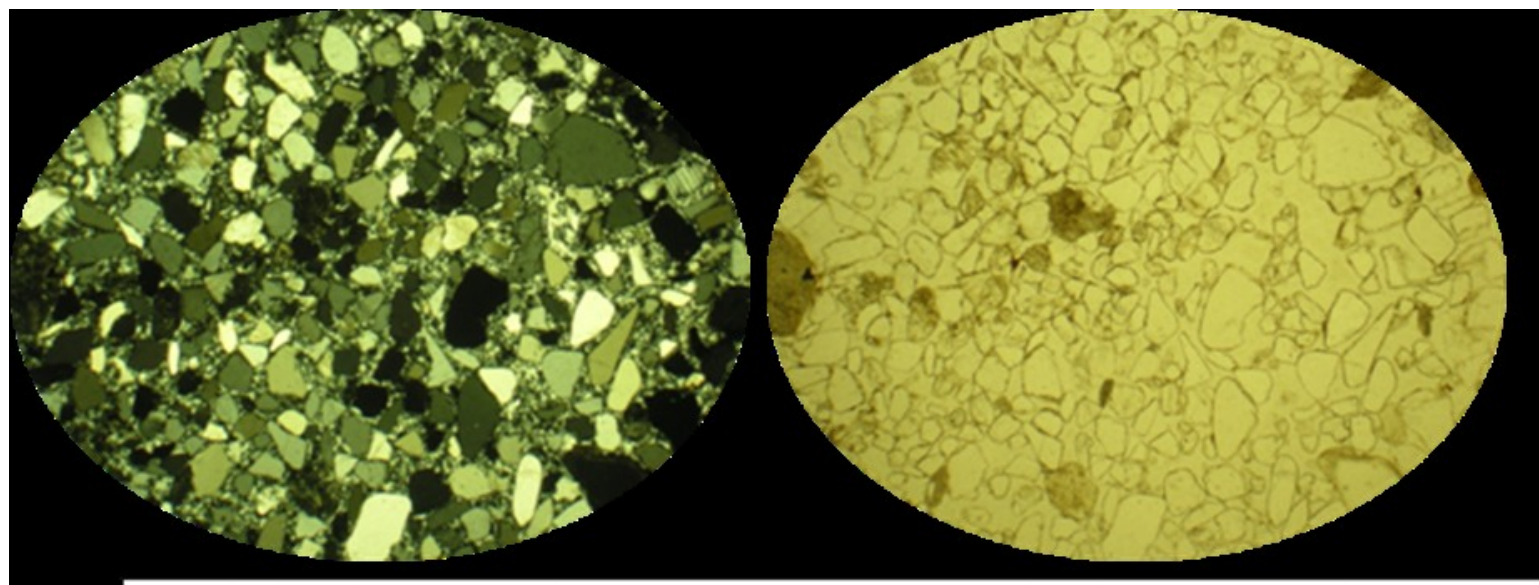

Descripción del corte: El corte presenta textura clástica (clasto - sostén) y matríz microcristalina cuarzosa (muy escaza). Entre los clastos predomina el cuarzo, se observa además feldespato potásico, escazas plagioclasas, clorita (se ve como "plumoso y tiene extinción radial), coirón y fragmentos líticos. Los granos son angulosos y de tamaños variados. 


\section{2) Muestra PD/27:}

Atribución macroscópica: Andesita

Nombre de la roca: ANDESITA

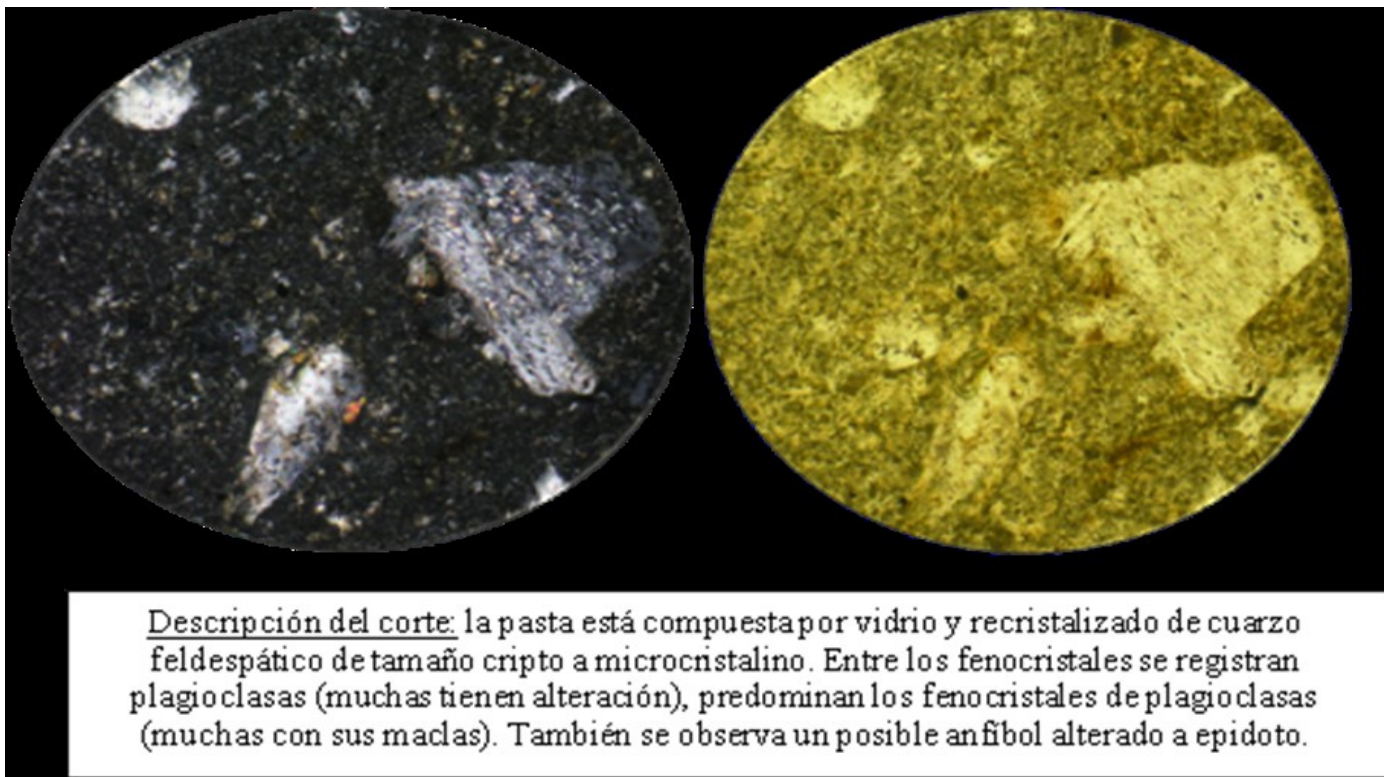

\section{MUESTRAS ARQUEOLÓGICAS}

\section{8) Muestra AV 1 M1/4:}

Atribución macroscópica: Indeterminada.

Nombre de la roca: IGNIMBRITA

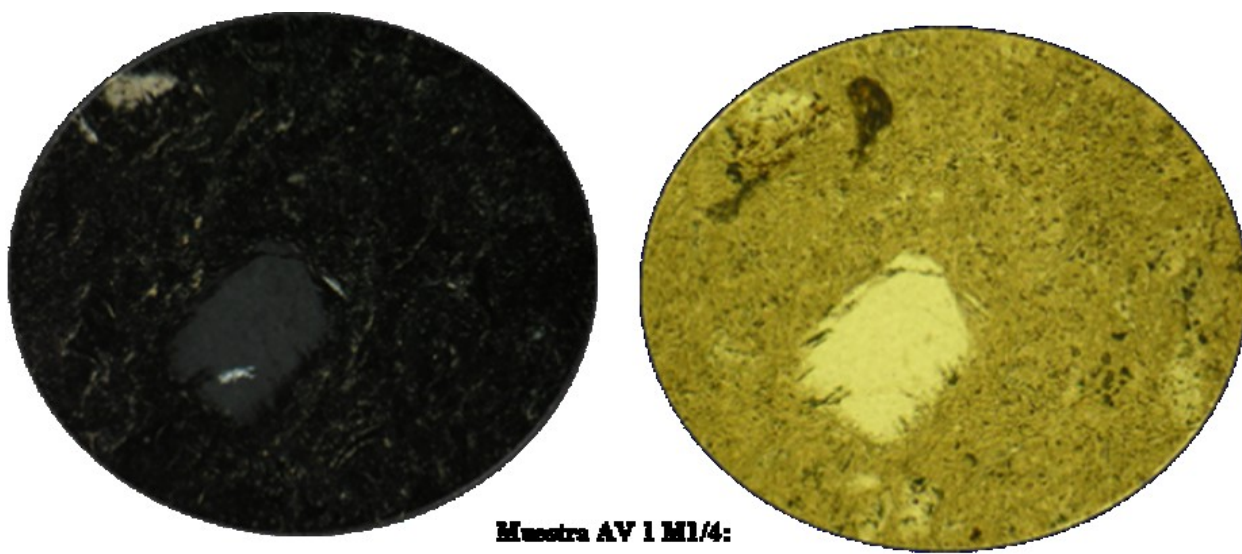

Descripción del corte: El corte presenta matriz vítrea destacándose por su abundancia las trizas vítreas, y en menor medida se observan escasos fragmentos de pómez de tamaño reducido (estos conservan caviculos?). No se observa la presencia de litoclastos. Se observa, además rastros de alteración. 


\section{0) Muestra ER/28}

Atribución macroscópica: Cuarcita.

\section{Nombre de la roca: ARENISCA CUARZOSA}

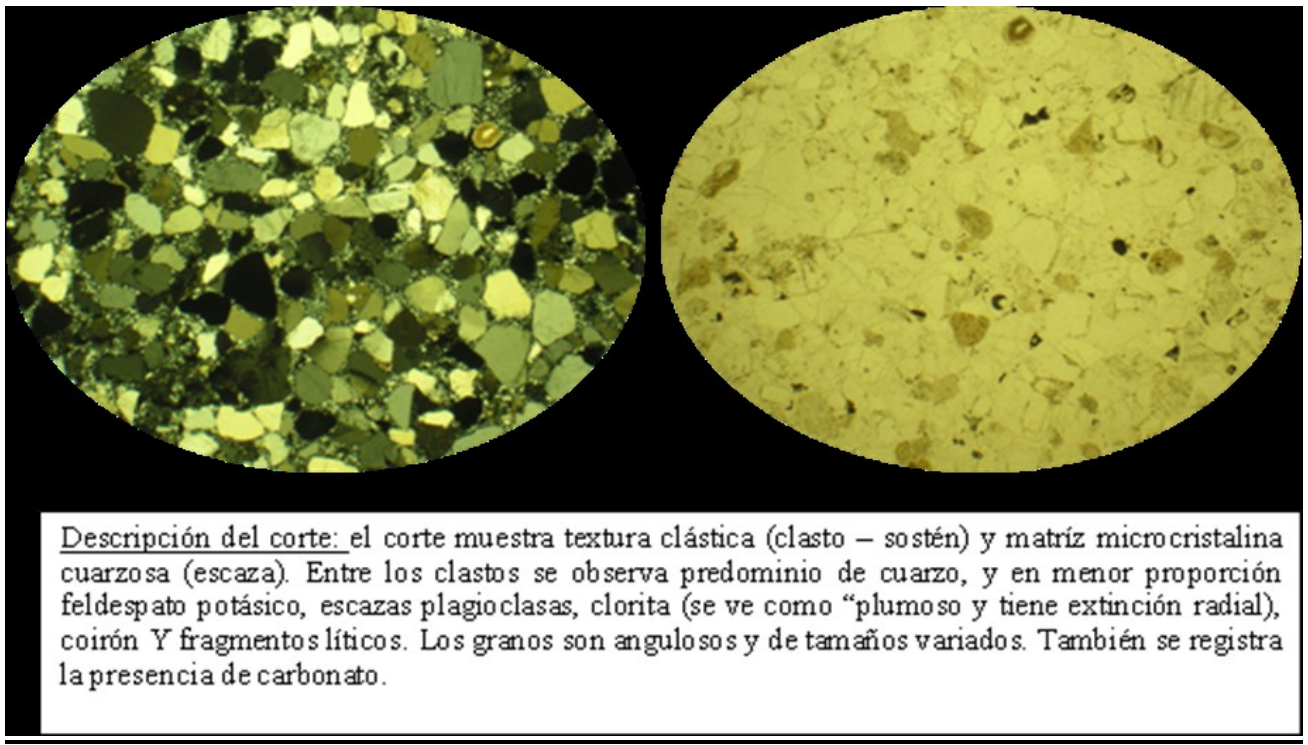

\section{2) Muestra RE 1M1/211}

Atribución macroscópica: Silíce.

Nombre de la roca: ROCA SILICEA RELACIONADO CON DEPÓSITOS DE VETA.

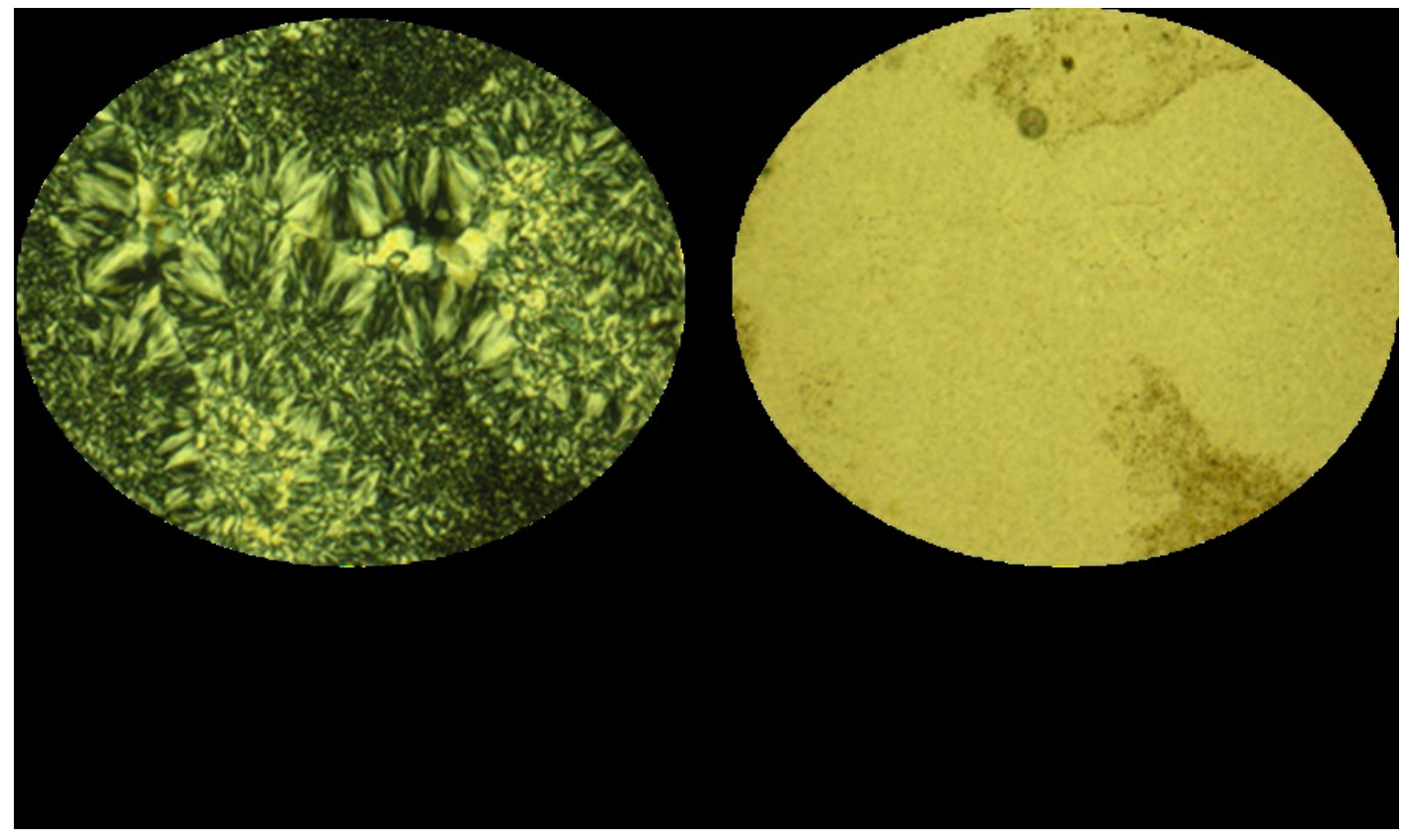



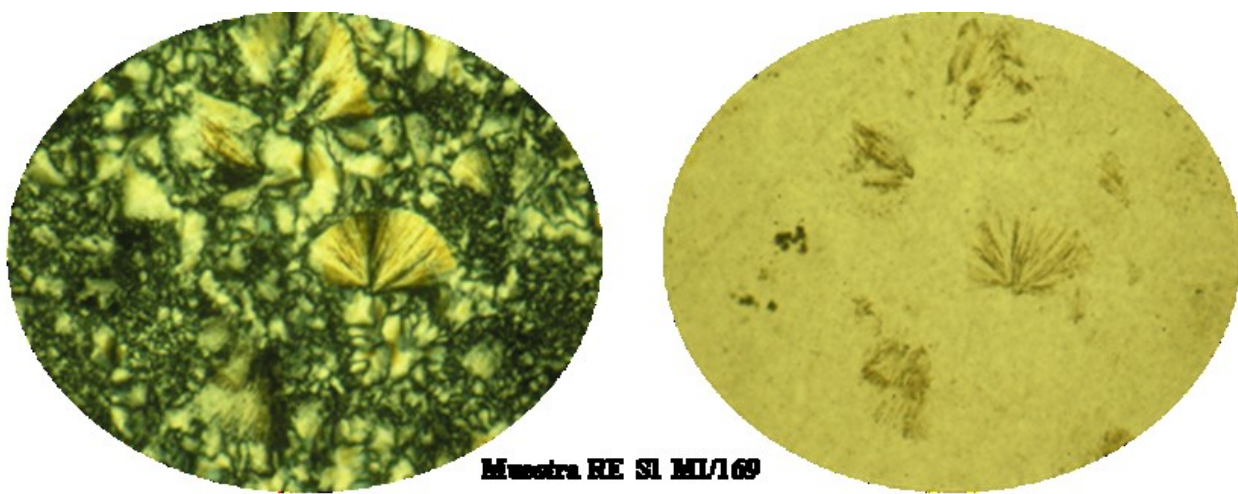

Descripgifn del corte: texbura colofome caracterizada por bandes de gramulometrla mus fina con contomos de esfericas arrifonadas. Está constibuida por cuarso micro a cripto - cristalino (temeño <1mm) del tipo calcedenia Se obserran adembs, asociaciones de esfenditas -estructuras circulares a subcirculares de crecimiento de cuarzo florosoradiado a partir de un centro. Se reconocio la preseacia de bendas cuncentricas que estén remarcailas por inchusiones de minerales máficos. Tambito se registra masas de calcita con reemplaw de cuares. Si bien predomina la testura esferulita en menor proporcition se registró sectores con tecturas en cresta en donde se observa el crecimiento de cristales de cuarzo de hibito priemsticos paralelos o sub-paralelos (inicia en el bonde la caridad y crece hacia adentro - similar a las geodas-l, por lo cual desarsollan caras eudraies (diente de perro o peine). Dentro de esta matriz criptocristalina se destaca la presencia de cristales de curro sub-ehudrales alongados y a veces intercrecidos, que tienen un tamafio de grano fino $(0,1 / 1 \mathrm{~mm})$ constituyendo una estructura sacaroide.

25) Muestra RELIZ 260

Nombre de la roca: RIOLITA

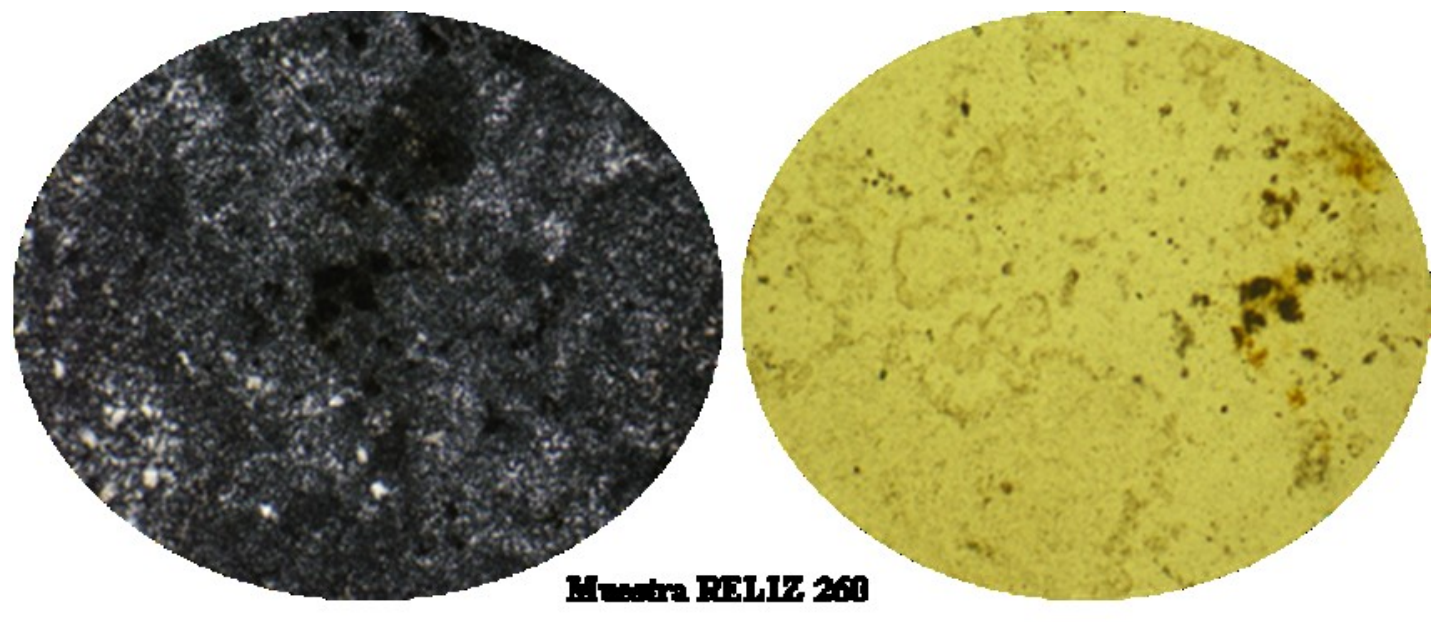

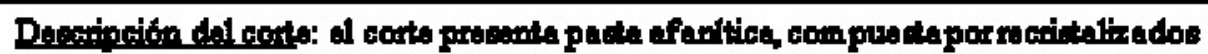

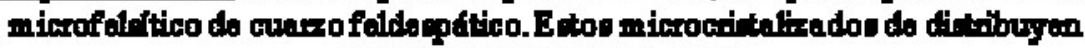
inogilam ante colbra la pade. 


\section{6) Muestra Reliz S1 M1/195}

Atribución macroscópica: xilópalo

Nombre de la roca: SILEXITA CUARZO DE RELLENO DE VETA CRIPTOCRISTALINO O CUARZO DE VETA.

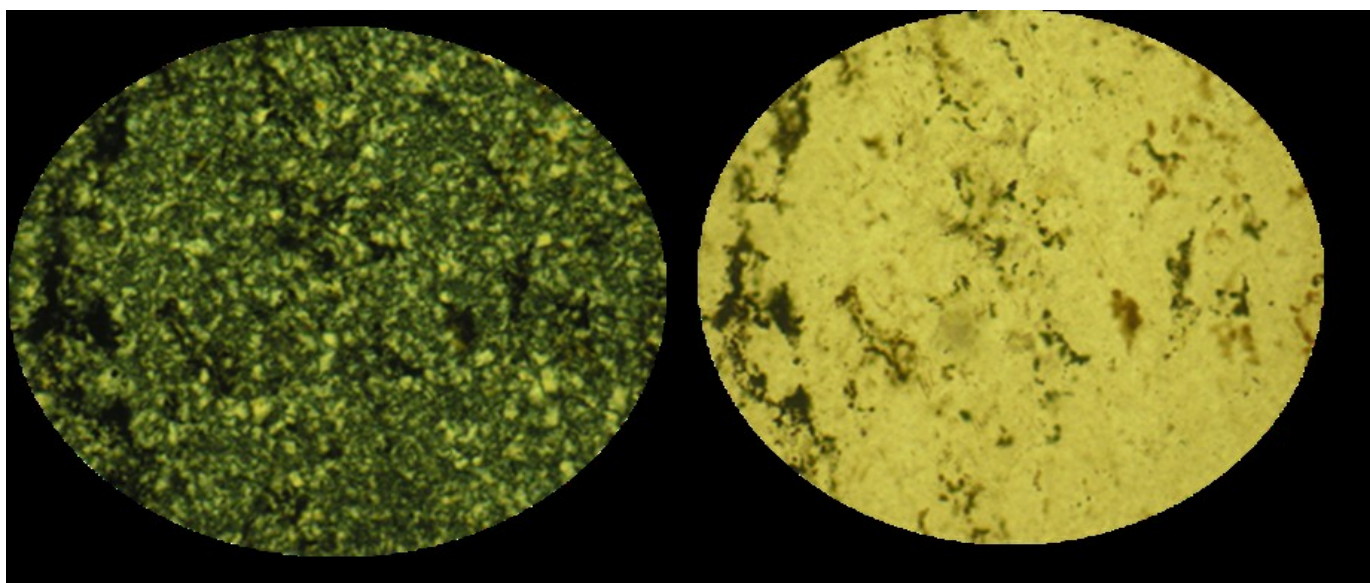

Descripción del corte: en la textura se observa una estructura masiva de cuarzo microcristalino constituyendo un mosaico de granos sub-ehudrales. No se observa una dirección de crecimiento preferencial. En la pasta se observaron esferulitas y minerales opacos y óxidos diseminados en la pasta. Se esboza el desarrollo de esfenUlita.

18) Muestra AV/6:

Atribución macroscópica: Ignimbrita

Nombre de la roca: IGNIMBRITA

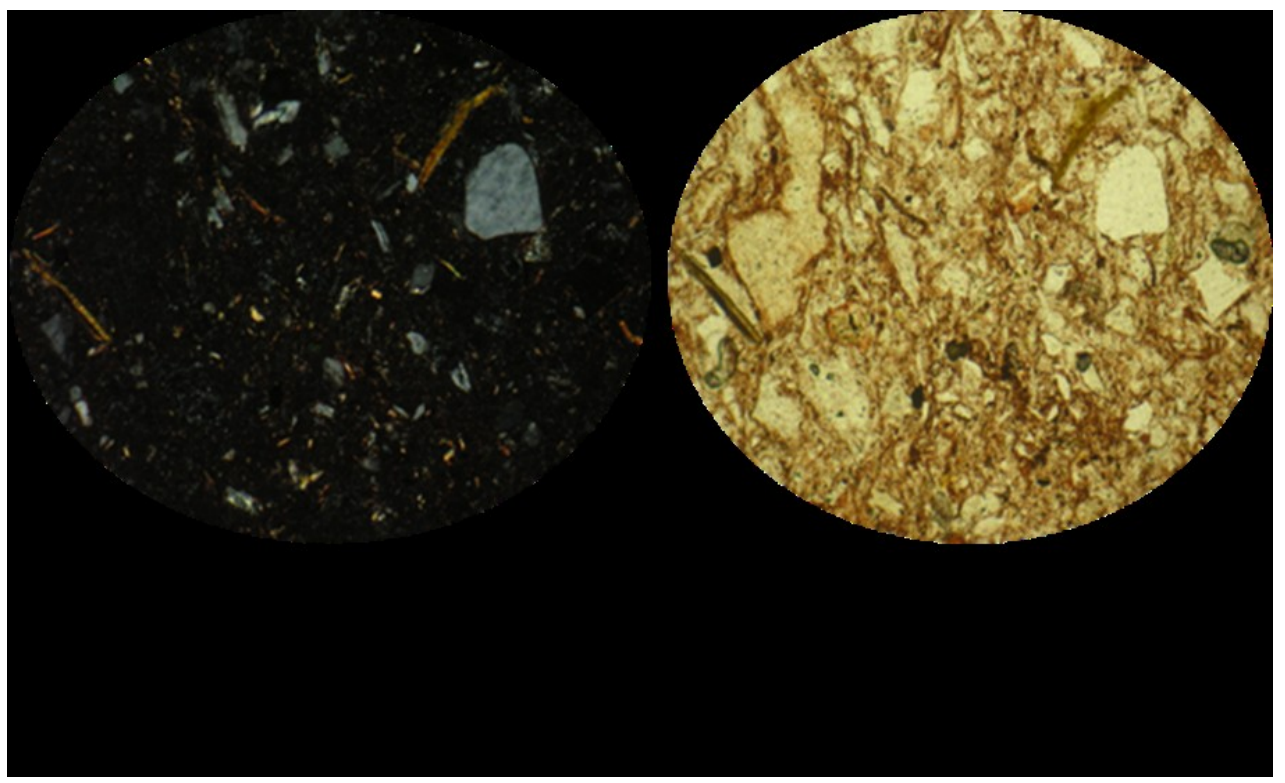




\section{9) Muestra AV/ 5:}

Atribución macroscópica: Riolita

\section{Nombre de la roca: IGNIMBRITA DE BAJO GRADO}

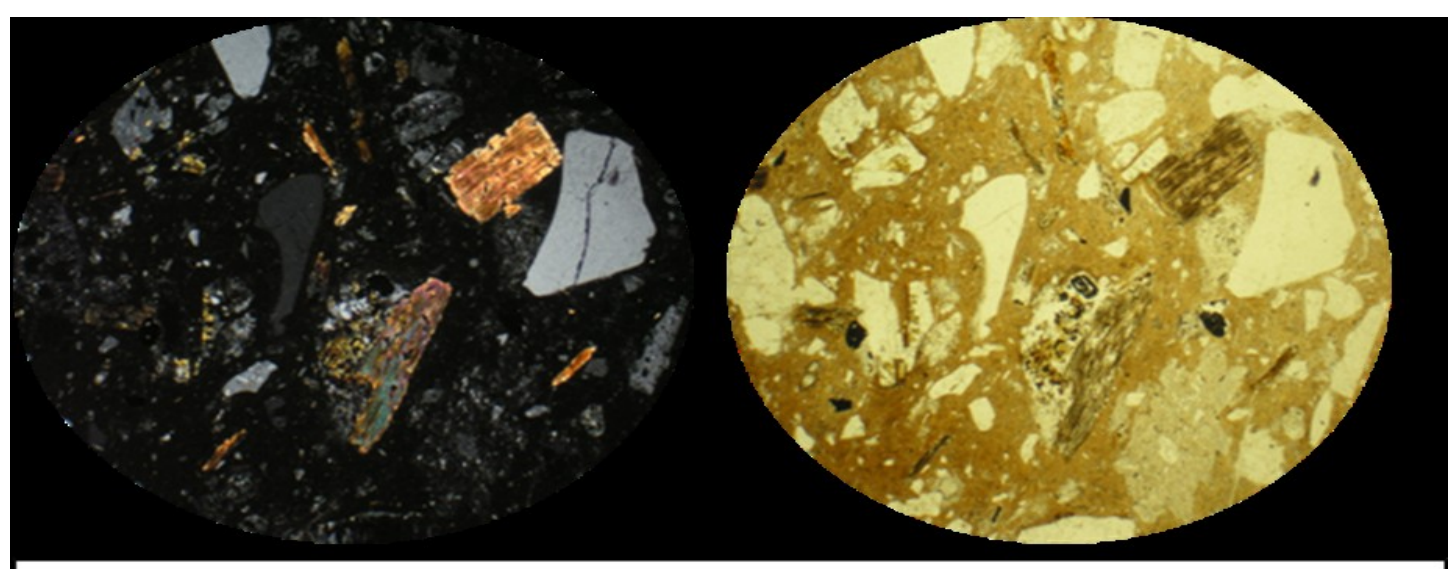

Descripción del corte: el corte presenta matriz vitrea compuestaprincipalmente por numerosas trizas vítreas y pequeños pómez. Se observan litoclastos de bajo soldamiento y los fiames son de mayor tamaño, se encuentran deformados, los bordes están desdibujados y se confunden con la matríz.

\section{0) Muestra PC/23:}

Atribución macroscópica: basalto.

Nombre de la roca: TRAQUITA / ANDESITA

Descripción del corte: el corte muestra pasta afanítica, compuesta principalmente por vidrio y microlitas de feldespatos alcalinos. También hay escasos microfenocristales de plagioclasa que se destacan en la pasta. Entre los fenocristales se reconocieron plagioclasa y feldespatos alcalinos. Entre los microfenocristales se registró sanidina y escasos piroxenos alterados a epidotos. La textura es traquítica (las plagioclasas están orientadas) y se registran numerosos minerales oscuros. El vidrio está alterado (mucho óxido de hierro por eso la coloración rojiza). Tiene (1) feno de sanidina - sacarle foto-. Destacar además el tamaño pequeño de los fenocristales. 


\section{1) Muestra RE 1M1/18}

Atribución macroscópica: Basalto.

Nombre de la roca: ANDESITA / BASALTO

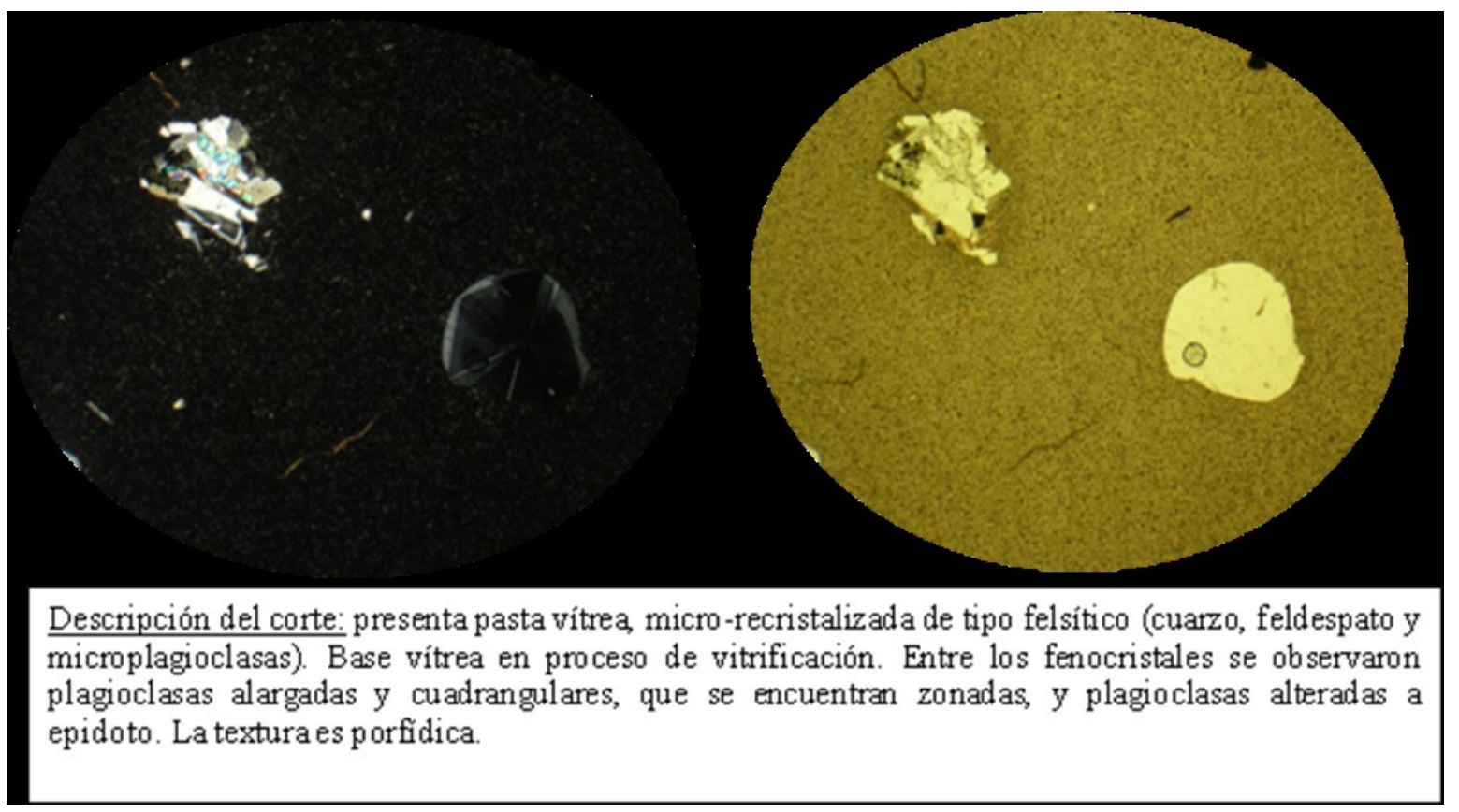

\section{4) Muestra LB-7:}

Atribución macroscópica: Riolita

\section{Nombre de la roca: IGNIMBRITA}

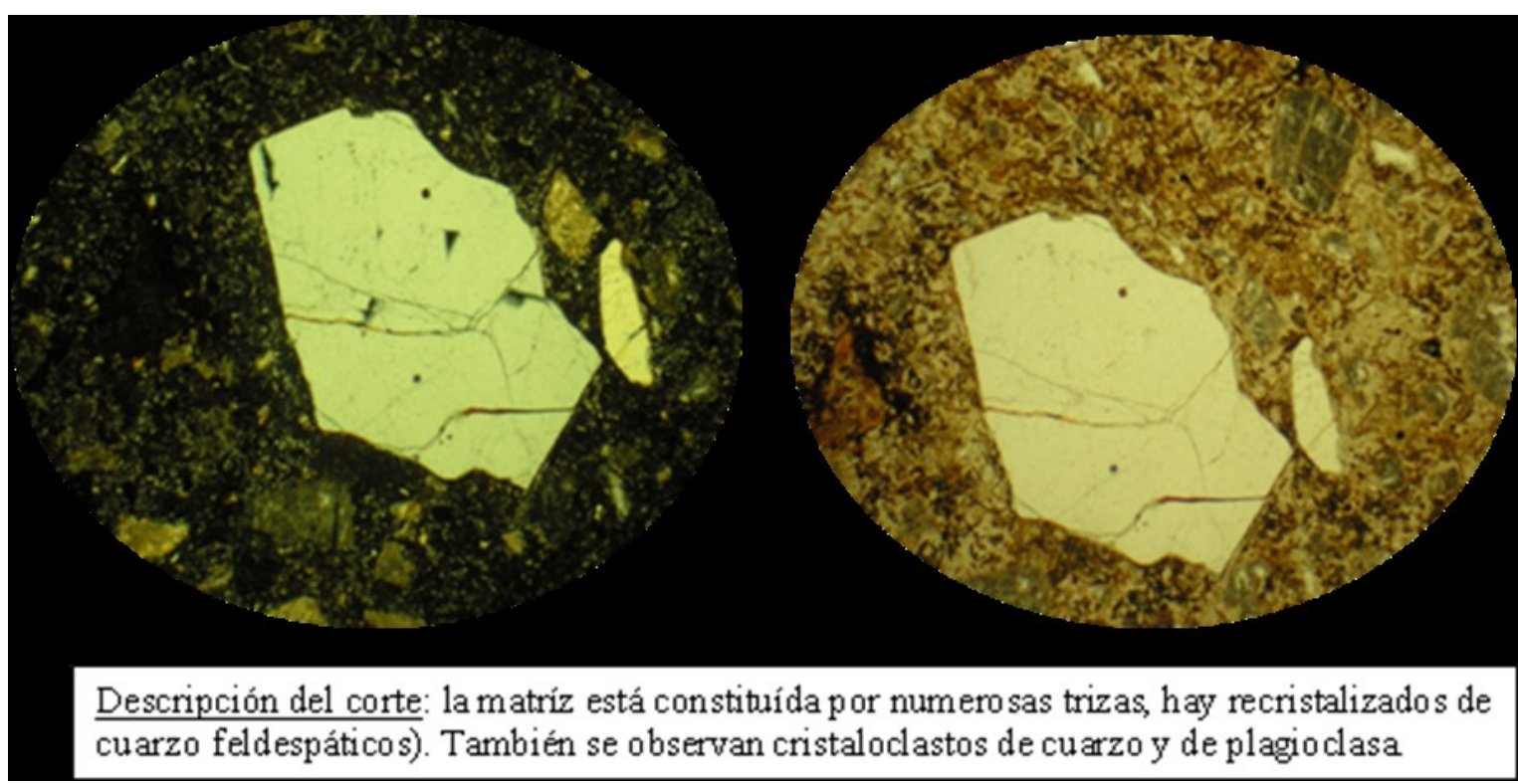




\section{7) Muestra AV 1M1/9:}

Atribución macroscópica: riolita.

Nombre de la roca: FENORIOLITA

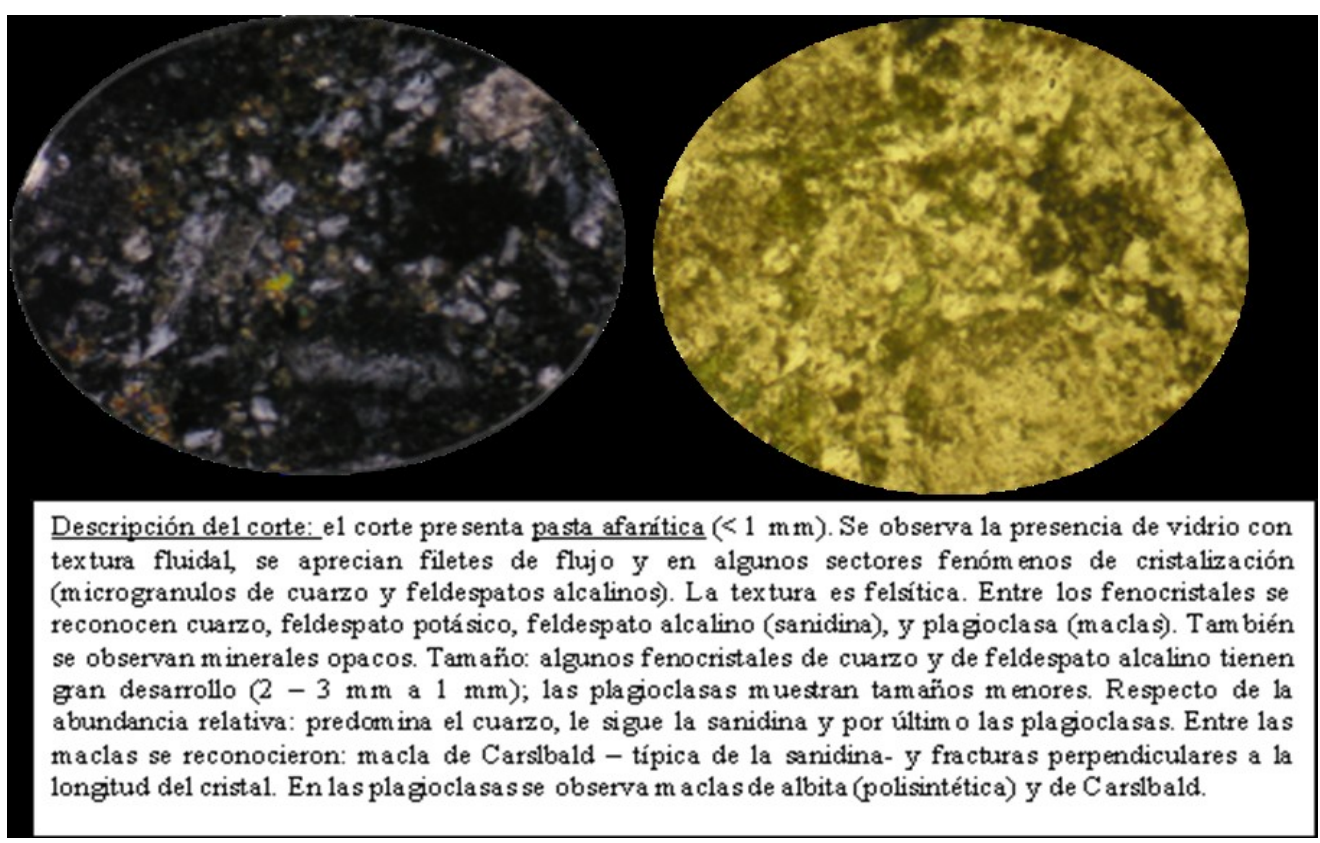

\section{4) Muestra LB-7:}

Atribución macroscópica: Riolita

Nombre de la roca: IGNIMBRITA

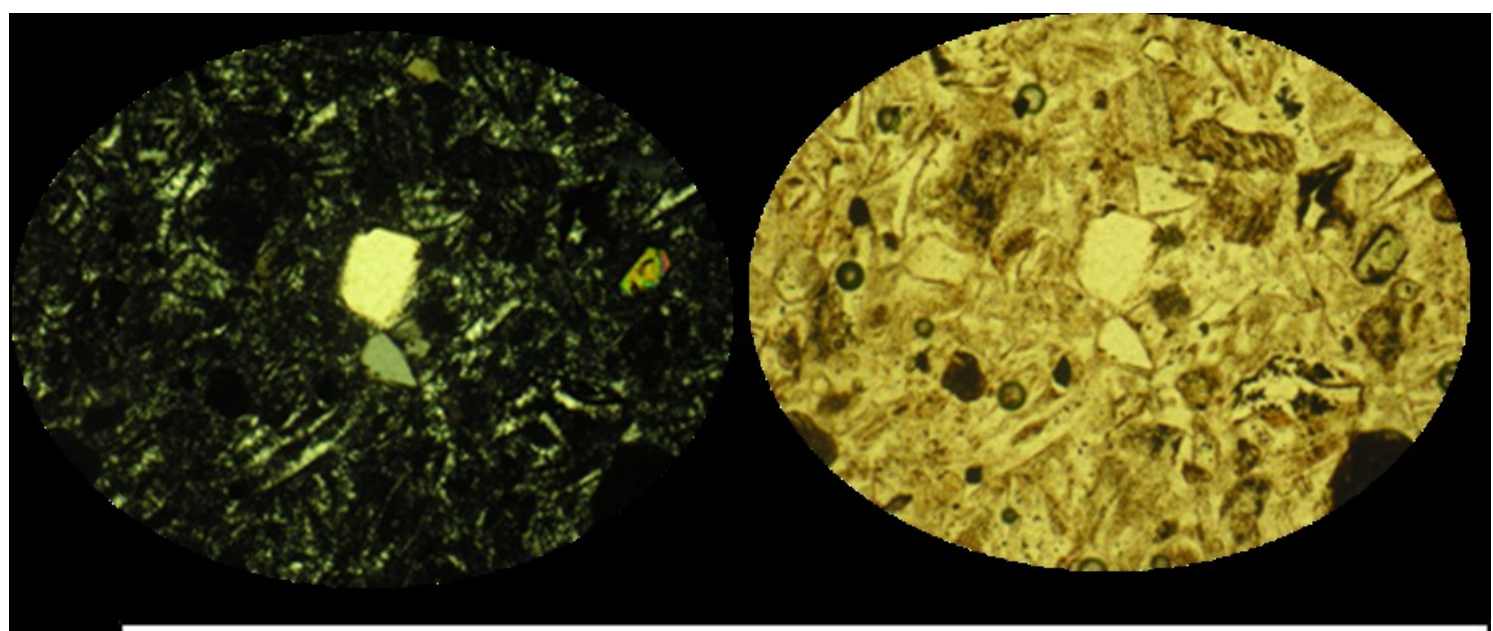

Descripción del corte: la matríz está constituída por numerosas trizas, hay recristalizados de cuarzo feldespáticos). También se observan cristaloclastos de cuarzo y de plagioclasa 